


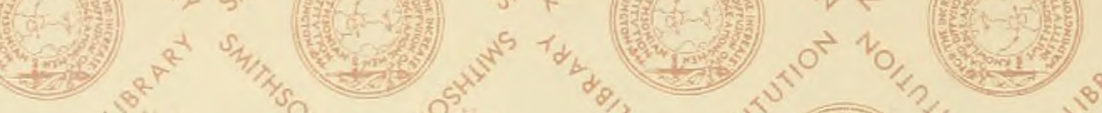

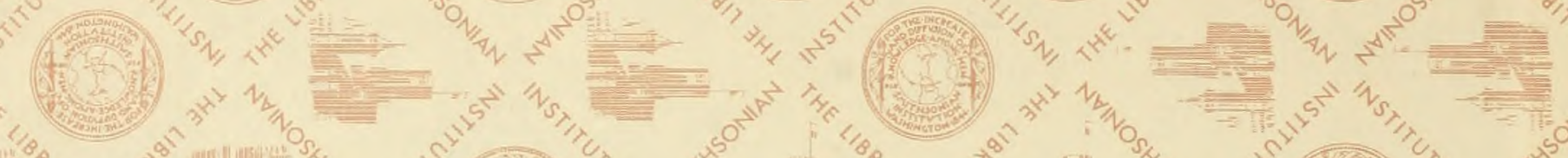

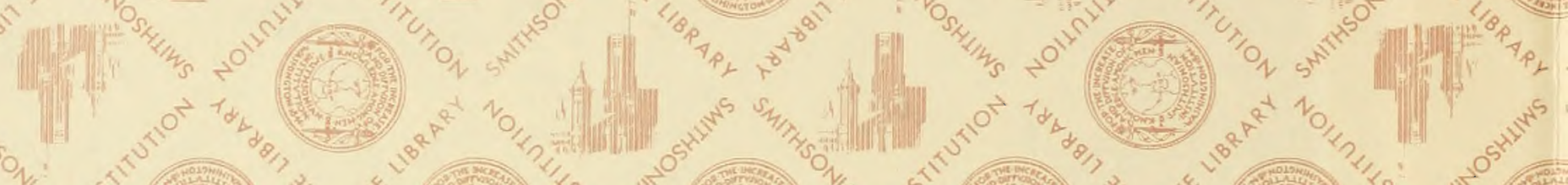

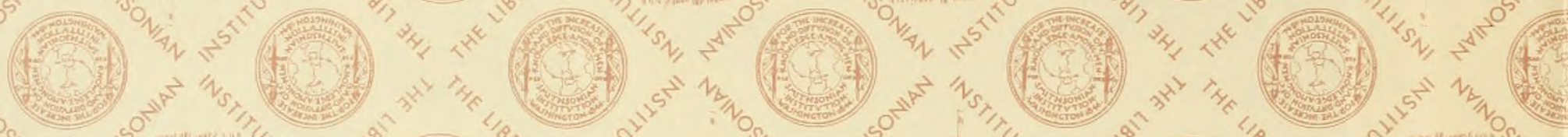

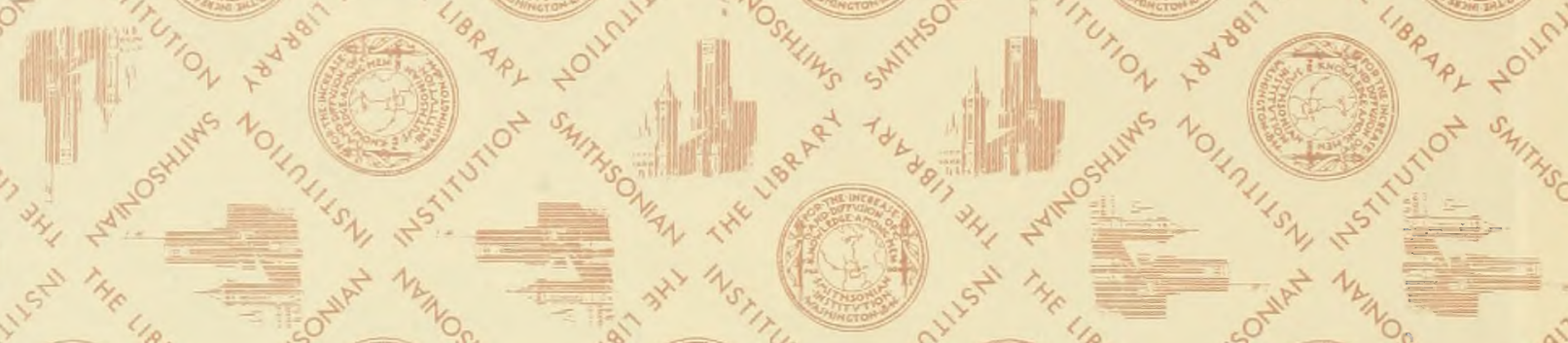

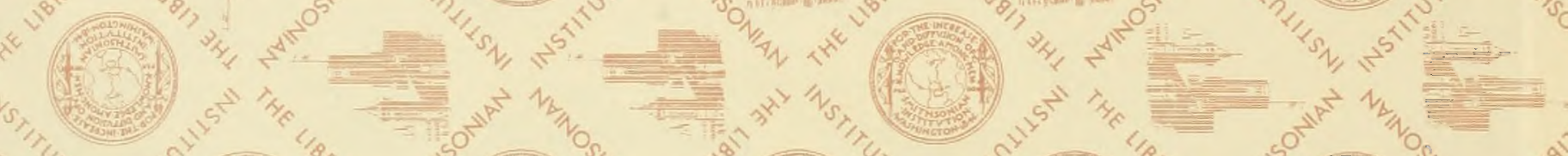

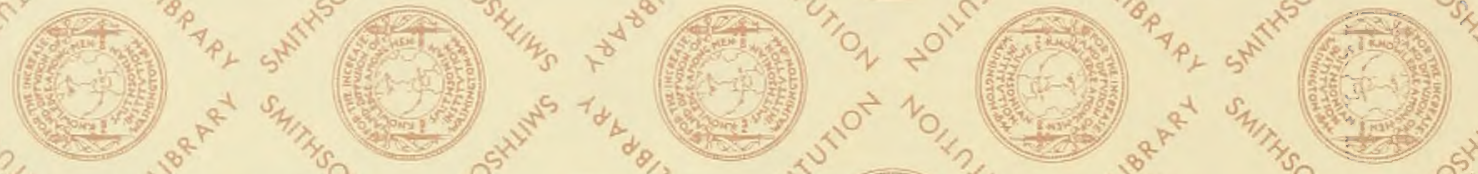

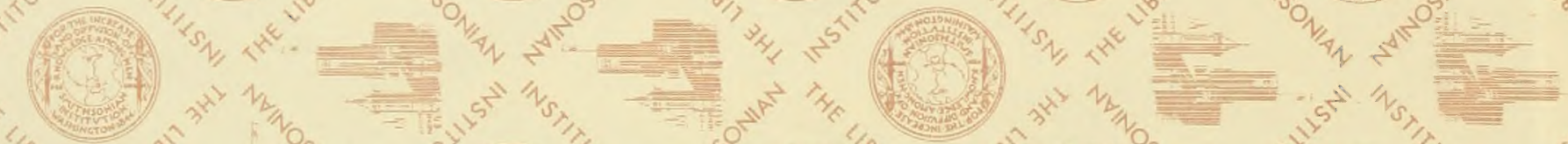

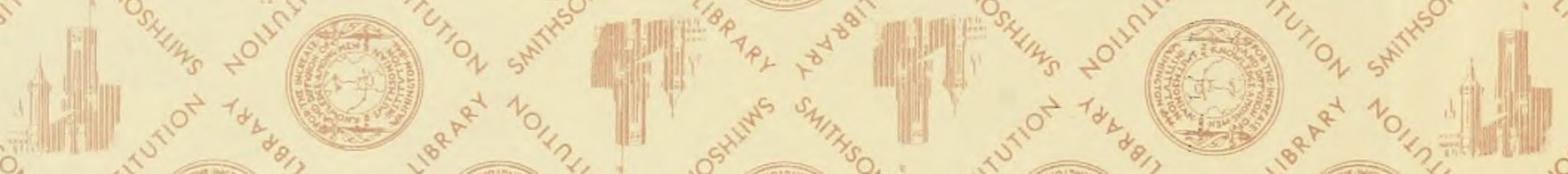

$\left(\begin{array}{lll}0 \\ 0\end{array}\right.$

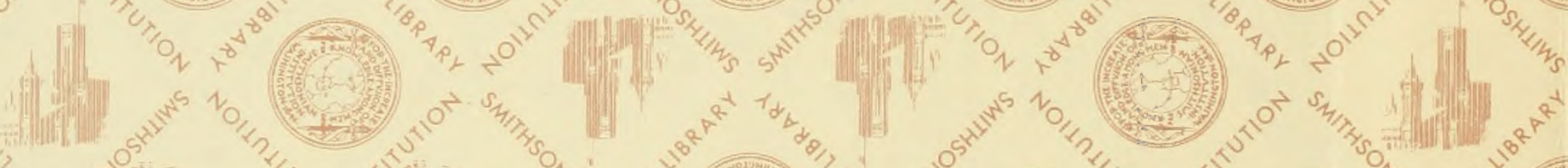

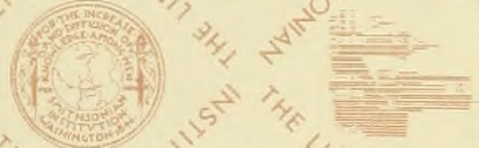

(1)

$\left(\frac{1}{2}\right)$

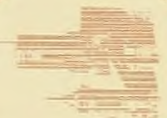

$\Rightarrow$

(s)
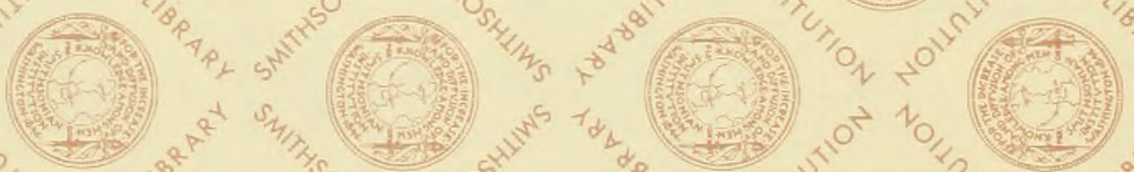

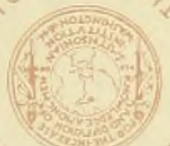

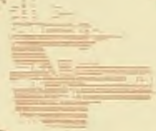

$\left(\begin{array}{cc}5 \\ 5\end{array}\right.$

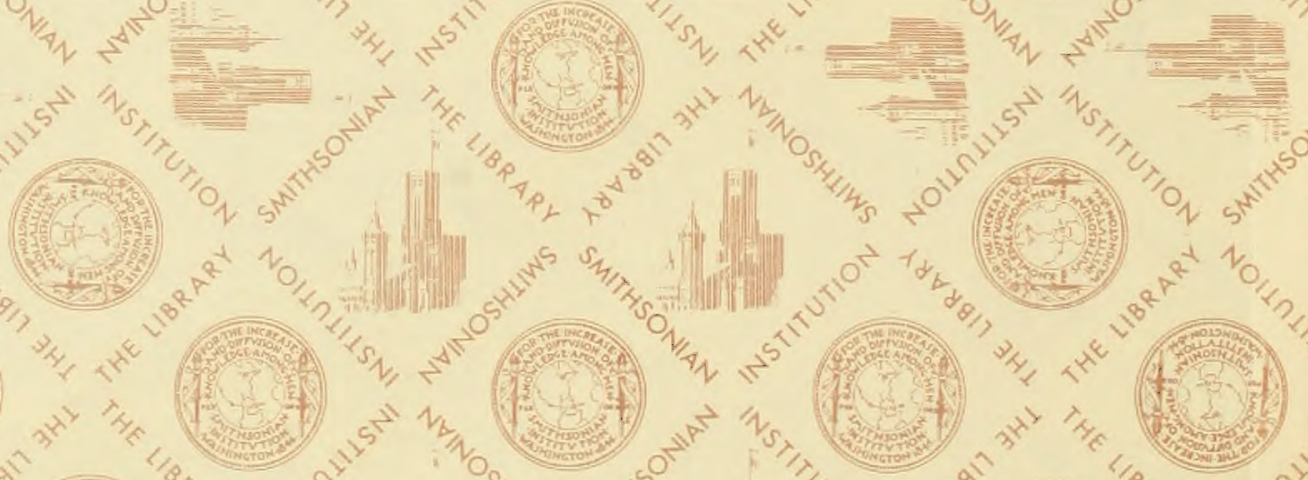

(3)
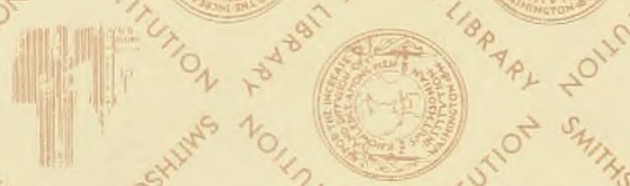

(i) 1 in
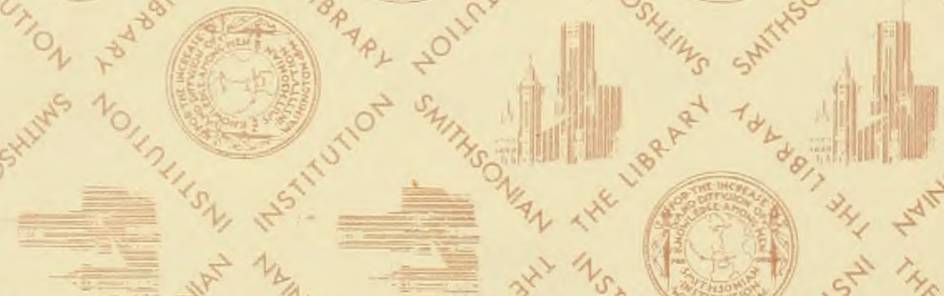

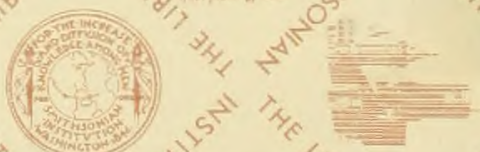
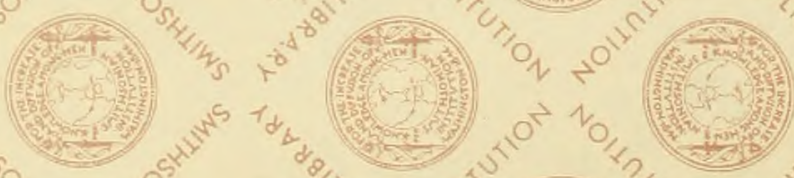

$=1 / 4,450$

. 





\title{
WISSENSCHAFTLICHE ERGEBNISSE
}

\author{
DER \\ dEUTSCHEN TIEFSEE-EXPEDITION \\ AUF DEM DAMPFER „VALDIVIA“ 1898-1899
}

IM AUFTRAGE DES REICHSAMTES DES INNERN

HERAUSGEGEBEN VON

\section{CARL CHUN}

PROFESSOR DER ZOOLOGIE IN LEIPZIG LEITER DER EXPEDITION

S E C H S T E R A N D

TEXT

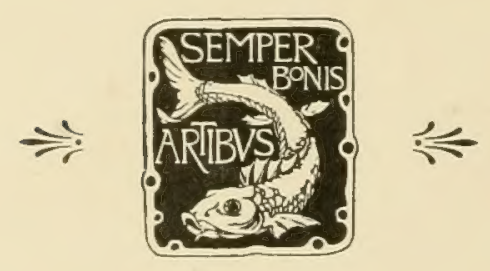

J E N A

VERLAG VON GUSTAV FISCHER 
INVZ

WISSENSCHAFTLICHE ERGEBNISSE DER DEUTSCHEN TIEFSEE-EXPEDITION AUF DEM DAMPFER „VALDIVIA“ 1898-1899。 BAND VI

\title{
BRACH YURA
}

BEARBEITET VON

\author{
DR. FRANZ DOFLEIN
}

PRIVATDOZENT AN DER UNIVERSITÄT MÚNCHEN

II. KONSERVATOR DER ZOOLOGISCHEN STAATSSAMMLUNG

MIT 58 TAFELN, EINER TEXTTAFEL

UND 68 FIGUREN UND KARTEN IM TEXT

\section{TEXT}

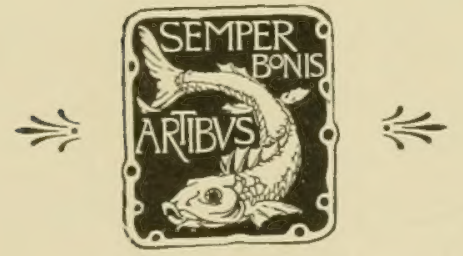

J E N A

VERLAG VON GUSTAV FISCHER

1904

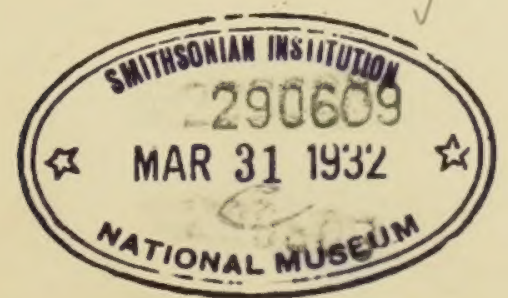


Uebersetzungsrecht vorbehalten 


\section{Inhaltsverzeichnis.}

I. Systematischer und faunistischer Teil

Vorbemerkung

Dromiacea .

Gattung Homolodromia A. MI.-E. Homolodromia Bouvieri n. sp.

Gattung Dromia FABR.

Dromia bicomis (STUDER) .

D. spinosa ( $\mathrm{ST}$.)

$D$. atlantica n. sp.

Gattung Pseudodromia ST. Pseudodromia latens ST.

Gattung Homola LEACH Homola barbata orientalis HENDERSON .

Homola (Paromola) profundorum ALC. u. AND.

Gattung Hypsophrys WOOD-MASON Hypsoplirys longipes ALC. u. AND.

Gattung Homologenus HeNDERSON Homologenus Braneri

Genus Homolochunia nov. gen. Homolochunia Valdiviae n. sp.

Oxystomata

Gattung Ethusa Roux

Ethusa andamanica $\mathrm{A} \mathrm{COCK}$.

E. Zurstrasseni n. sp.

E. mascarone HERBST

E. somalica n. sp.

E. (Ethusina) abyssicola S. J. Sirth

Gattung Dorippe Farricius Dorippe lanata (L.)

Gattung Cymonomus A. M.-EDT

Cymonomus gramulatus (NORMANN) 
Gattung Calappa FABriclus . . . . . . . . . . . . . . . . . . . . . . 35

Calappa lophos (HerbST) . . . . . . . . . . . . . . . . . . . . . . . . 35

Gattung Mursia Desmarest . . . . . . . . . . . . . . . . . . . . 36

Mursia cristimana LATREILLE . . . . . . . . . . . . . . . . . . . . . . 38

M. armata $\mathrm{DE} \mathrm{HAAN}$. . . . . . . . . . . . . . . . . . . . . . . . . . 39

M. armata typica $\mathrm{DE}$ HAAN . . . . . . . . . . . . . . . . . . . . . . . 40

M. amata curtispina MIERS. . . . . . . . . . . . . . . . . . . . . . . 40

11. amata hawaiensis RATHBUN . . . . . . . . . . . . . . . . . . . . . 4 I

M. armata bicristimana ALC. u. AND. . . . . . . . . . . . . . . . . . . 4I

Gattung Pariphiculus Alc. . . . . . . . . . . . . . . . . . . . . . . 4 4

Pariphiculus coronatus ALC. u. AND. . . . . . . . . . . . . . . . . . . 41

Gattung Randallia ST. . . . . . . . . . . . . . . . . . . . . . . . . . 42

Randallia pustulosa WOOD-MASON . . . . . . . . . . . . . . . . . . . . 42

Gattung Parilia WOOd-MASON . . . . . . . . . . . . . . . . . . . . . 44

Parilia Alcocki Wood-Mason . . . . . . . . . . . . . . . . . . . . . 47

Gattung Philyra LEACH . . . . . . . . . . . . . . . . . . . . . 45

Plityra punctata BELL . . . . . . . . . . . . . . . . . . . . . . 45

Pll. laminata n. sp. . . . . . . . . . . . . . . . . . . . . 46

Gattung Ebalia LEACH . . . . . . . . . . . . . . . . . . . . . 46

Ebalia (Phlyxia) atlantica M.-EDw. u. Bouvier . . . . . . . . . . . . . . . 46

E. sulumensis n. sp. . . . . . . . . . . . . . . . . . . . . . . . . . . 47

Gattung Atlantotlos n. g. . . . . . . . . . . . . . . . . . . . . . . . . ty Allentotles rumbifer n. spe. . . . . . . . . . . . . . . . . . . . . . . 50

Gattung Cosmonotus AdAMs u. White . . . . . . . . . . . . . . . . . 5 I Cosmonotus Grayi AdAMS u. WHItE . . . . . . . . . . . . . . . . . . . 5 I

Gattung Lyreidus DE HAAN . . . . . . . . . . . . . . . . . . . . . 52 Lyreidus tridentatus $\mathrm{DE} \mathrm{HAAN}$. . . . . . . . . . . . . . . . . . 52

Oxyrrhycha. . . . . . . . . . . . . . . . . . . . . . . 53

Gattung Cirtomuia MIEks. . . . . . . . . . . . . . . . . . . . . . . . . 53

Cytomaia Sullmi Mifrs . . . . . . . . . . . . . . . . . . . . . . . . 53

C. Suhmi typica Miers . . . . . . . . . . . . . . . . . . . . . . . 54

C. Suhmi platyceros nov. sbsp. . . . . . . . . . . . . . . . . . . . 55

Gattung Platymaia Miers . . . . . . . . . . . . . . . . . . . . . . 59

Platymaia Wyville-Thomsoni MIERS . . . . . . . . . . . . . . . . . . 59

Gattung Stenorhynchlis LAMARCK . . . . . . . . . . . . . . . . . . . . 69

Stenorhynchus rostratus (ILINE) . . . . . . . . . . . . . . . . . . . . . hy

St. longirostris (FABRICIUS) . . . . . . . . . . . . . . . . . . 70

St. falcifer StimpSON . . . . . . . . . . . . . . . . . . . . 70

Gattung Physachaeus Alcock . . . . . . . . . . . . . . . . . . . 71

Physuchatus ctemurus Alconk . . . . . . . . . . . . . . . . . . . . . . T1

Gattung Inachus FABRicius . . . . . . . . . . . . . . . . . . . . . . 72

Inachus dorsettensis (PENN.) . . . . . . . . . . . . . . . . . . . . . 72

1. leptochirus LEACH . . . . . . . . . . . . . . . . . . . . . . 73

1. antarcticus n. sp. . . . . . . . . . . . . . . . . . . . . 77

Gattung Lispognathus A. M.-EDw. . . . . : . . . . . . . . . . . . . . . 75

Lispognathus Thonsoni NorMANN . . . . . . . . . . . . . . . . . 75 
Gattung Pleistacantha Mirers emend.

Gattung Menaethius MI.-EDw.

.Menaethins monoceros (L.ITREILLE)

Gattung Dyas LEACII

Dyas coarctatus LEACH

Gattung Eurynome LEACH

Eurynome aspera (PENAANT).

Gattung Pisa LEACH .

Pisa carinimana MIERS

Gattung Micropisa STIMPSON

Micropisa violacea A. MI.-EDw.

Gattung Scyramathia A. MI.EDW. .

Scyramathia Hertwigi DofLEIN

S. pulchra MiERs

S. Rivers-Andersoni AlCoCK

S. globulifera WOOD-MASON .

Gattung Hyastemus WHite

Hyastenus brevirostris n. sp. .

Cyclometopa.

Familie Parthenopidae

Gattung Lambrus LEACH . . . Lambrus macrocheles (HERBST).

Familie Hymenosomidae

Gattung Halicarcinus IVHITE

Halicarcinus planatus (FABRICIUS)

Gattung Dymenosoma LEACH Dymenosoma orbiculare DESMAREST

Familie Atelecyclidae .

Gattung Trichopeltarium M.-EDw.

Trichopeltarium Alcocki DOFLEIN .

Gattung Atelecyclus LEACri Atelecyclus septemdentatus MONTAGU

Familie Portunidae

Gattung Benthochascon ALCOCK Benthochascon Demingi AlCock u. ANDERSON

Gattung Ovalipes RATHBUN Ovalipes trimaculatus DE HAAN

Gattung Elliptodactylus n. g. . Elliptodactylus migosus n. sp.

Gattung Portunus FABRicius Portumus holsatus FABRICIUS

Gattung Caphyra GUERIN Caphyra rotundifrons MIILNE-EDW.

Gattung Charybdis DE $\mathrm{HAAN}_{\mathrm{A}}$ Charybdis (Goniosoma) quadrimaculata A. M.-EDW. 
Cl. (Goniosoma) natator (HERBST) . . . . . . . . . . . . . . . . . . . . Q .

Ch. (Goniohellenus) loplites WOOD-MASON . . . . . . . . . . . . . . . . . y.

Gattung Neptumus DE HAAN . . . . . . . . . . . . . . . . . . . . . . . 97

Neptunus (Neptumus) sanguinolentus (HERBST) . . . . . . . . . . . . . . . . 9.

N. (Hellenus) tuberculosus M.-EDW. . . . . . . . . . . . . . . . . . . . . gs

N. pelagicus LEACH. . . . . . . . . . . . . . . . . . . . . . . . . . . 95

N. (Achelous) pubescens DANA . . . . . . . . . . . . . . . . . . . . . 98

Gattung Scylla DE HAAN . . . . . . . . . . . . . . . . . . . . . . . . . g.

Scylla serrata (ForskiL) . . . . . . . . . . . . . . . . . . . . . . . . ys

Gattung Thalamita LATREILLE . . . . . . . . . . . . . . . . . . . . . . . 99

Thalamita Danae STMMPON . . . . . . . . . . . . . . . . . . . . . . . 99

Gattung Thalamitoides A. MILNE-EDW. . . . . . . . . . . . . . . . . . . . 9

Thalamitoides quadridens M.-EDT. . . . . . . . . . . . . . . . . . . . . . . 99

Gattung Callinectes STIMPSON . . . . . . . . . . . . . . . . . . . . . . . 99

Callinectes lavvatus ORDWAT . . . . . . . . . . . . . . . . . . . . . . . . . yil

Familie Xanthidae . . . . . . . . . . . . . . . . . . . . . . . . . . . Ioo

Gattung Pilmmnus LEACH . . . . . . . . . . . . . . . . . . . . . . . I00

Pilumus hivtellus var, inermis M.-EDT. u. BoUv. . . . . . . . . . . . . . . Ioo

P. verrucosipes StIMPSON . . . . . . . . . . . . . . . . . . . . . . . . . Ino

Gattung Cymo DE HAAN . . . . . . . . . . . . . . . . . . . . . . . . . IOO

Cymo Andreossyi (AUDOUIN) . . . . . . . . . . . . . . . . . . . . . . . IO0

Gattung Xantho LEACH . . . . . . . . . . . . . . . . . . . . . . . . . . IO I

Xantho exaratus (M.-EDT.) var. sanguinea M.-EDT. . . . . . . . . . . . . . Io I

X. Lamarcki M.-EDT. . . . . . . . . . . . . . . . . . . . . . . . . . Iо

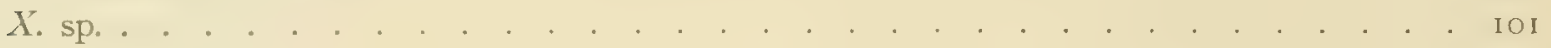

Gattung Liomera DANA . . . . . . . . . . . . . . . . . . . . . . . . . Io I

Liomera sp. . . . . . . . . . . . . . . . . . . . . . . . . . . . . . I I

Gattung Actaea DE HAAN . . . . . . . . . . . . . . . . . . . . . . . . I02 Actrea parvula (DE HAAN) . . . . . . . . . . . . . . . . . . . . . . . 102

A. lirsutissina (RÜPPEL) . . . . . . . . . . . . . . . . . . . . . . . . In 2

Gattung Plimmodius A. M.-EDI. . . . . . . . . . . . . . . . . . . . . . . I! Phymodius ungulatus (M.-EDW.) . . . . . . . . . . . . . . . . . . . . . 102

Gattung Chlorodius LEACH em., A. M.-EDw. . . . . . . . . . . . . . . . . . 103 Chlorodius niger (FORSK.) . . . . . . . . . . . . . . . . . . . . . . . . IO3

Gattung Etisus M.-EDr. . . . . . . . . . . . . . . . . . . . . . . . . . 103 Etisus dentatus (HERBST) . . . . . . . . . . . . . . . . . . . . . . . . 103

Gattung Daira DE HAAN . . . . . . . . . . . . . . . . . . . . . . . . . IO4 Daira perlata (HERBST) . . . . . . . . . . . . . . . . . . . . . . . . 104

Gattung Trapezia LATREILLE . . . . . . . . . . . . . . . . . . . . . . . I Trapezia cymodoce (HERBST) . . . . . . . . . . . . . . . . . . . . . . . 10+ T. ferruginea guttata RÜPPEL . . . . . . . . . . . . . . . . . . . . . . 104

Gattung Tetralia DANA . . . . . . . . . . . . . . . . . . . . . . . . . . 105 Tetralia glabervima (HERBST) . . . . . . . . . . . . . . . . . . . . . . Inj

Familie Potamonidae . . . . . . . . . . . . . . . . . . . . . . . . . . . Io5

Gattung Potamon SATIGNT . . . . . . . . . . . . . . . . . . . . . . . 10;

Untergattung Potamonautes MACLEAI . . . . . . . . . . . . . . . . . . . I0.5 
Potamon (Potamonautes) Aubryi (AI.-EDw:)

P. (Potamonautes) perlatum) (M.-EDW.)

Gattung Geryon KRÖGER

Geryon affinis M.-EDw. u. Bouv.

Zur Anatomie von Geryon affinis M.-EDw. u. Bouv.

G. Paulensis DOFleix

Gattung Carcinopla.x M.-EDw.

Carcinoplax longimanus DE HAAN.

C. longimanus indicus n. sbsp.

C. longimanus japonicus (DE HAAN)

C. longipes (IVOOD-MASON)

Gattung Goneplax LEACH

$11 \%$ Goneplax angulata (PENNANT)

Psopheticus stridulans WOOD-MASON . . . . . . . . . . . . . . . . I

Gattung Pilummoplax STMMPSON . . . . . . . . . . . . . . . . . . . 11 Pilumoplax heterochir (STUDER) . . . . . . . . . . . . . . . . . . . . 11 P. americana RATHBUN. . . . . . . . . . . . . . . . . . . . . . . . 1 1,

Gattung Litocheira KINAHAN . . . . . . . . . . . . . . . . . . . . . . 121 Litocheira Kingsleyi (Mrers) . . . . . . . . . . . . . . . . . . . . . . 121

Gattung Camatopsis AlCock. . . . . . . . . . . . . . . . . . . . . . I I Camatopsis rubida AlCOCK U. AND. . . . . . . . . . . . . . . . . . . . I I I

Gattung Hexaplax n. g. . . . . . . . . . . . . . . . . . . . . . . . . . I I2 Hexaplax megalops n. sp. . . . . . . . . . . . . . . . . . . . . . . . 12

Gattung Pimotheres Latreille . . . . . . . . . . . . . . . . . . . 1 12; Pinnotheres n. sp. . . . . . . . . . . . . . . . . . . . . . . . . . $12 t$ P. villosissimus n. sp. . . . . . . . . . . . . . . . . . . . . . . $12=$

Gattung Ocypoda FABRICIUS . . . . . . . . . . . . . . . . . . . . IzU Ocypoda Kulli DE HAAN . . . . . . . . . . . . . . . . . . . . . . . 121

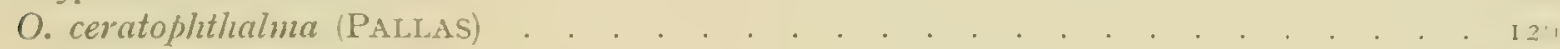

O. africana DE MAN . . . . . . . . . . . . . . . . . . . . . 12-

O. cursor $(\mathrm{LEACH})$. . . . . . . . . . . . . . . . . . . . . . . . . . 12-

Gattung Uca LEACH . . . . . . . . . . . . . . . . . . . . . . . . 127 Uca Tangieri (EYDOUx) . . . . . . . . . . . . . . . . . . . . . . . 12Uca anmilipes M.-EDT. . . . . . . . . . . . . . . . . . . . . . . 124

Gattung Dotilla StrMpson . . . . . . . . . . . . . . . . . . . . . I Dotilla fenestrata HrlgeNdoRF . . . . . . . . . . . . . . . . . . . . . 1zín

Gattung Macrophthalmus LATREILLE . . . . . . . . . . . . . . . . . . I21) Macrophthalmus dilatatus DE HAAN . . . . . . . . . . . . . . . . . . . I2.1

Gattung Geograpsus Stimpson . . . . . . . . . . . . . . . . . . . . . . 1 111 Geograpsus Grayi M.-EDw. . . . . . . . . . . . . . . . . . . . . 12 ,

Gattung Pachygrapsis Ravidal . . . . . . . . . . . . . . . . . . . . 1 12 Pachygrapsis simplex (Herklots) . . . . . . . . . . . . . . . . . . . . 12 P. aethiopicus HILGENDORF . . . . . . . . . . . . . . . . . . . . . . . . . 1;

Gattung Planes LEACH-BELL . . . . . . . . . . . . . . . . . . . . . . . 1,3 Planes minutus (LrNé). . . . . . . . . . . . . . . . . . . . . . . 1 i, 
Gattung Sesamma SAT . . . . . . . . . . . . . . 130

Sesarma Meinerti DE MAN . . . . . . . . . . . . . . . . . . . . . I30

Sesarma sp. . . . . . . . . . . . . . . . . . . . . . 130

S. sp. . . . . . . . . . . . . . . . . . . . . . . . I30

Gattung Leiolophus Miers . . . . . . . . . . . . . . . . . . . . . . I3I

Leiolophus planissimus HerbST . . . . . . . . . . . . . . . . . . . . I3I

Gattung Gecarcinus LATREILLE . . . . . . . . . . . . . . . . . . . . . I3I

Gecarcinus lagostoma M.-EDW. . . . . . . . . . . . . . . . . . . . . I31

Gattung Cardisoma LAtreille . . . . . . . . . . . . . . . . . . . I3 I

Cardisoma guanhumi LATREILLE . . . . . . . . . . . . . . . . . . 131

Gattung Retropluma GILI. . . . . . . . . . . . . . . . . . . . 131

Retropluma Chumi n. sp. . . . . . . . . . . . . . . . . . . . 131

Litteraturverzeichnis zum I. Teil . . . . . . . . . . . . . . . . . . . . . 134

II. Biologischer Teil . . . . . . . . . . . . . . . . . . . . . . . I39

A. Beschreibung von Sinnesorganen einiger Tiefseekrabben . . . . . . IfI

I. Bau der Augen einer Anzahl von Krabben aus verschiedenen Tiefen . . . . . . I4I

Terminologie des Augenbatues . . . . . . . . . . . . . . . . . . . . 141

I. Homolodromia Bonzieri Dnfletx . . . . . . . . . . . . . . . . . I43

2. Hypsophrys longipes Alc u. AxD.. . . . . . . . . . . . . . . . I+5

3. Homolochmia Taldiziae Doflet . . . . . . . . . . . . . . . . 147

4. Ethusina abyssicola S. J. Sinth . . . . . . . . . . . . . . . . I50

5. Ethusa somalica DofleIN . . . . . . . . . . . . . . . . I5 I

6. Cymonomus granulatus NorM. . . . . . . . . . . . . . . . . . . 1.52

7. C. menefere ORTMANN . . . . . . . . . . . . . . . . . . 154

7а. C. muifera melanomma DofL. . . . . . . . . . . . . . . . . . 154

7b. C. uncifera glancomma ALC. . . . . . . . . . . . . . . . . . . 156

s. Cyclodorippe dromioides ORT. . . . . . . . . . . . . . . . . . . 157

9. Cyrtomaia Sulmi Mrers . . . . . . . . . . . . . . . . 158

Io. Platymaia Wyville-Thomsoni MIERs . . . . . . . . . . . . . . . . 160

I. Physachaeus ctenums Alc. . . . . . . . . . . . . . . . . . I65

12. Lispognathus Thomsoni NoRM. . . . . . . . . . . . . . . . . I68

13. Pleistacantha Moseleyi Miers . . . . . . . . . . . . . . . . I68

I +. Scyramathia Hertaigi Doflem . . . . . . . . . . . . . . . . . ITI

I5. S. Rivers-Andersoni ALC. . . . . . . . . . . . . . . . . . I72

16. Trichopeltarium Alcocki DOFLEIN . . . . . . . . . . . . . . . . I73

17. Geryon affinis M.-EDw. u. BouvieR . . . . . . . . . . . . . . . . 175

18. Hexaplax megalops DofLEIN . . . . . . . . . . . . . . . . . I77

II. Ueber den Bau der Geruchsorgane einiger Tiefseekrabben . . . . . . . . . . I78

I. Homolodromia Bouvieri DofleIN . . . . . . . . . . . . . . . . 182

2. Honolochunia Valdiviae DOFLEIN . . . . . . . . . . . . . . . I 83

3. Cymonom granulatus NoRM. . . . . . . . . . . . . . . Is3

4. Cyclodorippe uncifera glancomma ALC. . . . . . . . . . . . . . . I84

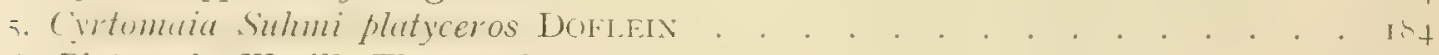

6. Platymaia Wyville-Thomsoni Miers. . . . . . . . . . . . . I85

7. Pliysachaeus ctemurus Alc. u. AND. . . . . . . . . . . . . . I 85

8. Geryon affinis M.-Edw. u. BouvieR . . . . . . . . . . . . . . I 86 
III. Die Statocysten einiger Tiefseekrabben

1. Homolodromia Bonvieri DofleIN

2. Dromia atlantica DofleIN

3. Homolochunia Valdiviae DofLEIN .

1. Cymonomus granulatus NORM.

5. Cyclodorippe uncifera glaucomma ALC. .

6. Cyrtomaia Sulmi platyceros DofL.

7. Physachaeus ctenuras ALC.

8. Geryon affinis M.-EDw. u. Bouv.

B. Biologie der Tiefseekrabben . . . . . . . . . . . . . 11,

1. Bewegung und Habitus . . . . . . . . . . . . . . . . . . . . . . . . 11,6

2. Körpergröße . . . . . . . . . . . . . . . . . . r ז

3. Ernährung und Atmung . . . . . . . . . . . . . . . . . . . . . . 2n,

4. Angriffs- und Schutzvorrichtungen . . . . . . . . . . . . . . . . . . . 212

5. Sinnesorgane . . . . . . . . . . . . . . . . . . 216

A. Biologische Bedeutung des Augenbaues bei den Krabben . . . . . . . . . . z, n

Der Sehvorgang im Auge der Tiefseekrabben . . . . . . . . . . . . . 214

I. Einfache Dämmerungsaugen . . . . . . . . . . . . . . . . . . . 2 $I^{\prime \prime}$

II. Iridopigmentäre Augen . . . . . . . . . . . . . . . . . . . . . 211

III. Reflektoraugen . . . . . . . . . . . . . . . . 220

IV. Pigmentlose Augen . . . . . . . . . . . . . . . . . . . . . . 222

V. Linsenaugen . . . . . . . . . . . . . . . 224

Verglejch des Augenbaues bei Tieren mit versciliedener Lebensweise . . . . . . 227

Die Ursachen der Rückbildung der Augen . . . . . . . . . . . . . . . 2.37

B. Bedeutung des Baues der Geruchsorgane für die Lebensweise der Tiefseekrabben . 2 †

C. Ueber die biologische Bedeutung der Statocysten bei den Tiefseekrabben . . . . 252

D. Die Entwickelung des Tastsinnes bei den Tiefseekrabben . . . . . . . . . . $25 \%$

6. Fortpflanzung . . . . . . . . . . . . . . . . 25:

Zusammenfassender Ueberblick über die Biologie der Tỉefseekrabben . . . . . . . . . 21,

Litteraturverzeichnis zum II. Teil . . . . . . . . . . . . . . . . . . . . . . 21,3

\section{Tiergeographischer Teil}

Horizontale Verbreitung litoraler und sublitoraler Brachyuren . . . . . . . . . . . . 2t:

A. Atlantik . . . . . . . . . . . . . . . . . . . . . . . 21 .

B. Antarctis . . . . . . . . . . . . . . . . . 2(t)

C. Indopacifik . . . . . . . . . . . . . . . . . . . . . . . . . . . . $2^{2}$

Horizontale und vertikale Verbreitung der Brachyuren des tiefen Wassers . . . . . . . 2-0)

IV. Teil

ェ. Herkunft der Tiefseekrabben . . . . . . . . . . . . . . . .

2. Die Artbildung der Tiefseekrabben und das Doederlern'sche Prinzip . . . . . . . . 2 zu

I. Cymonomus gramulatus typicus Norarax 1873 . . . . . . . . . . . . . . . . . . . . . $22_{3}$ 
2. C. gramulatus Nomani LANRESTER Igo3 . . . . . . . . . . . . . . . . . 283

3. C. granulatus n. subsp. HANSEN . . . . . . . . . . . . . . . . . . . . 283

4. C. granulatus Valdiviae LANK. . . . . . . . . . . . . . . . . . . . . . 284

5. C. granulatus quadratus M.-E. . . . . . . . . . . . . . . . . . . . . 284

Iitteraturverzeichnis zum IV. Teil . . . . . . . . . . . . . . . . . . . . . . 284

V. Teil. Tabellen . . . . . . . . . . . . . . . . . . . . . . . . . . 285

Tabelle I . . . . . . . . . . . . . . . . . . . . . . 288

Tabelle II . . . . . . . . . . . . . . . . . . . . . . . . . . . 307

Tabelle III . . . . . . . . . . . . . . . . . . . . . . . . . . . . . . . . . . . 308

Tabelle IV . . . . . . . . . . . . . . . . . . . . . . . 308 


\section{Einleitung.}

In der vorliegenden Bearbeitung der Brachyuren der Tiefsee-Expedition habe ich versucht, die Ausbeute in möglichst vielseitiger Weise auszunützen. Der Liberalitït der Expeditionsleitung bin ich sehr zu Dank verpflichtet dafür, daß sie mir die volle Verfügung über das Material gab. So konnte ich mancherlei, wie ich hoffe, interessante Befunde erzielen, ohne dabei die wertvollen und seltenen Objekte zu verstiummeln.

Es waren ungefähr 150 Arten Brachyuren von der Expedition erbeutet worden; die meisten von ihnen wurden so ausgezeichnet konserviert, daß die Mehrzahl der in dem Kapitel über „Biologie“ niedergelegten Befunde an dem Material der Expedition gewonnen werden konnten.

Die Anzahl von neuen Gattungen und Arten war keine auffallend große; von überraschenden Formen wäre unter den Brachyuren nur die Homolochunia Valdiziae zu nennen. Aber was wichtiger und interessanter ist, unsere Expedition erbeutete Vertreter fast sämtlicher bisher aus der Tiefsee bekannt gewordenen Gattungen. Und zwar waren Formen, welche bisher nur in I-2 Exemplaren bekannt geworden waren, zum Teil in ganzen Serien vertreten.

Das gab mir Anlaß, eine Anzahl von Formen zu revidieren; eine Reihe von Arten mußte mit anderen vereinigt werden.

Was die in diesem Buche angewandte Systematik angeht, so habe ich mich nicht dem Beispiel von Ortanan anschließen können, welcher die 3 Gruppen kurzschwïnziger Dekapoden als selbständige Abteilungen den übrigen Abteilungen der Unterordnung Reptantia BoAs gleichgeordnet hat.

Ich muß allerdings darauf verzichten, an dieser Stelle eingehender auseinanderzusetzen, warum ich die Dromiaceen und Oxystomen als nähere Verwandte der höheren Krabben betrachte, als es die Paguriden, Galatheiden und Hippiden sind. Ich schließe mich der Klassifikation von BORRADAILE in diesem Punkte an und nehme auch seine Bezeichnung der von Ortalann als Brachyura s. str. bezeichneten höheren Krabben als Brachygnathen an. Durch diese Veränderung wird das große Verdienst, welches sich OrTmann im Anschlusse an Boss um die Klärung der Verwandtschaftsverhältnisse der Dekapoden erworben hat, in keiner Weise geschmälert. Die neuerliche Annahme der alten Milne-Edwards'schen Gruppe der Brachyuren basiert vielmehr auf neueren Untersuchungen; vor allen Dingen waren hier die Untersuchungen von Bouvier über die Verwandtschaft der Dromiaceen von Einfluß.

Die Stellung, welche ich der Gattung Geryon in System angewiesen habe, und die damit zusammenhängenden Veränderungen werde ich an anderer Stelle crörtern. 
In dem tiergeographischen Kapitel hatte ich Gelegenheit, eine Reihe von überraschenden Thatsachen zusammenzustellen, welche das Material unserer Expedition festzustellen erlaubte. Diese betreffen besonders die Ausbreitung der Formen des nordatlantischen Oceans bis weit nach Süden, ferner die sehr weite Verbreitung mancher Formen der großen und mittleren Tiefen über die ganze Erde; schließlich wäre hier noch der Nachweis zu envähnen, daß viele Formen, welcne bisher aus verschiedenen Meeren als verschiedene Arten beschrieben wurden, identisch sind; es gilt dies besonders von japanischen und indischen Formen.

Es ist wohl nicht verwunderlich, wenn ich in dem Kapitel über die Biologie der Tiefseekrabben neben vielen thatsächlichen Befunden auch viele offene Fragen anzuführen hatte. Ich denke, mit ihrer Zusammenstellung dem Fortschritt der Wissenschaft zu nützen; denn wenn nicht der specielle Kenner einer Gruppe solche Fragen aufstellt, so wird manche Gelegenheit zu ihrer Lösung unbenützt vorübergehen.

Schließlich sei noch erlaubt, ein Wort über die am Schlusse angefügten Tabellen zu sagen. Sie sind entstanden aus Verzeichnissen, welche ich mir zur Verarbeitung der Thatsachen in Form von Zettelkatalogen angelegt hatte. Ich veröffentliche sie, damit man an ihrer Hand meine Resultate nachprüfen kann, und außerdem, weil sie gleichzeitig ein reiches, in vieler Beziehung noch ausnützbares Naterial darstellen.

Die Abbildungen, welche diesem Werke beigegeben sind, haben eine verschiedene Entstehungsweise und Reproduktionstechnik. Ich möchte dies hier anführen, um jedem Benutzer zu ermöglichen, den Grad der Naturtreue jeder einzelnen Abbildung abzuschätzen.

Tafel I-IV sind nach Aquarellskizzen, welche von Herrn WINIER wăhrend der Expedition nach den frischen Tieren gemacht wurden, in Lithographie reproduziert, zu welchem Zwecke eine genaue Zeichnung nach dem konservierten Objekt von Herrn Gustav Keller angefertigt wurde.

Tafel V-XXXVIII sind direkte Reproduktionen von photographischen Naturaufnahmen in Kupferdruck; sie sind daher vollkommen naturgetreu und gestatten an vielen Teilen des Körpers eine direkte Messung; zu diesem Zwecke ist für jede Figur auf dem Schutzblatte die genaue Angabe der Vergrößerung beigegeben.

Die übrigen Tafeln, sowie die Textfiguren sind mit möglichst großer Naturtreue nach den Präparaten von der geschickten Hand des Malers Herrn Lorenz MüLlek-Mainz gefertigt. Sie geben die oft sehr charakteristische Farbe des konservierten Objektes wieder; bei den Schnittpräparaten sind die Farben schematisch zur Erhöhung der Uebersichtlichkeit gewähIt. Nur bei den Farben der Pigmente wurde ebenfalls die größte Naturtreue angestrebt.

Den Firmen Verlagsanstalt Bruckmann in München und Werner \& Winter in Frankfurt am Main, welche bei der Anfertigung der Tafeln die größte Mühe aufwandten und in vieler Beziehung sich sehr entgegenkommend zeigten, sei hiermit der beste Dank dafür ausgesprochen.

München im November 1903. 
I. Systematischer und faunistischer Teil.

Deutsche Tiefsee-Lxypedition 1898-1899. Idd, VI. 
Eingegangen den 20. Juli 1903.

C. Chun. 
In dem nachfolgenden Abschnitt sind sïmtliche während der deutschen Tiefsec-Expedition erbeuteten Brachyuren in systematischer Reihenfolge angeführt, und es ist bei jeder cinzelnen Art ihre Verbreitung in möglichst vollständiger Weise auf Grund der Litteratur angegreben. Alle zusammenfassenden Betrachtungen über die hier zusammengestellten Einzelbeobachtungen sind jedoch auf die späteren allgemeinen Kapitel verwiesen.

Da die Bezeichnungsweise der einzelnen Teile des Brachyurenkörpers bei verschiedenen Autoren eine wechselnde ist, so habe ich auf der letzten Tafel dieses Werkes eine schematische Abbildung mit Angabe der von mir benutzten Nomenklatur entworfen. Bei der WTahl der Namen für die einzelnen Teile des Körpers habe ich mich stets von praktischen Gesichtspunkten leiten lassen, wenn unter mehreren gebräuchlichen Bezeichnungen eine auszuwählen war.

Die Abkürzungen der Litteraturcitate finden ihre Erklärung in einem Verzeichnis, welches am Schluß dieses systematischen Teiles angefügt ist.

Das von mir zur Anwendung gebrachte System ergiebt sich aus der nachfolgenden Uebersicht:

Klasse: Crustacea.

Unterklasse: Malacostraca.

Ordnung: Decapoda.

I. Unterordnung: Natantia (Caridea).

II. Unterordnung: Reptantia.

I. Tribus: Eryonidea.

II. Tribus: Loricata.

III. Tribus: Nephropsidea.

IV. Tribus: Thalassinidea.

V. Tribus: Paguridea.

VI. Tribus: Galatheidea.

VII. Tribus: Hippidea.

VIII. Tribus: Brachyura.

I. Subtribus: Dromiacea.

II. Subtribus: Oxystomati.

III. Subtribus: Brachygnatha. 
Ich glaube, daß sich durch eingehendes Studium der zahlreichen Tribus der Reptantia eine weitere Gruppierung derselben ergeben wird, so daß sich das System wiederum vereinfachen lassen wird. Das etwas umständliche, oben skizzierte System giebt aber ein vollkommeneres Bild unserer gegenwärtigen Kenntnisse der Unterordnung der Reptantia, als ein in künstlicher Weise vereinfachtes System. Beim Unterricht von Anfängern in der Zoologie wird man das praktische MILNe-EDWARDs'sche System nicht missen wollen; bei der wissenschaftlichen Arbeit würde es aber ein Hindernis sein, wollte man die trennenden Spalten künstlich überbrücken. Hier müssen wir vorläufig trennen und sauber auseinanderhalten, was wir in Zukunft vielleicht wieder vereinigen dürfen.

\section{Dromiacea.}

\section{Gattung Homolodromia A. MiLne-Edwards.}

I880 Homolodromia A. Milne-Edwards, Bull. Mus. Comp. Zool., Vol. VIII, p. 32.

1884 Homolodromia A. Mirne-Edwards, Bull. Assoc. Sci. France, i883 (Décembre).

1897 Homolodromia E. L. Bouvier, Bull. Soc. Phil. Paris, Sér. 8, Vol. VIII, p. 37 ff.

1902 Homolodromia E. L. Bouvier, Mem. Mis. Comp. Zool., Vol. XXVII, p. 9, Taf. I.

\section{Homolodromia Bouvieri n. sp.}

Taf. V, Fig. I-3; Taf. XXXVIII, Fig. 9-I3; Taf. XLIII, Fig. $3^{1}$ ).

Die Gattung Homolodromia wurde von Milne-Edwards für eine Tiefseekrabbe aus den westindischen Gewässern aufgestellt, welche Bouvier (1897) als die primitivste bisher bekannt gewordene Dromiide und damit primitivste recente Krabbe erkannte.

Die „Valdivia“ fing eine nahe verwandte Art, welche leider - wie auch Homolodromia paradoxa M.-EDw. - nur durch ein männliches Exemplar vertreten wird.

Die Skulptur des Cephalothorax ist an meinem Exemplar nicht mit Deutlichkeit zu erkennen, denn der Cephalothorax ist so weich, daß er an manchen Stellen beim Fangen und Konservieren gefaltet und eingedrückt worden war.

$\mathrm{Ob}$ die Weichheit des Cephalothorax für Homolodromia Bonvieri wie für manche anderen Tiefseekrabben charakteristisch ist, oder ob es sich um ein frisch gehäutetes Exemplar handelt, kann ich nicht entscheiden, doch neige ich mich der letzteren Annahme zu, da auch die Extremitäten, besonders auch die Scheren, so weich waren, daß eine Benutzung derselben durch das Tier kaum möglich erscheint.

Auch außer der Skulptur des Cephalothorax waren manche Details des Baues infolge der Weichheit des- Stückes schwer zu untersuchen; dennoch gelang es mir, die Zugehörigkeit zur Gattung Homolodromia mit Sicherheit zu enveisen. Ich will nun zunächst die Diagnose der

I) Im systematischen Teil ist im allgemeinen nur auf die für die Systematik wichtigen Abbildungen verwiesen. Die zu jeder Art gehörigen Abbildungen aus sämtlichen Teilen dieses IVerkes sind am Schluß übersichtlich zusammengestellt. 
neuen Art geben, um sodann mit der senaueren Beschreibung eine Hervorhebung der Unterschiede gegenüber Dicranodromia, besonders D. Baffini (ALc. u. AxD.), sowie gegrenüber Homolodromia paradoxa M.-EDw. zu verbinden.

Homolodromia Bouvieri ist durch eine dichte filzige Behaarung des vorn abgerundeten, hinten gerade abgeschnittenen, länglichen Körpers ausgezeichnet. Das Rostrum besteht aus zwei flachen Spitzen, zwischen ihren Basen entspringt ein schmaler Wulst, welcher nach hinten bis zum Augensegment reicht (wie bei $H$. paradoxa). Die Furchen auf dem Cephalothorax sind nur sehr undeutlich zu erkennen, entsprechen aber anscheinend denjenigen von H. paradora. Doch schnüren sie den Cephalothorax bei wẹitem nicht so stark ein wie bei der atlantischen Art. Auch sind die Branchialregionen nicht so schr hervortretend. Der Seitenrand des Cephalothorax verlïuft ziemlich gleichmäßig. Eine Kante ist natürlich nicht vorhanden.

Jederseits ist ein krïftiger Anterolateralstachel vorhanden, welcher selbst einige kleine Zähnelungen aufweist.

Die Augenstiele sind lang und schlank; sie sind wenig beweglich und tragen eine kleine, vollkommen pigmentlose Cornea.

Die inneren und äußeren Antennen gleichen sehr denjenigen von H. paradoxa. Die inneren sind sehr lang und tragen ebenso wie die äußeren sehr lange Sinneshaare (s. Taf. XLIV, Fig. I u. 2 u. Taf. XLIII, Fig. 3). Näheres über die Sinnesorgane findet man unten im Abschnitt II dieses Werkes. Zur Seite nach außen von den äußeren Antennen befindet sich ein Antennalstachel, welcher aber nicht annähernd die Größe des Anterolateralstachels erreicht.

Die äußeren Gnathopoden sind fast noch schlanker als bei H. paradoxa. Die Kiemenformel ist dieselbe wie bei dieser Art (s. unten).

Die Scherenfüße sind etwas länger und kräftiger als bei H. paradoxa. Auch sind kcine Dornen auf ihnen erkennbar. Ebenso fehlen Dornen an den Meropoditen und Propoditen der Schreitbeine.

Die Beine sind sämtlich mit dichter filziger Behaarung versehen, welche an den distalen Gliedern abnimmt. Die Enden und die untere Seite der Scheren sind nur wenig behaart, so daß hier die körnelige Oberfläche frei zu sehen ist.

Auf dem Basopoditen des 5. Pereiopoden befindet sich neben der $\delta$ Genitalöffnung ein ventral emporragender spitzer Stachel.

Auch das Abdomen gleicht demjenigen von H. paradoxa; es ist aber wie die ganze Unterseite ebenfalls stark filzig behaart.

Ich habe oben schon erwähnt, daß ich zunächst versucht war, die mir vorliegende Art mit Dicranodromia Baffini (Alcock u. Axderson) zu identifizieren.

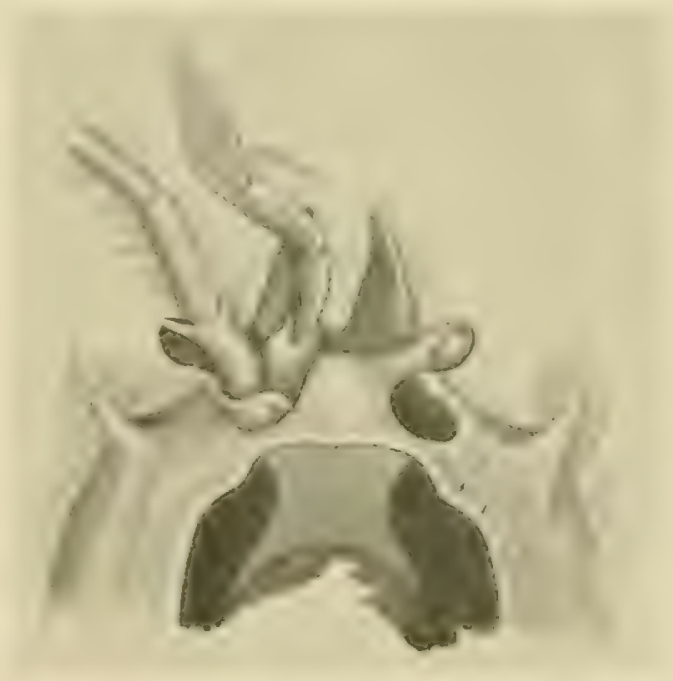

Fig. I. ITomolodromic Bowvieri Dort. Epistomialregion von unten.

Diese Art ist von ALcock eingehender beschrieben, und abgebildet worden unter dem Namen Arachnodromia Baffini ALc. u. AxD. (in: An account of the deep sea Brachyura collected by the R. Indian Marine Survey Ship Investigator, Calcutta 1899). Bouvier hat 1902 die Art zur 
Gattung Dicranodromia gezogen, was mir ganz berechtigt erscheint. Homolodromia Bouvieri unterscheidet sich von dieser Art nun sofort durch den Mangel von orbitaartigen Bildungen, ferner durch die bei weitem erheblichere Länge der 2. und 3. Pereiopoden. Diese stimmt mit Honolodromia paradora überein, weicht aber von dem Verhalten der Dicranodromien.ab. Als weiterer Unterschied kommt hinzu die geringe Ausbildung des Antennalstachels, die abweichende Gestaltung des Epistoms (Textfig. 1), die Kleinheit und Pigmentlosigkeit der Augen, sowie die schmaleren, mehr fußförmigen 2. Gnathopoden bei H. Bowvieri. Auch sind bei D. Baffni die Extremitäten gedrungener, die Dactylopoditen der 2. und 3. Pereiopoden kürzer, weniger gebogen und breiter, die Scherenfüße kürzer und plumper und schließlich die Endbildungen der 4. und 5. Pereiopoden nur subchelat, während bei H. Bouvieri deutliche kleine Scheren vorhanden sind.

Von Homolodromia paradova unterscheidet sich H. Bonvieri hauptsächlich durch die Form und Behaarung des Cephalothorax, den Mangel von Stachelbildungen auf den Extremitäten, die Kleinheit und Pigmentlosigkeit der Augen.

Im Nachfolgenden seien noch einige Details des Baues geschildert.

Die beiden Hörner des Rostrums sind dorsoventral stark abgeplattet. Eine Stirnfurche auf dem nicht mehr getrennten Teil des Rostrums ist trotz der Behaarung erkennbar. Die Anterolateralzähne sind kegelförmig, mit einigen feinen Dörnchen versehen. Auch sind sie gleich den Rostralhörnern stark behaart.

Die Cornea ist klein, weiß und bedeckt nur den vorderen Teil der Augenstiele.

Die inneren Antennen sind ähnlich denjenigen von $H$. paradoxa, doch ist ihr Basalglied noch etwas mehr erweitert, auch scheinen sie am Stielteil stärker behaart.

Die Geißeln der äußeren Antennen, welche im allgemeinen ganz mit denjenigen von H. paradoxa übereinstimmen, sind sehr lang, bei meinem Exemplar aber offenbar nicht ganz erhalten. Sie sind ziemlich gleichmäßig mit langen Sinneshaaren bedeckt (Taf. XLIII, Fig. 3).

Die Kauwerkzeuge weichen in einigen Punkten von denjenigen von $H$. paradoxa ab: an den 2. Gnathopoden ist die Verwachsungsstelle von Basopodit und Jschiopodit noch deutlich er kennbar. Die Ränder von Coxopodit, Basopodit, Ischiopodit und Meropodit tragen ziemlich starke Stacheln von Dornenform mit breiter Basis. Auch der Rand des Exopoditen ist mit solchen versehen (Taf. XXXVIII, Fig. Io).

Die 2. Gnathopoden sind, wie schon hervorgehoben, sehr schlank und nach dem Macrurentypus gestaltet.

Hervorzuheben ist ferner das Vorhandensein von zwei Podobranchien, sonst stimmen die Anhänge vollkommen mit denjenigen von $H$. paradoxa überein. Auf den I. Gnathopoden fällt die sehr starke Beborstung der Endglieder auf (Taf. XXXVIII, Fig. I I).

Besonders abweichend von derjenigen von $H$. paradoxa gestaltet ist die 3. Maxille. Der äußere Teil des Endopoditen und besonders auch derjenige des Exopoditen stellen breitere Lamellen dar; auch ist bei letzterem das I. Glied auffallend nach außen verbreitert (Taf. XXXVIII, Fig. I2). Auch bei der 2. Maxille sind die Teile anders gestaltet, soweit ich mein beim Präparieren leider etwas zerrissenes Exemplar ergänzen kann (Taf. XXXVIII, Fig. I3). Ebenso verhält sich die I. Maxille. 
Dic Kiemenformel ist folgende:

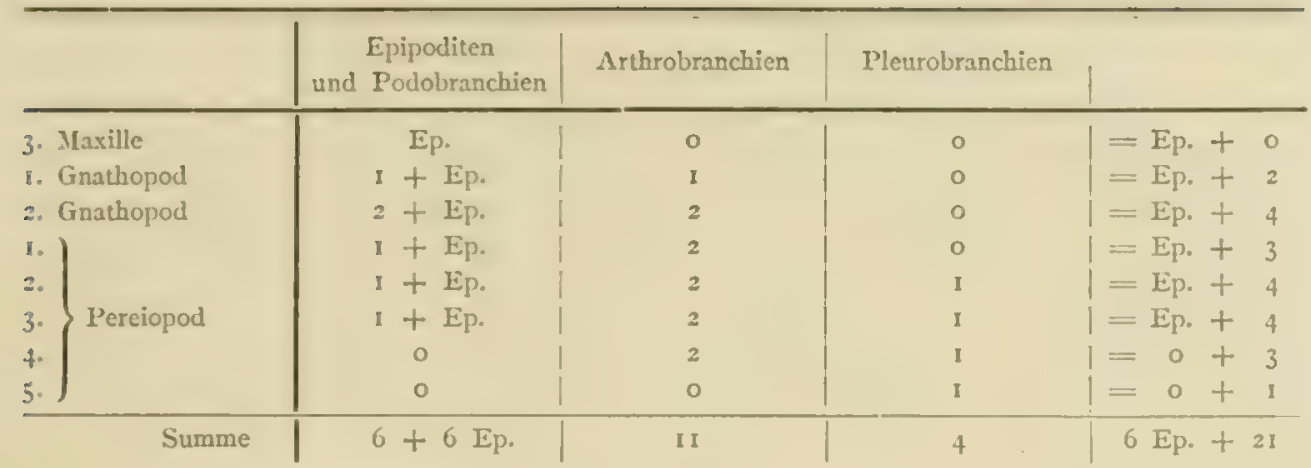

Die Kiemen bestehen aus $4-6$ Reihen von Filamenten.

Die Scherenfüße sind ziemlich lang, aber nicht sehr schlank. Die Finger sind nur halb so lang wie die Palma, beide gezähnelt und mit Riefen, welche von den Zähnen ausgchen, bedeckt. Leider sind die Finger bei meinem Exemplar beschädigt. Es hat aber offenbar der unberregliche mit 2 scharfen Spitzen den berreglichen umfaßt.

Das 2. und 3. Beinpaar ist lang und schlank; das 4. und 5. viel kürzer und dorsal verschoben.

Wie auf den Photographien Taf. V, Fig. I-3 deutlich zu sehen ist, sind die Scherchen des 4. und 5. Beinpaares zum Ergreifen von Gegenständen wohl geeignet. Sie sind fast genau so gebildet wie bei $H$. paradoxa. Das verdickte distale Ende des Propoditen ist zu einem schlanken Fortsatz verlängert, welcher mehrere Dornen trägt, zwei derselben sind meist größer als die anderen, und zwischen sie legt sich der Dactylopodit, welcher sehr scharf dornförmig und gekrümmt ist, als beweglicher Scherenfinger bei geschlossener Schere hinein.

Das Abdomen ist durch verlängerte Epimeren, welche sich untereinander nicht berühren, ausgezeichnet. Es ist genau so grebildet, wie Bouvier es für H. paradoxa schildert. Ebenso die Anhänge, wie die Narbe am 6. Glied. Die Genitalfüße des I. Paares sind etwas schlanker als bei $H$. paradoxa.

H. paradoxa wurde vom "Blake" bei Nevis (kleine Antillen) in einer Tiefe von $650 \mathrm{~m}$ gefangen.

Homolodromia Bonvicri erbeutete die "Kaldivia"-Expedition an der ostafrikanischen Küste in einer Tiefe von $863 \mathrm{~m}$, auf Station $247\left(3^{\circ} 38,8^{\circ} \mathrm{S} . \mathrm{B}_{\text {, }} 40^{\circ} 16,0^{\circ}\right.$ O. L. $)$.

Naße:

Länge des Cephalothorax . . . $18 \mathrm{~mm}$
Breite des Cephalothorax . . . . 10 "
Länge des 3. Pereiopoden . . . $45 "$
Lünge des Scherenfußes . . . $26 "$

Die übrigen Maße können direkt aus den Abbildungen Taf. V, Fig. I-3 entnommen werden, welche bei einer Vergrößerung von 2,1: I aufgenommen sind. 


\section{Gattung Dromia Fabricius. \\ Dromia bicornis (STUDER).}

Taf. VI, Fig. 3-5.

I882 Dromidia bicomis STUDER, in: Abhandlungen Berl. Akad., i 882 (I883), S. 20 (der Abhandlung), Taf. I, Fig. 9a u. b. I 888 Dromidia bicomis Hendersor, in: Challenger Anomura, p. I3.

Diese zierliche Art ist offenbar charakteristisch für die Region der Agulhasbank, in deren Bereich sie von der "Gazelle", dem "Challenger" und jetzt wiederum von der „Valdivia" erbeutet wurde.

Henderson hat der Beschreibung Studer's nichts hinzugefügt. Mir stehen etwas mehr Exemplare zur Verfügung. Ich kann daher STUder's Beschreibung in einigen Punkten richtigstellen und erweitern.

Die ungleiche Entwickelung der Stirnhörner, welche STuder für seine sämtlichen Exemplare konstatiert, ist offenbar eine Folge davon, daß dieselben sehr leicht abbrechen und heilen. Unter meinem Material finden sich sowohl Exemplare mit gleich großen Stirnhörnern, als auch solche mit verschieden großen. Bei letzteren ist aber stets das Ende des kürzeren Hornes abgestumpft und zeigt Spuren einer mit unvollständiger Regeneration verbundenen Heilung.

Der Cephalothorax ist auffallend kugelig; er ist, wie die Photographien auf Taf. VI, Fig. 3 u. 4 erkennen lassen, mit einem ziemlich langen, dichten Borstenkleid bedeckt, unter welchem, besonders bei jüngeren Exemplaren, ein kurzer Filz sichtbar wird.

Außer den Stacheln, welche in Gruppen am Vorderseitenrand stehen, lassen sich solche zerstreut auf der Oberfläche des Cephalothorax erkennen. Doch sind sie hier bei älteren Exemplaren nicht mehr zu finden.

Ebenso finde ich den oberen Augenhöhlenrand bei größeren Exemplaren nur an der äußeren Ecke mit Dornen besetzt, bei jüngeren finde ich Dornen auch am oberen Rand entlang. Der stark vorragende Zahn an der inneren Spalte des unteren Augenhöhlenrandes ist von oben sichtbar.

Die vorderen Beinpaare sind bei meinen Exemplaren stacheliger, als man nach Beschreibung und Abbildung von STUDER vermuten sollte.

Der Meropodit der I. Pereiopoden ist prismatisch mit abgerundeten Kanten. An den Kanten stehen Reihen von etwas stärkeren Dornen, während die Flächen nur einige zerstreute feine Dörnchen tragen, besonders die untere. Der Carpopodit zeigt distal oben und außen je einen kräftigen Stachel, einen schwächeren auf der Mitte der Innenseite. Außerdem sind noch unregelmäßig feinere Dörnchen verteilt.

Die Scheren sind seitlich ein wenig komprimiert, mit abgrundeten Kanten, an der Basis der Finger höher als am Carpalgelenk. Die Länge der Finger beträgt nicht ganz ein Drittel der Länge der ganzen Schere.

An der inneren oberen Kante steht eine Reihe von Dornen etwa bis zur Fingerbasis hin. Einige schwächere Dornen sind auf der Oberfläche der Scheren zerstreut. 
Die kräftigen, mit groben Zähnen besetzten Finger klaffen an der Basis weit auseinander. Die Spitze des unbeweglichen Scherenfingers ist grespalten, so daß die Spitze des beweslichen zwischen 2 Zacken hineingreift.

Von den hinteren Pereiopoden sind besonders der Carpopodit des 2. und 3. auf der oberen und äußeren Fläche bedornt. Die Endglieder derselben Beine sind kräftig und mit hornigrer Klaue versehen.

Der lange, rückwärts gerichtete Dorn an dem Coxopodit des 2. Pereiopoden beim $\delta$ ist sehr auffallend.

Die kleine Schere des 4. Pereiopoden zeigt kräftige Endklauen, besonders diejenige des beweglichen Fingers ist sehr lang und greift im weiten Bogen um diejenige des unberreglichen hinaus. Die Schere des 5. Pereiopoden ist ganz ähnlich gebildet.

Das Abdomen des $\delta$ ist 7 -gliedrig. Es ist an der Basis an beiden Seiten eingrekerbt, was dadurch zu stande kommt, daß das I. Glied sich von der Basis bis zum nächsten Gelenk ziemlich stark verschmälert, während das 2. Glied sich um ebensoviel in der gleichen Richtung verbreitert. Dadurch entsteht ein dreieckiger Ausschnitt beiderseits. Von da aus verlaufen die Konturen des Abdomens sanft konvergierend, bis das 7 . Glied als ungefähr gleichseitiges Dreieck mit einer aufgesetzten pfriemenförmigen, feinen Spitze abschließt. Die Mitte jedes Abdomengliedes ist gewölbt, die Seitenteile abgeflacht.

Das Abdomen des $q$ ist deckelförmig, stark gewölbt. Das I. Glied ist auffallend niedrig, das 2. sehr breit, dadurch wird die Form der ebenfalls vorhandenen Kerbe bestimmt. Auf der Oberfliiche besonders der letzten Glieder kann man ebenfalls eine Darmregion und hier sehr breite, gewölbte Seitenteile unterscheiden.

Unter dem Abdomen eines $q$ fand sich ein nicht zur Entwickelung gelangtes ovales Ei von $2 \mathrm{~mm}$ Lïngsdurchmesser. Sonst fanden sich keine Geschlechtsprodukte. - Beim ơ setzt sich das Vas deferens in Form eines starren Pfriemens bis zur Basis des 2. Thorakalfußes hin fort.

Die Augen sitzen auf ziemlich langen Stielen, welche seitlich in die Orbiten geklappt werden. Die Cornea ist klein, das Pigment dunkel.

Die äußeren Antennen sind am 2. Stielglied mit einem seitlichen Fortsatz versehen, die Geißel ist mit Härchen bedeckt.

Die inneren Antennen sind am I. und 2. Glied mit gefiederten Haaren bedeckt; die Sinneshaare der Endgeißel sind lang und fein.

Fundorte:

Station 93, vor Capstadt, $106 \mathrm{~m}$ Tiefe, $30^{*}, 33^{\circ} 43,6^{\circ} \mathrm{S} . \mathrm{Br}$., $18^{0}$ o, $3^{\prime} \mathrm{O}$. L.

Station Ioo, Francisbucht, Ioo m (?), 3 junge, 3 enwachsene, $34^{\circ} 8,9^{\prime} \mathrm{S} . \mathrm{Br}, 24^{\circ} 59,3^{\circ} \mathrm{O}$. L.

Station I13, Cap der guten Hoffnung, $318 \mathrm{~m}, 2$ o $^{\circ}$ f $34^{\circ} 33,3^{\circ} \mathrm{S} . \mathrm{Br}$, $18^{0} 21,2^{\circ} \mathrm{O}$. L.

Verbreitung: Cap der guten Hoffnung, immer nur in der nämlichen Gegend gefunden: $34^{\circ}$ 1 3,6 $6^{\prime} \mathrm{S} . \mathrm{Br} ., 8^{0}$ o, $7^{\prime} \mathrm{O}$. L., 2 I 4 m Tiefe („Gazelle“); Agulhasbank: $35^{\circ} 4^{\prime} \mathrm{S} . \mathrm{Br}$, I $8^{0} 37^{\prime} \mathrm{O}$. L. $274 \mathrm{~m}$ Tiefe („Challenger").

\section{Dromia spinosa (STUDER).}

Taf. VI, Fir. I u. 2.

Dromidia spinosa STUDER, Crustaceen der "Gazelle" von Westafrika, in Abhandl. d. Ij. pr. Ak. d. Wissenschaften zu Berlin 1882 , S. 22 (der Abh.) Fig. roa und b. 
Diese Art ist, soweit ich feststellen kann, erst einmal, und zwar von der "Gazelle“ in derselben Gegend gefunden worden; und zwar lag STUDER nur ein einzelnes Weibchen vor. Die „Valdivia“ erbeutete mehr von dieser Art, nämlich außer einigen zerrissenen Exemplaren 2 große Männchen und mehrere kleinere Weibchen in gut erhaltenem Zustand.

Diese großen $\delta$ weichen in mehreren Punkten von dem von STUDER beschriebenen $q$ ab. Besonders auffallend ist die starke Skulptur des Cephalothorax und die bedeutende Größe der Scherenfüße (siehe Taf. VI, Fig. I).

Die Länge des Cephalothorax des einen of beträgt $27 \mathrm{~mm}$, der Abstand der Spitzen der zweiten Seitenranddornen $28,5 \mathrm{~mm}$, die Länge der Scherenfüße ungefähr $75 \mathrm{~mm}$. Die übrigen Maße sind ja durch die Photographien Taf. VI, Fig. I u. 2 gegeben (Vergrößerung 2,25: r).

Durch die fast parallelen mittleren Teile der Seitenränder und den gerade abgestutzten Hinterrand erscheint der Umriß des Cephalothorax fast viereckig.

Außer dem Höckerchen an der Außenseite des oberen Augenrandes findet sich etwa in der Mitte des unteren ein starker Dorn. Der Querwulst hinter dem Cardialhöcker ist kräftig ausgebildet.

Das Abdomen zeigt die Seitenteile der Segmente deutlich abgesetzt. Das 2. bis 6. Segment zeigen in der Mediane je 2 Querwülste hinter einander, von denen der vordere beim 2. bis 4. Segment mehr höckerförmig ist. Das dreieckige 7 . Segment endigt mit einer pfriemenartigen Spitze.

Das Vas deferens setzt sich in Form eines langen, starren, pfriemenförmigen Gebildes über die Oberfläche des Basopoditen des 5. Pereiopoden hinaus fort; das Gebilde erreicht mit seiner Spitze den Basopoditen des 3. Pereiopoditen.

Fundorte:

Station 92, vor Capstadt, I $78 \mathrm{~m}$ Tiefe, 2 große 8 , 2 kleine $q$, I kleines + , $33^{0} 41,2^{\prime} \mathrm{S}$. Br. I $8^{\circ} 0,5^{\prime}$ O. L.

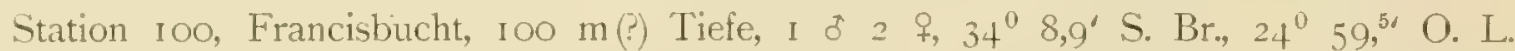

Verbreitung: Cap der guten Hoffnung, $34^{0}$ I $3,6^{\prime} \mathrm{S}$. Br., I $8^{0}$ O, $7^{\prime}$ O. L., $214 \mathrm{~m}$ Tiefe (,Gazelle").

Es ist bemerkenswert, daß wie von der "Gazelle“, so auch von der "Valdivia“ (auf Station 100) Dr. bicomis und spinosa am gleichen Orte vergesellschaftet gefunden wurden.

\section{Dromia allantica n. sp.}

Taf. VII, Fig. 3 u. 4 .

Es liegen mir von der Congomündung 2 Exemplare einer Dromia vor, welche ich mit keiner der bisher beschriebenen Formen identifizieren kann. ORTMLAN enwähnt in der Bearbeitung der Dekapoden der Planktonexpedition S. 53 eine Dromia, welche in einem Exemplar bei Ascension gedredgt wurde, und welche er für eine neue Art hält. Da das Exemplar ein Männchen war, verzichtete er auf eine Beschreibung. Möglicherweise ist es dieselbe Art, welche mir vorliegt, und zrar sind meine Exemplare ebenfalls $\delta$, und wahrscheinlich junge Tiere. Trotzdem wage ich es, die Art zu beschreiben, da ich der Ansicht bin, daß die beigegebenen Photographien (Taf. VII, Fig. 3 u. 4) eine Identifizierung stets ermöglichen werden. 
Dromia aflantica unterscheidet sich in auffallender Weise von den übrigen Formen der Gattung, besonders von. Dr. anulgaris und mumphii durch die Schlankheit des Umrisses, der Cephalothorax (mit dem Rostrum) ist so lang wie breit. Die Oberfläche desselben ist ziemlich glatt, nur die Cardiacalregion ist deutlicher ausgeprägt.

Die Stirn ist mit 2 spitzen 7ähnen bewaffnet; median zwischen ihnen, aber weiter unterhalb, findet sich ein dritter Zahn, welcher kürzer ist. Er schließt sich direkt an das Epistom an und sieht fast wie ein Fortsatz desselhen aus.

Die Orbiten sind ziemlich groß; in der Nitte ihres Oberrandes findet sich ein großer Zahn; die iußere Ecke ist nicht sehr scharf, ohne Zahn; am Unterrand befindet sich ein sehr spitzer langer Zahn vor dem Innenwinkel, welcher selbst ebenfalls zu einem Dorn ausgezogen ist.

Schief hinter demsellen steht auf dem Pterygrostom ein Zahn. Am Seitenrand sind 4 Zähne erkennbar, von denen die 3 vorderen spitz, gleich groß sind und etwa gleich weit voneinander entfernt. Der dritte steht am weitesten nach außen vor. Der vierte kleinere bezeichnet die Ecke des Hinterrandes.

Die Pterygostomialregion ist durch eine Längsnaht in 2 Teile greteilt, welche sich auch durch die Fïrbung in auffallendster Weise unterscheiden. Während der äußere Teil bei dem in Spiritus aufbewahrten Exemplar fast weiß ist, wie die Oberseite, ist der innere Teil dunkelbraun gefärbt. Es ist das auch deutlich auf der Abbildung Taf, VII. Fig. 4 zu erkennen.

Das Abdomen des $\delta$ reicht bis zur Basis der Scherenfüße. Die äußere Kontur des Abdomens zeigt an der Basis jederseits eine etwa dreieckige Einschnürung, welche durch die plötzliche Verschmälerung des niedrigen I. und die entsprechende Verbreiterung des 4mal so hohen 2. Gliedes bedingt ist. Das 3.-5. Glied zeigen eine allmähliche Verschmälerung. Alle zeigen deutliche Seitenteile und die durch den Verlauf des Darmes bedingte Erhebung des mittleren Teiles. Das 6. Glied ist etwas stärker verschmälert, während das 7. wieder etwas breiter ist. Letzteres ist ziemlich lang, länger als das 6., breit abgerundet. Die Telsoidschuppen an seiner Basis sind klein, spitzig und nach hinten gerichtet.

Vor dem Abdomen ist eine flache Platte des Sternums sichtbar, welche bis zur Basis der 2. Gnathopoden reicht. Sie besitzt fein gezähnelte Kanten und ist auf der Abbildung Fig. 4 deutlich sichtbar.

Die Beine sind sämtlich ziemlich kurz, mit scharfen Klauen versehen. Das I. Beinpaar mit der großen Schere ist das längste, das 4. das kürzeste. Der Meropodit des Scherenfußes ist an der unteren Seite mit einer gekörnelten Kante versehen, ebenso die Schere selbst.

Die Scherenfinger nehmen etwa $1 / 3$ der ganzen Scherenlänge in Anspruch.

Das ganze, hell gefärbte Tier ist mit kurzen Haaren bedeckt, welche aber keinen solchen Filz bilden wie bei Dromia vulgaris. Allerdings ist das eine Exemplar, welches in frisch gehäutetem weichen Zustande gefangen wurde, am ganzen Körper filzig, das andere, harte Exemplar entspricht aber der oben gegebenen Beschreibung und ist auch in den Figg. 3 u. 4 auf Taf. VII abgebildet.

2 d, Station $7 \mathrm{r}$, Kongomündung, in einer Tiefe von $44 \mathrm{~m}$. 


\section{Gattung Pseudodromia STInIPSON.}

I858 Pseudodromia Strmpson, Proc. Ac. Nat. Science Philadephia, p. 64.

I 888 Pseudodromia Henderson, Challenger Anomura, p. I5.

1892 Pseudodromia Henderson, Trans. Linn. Soc., Ser. 2, Vol. V, p. 406.

I899 Psendodromia Alcock, Journ. As. Soc. Bengal, Vol. LXVIII, II, p. I49.

I 900 Pseudodromia Stebing, Department of Agriculture, Cape of good Hope, Marine Investigations in South Africa South African Crustacea, p. 23.

igor Pseudodromia Ortmann, in: Bronn's Klassen 11. Ordnungen, Bd. V, II. Arthropoda, Crustacea, Malacostraca, p. I I 55 .

\section{Pseudodromia latens Stimpson.}

Taf. VIII, Fig. I-6.

I858 Psendodromin latens StIMIPSON, wie oben.

I888 Pseudodromia latens Henderson, wie oben, p. i6, Taf. I, Fig. 8.

Iq00 Pseudodramia latens Stebing, wie oben, p. 24.

Von dieser durch ihre biologischen Eigentümlichkeiten interessanten Form wurden je i $\delta$ und I $q$ von der Expedition an zwei voneinander entfernten Orten gefunden.

An beiden finde ich die von Sterbrng gegebene Beschreibung in allen wesentlichen Punkten bestätigt. Von geringen Abweichungen wäre zu bemerken, daß die Behaarung bei meinen Exemplaren nicht so lang ist, daß sie die Stirnzähne verbergen könnte. An dem länglichen Cephalothorax sind folgende Skulpturen erkennbar. Von der Mitte der Stirn läuft eine Furche nach hinten, welche sich auf der Regio protogastrica gabelt und dann verläuft.

Auf der Grenze zwischen der Regio gastrica und R. cardiaca liegen nahe der Medianlinie zwei porenartige Vertiefungen. Seitlich ist die Regio cardiaca sehr scharf durch 2 eigenartige tiefe Furchen abgegrenzt. Die Linea cervicalis ist schwach sichtbar. Auf der Hepaticalregion ist jederseits eine blatternnarbenähnliche Struktur erkennbar. Der Vorderseitenrand zeigt auf beiden Seiten nach dem Stirnzahn zwei stumpfe, zahnartige Vorragungen.

Der Cephalothorax des of ist $24 \mathrm{~mm}$ lang und $20 \mathrm{~mm}$ breit.

Wie schon die früheren Bearbeiter berichteten, steckt das Tier in einer Hülle, welche, wie Henderson und Stebbing richtig vermuteten, einer koloniebildenden Ascidie zuzuschreiben ist.

Die betreffende Art wird von Michaelsen in diesen Ergebnissen in der Abhandlung über die Ascidien der "Valdivia“-Expedition beschrieben werden. Er hat ihr den Namen Synandrocarpa domnucula Michaflsen gegeben. An dieser Stelle möchte ich auf den Bau dieser Ascidie nur so weit eingehen, als es zur Darlegung der Biologie von Pseudodromia latens notwendig ist.

Die Ascidie hat um die Dromia ein Gehäuse gebaut, welches annähernd kugelig gestaltet ist, und welches in seinem Aussehen an den Schwamm Suberites domuncula erinnert, welcher im Mittelmeer so häufig die jungen Dromia vulgaris umschließt.

Die Wand der Kugel ist durchaus nicht membranös, wie frühere Beobachter nach ihren offenbar schlecht konservierten Exemplaren meinten, sondern dick und fleischig, an dem einen meiner Exemplare, welches durchschnitten ist, 6- Io $\mathrm{mm}$ dick. 
Wic auf Fig. I der Taf. VIII zu erkennen ist, läßt die Umwachsung durch die Ascidic nur eine etwa dreieckige Oeffnung in der Gegend des Kopfes für Sinnesorgane und Mundöfnung der Krabbe frei.

Das Innere der Höhle, welche die Synandrocarpa gebildet hat, ist ganz ylatt, wie poliert, so daß die Pseudodromia offenbar recht gut in dem Gehäuse ihren Körper drehen und wenden kann.

In welcher Weise die allmähliche Umwachsung der Krabbe stattgefunden hat, ist an den Objekten nicht zu erkennen, Spuren einer früher vorhandenen Molluskenschale, welche etwa später wieder aufgelöst worden wäre, sind nicht zu erkennen.

Betrachten wir nun, welcherlei Anpassungen an die umschlossene Lebensweise der Körper der Krabbe zeigt oder, richtiger ausgedrückt, welche Baueigentümlichkeiten der Krabbe wir als zweckmäßig für diese Lebensweise erkennen können.

An den Rändern der Meropoditen der 2. Gnathopoden hat schon Stembing die lange, fransenartige Behaarung beobachtet, welche nach außen vorragt. Dieselbe wirkt offenbar wie eine Reuse für kleine Teile von organischer Materie; wir haben darin einen Apparat zu erkennen, wie wir ihn öfter bei Tieren finden, welche sich von kleinen Organismen ernähren, vergl. z. B. die Walbarten. Es ist wahrscheinlich, daß diese Einrichtung eine Anähnlichung der Ernährungsweise des einen Symbioten an seinen Genossen herbeiführt. Krabbe und Ascidie werden die gleiche Nahrungsart verwenden können, und die Nahrung herbeistrudelnde Bewegung des einen wird jeweils dem anderen nuitzen.

Die scharfen (gelb gefärbten) Krallen an den Pereiopoden werden der Krabbe vorzüglich dazu dienen, sich in ihrer wohnlichen Höhle festzuhalten. Dagegen bin ich im Zweifel, ob die Länge und eigenartige Form der 5. Pereiopoden vorwiegend dem Festhalten dient. Mir scheint es vielmehr, daß sie recht greeignet sind, dem Inwohner zu helfen, die Thüre seines Hauses jederzeit offen $z u$ halten und gegebenen Falles sich im eigentlichsten Sinne des Wortes aus seinem Hause zu "drücken“.

Die glatte Form des Cephalothorax sowie der Mangel an Ecken und Stacheln an ihm und den Extremitäten ermöglichen es der Krabbe jedenfalls auch, in ihrem Hause sich bewegen und nötigenfalls es verlassen zu können. Eine weitere nützliche Einrichtung zu diesem Zweck ist auch die tiefe Rinne, welche jederseits von der Intestinalregion schief nach vorn zum Vorderseitenrand läuft und, wie Henderson und Stebbing schon hervorhoben, den Carpopoditen der 5. Pereiopoden bei deren Ruhelage in sich aufnimmt.

Ueber die Sinnesorgane will ich an dieser Stelle nichts weiter envähnen, vergl. den Abschnitt über Biologie.

Das Abdomen des $q$ ist, wie auch sonst bei Dromiiden, relativ schmal und offenbar nicht genügend, um die Menge von Eiern, welche das Tier hervorbringt, zu bedecken. Dafür ist durch folgende Einrichtung gesorgt, welche Stebing schon untersuchte, und mit den Worten schildert:

„In the female, the first pleopods are small, uniramous, cylindrical, apparently seven-or eight-jointed, but the articulation very indistinct. The next four pairs are biramous, the outer branch long, laminar, the first joint curved, narrowest at the two ends, inner surface concave, longer than the remaining joints together, these being flat, eight to ten in number, successively narrowing, the whole branch fringed with long plumose setae, more densely on the outer than 
on the inner margin; the inner branch cylindrical, narrow, of twelve or fourteen joints, of variable length, carrying long setae, chiefly on the distal half of each joint. When the pleon of the female is distended with a multitude of eggs, the outer rami of these pleopods, especially those of the second and third pair stand out from the segments clasping round the brood", vergl. Taf. VIII, Fig. 5.

$\mathrm{Ob}$ wir auch in dieser Einrichtung eine Anpassung an Besonderheiten der Lebensweise erblicken dürfen, muß dahingestellt bleiben. Jedenfalls gehört diese Ausbildung des Brutpflegeapparates $z u$ den interessantesten, welche wir bei den Krabben kennen lernen. Die vielen kleinen und großen Abänderungen, welche an Sternum und Abdomen der Krabben immer wieder in hundertfältiger Form dasselbe Thema variieren und stets die wechselnden Schwierigkeiten der Brutpflege überwinden, verdienen die größte Bewunderung des Naturforschers.

Das mir vorliegende Männchen zeigt eine interessante Monstrosität. Es ist nämlich die Fingerpartie der Schere verdoppelt. Auf diese Mißbildung werde ich im Abschnitt III dieses Werkes zurückkommen.

I o Station 243, bei Dar-es-Salaam, $6^{0} 39$, I $^{\prime} \mathrm{S} . \mathrm{Br}$, $39^{\circ} 30,8^{\prime} \mathrm{O}$. L., in einer Tiefe von ca. $400 \mathrm{~m}$.

I \& Station 700, Francisbucht, Capland, $34^{\prime \prime} 8,9^{\prime} \mathrm{S} . \mathrm{Br}, 24^{\circ} 59,3^{\prime} \mathrm{O}$. L., in einer Tiefe von ca. IOO $\mathrm{m}$.

Verbreitung: Capregion: Simonsbai, 20 m (Stmpsox, Hendersor); False Bay, 50 m (STERBING).

Die geographische Verbreitung dieser Form verdient insofern erörtert zu werden, als der Fundort für das von der „Valdivia"-Expedition erbeutete o ein sehr auffallender ist. Wir wissen, daß im allgemeinen die Capregion in ihrer marinen Fauna viele Besonderheiten zeigt; und wie besonders ORTMiann hervorgehoben hat, liegt die Grenze zwischen indopacifischen und capischen Formen entsprechend einer Stromgrenze in der Nähe von Port Elizabeth (vergl, hierzu auch Abschnitt IV dieses Werkes). Es ist infolgedessen zunächst auffallend, die gleiche Form an zwei so weit voneinander entfernten Punkten der gleichen Küste unter ganz verschiedenen Klimaten und in ganz verschiedenen Gebieten zu finden.

Erwägen wir aber, daß die marine Fauna der Capregion außer atlantischen und eigenen, resp. antarktischen Elementen auch indopacifische Beimischungen enthält; ferner, daß die Gattung Pseudodromia nach den anderen von Henderson und Alcock beschriebenen Formen eine hauptsächlich indopacifische und tropische Gattung zu sein scheint, so ist wohl der Fund der Art an der deutsch-ostafrikanischen Küste durch die „Valdivia“-Expedition so auszulegen, daß wir die Gattung Pseudodromia als einen indopacifischen Anteil der Capfauna anzusehen haben.

Er stellt also eine interessante Bereicherung unserer Kenntnisse von der Verbreitung der Gattung Pseudodromia und von der Zusammensetzung der Capfauna dar.

\section{Gattung: Homola LEACH.}

\section{Homola barbata orientalis HENDERSON.}

Synonymie: a) für Homola barbata FABRICIUS.

I793 Cancer barbaius FABRICIUs, Ent. Syst., Vol. II, p. 460, No. 76. 
I 706 Cancer barbans Heknst, Krabben und Krebse, Taf. XLII, Fig. 3.

1815 Dorippe spinifrons L.ıM.ıkck, Hist. nat. des anim. sans vert, Vol. V, p. 245.

1815 Homole spinifrons Lexci, Zool. Miscell., Vol. II, Taf. LXXXVIII.

188 I Homoli barbata S. I. Smiti, Proc. U. S. Mus., Vol. III, p. 420.

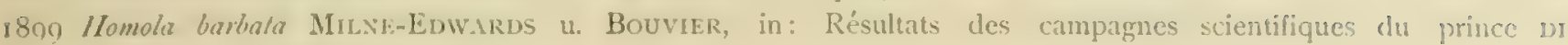
Moxico Tome XIII, p. II.

1000 Homola barbala Milxi-Enwards u. Bouvisk, in: Expéditions scientifiques du Travailleur et du Talisman Crustacés décapodes, I., p. ro.

Ino2 Homola barhah Milne-Edwaids u. Bouviek, in: Mem. Mus. Comp. Zonl. Harvard, Vol. XXVII, p. 26. 1002 Llomola borbata Stenmisg, South African Crustacea, Vol. II, p. 22.

An letzteren Orten weitere Litteratur; so auch unter Homola spinifrons bei ORTMANs, in \%onl. Jahrb. Syst. Vol. VI, I 902, p. $5+2$.

b) für sbsp. orientalis HeNDERSON.

1888 IJomola orientalis Hexperson, in: Challenger Report, Anomura, p. I9, Taf. II, Fig. I.

1880 Homola andamanica Alcock, in: Investigator Deep-Sea Brachyura, 1) 7.

1809 I1omola andamanica ALCock, in: Illustrations Zool. Investigator, Crustacea, Taf, XL, Fig. I.

I 899 Homola andamanica Arcock, in: Journ. Asiatic Soc. of Bengal, Vol. LXVIII II, p. I56.

1002 IJomole orientalis Dolles, in: Abh. K. bayr. Ak. Wiss. II. Kl., Bd. 2 I, III. Abt., p. 65I, Taf. IV., Fig. 5 u. 6.

Es liegt mir von der indopacifischen Form der Homola barbata FABricius ein Exemplar von der "Valdivia“-Expedition vor, welches derselben Gegend entstammt, wie die von Alcock beschriebenen Stücke von Homoia andamanica. Ein genauer Vergleich mit der Beschreibung Alcock's zeigt die Uebereinstimmung meines Exemplares mit seiner Diagnose und Abbildung. Ebenso zeigte ein genauer Vergleich mit den von mir früher beschriebenen, im Münchener Museum befindlichen Exemplaren von $H$. orientalis, daß sich keine Unterschiede zwischen beiden Formen auffinden lassen. Die Abbildung bei HeNDERson ist offenbar sehr schlecht ausgefallen; da auch die Abbildung in meiner früheren Abhandlung nicht gut ist, so gebe ich hier auf Taf. V nebeneinander Bilder eines Exemplares aus dem Meerbusen von Bengalen (Fig. 5) und eines solchen aus Japan (Fig. 5).

Ferner habe ich Exemplare von Homola barbata typica des Münchener Museums verglichen. Aus den Figuren kann man mit Deutlichkeit ersehen, daß es, im Grunde genommen, nur die Stacheln am Hinterrande des Meropoditen såmtlicher Pereiopoden sind, welche die indopacifische Form von der mediterranen unterscheiden.

Von geringeren Abweichungen, welche sich feststellen lassen, hebe ich noch folgende hervor: typica hat am 2. Glied des Stieles der äußeren Antemen vorn außen einen Stachel, welcher bei orientalis fehlt oder nur angedeutet ist. Einen erheblichen Unterschied in der Cornealregion der Augenstiele kann ich nicht erkennen. Bei meinen indopacifischen Stücken ist der Rand des Mundfeldes etwas schärfer, die Kerbe in der Mitte vorn etwas enger als bei typica. Der Epistomstachel ist bei beiden Formen gut entwickelt.

Da wir praktisch die Zugehörigkeit zu einer Art nur auf diejenigen Individuen ausdehnen dürfen, welche in allen Merkmalen übereinstimmen, oder deren etwaige Abweichnungen bei Untersuchung zahlreicher Individuen sich durch Uebergänge mit der Stammform verbunden zeigen, so wäre die Unterscheidung beider Formen als Arten zu verteidigen. WVenn wir überlegen, daß das einzige unterscheidende Merkmal ein sehr unwesentliches ist, so erscheint es richtiger, beide nur als Formen durch ternäre Nomenklatur zu unterscheiden. 
Wir wissen nämlich, daß bei den Crustaceen die Bestachelung z. B. bei jungen Tieren oft sehr abweicht von derjenigen der Erwachsenen. Ferner habe ich Anhaltspunkte dafür, daß das Vorkommen in der Tiefe die Ausbildung eines reicheren Stachelkleides begünstigt. Ferner ist durch Untersuchungen festgestellt, daß bei Crustaceen Verschiedenheit im Salzgehalt des Mediums von Einfluß auf die Ausbildung der Stacheln sein kann. Alle diese Dinge weisen darauf hin, daß es sich bei den Formen von Homola barbata wohl um Verschiedenheiten handeln kann, welche durch die Unterschiede in den Lebensgewohnheiten und im Aufenthaltsorte bedingt sein können. Es könnte sich also wohl um Standortsvarietäten handeln.

Ich fasse also die Formen zu einer Art zusammen. Auch Alcök hat bei Beschreibuug seiner H. andamanica vermutet, daß es sich nur um eine Varietät von bar-bata handele. Dagegen sind die beiden Arten $H$. vigil M.-EDw. und H. megalops ALc. wohl sichere Arten.

Das einzige von der "Valdivia"-Expedition mitgebrachte Exemplar ist ein kleines of von Station 193.

Es wurde am I. Februar in einer Tiefe von $132 \mathrm{~m}, 9$ Seemeilen südlich von P. Nias (NW. von Sumatra) gefangen.

Ve'rb reitung der var. orientalis: Indischer Ocean: Andamanensee, I44-I65 m (ALcock); Stiller Ocean: Kleine Key-Insel, 256 m, Zebu, Philippinen, i 74 m (Hendersox); Japan, Sagamibai (DofLeIN).

\section{Homola (Paromola) profundorum Alcock u. ANDERSON.}

$$
\text { Titf. VII, Fig. I } 11.2 \text {. }
$$

Homola profundorm Alcock u. AxDersox, Annals and Magazine of Natural History, i899, p. 5.

Homola profundonum Alcock, Investigator Deep-Sea Brachyura, Calcutta 1899, p. IO, Taf. I, Fig. 2.

Homola (Paromola) profundorum Alcock, Materials for a carcinological Fauna of India. No. 5. The Brachyura primigenia or Dromiacea, in: Journ. Asiatic Society of Bengal, Vol. LXVIII, II, I899, p. I59.

Von dieser Art waren bisher nur 3 junge Weibchen durch den „Investigator“ belannt geworden. Die „Valdivia“ erbeutete ein bedeutend größeres Männchen in der Nähe der ostafrikanischen Küste. Alcock vermutet eine nahe Verwandtschaft mit Homola Cuvvieri Risso. Bisher sind von H. profundom nur kleine Exemplare erbeutet worden, während mir im Münchener Museum nur sehr große Exemplare von H. Cuvieri zum Vergleich zur Verfügung stehen. Somit kann ich der Frage nicht näher treten, ob es sich eventuell nur um eine Varietät der Mittelmeerform handelt.

Die Form des Cephalothorax des mir vorliegenden o ist etwas weniger schlank als bei den jungen + , welche ALcock beschreibt. Das Rostrum ist im Verhältnis zur Körperlänge kürzer, indem es nicht ganz $1 / 4$ der Länge des übrigen Cephalothorax erreicht. Dasselbe gilt für die beiden zur Seite des Rostrums befindlichen Dornen. Antennal- und Hepaticaldorn sind gut entwickelt, ebenso der Zahn in der Mitte des Seitenrandes.

Die Skulptur des Cephalothorax ist sehr deutlich ausgeprägt, besonders die Linea anomurica und homolica. Das, feine samtartige Haarkleid, welches den Cephalothorax überzieht, ist so zart, daß es keine Unebenheit verdeckt.

Die Augenstiele sind ziemlich kurz und dick. Die Pigmentierung der Cornea ist nur in Form eines dunklen Kranzes sichtbar, während der centrale Kreis weiß erscheint (ob Artefakt durch die Konservierung?). 
Die Scherenfüße entsprechen der Beschreibung Alcock's, nur sind die sämtlichen Stacheln stärker ausgebildet. Auf dem 'Carpopodit findet sich innen und außen je eine Reihe von Domen. Außen ist der letzte Dorn, innen die beiden letzten durch Größe ausgezeichnet. Die Finger sind bei meinem Exemplar dunkel gefärbt.

Wie Arcock schon hervorhob, sind die Endbildungen der 5. Pereiopoden eher chelat als subchelat; sie stellen sehr wohl zum Greifen geeignete Zangen dar.

Das 7-gliedrige Abdomen ist lanzettförmig; am I.-6. Glied ist deutlich die Röhre für den Darm median erkennbar. Der Rand ist ringsum etwas erhoben. Nach dem schmalen, etwa quadratischen 1. Glied verbreitert sich der Umriß bis zum 5. Glied, das 6. ist ein wenig, das 7. bedeutend verschmälert. Auf dem I. Glied sitzt median ein kleiner Stachel; das 7. Glied ist fast umgekehrt herzförmig.

Die Genitalfüße sind sehr ungleich; die vorderen dick und zu einer Röhre gerollt, die hinteren viel dünner und griffelförmig.

I $\delta^{\prime}$, Station 258, ostafrikanische Küste, $2^{0} 5^{8,5^{\prime}} \mathrm{N}$. Br., $46^{\circ} 5^{\circ}, 8^{\circ} \mathrm{O}$. L., in einer Tiefe von $1362 \mathrm{~m}$.

Verbreitung: Indischer Ocean: Travancore-Küste (westlich von der Südspitze Vorderindiens), $786 \mathrm{~m}$ (ALcock).

\section{Gattung Hypsophrys WoOd-Mason.}

I801 Ann. MIag. Nat. Hist., ser. VI, Vol, 7, p. 269.

\section{Hypsophrys longipes AlCOCK u. ANDERSON.}

Taf. NI, Fin. I L. 2.

1899 Aicock u. Axderson, Ann. Mag. Nat. Hist., ser. VII, Vol. 3, p. 6.

1899 Alcock, Investigator Brachy'ura, p. I5, Taf. I, Fig. I.

1899 Alcock, Materials for a carcinological Fauna of India. No. 5. The Brachyura primigenia or Dromiacea, in: Journ. Asiatic Soc. of Bengal, Vol. LXVIII, II, p. I64.

Die Gattung Hy'psophry's steht Homola sehr nahe; immerhin unterscheiden sich die beiden bekannten Arten durch eine ganze Reihe von Merkmalen von Homola, so daß es angebracht ist, die Gattung vorläufig aufrecht zu erhalten. Ist doch die Schaffung zahlreicher Gattungen stets im Interesse der Uebersichtlichkeit und dabei von geringerer theoretischer Wichtigkeit.

Nach der Aufzählung von Alcock sind folgende Unterschiede bei Hysopliry's gegrenüber Homola zu konstatieren:

I) sind die Augenstiele ähnlich denen von Dromia, indem das lange Basalglied, wie es bei Homola vorhanden ist, bei Hypsophry's fast ganz fehlt; ich finde trotzdem die Augen mehr denen von Homola als von Dromia ähnlich. Man vergleiche hierzu auch die Angaben im Abschnitt über Biologie;

2) sind die Flächen, gegen welche die Augen sich zurückschlagen, schon etwas grubenartig gestaltet, bilden einen Uebergang zu den entsprechenden Bildungen bei Dromia;

3) sind die 2. Gnathopoden auffallend beinartig gebildet, indem der Meropodit noch schmaler ist als bei Homola; 
4) und dies ist eigentlich der auffallendste Unterschied, sind die Scherenbildungen der 5. Pereiopoden abweichend gestaltet. Während bei Homola der Propodit kurz, manchmal fast dreieckig ist, gegen welchen sich ein ziemlich ansehnlicher Dactylopodit zurückschlägt, finden wir bei Hypsophry's einen dünnen, schlanken, langen Propodit, dessen distales Ende nur wenig verbreitert ist; gegen das letztere schließt der ganz kleine Dactylopodit, welcher fast nur so lang ist, wie der Propodit breit. Doch bilden die chelaten Bildungen an den 5. Pereiopoden von Homola profundomm, megalops, barbata eine Reihe, welche zu einer Ausbildung, wie sie bei Hypsophry's vorliegt, hinführt.

Bei Hypsophry's longipes fällt an meinen noch kleinen Exemplaren die relative Größe der wohlpigmentierten Augen auf. Bemerkenswert ist auch die Größe der Basalglieder der inneren Antennen.

Die Finger der Schere sind an den Spiritusexemplaren blaßbraun gefärbt.

Die Dactylopoditen der Pereiopoden 2-4 sind sensenklingenförmig, flach und relativ breit. Vielleicht ist das Tier mit ihrer und der langen Beine Hilfe im stande, sich zeitweise im Wasser schwebend zu erhalten.

Beide Exemplare, welche mir vorliegen, sind klein, jedenfalls noch nicht erwachsen.

I ô, Station 2I I, Westeingang des Sombrero-Kanals (Nikobaren), $805 \mathrm{~m}$ Tiefe.

I + , Station 185, Westküste von Sumatra, Höhe von Benkulen, $614 \mathrm{~m}$ Tiefe.

Verbreitung: Indischer Ocean: bei der Küste von Travancore (westlich der Südspitze von Vorderindien), $786 \mathrm{~m}$ Tiefe (Ацсоск).

\section{Gattung Homologenus Henderson.}

I 888 Hexdersox, Challenger Anomura, p. 20.

\section{Homologenus Braueri n. sp.}

Taf. XI, Figr ì u. 4 .

Die Gattung Homologennes ist bisher durch eine Art vertreten, von welcher 4 Exemplare bekannt geworden sind. Es ist dies Homologenus rostratus MrLne-Edvards, von welcher Art die "Blake" ein kleines o und der "Talisman" ein o und ein $q$ erbeutete (s. Mem. Mus. Comp. Zool. Harvard, Vol. XXVII, I902, p. 29, und Expéditions scientifiques du Travailleur et du Talisman, Crustacés décapodes, Paris i900, I, p. I I, beide von Minne-Edvirds und Bouvier). Außerdem enthalten die Sammlungen des Fürsten vox Monaco ein Exemplar (ठ) [Résultats des campagnes scientifiques par Alpert I prince de Monaco, Fasc. XIII, Crustacés décapodes, par Minne-Edwards et Bouvter, i 899]. In Bezug auf das von Henderson beschriebene, aber keiner bestimmten Art zugeteilte Stück (Challenger Anomura, I888, p. 2 I) schließe ich mich der Meinung von Milne-Edwards und Bouvier an, welche die Zugehörigkeit zur Gattung Homologemus bezweifeln.

Während die bisher bekannten Stücke sämtlich aus der Tiefe des Atlantischen Oceans stammen, ist das „Valdivia“-Exemplar der Gattung an der ostafrikanischen Küste erbeutet worden. Zudem weicht es in einer Reihe von Merkmalen ab, so daß mir die Aufstellung einer neuen Art notwendig erscheint. 
Die auffallendsten Merkmale, welche H. Braueri von $H$. rostratus unterscheiden, sind folgende:

I) Der Cephalothorax ist etwas schlanker:

\section{H. rostratus H. Braneri}

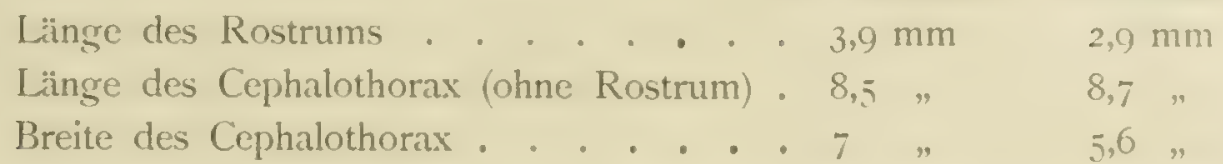

aber infolge des kürzeren Rostrums macht er eher einen gedrungeneren Eindruck.

Die an der Basis des Rostrums befindlichen Dornen stehen dichter an demselben, so daß sie zu demselben zu gehören scheinen.

2) Der ganze Körper und die Extremitäten sind weniger stachelig als bei H. rostratus. Der Cephalothorax zeigt außer einigen großen Stacheln nur Körnelung, die Pereiopoden 2-5 zeigen nur vereinzelte Stacheln.

3) Es sind weniger große Dornen auf der Dorsalfläche des Cephalothorax vorhanden (s. unten); so fehlen z. B. die Stacheln auf der hinteren Branchialregion.

4) Es ist die Schere am 5. Pereiopoden etwas anders gestaltet als bei rostratus, indem die Stacheln an der Basis des Propoditen fehlen.

Gehen wir zur Betrachtung der Einzelheiten über, so ist zunächst hervorzuheben, daß der vordere Teil des Cephalothorax schlank ist, die Auftreibung der Branchialregion beginnt erst hinter dem großen Seitenstachel und ist daher auffälliger als bei H. rostratus.

Die Oberseite des Cephalothorax ist fein gekörnelt, die Körner sind abgerundet, zeigen keine Neigung, in Stacheln überzugehen; außerdem finden sich einige längrere Hatare auf der vorderen Region des Cephalothorax.

Von den Stachelbildungen des Cephalothorax sind die auffallendsten die großen Stacheln, welche ganz vorn auf den Seiten der Branchialregionen, unmittelbar hinter der Linea anomurica stehen. Sie sind an der Basis ziemlich stark, haben ungefähr die Länge des Rostrums und sind seitlich und nur wenig nach vorn gerichtet. Zwischen diesem Branchialstachel und dem Stachel an der Basis des Rostrums befinden sich 2 Stacheln, welche beide relativ kürzer sind als die entsprechenden bei $H$. rostratus. Der innere davon, welcher nach vorn, außen und ziemlich stark nach unten gerichtet ist, befindet sich an der Basis der äußeren Antennen: es ist der Antennalstachel; etwas außer- und oberhalb sitzt der zweite, der Vorderseitenrandstachel, welcher nach vorn und außen gerichtet ist.

Mitten auf der Gastralregion befindet sich ein ziemlich ansehnlicher Stachel, welcher senkrecht in die Höhe ragt. Sonst befinden sich oben auf dem Cephalothorax keine weiteren Stacheln. Es fehlen also die bei rostratus vorhandenen Stacheln auf der hinteren Branchialgregrend, die Epigastricalhöcker und die postfrontalen Dornen. Vielleicht entsprechen den letzteren ein Paar etwas größere Körner auf den Postfrontalregionen. Ein ähnliches Paar findet sich ganz hinten auf dem Cephalothorax zu beiden Seiten der Cardialregion.

Auf der Pterygostomialregion finden, sich zwei Reihen von kleinen Stacheln, von denen die eine vom Antennalstachel sich ziemlich gerade nach hinten erstreckt, die andere rom Anterolateralstachel aus nach hinten fast eine Kreislinie beschreibt.

Auf dem unteren Teil der Branchialregion fällt nur ein größerer Stachel auf. 
Die Linien und Furchen auf dem Cephalothorax scheinen mir weniger scharf ausgeprägt als bei rostratns, soweit ich nach den Abbildungen urteilen kann. Die Linea anomurica ist deutlich, sonst sind aber die Regionen nicht sehr deutlich abgegrenzt.

Von dem Gastricalstachel aus fällt der Cephalothorax nach vorn steil ab, in gleicher Richtung ist das Rostrum steil abwärts geneigt. Von dem Stachel aus zieht sich eine Furche abwärts, welche sich auch auf das Rostrum fortsetzt, und dieses dadurch in seinen beiden hinteren Dritteln etwa rinnenförmig gestaltet. Auf dem Rande der Rinne stehen in der Nitte des Rostrums ein Paar Stacheln von ansehnlicher Länge, und an der Basis das schon erwähnte Paar von Stacheln. Wie bei rostratus biegt sich das Rostrum vor den Stacheln in seinem vorderen Ende noch stärker abwärts; ebenso ist die Stirn sehr schmal, indem der Cephalothorax unmittelbar neben den Basalstacheln des Rostrums steil zum Antennalstachel abfällt.

Die Verhältnisse der Orbiten- und Antennenregion sind ganz entsprechend rostratus. Die Augen ragen trotz ihrer kurzen Stiele weit vor. Die Konfiguration der Augen erinnert bei der Gattung, wie schon Bouvier hervorhebt, sehr an die Verhältnisse bei Hypsophry's. Die Augen sind deutlich dunkel pigmentiert.

Auch die äußeren und inneren Antennen sind im allgemeinen so wie bei rostratus, doch ist die Geißel der ersteren nicht nackt, sondern mit deutlichen langen Sinneshaaren an jedem Glied versehen.

Da mir nur ein Exemplar vorliegt, habe ich die Endostomverhältnisse, Kiemen und Mundgliedmaßen nicht genauer untersucht. Soweit ich es jedoch ohne Verletzung des Exemplares thun konnte, fand ich Uebereinstimmung mit rostratus.

Die 2. Gnathopoden zeigen wie bei rostratus auf den einzelnen Gliedern Dörnchen, doch sind dieselben offenbar viel feiner.

Die Extremitäten sind ganz allgemein weniger reich an stachelartigen Haaren als bei rostratus. Dies fällt vor allem an den Scherenfüßen auf, welche im allgemeinen in der Form an diejenigen von rostratus erinnern.

Der Meropodit zeigt nicht den starken Dorn am distalen Ende wie bei rostratus. Der Carpopodit ist etwas stärker geknickt und zeigt außer einigen kleineren Dornen einen starken Stachel an der oberen vorderen Ecke. Die Finger sind etwa ebenso lang wie die Palma. Die ganze Schere ist in der Längsachse nach innen etwas gekrümmt.

An den übrigen Pereiopoden sind auffallend die beiden Stacheln oben und unten am distalen Ende der Meropoditen.

Das Abdomen des mir vorliegenden $q$ ist in der allgemeinen Form entsprechend dem Typus der übrigen Homoliden. Das kleine I. Glied besitzt einen Höcker auf der Mitte, das 2. einen spitzen Stachel an derselben Stelle. Das 3. und 4. Glied besitzen nach außen stark vorspringende Ecken. Ebenso sind die vorderen Ecken des 5. Gliedes etwas stachelartig. Das 6. Glied hat von allen die größte Länge; es ist am Hinterrande viel schmäler als am Vorderrande, indem es zu dem kleinen, herzförmigen Telson zuläuft.

Durch die mittleren Glieder schimmert der.Darm durch. Symmetrisch zu ihm befinden sich auf dem 4. und 5. Glied seitlich 2 Höcker, welche auf dem 5. ziemlich spitz sind.

Mein Exemplar ist ein + von der Station 262, nahe der ostafrikanischen Küste, bei Somaliland, $4^{\circ} 40,8^{\circ} \mathrm{N}$. Br., $4^{\circ} 39,0^{\circ} \mathrm{O}$. L., aus einer Tiefe von $124^{2} \mathrm{~m}$. 
Die Form steht jedenfalls Homologemus rostratus sehr nahe. Die meisten bisher bekannt gewordenen Stücke scheinen mir wie auch meines keine erwachsenen Tiere zu sein. Mein Exemplar ist das erste der Gattung, welches außerhalb des Atlantischen Oceans gefunden wurde. Bemerkenswert ist, daß die Gattung nur in Tiefen von über rooo $\mathrm{m}$ grefunden wurde. Die Fundorte von Homologemus rostratus sind bisher gewesen:

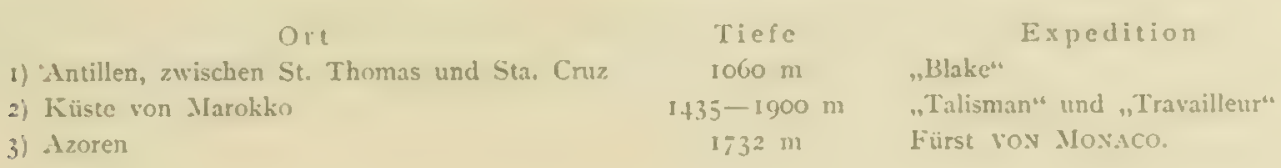

\section{Genus Homolochunia nov. gen.}

Die Familie der Latrillidac enthält bisher 2 Gattungen:

1) Latreillia Roux,

2) Latreillopsis HENDERson.

Latrillia ist ausgezeichnet durch den lang ausgezogenen, fast cylindrischen Halsteil des Cephalothorax, welcher denselben birnförmig erscheinen läßt, durch kurze Antennen und durch Verschmelzung der Abdominalsegmente 4-6 beim o

Latrillopsis hat einen mehr vierseitigen Cephalothorax, lange Antennen und in beiden Geschlechtern 7 freie Abdomensegmente.

Homolochunia, die neue Gattung, welche ich hier zu beschreiben gedenke, steht in allen diesen Punkten Latreillopsis sehr nahe. Der Cephalothorax ist auffallend viereckig in der Gestalt, aber seine Ausstattung mit Dornbildungen sowie die Form der Scheren an den 5. Pereiopoden weichen hinreichend von den entsprechenden Teilen von Latrillopsis ab, um die Aufstellung einer neuen Gattung zu rechtfertigen.

Der Cephalothorax ist viereckig, ziemlich hoch gewölbt, die Branchialgegenden sind zum Unterschied von Latreillopsis nur wenig vorgewölbt. Die Basalglieder der 4 hinteren Pereiopoden ragen deutlich seitlich unter dem Cephalothorax hervor. Die Stimregion ist relativ breiter als bei Latreillopsis, das Rostrum ist kräftig dornförmig: es ist dreieckig mit konkaven Seitenkonturen und breiter Basis. Unter den Seiten des Rostrums entspringen die Augenstiele. Die beiden großen Dornen, welche in weitem, nach unten konkavem Bogen seitlich vom Rostrum emporragen, sind selbst mit 3 großen Stacheln versehen, welche ihnen ein verzweigtes Aussehen geben. Der Augenursprung befindet sich median von diesen Dornen entfernt.

Eine sehr deutliche Linea anomurica ist vorhanden.

Augen groß, auf langen Stielen, aber die Stiele sind bei weitem nicht so lang wie bei Latrillia und Latrcillopsis. Aeußere Antennen lang, besonders der Stiel, dessen 3. und 4. Glied von oben nach unten klingenförmig abgeplattet sind. Innere Antennen mit langem Stiel und kurzer Geißel. Das Epistom ist deutlich vom Gaumen getrennt und in Form einer eigenartigen wulstartigen Platte ausgebildet, zu deren beiden Seiten die ausführenden Kanäle tief einschneiden.

Mundöffnung ringsum scharf abgegrenzt, vorn breiter als hinten. Die zweiten Gnathopoden schließen auch außen überall dicht an, ihr Ischiopodit und Meropodit sind ziemlich breit. Median lassen sie aber einen breiten Spalt zwischen sich klaffen. 
Die Scherenfüße sind lang und beim Männchen ziemlich kräftig. Sie sind kürzer, aber dicker als die Pereiopoden 2-4. Meropodit und Carpopodit sind prismatisch, während die entsprechenden Glieder der Schreitbeine cylindrisch sind.

Die Beine sind lang, aber bei weitem nicht so dünn wie bei den beiden anderen Gattungen der Familie.

Das 5. Pereiopodenpaar trägt große, starke Scheren von merkwürdiger Bildung. Sie erinnern in der Form einigermaßen an die zarten Scheren von Homologemus rostratus, nur sind sie viel stärker und gröber gebaut.

Der Propodit ist relativ kurz und dick, an seiner Basis befindet sich ein langer, starker, in spitzem Winkel divergierender Dorn. Er bildet den unbeweglichen Finger der Schere. Der Dactylopodit zweigt bei geschlossener Schere in scharfem (fast rechtem) Winkel vom Propodit ab. Die Spitzen der Scherenfinger berühren sich, aber zwischen ihnen selbst bleibt ein weiter offener Raum.

Das Abdomen besteht in beiden Geschlechtern aus 7 freien Gliedern.

Die Kiemen sind auffallend zahlreich und ebenso die Epipoditen; die Verhältnisse erinnern sehr an die Homoliden. Näheres siehe unten in der Diagnose der Art.

Die einzige Art der Gattung wurde im Indischen Ocean, an der ostafrikanischen Küste gefunden.

\section{Homolochunia Valdiviae n. sp.}

Taf. I, Fig. I u. 2; Taf. IX, Fig. I-8; Taf. X, Fig. I u. 2; Taf. XLIII, Fig. I.

Die „Valdivia"-Expedition erbeutete von dieser interessanten bizarren Art 4 Exemplare. Ein großes erwachsenes Männchen, ein ziemlich junges Männchen und 2 eiertragende Weibchen von der Größe des ersten Männchens. Ich lege meiner Beschreibung zunächst das erwachsene ¿ zu Grunde, obwohl ein Pereiopod etwas verletzt und ein anderer offenbar einmal verloren und nicht in der vollen Größe regeneriert worden ist.

Der Cephalothorax ist dick und plump mit einer sehr stark skulptierten Oberfläche. Die Frontalregion ist durch mehrere sehr auffallende Stachelbildungen ausgezeichnet. Das mit breiter Basis beginnende Rostrum läuft in eine scharfe Stachelspitze aus. Es ist dreieckig, flach, mit starkem, wulstartigem Rande. In den Ansichten von oben (Taf. I, Fig. 2; Taf. IX, Fig. 2) erscheint es stark verkürzt, da es steil nach unten geneigt ist. Seitlich von ihm erheben sich die beiden Supraorbitaldornen in Form von langen, etwas verzweigten Stirngeweihen. Sie sind fast so lang wie der Cephalothorax ohne Rostrum, und dabei ziemlich kräftig. Sie entspringen in einem Abstand voneinander, welcher die Breite der Basis des Rostrums ausmacht, und divergieren in ihrem Verlauf nur wenig. Sie steigen in ihrer allgemeinen Richtung im Verhältnis zum Cephalothorax ein wenig auf und sind dabei in einem nach unten konkaven Bogen gekrümmt. Seitlich sind sie ein wenig abgeplattet, oben und unten mit einer nicht scharfen Kante versehen. Auf der oberen, konvexen Kante erheben sich 3 Dornen in ziemlich regelmäßigen Abständen. Das ganze Stimhorn mißt $32 \mathrm{~mm}$, der I. kleine Dorn erhebt sich I I $\mathrm{mm}$ von der Basis entfernt, der Rest von $21 \mathrm{~mm}$ ist in Strecken von je $7 \mathrm{~mm}$ geteilt. $7 \mathrm{~mm}$ von dem 1. kleinen Dorn erhebt sich der 2. kleine Dorn, $7 \mathrm{~mm}$ von demselben der 3. große Dorn, welcher selbst $6 \mathrm{~mm}$ lang ist, während das spitze Ende des Stirnhorns selbst wieder $7 \mathrm{~mm}$ mißt. Dadurch bekommt dieses 
Ende ein gegabeltes Aussehen. Unmittelbar hinter diesen Stirnhörnern und etwas segren die Medianlinie verschoben befindet sich jederseits ein kurzer, scharfer Postfrontalstachel. An den vorderen Seitenecken des Cephalothorax befindet sich je ein großer starker, in der Wagrechten etwas nach innen gekrümmter Dorn. Dieselben sind ungefähr so lang, manchmal auch ein wenig längrer als das Rostrum. Dieser Anterolateralstachel sitzt also außen auf der kleinen, wie bei Latrillopsis merkwürdig abgesetzten Regio hepatica. Unterhalb von ihm befindet sich auch hier ein kleinerer, aber immerhin noch ansehnlicher Stachel.

Betrachten wir nun den Cephalothorax von oben, so erscheint er sehr uneben; die dichte, aber kurze filzige Behaarung verdeckt die Skulptur nicht. Die Bedeckung des Cephalothorax besteht außer hakenförmigen Borsten aus den von mir so genannten Filzhaaren (s. Abschnitt II Biologie der Tiefseekrabben über Körperbedeckung). Die Cervikalfurche und die Linea branchialis und homolica sind sämtlich deutlich zu sehen. Die Regio gastrica ist rundlich emporgewölbt. Jederseits schief von ihr nach vorn befindet sich ein weiterer Höcker zwischen ihr und dem Anterolateralstachel.

Auf der langgestreckten Regio cardiaca befinden sich vorn und hinten nahe der Mittellinie je 2 flache Tuberkel. Von den Gegenden dieser Tuberkel ziehen vorn und hinten leistenartige Erhöhungen zu den Seiten hinunter. Zwischen beiden beginnt die Branchialfurche. Mit den in der Längsachse befindlichen Erhebungen zusammen bilden diese Leisten die Form eines griechischen Kreuzes.

Die vordere Erhöhung endet seitlich vor der Linea homolica mit einem größeren Höcker.

Die hintere läuft auf einem Höcker aus, welcher bereits jenseits der Linea homolica auf der Branchialregion steht.

Zwischen beiden befindet sich näher der hinteren Erhöhung ein quergestreckter Höcker.

Die Regio intestinalis ist etwas mehr abgeplattet als der vor ihr gelegene Teil des Cephalothorax. Ihre Nitte nimmt eine in der Längsachse des Körpers verlaufende breite Leiste ein, welche sich vom Hinterrand bis zur Regio cardiaca erstreckt. Beiderseits sind flache Höcker bemerkbar, von tiefen Furchen umgeben; die Mitte der Höcker ist mit einem kurzen, stumpfen Stachel besetzt. Der Hinterrand des Cephalothorax ist wenig ausgerandet.

Auf den Seiten des Cephalothorax befinden sich noch folgende Höcker- und Stachelbildungen:

I) ein Höcker mit Stachel auf dem dreieckigen Feld, welches von Linea homolica, Cervikalund Branchialfurche eingeschlossen wird;

2) eine Reihe von 3 Höckern dicht hinter der Branchialfurche, und von oben nach unten parallel derselben angeordnet;

3) ein kleiner Stachel in dem untersten vorderen Winkel der Branchialregion;

4) ein Stachel auf einem kleinen Felde, welches zwischen dem Mundrand und der Hepatikalregion gelegen ist.

Außerdem finden sich noch ein kleiner Stachel an der Basis der äußeren Antennen und ein ziemlich ansehnlicher an der vorderen Ecke des Mundrandes.

Die Augenstiele sind beweglich, lang, aber relativ nicht so lang wie bei Latreillia und Latreillopsis. 
Die äußeren Antennen sind ein gut Stück kürzer als die Stirnhörner. Der Stiel ist länger als die Geißel. Am längsten ist das 3. Glied des Stieles, welches auch wie eine Lamelle von oben nach unten abgeplattet ist.

Auch die inneren Antennen haben einen langen Stiel und kurze Geißeln.

Sämtliche Pereiopoden sind schlank, zum Teil sind sie sehr lang. Die filzige Behaarung ist, besonders an den distalen Gliedern, viel geringer als am Cephalothorax.

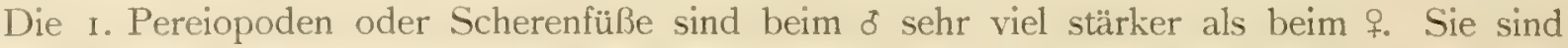
etwas länger als der Cephalothorax mit den Stirnhörnern.

Der Ischiopodit besitzt an der Außenkante 2 hintereinander gelegene Stacheln, von denen der größere die Vorderecke einnimmt.

Der Meropodit ist prismatisch, in dem mittleren Teil stark von den Seiten her abgeplattet, an den Gelenken etwas stärker. Auf der oberen Kante befindet sich proximal ein kleiner Dorn (bei meinem ठ Exemplar nur links), distal am Gelenk findet sich ein größerer.

Der kurze unbewehrte Carpopodit ist fast vierkantig.

Die Schere ist schlank, die Länge verhält sich zur größten Breite wie 3: I . Dic Palma ist etwas aufgeblasen, die Kanten sind abgerundet.

Die Finger sind seitlich abgeplattet und nach innen beide gleichmäßig etwas gekrümmt. Der bewegliche hat oben 2 scharfe Kanten, welche zur Spitze konvergieren. Die Schneide ist nahe der Basis mit 2 groben, stumpfen Zähnen besetzt.

Der unbewegliche Finger hat nach unten eine scharfe Kante, die Schneide ist in der Mitte etwas erhaben, ohne daß aber eine Zahnbildung vorhanden wäre. Die Finger klaffen an der Basis, berühren sich aber im letzten Drittel.

Von den übrigen Pereiopoden ist das 3. Paar das längste, das 2. ist schwächer und kürzer, das 4. ist fast ebenso groß und dick, das 5. ist erheblich kleiner und trägt eine Schere. Die Beine sind sämtlich nicht sehr stark und die einzelnen Glieder cylindrisch.

Am längsten sind bei sämtlichen Beinen die Meropoditen. Sie tragen auf der Oberseite beim 2.--4. Paar eine Reihe kräftiger Dornen; am kräftigsten ist der Dorn, welcher distal über dem Gelenk steht; von ihm aus verläuft proximal eine kurze Strecke weit eine scharfe Kante. (Es ist hervorzuheben, daß die Dornen bei dem regenerierten 4. linken Bein fehlen, mit Ausnahme des Enddornes.)

Die Carpopoditen sind sämtlich kurz, die Propoditen sehr lang, die Dactylopoditen kräftig, relativ lang und etwas gebogen; die kurze Endklaue ist hornig.

Unten distal findet sich an den Propoditen beim 2. Paar ein kräftiger Stachel, beim 3. und 4. je 2 kleinere (beim Regenerat fehlend).

Beim 5. Pereiopodenpaar ist der Meropodit stark, mit einem großen Dorn über dem distalen Gelenk, sonst ohne Stachelbildungen. Der Carpopodit ist etwas mehr als halb so lang als der Meropodit. Der Propodit ist bei der gewöhnlichen Haltung der Schere in seiner Hauptachse in einem stumpfen Winkel zur Hauptachse des Carpopoditen gestellt. Annähernd in der Richtung des letzteren verläuft ein schlanker Dorn, welcher an der Basis des Propoditen entspringt. Er stellt den unbeweglichen Finger der Schere dar, während der Dactylopodit den beweglichen Finger bildet. Dieser Dorn ist fast so lang wie der Carpopodit und $2 \frac{1}{2}$ mal so lang wie der Propodit selbst; er ist an der Spitze leicht nach außen gebogen und bildet mit 
dem entsprechend nach innen gebogrenen Dactylopoditen einen Spitzhorgen. Bei geschlossener Schere glcicht der freie Raum einem spitzbogigen Fenster, nur ist die Basis nicht rechtwinklig, sondern der Winkel zwischen dem Propoditen und seinem Dorn ist ein spitzer, der zwischen Propodit und Dactylopodit ein stumpfer. Alle Teile sind cylindrisch, die Scherenfinger sehr spitz.

Die Schere der 5. Pereiopoden ist bei of und $q$ ziemlich gleich stark gebildet.

Das Abdomen ist in beiden Geschlechtern 7-gliedrig. Die Form beim $\delta$ ist diejenige cines Blattes mit gewellten Rändern. Die beiden I. Glieder sind schmal, dann verbreitert sich das Abdomen bis zum 5., das 6., lïngste Glied ist zum kleinen 7. stark verschmälert.

Die Vorvölbung für den Darmkanal ist ziemlich stark und trägt auf dem 2., 3. und 4. Segment in der Mitte und auf dem 6. Segment am distalen Ende einen Dorn. Die Seitenteile zeigen auf dem 4. und 5. Segment je einen spitzen Höcker auf der Mitte der Fläche.

Die Vorderecke steht an sämtlichen Segmenten etwas vor. Der Seitenrand ist etwas aufgrewulstet, auch an der Basis des 7. Segmentes, das Ende desselben, welches etwa die Form eines entfederten Vogelbürzels besitzt, hat flachen Rand.

Die ơ Geschlechtsöffnung befindet sich auf der Basis der 5. Pereiopoden, und das Vas deferens ragt ein wenig hervor.

Die Genitalbeine sind bemerkenswert gestaltet. Das vordere Paar ist viel stïrker entwickelt als das hintere, die basalen Teile beider Beine sind median verwachsen. Beide bilden zusammen ungefähr die Form einer Lyra. Ihre eigentümliche Form zeigt Fig. I der Taf. IX. Das 2. Paar ist einfacher gebaut, schwächer, die basalen Teile sind, wenn auch sehr genähert, doch nicht verwachsen.

Die Nundgliedmaßen sind weiter unten vom $q$ geschildert.

Vom ơ sei hier noch die Färbung erwähnt, wie sie nach einer auf der Expedition angrefertigten Skizze nach dem lebenden Tier sich darstellt (Taf. I, Fig. I u. 2). Im allgemeinen ist das ganze Tier hell-fleischrot und zeigt somit die Farbe, welche bei den.Tiefseekrebsen so sehr verbreitet zu sein scheint (vergl. Abschnitt II, Biologie). Die jungen Tiere haben eine etwas mehr zu Karmin neigende Färbung.

Bei der Betrachtung der Weibchen fallen vor allen Dingen die viel kürzeren und schwächeren Scherenfüße (r. Pereiopoden) auf. Sie sind die dünnsten sämtlicher Pereiopoden. Die einzelnen Glieder sind ziemlich cylindrisch, auch die Schere selbst ist annähernd cylindrisch, nur von den Seiten her etwas komprimiert. Die Finger sind wie beim of seitlich stark komprimiert und nach innen grekrümmt. Die Fingerschneiden klaffen kaum, sie sind ein wenig gewellt, Zähne finden sich aber keine auf ihnen.

Die beiden $q$ der "Valdivia"-Ausbeute tragen sehr zahlreiche Eier unter dem breit-löffelförmigen Abdomen. Infolgedessen ragt letzteres in der Dorsalansicht weit nach hinten vor. Es besteht wie beim of aus 7 freien Gliedern. Das I. ist schmal, vom 2. ab sind Seitenteile vorhanden, das 2., 3. und 4. nehmen allmählich an Breite und Länge zu. Am breitesten und höchsten ist das 5. Annähernd ebenso groß ist das 6., welches trapezförmig ist, recht klein das 7., welches ebenso geformt ist wie beim to.

Die Darmkapsel ist vom I.-6. Glied sehr deutlich erhaben und trägt entsprechende Stachelhöcker wie beim $\delta$. Die vorderen Seitenecken des 5. und 6. Segmentes sind in scharfe Dornen ausgezogen. 
Die sehr zahlreichen Eier sind für eine Tiefseeform auffallend klein. Ihre Farbe ist rotgelb. Eines der Weibchen wurde dazu verwendet, Einzelheiten des Baues festzustellen. Bei demselben ließ sich folgende Kiemenformel feststellen:

\begin{tabular}{|c|c|c|c|c|c|}
\hline & Podobranchien & $\begin{array}{l}\text { Arthr } \\
\text { vordere }\end{array}$ & $\begin{array}{l}\text { achien } \\
\text { hintere }\end{array}$ & Pleurobranchien & \\
\hline $\left.\begin{array}{l}\text { 3. Maxille } \\
\text { 1. Gnathopod } \\
\text { 2. Gnathopod } \\
\text { I. } \\
\text { 2. } \\
\text { 3. } \\
\text { 4. } \\
\text { 5. }\end{array}\right\}$ Pereiopod & $\begin{array}{c}\text { Ep. } \\
\text { I }+ \text { Ep. } \\
0+\text { Ep. } \\
0+\text { Ep. } \\
0+\text { Ep. } \\
0+\text { Ep. } \\
0 \\
0\end{array}$ & $\begin{array}{l}0 \\
0 \\
1 \\
1 \\
1 \\
1 \\
0 \\
0\end{array}$ & $\begin{array}{l}0 \\
0 \\
1 \\
1 \\
\text { klein } \\
\text { klein } \\
0 \\
0\end{array}$ & $\begin{array}{l}0 \\
0 \\
0 \\
0 \\
I \\
I \\
I+I(?) \\
0\end{array}$ & $\begin{array}{l}=0+\text { Ep. } \\
=1+\text { Ep. } \\
=2+\text { Ep. } \\
=2+\text { Ep. } \\
=3+\text { Ep. } \\
=3+\text { Ep. } \\
=1+\mathrm{I}(?) \\
=0\end{array}$ \\
\hline Summe & $\mathrm{I}+6 \mathrm{Ep}$ & 4 & 4 & $3+$ rud. & $=12(13)+6 \mathrm{Ep}_{\mathrm{p}}$ \\
\hline
\end{tabular}

Auffallend ist bei dieser Formel die große Anzahl von Kiemen und von Epipoditen. Bei dem 4. Pereiopoden findet sich außer einer wohlentwickelten Pleurobranchie ein kurzer Anhang, welchen ich für eine rudimentäre Pleurobranchie halte. Das Vorhandensein von Epipoditen auf den 3 ersten Pereiopoden entspricht dem Verhalten bei den Homoliden. Auch sonst scheint mir Homolochunia in der Mitte zwischen den Homoliden und den bisher bekannten Latreilliden zu stehen. Morphologisch bildet sie in den meisten Beziehungen eine Brücke zwischen Homola Cuvvieri und Latreillopsis bispinosa.

Die Mundteile sind abgebildet auf Taf. IX, Fig. 3-8.

Die 2. Gnathopoden sind ziemlich breit und bilden bereits einen deutlichen Munddeckel, indem das klaffende Stück in der Mitte nicht mehr sehr groß ist. Die Verbreiterung nach außen an dem Coxopoditen ist deutlich. Das Fehlen der Podobranchie erinnert an die Homoliden. Der Meropodit ist hauptsächlich an der äußeren Seite nach der Mitte verbreitert und bildet dort einen Stachel; ein 'zweiter spitzer Stachel steht in der Mitte auf dem Meropoditen, an der Grenze des I. und 2. Drittels seiner Länge; von dort aus ist auch die Oberfläche des Meropoditen stark abwärts geneigt. Die übrigen Mundgliedmaßen ähneln sehr denjenigen von Latreillia. Hervorzuheben ist noch, daß der zweigliedrige äußere Abschnitt der I. Maxille an seinem distalen Ende blattartig verbreitert ist.

Auffallend ist, daß an verschiedenen Exemplaren sich deutliche Spuren von früher erlittenen Verletzungen und Regenerate zeigen. Es weist dies darauf hin, daß die Homolochunien von Feinden eifrig verfolgt werden.

An dem jungen Exemplar ist hervorzuheben, daß es, obwohl ein $\delta$, noch die zarten Scheren des $q$ besitzt. Die verschiedenen Stachelbildungen und Skulpturen sind bei ihm besonders deutlich. Wie Taf. I, Fig. 2 zeigt, ist das ganze Tier ebenso gefärbt wie das alte, nur sind die Farben etwas zarter.

Die "Valdivia"-Expedition erbeutete 4 Exemplare dieser Art, sämtlich an der ostafrikanischen Küste:

I J juv., Station 25I, ostafrikanische Küste, I $^{0} 40,6^{\circ} \mathrm{S}$. Br., $4 \mathrm{I}^{0} 47, \mathrm{I}^{\prime} \mathrm{O}$. L., in einer Tiefe von $693 \mathrm{~m}$.

I J, erwachsen, 2 q, erwachsen, mit Eiern, Station 254, ostafrikanische Küste, o ${ }^{0} 29,3^{\prime} \mathrm{S}$. Br., $42^{\prime} 47,6^{\prime}$ O. L., in einer Tiefe von $977 \mathrm{~m}$. 


\section{Oxystomata.}

\section{Gattung Ethusa Roux.}

Elhusa andamanica AI.COCK.

Taf. XIII, Fig. 7 u. 8.

180.t Elhusa andamanica Arcock, Amn. Mag. Nat. Hist., Ser. 6, Vol. XIII, p. 405.

I80,5 Elhusa andamanica Alcock, Illustrations Zool. Investigator, Crustacer, III, Taf. XIV, Fig. 8 .

Isigh) Eithusa andamanica AICOCk, Materials for a carcinological Fauna of India. No. 2. The Brachyoura oxisema, in: Journ. As. Soc. Bengal., Vol. LXV, II, p. 284.

IVie Alcock, so liegt auch mir von dieser Art das $\delta$ in nicht ausgewachsenem Zustande vor. Die Uebereinstimmung mit Alcock's Beschreibung ist eine allgemeine. Die cinzige Abweichung, welche ich erwähnen kann, ist, daß bei meinem Exemplar die Stirnregion, ebenso wie der übrige Cephalothorax unbehaart ist, während Alcock eine die Stirndornen verdeckende Behaarung beschreibt. Dagegen habe ich einige Einzelheiten hervorzuheben, welche dieser Autor nicht erwähnt hatte. Alcock meint, daß E. andamanica eventuell nur eine Varietät von E. oricntalis Mrers darstelle (s. MIrers, Challenger Brachyura, i886, p. 330, Taf. XXVII, Fig. 4), welche bei den Fiji-Inseln in einer Tiefe von $562 \mathrm{~m}$ gefangen worden war.

Von dieser Form weicht $E$. andananica nach meinem Exemplar in folgenden Punkten ab:

Ethusa andamanica Alc.

I. Abdomen des of 5-gliedrig $(3+4+5)$.

II. Endglied desselben stumpf.

III. 2. Gnathopoden skulptiert (s. unten).

IV. Dactylopoditen der 2. Pereiopoden kürzer als die Propoditen.

V. Dactylopoditen der 3. Pereiopoden ebenso lang wie die Propoditen.
Ethusn oricutalis MIERS

I. Abdomen des o 7 -gliedrig ${ }^{-1}$.

II. Endglied desselben spitzig.

III. 2. Gnathopoden nach der Abbildung ziomlich glatt.

IV. Dactylopoditen beider ein wenig länger V. I als die Propoditen.

Die Skulptur der 2. Gnathopoden besteht bei E. andamanica darin, daß auf dem Ischiopoditen in der Mitte eine deutliche Furche verläuft. Auf dem Meropoditen lassen sich 2 solche Furchen erkennen; die Oberfläche des Meropoditen außerhalb und zwischen diesen Furchen erscheint zu leichten Leisten erhöht. Auf diesen ist die überall vorhandene Körnelung etwas stärker. Der Vorderrand des Meropoditen ist durch diese Skulptur in seiner Form etwas beeinflußt, indem den Furchen leichte Einkerbungen, den Leisten leichte Vorragungen seiner Kontur entsprechen.

I $\delta$, noch nicht ausgewachsen, Station 2 I I, Westeingang des Sombrero-Kanals (Nikobaren), $7^{\circ} 4^{8,8^{\prime}}$ N. Br., $93^{\circ} 7,6^{\circ}$ O. L., in einer Tiefe von $805 \mathrm{~m}$.

Verbreitung: Indischer Ocean: Andamanen, $345-530 \mathrm{~m}$ Tiefe (Alcock).

I) Dabei waren die „Challenger"-Exemplare zicmlich ausgewachsen, jedenfalls doppelt so groß als das der „Valdivia"-Expedition. Es kann sich also nicht bei oricnfalis um ein jüngeres Stadium von andamanica handeln. 


\title{
Ethusa Zurstrasseni n. sp.
}

\author{
Taf. XIII, Fig. 3 u. +.
}

Diese neue Art gleicht im Habitus der E. andamanica Alc., doch weicht sie bei genauerer Betrachtung in einer ganzen Reihe von Eigenschaften von ihr ab.

Der Cephalothorax ist länger als breit, die Branchialregionen sind, wenn auch nicht stark, so doch in deutlich erkennbarer Weise aufgetrieben. Die Oberfläche ist ziemlich flach, eine feine Granulation ist mit bloßem Auge schwach, mit der Lupe deutlich erkennbar. Die Cardialregion ist deutlich umgrenzt, nur nach hinten ist die Abgrenzung nicht scharf.

Die Urogastrikalregion ist von der mesogastrischen nicht abgegrenzt; diese ist überhaupt nicht umgrenzt, von ihr zieht sich ein schmaler Zwickel, welcher etwas deutlicher abgegrenzt ist, zum Stirneinschnitt. Eine Abgrenzung der metagastrischen Regionen gegen sie ist nicht erkennbar. Dagegen sind Branchial- und Hepatikalregionen ziemlich deutlich abgegrenzt. (WVegen der Bezeichnungen der Regionen siehe letzte Tafel des Atlas.)

Die Branchialfurche ist etwas deutlicher als die Cervikalfurche. Vor der Cervikalfurche zeigt die Kontur des Seitenrandes eine kleine Ausbauchung.

Der Stirnausschnitt ist breit, in der Form eines gleichseitigen Dreieckes.

Von den Frontaldornen ragen die innersten am weitesten vor, die äußeren sind ein wenig kürzer. Der Basalteil, welcher sie trägt, ist breit. Der Ausschnitt, welcher die beiden Dornen jeder Seite trennt, ist nicht tief; zudem erhebt sich an seinem Grunde ein weiteres kleines Höckerchen, so daß bei dieser Art die Stirn eigentlich 6-zähnig ist. Der Einschnitt zwischen dem äußeren Stirndorn und dem Orbitaldorn ist spitzwinklig. Der Umriß des äußeren Stirndornes zeigt an der Stelle, wo der Augenstiel zum Vorschein kommt, eine leichte Ausbauchung.

Der äußere Orbitalstachel ist spitz, dreieckig, dorsoventral abgeflacht und hat einen leicht granulierten Rand. Er bleibt in seiner Länge um einiges hinter dem äußeren Stirndorn zurück.

Einige zerstreute Haare sind auf der vorderen Region des Cephalothorax bemerkbar.

Die Augenstiele sind dünn und kurz. Die Cornea ist normal und sehr dunkel pigmentiert.

Die äußeren Antennen überragen mit ihrem Stiel gerade die Stirndornen, die Geißel ist fast so lang wie der Cephalothorax und mit Sinneshaaren bedeckt.

Die inneren Antennen haben ein ziemlich dickes Basalglied; sie überragen mit dem ganzen letzten Stielglied die Stirndornen. Doch sind die Sinneshaare nicht besonders stark entwickelt.

Das Mundfeld ist lang und spitz; die ausführenden Kanäle münden erst dicht hinter dem Stirnausschnitt, während $z$. B. bei $E$. andamanica ein ganz deutlicher Zwischenraum, bei meinem Exemplar $0,8 \mathrm{~mm}$ vorhanden ist.

Ich mache auf dieses Merkmal besonders aufmerksam, da es vielleicht sich zur Abgrenzung der Arten, besonders zur Anfertigung eines Bestimmungsschlüssels, nützlich erweisen wird.

Die 2. Gnathopoden haben eine Mittelfurche auf dem Ischiopodit, der Meropodit ist klein und fast glatt.

Die Scherenfüße sind klein, in geringem Maße ungleich, der rechte ein wenig größer. Sie sind glatt, unbehaart, der Carpopodit kurz, abgerundet, die Palma doppelt so lang wie die Finger. Letztere haben glatte Schneiden und klaffen an der Basis ein wenig. 
Die 2. und 3. Pereiopoden sind kräftig dorsoventral abgeplattet, die Meropoditen tragen am distalen oberen Rand einen stumpfen Zahn. Die Dactylopoditen sind lïnger als die Propoditen.

Die 4. und 5. Pereiopoden sind kurz, die Dactylopoditen sehr klein.

Das Abdomen ( $\delta)$ ist schlank, 5-gliederig, indem das 3.-5. Glied venwachsen sind. Vor dem vorletzten Glied ist das Abdomen etwas verschmälert, das vorletzte Glied sellsst hat einen 3-lappigen Hinterrand, das letzte ist breit abgerundet.

I đo, Station 254; Ostafrikanische Küste, $0^{\circ} 29,3^{\prime} \mathrm{S}$. Br., $42^{\prime \prime} 47,6^{\prime}$ O. L., aus ciner Tiefe von $977 \mathrm{~m}$.

\section{Ethusa mascarone HERBST.}

I782 Cancer mascarone Herist, Krabben und Krebse, Vol. I, S. I9I, Taf. II, Fig. 69.

I-82 Dorippe mascarone Roeser, Genera Insectorum, Taf. XXXII, Fig. X.

I 828 Ethusa mascarone Roux, Crust. d. 1. Méditerranée, Taf. II.

1837 Ethusa mascarone H. Milde-Edwards, Hist. nat. d. Crust., Vol. II, p. I62 (daselbst Litteratur).

I863 Ethusa mascarone Hel.ter, Crust. südl. Europa, S. I42 (Litt.).

I892 Ethusa mascarone Ortmanx, in: Zool. Jahrb. Syst., Bd. VI, S. 560 (Litt.).

1900 Elhusa mascarone A. Milfe-Edwards u. Bouvier, Crust. Décap. Travailleur et Talisman, p. 22 (Litt.),

Es scheint mir noch nicht ganz sicher zu sein, ob E. mascarone und amcricana M.-EDw. getrennte Arten sind. Zwar haben Mrive-Edwards und Bouvier (Mém. Mus. Comp. Zool., Vol. XXVII, I902, p. 67) eine Reihe von Merkmalen angegeben, durch welche sich americana gut unterscheiden läßt. Zunächst muß auch zugegeben werden, daß, wenn die zwischen den Verbreitungsgebieten der beiden Formen gelegenen Meere keine Zivischenformen beherbergen, das Vorkommen einer besonderen Form, welche scharf getrennt ist von der atlantischen Form, im Karaibischen Meer und an der Westküste von Amerika wahrscheinlicher ist als das Gegenteil. Aber das Auffinden von Zwischenformen ist sehr wohl möglich, und von den Exemplaren, von E. mascarone aus dem Mittelmeer, welche ich sehen konnte, zeigen verschiedene einzelne der Merkmale, welche MrLne-Edwards und Bouvter für E. americana angeben. So variieren die Stimzähne und die äußeren Orbitalzähne ziemlich erheblich, ein Exemplar vom Kongo zeigt die Tuberkel auf Branchial- und Cardialregion, obwohl es sonst vollkommen mascarone gleicht. Auch am Abdomen der $\delta$ aus der Adria lassen sich Variationen feststellen, wenn auch bei keinem die Breite des 3. Abdomensegmentes erreicht wird, welche MILNE-EDwards und BouviER für americana abbilden.

Der Fundort der Exemplare der „Valdiva“-Expedition ist ein sehr auffallender. An anderer Stelle (Abschnitt IV) werde ich näher darauf eingehen, daß an der Kongomündung sich noch eine ganze Anzahl nordatlantischer und mediterraner Formen fand.

Station 7 r, vor der Kongomündung, $44 \mathrm{~m}$,

Das eine Exemplar hielt nach der Notiz von Dr. Brasar eine Corallinee mit den hinteren Pereiopoden über sich, und zwar um so krampfhafter, je mehr sie sich beunruhigt fühlte.

Verbreitung: Nittelmeer und anschließende Teile des Atlantischen Oceans: Mittelmeer, 40-75 m ("Travailleur“ in Milne-Edwards); Adria (Heller, genaue Fundorte s. Carus, Fauna mediterranea, Vol. I, p. 500); Griechenland: Sarronica (Guérrs); Atlant. Ocean: Canarische Inseln (Mrers); Senegambien: Goree (MIrers); Cap Verden: Insel Branca („Talisman“: Mirne-Edwards und Bouvier). 


\section{Ethusa somalica n. sp.}

Taf. XIII, Fig. 5 u. 6.

Der Umstand, daß Angehörige der Gattung Ethusa meist nur in vereinzelten Exemplaren gefunden werden, macht die Aufstellung neuer Arten sehr mißlich. Bei dem großen Interesse, welches die Tiere dieser Gattung in biologischer Beziehung haben, ist es notwendig, die sämt lichen aufgefundenen Formen in der Litteratur besonders zu bezeichnen. Ist einmal ein großes Naterial in dieser Weise bekannt geworden, so wird es bei einer Revision der Gattung nicht mehr so schwierig sein, den Bestand an Arten auf das natürliche Maß zurückzuführen. Es wird diese zukünftige Arbeit ein um so höheres Interesse besitzen, wenn es gelingt, die Abhängigkeit der einzelnen Formenreihen von den äußeren Bedingungen festzustellen. Vorläufig sind wir aber durch die Unsicherheit unserer Vermutungen über diesen Gegenstand genötigt, alle abweichenden Formen, besonders wenn sie aus Gegenden stammen, welche von der Heimat der nächstverwandten Formen entfernt sind, als besondere Arten $z \mathrm{u}$ beschreiben.

In der allgemeinen Erscheinung ähnelt Ethusa somalica am meisten E. indica ALcock und E. pygmaca ALc. Doch weicht sie bei genauerer Untersuchung in zahlreichen Punkten ab.

Der Cephalothorax des uns vorliegenden $q$ ist länger als breit; die Kiemenregionen sind aufgetrieben, aber nicht so sehr wie bei indica. Die Cardialregion, welche nach vorn keine scharfe Grenze hat, ist breit und erhaben; nicht zwischen den Branchialregionen eingesunken, wie bei indica.

Die übrigen Regionen sind nur undeutlich abgegrenzt. Die Oberfläche des Cephalothorax ist ziemlich glatt, geringe Granulationen vorhanden.

Die äußeren Orbitalstacheln ragen nicht über die Frontalstacheln hinaus. Sie sind mehr stachelförmig und haben keine so breite Basis, wie bei indica und pygmaca. Auch ist keine Haarbedeckung an der Stirngegend vorhanden.

Die Stirndornen sind ziemlich ungleich, je der innere breiter und kürzer, der äußere schlanker und spitzer. Der dreieckige Stimausschnitt ist fast rechtwinklig.

Die Augenstiele sind kaum berveglich, die Cornea ist sehr klein, aber mit deutlichem dunklem Pigment versehen.

Die Basis der inneren Antennen ist ziemlich stark aufgetrieben, die Sinnesbehaarung nicht auffällig entwickelt.

Die Scherenfüße sind symmetrisch gebaut, die Schere selbst ist schlank, die Finger etwa so lang wie die Palma, und etwas nach innen gekrümmt. Die Schneiden haben einen welligen Rand und schließen in der ganzen Länge aufeinander.

2. und 3. Pereiopodenpaar sind lang und schlank, das 3. am längsten, beide mit langen Dactylopoditen, das 4. und 5. sind kurz mit kleinen, krummen Dactylopoditen.

Das Abdomen des $q$ ist breit, 7 -gliederig.

Die 2. Gnathopoden sind schlank, vorn erheblich schmäler als hinten.

Ein + von Station $25^{8}$ an der ostafrikanischen Küste, Somaliland, $2^{0} 58,5^{\circ}$ N. Br., $46^{0}$ $50,8^{\prime}$ O. L., in einer Tiefe von $1362 \mathrm{~m}$. 


\title{
Ethusa (Ethusina) abyssicola S. J. Sinin.
}

\author{
Thi . XIII, liti.. 1 u. 2
}

188. Elhusina abrssicola S. J. SuItr, Ann. Rep. Comm. Fish and Fisheries for I882, p. 394, Taf. II, Tig. I, 1 a.

1807 Ethusina abyssicola E. L. Bouvier, Bull. Soc. philom. Paris, Sér. 8, Vol. IX, p. 66.

I 809 Elhusina abjssicola A. Milve-Emw:urns et E. L. Bouvier, Rés. Camp. scient. Monaco, Vol. XiII, p. I8.

noo Ethusina abyssicola A. MInxe-Enwarns, Exp. scient. Travailleur et Talisman, Crustacés décapodes, p. 29,

Taf. I, Fig. 6.

Auch bei der Untergattung Ethusina sind vielfach die Grenzen der Arten noch ungenau definiert. Aber die sich mehrenden Funde tragen bereits dazu bei, gewisse Unterschiede an den crbeuteten Exemplaren als Alters- oder Geschlechtsmerkmale erkennen zu lassen. Auch lernen wir die individuelle Variationsbreite etwas besser kennen, und so kann man allmählich bereits daran denken, die Zahl der früher beschriebenen Arten zu reduzieren.

Ethusina aby'ssicola ist bisher mit Sicherheit von verschiedenen Punkten im Osten und Westen des Atlantischen Oceans nachgewiesen. Auch glaubten Mirne-Edwards und Bouvieiz Ethusina Challengeri Miers') für eine Varietït von E. abyssicola halten zu dürfen.

Auch mir erscheint die Aehnlichkeit sehr groß, aber mir steht kein ausreichendes Material zur Verfügung, um dieser Frage näher treten zu können.

Ein ausgewachsenes o einer Ethusina-Art von der Küste von Ostafrika ist aber so übereinstimmend mit den Beschreibungen und Abbildungen von S. J. Sirrt und BouvieR und MrLneEDWARDS, daß mir die Zugehörigkeit zu E. abyssicola unzweifelhaft dünkt.

Die Frontalstacheln sind kurz, die inneren breiter als die äußeren. Hinter der Stirnregion zieht sich eine Furche quer über den Cephalothorax. Die äußeren Orbitalstacheln sind sehr kurz die Augen unbeweglich, die Augenstiele kurz, von oben gerade noch sichtbar, die Cornea klein, aber deutlich dunkel pigmentiert. Das Basalglied der inneren Antennen ist sehr stark angeschwollen.

Die Ausführgänge vor den 2. Gnathopoden sind relativ kurz, sic bilden ein niedriges Dreieck. Die 2. und 3. Pereiopoden sind sehr lang, die Scherenfüße mäßig groß und symmetrisch. Die Glieder $3-5$ des o Abdomens sind verwachsen.

Die Abweichungen vom Typus, welche ich feststellen konnte, sind nicht sehr bedeutend. Der Cephalothorax ist etwas länger, als er in der Branchialregion breit ist. Die Breite in der Stirngegend verhält sich zur Länge $=4: 19$, in der Augengegrend $=6: 19$. Die Stirnzähne sind etwas verschieden: der innere ist breiter und kürzer, der äußere länger und spitzer. Auf der Unterseite der Augenstiele kann ich keine Lïngskante erkennen. Die Hände sind etwas schlanker gebaut als beim Typus. Um einen Vergleich jederzeit zu ermöglichen, gebe ich auf Taf. XIII, Fig. I u. 2 eine Abbildung meines Exemplars von der Ober- und Unterseite.

I ơ, Station 240, ostafrikanische Küste, vor Sansibar, 6" I 2,9 S. Br., 4 I $^{0}$ I 7,3 O. L., in einer Tiefe von $2950 \mathrm{~m}$.

Verbreitung: Atlantischer Ocean in Tiefen von 2750-4I00 m: ostamerikanische Küste auf der Höhe von Maryland und Delaware, 2743-3175 m (Albatross: S. J. Swrmi); zwischen den Azoren und Frankreich, 3975-4060 m; Azoren, 2995 m; Cap Verden, 3655 m („Talisman“:

1) Ethusina Challengeri MUERs, in: Challenger Brachyura 1886, p. 331, Taf. VIII, Fig, 2 u. 2c. F.Axos, in: Mem. Mus. Comp. Zool., Vol. XVIII, 1895, p. 36. 
Bouvier und Milne-Edwards); Indopacifischer Ocean (E. Challengeri Miers): Japanisches Meer, $3440 \mathrm{~m}$ („Challenger": MIIERS); westamerikanische Küste zwischen Acapulco und den Galapagos, 408 I m (Albatross: Faxon).

\section{Gattung Dorippe Fabricius.}

\section{Dorippe lanata (L.).}

I71,6 Cancer lanatnes (I) Lixié, Syst. nat. ed. I2, Vol. II, p. 1044.

1733 Cancer facchino Herist, Krabben und Krebse, Bd. I, Taf. II, Fig. 68.

181,2 Dorippe lanata Bosc, Hist. nat. Crust., Vol. I, p. 208.

I 813 Dorippe lanata Heller, Crust. südl. Europa, p. I38, Taf. IV, Fig, 9 (Litt.).

Isirz Dorippe lanata Ortaraxx, Zool. Jahrb. Syst., Bd. VI, p. 56I (Litt.).

I‘x) Dorippe lanata A. Milne-Edwards und Bouvier, Expéd. scient. Travailleur et Talisman, Crustacées décapodes, Fil. I, 1. 33

Die von der "Valdivia"-Expedition an der Kongomündung erbeuteten Dorippen gehören thatsächlich zu D. lanata L. und nicht zu D. amnata Whrte (s. Miers, Ann. Mag. nat. Hist., Ser. 5, Vol. VIII, p. 269, Taf. XV, Fig. 4 u. 4a).

Sie unterscheiden sich von letzterer in der Skulptur des Cephalothorax, ferner dadurch, daß der Branchialstachel gering entwickelt ist. Das 3. Glied des of Abdomens ist verschieden gestaltet, ebenso die Scheren.

Ferner ist hervorzuheben, daß bei meinen Exemplaren die Meropoditen der 2. und 3. Pereiopoden eine deutliche Reihe von Stacheln am oberen Rande tragen.

Ein genauer Vergleich mit Exemplaren des Münchener Museums, welche aus der Adria stammen, ergab ebenfalls vollkommene Uebereinstimmung mit lanata $\mathrm{L}$.

Es ist also unzweifelhaft, daß mit den übrigen mediterranen und nordatlantischen Formen in der Gegend der Kongom ündung D. lanata auftritt.

Es ist dies um so bemerkenswerter, als sie außerhalb des Mittelmeeres bisher nur in unmittelbarer Nachbarschaft der Straße von Gibraltar gefunden worden war. Man glaubte bisher, sie sei in den tropischen Teilen des ostatlantischen Oceans durch Dorippe armata vertreten, welche in der Region von den cap-verdischen Inseln bis nach Benguela gefunden worden war (s. Mllnne-Edwards und Bouvier, Exp. scient. „Travailleur“ et „Talisman“, Crust. décapodes, 1900, p. 32).

Da mir kein Material von der letzteren Art vorliegt, so kann ich nicht untersuchen, ob es sich nur um eine Varietät handelt. Es erscheint mir aber dies nach den Schilderungen der frïheren Beobachter nicht wahrscheinlich.

Station 7I, Kongomündung, $44 \mathrm{~m}$ Tiefe.

Verbreitung: Mittelmeer, 40-75 m: Algier (LucAs); Frankreich (M.-EDw. u. a.); Italien (s. Carus, Faun. Med., Vol. I, p. 499); Griechenland: Sarronica, Chekrèh (Guérin); Adria (Helter u. a.); Atlantischer Ocean: Meerbusen von Cadiz und westlich davon gelegene Meeresteile bis $36^{\circ} 26^{\circ}$ N. Br., $8^{\circ} 47^{\circ}$ O. L. („Talisman“: Milne-Edwards und Bouvier). 


\section{Gattung Cymonomus A. Milne-Edwards.}

\section{Cymonomus gramulatus (NORMAN).}

Taf. XI, Fig. 5, 'Taf. XII, Fig. I-3

1873 Ethusa gramulata Norasas, in: Tromsos, The depths of the sea, p. I 76

I881 Cymonomus granulatus A. MrLxe-Edwards, C. R. Ac. Sci. Paris, für r88I.

Igoo Cymonomus granulatus MiLxE-Edwards et Bouvier, Expéditions scientifiques du Travailleur et du Talisman, Crustacés décapodes, I. Brachyures et Anomoures, p. 34 (Litt.).

An der ostafrikanischen Küste fing die „Valdivia“-Expedition eine kleine Krabbe mit rückgebildeten Augen, welche so sehr mit Cy'monomus granulatus (NoRMras) aus dem mittleren Ostatlantik übereinstimmt, daß ich sie zu dieser Art rechne. Ich möchte aber nicht unterlassen auf einige Abweichungen im Bau hinzuweisen, welche sich erkennen lassen, aber welche nicht sehr bedeutend sind. Da nach den Schilderungen von Normax und Mirne-Edwards und Bouvier die atlantische Form ziemlich variabel zu sein scheint, so möchte ich auf die geringen Verschiedenheiten meines Exemplares keine neue Art begründen.

Bei demselben ist die Granulation des Cephalothorax nicht so stark wie sie nach den Abbildungen von MilNe-EdWards und Bouvier bei den atlantischen Exemplaren sein muß. Auch ist das Rostrum dünn und schmal. Die Regionen auf dem Cephalothorax sind besser ausgeprägt, besonders die Gastrikalregion.

An den Augenstielen ist keine Spur einer Cornea zu erkennen. Näheres über sie findet man im Abschnitt über Biologie der Tiefseekrabben.

Auch auf den äußeren Gnathopoden (s. Taf. XXXVIII, Fig. 8) und Pereiopoden sind die Granulationen mäßig. Behaarung ist ziemlich reichlich vorhanden, doch ist die Oberseite ziemlich frei.

Auffallend war die schwarze Färbung des Basalgliedes der inneren Antennen.

Das Abdomen des mir vorliegenden Weibchens endet mit einem dreieckigen Glied, welches mäßig schlank zuläuft. Es weicht dies von den ostatlantischen Exemplaren ab und erinnert eher an C. quadratus MILve-EDWards und Bouvier aus dem Karaibischen Meer und von der Ostküste von Nordamerika (s. Memoirs Mus. Comp. Zool. Cambridge, Vol. XXVII, No. I, p. 81 , Taf. XVII).

Auch dieser Form ähnelt ja das mir vorliegende Exemplar in manchen anderen Beziehungen, so in dem vollkommenen Mangel der Cornea, der Schlankheit des Rostrums, der Deutlichkeit der Regionen des Cephalothorax. Doch weicht es von diesem vor allem in der Gestaltung der Propoditen der beiden hinteren Pereiopodenpaare ab.

Die Eier sind oval und sehr groß (der Längsdurchmesser I mm), Taf. XII. Fig. 3. ES sind ihrer nur wenige, bei meinem Exemplar ${ }_{5} 5$ Stück.

I f, Station 253, nahe der ostafrikanischen Küste, O $\mathrm{O}^{\circ} 27, \uparrow^{\prime} \mathrm{S} . \mathrm{Br}, 42^{\circ} 47,8^{\circ} \mathrm{O}$. L., in einer Tiefe ron $638 \mathrm{~m}$.

Verbreitung: Ostatlantischer Ocean: von Irland, 200-675 m (Norman) zum Golf von Biskaya, 535-I I90 m (Mrlive-Edwards und Bourter: "Travailleur"s); Küste ron Portugal (M.-EDw. u. B., Moxaco) bis zur Saharaküste, $655 \mathrm{~m}$ (M.-EDw. u. B.: „Talisman“); Mittelmeer: Golf von Narseille, bei Corsica, $307-5.55 \mathrm{~m}$ (M.-EDW. u. B.: „Travailleur"). 


\section{Gattung Cyclodorippe A. Milne-Edwards.}

\section{Cyclodorippe uncifera ORTMANN.}

Taf. XII, Fig. $4-7$, Taf. XXXVIII, Fig. 6 u. 7.

I892 Ciclodorippe mifera OrTManv, Zool. Jahrb. Syst., Bd. VI, S. 560 (Oktober 1892).

I894 Cymonomops glancomma Alcock, Ann. Mag. Nat. Hist., Ser. 6, Vol. XIII, p. 406.

I89.4 Cymonomops glaucomma ALCOCK, Illustr. Zool. Investigator, Crustacea, Taf. XIV, Fig. 9.

I896 Cymonomops glaucomma AlCock, Materials for a carcinological fauna of India, No. 2, The Brachyura Oxystoma, in: Journ. As. Soc. Bengal, Vol. LXV, II, p. $286 / 7$.

I902 Cyclodorippe uncifera Ortar., Doflein, Ostasiatische Dekapoden, in: Abh. bayr. Ak. Wiss. München, II. Kl., Bi.. XXI, 3. Abt., s. 17.3 .

In dem Material der „Valdivia“-Expedition fanden sich 3 Exemplare einer Cyclodorippine vor, welche sich unschwer als Cymonomops glaucomma ALcock bestimmen ließ. Ein Vergleich mit Cyclodorippinenmaterial des Münchener Museums zeigte zu meinem Erstaunen, daß die Art identisch ist mit der von DOEDERLEIN in Japan entdeckten, von ORTMANn beschriebenen Cyclodoritpe uncifera ORTM.

Dabei stellten sich noch einige biologische Befunde von großem Interesse heraus, auf welche ich an anderer Stelle zurückkommen werde (s. Biologischer Teil).

Nachdem sich die Identität der 2 bisher unterschiedenen Arten herausgestellt hatte, war es zunächst fraglich, ob es nicht den natürlichen Verhältnissen entspräche, die von ALcock begründete Gattung wenigstens als Subgenus für die Cyclodorippen mit pigmentlosen Augen beizubehalten.

So wie Alcock hatte auch Ortmann die Pigmentlosigkeit der Augen bei seinen Exemplaren hervorgehoben und ich konnte mich von der Richtigkeit dieser Angaben an den Exemplaren des Straßburger Nuseums überzeugen, welche mir Herr Prof. Doederlein zur Untersuchung freundlichst zuschickte.

Nun hat aber das sonst vollkommen mit der Beschreibung übereinstimmende Exemplar der Münchener Sammlung, welches Dr. HABerer in der Sagamibai, also an dem gleichen Fundort, von welchem Ortuann's Exemplare stammten, gesammelt hatte, deutlich pigmentierte A ugen.

Vir müssen also bei der Art, wie es ja auch schon für andere Arten festgestellt wurde (z. B. Bathyplax), zwei Formen unterscheiden. Das Exemplar des Münchener Museums stammt nämlich aus geringer Tiefe. Ich habe Grund, anzunehmen, daß die Tiefe, aus welcher es stammt, zwischen 50 und $100 \mathrm{~m}$ liegt. Die von OrTMann beschriebenen Stücke waren in einer Tiefe von $180-360 \mathrm{~m}$, die des "Investigator" zwischen 400 und $800 \mathrm{~m}$, die der "Valdivia" Expedition in 463 und $638 \mathrm{~m}$ Tiefe gefangen worden.

Wir können also mit Recht annehmen, daß der Lichtmangel in irgend einem Zusammenhang mit dem Pigmentmangel der Augen bei den in der Tiefe lebenden Individuen steht.

Ich unterscheide also die Formen mit und ohne Pigment nicht als besondere Arten oder Varietäten, des näheren werde ich von diesen Dingen an anderer Stelle handeln (siehe im biologischen Teil). Sollte es für praktische Zwecke nützlich sein, so kann man beide Formen als 
Forma glancomma und F. melanomma einander gegenüberstellen. Doch giebt es offenbar Uebergangsstufen.

Die Eingangsöffnung zum Kiemenraum vor der Basis der Scherenfüße ist rudimentär, bei den jüngeren Exemplaren ist sie deutlicher als bei den alten, vielleicht sogar noch durchlässig.

Die Ausführungsöffnung reicht, lang und schmal, bis zum Rostrum; sie hat die Form eines spitzwinkligen Dreiecks. Die Leiste, welche sie seitwärts begrenzt, ist verdoppelt, so daß sie eine Rinne bildet, welche von der Vertiefung, in welcher die inneren Antennen sitzen, nach hinten verläuft und dabei allmählich verstreicht.

Die 2. Gnathopoden entbehren, soweit ich feststellen konnte, des Epipoditen; der Exopodit ist ohne Geißel.

Die 2. Gnathopoden sind in ihrer Gesamtform nicht flach, sondern stark gewölbt, cntsprechend der Form des Mundfeldes, welches sich von der Ventralseite stark nach vorn und oben streckt.

Der Meropodit ist stark nach vorn verlängert; der Carpopodit inseriert an der Innenseite desselben, so daß der Fortsatz des Meropoditen die 3 Endglieder fast bedeckt (Taf. XXXVIII, Fig. 6). Das 6. Glied des I. Gnathopoden besitzt einen Fortsatz, so daß eine subchelate Bildung entsteht. Aeußerer Lappen der 3. Maxille löffelförmig gebildet.

Das Abdomen ist bei dem $\delta$ sehr klein und besteht aus 5 Segmenten. Alcock erwähnt, daß bei dem of 6 Segmente vorhanden sind, von denen 2 oder 3 verschmolzen seien. OrTMANiv führt für das o 6 Segmente an. Bei dem mir vorliegenden $\delta$ aus Japan und den beiden $\delta$ von der ostafrikanischen Küste kann ich nur 5 Segmente auffinden.

Das Abdomen des $q$ hat deutlich 6 Segmente; das letzte, aus Verschmelzung von 2 Segmenten entstandene ist sehr groß.

Die weibliche Genitalöffnung befindet sich an der Basis der 3. Pereiopoden.

Die Eier sind sehr groß. Ihr Durchmesser beträgt über $1 / 2 \mathrm{~mm}$.

Sonst hätte ich der Beschreibung von Ortaranx und Alcock nichts hinzuzufügen. Details der Form lassen sich aus den Photographien Taf. XII, Fig, $4-7$ und den Zeichnungen Taf. XLVI Fig. $3-7$ entnehmen.

I +. Station 245, im Sansibarkanal, $5^{\circ} 27,9^{\prime}$ S. Br., $39^{\circ}$ I $8,8^{\prime}$ O. L., in einer Tiefe von $463 \mathrm{~m}$.

$2 \delta^{\prime}$, Station 253, ostafrikanische Küste, $0^{0} 27,4^{\prime} \mathrm{S} . \mathrm{Br}, 42^{\circ} 47,3^{\circ} \mathrm{O}$. L., in einer Tiefe von $638 \mathrm{~m}$.

Verbreitung: Indopacifisch: Japan: Sagamibai (i $80-360$ m Ortarann, Doflein, $50 \mathrm{~m}$ ); Andamanen, 400-800 m (AlCOCK).

\section{Gattung Calappa Fabricius. \\ Calappa lophos (HERBST).}

I790 Cancer lophos Hersst, Krabben u. Krebse, Bd. I, S. 29I, Taf. XIII, Fig. 77.

I 798 Calappa lophos Farricius, Ent. Syst., Suppl., p. 346.

1837 Calappe lophos Milase-Enwards, Hist. nat. Crust., Vol. II, p. IO4 (Litt.).

1850 Calappa lophos DE HAAx, Fauna japonica, Crust., p. 72 , Taf. XX, Fig. I. 
1892 Calappa lophos OrTMans, Zool. Jahrb. Syst., Bd. VI, S. 364.

I 896 Calappa lophos AlCock, Materials carcin. India, No. 2, Brachyura oxystoma, in: Journ. As. Soc. Bengal, Vol. LXV, II, p. I 44 (Litt.).

Die beiden mir vorliegenden jugendlichen Exemplare dieser Art weichen in einigen Punkten sowohl von den Angaben Ortmans's in seiner Tabelle, als auch von Alcock ab. Gegenüber ersteren ist hervorzuheben, daß der äußere Lappen der 3. Maxille an der Spitze nicht abgestutzt, sondern deutlich spitzwinklig ausgerandet ist. Bei 2 großen Exemplaren der Münchener Sammlung aus Japan sind dieselben abgestutzt; es handelt sich also möglicherweise um ein mit dem Alter abweichendes Merkmal.

Nach Alcock soll die Vorderwand des endostomialen Septums tief konkav sein; das ist weder bei den alten japanischen Exemplaren der Fall, bei welchen vielmehr der Vorderrand nur schief abgestutzt ist, noch bei den ostafrikanischen der „Valdivia“-Expedition, bei welchen der Vorderrand etwas konvex hervorragt.

Im übrigen stimmen die Exemplare der „Valdivia“-Expedition mit denjenigen der Münchener Sammlung aus Japan und mit den Abbildungen DE HAAN's gut überein. Das für die erwachsenen Stïcke charakteristische Verhältnis der Breite zur Länge haben sie noch nicht erreicht.

2 ơ, jung, Station 244, Dar es Salaam, $50 \mathrm{~m}$ Tiefe.

Verbreitung: Indopacific: Indien (Milne-Edivards); Andamanen, Ostküste von Indien vom Gangesdelta bis Pondichery (Alcock); Madras (Heller); Ceylon (Alcock); Persischer Golf (Alcock); China (DE HAAN); Japan (dE HAas, Doflein); Amboina (DE Mav); Port Jackson? (Miers).

\section{Gattung Mursia Desiarest.}

I886 Mrits, Challenger Brachyura, p. 290 (Litt.).

1896 Alcock, Carcin. Fauna India, No. 3, Brachyura oxystoma, in: Journ. As. Soc. Bengal, Vol. LXV, II, p. 148 (Litt.).

Mursia ist eine indopacifische Gattung, welche vom Cap der guten Hoffnung bis zu den Sandwich-Inseln verbreitet ist. Die ihr nahestehende Gattung Platymera bewohnt die westamerikanische Region vom Feuerland bis nach Californien.

Es sind von der Gattung Mursia bisher 6 Arten beschrieben worden.

r) Mursia cristimana Latr. (s. unten), von der Region des Caps der guten Hoffnung, $90-275 \mathrm{~m}$ Tiefe.

2) M. armata DE HAAN (s. unten), von Japan und China, IOO-200 m Tiefe.

3) M. curtispina Miers (s. unten) (Challenger Brachyura, I886, p. 29I, Taf. XXIV, Fig. 2), von den Fidji-Inseln, $575 \mathrm{~m}$ Tiefe.

4) M. bicristimana Alc. u. Avd. (s. unten), bei Ceylon, 250-750 m Tiefe.

5) M. hawaiensis Rathbun (Proc. U. S. Nat. Mus., I893, Vol. XVI, p. 252), bei den Sandwich-Inseln, $540 \mathrm{~m}$ Tiefe.

6) M. aspera Alcock (Investigator Deep Sea Brachyura, Calcutta I899, p. 24), bei den Malediven gegen $400 \mathrm{~m}$ Tiefe. 
Betrachten wir das Verbreitungsgebiet dieser Formen, so bemerken wir, daß M. cristimana, von den anderen Formen isoliert, das in vielen Beziehungen eigenartige Capgebiet bewohnt, während die 5 übrigen Formen im eigentlichen Sinne indopacifisch sind.

Damit stimmen die morphologischen Verhältnisse in überraschender Weise überein. Vährend $\boldsymbol{M}$. cristimana in der Skulptur des Cephalothorax, in der Gestalt seines Hinterrandes und in Umriß und Skulptur der Scherenfüße stark von sämtlichen anderen Formen abweicht, sind diese nur durch geringe Abweichungen voneinander unterschieden. Zum Teil sind diese Formen noch dazu durch Uebergïnge verbunden; bei anderen scheinen die abweichenden Merkmale zwar nach unseren bisherigen Kenntnissen nicht in Uebergängen zu dem Verhalten bei anderen Formen zu führen; ihre Verschiedenheiten sind aber so gering, daß sie nicht zur Aufstellung von besonderen Arten genügen (vgl. S. I 5 u. I6).

Ich unterscheide daher von Mursia nur 2 Arten:

I) Mursia cristimana LATR. und

2) Mursia armata DE HAN.

Von letzterer Art sind jedoch einige Formen zu ,unterscheiden, worauf ich unten noch eingehe (S. 40).

IVas nun die senkrechte Verbreitung der Gattung angreht, so ist bemerkenswert, daß $M$. armata in ihren verschiedenen Varietäten im eigentlichen Warmwassergebiet des indopacifischen Oceans stets in Tiefen zwischen 250 und $750 \mathrm{~m}$ gefunden wurde. Wo jedoch die Gattung ihren Verbreitungsbereich weiter nach Norden oder Süden erstreckt, also an den japanischen Fundorten der $M$. armata und in dem gesamten Verbreitungsgebiet von $M$. cristimana, in der Nähe der Südspitze Afrikas fanden sich Exemplare zum Teil in Mengen in Tiefen von weniger als $100 \mathrm{~m}$.

Bei sämtlichen von mir untersuchten Arten und Formen ist die Außenseite der Scheren mit II Haupthöckern besetzt, von denen 9 in 3 Reihen angeordnet sind, welche entsprechend dem Umriß der Palma gegen das Carpalgelenk etwas konvergieren.

Die Höcker dieser 3 Längsreihen sind so übereinander angeordnet, daß sie auch 3 schiefe Querreihen bilden.

Die 2 letzten Höcker befinden sich in dem Raume, welcher zwischen der obersten Längsreihe von Höckern und dem Kamme am oberen Rande der Palma übrig bleibt.

Die Oberfläche der Palma zwischen den Höckern ist mit Körnern bedeckt, welche bisweilen reihenweise angeordnet sind, und von denen einzelne bei verschiedenen Formen eine ansehnliche Größe erreichen.

Die Höcker der 3 Längsreihen haben bei den verschiedenen Arten und Formen eine verschiedene Gestalt und können stachelartig sein (cristimana), dornenförmig sein, wobei besonders diejenigen der untersten Reihe von oben nach unten abgeplattet sind (curtispina, haruaiensis), kuppelförmig sein (armata), die abgeplatteten Dornen der unteren Reihe können untereinander verschmelzen, während die der mittleren Längsreihe durch dazwischen liegende größere Körner zu einer zweiten Leiste verbunden erscheinen (bicristimana), oder schließlich kann die ganze Oberfläche so mit scharfen Körnern bedeckt sein, daß die Quer- und Längsreihen darunter verschwinden (aspera). 
Bei den toten, in Spiritus aufbewahrten $\delta$ und $q$ der sämtlichen mir vorliegenden Formen ist mir aufgefallen, daß beim Hervorholen aus den Gläsern nicht selten ein Geräusch durch Aneinanderreiben gewisser Teile hervorgebracht wurde, welches sehr an das Schrillen gewisser Heuschrecken erinnerte. Genauere Untersuchung zeigte, daß sich an der Innenseite des beweglichen Scherenfingers nahe dem Außenrande eine Längsreihe von leistenartigen Körnern befindet, welche sehr an das Stimmorgan der Ocypoden erinnert.

Während auch die übrigen Kanten der Scherenfinger mit Körnerreihen versehen sind, sind nur in dieser Reihe die Körner zu Querleistchen ausgezogen. Die Reihe besteht je nach der Größe der Individuen aus 30-40 Leistenkörnern.

Sie wirkt, um den Ton zu erzeugen, gegen eine quere Körnerleiste, welche am Vorderrand des Ischiopoditen der 2. Gnathopoden hinzieht. Auch mag bei der Tonerzeugung die allgemeine Körnelung der Außenseite der 2. Gnathopoden mitwirken. Hauptsächlich ist aber jedenfalls die Leiste wirksam.

Die Leisten auf dem beweglichen Finger der Schere scheinen bei den verschiedenen Formen nicht auffällig unterscheidbar zu sein, also keinen Anhaltspunkt für systematische Verwendung zu bieten. Ich kann dies aber noch nicht entscheiden, da die mir zur Verfügung stehenden Exemplare bei einzelnen Formen von verschiedener Größe sind.

Ueber die Verwandtschaftsverhältnisse der Gattung will ich an dieser Stelle nur bemerken, daß es nötig sein wird, Platymera Gaudichaudii von der westamerikanischen Küste zur Gattung Mursia zu ziehen, mit welcher sie durch M. armata var. bicristimana sowohl in der Bildung der Schere, als auch der äußeren Gnathopoden verbunden wird. Von atlantischen Gattungen ist möglicherweise Acanthocarpus Stmpsox miteinzubeziehen.

Das würde ferner die Umgruppierung einiger weiteren Gattungen zur Folge haben, wie Paracyclois Miers und Cryptosoma Brullé.

\section{Mursia cristimana LATREILLE.}

Taf. XVI, Fig. 5-I2; Taf. XVIII, Fig. I.

I829 Mursia cristimana LAtreilie, in: Cuvier, Règne animal, éd. 2, p. 39.

I836 Mursia cristata Mrlne-Edwards, in: Atlas zu Cuvier, Règne animal, ed. 3, Taf. XIII, Fig. I u. Ia.

I837 Mursia cristata Milde-Edwards, in: Hist. nat. Crust., Vol. II, p. 109 (Litt.).

I848 Cyplosoma orientis Adaxs u. WhITE, in: Zoology Voy. Samarang, p. 62, Taf. XIII, Fig. 4.

I886 Mursia cristimana LATR. Miers, in: Challenger Brachyura, p. 29 I (Litt.).

Von den sämtlichen Formen von M. armata ist $M$. cristimana durch folgende auffallende Merkmale unterschieden:

I) Die Stirn läuft in einen spitzen, scharfen Zahn aus.

2) Der Hinterrand ist glatt, ohne Stachelbildungen, nur leicht gewellt und von einem feinen Körnerband eingefaßt.

3) Der Unterrand der Scheren ist mit groben Zähnen besetzt, welche höchstens in der Zahl von 8-9 auftreten. Selbst bei ganz kleinen Exemplaren ist die Größe dieser Zähne auffallend, wenn man sie mit den feinen Zähnchen der Formen von armata vergleicht.

Bei meinen Exemplaren ist ferner die Fissur von oberen Rande der Orbita sehr tief und deutlich weit offen. Die Innenränder der Ischiopoditen der 2. Gnathopoden sind mit gewellter 
Zähnelung versehen, während bei den übrigen Formen prismatische Zähnchen diese Ränder einfassen.

Die Körnelung des Cephalothorax zeigt deutlich die 5 Lüngsreihen großer Höcker, zwischen welchen die Oberfläche des Cephalothorax mit Körnern von mittlerer Feinheit bedeckt ist.

Die größten Höcker sind mit ihrer Umgebung im Leben grellrot gefärbt, die sonstige Oberfläche hellbraun. Bei einzelnen Exemplaren hat diese Färbung im Spiritus ziemlich gut srehalten.

Das Material der „Valdivia“-Expedition ist dadurch interessant, daß eine ziemlich vollständige Serie der postlarvalen Entwickelung sich aus demselben zusammenstellen läßt. Aus derselben ergiebt sich, daß während des Heranwachsens eine in die Augen fallende Veränderung in folgenden Punkten eintritt:

I) Das Verhältnis der Länge zur Breite ändert sich; die alten Tiere sind relativ viel breiter als die jungen (s. Abbildung Taf. XVI, Fig. 5-I2).

So sind:

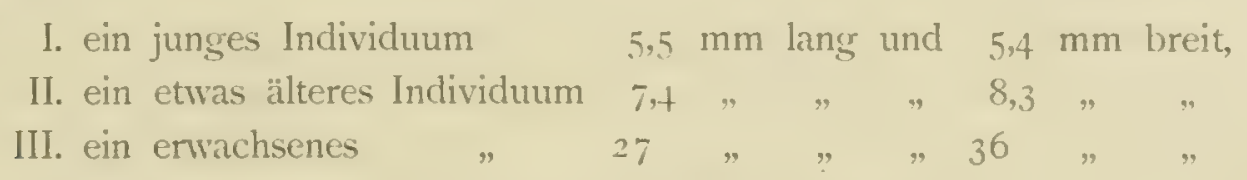

Also verhalten sich Länge und Breite bei ihnen, wie folgt: I. 5:5, II. 5:5,60, III. 5:6,67.

2) tritt die Granulation des Cephalothorax ganz allmählich auf; dabei beginnen erst ziemlich spät die großen Höcker sich von den kleinen Körnern zu unterscheiden;

3) treten die Stacheln auf der Außenfläche der Scheren erst spät hervor;

4) ist in den jungen Stadien naturgemäß die Stirn relativ viel stärker entwickelt als bei den älteren; ebenso verhält es sich mit den Augen;

5) sind bei den jungen $\delta$ die Abdomensegmente $3-5$ noch nicht verwachsen.

Die „Valdivia"-Expedition fing Exemplare von Mrursia cristimana an folgenden Stellen: $20^{\circ}, 1$ q, Station 92, vor Capstadt, $33^{\circ}+1,2^{\circ} \mathrm{S} . \mathrm{Br}$, $18^{\circ} 0,3^{\prime} \mathrm{O}$. L., in $778 \mathrm{~m}$ Tiefe,

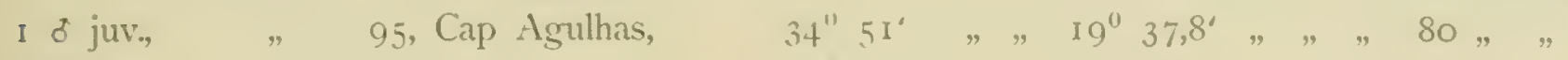

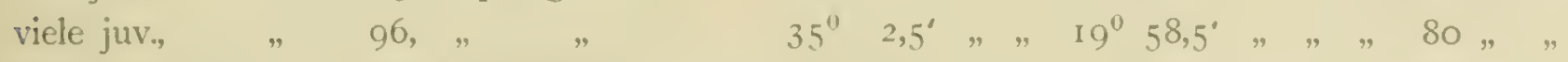
I $\delta$ u. juv., " I

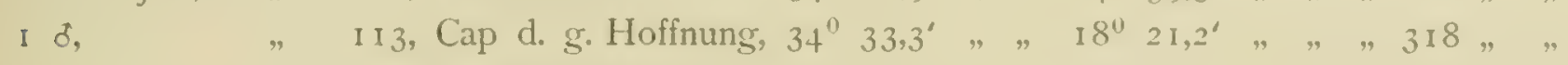

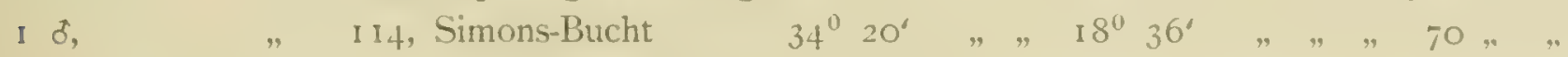

Verbreitung: Capregion (MIILne-Edwards, dE HAan, Krauss): Cap der guten Hoffnung, Sea Point, Agulhasbank (Mrers); Tafelbucht (STUder).

\section{Mursia armata DE HAAN.}

Wie oben angegeben, fasse ich die 5 übrigen beschriebenen Arten der Gattung Inursia zusammen. Es scheint mir aber notwendig, 3 Subspecies zu unterscheiden. 
a) Mursia armata typica DE HAAN.

Taf. XvII, Fig. I; Taf. XVIII, Fig. 2.

I8.30 Mursia armata DE HAAx, Fauna japonica, p. 73, Taf, XIX, Fig. 2, I85o, Decas quarta, I839 (!).

1830 Thealia acanthophora Lucas, Ann. Soc. Ent. France, Vol. VIII, p. 479, Taf. XXI, Fig. I-3.

I 802 Mursia amata ORTManN, Zool. Jahrb. Syst., Bd. VI, S. 564.

Ig02 Mursia armata Doflein, Abl. K. bayr. Ak. Wiss. München, II. Kl., Bd. XXI, 3. Abt., S. 053.

Diese Form ist durch die sehr großen Seitenstacheln ausgezeichnet, welche je halb so lang sind, als der Cephalothorax am Hinterrande ihrer Basis. Die Bewaffnung des Hinterrandes besteht aus 2 flachen, stark granulierten Dornen an den Ecken und einem medianen flachen Höcker. Die Stirn läuft spitz zu; auf der Außenfläche der Scheren sind die Höcker kuppelförmig stumpf (nach einem Exemplar des Münchener Museums). Der Vergleich der Beschreibungen und Figuren von LuCAs und von DE HAAN mit Exemplaren von $M$. armata zeigt, daß Thealia acanthophora Lucas absolut identisch ist. Die Priorität von beiden im gleichen Jahre veröffentlichten Benennungen wird wohl die DE HAAx'sche haben, da die Sitzung der Société entomologique, in welcher Lucas über seine neue Art vortrug, erst im Oktober 1839 stattfand, der Druck der Abhandlung jedenfalls noch etwas später erfolgte.

Nach Ortmanx, welcher die folgende Form (curtispina Miers) schon mit armata zu einer Art vereinigte, scheinen beide Formen durch kontinuierliche Uebergänge verbunden zu sein und an den gleichen Fundorten vorzukommen (s. auch S. 41).

Bei jungen Exemplaren scheinen die Seitenstacheln stets relativ viel länger zu sein, als bei alten.

Verbreitung: Japan (DE HaAx): Tokiobai, Sagamibai, 90-i80 m Tiefe (Ortmanx, Doflein); China (LuCAs).

\section{b) Mursia armata curlispina MIERS.}

Taf. XVII, Fig. 2; Taf. XVIII, Fig. 3.

I886 Mursia curtispina Miters, Challenger Brachyura, p. 29I, Taf. XXIV, Fig. 2.

I802 Mursia armata DE HAax, p. pte., Ortuanx, Zool. Jahrb. Syst., Bd. VI, S. 564.

I899 Mursia aspera Alcock, Investigator Deep Sea Brachyura, Calcutta, p. 24, u. Illustrations of the Zoology of the Investigator, Crustacea, Heft VII, Taf. XL.

Von dieser Form liegen mir ein $\delta$ und ein $q$ aus der Ausbeute der "Valdivia“ vor. Während bei typica die Länge der Seitenstacheln zusammen der Breite des Cephalothorax gleich kommt, erreichen sie bei curtispina zusammen nur $1 / 5$ der Cephalothoraxbreite.

Der mittlere Stirnzahn ist bei meinen Exemplaren nicht ganz stumpf. Die Zähne der Hinterrandes sind glatt, dorsoventral abgeplattet; die äußeren größer als der mediane. Die Stacheln auf der Außenseite der Scheren sind oben stumpf, weiter unten sind sie groß, dreieckig, von oben nach unten flachgedrückt.

Die zıvischen den größeren Höckern stehenden Körner der Cephalothoraxskulptur variieren stark in der Größe; sind sie stark ausgebildet und zu kleinen, stachelartigen Bildungen erhoben, so entsteht offenbar die von Alcock als $M$. aspera beschriebene Form. Möglicherweise ist ihre Entstehung von den Wohnortsbedingungen abhängig. 
I J, I f́, Station I99, $0^{\prime \prime} 15,5^{\circ}$ N. Br., $98^{\circ} 4^{\circ}$ O. L., dicht unter der Südküste ron Nias in einer Tiefe von $470 \mathrm{~m}$.

Verbreitung: Indopacifisch: Fidji-Inseln, $576 \mathrm{~m}$ Tiefe (Mrerss); Japan, 90- $180 \mathrm{~m}$ Ticfe (Ortanan); Malediven, $38+\mathrm{m}$ Tiefe (Alcock).

\section{c) Mlursia armala hawaiensis RATHBUN.}

1893 Mfursia haraiensis Ratinus, Proc. U. S. National Museum, Vol. XVI, p. 252.

Wahrscheinlich ist diese Subspecies mit der folgenden zu vereinigen, welche dann ihren Namen anzunehmen hiitte.

Die Beschreibung Miss Rathnun's ist aber zu einer genauen Identifizierung nicht ausführlich genug, und der vorläufigen Beschreibung ist bisher keine ausführliche von Abbildungen begleitete gefolgt. Jedenfalls wäre die Ungleichheit der Schere kein genügendes Unterscheidungsmerkmal, da sie wohl auf Regeneration zurückzuführen ist.

Verbreitung: Sandwich-Inseln, $540 \mathrm{~m}$ Tiefe (Ratrbun).

\section{d) Mursia armata bicristimana Alcock u. Anderson.}

Taf. XVII, Fig. 3 und Taf. XVIII, Fig. 4.

I804 Mfursia bicristimana Alcock u. Andersor, in: Jutrn. Asiat. Soc. Bengal, Vol. LXIII, 2, p. I79; Ill. Zool. Investigator Crustacea, Taf. XXIV, Fig. 5.

I 896 Mursia bicristimana Alcock, Carcinological Fauna of India, in: Journ. Asiat. Soc. Bengal, Vol, LXV, 2, p. I50. I 899 .Mursia bicristimana Alcock, Investigator Deep Sea Brachyura, p. 23.

Bei dieser Subspecies ist der Hinterrand an beiden Seiten mit einem dreieckigen, kurzen, flachen Zahn versehen, während in der Mitte sich nur eine schwache Vorwölbung befindet. Die 3 Dornen der unteren Reihe auf der Palma der Schere sind durch eine Leiste miteinander verbunden, ohne dadurch selbst unsichtbar zu werden, die beiden distalen sind als wellenförmige Vorwölbungen, der proximale als scharfer Zahn auf der Leiste sichtbar.

Die "Valdivia"-Expedition brachte von dieser Art I $q$ von Station 208 mit, von $6^{\circ} 54^{\text {" }}$ N. Br., $93^{\circ} 28,8^{\circ}$ O. L., im Südwesten von Groß-Nikobar aus einer Tiefe von $296 \mathrm{~m}$.

Verbreitung: Ceylon, 260-732 m Tiefe (Alcock).

\section{Gattung Pariphiculus Alcock.}

I 896 A L.cock, Joum. As. Soc. Bengal, Vol. LXV, 2, p. 257.

\section{Pariphiculus coronatus (Alcock u. Anderson).}

Taf. XIV, Fig. 7 .

I894 Randallia coronata Alcock u. Andersox, Journ. As. Soc. Bengal, Vol. LXIII, II, p. I74.

1896 Pariphiculus coronatus ALcock, ibid., Vol. LXV, 2, p. 258, u. Illustr. Zoology Investigator, Crustacea, Taf. XXIV, Fig. 2.

I 899 P'ariphiculus coronatus Alcock, Investigator Deep Sea Brachyura, p. 30.

Die deutsche Expedition fing das bisher unbekannte of dieser Art. Von Unterschieden fällt an meinem Exemplar gegenüber dem $q$ des „Investigat or“ auf, daß die Granulierung des Cephalothorax, welche nach Entfernung des filzigen Ueberzuges hervortritt, stärker ist. 
Die Form und Bedornung der Ränder und Regionen des Cephalothorax weicht nicht von der Beschreibung Alcock's für das $q$ ab.

Die Scherenfüße sind $\mathrm{I}^{4} / 5$ mal so lang als der Cephalothorax (beim ${ }^{+} \mathrm{I}^{2}{ }_{3}$ mal). Die Palma ist fast gerade so lang als die Finger, welche in der Form mit denen des $q$ übereinstimmen.

Die 2. Gnathopoden sind sowohl auf dem Innen- als auch auf dem Außenast mit je einer Reihe kräftiger Körner auf der Oberfläche versehen.

Das Abdomen des ơ ist etwa lanzenspitzenförmig. Das 2. Flied trägt in der Medianen einen kurzen Stachel.

Das 3.-5. Segment sind verwachsen, das 6. und 7. frei. Das durch die Verwachsung entstandene große Glied verschmälert sich allmählich von der Basis gegen das distale Ende zu. Kerben an seinen Rändern deuten die Grenzen der verwachsenen Segmente an. Das erste derselben ist das breiteste des Abdomens, indem seine Ränder im Bogen wéit nach außen vorragen. Das 6. Segment ist einfach trapezförmig, das 7. sehr lang-dreieckig; das Ende läuft in eine lange, fast pfriemenartige Spitze aus.

Außer den schon von Alcock hervorgehobenen Unterschieden gegenüber Randaltia wäre noch zu erwähnen, daß die Augen viel kleiner und dünnstieliger sind und eine kleine Cornea besitzen.

Auch sind die äußeren Antennen relativ größer.

I d, Station 208, bei Groß-Nikobar, $6^{\circ} 54^{\circ} \mathrm{N}$. Br., $93^{\circ} 28,8^{\prime}$ O. L., in einer Tiefe von $296 \mathrm{~m}$.

Verbreitung: Bai von Bengalen (Coromandelküste), $20+\mathrm{m}$ 'Tiefe („Investigator": ALCo(k).

\section{Gattung Randallia Stmipson.}

1857 Stimpson, Journai Boston Soc. Nat. Hist., Vol. VI, p. 47 I.

I886 Miers, Challenger Brachyura, p. 316.

I 806 Alcock, Carc. Fauna India, in: Journ. As. Soc. Bengal, Vol. LXV, 2, p. IgI.

Ueber die Zugehörigkeit der Arten, welche von den verschiedenen Autoren zur Gattung Randallia gezogen werden, habe ich mir auf Grund der Litteratur kein Urteil bilden können. Das Material von der Gattung und ihren Verwandten, welches ich bei der Untersuchung heranziehen konnte, ist $z u$ gering, um mir eine Revision $z u$ gestatten. Doch kann ich mich des Eindruckes nicht erwehren, daß die von ALcock angenommene Einteilung sehr künstlich ist und daß bei genügendem Material und Berücksichtigung der verschiedenen Lebensverhältnisse sich nicht nur die Abgrenzungen der Arten, sondern auch der verwandten Gattungen wesentlich verschieben werden.

\section{Randallia pustulosa WOOD-MASON,}

Taf. XIV; Fig. I-6

I862 Randallia prestulosa Wood-Mason, Ann. Mag. Nat. Hist., I891, p. 266.

I892 Randallia pustulose Alcock, Illustrations Zool. Investigator, Crustacea, Taf. V, Fig. +.

I 896 Randallia pustulosa Alcock, Carc. Fauna of India, in: Joum. As. Soc. Bengal, Vol. LXV, 2, p. I96.

1899 Randallia pustulosa Alcock, Investigator Deep Sea Brachyura, Calcutta, p. 27. 
Von dem Material der "Valdivia"-Expedition gehört zu dieser Art zunächst ein schönes großes Weibchen. Es hat eine Länge und Breite von etwa $36 \mathrm{~mm}$, während das größte Exemplar des „Investigator" 3 I mm maß. Mein Exemplar zeigt demgemäß einige Merkmale des höheren Alters. Die Höcker am Seitenrand sind vollkommen stumpf und verschwinden zwischen den sehr starken Höckern, welche den ganzen Cephalothorax oben bedecken.

Der Stachel auf der Intestinalregion ist zu einem stumpflichen Höcker reduziert, welcher den Hinterrand nicht mehr überragt.

Die Pereiopoden sind sämtlich deutlich granuliert.

Das \& trägt zahlreiche kleine Eier unter dem Abdomen. Letzteres ist auf der Unterseite (Dorsalseite) sehr glatt für das bloße Auge, doch erkennt man mit der Lupe cine feine Punktierung, herbeigeführt durch zahlreiche feine Höckerchen.

Wie Alcock hervorhob, existiert bei dieser Art eine Verbindung des Brutraumes unter dem Abdomen mit der Kiemenhöhle. Wer den außerordentlich dichten Verschluß, welcher durch das Andrücken des Abdomens gegen das Sternum herbeigeführt wird, ins Auge faßt, sieht ohne weiteres ein, daß hier eine Zufuhr von frischem Atemwasser zu den in der Entwickelung begriffenen Eiern unbedingt erforderlich sein mußte.

Außer diesem Exemplar von der Gegend von Groß-Nikobar brachte die Expedition 3 weitere von der ostafrikanischen Küste heim, welche unzweifelhaft zur selben Art gehören, sich aber durch eine Reihe von Abweichungen auszeichnen, welche sowohl für die verschiedenen Altersstadien charakteristisch als auch die Merkmale einer besonderen geographischen Varietät darstellen können. Ich bin geneigt, erstere Möglichkeit anzunehmen.

Schon Alcock hebt eine Anzahl von Charakteren hervor, welche das junge Tier ron dem enwachsenen unterscheiden. Er nennt die mehr kreisförmige Gestalt, die Stacheln des Randes, die feinere Granulation der Oberflïche.

Die Figuren, welche ich auf Taf. XIV, Fig. I-6 gebe, zeigen diese Unterschiede. Sie zeigen auch, wenn wir die 3 Stadien von Ostafrika mit dem älteren indischen vergleichen, daß die Granulationen beim Heranwachsen des Tieres successive stärker werden, während die Stacheln relativ kleiner werdend, schließlich zwischen den Granulationen verschwinden. Am auffälligsten ist dies für den Stachel auf der Intestinalregion, welcher bei dem jungen Tiere stark emporragt, allmählich aber immer mehr schwindet. Bei den älteren Stadien ist er nicht nur relativ, sondern absolut kleiner als bei jungen.

Die beiden kleinen Exemplare sind ebenfalls Weibchen. Sie zeigen auf der Mitte des 3. Sternalsegmentes die Genitalöffnungen, auch sind am Abdomen die typischen weiblichen Anhänge vorhanden. Das Abdomen selbst jedoch besitzt die männliche Form, wie aus Fig. 2 zu ersehen ist. Die Segmente 4, 5 u. 6 sind zwar schon verwachsen, zeigen aber noch deutliche Abgrenzungen. Das Abdomen nimmt also offenbar erst in späten Stadien, nahe der Geschlechtsreife, die für das $q$ typische Form an, oder es handelt sich um pathologische Exemplare.

Es ist von großem Interesse, zu bemerken, daß offene Kommunikationen der noch unentwickelten Bruthöhle mit der Kiemenhöhle noch nicht vorhanden sind - eine teleologisch wohl verständliche Erscheinung, da sie in diesem Stadium noch nicht gebraucht werden. 
Ferner verdient hervorgehoben $z u$ werden, daß sich bei eintretender Geschlechtsreife die Form des Sternums mit derjenigen des Abdomens stark verändert, indem es sehr vertieft wird und die vom Abdomen bedeckte Fläche bis an die Basen der Pereiopoden hinübergreift (Taf. XIV, Fï. ₹.

I + , enwachsen, mit Eiern, Station 208, im Südwesten von Groß-Nikobar, $6^{0} 54^{\prime}$ N. Br., $93^{\circ} 28.8^{\circ}$ O. L., in einer Tiefe von $296 \mathrm{~m}$.

2 \& juv., I $q$, fast enwachsen, ohne Eier, Station 254, nahe der ostafrikanischen Küste, $0^{\circ} 29,3^{\prime} \mathrm{S}$. Br., $42^{0} 47,6^{\circ}$ O. L., in einer Tiefe von $977 \mathrm{~m}$.

Verbreitung: Indischer Ocean: Andamanen, Laccadiven; Travancore, 402-782 m (Alcock: „Investigator").

\section{Gattung Parilia WoOd-Mason.}

\section{Parilia Alcorki WOOD-MASON. \\ Taf. XIV, Fig. 8 und 9 .}

I8q I Parilia Alcockii Woon-MLson, Ann. Mag. Nat. Hist., Ser. 6. Vol. VII, p. $26+$.

I 802 Parilia Alcockii, Illustrations Investigator, Crustacea, Taf. V, Fig. 3 und 3 a.

I89t Parilia Alcackii Alcock und Anderson, Journ. As. Soc. Bengal, Vol. LXIII, 2, p. I77.

I806 Parilia Alcockii ALCock, ebenda. Vol. LXV, 2, p. 198.

Leider liegt mir von dieser Art nur I Exemplar ohne Scheren vor. Ich hielt dasselbe ursprünglich für den Vertreter einer neuen Art von Randallia, bis ich die Abbildung erhielt und durch genauen Vergleich feststellen konnte, daß es sich um die schon seit 189 I bekannte Art der Gattung Parilia handelt.

Der Cephalothorax ist ungefähr kreisrund, stark gewölbt, seine Länge ist $=34 \mathrm{~mm}$, seine Breite $=3 \mathrm{I} \mathrm{mm}$; von Regionen ist kaum etwas erkennbar. Nur die Intestinalregion erscheint von ganz zarten, feinen Furchen umzogen. Deutlich ist dagegen eine kielartige Kante, welche etwas vor der Mitte des Cephalothorax sichtbar wird und in der Mediane nach hinten verläuft. Sie wird nach hinten immer deutlicher und läuft schließlich auf dem Intestinalstachel aus. Bei Arten der Gattung Randallia ist diese Kante durch eine Reihe von Höckern angedeutet (s. Taf. XIV, Fig. 8).

Die Oberfläche erscheint für das bloße Auge fast glatt, mit der Lupe erkennt man eine gleichmäßige Bedeckung mit feinen, sehr gleichmäßigen Granulationon; die Zwischenräume zwischen denselben sind von noch feineren Körnchen erfüllt.

Die Stirn ist schmal und in zwei breite, dreieckige Zähne geteilt, deren Ränder scharf sind.

Der Mundrand ragt über den Stirnrand deutlich vor; die Pterygostomregionen dagegen sind nur wenig vorgewölbt.

Der Seitenrand verläuft sehr gleichmäßig und ohne stärkere Einkerbung. In seinem Verlauf zeigt er 5 Zähne, 2 weitere begrenzen den Hinterrand. Am Vorderseitenrand stehen 3 ziemlich gleich große, in gleichen Abständen bis zur Umbiegung in den Hinterseitenrand verteilt, zwischen dem 2. und 3. derselben steht ein kleiner Zahn. Nahe dem Eckzahn des Hinter- 
randes steht der einzige Zahn des Hinterscitenrandes; der Hinterseitenrand selbst ist ganz stumpf und nicht sehr deutlich. Alle diese Zähne sind mehr oder weniger höckerförmig und stumpf. Sie sind mit den gleichen Granulationen bedeckt wie der ganze Cephalothorax.

Die beiden Eckzähne des Hinterrandes sind abgeflacht spitz und cbenfalls granuliert.

Der Intestinalzahn ist groß, spitz und gegen das Ende aufwärts gebogen.

Die Augren sind mäßig groß; die Fissuren im oberen Rand der Orbita eng und tief, die im Außenrand ist weit offen und weniger tief.

Die 2. Gnathopoden sind sehr fein granuliert und am vorderen Ende 'mit ziemlich langen Haaren auf Exognath und Endognath bedeckt.

Die Pereiopoden sind auf der Unterseite und an den ganzen distalen Cxliedern glatt. Die Rück- und Oberseite von Meropodit, Carpopodit und selbst des proximalen Endes des Propodit sind mit spitzen, kleinen Stacheln bedeckt.

Die Dactylopoditen sind oben fast bis an die Basis, unten nur bis zur Hälfte mit feinen, einreihigen Haarbürsten bedeckt.

Das mir vorliegende Stück ist ein unreifes WVeibchen; das Abdomen hat die typische Form des männlichen (Taf. XIV, Fig. 9). Es ist lang und schlank, alle 7 Glieder sind frei, das 1. Glied schmal, das 2. hat an den Seiten schmale, fingerförmige Fortsätze, 3, 4 und 5 sind etwa gleich breit, aber von zunehmender Höhe, am höchsten ist das 6., welches sich distal schon stark verschmälert; fast gleich hoch das 7., welches die Form eines spitzwinkligen, gleichschenkligen Dreieckes hat.

An der Unterseite des Abdomens finden sich weibliche Anhänge, auf dem 3. Sternalsegrment weibliche Genitalöffnungen.

I $q$ juv., Station 202, im Nias-Nordkanal, I 2 Seemeilen südlich von Bangkam, I $^{0} 48,1^{\prime}$ N. Br., $97^{\circ} 6^{\circ} \mathrm{O}$. L., in einer Tiefe von $14 \mathrm{I} \mathrm{m}$.

Verbreitung: Ostküste von Vorderindien, I $30-450 \mathrm{~m}$ (Alcock).

\section{Gattung Philyra LEACH.}

I902 Stebing, in: Cape of good Hope, Deptmt. of Agriculture, Marine Investigations in Southafrica. South African Crustacea, Pt. 2, p. I7 (Litt.).

\section{Philyra punctata BELL.}

Taf. XV, Fig. I-4.

1855 Philyra punctata Bell, Transact. Linn. Soc. London, Vol. XXI (1852-55), p. 301, Taf. XXXIII, Fig. 2 1902 Philyra punctata Stebing, a. a. O. p. I 7 (Litt.).

Den Beschreibungen dieser Form habe ich nichts hinzuzufügen; da aber die in von BELL. gegebene Abbildung sehr wenig gut ist, so habe ich einige Photographien auf Taf. XV beigefügt.

I $\delta, 5$, Station IoO, Francisbai, in geringer Tiefe.

7 t u. $f$, Station IO I, Algoabai, in geringer Tiefe.

I verletztes $\delta$, Station 9gb, Plettenbergbai, in geringer Tiefe.

Verbreitung: Simonsbai, 6-15 m (Bell); Mosselbai (Stebring). 


\title{
Philyra laminata n. sp.
}

Taf. IV, Fig. 5 und 6.

Die Oberfläche des Cephalothorax ist bei dieser Art merkwürdig mit Granulationen und feinsten Kanten bedeckt, so daß fast derselbe Eindruck hervorgerufen wird, wie von der Haut einer Orange oder Citrone.

Die Form des Cephalothorax ist ziemlich kreisrund, stark gewölbt, der Hinterrand ist von zwei rundlichen Lappen begrenzt.

Von Regionen ist nur die Intestinalregion zu erkennen, welche auch nur zart abgegrenzt ist (Taf. XV, Fig. 6). Stachelbildungen sind keine vorhanden.

Die Stirn ist in zwei Lappen eingekerbt, die Augen sitzen in deutlichen tiefen Orbiten.

Die Pterygostomialregion ragt etwas weiter vor als das Epistom, welches mit den Mundteilen nur wenig vorsteht.

Das Abdomen des jungen J, welches allein von dieser Art mir vorliegt, ist schlank gebaut; es ist wie die ganze Unterseite regelmäßig granuliert. Sämtliche 7 Segmente sind erkennbar, doch beginnen die Grenzen, welche die Segmente 4-6 trennen, schon undeutlich zu werden (Taf. XV, Fig. 5).

Die Scherenfüße sind kurz und gedrungen. Die Scheren selbst sind kaum halb so lang als der Cephalothorax. Die Palma ist kürzer als die Finger, birnförmig geschwollen, während die Finger scharf, schlank, seitlich abgeplattet und etwas nach innen gekrümmt sind. Sie haben feine Zähnchen auf den Schneiden, welche ziemlich dicht schließen.

Die übrigen Pereiopoden sind besonders oben und hinten granuliert. Sie sind dünn, schlank, die Dactylopoditen sind sehr gerade, spitz-griffelförmig.

Das 5. Pereiopolenpaar ist oben granuliert und ist am Meropodit, Carpopodit und Propodit durch eine Lamelle verbreitert.

Das Mundfeld ist relativ breit. Die 2. Frnathopoden außen sehr fein granuliert, Exognath und Endognath etwa gleich breit (Taf. XV, Fig. 5).

I J juv., Station 202, im Nias-Nordkanal, I 2 Seemeilen südlich von Bangkam, I" 48, I' N. Br., $97^{\circ} 6^{\prime}$ O. L., in einer Tiefe von $14 \mathrm{I}$ m.

Im allgemeinen Aussehen erinnert die Art am meisten an. Ph. remmoosa Hexderson (Trans. Linn. Soc. London, Zool. (2), Vol. V, I893, p. 399, Taf. XXXVII, Fig. IO-I2), von welcher sie sich aber schon auf den ersten Blick durch die Lamellen an den Hinterbeinen unterscheidet.

\section{Gattung Ebalia LeACH.}

1855 Litt. BeLL, Trans. Linn. Soc, London, Vol. XXI, I $852-55$.

inoo Mitne-Edwards u. Bouvier, Exp. scient. Travailleur et Talisman, Crustacés décapodes, Brachyures et Anomoures, $\mathrm{p} . \mathrm{fI}$

\section{Ebalia (Phlyxia) atlantica MILnE-Edwards u. BOUvier.}

\author{
Taf. XVI, Fig. 4 .
}

1898 Ebalia atlantica Mircke-Edwards u. Bouvier, in: Bulletin du Musée Paris, T. IV, p. 32.

InO0 Ebalia allantica MILxE-EDwards u. Bouvier, Expéd. scient. Travailleur et Talisman, Crustacés décapodes, Brachyures et Anomoures, p. 5 I, Taf. XIII, Fig. 4-10. 
Unsere Expedition fing auf der Seinebank eine Ebalia, welche mir mit E. atlantica identisch zu sein scheint, obwohl sie in einigen Punkten, welche ich aber für unwesentlich halte, abweicht. Möglichenveise sind die Abweichungen darin begründet, daß mein Exemplar ein junges Weibchen ist.

Von solchen Abweichungen wäre hervorzuheben die große Schlankheit der Scheren, deren Palma mehr als $2 \frac{1}{2}$ mal so langr als breit ist. Ferner ist die Oberfläche des Cephalothorax sehr fein granuliert.

Auch lassen sich vor der Intestinalregion 4 helle Flecken erkennen, welche etwa in einem Halbkreis angeordnet sind (vergl. Taf. XVI, Fig. 4).

Der Einschnitt in der Mitte der Stirn ist tiefer und schärfer als bei dem Typus der französischen Autoren, ebenso ist die Einkerbung der beiden so entstandenen Stirnlappen, also die Vierteilung der Stirn, deutlicher. Es ist die Form daher eine typische Phlyxia.

Alle diese Abweichungen, welche nicht als Geschlechtsmerkmale aufzufassen sind, scheinen mir auf individueller Variation zu beruhen, um so eher, als auch Milne-Edivards u. Bouvieir nur je ein $\delta$ und $q$ zur Untersuchung hatten. Zu betonen ist, daß die Verhältnisse am letzten Segment des Abdomens genau der Schilderung von MiLxe-EDwards u. Bouvier entsprechen Es ist nämlich dies Segment beim $q$ zum Teil durch den Ischiopoditen des 2. Gnathopoden bedeckt, wodurch offenbar, wie MILNE-EDwARDs u. Bouvier hervorheben, ein hermetischer Verschluß des Brutraumes herbeigeführt wird.

I 7. Station 25, Seinebank, $33^{\circ} 43,8^{\circ}$ N. Br., I. $4^{\prime \prime} 20^{\prime}$ IV. L., in einer Tiefe von ca. $50 \mathrm{~m}$.

Verbreitung: Cap-verdische Inseln: Inselchen Branco, $60 \mathrm{~m}$ Tiefe („Talisman“; MilneEdwards u. Bouvier).

\section{Ebalia salamensis n. sp.}

Taf. XVI, Fig. I-3.

Von der vorher beschriebenen atlantischen Form, welcher sie im Habitus ziemlich ähnlich ist, unterscheidet sich diese Art sogleich durch die Stirnbildung. Diese ist fast geradlinig abgeschnitten, der mediane Einschnitt erscheint nur als seichte Kerbe, eine Ausrandung der beiden Stirnlappen ist kaum angedeutet. Vergl. Fig. I, Taf. XVI. IVas die Art aber vor allen Dingen bemerkenswert macht, ist, daß sie auf dem ganzen Cephalothorax mit Tuberkeln bedeckt ist, welche in weiter Ausdehnung langgestielt pilzförmig sind.

Es ist mir nicht gelungen, die vorliegende Form mit einer der bekannten Ebalien zu identifizieren; so beschreibe ich sie als neue Art. Es ist allerdings gerade bei dieser Gattung schwer, alle die zahlreichen, ziemlich variablen Arten auszuschließen; da mir aber 3 gute, einander sehr ähnliche Exemplare von 2 nahe bei einander gelegrenen Stationen aus einer Gegend, in welcher noch nicht in der Tiefe gefischt wurde, vorliegen, so glaube ich, einige Bürgsschaft für die Sicherheit der neuen Art zu haben.

Der Umriß des Cephalothorax ist ein unregelmäßig sechseckiger, indem Stirn- und Hinterrand zwei ganz kurze, die Hinterseitenränder mittellange, die Vorderseitenränder die längrsten Seiten bildet.

Den Stirnrand habe ich oben schon beschrieben, der Vorderseitenrand ist in der Hepatikalregion ausgebaucht, der Hinterseitenrand ist ziemlich gerade, der Hinterrand ist durch 2 drei- 
eckige, ziemlich große Vorragungen, welche zwischen sich einen abgerundet dreieckigen Ausschnitt lassen, geziert.

Teile der Mundregion ragen über den Stirnrand nicht vor, dagregen sind die pilzförmigen Tuberkel der Pterygostomialregion von oben zu sehen.

Hinter der Stirn ist die vordere Region des Cephalothorax etwas eingesunken, weiter nach hinten ist die Oberfläche ziemlich bucklig. Die Hepatikalregionen sind stark gewölbt; eine mäßige Vorwölbung zeigt sich mitten auf der Cardialregion, 2 etwas stärkere Buckel liegren symmetrisch etwas vor demselben, seitlich von der Gastralregion. Auch auf den Branchialgegenden findet sich je ein schwacher Höcker.

Den stärksten Buckel stellt die Intestinalregion vor, welche stumpf-kegelförmig vorgewölbt ist, ohne jedoch in einen Stachel ausgezogen zu sein.

Die Intestinalregion ist deutlich von Furchen umzogen, die Gastralregion nur undeutlich im hinteren Teile seitlich abgegrenzt.

Die Augen sind kurzgestielt, kugelig, schwarzbraun pigmentiert und mit deutlichen Facetten versehen. Die äußeren Antennen sind sehr dünn, aber nicht auffallend verkürzt und wohl ausgebildet. Die inneren Antennen sind klein und unter die nach unten stark umgeschlagene Mittelpartie der Stirn zurückziehbar. Die Seitenteile der Stirn strecken sich als schützende Dächer über die Augen hinaus, ohne die Cornea derselben jedoch vollständig zu bedecken.

Auch auf der Unterseite des Cephalothorax verbreiten sich die pilzförmigen Höcker. Doch sind sie hier teilweise durch kurz- oder gar nicht gestielte Knöpfchen ersetzt. Gleiches gilt von der Außenfläche der 2. Gnathopoden. Letztere sind mäßig breit, der Exognath fast ebenso breit wie der Endognath. Der Carpopodit ist kaum halb so lang wie der Meropodit.

Das Abdomen des $\delta$, nur solche liegen mir vor, ist 5-gliedrig, indem die Glieder 3, 4 und 5 miteinander verwachsen sind.

Die Gesamtform des Abdomens ist ungefähr pfeilspitzenförmig. Einen kurzen Stiel bilden die ganz niedrigen und ziemlich schmalen ersten beiden Glieder. Die eigentliche Spitze besteht zunächst aus einem großen Glied, welches aus der Verschmelzung der Segmente 3-5 entstanden ist. Zwei nach hinten und unten vorspringende Wülste seines hinteren Teiles stellen die Widerhaken der Pfeilspitze dar. Auf das große Glied folgt als ganz kleines das 6. Segment, während das Endglied eine lange, dünne Spitze bildet, welche nicht ganz bis an die Basis der 2. Gnathopoden hinreicht.

Die Scherenfüße sind ziemlich lang und schlank; der Meropodit dünn und etwa so lang wie die Schere, der Carpopodit kurz, die Schere schlank, ein wenig seitlich komprimiert. Die Finger sind dünn, mit feinen scharfen Zähnchen besetzt, an der Spitze nicht ganz dicht schließend und in dieser Region etwas nach innen gebogen. Die Finger haben nur etwa die halbe Länge der Palma.

Die übrigen Pereiopoden sind dünn und schlank, die zarten Dactylopoditen sind gerade und griffelförmig. Alle Pereiopoden sind besonders oben und hinten dicht granuliert. Die Granulationen werden am Hinterrand des Meropoditen des 5. Paares sogar pilzförmig. 
28, Station 242, außerhalb Dar-es-Salâm, $6^{\circ} 34,8^{\prime} \mathrm{S}$. Br., $39^{\prime \prime} 35,5^{\prime}$ O. L., in ciner Ticfe von $404 \mathrm{~m}$.

1 o, Station 24.3, außerhalb Dar-es-Salâm, $6^{\circ} 39, \mathrm{I}^{\prime}$ S. Br., $39^{\circ}$ 30,8' O. L., in ciner Tiefe von ca. $400 \mathrm{~m}$.

\section{Gattung Atlantotlos n. g.}

Trotz langen Nachsuchens in allen mir zugänglichen WVerken konnte ich keine Gattung ausfindig machen, welcher die mir vorliegende Art zuzuordnen wäre. Im Habitus zeigt sie am meisten Aehnlichkeit mit der Gattung Tlos Adans und WHITE, von welcher eine Reihe von Arten aus dem indopacifischen Gebiet durch Adams und White, Mirne-Edwards und Alcock bekannt greworden sind. Doch unterscheidet sie sich in verschiedenen Punkten von ihr.

Der Cephalothorax ist unregelmäßig sechseckig, die Ränder sind erheblich verbreitert, so daß ein großer Teil der Pereiopoden in eingeschlagenem Zustand unter denselben verborgen ist. Er ist stark bucklig, aber in der Oberflächenbeschaffenheit fast glatt, nur fein granuliert.

Die Stirn ist schmal, ragt kaum nach vorn vor; die Ränder sind an den Ecken und in der Mitte nach unten umgreschlagen. In der Mitte ist die Stirn mit einer kleinen Ausrandung versehen, welche aber nur von vorn, nicht von oben zu sehen ist.

Die Orbiten sind fast ganz geschlossen, am oberen Rande etwas ausgerandet und mit 2 ticfen Fissuren versehen; die umgebogenen Ecken der Stirn erreichen zwar den unteren Rand der Orbita nicht; aber das in die Lücke eingekeilte Basalglied der äußeren Antennen schließt dieselbe ziemlich vollständig. Allerdings ist keine gleichmäßige Höhe des Orbitarandes daclurch erreicht.

Die Geißel der äußeren Antennen fehlt. Die inneren Antennen sind schief eingeschlagen.

Die äußeren Gnathopoden schließen die Nundhöhle dicht ab. Der Exognath ist ziemlich breit, fast so breit wie der Endognath. Der Carpopodit ist am Innenrand mehr als halb so lang wie der Meropodit.

Die Scheren sind mäßig groß, mit geflügelten Kanten, die Finger sind schmal, scharf und spitz.

Die übrigen Pereiopoden sind kurz und stachelig.

Am Abdomen des IVeibchens sind die Glieder 3-6 verwachsen, das 7. Glied ist sehr klein und schiebt sich dicht an die Meropoditen der 2. Gnathopoden hin.

Von Nursia ist die Gattung durch den Mangel der Antennengeißel, die nicht offene Kommunikation der Orbita und inneren Antennenhöhle und den breiten Zwischenraum zwischen Orbita und Mundrand unterschieden; die Gattung gehört also zur Gruppe der Oreophoroida Alcock, unterscheidet sich aber schon durch den ganzen Habitus von Actacomorpha Mierzs, Heteronucia Alcock, von Merocryphus M.-Enw. und Uhlias Stmmson durch die Form des Cephalothorax, von Cryptocnemus Strupson durch Rostrum und anderes, von Orcophornes RürpeL. und Spelacophorns M.-EDw. durch den Charakter der Oberflächenbeschaffenheit. Von Tlos Adaus und IVHrre, dem sie sonst in vielen Punkten ähnelt, unterscheidet sich die Gattung durch die 
wenig vorgezogene Stirn, die Form der Scheren und die Beschaffenheit der Orbiten, besonders auch die 2 langen Fissuren im oberen Rande. - Tlos ist eine bisher nur indopacifische Gattung.

\section{Allanlollos rhombifer n. sp.}

Taf. XV, Fig. 7 und 8 .

Der sehr unebene Cephalothorax ist von lamellenartigen Rändern eingefaßt, dieselben zeigen in der Hepatikalgegrend eine tiefe, aber eng geschlossene Spalte (Hepatikalspalte). Von der wenig vorspringenden Stirn und der kleinen Orbita aus verläuft der Rand zunächst wenig geschwungen bis zu dem Spalt; dann ragt er bogenförmig ziemlich stark nach außen vor, um dann, nach hinten plötzlich umbiegend, fast parallel der Sagittalachse zu verlaufen. Sodann ragt die Randpartie in der Mitte der Branchialregion in Form eines stumpfen Seitenstachels auf jeder Seite vor. Der Spitzenwinkel dieses Seitenstachels ist fast $80^{\circ}$. Der Hinterrand dieses Stachels geht nach einer ganz leichten Einbuchtung fast geradlinig in den Hinterseitenrand des Körpers über. Kurz ehe der letztere in den Hinterrand übergeht, biegt er in einem Winkel von $145^{\circ}$ nach hinten um, um dann mit scharfer Ecke (ungefähr $\mathrm{I}_{20}^{\circ}$ ) an den kurzen geraden Hinterrand zu stoßen.

Um die Unebenheiten der Cephalothoraxoberfläche darzustellen, geht man am besten von der Gastrikalregion aus. Von deren hinterem Teil aus strahlen nach vier Richtungen Skulpturen aus:

I) Nach vorn verläuft geradeaus gegen die Mitte der Stirn eine stumpfe Kante. Ich nenne dieselbe Mediankante. Auf der Stirn gabelt dieselbe sich in 3 zart angedeutete Kanten, von denen die mittelste zur Stirnmitte, die seitlichen je zu einer äußeren Stirnecke laufen.

2) Schief nach hinten läuft je eine scharfe Kante quer über die Branchialregion, über den Seitenstachel bis auf dessen Spitze hinaus. Ich nenne diese Kanten die Branchialkanten. Sie lassen hinten zwischen sich einen Winkel von ca. $130^{\circ}$.

3) Dieser Winkel bezeichnet gleichzeitig annäherungsweise die vordere Grenze der Cardialregion. Sie ist vorn flach, nach hinten mehr gewölbt, und ihr Hinterrand ist gerade und sehr deutlich. Seitlich ist sie nur in ihrem hinteren Teil einigermaßen deutlich abgegrenzt. Viel deutlicher ist die stark kuppelförmig vorgewölbte Intestinalregion, sie fällt auch nach hinten steil $\mathrm{ab}$ und endet vor dem lamellenartig vorragenden Hinterrand.

Seitlich von dem wulstförmigen Rücken, den Cardial- und Intestinalregion bilden, und hinter der Branchialkante fällt der Cephalothorax steil zum Hinterseitenrand ab; ebenso ist vorn jederseits die Region zwischen der Branchialkante und der Mediankante tief ausgremuldet.

Der Teil vor der Hepatikalspalte ist wiederum etwas in die Höhe gewölbt, so daß er höher liegt als die Randpartie zwischen Hepatikalspalte und Branchialkante. Die Oberseite des Cephalothorax ist mit kleinen, glatten Höckerchen bedeckt, welche die ganze Fläche fein polygonal gefeldert erscheinen lassen.

Das Abdomen des Weibchens ist breit-löffelförmig und schließt sehr dicht an (Taf. XV, Fig. 7). Die 2 ersten Segmente sind sehr schmal und frei. Das 3. ist mit den folgenden unvollständig verwachsen (man sieht nur in der Mitte die Segmentgrenze nicht mehr) und $1 / 2$ mal breiter als die beiden ersten zusammen. Das 4., 5. und 6. sind vollständig verwachsen, das 7., 
welches die Form eines Wappenschildes hat, ist ganz klein, frei und sitzt mit geradem Vorderrande an dem stark sich verschmälernden Hinterrande des 6. Sermentes an. Die Außenseite des Ablomens ist mit deutlichen flachen Höckerchen in unregelmïßigen Alsstïnden bedeckt.

Von der P'terygostomialgegend wäre zu bemerken, daß sie ziemlich breit ist, wic auch der Teil der Unterseite, der sich, an sie anschließend, nach hinten bis gegen den Hinterrand hin erstreckt. Eine Pterygostomialrinne ist deutlich und erstreckt sich bis zur Hepatikalspalte.

Hinter derselben ist die Unterseite mit starken, rauhen Tuberkeln besetzt; nach hinten am Seitenstachel und gegen den Hinterrand hin ist sie wieder ganz glatt.

Die Augen sind klein; über die Sinnesorgane ist das deutlich Erkennbare und ohne Verletzung des Exemplares zu Untersuchende schon in der Gattungsdiagnose gesagt; ebenso von den :̈ußeren Gnathopoden.

Die Scherenfüße sind kurz und relativ kräftig; der Neropodit ist dreikantig-prismatisch; am proximalen Ende ist er ringsum mit Zähnchen und Höckerchen besetzt; distal setzen sich solche Zähnchen nur auf der unteren. Kante fort, während die obere und hintere gekielt sind.

Der Carpopodit ist oben stark gekielt. Die Schere ist gedrungen; die Palma und die Finger sind etwa gleich lang, die Palma ist nach den Seiten etwas aufgeblasen, oben gekielt, unten scharf grekantet, etwas länger als hoch. Die Finger sind seitlich abgeplattet, scharf, mit feinen Zähnchen auf den Schneiden besetzt, mit den Spitzen einander kreuzend. Die Finger sind etwa gleich breit.

Die übrigen Pereiopoden sind kurz und gedrungen. Meropodit, Carpopodit und Propodit sind behaart und mit vielen spitzen und stumpfen Stacheln bedeckt. Die Dactylopoditen sind sehr schlank, krallenartig und mäßig behaart.

I f, Station 71, Kongomündung, $6^{0} 18,7^{\prime} \mathrm{S}$. Br., $12^{0}$ 2, I' O. L., $44 \mathrm{~m}$ Tiefe.

\section{Gattung Cosmonotus Adans u. White.}

I848 Cosmonohus Adsars u. Winite, „Samarang" Crustacca, p. 60.

1896 Cosmonolns Alcocr, Joum. As. Soc. Bengal, Vol. LXV, Pt. 2, p. 29 I (das. Litteratur).

\section{Cosmonolus Grayi Adams u. White.}

Taf. XVIII, Fig. $5^{--} 8$.

1847 Cosmonolus Grayi Ad.1xs u. Writte, Proc. Zool. Soc. London, 1). 227, 2 Holzschnitte

1848 Cosmono/ns Grayi Anums u. Wuite, Ann. Mag. N. Hist., (2) Vol. II, p. 287.

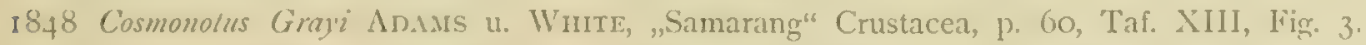

I858 Cosmonohes Grayi Stimpson, Proc. Ac. N. Hist. Philadelphia, p. 24 I.

1888 Cosmonolus Grayi Hexnersox, Challenger Anomura, p. 33.

"1889 Cosmonolus Grayi Caxo, Boll. Soc. Nat. Napoli, Vol. III, p. 256.

1896 Cosmonolus Grayi Alcock, Journ. As. Soc. Bengal, Vol. LxV, I't. 2, 1). 20 I.

Von dieser bizarren Form fing die Expedition eine ganze Reihe wohlerhaltener Exemplare, und ich benutze die Gelegenheit, um gute Abbildungen zu geben.

Für die Betrachtung der Morphologie des Tieres dürften die beiden tiefen, engren Fissuren am Vorderrande, welcher zugleich der Oberrand der langugestreckten Orbita ist, von Bedeutung sein. 
Die sehr langgestielten Augen werden wohl von dem Tier, wenn es im Sand vergraben sitzt, hervorgestreckt werden.

I I juv. und ad., Station 244, außerhalb Dar-es-Salâm, 50 m Tiefe.

Verbreitung: Indopacifik: Nordspitze von Formosa, $65 \mathrm{~m}$ (STrmpson); Amboina, $30 \mathrm{~m}$ („Challenger“: Henderson); Borneo (Adans und White); Persischer Golf (Alcock).

\section{Gattung Lyreidus DE HAAN.}

1850 DE HAAN, Fauna japonica, Crustacea, p. I38.

Iis-9 Miers, Proceedings Zool. Soc. London, p. 45.

ihsi S Simtin, Proc. U. S. Nat. Mus., Vol. III, p. 420.

I 888 Henderson, Challenger Anomura, p. 33.

I 899 Alcock, Investigator Deep Sea Brachyura, Calcutta (das. cinige weitere Litteratur) p. 38.

\section{Lyreidus tridentatus DE HAAN.}

I850 Lyreidus tridentatus DE HAAN, Fauna japonica, Crustacea, p. I.40, Taf. XXXV, Fig. 6.

I879 Lyreidus elongatus Miers, wie oben, p. 46.

1882 Lyreidus tridentatus HASwell, Catal. Australian Crustacea, p. I44.

1888 Lyreidus tridentatus HENDERSON, wie oben, p. 33.

I 893 Lytridus tridentatus Ortainx, Zool. Jahrb., Syst., Bd. VI, S. 574.

1902 Lyreidus tridentalus Doflein, Abh. k. b. Al. Wiss., II. K1., Bd. XXI, Abt. 3, S. 654 .

Ich bin vollkommen überzeugt, daß OrTManN mit Recht die erste Vermutung von Mlers für den Thatsachen entsprechend hält, daß nämlich $L$. clongatus Mrers nur eine Variation von tridentatus ist, nicht einmal eine konstante Varietät.

Das Exemplar von der "Valdivia“-Expedition gleicht meinen japanischen Stücken sehr; es ist nur ein wenig schlanker, besonders gegen die Stirnregion hin, hat auf dem 3. Segment einen kleinen, spitzen, aufwärts gekrümmten Stachel und am Unterrande der Palma außer den 3 großen Zähnen zwischen dem hintersten und mittleren derselben 2 ganz kleine Höckerchen, und hinter dem hintersten einige kaum sichtbare Granulationen.

I đo, Station 242, bei Dar-es-Salâm, in einer Tiefe von ca. $400 \mathrm{~m}$.

Verbreitung: Indopacifik: Japan (DE HAaN): Kadabai (MIERs), Tokiobai (DorleIN), Sagamibai (Ortmanx, Doflern); Australien: Port Jackson (Hasweld, Henderson: „Challenger"); Port Stephens (Hasweli); Fiji-Inseln: Kandavu, 380 m (Hexderson: „Challenger"); Neu-Caledonien (Ortmann).

Der Fund der „Valdivia“-Expedition stellt also fest, daß die im östlichen Indopacifik verbreitete Form offenbar auch weit nach Westen geht. Bemerkenswert ist, daß die Art bei Dar-es-Salâm wie bei den Fiji-Inseln, also an den tropischen Fundorten, in der Tiefe gefunden wurde (ca. $400 \mathrm{~m})$. Ueber die Exemplare von Neu-Caledonien im Straßburger Nuseum steht nicht fest, aus welcher Tiefe sie stammen, da sie jedoch nicht von einer Expedition erbeutet wurden, so ist zu vermuten, daß sie aus geringer Tiefe stammen. Es gehört also die Art möglicherweise zu den Formen, welche wohl in größeren Tiefen besonders in den Tropen regelmäßig leben, in gewissen Perioden des Jahres aber in seichteres Wasser wandern, um dort das Brutgeschäft zu vollzichen. 
Ob Lyreidus Channeri Wood-MLson eine gute Art oder nur cine Varictït ron I. fritchtatus ist, ist ohne großes Material nicht mit Sicherheit zu entscheiden. Doch ist erstere linrm nach der Abbildung von Wood-MLson (Journ. As. Soc. Bengal, Vol. LV, II, 1. 206, Taf. II, Fig. I - S), ziemlich deutlich unterschieden. Für letztere $A \mathrm{rt}$ ist auch die verbesserte Beschreibun: zul verglcichen: s. Alcock am oben angeführten Ort.

\section{Oxyrrhyncha.}

\section{Gattung Cyrtomaia Miers.}

I 886 Miris, in: Challenger Brachyura, p. I4.

\section{Cyrtomaia Suhmi MIERS.}

Taf. XIX; Taf. XL; Taf. XLIII, Fig. 4; Taf. XLV, lig. I-5.

1886 Cytomain Sulmi Miers, Challenger Brachyura, p. I6.

I804? Cyrlommia Smilhi Ratinus, in: Proc. U. S. Nat. Mus., Vol. XVI, I893, p. 228.

I899 Cyrlomaia Suhmi Alcock, in: Investigatur Deep Sea Brachyura, p. 45.

Igo3 Cyromain Suhmi Mrers, in: Cruv, Aus den Tiefen des Weltmecres, 2. Aufl., S. 530, Abbildung (Doflers phot.).

Aus dem Fund, welchen die „Albatroß"Expedition in der Nähe der Sandwichinseln gemacht hat und welcher ein zur Gattung Cy'romaia gehöriges of von einer Spannweite von I $1 / 2$ Fuß zutage förderte, hann man schließen, daß die meisten der wenigen bisher von Expeditionen erbeuteten Exemplare nicht ausgewachsen waren.

Auch die Serie von Exemplaren, welche die „Valdivia“-Expedition an verschiedenen Stellen aus der 'licfe des Indischen Oceans hervorholte, gehören zu den kleinen bis mittelgroßen Stücken. Sie lassen eine Reihe von den Erscheinungen an sich erkennen, welche wir bei Platymaia als charakteristisch für die verschiedenen Wachstumsstadien konstatieren werden.

Die verschiedenen Stücke der Ausbeute weichen aber auch in einem Punkte voneinander ab, welcher vom Wachstum unabhängig ist, wie die Vergleichung gleich großer Individuen zeigt.

Es befindet sich nämlich unter den Exemplaren aus dem Mentaweibecken ein ziemlich großes $q$, dessen Rostraldornen länger sind, im distalen Teil abgerundeter und weniger stark divergieren als bei einem gleich großen Exemplar von der ostafrikanischen Küste. Außerdem sind die paarigen Gastralstacheln mehr schief nach vorn gerichtet und divergieren nicht sehr stark, withrend sie bei dem großen ostafrikanischen Exemplar, besonders aber bei anderen Stücken aus Ostafrika, steil aufgerichtet, selbst ein wenig nach hinten gerichtet sind und ziemlich stark divergicren.

Ein genauer Vergleich der einzelnen Exemplare ergab, daß die sämtlichen Exemplare aus dem Mentaweibecken sich durch diese und einige andere Merkmale konstant von den ostafrikanischen unterschieden.

Nach reiflicher Erwägung des gegenseitigen Verhältnisses beider Formen bin ich zu folgendem Ergebnis gekommen: Beide Formen unterscheiden sich nur in geringfügiger Weise, 
und zwar viel weniger als sie sich beide von Cy'tomaia Murrayi unterscheiden. Da der Unterschied beider Formen sich regelmäßig an den Stücken aus der gleichen Gegend feststellen läßt, so muß er irgendwie auf die Benennung Einfluß haben. Zwei Methoden sind da möglich:

I) eine neue Art aufzustellen;

2) die Formen als Angehörige der gleichen Species zu betrachten, sie aber als Angehörige je einer dem Speciesbegriff untergeordneten Kategorie zu bezeichnen.

Ich habe mich für letztere entschieden, da zu den oben angegebenen Punkten noch der Umstand hinzukommt, daß, abgesehen von den unterscheidenden Merkmalen, die beiden Formen in ganz minutiösen Details übereinstimmen.

Da die Abweichungen beider Formen voneinander nicht größer sind als die von Uebergangsformen, so bezeichne ich sie mit trinärer Nomenklatur. Dabei lasse ich es unentschieden, ob wir es mit einer geographischen Varietät oder mit einer Standortsvarietät zu thun haben. Und zwar stimmt offenbar die Form aus dem Mentaweibecken mit der von Miers beschriebenen typischen Form überein; ich nenne sie daher Cy'tomaia Sulmi typica; die ostafrikanische Form bereitet größere Schwierigkeiten, da sie nach der Beschreibung, welche Miß RATHBun von ihrer C. Smithi gegeben hat, dieser Form offenbar sehr nahe steht. Da aber die Autorin keine Abbildungen veröffentlicht hat und da sie ferner diejenigen Merkmale, welche mir als unterscheidend auffallen, nicht besonders hervorhebt, so kann ich vorläufig nicht entscheiden, bis zu welchem Grade C. Smithi mit der ostafrikanischen Form von C. Sulhmi übereinstimmt. Jedenfalls ist aber auch die ostpacifische Form nicht als besondere Art zu betrachten, sondern gehört offenbar ebenfalls in den Formenkreis von C. Sukmi.

Die neue Form von der ostafrikanischen Küste nenne ich Cyrtomaia Sulmi platyccros nov. sbsp.

\section{Cyrlomaia Suhmi ypica Miers.}

Taf. XIX, Fig. I und 2.

i886 Cyrtomaia Suhmi Miters, Challenger Brachyura, p. I6.

I 899 Cyrtomaia Sutimi Alcocr, Investigator Deep Sea Brachyura, p. 45.

Die Form aus dem östlichen Indik (typica) erscheint auf den ersten Blick schlanker als diejenige aus dem westlichen Indik. Während bei der ersteren die Länge des größten $q$ (vom Grund des Einschnittes zwischen den Rostraldornen bis zur Nitte des Hinterrandes gemessen) $21 \mathrm{~mm}$, die größte Breite (dicht hinter den großen Branchialstacheln gemessen) ebenfalls $21 \mathrm{~mm}$ beträgt, verhalten sich die gleichen Naße bei $C$. Sulmi platyccros $=2$ I:23,3. Dies Verhältnis verschiebt sich noch weiter, wenn man dazu nimmt, daß bei typica die Rostralstacheln $5 \mathrm{~mm}$, bei platyceros $2,5 \mathrm{~mm}$ messen.

Auch der basale Teil des Rostrums ist schlanker als bei platy'cros, die Augen stehen in den weiteren Orbiten freier, und sie selbst sind kleiner und etwas blasser pigmentiert als bei der ostafrikanischen Form.

Die Stacheln sind bei typica durchweg länger und stärker, die Fläche des Cephalothorax aber glatter und ohne die zahlreichen Granulationen, welche flatyccros zeigt.

Die beiden großen Gastrikalstacheln sind mehr parallel und nach vorn geneigt. Der 
mittlere Gastrikalstachel ist lïnger. Ehenso die Hepatikal- und sämtliche Stacheln der weniger aufgetriebenen Branchialregion.

Die Stachelreihe dagegen, welche die Kante zwischen Ober- und Unterseite der Branchialregionen sïumt, besteht aus kleineren und weniger regelmäßigen Stacheln.

Betrachtet man die Stücke von hinten, so bemerkt man, dal3 die Umbiegung von der Hinterseite zur Unterfläche, welche bei anliegendem Abdomen zwischen dessen 2. und 3. Glied ihre Stelle hat, bei typica eine viel plötzlichere ist.

Das Abdomen ist bei den gleich langen Weibchen der beiden Formen verschicden gestaltet: bei typica ist es um ein beträchtliches schmäler als bei platyceros. Das Abdomen des sehr kleinen ơ ähnelt durchaus dem von platyccros-Männchen. Beim jüngsten Exemplar stehen am Hinterrande der Abdomensegmente statt der kurzen Stacheln oder Höcker je 2 lïngere fcine Stacheln.

Für sonstige Details verweise ich auf die Abbildungen.

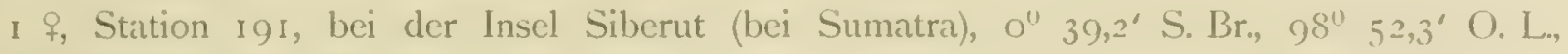
in ciner Tiefe von $750 \mathrm{~m}$.

I o juv., Station 196, bei der Insel Nias, $0^{\circ} 27,3^{\prime} \mathrm{N}$. Br., $98^{\circ} 7,4^{\prime} \mathrm{O}$. L., in ciner 'Tiefe von $646 \mathrm{~m}$.

I o juv., Station 2 ro, bei Groß-Nikobar, $6^{\circ} 53, \mathrm{I}^{\prime} \mathrm{N} . \mathrm{Br} ., 93^{\circ} 33,5^{\prime} \mathrm{O}$. L., in einer Tiefe von $752 \mathrm{~m}$.

I verletztes $\delta^{\circ}$, Station 2 II, Sombrero-Kanal, $7^{0} 48,8^{\circ} \mathrm{N}$. Br., $93^{\circ} 7,6^{\circ}$ O. L., in einer Tiefe von $805 \mathrm{~m}$.

Verbreitung: Indopacifik: Bei den Tulur-Inseln $\left(4^{0} 33^{\circ} \mathrm{N} . \mathrm{Br}\right.$., $127^{\circ} 6^{\circ} \mathrm{O}$. L.), in einer Tiefe von 915 m („Challenger": Mrers); Travancore-Küste, in einer Tiefe von $786 \mathrm{~m}$ („Investigator": Alcock).

2. Cyrtomnin Suhmi platyceros nov. sbsp.

Taf. XIX, Fig. 3; Taf. XL, Fig. I-7; Taf. XLIII, Fig. 4; Taf. XLV, Fig. I-5.

1903 Cyrtomaia Sulmi Mirers, in: Criux, Aus den Tiefen des Weltmeeres, 2. Aufl.. S. 350, I Abbild. (Doflein phot.).

Das größte Exemplar der Serie ist ein $q$ von der ostafrikanischen Küste (Station 258), welches von der Spitze des Rostrums bis zum Hinterrande des Cephalothorax nicht $\mathrm{ganz} 2 \frac{1}{2} \mathrm{~cm}$ (23,5 mm) mißt. Die Breite des Cephalothorax an der breitesten Stelle stimmt fast genau mit der Länge überein $(23,3 \mathrm{~mm})$. Die Stirn ist mäßig breit und mit 2 scharfen, spitzen Stacheln versehen, welche dorsoventral abgeplattet sind und zwischen welchen der ebenfalls spitze Epistomstachel hervorschaut. Dadurch, daß die Branchialregionen weit nach außen ausgebaucht sind, ist der Umriß des Körpers breit umgekehrt-herzförmig. Der Hinterrand ist glatt und ragt in der Mitte etwas vor. Der Cephalothorax ist stark gewölbt, der Abfall sowohl nach den Seiten als auch zu Stirn und Hinterrand ist sehr steil. Die Oberfläche ist reichlich mit Stacheln bedeckt, welche aber in weiten Abstïnden einzeln auf den Regionen verteilt sind, zwischen ihnen sind, besonders bei den größeren Exemplaren, zahlreiche Granulationen zu bemerken.

Die Regionen sind zum Teil recht deutlich abgegrenzt. Die Cardial- und Gastrikalregion sind durch tiefe Furchen seitlich abgegrenzt; dadurch erscheinen auch die Branchialgegenden sehr deutlich begrenzt. 
Die Gastrikalregion ist sehr erhaben und zeigt auf ihrer obersten Fläche ein ungefähr rautenförmiges Feld. Dies Feld, dessen eine Diagonale mit der Sagittalachse des Tieres zusammenfällt, ist an der hinteren Ecke von einem scharfen, mittelgroßen Stachel begrenzt. Die beiden seitlichen Ecken sind von je einem großen schlanken Stachel eingenommen. Dieses Stachelpaar, welches sehr charakteristisch ist, ist das größte auf dem Cephalothorax. Die Stacheln stehen mehr oder weniger schief nach vorn geneigt und divergieren mit ihren Spitzen (Taf. XIX, Fig. 3).

Die vordere 4. Ecke der Raute ist ohne Stachelbildung, ist aber trotzdem recht deutlich. Es laufen nämlich in ihr 2 leistenförmige Wülste zusammen, welche von den Eckstacheln, mit leichter Biegung nach innen, nach vorn und abwärts gegen die Mitte der Stirn verlaufen. Nachdem sie in der Mediane zusammengestoßen sind und dort die Ecke der Raute gebildet haben, wenden sich ihre Fortsetzungen wieder etwas nach auswärts und enden auf den beiden Spitzen des Rostrums. Bei manchen Exemplaren sind diese Wülste mit Haaren bedeckt, welche hakenförmig umgebogen sind und vielleicht als Angelhaare zum Zwecke der Maskierung zu betrachten sind. Von meinen Exemplaren war allerdings keines maskiert.

Auf der Diagonale verläuft ein Wulst, auf dessen Mitte, also etwa in der Mitte der Raute, ein weiterer kleiner Stachel steht; bei kleineren Exemplaren ist derselbe meist kaum angedeutet.

Auf der Cardialregion stehen 2 scharfe Stacheln, welche fast parallel verlaufen, mäßig lang sind und zwischen sich einen scharfen tiefen Einschnitt zeigen. Sie stellen zugleich die höchsten Erhebungen eines gebirgskammartigen Wulstes dar, welcher quer über die Mitte der Cardialregion verläuft und sich andeutungsweise noch seitlich auf die Branchialregionen fortsetzt.

Auf der Regio hepatica sind 2 Stacheln vorhanden, von denen der vordere der größere und als äußerer Orbitalstachel zu betrachten ist. Von dem großen Gastrikalstachel verlaufen 2 starke Leisten nach abwärts. Die hintere, glatte läuft auf den äußeren Orbitalstachel, die vordere, mit kleinen Höckern bedeckte, läuft zur Mitte des oberen Orbitalrandes.

Außerdem sind auf der Branchialregion noch einige Stachelbildungen der Oberseite zu bemerken. Ein größerer Stachel liegt auf der Fläche derselben, seitlich nach vorn, ein kleinerer hinter ihm. Einige Gruppen mäßiger Stacheln und Höcker liegen unmittelbar hinter der Cervikallinie. Zerstreut liegen noch einige kleine Stacheln und Tuberkel.

Die Branchialregion wird gegen die Unterseite begrenzt durch eine schöne regelmäßige Reihe kleiner Stacheln; eine gleiche beginnt etwa in der Mitte ihres Verlaufes oberhalb von ihr und verläuft ihr parallel bis gegen den Hinterrand.

Die Pterygostominalgegenden und die Unterseiten der Branchialgegenden sind platt und glatt. Der vom Abdomen nicht bedeckte Sternalteil trägt eine ganze Anzahl spitzer Stacheln. Ein Wulst vor der Spitze des Abdomens im Halbkreis angeordnet, trägt sechs solche, von denen die größten die äußersten sind. Zwischen der Basis der 2. und 3. Pereiopoden und dem Rand des Abdomens steht je ein Paar von Stacheln.

Das Abdomen des offenbar noch nicht geschlechtsreifen $q$ ist ziemlich schmal, aber breiter als bei dem gleich großen $q$ der Subspecies typica, spatelförmig und 7 -gliedrig.

Auf dem I. Segment steht vor dem Hinterrand ein Stachel, auf dem 2. bis 5. an derselben Stelle zwei kleine Höcker, auf dem 6. wieder ein einzelner Stachel. Auf dem 7. Segment, welches etwa halbkreisförmig ist, stehen 2 Höckerchen kurz hinter dem Vorderrande. 
Die äußeren Antennen haben relativ lange Geißeln mit langen Sinneshaaren. Das Basalglied ist mit dem Epistom verwachsen; auf der abgeplatteten, von scharfen Kanten seitlich legrenzten Unterfliche zeigt es ganz proximal die große Exkretionsöffnung, welche durch ein wohl entwickeltes Operkulum rerschlossen wird. Nahe der Außenkante stehen weiter worn 2 Dornen, welche nach atußen und rückwärts gerichtet sind. Am distalen Ende ragt ein kräftiger Dorn nach vorn und außen; derselbe ist von oben deutlich sichtbar und reicht so weit nach rorn, daß er mit dem vorderen Hejatikaldorn einen recht wirksamen Schutz für das Auge darstellt (vergl. auch Taf. I XXIII, Fig. 4 und Taf. XIX, Fig. 2).

Die innere Antenne hat ein sehr großes Basalglied, welches in einer tiefen Höhle ruht (rgl. Taf. XIX, Fig. 2) in welche auch die beiden gleich großen anderen Stielylieder, sowic clie Geißeln zurückgeschlagen werden können. Die äußere Geißel trägt sehr lange feine Sinneshaare.

Die Augen sitzen in orbitaartigen, aber nicht sehr tiefen Höhlungen und sind ron den beiden oben bezeichneten Stacheln seitlich geschützt. Noch oben überragt sie ein schwacher Supraorbitalzahn an der Seite des Rostrums, wïhrend sie nach unten ganz freien Ausblick haben.

Die Augen selbst sind ziemlich groß mit ebenfalls großer, blaßbraun gefärbter Cornea. Die von Facetten freie Spitze ragt in form eines Hörnchens vor und trägt einige Sinneshaare.

Näheres über den feineren Bau etc. findet sich im biologischen Alschnitt, s. auch Taf. XLV, Fig. $1-5$.

Das Epistom ist eine breite Fläche, von der nach vorn sich die schmale Brücke zwischen den Höhlen der inneren Antennen zu einem kräftigen, nach unten ragenden medianen Stachel hinzieht.

Die Mundbucht ist fast quadratisch gestaltet, nur daß an ihrem Hinterrand das vorderste Sternalsegment dreieckig weit vorragt. Letzteres ist in eine feine Spitze ausgezogren und nach hinten durch eine deutliche Segmentgrenze abgresetzt.

Die 2. Gnathopoden, welche median nicht zusammenstoßen, sind medianwärts am Ischopoditen durch eine lamellenartige Platte, welche am Rand mit Dörnchen besetzt ist, verbreitert.

Der Meropodit ist viereckig, nach vorn verbreitert und nach innen und unten vorn etwas umgebogen. Seine Außenecke ist fast rechtwinklig. Der Außen- und Vorderrand ist mit schlanken Stacheln bedeckt.

Der Carpopodit ist an seiner vorderen inneren Ecke eingelenkt. Die Oberfläche des ganzen 2. Kieferfußes ist mit Höckern und einer. Reihe von Stacheln bedeckt, deren Anordnung aus Fïg. I, Taf. XL zu entnehmen ist.

Das Basalglied trägt eine sehr kleine, nur aus wenig Blättern zusammengesetzte Podobranchie und einen geißelförmigen Epipoditen.

Der erste Gnathopod (Taf. XL, Fig. 2) trïgt außer letzterem eine wohlentwickelte Podobranchie.

Der Epipodit der 3. Maxille ist an der Basis sehr breit, rerjüngt sich dann plötzlich zu einem geißelförmigen Gebilde. Es ist mit langen Haaren besetzt. Fig. 3 auf Taf. XL zeigt die eigenartige Bildung dieser Maxille.

Fig. + und 5 der gleichen Tafel zeigen die 2. und 1 . Maxille.

Die kräftige Mandibel (Fig. 6) trägt einen deutlichen wohlentwickelten Yalpus. 
Die Scherenfüße sind in beiden Geschlechtern lang, schlank und dünn. Doch vermute ich, daß sie bei erwachsenen Männchen keulenförmig verdickt sein werden.

Meropodit und Palma sind vierkantig, prismatisch; auf den Kanten stehen Reihen langer Stacheln, zwischen denen kürzere Stacheln und Haare eingeschaltet sind. Der Carpopodit ist etwas verdickt und hat nur oben, hinten und vorn je eine stacheltragende Kante.

Die Palma ist doppelt so lang als die Fingerregion. Die Finger sind seitlich komprimiert, etwas nach innen gebogen und gegen die Palma in einem stumpfen Winkel nach unten abgeknickt.

Die Bestachelung der Palma hört unmittelbar an ihrer Basis auf. Nur auf die obere Kante des beweglichen Fingers gehen noch I-2 Stacheln über (Taf. XIX, Fig. 3).

Die Schneide der Finger ist scharf und mit feinen Zähnchen bedeckt; beide Finger enden mit einer feinen Spitze.

Die 2. Pereiopoden sind die längsten, während die 3.-5. erheblich kürzer sind und vom 3. zum 5. allmählich an Länge abnehmen.

Während die 3 ersten Pereiopodenpaare stark bestachelt sind, sind die beiden letzten mit Ausnahme des Stachels am oberen distalen Rand des Meropoditen, welcher an sämtlichen Pereiopoden in ziemlich kräftiger Ausbildung vorhanden ist, vollkommen stachellos.

Im Gegensatz zu dem prismatischen Scherenfuß sind die Schreitbeine in sämtlichen Gliedern rundlich, mit Ausnahme des seitlich abgeplatteten Dactylopoditen, welche an 3.- 5. Paar mit feinen Haarsäumen versehen sind.

Der 2. Pereiopod ist am Meropodit, Carpopodit, Propodit und Dactylopodit mit zahlreichen Stacheln bedeckt; während die Oberseite nur kleinere Stacheln trägt, ragen von den Seiten nach unten zwei regelmäßige Reihen langer Stacheln vor, welche dadurch ein eigenartiges Aussehen erhalten, daß zwischen je zwei Stacheln immer ein langes steifes Haar eingeschaltet ist.

Am 3. Pereiopoden wiederholt sich die gleiche Erscheinung, allerdings in schwächerer Form: auch ist hier der Dactylopodit stachelfrei.

Die Kiemen sind relativ zahlreich und wohlentwickelt, wie man schon aus der Größe der Branchialregionen entnehmen kann. Die Kiemenformel ist folgende:

\begin{tabular}{|c|c|c|c|c|}
\hline & Podobranchien & Arthrobranchien & Pleurobranchien & \\
\hline 3. Maxille & Ep. & o & 0 & I Ep. \\
\hline I. Gnathopod & Ep. +1 & 0 & 0 & $\mathrm{I} E \mathrm{p} .+\mathrm{I}$ \\
\hline 2. Gnathopod & Ep. + I & 0 & 0 & $1 E \mathrm{p} \cdot+1$ \\
\hline \multirow{5}{*}{ Pereiopod } & 0 & 2 & 2 & 4 \\
\hline & 0 & 1 & 1 & 2 \\
\hline & 0 & 1 & 1 & 2 \\
\hline & 0 & 0 & o & o \\
\hline & 0 & o & o & 0 \\
\hline Summe & $3 \mathrm{Ep} .+2$ & + & + & 3 Ep. + 10 \\
\hline
\end{tabular}

Der Ansatzpunkt der 4 ron mir als Arthrobranchien bezeichneten Kiemen ist so weit oben, daß ich nicht ganz sicher bin, ob sie nicht doch schon als Pleurobranchien anzusehen sind.

Bei den $f$ fällt auf, daß die Pleopoden aus zwei kräftigen Aesten bestehen, welche nur granz kurze oder gar keine Härchen tragren (Taf. XL, Fig. 7). 
Bei den $\delta$ ist das Abdomen ebenfalls 7 -ghliedrig, das erste Segment ist schmal, das 2 und 3 . sind etwas breiter, das 4 . ist schmäler, das 5 . und 6 . noch etwas schmäler und parallelseitig, das \% Segment ist halbkreisförmig. Die Bestachelung entspricht derjenigen des f; der Hinterrand des 6. Segments ragt an den Aulenecken spitz vor.

Das erste Paar der Genitalfüße ist lang, zweiästig und endet spitz, während das zweite Paar nur aus kurzen Röhrchen besteht.

Cyrtomain murayi Mress von der "Challenger"-Expedition scheint durch die form des Cephalothorax, die größere Anzahl von Stacheln auf dessen Oberfläche, das Vorhandensein eines Präiorbitalstachels und durch die abgeplatteten und mit Haarsäumen versehenen, an Platymaid errinnernden Carpopoditen und Propoditen der 4. und 5. Pereiopoden, von den Formen, welche ich unter dem Namen C. Sulmi zusammenfasse, deutlich abzuweichen.

Von Cy,tomaia Sulmi platyceros n. sbsp. erbentete die "Valdivia“-Expedition folgende Exemplare:

I gr. $q$, Station 258, nahe der ostafrikanischen Küste, 2" $58,5^{\prime}$ N. Br., $46^{\prime \prime} 50,8^{\prime}$ O. L., in einer Tiefe von $1362 \mathrm{~m}$.

I o jur, Station 263, bei Somaliland, 4" 4 r, $9^{\prime}$ N. Br., $48^{\prime \prime} 38,9^{\circ}$ O. L., in einer Tiefe ron $823 \mathrm{~m}$.

2 I $^{*}$, Station 264, bei Somaliland, 6" I $8,8^{\prime} \mathrm{N}$. Br., $49^{\prime \prime} 32,5^{\circ}$ O. I., in einer Tiefe von $1079 \mathrm{~m}$.

3 ठ 2 \%, Station 266, bei Somaliland, $6^{\prime \prime} 44,2^{\prime} \mathrm{N}$. Br., $49^{\prime \prime} 43,8^{\circ}$ O. L., in einer Tiefe ron $74 \mathrm{I} \mathrm{m}$.

Demnach ist nach meiner Anschauung Cy'tomaia Sulhmi Mrers in verschiedenen Sul)species im indopacifischen Ozean ron den Sandwichinseln bis zur ostafrikanischen Küste in Tiefen von $700-1400 \mathrm{~m}$ verbreitet.

\section{Gattung Platymaia Miers.}

I886 Platymaia Miers, Challeng'er Brachyura, p. I2.

I893 Platymaia Stebing, History of Crustacea, Internat. Sci. Ser. Vol. LXXiv, p. I IO

1895 Platymaia Alcock, Journ. As. Soc. Bengal, Vol. LXIV, Pt. 2, p. I8o.

1899 Plalymaia Alcock, Investigator Deep Sea Brachyura, p. 45.

1902 Plafymaia Stebisisg, Cape of Good Hope, Department of Agriculture, Marine Investigations in South Africa. South African Crustacea, Pt. 2, p. 2, Cape Town.

\section{Plalymaia aysoille-lhomsomi MIERS.}

Taf. II, XX, XXI, XXII, XXIII, XXXIX, XliI, Fig. 5 u. 6, Taf. L, Fig. 2, 5 u. 6, Textfigur 2-0.

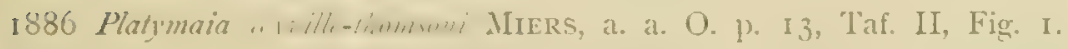

189 I Platymaia with-thmmmi Wood-MLsox u. Alcock, Ann. Mag. Nat. Hist., 6. Ser., Vol. VII, r8g1, p. 258.

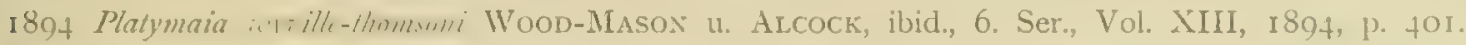

1895 Platymaia w will thmmmi Alcock, Journ. As. Soc. Bengal, Vol. LXIV, Pt. 2, p. I8 I.

1896 Platymain wyzille-thomsoni ALCock, Illustrations of the Zoology of the Investigator: Crustacen, I'af. ATI.

1899 Plalymaia a ville-thmmini Alcock, Investigator Deep Sea Brachrura, p. 45.

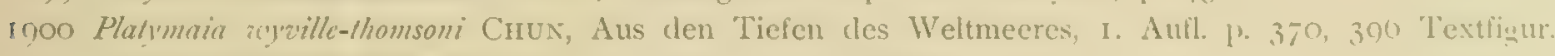

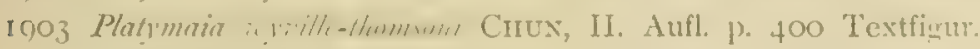

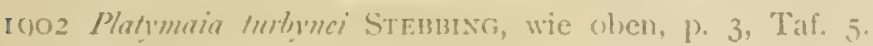


Die "Valdivia“-Expedition hat eine so stattliche Serie verschiedener Altersstadien von dieser bizarren Form heimgehracht, daß wir mit Hilfe derselben einen nicht uninteressanten Einblick in die postembryonale Entwickelungsgeschichte einer Tiefseekrabbe gewinnen können. Allerdings wurden keine ganz ausgewachsenen Männchen von den Dimensionen erbeutet, wie Alcock eines I 896 abgebildet hat. Daher habe ich der Speziesdiagnose für das erwachsene Tier nichts Vesentliches hinzuzufügen.

Alcock lagen auch Entwickelungsstadien verschiedenen Alters vor; er hat aber nur in ganz kurzen Worten dieselben beschrieben, ohne die Formverschiedenheiten in Beziehung zu den Lebensverhältnissen zu setzen.

An meinen Exemplaren glaubte ich eine solche Mlenge interessanter Dinge feststellen zu können, daß ich die einzelnen Stadien im nachfolgenden eingehend beschreiben werde. Außerdem scheint es mir nützlich, durch eine Reihe von Abbildungen die zu schildernden Verhältnisse zu erläutern. Zum Schluß gedenke ich dann ein Bild des gesamten Lebens der Art zu geben, wie ich es aus dem Bau derselben ablesen zu können glaube.

Zunächst beschreibe ich nur ostafrikanische Exemplare, welche in der Nähe von Dar-esSalâm an denselben oder nahe beieinander liegenden Stationen erbeutet worden waren.

Wie schon Alcock hervorgehoben hat, sind die jungen Exemplare am Cephalothorax mit Stacheln bedeckt; diese Stacheln werden beim Heranwachsen der Tiere kürzer, bis schließlich bei den großen Exemplaren nur noch stumpfe Höcker oder kaum mehr Andeutungen ron solchen übrig bleiben.

Die jüngsten Stadien, welche mir vorliegen, sind wohl die jüngsten, welche bisher von der Art gefunden worden sind. Sie stimmen in den wesentlichen Punkten sehr wohl mit Platymaia turbynei Stebbrag, überein, obwohl sie offenbar jünger sind als die Exemplare, welche Stebring zur Aufstellung seiner Art benutzte.

StebBing hat vollkommen recht, wenn er die große Verschiedenheit zwischen seinen Exemplaren einerseits und dem Typus bei Mitrs und den Exemplaren Alcocks andererseits betont. Nur eine so vollständige Reihe von Stadien, wie sie mir vorliegt und in welchen von gleichen oder einander benachbarten Fundorten verschiedene Stadien in denselben Fängen enthalten waren, konnte die Identität der beiden Arten nachweisen.

Stadium I. (Taf. XX, Fig. I u. 2, Taf. XXI, Fig. I.) Die jüngsten Stadien haben ein sehr auffallendes Aussehen, indem die Beine im Verhältnis zum Cephalothorax noch länger sind, als bei den erwachsenen Exemplaren.

Auch der Bau des Cephalothorax weicht in seinen Verhältnissen von dem des Erwachsenen ab. Das Exemplar, welches ich der Beschreibung zu frunde lege, mißt von der Spitze des Rostrums bis zur Mitte des Hinterrandes $9,7 \mathrm{~mm}$, die größte Breite ist $8,3 \mathrm{~mm}$, bei einem ziemlich großen Exemplare hetragen die gleichen Maße 59,6:58 $\mathrm{mm}$.

Das Verhältnis der Länge zur Breite ist also:

$$
\begin{aligned}
& \text { 1) Junges . . 1 1:0,86 } \\
& 2 \text { N1tes . 1:0,9\% }
\end{aligned}
$$

Die Veränderung der Verhältniszahlen rührt einmal von der relativ bedeutenden Ausbildung des Rostrums bei dem jungen Tier, sodann von der während des Wachstums zunehmenden Vorwölbung der Branchialregionen her. 
Der Umril der Cephalothorax erscheint infolgedessen bei dem jungen Tier brcit dreicckig, bei dem alten fast kreisrund. Ferner sind bei dem ersteren die Pterygostomial- und dic Hepratikalregionen wenig ausgebildet: desgleichen die Intestinalregion, was zur Folge hat, dal3 der Hinterrand bei der Ansicht von oben fast gerade abgeschnitten scheint, während er beim enwachsenen 'lier stark bogrenförmig nach außen vorragt.

Der Cephalothorax zeigt die Einteilung seiner Oberfläche in Regionen nnch deutlicher als das erwachsene Tier; auch sind einige Grenzen zwischen Regionen sichtlar, welche bei dem erwachsenen Tier venwischt sincl.

So kann man an der Regio gastrica eine Area mesogastrica, eine urogastrica und je cine protogastrica erkennen (vgl. die Bezcichnungen auf der letzten Tafel dieser Arbeit).

Die Stachelbedeckung des Cephalothorax ist eine sehr reichliche. Schon die Stacheln des Rostrums sind relativ stärker ausgebildet als beim erwachsenen lier. Zunächst ist hervor\%uheluen, daß der mittlere Stachel der lïngste ist, wie es Stebinscr für $P$. hurbynei beschrieben hat. Auch dic Seitenstacheln des Rostrums sind lange, spitz und gerade nach vorn grestreckt.

Die ganze Form des Rostrums erinnert mehr an die Verhälnisse ciner Zoëalarve, wenn man sic mit derjenigen des ausgebildeten Tieres vergleicht.

Auf der Oberfläche des Cephalothorax sind an Stacheln zu erkennen:

Zwei kleine Stacheln auf dem hinteren Teil des Rostrums, je ein kriftigerer Stachel auf der Regio meso-, uro- und jeder protngastrica; zwei kräftige Stacheln auf der Regio cardiaca, zwei feine, etwas divergierende Stacheln auf der Intestinalregion. Ferner finden sich einige spitze krïftige Stacheln auf der Hepatikal-, Pterygostomial- und Branchialregion. Alle diese Stacheln sincl nach vorn etwas hakenförmig umgeloogen.

Ferner sind eine ganze Reihe recht kräftiger Stacheln am Seiten- und Hinterrand des Cephalothorax verteilt, es sind deren jederseits etwa zehn größere und verschiedene kleinere. Besonders stattlich sind die beiden Stacheln an den Ecken des Hinterrandes.

Die Orbita ist nicht sehr tief, an der äußeren Ecke befindet sich ein kräftiger stachel.

Das Epistom ist klein, flach-dreieckig, gregen das Mundfeld scharf abgegrenzt.

Die Augren sind $\mathrm{kuglig}$, blalpigmentiert und zeigen Goldglanz. Fenauere Schilderung findet sich im Abschnitt II (vgl. auch Taf. XLIX, Fig. 2).

Von der Gestaltung beim erwachsenen Tier weichen ferner die Pereiopoden erheblich al). Am wenigsten noch die Scherenfüße. Sie sind schlank und relativ lïnger als bei den älteren Stadien; Meropodit, Carpopodit und Palma tragen kräftige Stachelreihen. Die Scherenfinger sind messerklingenartig scharf, etwas nach unten und einwärts gebogen. Sie berühren sich nur im rorderen Drittel, die Schneiden sind mit feinen Zähnchen bedeckt.

An den übrignen Pereiopoden fällt die bedeutende Länge auf, sowie der Umstand, dali sämtliche Glieder etwas dorso-ventral abgeplattet sind und ohne erhebliche Anschwellungen von einem Ende zum anderen ziemlich parallelseitig gebaut sind.

Dic 2. Pereiopoden zeigen in feinen Stachelreihen mit zwischen den Stacheln eingestreuten Hataren die Anlagren zu ihren späteren furchtbaren Stachelkämmen.

Das 3. Pereiopodenpaar ist kürzer als das 2. und zeigt auch spärlichere Stachelbedeckung, Haare sind keine oder fast keine erkennloar. 
Das 4. und längste Pereiopodenpaar zeigt nur am Vorderrande des Meropoditen eine Reihe von wenigen kleinen Stacheln, dagegren sind Carpopodit, Propodit und Daktylopodit am Vorderrande mit Fransen von feinen, langen Fiederhaaren bedeckt (Taf. XX, Fig. I u. 2).

Das 5. Pereiopodenpaar ist nicht sehr viel kürzer als das 4.; zeigt so gut wie gar keine Stacheln mehr an den Gliedern und ist mit den gleichen zierlichen Fransen greschmückt wie das 4 . Paar.

Die Unterseite des Cephalothorax ist ganz glatt, nur leicht konkav. Die Fläche ist ungefähr in Form eines Sechsecks ausgebildet. In der Mitte desselben zieht sich das schmale 7-gliedrige Abdomen hin. Am Vorderrande der Sternalfläche stehen 6 Stacheln, in der Mediane zwei kleine und jederseits zwischen ihnen und der Basis der 2. Pereiopoden zwei kriftige Dornen.

Außerdem trägt die Basis des 1 .- 4. Pereiopoden je einen Stachel.

Stadium II (Taf. XXI, Fig. 2). Obwohl clas nächstyrößere Stadium, welches mir vorliegt, nur um $3 \mathrm{~mm}$ länger ist als das soeben beschriebene, zeigt es schon die Eigenschaften des Grundbewohners. Die Augen haben eine entsprechende Ausbildung wie bei dem erwachsenen Tier, indem sie langgrestreckt sind und nach vorn und unten schauen (vgl. Taf. L, Fig. 5 u. 6); die Beine sind im Verhältnis zum Cephalothorax nicht mehr so sehr lang, obwohl sie immer noch dem Tier ein sehr auffallendes Aussehen verleihen; und schließlich hat auch der Cephalothorax annähernd das gleiche Verhältnis der Länge zur Breite, wie beim enwachsenen Tier: Länge Io mm, Breite 9,5 mm (ohne Stacheln), also I : 0,95 (erwachsen I : 0,97).

Das Aussehen des Tieres stimmt jetzt und in den nächstfolgenden Stadien vollkommen mit der Beschreibung überein, welche Stebring von $P$. turbynei gegeben hat. Das Rostrum ist durch die Länge des Mittelzahnes ausgezeichnet; die Stachelbedeckung des Cephalothorax ist im wesentlichen geblieben; doch sind einige Stacheln schwächer ausgebildet, andere kräftiger greworden. Besonders treten jetzt je drei Stacheln an den Seitenrändern hervor; ebenso je einer an den Ecken des Hinterrandes. Der letztere ragt schwach bogenförmig vor. Die Stacheln auf der Gastrikal-, Cardial- und Branchialregion sind kräftig und hakenförmig nach vorn umgebogen. Zwischen den Hauptstacheln beginnen zahlreiche Tuberkel und stumpfe Höcker hervorzutreten.

Die Extremitäten sind denjenigen des erwachsenen Tieres schon ähnlicher geworden. Die Scherenfüße sind wenig verändert; das zweite Pereiopodenpaar jedoch hat viel stärkere Stacheln und Borsten bekommen, welche bereits kammartige Anordnung annehmen. Die sämtlichen Glieder der Pereiopoden sind etwas breiter und platter geworden als bei dem jüngsten Stadium; doch sind sie noch recht schmal, auch die Propoditen. Sie entsprechen also der Beschreibung Stebrings von $P$. turbynei.

Vor allen Dingen auffallend als Unterschied zwischen diesen und dem jüngsten Stadium ist die Verkürzung der Beine. Obwohl der Cephalothorax des Stadiums II größer ist als der des Stadiums I sind doch die hinteren Pereiopodenpaare um ein erhebliches kürzer geworden. Ja, der Cephalothorax muß auf das Doppelte seiner Größe heranwachsen, ehe die Meropoditen der hinteren Beinpaare wieder die Länge erreicht haben, welche sie in dem larvenartigen Stadium I schon besessen hatten. Besser als alle Beschreibung werden die Photographien der Taf. XX u. XXI, Fig. I u. 2 dieser Verhältnisse illustrieren. 
Aulier der Verkürzung der Meropoditen ist diejenige der Propoditen auffallend. Das 3. und 4. Pereiopodenpaar sind fast gleich lang geworden, das 5. ist etwas kürzer als sic. Auch das 2. ist relativ länger geworden.

Das 3. Paar hat nun auch an Carpopodit, Propodit und Daktylopodit die feinen I latarfransen erhalten, doch sincl sie überall kürzer geworden als bei Stadium I.

Stadium III (Taf. XXI, Fig. 3). Mehrere Exemplare der Sammlung reprïisentieren ein 3. Stadium, dessen Cephalothoraxlänge $15 \mathrm{~mm}$ beträgt; die Breite ist auf diesem Stadium fast gleich der Lïngre. Im Habitus ist gregenüber dem Stadium II kein großer Unterschied zu erkennen. Noch ist der Mittelstachel des Rostrums der längste. Die Stacheln auf dem Cephalnthorax sind relativ kürzer und stärker geworden; einige, besonders diejenigen der Crastrikalresionen, sind schon in Höcker umgrewandelt. \%wischen diesen erscheint jetzt die Oherflïche des Cephalothorax gainzlich mit glatten Höckern bedeckt.

Die Pereiopoden 2-5 haben viel breitere, flache Glieder bekommen, auf den Meropocliten und Propoditen ist je ein orangefarbiges Querband zu erkennen. Die Dornen sind sümtlich stärker greworden; die Haarfransen sind relativ kürzer und etwas weniger zart.

Doch ist hervorzuheben, daß die Länge der Beine jetzt erst wieder etwa die gleiche ist wie hei dem Stadium I.

Stadium IV (Taf. XXI, Fig. 4). Die Exemplare dieses Stadiums haben einen Cephalothorax von $20-2.3 \mathrm{~mm}$ Länge und $19-22 \mathrm{~mm}$ Breite.

Das allgemeine Aussehen nähert sich immer mehr dem der erwachsenen Form. Die Beinglieder werden platter und breiter. Die Stacheln des Cephalothorax werden relativ kürzer und nehmen an Zahl ab. Die Oberfläche ist über und über mit kleinen Höckern hedeckt. zwischen denen clie Stacheln oder an deren Stelle gretretene größere Höcker stehen.

Das Rostrum ist schon etwas weniger stark nach oben gekrümmt, auch ist es gegrenüber den jungen Stadien an der Basis relativ viel breiter. Auch sind die 3 Stacheln jetzt fast gleich groß. Auffallend groß ist der äußere Orbitalstachel und ein dicht unterhalb von ihm befindlicher weiterer Stachel.

An den Propoditen und Daktylopoditen der 3 hinteren Beinpaare sieht man außer der Haarfranse am vorderen Rande auch eine zweite Haarfranse allmählich deutlich werden; die Haare derselben entspringen auf der oberen Seite der platten Glieder nahe dem Hinterrande und liegren der Oberfläche der Flieder glatt an, so daß die ganze Bildung nur bei genauem Hinblicken erkannt wird.

Fig. 2. Sternum des jungen of von Patymaiu Hyzille-Thomsoni MIRs. Staclium IV. Nat. Größe.

Irig. 3. Sternum des jungen $q$ von Platumair IVyrille-Thomsoni Mrs. Starlium IV. Nat. Grölle.

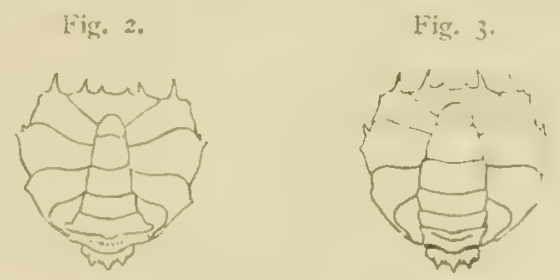

Auf diesem Stadium grelang es mir bei meinem Material auch erst die Männchen ron den. Weibchen mit Sicherheit $z u$ unterscheiden. In beiden Feschlechtern ist das Abdomen noch schlank, lanzettförmig mit abgrestumpftem Ende. Beim đo ist das Abdomen immerhin etwas schmäler als beim f, die Seitenränder haben eine etwas konkave Begrenzungslinie, während sie bei den $q$ leicht konvex ist (Textfig. $2 u .3$ ). 
Stadium V (Taf. XXII, Fig. I). Das V. Stadium, dessen Cephalothoraxlänge ca. $31 \mathrm{~mm}$ und dessen Breite ca. $30 \mathrm{~mm}$ beträgt, unterscheidet sich im wesentlichen nur durch die Größe rom IV. Die Stacheln sind noch weniger geworden, die Körner sind gröber und zahlreicher, die Extremitïten kräftiger und breiter.

Die Intestinalregion springt nun immer mehr vor, und dadurch erhält der Hinterrand eine immer mehr konvexe Kontur.

Im Gegensatz zu den Stacheln des Cephalothorax werden diejenigen an den Extremitäten immer kräftiger.

Am hinteren unteren Rande des Gesamthörpers, auf der Mitte des 1. Abdomensegmentes treten 3 größere Stacheln zwischen mehreren kleinen immer deutlicher hervor. Sie waren übrigens schon am Stadium IV erkennbar. Beim $\delta$ ist das 1. Glied des Abdomens schmal, das 2. und 3. breit, die letzten runder, schmal. Auf dem letzten sind zwei mediane Höcker sichtbar. Die 6 Stacheln am Vorderrand der glatten Unterfläche sind jetzt sehr stark und deutlich. Auf den einzelnen Sternalsegmenten treten zwischen dem Rand des Abdomens und den Pereiopodenbasen einzelne Höcker und Stacheln auf.

Während von allen jüngeren Stadien nur Exemplare von der Ostafrikanischen Küste vorhanden waren, sind einige of von Stadium V auf Station 208 bei den Nikobaren gefischt worden.

Stadium VI. Stadium VI ist nur durch ein $\subsetneq$ von Station 208 in der Nähe der Nikobaren vertreten. Es mißt in der Länge des Cephalothorax $40 \mathrm{~mm}$, in der Breite $38 \mathrm{~mm}$. Gegenüber dem Stadium V stellt es im allgemeinen keinen besonderen Fortschritt, abgesehen von der Größe dar. Es sei hier nur wegen der Weiterbildung des weiblichen Abdomens erwähnt. Derselbe hat sich erheblich verbreitert, auch ist seine Oberfläche mehr skulptiert, indem sowohl in der Nitte die Darmröhre hervortritt, als auch die Ränder etwas gewölbt sind. Stachelbildungen und Höcker sowohl auf der Oberfläche der Abdominalsegmente besonders in Reihen an deren Vorderrand, als auch auf der freien Sternalflïche werden zahlreicher.

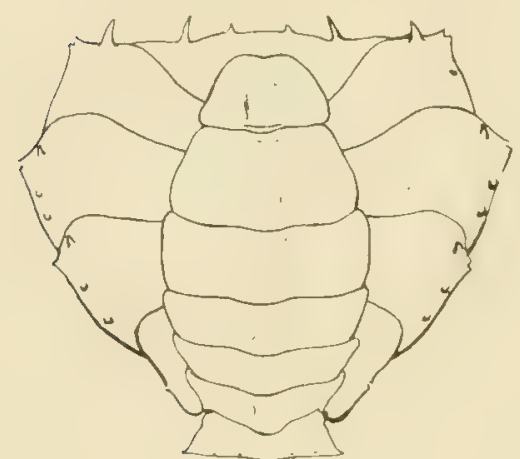

Fig. 4. Sternum des y' von I'lat" maia Hyoille-Thomsoni. Stadium VII. Nat. Grölie.

\section{noch wachsen kann, wie wir dies ja auch von zahlreichen anderen Dekapoden wissen.}

Das Abdomen des $q$ rom Stadium VII mißt + I: $22 \mathrm{~mm}$, bedeckt also kaum die Hälfte der Sternalbreite. Es liegt nicht fest an; die Ränder sind stark umgebogen. Zwischen den einzelnen Segmenten zeigt der Rand Kerben, besonders vor dem 7. Segment, indem die Seg- 
mente mit den $A$ uenrïndern nicht direkt aneinander stoßen. Das $\%$ Segment ist am freien Rand ausgerandet. Ls sind auf seiner Mitte zwei deutliche, seitlich mehrere undeutliche Stacheln sichtbar. Die Pleopoden sind schon wohl ausgebildet. - Die Genitalöfnungen sind auf cliesem Stadium noch geschlossen.

Stadium VIII (Textfig. 5). Dieses Stadium ist durch ein o von $57,5 \mathrm{~mm}$ Cephalothoraxlïnge und -breite vertreten, welches wiederum von der Ostafrikanischen Küste stammt (Station 245). \%u diesem oder zum nächstfolgenden Stadium ist auch ein $\delta$ von den Nikobaren (Station 208) zu rechnen, welches $58 \mathrm{~mm}$ lang und $60 \mathrm{~mm}$ breit ist. Das o kann mit denjenigen des Stadiums IX zusammen betrachtet werden, von denen es sich nur durch etwas geringere Größe unterscheidet.

Ebenso verhält es sich mit dem $f$, nur ist das Abdomen noch nicht zu voller lintwickelung gekommen. Sonst sei nur hervorgehoben, daß jetzt die Stacheln des Rostrums etwa yleich groß, die lateralen sogar etwas größer sind, daß die Oberfliiche des Cephalothorax nur noch Höcker und Granulationen, gar keine Stacheln mehr trägt und daß die Beine sehr breit, glatt und kräftig sind.

Das Abdomen ist schon sehr verbreitert, doch hat es seine vollkommene Ausbildung noch nicht erreicht: seine Seitenründer sind noch $u \mathrm{~m}$ einiges von den Basen der Pereiopoden entfernt (Textfig. 5). Seine Länge auf der Unterfläche beträigt $45 \mathrm{~mm}$, seine Breite $32 \mathrm{~mm}$. Die üußere Fläche ist ziemlich glatt, einzelne Dornen sind sichtbar, auf dem letzten Segment steht eine Querreihe ron 6 größeren und einigen kleineren Dornen.

Die Pleopoden sind wohl entwickelt, der innere Ast ist stark abgeknickt, die Aeste sind mit langen Haaren bedeckt.

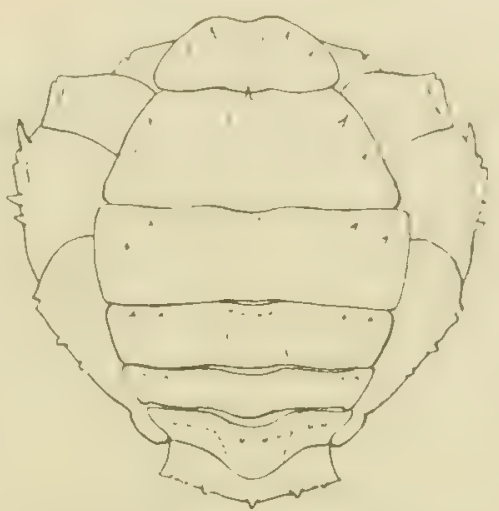

Fig. 5. Sternum des $q$ von Platymaio II yzille-Thomsoni MRs. Stadium VIII. Nat. Grölie.

Stadium IX (Taf. II, Taf. XXII, Fig. 2; Taf. XXIII, Fig. I u. 2. Auf der Tafel durch cin Versehen als Stadium VII bezeichnet). Dieses älteste Stadium, welches mir vorliegt, ist durch greschlechtsreife Tiere repräsentiert. Es liegen mir vor

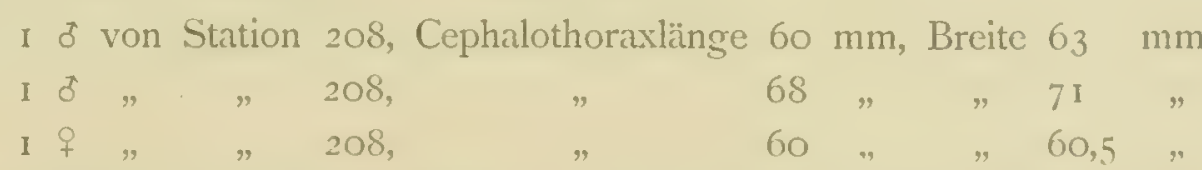

Obwohl geschlechtsreif, sind diese Exemplare also noch nicht vollkommen ausgewachsen, denn Alcock enwähnt Exemplare von 75-100 mm Durchmesser. Auch sind nach seiner Abbildung (Illustrations of the Zoology of the Investigator, Crustacea, Taf. XVI, 1806) die Scherenfüße ciner weiteren Entwickelung fähig, als die größten Exemplare der „Valdivia“-Expedition sie zeigen.

Das größte o ist leider nicht ganz vollstïndig erhalten, ich lege daher der nachfolgenden Beschreibung das zweitgrößte Exemplar zu Grunde, welches auch von Herrn F. Wixter nach dem Leben skizziert worden war und in der Farbentafel (Taf. II) wiedergegeben ist.

Im großen und ganzen kann ich nur die Beschreibungen ron Mrers und Alcock bestätigen. Nur in einigen Punkten möchte ich Ergänzungen hinzufügen.

Zunäichst ist hervorzuheben, daß, besonders bei den $\delta$, die Breite des Cephalothorax die Lüinge übertrifft. Auf der Oberfläche des Cephalothorax finden sich nur noch Granulationen, keine Stacheln mehr. Die Recrionen sind stark aufgetrieben, besonders die Branchialregionen. Dic Gastrikalregion bilclet einen hohen WVulst, von dem die Oberfläche zur Hepatikal- und 
Branchialregion steil abfällt. Die Cervikalregion ist sehr tief. Die Kardialregion tritt sehr wenig hervor, während die deutlich abgregrenzte Intestinalregion nach hinten kuppelförmig vorspringt. Die kleine wohl abgegrenzte Hepatikalregion trägt die Stacheln, welche 'das Auge von außen schützen. Sie springt mit der Pterygostomialregion ziemlich stark vor das Auge hervor.

Auf die Pereiopoden gehe ich nur in Kürze ein, da sie von den früheren Autoren gut beschrieben sind und zudem ihre Form aus den Abbildungen vollkommen entnommen werden kann. An der Schere ist fast nur noch an den Fingern schwache Behaarung erkennbar, während bei den gleich großen $q$ noch ziemlich starke Behaarung vorhanden ist.

Die Fransensäume an den 3 hinteren Pereiopoden sind nur noch am Propoditen und dem basalen Teil der Daktylopoditen vorhanden; von den hinteren Haarreihen sind nur noch Spuren erkennbar.

Die vorderen sind jedoch während der Entwickelung zwar relativ immer kürzer, aber auch immer fester und starrer geworden, so daß sie jetzt wie Bürstchen sich ausnehmen.

Die Unterseite des Cephalothorax des ơ zeigt eine große glatte Fläche; die früher annähernd regelmäßig sechseckige Form ist dadurch verändert, daß die vordere Kante sich quer über den ganzen Cephalothorax hinzieht. An ihr stehen die 6 Stacheln, welche jetzt untereinander fast gleich groß sind (Taf. XXIII, Fig. 2).

Von dieser Kante fällt die Sternalfläche fast senkrecht zum Mundrand ab und bildet ein dreieckiges Feld. Der vordere Teil desselben ist durch eine Segmentgrenze abgeteilt, auf dem hinteren Teil stehen 3 Dornen im Dreieck angeordnet.

Das Abdomen des o ist annähernd T-förmig, indem an das relativ schmale erste Segment sich stark verbreiterte Segmente (2 und 3 ) anschließen, worauf die viel schmäleren Segmente 4-7 folgen. Besonders auffallend ist das 2. Segment gestaltet, welches einen langen Fortsatz seitlich über die Genitalöffnung hinaus sendet (s. Taf. XXIII, Fig. 2.)

Die Geschlechtsfüße des of sind sehr verschieden groß; das I. Paar ist kurz, reicht kaum zum Hinterrand des 2. Segmentes, während das I. griffelförmige bis über den Vorderrand des 7. Segmentes hinausreicht.

Das Vas deferens des Männchens reicht in Form einer langen Samenröhre bis an die Basis des ersten Geschlechtsfußes hinüber, ohne daß jedoch im Sternum eine Rinne bestände.

Die Mundgliedmaßen seien auch etwas eingehender beschrieben, da der Reichtum an Material eine eingehende Untersuchung derselben zuließ. Als Grundlage für die Beschreibung diente mir ein Exemplar vom Stadium 4, welches zerbrochen war, und daher ohne Nachteil weiter zerstückelt werden konnte. Doch habe ich mich überzeugt, daß während des Wachstums keine auffallenden Veränderungen erfolgen, genauer untersucht wurde noch Stadium 6, während bei den ältesten Stadien die Mundgliedmaßen nur so weit untersucht wurden, als dies ohne Schaden für die betreffenden Objekte geschehen konnte.

Die allgemeinen Formbeziehungen können aus den Abbildungen entnommen werden (Taf. XXXIX, Fig. I-5).

Der 2. Gnathopod ist sehr kräftig, mit vielen Stacheln und Borsten versehen. Der Ischiopodit ist sehr breit, wie ein Beil ausgebildet, an der Schneide gezähnt. Der Meropodit ist viel schmäler und trägt sehr starke Stacheln, welche eine Reihe fortsetzen, die sich auf einer Längskante auf dem Ischiopoditen hinzieht. Der Exopodit ist kräftig und trägt eine gegliederte Geißel. Es ist eine rudimentäre Podobranchie und eine sehr langer behaarter Epipodit vorhanden (Taf. XXXIX, Fig. I). Der I. Gnathopod ist ebenfalls kräftig, aber schlank; er zeigt eine wohl 
ausgebildete Podobranchic und ebenfalls einen langen blattförmigen, behaarten Epipoditen. Dic 3. Naxille ist durch den verbreiterten Lappen, welcher den Ausführungskanal aus der Kiemenhöhle bedeckt, ausgezeichnet. lierner ist der sehr lange Eipipodit bemerkenswert, welcher in scinem basalen Teil auffallend verbreitert ist (Taf. XXXIX, Fig. 2).

Der Epipodit der 2. Naxille ist durch die außerordentlich starke Muskulatur auffallend (Taf. XXXIX, Fig. 4). Die kleine I. Maxille schmiegt sich dicht der Mandibel an, welche sehr :ihnlich wie bei Cyrtomaia gebildet ist.

Die Kiemenformel der Species ist folgende:

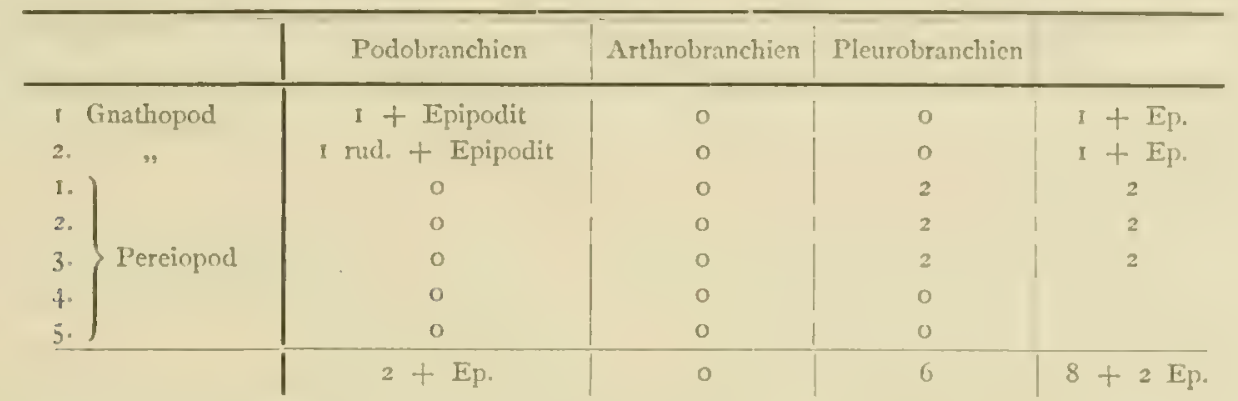

Die Einströmungsöffnungen der Atemhöhle liegen breit und groß vor der Basis der I. Pereiopoden und sind durch die kräftigen Basopoditen der 2. Gnathopoden verschließbar. Die Ausströmungsöffnungen sind relativ deutlich abgegrenzt und ein wenig vorgezogen.

Die äußeren Antennen sind glatt, zeigen keine auffallende Bildung; bemerkenswert ist, daß sie haum einige Härchen tragen (Taf. XLIII, Fig. 5).

Die inneren Antennen sind dagegen sehr ausgebildet (Taf. XLIII, Fig. 6) und werden im Abschnitt II näher beschrieben.

Von den Augen, welche im Abschnitt II eine eingehende Darstellung finden werden, sei hier nur bemerkt, daß sie bei dem Stadium I fast kugelig sind, zum Sehen nach allen Seiten eingerichtet. Bei den späteren Stadien sind sie offenbar mehr zum Sehen nach unten und vorn eingerichtet, nach oben ist eine facettenlose Fläche mit sehr dicker Cuticula gerichtet, welche das Auge schützt. Bei diesen Stadien ist das Auge oval langgestreckt, vorn etwas spitz. Es ist in allen Stadien relativ kurz gestielt (vgl. Taf. XLIX u. L, Fig. 2, 5 u. 6).

Bei dem $q$ des Stadiums IX ist das Abdomen zu voller Entwickelung gekommen, es mißt nun $45 \mathrm{~mm}$ in der Iänge und $38 \mathrm{~mm}$ in der Breite. Nit den Rändern stößt es fast an die Stachelreihe an, welche sich an den Basen der Pereiopoden längs hinzieht (s. Taf. XXII, Fig. 2).

Im allgemeinen ist das Abdomen glatt, in den peripheren Partien stehen einige Stacheln. Vor dem Hinterrande jedes Segmentes steht auf den vorderen Segmenten je eine Höckerreihe, welche nach hinten immer kleiner wird. Am Hinterrand des 6. Segmentes steht median nur noch I Stachel, auf der Mitte des 7. Segmentes ein Stachelpaar.

Die Pleopoden tragen Massen von kleinen Eiern vom Durchmesser von o,6 mm. Die Geschlechtsöffnung ist nun natürlich offen; sie liegt auf einem meist nach vorn gezogenen Lappen des 3. Sternalsegmentes.

Die Färbung der Tiere vom Stadium IX ist nach einer nach dem Leben gefertigten Skizze von F. WnNter auf Taf. II dargestellt. Der Cephalothorax ist im allgemeinen rot und gelblichrot gefärbt, die Beine $2-5$ haben auf Meropodit und Propodit je ein breites rotes Band. Auch die Stacheln des 2. Beinpaares sind zum Teil gebändert. Die Scherenfüße sind ziemlich ganz rötlich gefärbt. 
Die jüngeren Exemplare zeigten auch noch Spuren der roten Färbung, besonders die Bänderung der Beine war noch im Spiritus erhalten, verblaßte jedoch allmählich immer mehr. Ich finde also in all diesen Punkten die Beschreibung Atcocks bestätigt, welcher allerdings die älteren Formen etwas anders gefärbt fand, als die jüngeren.

Aus all dem was wir über die Art feststellen konnten, sind wir im stande, uns das Bild des Lebens einer Tiefseckrabbe zu rekonstruieren. Und wir werden später im Abschnitt II bei Betrachtung des feineren Baues der Augen dasselbe noch etwas vervollständigen können.

Die Kleinheit der Eier weist darauf hin, daß das junge Tier in einem recht frühen Stadium das Ei verläßt. Als Zoëalarve durchschwimmt es das freie Wasser der Tiefenregion und kommt wohl auch in viel geringere Tiefen als das erwachsene Tier. Die kugeligen Augen ermöglichen ihm, nach allen Seiten Umschau zu halten, die langen, zarten, mit feinen Härchen bedeckten Beine sind zum Schwimmen, zum Schweben sehr geeignet. Dann läßt sich das Tierchen auf den schlammbedeckten Meeresgrund nieder. Die nächste Häutung verwandelt es vollkommen aus einem pelagischen Tier in einen Grundbewohner. Die Beine werden kürzer und kräftiger, die Augen werden länglich: die facettenbedeckte Fläche ist nicht mehr nach allen Richtungen gewandt, sondern vorwiegend nach unten und vorn. Die Stachelbildungen des Cephalothorax werden kräftiger, ebenso diejenigen der vorderen Beine und gevähren dem jungen Tier Schutz. Während des Wachstums werden die Stacheln des Cephalothorax kleiner nnd durch Höcker ersetzt, offenbar je mehr die Größe des Tieres und die Wehrhaftigkeit der vorderen Extremitäten, deren Stachelkleid immer gefährlicher wird, es schützen. Ueber die Bedeutung der roten Färbung des Tieres s. Abschnitt II.

Offenbar ist die Art sehr vielen Nachstellungen ausgesetzt, denn man findet viele Exemplare mit abgebrochenen, regenerierten oder in der Regeneration begriffenen Gliedmaßen.

Auch in Bezug auf ihren Nahrungserwerb scheinen die Platymaien es nicht ganz leicht zu haben. Zwar bildet nach meiner Untersuchung des Mageninhaltes Schlamm einen Hauptteil der aufgenommenen Masse, aber sie scheinen sich auch an lebende Tiere heranzuwagen.

Der Magen enthielt Schlamm, Foraminiferenschalen, sehr zahlreiche Schwammnadeln, Schalenfragmente von jungen Lamellibranchien; aber auch Stückchen von Spongien, Borsten und Panzerstïckchen, Muskeln von Crustaceen und deutlich erkennbare Fragmente von Entomostraken. Sind die Tiere erwachsen, so wird bei der Begattung die große Schere des Männchens wohl zum Festhalten des Weibchens dienen, oder sie wird beim Kampf mit den rivalisierenden Männchen ihre Wirkung zu thun haben. Offenbar ist die Art eine gesellige Form, welche an den Orten, wo sie vorkommt, den Meeresboden in großen Scharen bewohnt. Die "Valdivia“Expedition und der "Investigator" fingen sie in großer Anzahl.

Es liegren mir folgende Exemplare vor, von denen allerdings manche zerbrochen waren und für die Untersuchung der morphologischen Einzelheiten weiter zerstückelt wurden:

Stadium I 4 Stück Station 249 Ostafrikanische Küste $3^{0} 7^{\prime} \quad \mathrm{S} . \mathrm{Br}, 40^{0} 45,8^{\prime} \mathrm{O}$. L., Tiefe $748 \mathrm{~m}$

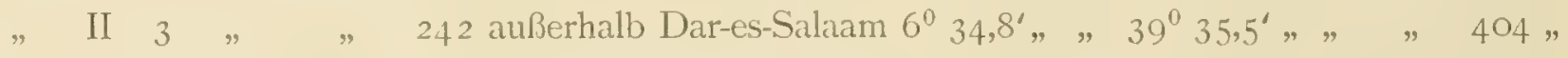

" II-III I Stück Station 208 SW. von Groß Nikobar $6^{0} 54^{\prime}$ N. Br. $93^{0} 28,8^{\prime}$ O. L. " 296 ”

" III $4 \quad \# \quad \# 242$ s. oben

" IV 2 " $" 242$ s. oben

"IV 3 ठै 2 \%, 245 im Sansibar-Kanal

"V $2 \delta^{\circ} \quad 208$ s. oben

" V $3 \delta^{\pi} \quad$ " 242 s. oben 
Stadium V I o Station 24,3 auBerhall Dar-es-Salaam $6^{0} 39,1^{\circ}$ S. Br. $39^{\circ} 30,8^{\circ}$ O. I. Tiefe $400 \mathrm{~m}$

\begin{tabular}{|c|c|c|c|}
\hline & VI I $q$ &, & 208 \\
\hline & VII I d I q &, & 208 \\
\hline & VIII I $q$ & $"$ & 24 \\
\hline & $\mathrm{IX} 20^{\circ} \mathrm{I} q$ & $"$ & \\
\hline
\end{tabular}

Verbreitung: "Indopacifik": Nördlich der Admiralitätsinseln I I $^{0} 4^{\prime}$ S. Br. I $46^{\circ} 39^{\prime} 40^{\prime \prime}$ O. L. in cincr 'Tiefe von $275 \mathrm{~m}$ („Challenger": MIrers); Andamanenmeer $238-740 \mathrm{~m}$ („Investigator": Alcock); Capregion: ca. $40 \mathrm{~km} \mathrm{~N}$. O. von Cap Natal, Tiefe $805 \mathrm{~m}$ (Stremixg).

Meine Fundorte verbinden also die bisher bekannten in sehr willkommener Weise und bestitigen die weite Verbreitung der Art. Die Tiefenverbreitung zeigt das Tier an die Dämmerregion gebunden, worüber im Abschnitt II Näheres berichtet wird.

\section{Gattung Stenorhynchus Lamarck. Stenorhynchus rostralus (LINNÉ).}

I76 I Cancer rostratus Linner Fauna suecica No, $202 \%$.

I8+9 Stenorhynchus phalangium (Prsw.), Mitxe-Enwards Atlas, Cuvier Règne animal, T. XXXIX, f. 3.

iS8 I Slenorhunchus rostratus (L.) var. spimulosus Mrers, in: Ann. Mag. Nat. Hist., Scr. V, Vol. VIII, p. 206.

$180+$ Sicnorlynchus rasiralus (L.) Ormmaxx, in: Zool. Jahrb., Abt. Syst., Bd. VII, S. 32 (hier Synonymic).

i goo Stenorhynchus phalangium Lixié (wohl lapsus calami für rostrahus L.) MrLxe-Edwards und Bouvier, Crustacés

Talisman, p. I5+ (daselbst übrige Synonymie).

Mrers. (8I) hat von dieser Art eine Varietät beschrieben, S. rostratus var. spimulosus, welche sich von der typischen Form durch die Bestachelung der Scherenfüße und die Form der Schere unterscheidet. In die Nähe dieser Varietät gehören zwei von der "Valdivia“Expedition in der Nähe der Congomündung erbeutete Exemplare. Die Form der Schere stimmt mit der Schilderung von Mifers überein, die Bestachelung steht in der Mitte zwischen derjenigen des Typus und der Varietiit.

In einem Punkt weichen aber meine Exemplare von den Beschreibungen ab; die Meropoditen der hinteren 3 Beinpaare tragen am vorderen Ende je einen, die des 2. Perniopodenpaares sogar mehrere Stacheln. Die Daktylopoditen sind kräftig und an den beiden hinteren Beinpaaren etwas sichelförmig gekrümmt.

Wenn ich trotz dieser allerdings geringen Abweichungen meine Exemplare zu S. rostratus rechne, so bestimmt mich dazu die Form des Rostrums, die Stachellosigkeit von Epistom und Scherenfüßen, sowie der gesamte Habitus der Exemplare.

Der Fundort ist von großem Interesse, indem er zeigt, wie weit nach Süden die Art sich verbreitet. Der südlichste, bisher bekannte Fundort waren die Cap Verdischen Inseln.

2 q Station 7 I von der Congomündung, $44 \mathrm{~m}$ Tiefe.

Verbreitung: Nordostatlantischer Ocean, von Norwegen und den Shetlandinseln bis zur Congomündung, bis zu ca. $100 \mathrm{~m}$ Tiefe.

Norwegen (G. O. SARs); Arendal (Mö̈rus); Skagerak (MIETZGER); Schweden: Bohuslän (Gös); Dänemark (Mernert); Gr. Belt (Mörius); Ostsee: Bülk bei Kiel (Mößius); Nordsee (Metzger); Shetlandinseln (Norman); Belgien (Vax Beneden); England (Bell); Kanal (MrlateEdwards); Mittelmeer (Hellfr, Carus); Adria (Heller, Stosstci); Golf von Cadiz (Talisman, M.-EDw. und Bouvier); Spanische Küste: Vigo (Mirers); Madeira (Strurson); Canarische 
Inseln (Travailleur: M.-Edwards und Bouvter); Azoren (Barrots); Senegambien (Miers); Cap Verdische Inseln (STUDER).

\section{Stenorhychus longirostris (FABRICIUS).}

I775 Cancer longirostris Fabricius, Syst. entom. p. 408, No. 42, p. pte.

$185^{8}$ Stenorhynchus tentirostris (LEACH), in: B ell, Brit. Crust., p. 6. Abbildung.

i 894 Stenorhynchus longirostris (FABr.) ORtMann, in: Zool. Jahrb., Syst., Bd. VII, S. 33 (hier Litteratur u. Synonymie). 1900 Sienominchus longirostris MimlNe-Edwards und Bouvier, Crustacés Talisman, T. XXII, fig. 6, p. I56.

I + Station 28 Cap Bojador $146 \mathrm{~m}$ Tiefe.

Verbreitung: Gemäßigter Teil des Nord-Ostatlantik und Mittelmeer; geht vom seichten Wasser bis I6 $35 \mathrm{~m}$ Tiefe.

Südwestliche Nordsee (Metzger); Belgien (van Beneden); südl. England (Bell); Kanal (Milne-Edwards); Mittelmeer (Milne-Ediwards, Heller, Carus, Ortmann); Adria (Heller, Stossich); Schwarzes Meer (Czerniawsiri); Spanische Küste, Marokko, Senegambien, Cap Verden („Travailleur“ und „Talisman“: Milne-Edwards und Bouvier).

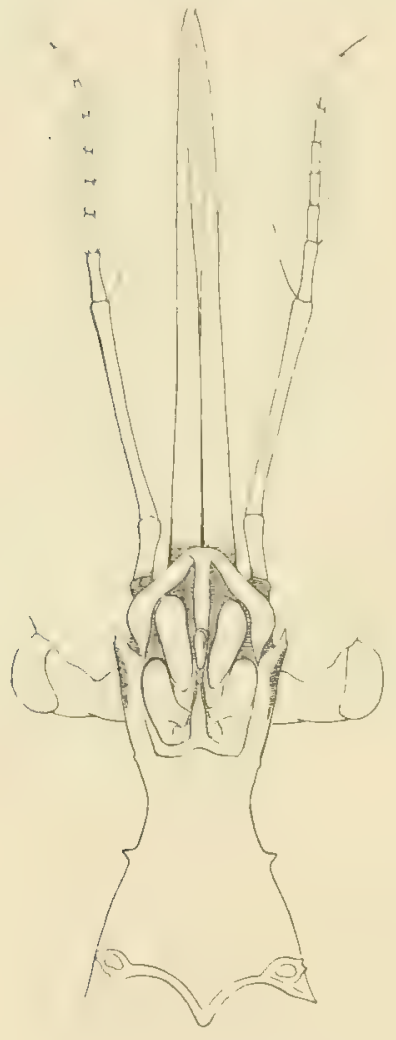

Fig. 6. Kopfregion von Stenorliynchus falcifer STM.

\section{Stenorhynchus falcifer STIMPSON.}

I857 Stenorhynchus falcifer Stmipson, Proc. Ac nat. Sci. Philadelphia, p. 2 I9. I886 Stenorhynchins falcifer MIIERs, Challenger Brachyura, p. 6.

Mir liegen von dieser Art 2 Exemplare vor, welche mit den Beschreibungen von Strmpsov und Miers recht gut übereinstimmen. Ich möchte daher nur einige Bemerkungen anfügen über die Beziehungen der Art zu den übrigen Stenorhynchus-Arten des Atlantischen Oceans. Milne-Edwards und Bouviek haben in den "Resultats des campagnes scientifiques" des Fürsten von Monaco, Vol. XIII, p. 48, eine Tabelle derselben und in den Ergebnissen der "Travailleur"- und "Talisman"-Expeditionen, Crustacés, p. I 54 ff., Beschreibungen von verschiedenen Formen gegeben. Aus denselben kann man entnehmen, daß S. falcifer STM. dem S. longirostris (FABr.) außerordentlich nahe steht. Ich vermute sogar, daß sich kontinuierliche Uebergänge von der einen zur anderen Art werden finden lassen, doch fehlt es mir an Material, um das zu untersuchen.

Doch bildet schon das Exemplar von S. Tongirostris von Cap Bojador, welches ich soeben erwähnt habe, eine Uebergangsstufe.

Der einzige durchgehende Unterschied zwischen beiden Formen scheint mir in der Bedornung des ersten Stielglieds der äußeren Antennen zu liegen. Während bei S. longirostris das I. Glied mit 3-6 Dornen besetzt zu sein pflegt, erhebt sich bei S. falcifor nur ein einziger Dorn auf dem I. Stielglied der äußeren Antennen, und zwar vor der Stelle, wo dasselbe von unten her von der Ausbauchung des Stirnrandes überragt wird (s. Textfig. 6).

Diese Ausbauchung, von welcher die nebenstehende Abbildung (Textfig. 6 Aus) einen Begriff geben soll, ist nach den Untersuchungen von MiLne-Edwards und Bouvier sehr 
charakteristisch für S. Iongirostris. An den mir vorliegenden Exemplaren von beiden Arten ist sie vollkommen gleichartig ausgebildet, was auch für die enge Zusammengehörigkeit der beiden Arten spricht.

I zerbrochenes of Station 9gb, Plettenbergbucht, Flachwasser bis $100 \mathrm{~m}$.

I junges zerbrochenes of Station roo, Francisbucht.

1 großes of Station 105, südlicher Teil der Agulhasbank, $35^{\circ} 29^{\prime} \mathrm{S}$. Br. $21^{\prime \prime} 25^{\prime} \mathrm{O}$. L. in einer Tiefe von $102 \mathrm{~m}$.

Verbreitung: Kapgebiet: Simonsbai 8-30 m (STmuson, „Challenger": Mreiss).

\title{
Gattung Physachaeus Alcock.
}

1895 Arcock, Journ. As. Soc. Bengal, Vol. Lxiv, 2, p. 174.

\section{Physachaeus clenurus ArCOCK.}

\author{
Taf. XXIV, Fig. I-4; Taf. XLII, Fig. I-7; Taf. XLVII.
}

1895 P'hysachacus ctcmunes Alcock, Journ. As. Soc. Bengal, Vol. LXIV, 2, p. 175, T. III, Fig. 2, 2a, 2b.

1 S95 I'hysachae"'s ctcmumes Alcock, Illustr. Zool. Investigator, Crustacea, T. XVIII, Fig. I, I it, Ib.

1899 I'hysachaeus clemurus Alcocis, Investigator Deep Sea Brachyura, p. 40.

ALcock hat sehr gute und auf meine Exemplare vollkommen zutreffende Beschreibungen dieser interessanten Tiefseeform gegeben. In Bezug auf die äußere Morphologie habe ich seinen Darstellungen kaum etwas hinzuzufügen. Ich kann nur unsere Kenntnis der Verbreitung der Form erweitern und einiges Interessante über den feineren Bau der Art mitteilen. Betrachtet man den ganzen Körper des Tieres bei stärkerer Vergrößerung, so fällt die Bedeckung von Körper und Extremitäten mit zahlrcichen Sinneshaaren auf. Ferner ist erst dann die Ornamentierung einzelner Beinglieder deutlich. Wir sehen an der Vorderseite sämtlicher Daktylopoditen eine Reihe von kleinen Höckern, welche offenbar die Rauhigkeit der Oberfläche zum Zweck des Festhaltens an Gegenstände vermehren. Aehnliche Höcker oder Dörnchen finden sich auch auf Carpopodit und Propodit des 2. Pereiopodenpaares und auch an den übrigen Pereiopoden können wir Spuren von solchen auf diesen Gliedern erkennen (vgl. Taf. XLII, Fig. 5). Außerdem ist auf dieser Fïgur zu sehen, daß unter den längeren Sinneshaaren die Schreitbeine vollkommen mit einem Ueberzug von feinen Haken- oder Angelhärchen bedeckt sind. Solche finden sich auch auf dem Cephalothorax. Sie dienen vorzüglich dazu, um das Tier mit Teilen von Hydroidpolypen etc. zu maskieren; auch bleibt der Schlamm zwischen ihnen hängen und macht das Tier an seinem natürlichen Aufenthaltsort für Verfolger jedenfalls schwer auffindbar.

Die eigenartige Form des $q$ - und $\delta$-Abdomens ist auf Taf. XLI, Fig. 3-5 dargestellt. Beim $q$ fällt vor allem die Ornamentierung des hinteren Randes des vorletzten Segmentes durch eine Reihe von 4 spitzen Stacheln auf. Das ó-Abdomen zeigt auf dem letzten Segment einen starken, aufrechten Stachel, welcher besonders bei seitlicher Ansicht sehr in die Augen fällt (Taf. XLII, Fig. 4). Bemerkenswert sind auch die sehr stark entwickelten Geschlechtsfüße des zweiten Paares, welche einen großen Teil des engen Raumes unter dem $\delta$-Abdomen in Anspruch nehmen (Taf. XXIV, Fig. 3).

Die vor dem Gastrikaldorn gelegrenen paarigen kleinen Dornen der Gastrikalregion sind besonders bei den ostafrikanischen Exemplaren sehr deutlich, während sie bei den indischen oft ganz verschwinden (Taf. XLII, Fig. I u. 2).

Die charakteristische Form des zweiten Gnathopoden ist auf Taf. XL11, Fig. 6 dargestellt. 
Die Kiemenformel ist auffallend, wenn mir bei der Präparation des etwas verletzten Individuums nicht ein Fehler passiert ist, was ich nicht annehme. Ich fand die Kiemen folgendermaßen verteilt:

\begin{tabular}{|c|c|c|c|c|c|}
\hline & I'exhlonanchien & Arthretsunchien & Pleurolusunchien & & \\
\hline 2. Gnathopod & I rud + Epipodit & 0 & I & $2+$ & Ep. \\
\hline I. Pereiopod & 0 & 0 & I gr. + I kl. & 2 & \\
\hline 2. & 0 & o & I & I & \\
\hline 3. & 0 & 0 & I & 1 & \\
\hline 4. $\quad "$ & 0 & $\circ$ & $\circ$ & 0 & \\
\hline 5. " & 0 & 0 & ㅇ. & 0 & \\
\hline
\end{tabular}

Von Interesse ist ferner die feinere Struktur der Sinnesorgane, über welche im Abschnitt II Näheres mitgeteilt ist.

IVie schon Ацсоск hervorgehoben hat, vereinigt die Form eine ganze Reihe von Merkmalen in sich, welche für Tiefseecrustaceen charakteristisch sind: die Pigmentlosigkeit der Augen (und, wie ich hinzufügen kann, die Größe der Facetten), die starke Entwickelung der Antennen, die Größe der Eier (Taf. XLII, Fig. 7), die Auftreibung der Kiemenhöhlen zeigen schon beim äußerlichen Anblick die Anpassung an die Tiefsee. Näheres hierüber findet sich im Abschnitt II. Vgl, auch die histologischen und anatomischen Bemerkungen im Abschnitt III.

I o Station 198, $0^{0} 16,5^{\prime}$ N. Br. $98^{\circ} 7,5^{\circ}$ O. L. Südküste von Nias in einer Tiefe von $677 \mathrm{~m}$

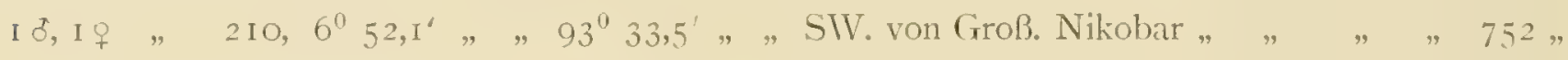
I $\quad " \quad 211,7^{0} 48,8^{\prime}, \quad " 93^{0} 7,5^{\prime}, \quad$ Westeingang des Som2 \%, I o " $253,0^{0} 27,4^{\prime}, " 42^{0} 47,3^{\prime}, "$ nahe der ostafrikanischen

Küste " , ” , 638 ,

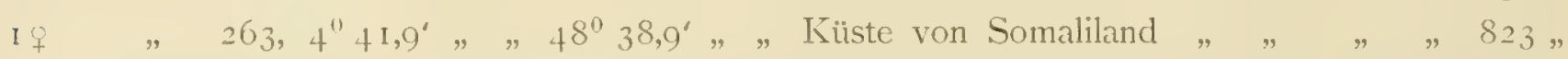

Verbreitung: Indischer Ocean von der Küste von Sumatra bis Ostafrika: Adamanensee, Malabarküste $338-740 \mathrm{~m}$ („Investigator": Alcock).

\section{Gattung Inachus FABRicius. \\ Inachus dorseltensis (PENN.).}

1777 Cincer dorsellensis Pexasan, Brit. Zool., Vol. IV, p. IO, f. I.

1793 Cancer scorpio Fibricius, Ent. syst., Vol. II, p. 462.

I 798 Inachus scorpio Fabricius, Suppl., p. $35^{8}$.

1893 Inachus dorseltensis (Penn.) Ortaiann, Zool. Jahrb. Syst., Vol. VI, p. 37 (das. Litteratur).

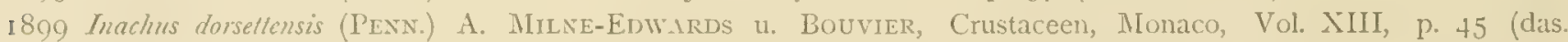
Bestimmungstabelle).

1000 Inachus dorseltensis (Penx.) A. Millxe-Edwards u. Bouvier, Crustacecn, Talisman, p. I43 (das. Litteratur).

Von dieser nordatlantischen Art hat die „Valdivia“-Expedition Exemplare von verschiedenen, weit voneinander entfernten Fundorten heimgebracht.

Ein ठ von $18 \mathrm{~mm}$ Cephalothoraxlänge wurde an der Küste von Schottland erbeutet, es zeigt alle charakteristischen Eigenschaften der Art in guter Ausbildung. Von einer Kallosität auf dem Sternum ist keine Spur, auf der Hepatikalregion liegt vor dem größeren Stachel noch ein kleinerer, auf der Gastrikalregion erhebt sich ein kräftiger Stachel und vor ihm eine gerade Querreihe von + kleinen Stacheln. 
Auch die Exemplare, welche in der Umgebung von Madeira und den Kanarischen Insel $\mathrm{n}$ in ca. $150 \mathrm{~m}$ Tiefe gefangen worden waren, thneln in ihrer Gestalt durchaus der l3cschreibung der typischen Form und dem nördlichen Exemplar. Beide Formen stimmen auch gut mit entsprechend großen Stücken der Münchener Sammlung aus der Adria überein.

Einige kleine Abweichungen bestehen darin, daß auf den Beinen, aul der Hepatikalregion und am Rande des Cephalothorax die Bestachelung und Granulierung eine etwas reichere ist. Das sind aber Unterschiede, welche für kleinere resp. jüngere Exemplare von viclen Arten sich feststellen lassen. Bei den ơ sind ferner die beiden schiefen granulierten Wülste auf dem Sternum vor dem Ende des Abdomens deutlich.

Das Auffallende liegt vielmehr in der Kleinheit der Exemplare selhst, von denen die größten 8-9 mm Cephalothoraxlïnge erreichen. Dabei sind die 9 Weibchen, welche auf der Seinebank gefangen wurden, sämtlich greschlechtsreif und tragen Eier unter dem Abdomen, welche sich in verschiedenen Stadien der Entwickelung befinden.

Wir haben es also offenbar mit einer Zwergform der Art zu thun, welche in diesem Tcil des atlantischen Oceans in einer gewissen Tiefe als Standortsvarietit vorkommt.

Gemeinsam mit anderen Thatsachen wird dieser Befund im Abschnitt II noch eingehender erörtert werden.

I großes ot Station 3, auf der Höhe von Aberdeen $57^{\circ} 26^{\prime}$ N. Br., I" $28^{\prime}$ IV. L., in einer Tiefe von $79 \mathrm{~m}$.

2 of 9 o kleine Form, Station 25 auf der Seinebank, $33^{\circ} 43,8^{\circ}$ N. Br., I $4^{\prime \prime} 20^{\prime}$ IV. L., in einer 'Tiefe von ca. $150 \mathrm{~m}$.

$2 \delta^{\circ}$ kleine Form, Station 28 bei Cap Bojador, $26^{\circ} 17^{\prime}$ N. Br., $14^{\prime \prime} 43,3^{\circ}$ IV. L., in einer Tiefe von $146 \mathrm{~m}$.

Verbreitung: Nordöstlicher Atlantik von Norwegen bis zu den Cap Verden: Norwegen (G. O. SArs); Schweden: Bohuslïn (Gö̈s); Dänemark (Metnert); Betr: Tromsö (MöBius); Nordsee (Merzger); Belgien (van Beneden); England (Belt); Kanal (Milne-Lidwards); Mittelmeer (Helter, Brandt, Carus); Adria (Heller, Stossichi); Spanische Küste: Ciibraltar, Cadiz; Marokkanische Küste, Saharaküste, Cap Verdische Inseln (,Travailleur" und "Talisman": Mirne-LDmariss und Bouvier).

\section{Inachus leplochirus LEACH.}

$18 \times 5$ Inachus leptochims Lescri, Malac. podophth. Brit., T. 22 b.

1834 Inachus leplorhinchus H. MndxE-EnWaris, Histoire nat. des Crust., Vol. I, p. 280 (lapsus calami),

I900 Inachus leplochinus A. Milve-EDwarns u. Bouver, Crust. Talisman, p. I.45 (das. Littcratur).

Von dieser seltenen Art erbeutete die „Valdivia“-Expedition 3 Stück, ebenfalls auf der Seinebank. Zwei davon sind $\delta$ von sehr verschiedener Größe, trotzdem hahen beide die Kallosität, jene perlenähnliche Bildung, auf dem Sternum vor dem Ende des Abdomens. Das Auftreten dieser Bildung wird in der Regel als ein Zeichen der Geschlechtsreife aufgefaßt, und scheint es in der That zu sein. Wir hätten also hier ebenfalls zwerghafte greschlechtsreife Individuen einer sonst größere Dimensionen erreichenden Art vor uns; BELL enwähnt sograr, daß I. leptochimus im enwachsenen /ustand die größte der englischen Inachus-Arten sei (British Stall-Eyed Crustacea, p. 19). Und das größte der mir vorliegenden o mißt nur $8,5 \mathrm{~mm}$ in der Länge.

Doch ist das Material zu grering, um eine Ansicht darüber äußern zu können. 
3 to, I ㅇ von Station 25, Seinebank, $33^{\circ} 43,8^{\circ} \mathrm{N}$. Br., $14^{0} 20^{\circ}$ W. L., in einer Tiefe von ca. $150 \mathrm{~m}$.

Verbreitung: England (Cranch, Prideaux nach Beli); Irland (W. Thompson, Bell); Adria: Spalato (Heller); Küste von Spanien (Milne-Edwards und Bouvier); Azoren (Hirondelle) Talisman, Mrrne-Edwards und Bouvier); Saharaküste (Talisman: Milne-Edwards und BOUVIER).

Inachus antarclicus n. sp.

Taf. XXVIII, Fig. 2 u. 3.

Leider in einem einzigen eiertragenden Weibchen liegt mir eine neue Art vor, welche den ersten Inachus repräsentiert, welcher von der südlichen Halbkugel bekannt wird.

Das Exemplar steht dem nördlichen Inachus leptochinıs am nächsten, ja ich schwanlite sogar längere Zeit, ob ich es nicht für ein großes Stück dieser Art halten sollte. Doch darf ich vorläufig kaum annehmen, daß Verschiedenheiten, wie sie sogleich erwähnt werden sollen, während des Wachstums sich einstellen.

Der dreieckige Cephalothorax ist ähnlich demjenigen von I. leptochimus, doch verläuft er nach vorn nicht so schlank, da die Gastrikalregion stark kugelig aufgetrieben ist. Die Regionen sind ziemlich deutlich. Auf der Mitte der Gastrikalregion erhebt sich ein einziger mächtiger Stachel; vor ihm sind zwei ganz flache Wülstchen eigentlich nur durch ihre etwas hellere Färbung erkennbar (Taf. XXVIII, Fig. 2). Vielleicht stehen bei jungen Exemplaren an diesen Stellen Stacheln.

Auf der Kardialregion erhebt sich ebenfalls ein kräftiger Stachel, unmittelbar hinter welchem ein kleiner Höcker steht. Ferner ist jede der Branchialregionen mit einem ansehnlichen Stachel bewehrt. Die Hepatikalregionen tragen eine Reihe feiner Zähnchen. Der Hinterrand des Cephalothorax ist etwas geschweift und ist stachellos.

Das Rostrum ist durch einen dreieckigen Ausschnitt geteilt und ist außerdem an den Seiten über den Orbiten mit einem kleinen accessorischen Stachel versehen. Obwohl es an den Spitzen etwas abgestoßen ist, ist es länger als der Stiel der äußeren Antennen.

Das Basalglied der äußeren Antennen trägt eine Reihe von feinen, deutlichen Stacheln ein größerer steht am distalen Ende.

Die Augen sind mäßig groß und pigmentarm.

Die Meropoditen der 2. Gnathopoden sind länglich und haben etwa die Länge des nicht vorspringenden Teiles des Ischiopoditen.

Die 2. und 3. Pereiopoden sind sehr lang, die 3. übertreffen die 4. um etwa ein Drittel ihrer Länge. Die Meropoditen sind distal nicht verdickt. Sämtliche Beine sind behaart.

Die Scherenfüße ähneln sehr denjenigen von I. leptochimus; der Meropodit ist etwas gebogen und trägt an der oberen und unteren Kante feine Stacheln, ebenso der Carpopodit am oberen Rande. Die Finger sind schlank, dünn, etwas nach innen gebogen; die fein gezähnelten Schneiden schließen dicht.

Das Abdomen des $q$ ist 6-gliedrig durch Verwachsung des 6. und 7. Gliedes; das 2. bis 5. Glied tragen in der Mediane einen Höcker. Die Eier haben einen Durchmesser von o,8 mm. I großes $q$ Station 104 bei der Agulhasbank, $35^{\circ} 16^{\prime} \mathrm{S}$. Br., $22^{0} 26,7^{\prime}$ O. L., in einer Tiefe von $155 \mathrm{~m}$. 


\section{Gattung Lispognathus A. MiLne-Edwards.}

1873 Domnchus Normas, in: Wrvidis-Thomson, The dephths of the sea, p. I74.

1880 Lispognathus A. Milvis-Enwards, Crustaceen in: Mission scient. du Mexique, p. $3+9$.

1900 Lispognathus A. MiLve-EDwards und Bouvier, in: Talisman Crustaceen, p. I47 (daselbst Litteratur).

\section{Lispognalhus Thomsoni NORMIAN.}

1873 Dumnchus Thomsoni NorMan, wie oben.

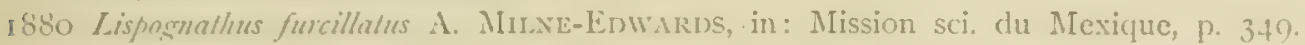

I8Si Lispogrnathus Thomsoni A. Mrr.Ne-LDwards, C. R. Ac. Sci. I'aris, p. 878 u. 0.32.

1886 Lisposmathus Thomsoni Mrers, Challenger Brachyura, p. 29, Taf. V, Fig. 2 (das. Litt.).

Inoo Lispognathus Thomsoni A. MiLcib-Edwards und Bouvier, Talisman Crustaceal, p. I\&8, Taf. III, Fig. 8; Taf, XXI, Fig. 8-It (das. newere Litt.).

Dic 38 Exemplare dieser Art, welche in der Ausbeute der "Valdivia"-Expedition enthalten sind, entstammen sehr verschiedenen Fundorten und sind von verschiedenem Alter und zeigen eine gewisse Variabilität. Die Reichhaltigkeit des Materials ermöglichte mir, die Zugrehörigkeit der verschicdenen Exemplare zur gleichen Art festzustellen, und ich gewann auch die Ueberzeugung, daß Lispognathus furcillatus M.EDw. nur auf ein junges Exemplar der Art basiert ist, denn die Abweichungen liegren durchaus im Bereich dessen, was ich von individueller Variation an meinem Material erkennen kann.

Zunächst liegen mir eine ganze Anzahl Exemplare vom typischen Fundort, den Meeren nördlich von Schottland, vor. Es sind $\delta$ und $q$ verschiedenen Alters; bei ihnen sind die Stacheln des Cephalothorax bald stärker bald schwächer, der Cephalothorax selbst, besonclers die Halsregion, ist bei manchen Exemplaren schlanker als bei anderen, und die Rostralhömer sind bei einem Exemplar fast vollkommen parallel, bei anderen mehr oder weniger stark divergierend. Auch die Länge der Rostraldornen ist bei den einzelnen Exemplaren sehr wechselnd.

Die gleiche Variabilität ließ sich bei den zahlreichen Exemplaren aus der Capregion feststellen. Hier wurden meist ziemlich große Stücke gefangen. Nit dem Alter schwinden die Angrelhaken auf den Extremitäten; die Stacheln auf dem Cephalothorax und auf den Scherenfüßen sind jedoch sehr stark und deutlich. Hier und da treten auch einige weitere Stachelbildungen auf; so treten bei ganz großen und starken Individiuen unten und seitlich an jedem Rostralstachel $\mathrm{I}-2$ kleine Nebenstacheln auf.

Das Exemplar von St. Paul ist leider am Rostrum stark verletzt, aber doch noch sicher bestimmbar. Die beiden Exemplare von Nias sind kleine schlanke Stücke mit kräftigen Dornen.

Von den ostafrikanischen Exemplaren ist das eine schlank und hat auffallend lange Rostralhörner, während das andere, ein sehr kleines Stück, kurze Rostralhörner besitzt.

$70^{\circ} 6 q$ Station 4 bei den Shetlandinseln $60^{\circ} 42^{\prime}$ N.Br. $3^{0}$ 10,3' IV.L. in einer Tiefe von $486 \mathrm{~m}$ $2 \delta^{\circ}$ juv. " IO südl. vom Thomsonrücken $59^{0} 37,3^{\prime}, \quad$ " $8^{0} 49,8^{\prime}$ " " " " " " " I326,

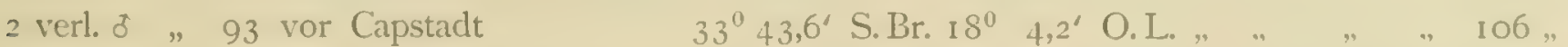
+ zerbr. $₫$ u. $\$$ Station 100 Francisbucht, geringste Tiefe, in welcher die Art bisher nachgewiesen wurde. 2 juv. zerbr. " $104 \mathrm{Im}$ Agulhasstrom $35^{\circ} 16^{\prime}$ S. Br. $22^{\circ} 26,7^{\prime}$ O. L. in einer Tiefe von $155 \mathrm{~m}$

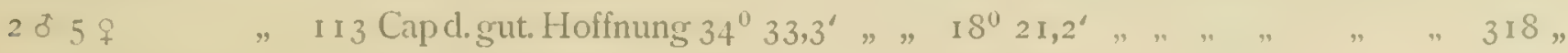

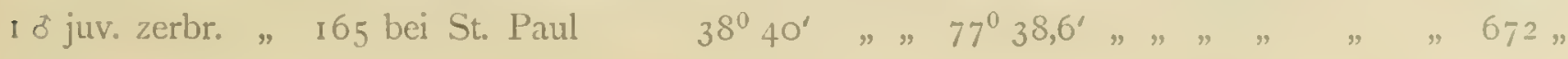


2 juv. Station 198 bei Nias $0^{\prime \prime} 16,5^{\circ} \mathrm{N}$. Br. $98^{\circ} 7,5^{\circ} \mathrm{O}$. L. in einer Tiefe von $677 \mathrm{~m}$

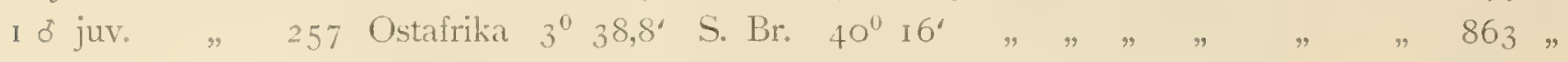

I $q$ juv. " 249 Ostafrika $3^{0} 7^{\prime} \quad, \quad, 40^{0} 45,8^{\circ}, \quad, \quad, \quad, \quad, \quad, 748$,

Damit ist für die Art eine fast kosmopolitische Verbreitung nachgewiesen; sie lebt in Tiefen von ca. IOO-2000 $\mathrm{m}$.

Verbreitung: Atlantischer Ocean: Bei den Far Oer (Norman); englische Küsten (fide Milane-Edwards und Bouvier); Biskayischer Golf, Küste von Spanien („Travailleur" und "Talisman": Mildxe-Edwards und Bouvier); Mittelmeer („Travailleur": M.-Edw. und Bouvier); Azoren (,Mlonaco": ML-EDw. und Bouvier); Kanarische Inseln, Küste von Marokko, Süden bis zu den Cap Verden („Talisman“: M.-EDw. und Bouvier); Westindien: Grenada (M.-EDw.). — Capregion: Agulhasbank („Challenger": Miers). Indischer Ocean (s. oben). Pacifischer Ocean: Sidney ("Challenger": Miters).

Soweit Bodentemperaturen der Fundorte gemessen wurden, liegen sie sämtlich zwischen $+5^{\circ}$ und $+10^{\circ} \mathrm{C}$; betrachten wir nun die Karten in Schotr's Atlas (dieses Werk Bd. I), so können wir erkennen, daß in der Durchschnittstiefe von $600-800 \mathrm{~m}$, in welcher Lispognathus Thomsoni vorzukommen pflegt, sämtliche bezeichneten Fundorte durch ein kontinuierliches Gebiet 5-Io-gradigen Wassers verbunden sind.

\section{Gattung Pleistacantha Miers emend.}

I 879 Plcisiacantha Miers, Proc. Zool. Soc. London, p. 24, Taf. I, Fig. I.

I88 i Ergasicus A. Milite-Edwards, C. R. Ac. Sci. Paris, Vol. XCIII, 28. Nov.

I886 Ergasticus M.-EDw.. Miers, Challenger Brachyura, p. 29.

I886 Echinopla.x Miers, Challenger Brachyura, p. 3 I.

I893 Plsistacantha Mrs., OrTManx, in: Zool. Jahrb. Syst., Bd. VII, I894, S. 39.

1899 Echinopla.x Mrs., Alcock, Investigator Brachy'ura, p. 42.

igoo Ergasticus M.-Enw., A. Mrlne-Edwards \& Bouvier, Talisman, Crustacés décapodes I, p. I39.

Pleistacantha Moseleyi (MIERs).

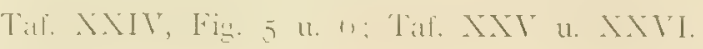

I886 Echinoplax Moseley'i Misers, Challenger Brachyura, p. 32.

I89I Echinoplax pungens IVOOD-MIAson, Ann. Mag. Nat. Hist., p. 259.

1895 Echimplai pungens Alcock, Journ. As. Soc. Bengal, Vol. LXIV, 2, p. I79.

I 896 Echinoplav prungens Alcock, Illustrations Investigator Crustacea, Taf. XVII, Fig. I (q).

I899 Echinoplar prengens ALcock, ibicl., Taf. XXXIX (o)).

1899 Echinoplax pungens ALCock, Investigator Brachyura, p. 43.

Die "Valdivia"-Expedition brachte von der ostafrikanischen Küste und von der Gegend von Sumatra verschiedene Stadien von Angehörigen der Gattung Pleistacantha mit. Ich vereinige unter diesem Namen die Angehörigen der 3 Gattungen Pleistacantha, Ergasticus und Echinoplax, welche clurch so geringe Unterschiede voneinander getrennt sind, daß es unnatürlich ist, sie voneinander zu trennen. Schon Miers selbst, Ortainnn und Alcock deuteten die Notwendigkeit dieser Vereinigung an. Und es ist sicherlich notwendig, die übermäßig zahlreichen Gattungen der Oxyrhynchen aufzulösen und die Arten in natürlicherer Weise zu gruppieren. Der Meinung von AlCock, daß auch Cy'tomaia den von mir vereinigten Formen angeschlossen werden sollte, kann ich vorläufig nicht beipflichten. 
Ferner habe ich es für richtig gehalten, Echinoplax MLscleyi Mirses und E. pungens WToonMASON zu vereinigen, indem ich annchme, daß ersterer nur ein Jugendstadium des letzteren ist. Dazu führte mich die Vergleichung der mir vorliegenden Exemplare.

Es sind dies zunächst einige junge Exemplare von der ostafrikanischen Küste. Von diesen gleicht besonders das jüngste der Abbildung, welche Mrers von seinem Echinoplax MYoseleyt gegeben hat. E. pungens soll sich von diesen hauptsächlich durch die Deutlichkeit der Regrionen auf dem Cephalothorax und durch das Längenverhältnis zwischen Rostrum und Cephalothorax unterscheiden. Nun sind aber bei den jungen Exemplaren die Regrionen undeutlich und werden mit dem zunehmenden Alter erst so scharf ausgeprïgt, wie Taf. XXVI, Fig. I es zeigt.

Die Rostralstacheln sollen bei E. Moseleyi mehr als die Hälfte, bei E. pungus weniger als ein Drittel der Cephalothoraxlänge erreichen. Die Maße, welche man erhält, sind sehr verschieden, je nach dem Punkte, den man als Basis des Rostrums annimmt. Mißt man von der Spitze der Rostralstacheln bis zu dem Punkte, wo diese zusammenstoßen, und von diesem Punkte bis zur Mitte des Hinterrandes des Cephalothorax, so erhält man für die 7 Exemplare, welche mir vorliegen, folgende Maße (nach der Größe geordnet):

\begin{tabular}{|c|c|c|c|c|}
\hline & & Rostraldornen & Cephalothorax & Verhältnis \\
\hline & $(I)$ & $3,6 \mathrm{~mm}$ & $14,8 \mathrm{~mm}$ & ca. $1: 4 \quad(1: 4,1)$ \\
\hline & (2) & $3,8 \quad$ " & I 5 & "I:4 (I:3,94) \\
\hline II. & 3) & 6,6, & 25 & $" 1: 4(1: 3,78)$ \\
\hline & $\left\{\begin{array}{l}\text { 4) } ठ \\
\text { 5) }\end{array}\right.$ & $\begin{array}{l}18,8 " \text { " } \\
\text { Rostrum abgebrochen }\end{array}$ & 63,5 & "1:3 (1:3,377) \\
\hline IV. & $\left\{\begin{array}{l}\text { 6) } q \\
\text { 7) }\end{array}\right.$ & $" \quad$ (etwas abgestoßen) & $\begin{array}{ll}67,3 \quad " \\
86,6 \quad "\end{array}$ & $\begin{array}{lll} & 1: 3 & (1: 3,05) \\
n & 1: 4 & (1: 4,3)\end{array}$ \\
\hline
\end{tabular}

Nach der Abbildung von Mrers war das Verhältnis bei seinem Exemplar 1:2,35. Es scheint mir dies im Bereich der individuellen Variation zu liegen, höchstens aber auf das Vorhandensein einer besonderen östlichen Subspecies hinzuweisen.

Sonst hätte ich den bisher gegebenen Beschreibungen nicht sehr viel hinzuzufügen. Wie die oben gegebene Tabelle zeigt, kann ich in meinem Material 4 Stadien unterscheiden.

Stadium I (Taf. XXIV, Fig. 5). Die jungen Stadien sind schlank, die Regionen auf dem Cephalothorax sind kaum zu unterscheiden. Cephalothorax und Extremitäten sind schr stachelig, zwischen den schlanken Stacheln stehen lange Haare; viele Stacheln tragen auf ihrer Spitze einige Haare. Einzelne Stacheln sind größer und kräftiger ausgrebildet: je einer auf der Regio epigastrica, gastrica, hepatica rechts und links, und weniger stark auf der Regio cardiaca. An den Daktylopoditen der Pereiopoden sind die Bürsten noch nicht ausgebildet.

Stadium II (Taf. XXIV, Fig. 6). Das Tier ist noch so bestachelt und behaart wic Stadium I, auch sonst ist es sehr ähnlich. Aber die geschlechtlichen Merkmale sind schon ausgebildet. Das Stück ist ein J, dem entspricht die Schmalheit des Abdomens, auch sind die Geschlechtsfüße schon aussrebildet. Die Bürsten auf den Daktylopoditen sind vorhanden, aber nicht sehr stark entwickelt.

Stadium III (Taf. XXV, Fig. I u. 2). Das Stadium ist durch 2 Exemplare vertreten, ein of und ein f. Die Regionen des Cephalothorax sind viel deutlicher geworden, besonders durch Auftreibung der Branchialregionen. Der Charakter der Bestachelung ist ein anderer 
geworden, die einzelnen. Stacheln sind relativ viel stärker, die Behaarung zwischen ihnen ist fast ganz verschwunden. Erst jetzt sind die Bürsten an den Daktylopoditen in vollkommener Ausbildung vorhanden. Die sekundären Geschlechtscharaktere des $\delta$ sind noch nicht ausgebildet.

Stadium IV (Taf. XXV, Fig. 3; Taf. XXVI). Erst in diesem Stadium sind die mächtigen Scheren des of entwickelt. Die Branchialregionen sind in auffallender Weise aufgetrieben, so daß die Cardialregion zwischen ihnen versenkt erscheint. Die Stacheln sind viel kürzer und kräftiger geworden. Behaarung ist kaum mehr vorhanden; auf den Beinen ist die Bestachelung viel geringer geworden, die Bürsten der Daktylopoditen sind dagegen sehr kräftig ausgebildet.

Das Abdomen ist ziemlich kurz, die vorderen Geschlechtsfüße sind lang, die hinteren ganz kurz, griffelförmig. Das Vas deferens ragt in Gestalt einer Samenröhre mehrere Millimeter weit vor.

Ob E. mbida Alcock (Journ. As. Soc. Bengal, Vol. LXIV, 2, I895, p. I79) eine besondere Art ist, oder ob das einzige bisher gefundene $q$ nur eine Aberration von unserer Form darstellt, wage ich nicht zu entscheiden. Daß bei den mir vorliegenden jungen Exemplaren einzelne Stacheln stärker ausgrebildet sind, könnte auf letztere Annahme hinweisen.

I o Station 194, südlich von P. Nias, $0^{0}{ }_{15} 2^{\prime}$ N. Br., $90^{\circ} 8,8^{\prime} \mathrm{O}$. L., in einer Tiefe von $614 \mathrm{~m}$.

2 d, I $q$ Station 208, bei Groß-Nikobar, $6^{\circ} 54^{\prime} \mathrm{N}$. Br., $93^{\circ} 28,8^{\prime} \mathrm{O}$. L., in einer Tiefe von $296 \mathrm{~m}$.

2 juv., 1 of juv. Station 242, bei Dar-eș-Salaam, $6^{\circ} 34,8^{\prime}$ N. Br., $39^{\circ} 35,5^{\prime}$ O. L., in einer Tiefe von $404 \mathrm{~m}$.

Pleistacantha Moseleyi (Mrers) kommt demnach im ganzen Indischen Ocean von den Philippinen bis zur ostafrikanischen Küste in der Nähe des Aequators in Tiefen von 200 bis $800 \mathrm{~m}$ vor.

Verbreitung: Philippinen, $9^{0} 26^{\prime}$ N. Br, $123^{0} 45^{\circ}$ O. L., in einer Tiefe von $686 \mathrm{~m}$ (MIERs: "Challenger"); Andamanen See 205-457 m Tiefe (Alcock: „Investigator").

\section{Gattung Menaethius Milne-Edwards.}

\section{Ilennethius monoceros (LATREILLE).}

I8I8 Pisa monoceros Latreilie, Encyclopédie, Vol. X, p. I39.

I 893 Menaethius monoceros (LatR.) ORTMAxi, Zool. Jahrb. Syst., Bd. VII, I894, S. 4 I (daselbst Littcratur und Synonymie).

I895 Menathizis monoceros ALCock, Journal Asiat. Soc. Bengal, Vol. LXIV, 2, p. I97 (daselbst ausführlich Litteratur und Synonymie).

Von dieser für Korallenriffe charakteristischen Form fand die Expedition 4 d und 4 i bei Mahe, Seychellen.

Verbreitung: Tropisch-indopacifisches Gebiet. Rotes Meer (Mrlne-Edwards, Heller); Tor (RÜppel); Djiddah (DE MAN); Seychellen (Rtchters); Mauritius (Mmine-EDivards, Adans und White, Richters); Réunion (A. Mmle-Edwards); Andamanen, Nikobaren (Alcock); Java: Insel Edam (de Man); Amboina (de Man); Sulu-See (Dana); Philippinen (Adans u. White); Hong- 


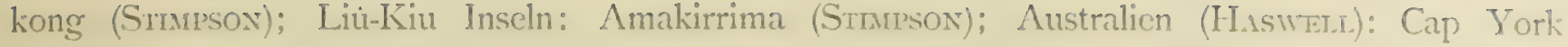
(„Challenger": Mrers); Neu-Caledonien (A. Mrlne-Liwards); Fidschi-Inseln (Daxi); Tongu-Tabu („Challenger“: Mirers); Samoa: Upolu (DANA); Sandwich-Inseln (DANA).

\section{Gattung Hyas LeACH. \\ Ilyas coarctalus LEACH.}

I815 IIyas coarclatus Ledcri, Malacostraca, Fig. 2 I b.

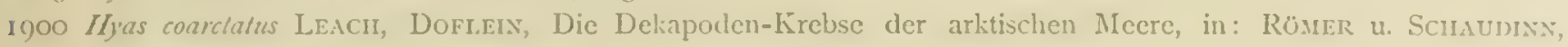
Fauna arctica, 13d. I, S. 353 (daselbst Litteratur).

6 Stück Station 3, Höhe von Aberdeen, Nordsee, in einer Tiefe von $79 \mathrm{~m}$.

Verbreitung: Arktisch-cirkumpolar. Näheres s. Doflein a. a. O.

\section{Gattung Eurynome LEACH. \\ Eurynome aspera (PENNANT).}

1779 Cancer asper Pexiant, Brit. Zool., Vol. IV, Taf. IX, Fig. 20

I8I5 Eurynome aspera LEAcr, Nalac. Brit. Podophth., Taf. XVII.

I893 Eurnome aspera (Pens.) Ortamsx, Zool. Jahrb., Syst., Bd. VII, I804, S. 57 (das. Litteratur).

1 goo Eurnome aspora MiLxe-Edwards u. Bouvier, Talisman Crustacea I, p. I 25, Taf. XIX, Fig. 7 -15 (das. Litteratus und Synonymie).

Das $\delta$ und +, welche mir vorliegen, gehören zur var. acuta MI.-EDw. u. Bouv., obwohl sie zwischen ihr und der typischen Varietät vermitteln. Die Rostralhörner sind mäßig lang, und die Höcker auf Gastrikal- und Cardialregion stehen ziemlich dicht bei einander. Doch sind die Stacheln auf der Branchialregion wohlausgebildet.

I $\delta^{\prime}, x$ I Station 28 bei Cap Bojador $26^{0}$ i $7^{\prime}$ N. O. Br., I $4^{0} 43,3^{\prime}$ IV. L., in einer Tiefe von $146 \mathrm{~m}$.

Verbreitung: Norwegen (G. O. SARs); Schweden: Bohuslän (GoËs); Kattegat und Sund (MIninert); England (BeLi); Canal und normannische Inseln (Milne-EdWards); Meerbusen von Biscaya (Mrlate-Edwards u. Bouvter); spanische Küste (dieselben); Mittelmeer (Heller, Carus); Adria (Heller, Stossicit); Azoren (Barrois).

Der var. acuta: Nordwestküste von Afrika: Cadiz, Madeira, Sudanküste, Arguinbank, Cap Verdische Inseln („Talisman“ und „Travailleur": MILNE-EDWards u. Bouvier).

\section{Gattung Pisa LEACH.}

\section{Pisa carinimana Miers.}

I879 Pisa carinimana Miers, Ann. Mag. N. H., 5. Ser., Vol. IV, p. I I, Taf. IV, Hig. 6.

I88 I Pisa carinimana Miers, Ann. Mag. N. H., 5. Ser, Vol. VIII, p. 207.

I893 Pisa carimimana OrtManv, Zool. Jahrb. Syst., Bd. VII, I894, p. 54.

Von dieser zierlichen Art liegen mir einige ơ und $q$ vor, welche sämtlich noch jung sind und infolgedessen weder die Leisten an der Hand deutlich zeigen noch eine Spur ron den Höckern auf der Gastrikalregion; das größte Exemplar mißt auch nur wenig über Io mm. Miers bemerkt selbst I88I, daß bei jungen Exemplaren diese Merkmale nicht erkennbar 
seien. Seine Abbildung und sonstige Beschreibung lassen jedoch meine Exemplare sicher bestimmen. Der Fundort ist sehr bemerkenswert.

4 ㅇ, $2 \delta$ (I verletzt) Station $7 \mathrm{I}$, Kongomündung, $6^{0}$ I 8,7 $\mathrm{S}$. Br., I $2^{0}$ 2, $\mathrm{I}^{\prime}$ O. L., in einer Tiefe von $44 \mathrm{~m}$.

Verbreitung: Nordwestafrikanischer Teil des Atlantiks: Canarische Inseln (MiErs), Senegambien (Miers, Ortmann).

\section{Gattung Micropisa Stimpson.}

I 857 Micropisa Stimpson, Proc. Ac. N. Sc. Philadelphia, p. 217.

1869 Phycodes Milne-Edivards, Rev. et Mag. de Zool., p. 374.

I881 IIerbstic MIıers, Ann. Mag. N. H., Ser. 6, Vol. VIII, p. 206.

\section{Micropisa violacea A. MiLne-EDw.}

I868 Micropisa violaca A. Milne-Edwards, Nouv. Arch. Mus. H. N. Paris, Vol. IV, p. 50, Taf. XVI, Fig. 3-6. I869 Phycodes antennatius A. Milne-Edwards, Rev. Mag. Zool., p. 374.

I88I Hcrbstia violacea (MI.-Edw.) Miers, in: Ann. Mag. N. H., Ser. 6, Vol. VIII, p. 206.

I 886 Herbstia violacea (M.-EDw.) Miters, Challenger Brachyura, p. 50.

Igoo Micropisa violacea Milne-Edwards u. Bouvier, Talisman Crustacea I, p. I3O.

An meinen Exemplaren, welche sonst gut mit der Beschreibung und Abbildung bei A. Milne-Edivards (r868) übereinstimmen, fällt mir auf, daß der Zahn auf dem i. Glied der äußeren Antennen zwar sehr stark ausgebildet ist, aber nicht spitz zuläuft, sondern ein breit abgestutztes Ende besitzt.

$2 \delta^{\circ}$, I $q$ Station 76 , Große Fischbucht, $16^{\circ} 30^{\circ} \mathrm{S}$. Br., I I ${ }^{0} 46^{\prime} \mathrm{O}$. L., in geringer Tiefe.

Der Fundort ist bemerkenswert, weil er eine Verbreitung der Art weit nach Süden beweist. Die Art erstreckt sich also durch die Tropen an der Westküste von Afrika und scheint wie im Norden so auch im Süden bis in gemäßigtere Regionen verbreitet zu sein.

Verbreitung: Saharaküste (Mnlne-Edwards u. Bouvier); Cap Verdische Inseln (MilneEdw. u. Bouv., Miers); Senegambien (Miers); Angola (Milne-Edwards).

\section{Gattung Scyramathia A. Milne-Edwards.}

I880 Scyramathio A. Milne-Edwardo, in: Bull. Mus. Comp. Zool., Vol. VIII, p. 3 II.

188 I Scyramathia A. Milne-Edwards, C. R. Ac. Sci. Paris S. dec., I88 I

I 885 Scyramathia SARS, Norwegian North-Atlantic Exp., Vol. VI, Crustacea, Pt. I, p. 6 u. 274.

I887 Anamathia (p. p.) S. I. Smitn, Rep. U. S. Fish Comm. for 1885, p. 625.

1889 Anamathia Pocock, Ann. Mag. "Nat. Hist., Ser. 6, Vol. IV, p. 425.

1893 Scyramathia Stebing, History of Crustacea, Internat. Sci. Ser, Vol. LXXIV, p. II 9.

I894 Scyramathic Milne-EDwards u. Bouvier, Crustacea Monaco, Vol. VII, p. I2.

I894 Anamathia (p. p.) M. J. Rathiun, Proc. U. S. Nat. Mus., Vol. XVII, p. 6I

I 895 Anamathia (p. p.) Faxon, Mem. Mus. Comp. Zool., Vol. XVIII, p. 8.

I895 Scyramathin Alcock, Journ. As. Soc. Bengal, Vol. LXIV, Pt. 2, p. 200.

1899 Scyrrmathic Alcock, Investigator Deep Sea Brachyura, p. 5 I.

I899 Scyramathia Milne-Edwards u. Bouvier, Crustacea Monaco, Vol. XIII, p. 43.

I900 Sejramathia Milne-Edwards u. Bouvier, Talisman Crust. Déc., Pt. I, p. I 3 I.

I002 Scyramathio SteßBIనig, South African Crustacea, Pt. 2, p. 5. 
Milne-Enwards und Bovver sowie Strembing haben sich in nenerer Zeit über die Abgrenzung und Synonymie der Gattung Scyramathia geäußert. Doch haben sie die Fragre nicht zum Abschluß gebracht. Auch mein Material ist nicht hinreichend, um sie in Angriff zu nehmen; denn nach meiner Ansicht wird eine Revision dieser Gattungen den Anstoß zu ciner Revision der Gattungsgrenzen bei den Oxyrhynchen überhaupt führen müssen. Wie in dieser Gruppe die Gattungsgrenzen zu eng und dabei wenig scharf grezogen sind, so gilt dies ganz besonders für die Gattungen Anamathia, Scyramathia, Scyra, Pugctlia und Verwandte.

Jedenfalls wird sich die von MILNE-LidWARDS und Bouvier (1900) angewandte Crattungsdiagnose nicht halten lassen; bei Anwendung derselben würden sich die indopazifischen Arten der Gattung nicht cinfügen lassen, was doch sicher nicht den natürlichen Verhältnissen entspräiche. Ja man wäre konsequenter WVeise genötigt, für die Formen mit Supraorbitalstachel, ohne Dornen auf dem Basalglied der äußeren Antennen und ohne Plattenhöcker auf dem Cephalothorax eine neue Gattung zu begründen.

Ich halte es für mehr der natürlichen Vervandtschaft entsprechend, wenn man die Gattungsdiagnose enveitert, indem man bei Beschreibung des Cephalothorax statt: Cephalothorax mit Stacheln und Plattenhöckern, sagt: Cephalothorax auf jenen Regionen mit Stacheln, welche durch mehr oder weniger platte Höcker ersetzt sein können; dies ist auch die Auffassung von Alcock.

Die Gattung würde nach meiner Ansicht also folgende Arten umfassen:

I. Atlantischer Ocean.

Syyramathic Carpenteri (Normin), Nordostatlantik.

Scyramathia Hertwigi Doflers, Capregion.

II. Indischer Ocean.

Scyramathia pulchra Miers, Von den Philippinen bis Ostafrika.

Scyramathia Rivers-andersoni Alcock, Von Sumatra bis Ostafrika.

Syyramathia Beauchampi (Alcock u. Anderson), Bai von Bengalen.

Scyramathia globulifera (IVood-Mason), Andamanen-See.

Scyramathia velutina MIIERs, Ki-Inseln bis Sumatra.

\section{Scyramathia Herlwigi DOHLEN.}

Taf. XxviI, Fig. I-7; Taf. XxvIII, Fig. I.

1 goo Scymmathia Ilcracigi Dofleis, Abbildung in: Cinus, Aus den Tiefen des Weltmeers, Jena, G. Fischer, I. Aufl., S. 497 .

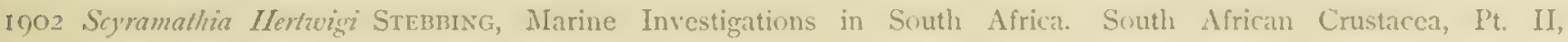
S. 7, T. VI.

Ig03 Syramalhia Hertagigi Abbildung in: Crus, Aus den Tiefen etc., II. Aufl., S. I7t.

Wie Stebring (s. o.) ganz richtig hervorhebt, steht diese Art Scyramathia Carpenteri (Norx.) sehr nahe. Ja, wenn mir nur ein einzelnes Exemplar oder wenige vorgelegen hätten, so würcle ich es nicht gewagt haben, die Form von der erwïhnten nordatlantischen zu trennen.

Als ich die Art mit dem Namen belegte und sie dadurch unterschied, war mir die ausführliche Beschreibung noch unbekannt, welche Mirave-EDWards und Bouvier von Sc. Carpenteri in der Bearbeitung der Anomuren und Brachyuren des Travailleur und Talisman gegeben haben. Nachdem diese erschienen ist, kann ich die Unterschiede zwischen beiden Formen 
genau präzisieren. Es ist mir aber zweifelhaft geworden, ob es sich um Arten handelt oder um Unterarten. Die Frage ist nicht wohl eher zu entscheiden, als bis etwa Exemplare von Fundorten bekannt werden, welche zwischen den bisherigen der beiden Formen gelegen sind.

Wie Sterbing erwähnt, ist der auffälligste Unterschied gegenüber S. Carpenteri die relative Kürze der Rostralhörner, welche bei den erwachsenen Exemplaren von Sc. Hertwigi nur 1/4 der Gesamtlänge des Cephalothorax, bei jüngeren Exemplaren manchmal $1 / 3$ erreichen, bei nicht wenigen aber auch nicht einmal $1 / 5$ ! Von den sämtlichen ca. 50 Exemplaren, welche die „Valdivia“-Expedition mitgebracht hat, erreicht kein einziges eine größere Länge der Rostralhörner. Ebenso stimmt dies für das Exemplar, welches StebBrng beschreibt. Also haben wir darin ein konstantes Merkmal der Form aus der Capregion zu erblicken.

Die Bewaffnung des Cephalothorax ist, wie ebenfalls SteBbrng schon erwähnt hat, derjenigen von Sc. Carpenteri sehr ähnlich; auch stimmt die südliche Form mit der nördlichen darin überein, daß die Cephalothoraxskulptur ziemlich variabel ist und daß sie während des Wachstums gewisse Veränderungen erfährt (Taf. XXVII, Fig. I-7).

Der Cephalothorax ist dreieckig, bei den jungen Exemplaren schlank (Taf. XXVII, Fig. I u. 4), bei den erwachsenen Stücken, besonders den $q$, in auffallendem Maße plumper

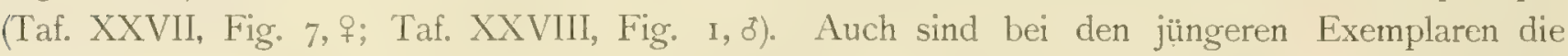
Regionen mehr gleichmäßig voneinander abgegrenzt, während bei den älteren besonders die Gastrikalregion stark aufgetrieben ist und nach vorn steil zur Stirn abfällt.

Auf der Oberfläche des Cephalothorax finden sich zahlreiche hakenförmige Angelhaare, durch welche mannigfache Organismen, besonders Schwammstückchen, zur Maskierung befestigt sind. Besonders zwei Reihen, welche sich von der Gastrikalregion auf die Rostralhörner hinabziehen, sind hervorzuheben.

Die Rostralhörner sind rund, kräftig und divergieren nur wenig, in einem Winkel von $20-30^{\circ}$. Der Supraokulardorn ist kräftig und spitz. Der Postokulardorn ist bei jungen Exemplaren ebenfalls relativ lang und sehr spitz, bei alten stumpf und gedrungen. Er ist durch eine leistenförmige Erhebung mit dem Hepatikaldorn verbunden; der letztere ist scharf, von der Seite (außen) abgeplattet dreieckig, ziemlich steil senkrecht aufgerichtet. Bei jungen Exemplaren sind beide Dornen selbständiger, bei alten vereinigen sie sich immer mehr zu einer kielartigen Bildung.

Auf der Gastrikalregion sind vier Höckerbildungen vorhanden. Auf der Regio epigastrica sitzt ein kleiner rundlicher Höcker, er ist bei älteren Stücken spitz. Auf den protogastrischen Regionen sitzt je ein Tuberkel, welcher die Gestalt einer scharfen, quergestellten Schneide hat. Auch er ist bei jungen Exemplaren undeutlich. Die ganze mittlere und hintere Gastrikalregion ist in der Medianlinie von einem niedrigen, oben abgeplatteten Höckergebilde eingenommen, dessen Breite bei den einzelnen Individuen sehr variiert (Taf. XXVII, Fig. I, 4-7; Taf. XXVIII, Fig. I).

Aehnlich steht es mit der großen breiten Platte auf der Kardialregion. Auch deren Form und Höhe ist sehr verschieden.

Auf der Mitte des Hinterrandes steht bei jungen Exemplaren ein scharfer Stachel, bei alten ein stumpfer Höcker.

Auf jeder der Branchialregionen sind 3 Erhabenheiten zu finden. Zunächst am Außenrande ist jederseits ein Seitenstachel zu finden, welcher nach vorn und außen ragt. Er ist jederzeit ziemlich ansehnlich. Doch ist er bei jungen Exemplaren von kreisrundem Querschnitt, bei 
alten Stücken ist derselbe fast dreieckig, indem die obere hintere Ilïche des Stachels cine platte Ebene mit scharfen Kanten darstellt. Doch sind bei manchen alten lixemplaren auch Seitenstacheln von rundem Querschnitt erhalten.

In der Mitte des Vorderrandes der Branchialregion erhebt sich jederseits ein uroßer, ohrenförmiger, platter Höcker. Derselbe ist bei allen Exemplaren schr deutlich ausgebildet.

In der Mitte zwischen dem Seitenstachel und dem Kardialhöcker erheht sich ein weiterer Höcker, welcher bei jungen Exemplaren rundlich ist, bei älteren aber ebenfalls die Tendenz hat, eine Querkante zu entwickeln.

Die Unterseite zeigt bei dem erwachsenen of eine auffallend tiefe Grube zwischen dem Hinterrand des Mundfeldes und der Abdomenspitze.

Das Epistom ist breit und platt; von den gekielten, stark vorragenden vorderen Mundecken zieht sich ein gezähnelter Kiel über die Pterygostomialregion hin.

Auf dem Sternum befinden sich zwischen den Basen der Pereiopoden und dem Rand des Abdomens vor dem 2.-4. Pereiopoden je eine ziemlich tiefe dreieckige Grube.

Das Abdomen ist bei beiden Geschlechtern 7-gliedrig. Dasjenige des $\delta$ ist an der Basis breiter, das 4. und 5. Glied sind schmäler als das 3., das 6. wieder etwas breiter als das 5., das 7. ist stumpf dreieckig.

Die Augen sind mäßig groß und sind blaß gefärbt (näheres S. Abschnitt II).

Die äußeren Antennen überragen mit der Spitze ihrer Geißel die Rostraldornen nur wenig; das Basalglied ist unten breit abgeflacht, seitlich gehielt; der Kiel ragt seitlich über das Rostrum hervor.

Das Mundfeld ist breit viereckig, der Meropodit des 2. Gnathopoden ist an der vorderen Außenecke breit flügelartig ausgezogen, die Ecke aber abgerundet. Der Carpopodit ist an der Innenecke eingelenkt.

Die Scherenfüße, welche bei den Jungen sehr schwach und dünn sind (Taf. XXVII, Fig. I u. 2, $\delta$ juv.), erreichen bei den alten $\delta$ sehr bedeutende Dimensionen (Taf. XXVIII, Fig. I). Sie sind mehr als doppelt so lang als der ganze Cephalothorax. Der Meropodit ist 4-kantig prismatisch, die oberen Kanten sind mit zahlreichen feinen Höckerchen besetzt. Der kurze Carpopodit ist oben mit 3 Kanten versehen, welche höckerig gezähnt sind.

Die sehr lange Schere ist oben und unten scharf gekantet, die Vorder- und Hinterseite ist je mit einem runden Wulst versehen. Die Palma ist fast 4 mal so lang als die Finger.

Die Finger schließen nur mit den feiner gezähnelten vorderen Hälften der Schneiden zusammen; die hinteren Hälften klaffen; der bewegliche Finger trägt in der Mitte dieses klaffenden Raumes einen großen, kuppelförmigen Zahn.

Bei jungen Individuen und bei $q$ sind die Schneiden gleichmäßiger gezähnelt und schließen besser zusammen.

Von den übrigen Pereiopoden ist das 2. Paar bei weitem das längste, das 3. überragt mit seinem Propoditen kaum den Carpopoditen des 2., das 4. und 5. sind viel kürzer.

Die Meropoditen sind cylindrisch, lang, schlank und vorn verdickt; die Carpopoditen sind kurz und etwas kantig; die Propoditen sind schlank, cylindrisch, vorn schwach verdickt; die Daktylopoditen sind schlank, leicht gebogen und enden mit einem gelben, durchscheinenden, hornigen Stachel. 
Viele Exemplare waren mit Schwammstücken, Ascidien, Cirripedien bedeckt. Bei vielen waren Regenerationen festzustellen, ferner fielen zahlreiche Exemplare durch starke Deformierung der Branchialregionen auf. Diese war durch parasitische Bopyriden veranlaßt.

Viele of und $q$ Station IO3, im Agrulhasstrom, $35^{\circ}$ 10,5 S. Br., $23^{\circ} 2^{\prime}$ O. L., in einer Tiefe von $500 \mathrm{~m}$.

Viele $\delta$ und $q$ Station I 1 3, Kap der guten Hoffnung, $34^{0} 33,3^{\prime}$ S. Br., I $8^{0} 21,2^{\prime}$ O. L., in einer Tiefe von $318 \mathrm{~m}$.

Verbreitung: Kapregion: auf der Höhe von Lionshead, in einer Tiefe von $256 \mathrm{~m}$ (STEBbing).

\title{
Scyramathio pulchra (MIERS).
}

Taf. XXVII, Fig. I2.

i886 Anamathia puldira Miers, Challenger Brachyura, p. 26, Taf, IV, Fig. I (ơ adult.).

I8q I Anamathin Livermorii Woon-Masor, Ann. Mag. N. Hist., Ser. 6, Vol. VII, p. 200 (o juv., $q$ ad.).

I895 Scyramathia Lizermorii Alcock, Illustrations Investigator, Crustacea, Taf. XIV, Fig. 3 (q).

1805 Scyramathia pulchra Alcock, Journ. As. Soc. Bengal, Vol. LXIV, Pt. 2, p. 262.

I809 Scyramathic puldm Alcock, Investigator Deep Sea Brachyura, p. 52

Von dieser eleganten Form brachte die „Valdivia“-Expedition einige nicht ausgewachsene Exemplare heim, welche sämtlich in den ostafrikanischen Meeren gefangen wurden. Ich kann an meinen Exemplaren keinerlei Abweichungen von den Beschreibungen von Miers und ALcock finden.

$3 q$ juv. Station 253, nahe der ostafrikanischen Küste, $0^{0} 27,4^{\prime} \mathrm{S} . \mathrm{Br}$, $42^{0}+7,3^{\circ} \mathrm{O}$. L., in einer Tiefe von $638 \mathrm{~m}$.

I of juv. zerbrochen Station 254, nahe der ostafrikanischen Küste, $0^{0} 29,3^{\circ} \mathrm{S} . \mathrm{Br}, 42^{0}$ 47,6 O. L., in einer Tiefe von $977 \mathrm{~m}$.

I J juv. zerbrochen Station 265, Somaliküste, $6^{\circ} 24, I^{\prime} \mathrm{N} . \mathrm{Br}, 49^{\circ} 31,6^{\prime} \mathrm{O}$. L., in einer Tiefe von $628 \mathrm{~m}$.

Verbreitung: Tropischer Indopacifik: Philippinen, Tiefe 686 m (Nirers: „Challenger“); Andamanen, 238-1026 m (Alcock: „Investigator").

\section{Scrrnmathia Rivers-Indersomi AlCOCK.}

\author{
Taf. XXVII, Fig. 8-II.
}

I895 Scymmathia Rivers-Andersoni Arcock, Journ. As. Soc. Bengal, Vol. LXIV, Pt. 2, p. 203.

I896 Scyramathia Rivers-dudersoni ALCOCk, Investigator Illustrations, Crustacea, Taf. XXII, Fig. 2, 4, 4a.

I899 Scymamathic Rizers-Andersoni Alcock, Investigator Deep Sea Brachyura, p. 53.

Auch von dieser bisher nur von der indischen Küste bekannten Art fand unsere Expedition Exemplare sowohl bei den Nikobaren, als auch an der ostafrikanischen Küste. Trotz genauer Untersuchung finde ich keine Unterschiede zwischen den östlichen und westlichen Exemplaren. Hervorzuheben ist, daß der Grad der Divergenz der Rostralhörner wie bei vielen anderen Formen, so auch hier erheblichen Variationen unterworfen ist. Bei manchen Exemplaren sind die Rostralhörner annähernd parallel, bei anderen divergieren sie um mehr als $60^{\circ}$; große Differenzen ließen sich bei sonst durchaus ähnlichen Exemplaren von gleichem Fundort feststellen (s. Taf. XXVII, Fïg. 8 u. 9). Bei den o scheint in der Regel die Divergenz geringrer zu sein als bei den ?. 
Ueber die Struktur des Auges findet sich Näheres im Abschnitt II.

Die Eier, welche of von recht verschiedener Größe tragen, sind relativ groß; cloch ist ihre Anzahl eine erhebliche.

$2 \delta^{\circ} 2$ juv. Station 2 II, Sombrero-Kanal, $7^{\circ} 4^{8,8^{\prime}}$ N. Br., $93^{\prime \prime} 7,6^{\circ}$ O. L., in einer Tiefo von $805 \mathrm{~m}$.

1 q jur. Station 252, ostafrikanische Küste, $0^{0} 24,5^{\circ} \mathrm{S} . \mathrm{Br}, 42^{\prime \prime} 49,4^{\prime} \mathrm{O}$. L., in cincr Tiefe von $1019 \mathrm{~m}$.

I q Station 258, ostafrikanische Küste, $2^{\prime \prime} 58,5^{\prime}$ N. Br., $46^{\prime \prime} 50,8^{\prime}$ O. L., in einer 'liefe von $1362 \mathrm{~m}$.

1 juv. Station 264, Somaliküste, 6" $6^{\prime \prime} 8,8^{\circ}$ N. Br., 49" 32,5. O. L., in einer 'liefe von $1079 \mathrm{~m}$.

I $\delta$ ad., 3 ad. 28 juv. Station 266, Somaliküiste, 6" $44,2^{\prime}$ N. Br., $49^{\prime \prime}+3,8^{\prime}$ O. L., in einer Tiefe von $74 \mathrm{I} \mathrm{m}$.

Verbreitung: Malabarküste $740-786$ m („Investigator“: Aıсоск).

\section{Scyramalhia globulifera (WOOD-M $\Lambda$ SON)}

I8gr Puscllia slobulifora Woon-MIsor, Ann. Mag. N. Hist., Ser. 6, Vol. VII, p. 260.

1805 Scyramathia slobilifern Alcock, Journ. As. Soc. Bengal, Vol. LXIV, Pt. 2, P. 205.

1806 Scyramathia slobulifera ALCock, Illustr. Zool. Investigator, Crustacea, Taf. XX, Fig. 3, 3a.

1899 Scyramathin globulifera ALcock, Investigator Deep Sea Brachyura, p. 55.

Von dieser Art fing die „Valdivia"-Expedition ein Exemplar, welches sehr klein ist (Lünge des Cephalothorax $7,5 \mathrm{~mm}$ ). Die Stacheln sind bei ihm noch schärfer ausgrebildet als bei dem envachsenen Tier, nach der Abbildung von Alcock zu schließen. Besonders sind Postokulardorn und Hepatikalstachel deutlich und je mit einer scharfen Spitze versehen. Auch sind die Rostraldornen dünner und schlanker. Auch der Supra- (eher Prä-)Okulardorn ist scharf zugespitzt.

Merkwürdig sind die zarten, aber dicken, keulenförmigen Haare, welche allenthalben von Cephalothorax und den Extremitäten abstehen.

Die Kugel unter dem Hepatikalstachel ist deutlich, aber kleiner als bei dem erwachsenen Tier.

I juv. Station 2 IO, SW. von Groß-Nikobar, $6^{\circ} 53,1^{\circ} \mathrm{N}$. Br, $93^{\circ} 33,5^{\circ} \mathrm{O}$. L., in einer Tiefe von $752 \mathrm{~m}$.

Verbreitung: Andamanensee 238-439 m („Investigator“: Wood-MAsov, Alcock).

\section{Gattung Hyastenus WHiTE.}

1847 IIyasicmus White, Proceed. Zool. Soc. London, p. 56.

1879 IIrasicnus Miers, Joum. Linn. Soc. Zool., Vol. XIV, p. 658 (das. Synonymic).

I 886 IIyastenus Miers, Challenger Brachyura, p. 55.

1895 /lyastenus Alcock, Journ. As. Soc. Bengal, Vol. LxIV, Pt. 2, p. 206.

\section{Hyastenus brevirostris n. $\mathrm{sp}$.}

Taf. XXVII, Fig. 13 u. I 4 .

Ein $q$ aus dem südwestlich von Sumatra gelegenen Meeresabschnitt betrachte ich als den Vertreter einer neuen Art. Ich ziehe sie zur Gattung Hyastenus wegen der allgemeinen Aehnlichkeit mit anderen Arten dieser Gattung. Doch hätte ich sie mit gutem Recht auch zu 
Pugettia oder Scyramathia stellen können, ein weiterer Beweis für die nahe Verwandtschaft der 3 Gattungen, welche bereits von SARS und ALcock betont wurde.

Wenn man den Filz, der die Oberfläche des Cephalothorax bedeckt, entfernt, so erkennt man, daß die Art zur 1. Gruppe der Hyastemıs-Arten nach ALcock gehört: nämlich zu denjenigen, deren Cephalothorax zahlreiche Höcker oder Stacheln und Rauhigkeiten zeigt. Unter ihnen nimmt sie durch die Kürze ihrer Rostraldornen eine extreme Stellung ein; ferner gehört sie durch ihre kurzen, gekielten Beine in die Nähe von $H$. pleione und Hilgendorfo. Die Kiele am Meropoditen der Scherenfüße sind etwas wellig, der Meropodit überhaupt etwas höckerig.

Der Cephalothorax ist dreieckig, doch stehen vorn die Hepatikalstacheln weit vor; hinten läuft der Rand in schlanker Kurve zum Mittelstachel des Hinterrandes. Er ist von einem sehr dichten Filz bedeckt, welcher aus eigenartig geformten Haaren besteht, wie sie bei filzigen Krabben weit verbreitet sind (vgl. Abschnitt II, Biologie der Tiefseekrabben unter Körperbedeckung). Auch die Beine tragen solchen Filz.

Die Regionen sind deutlich unterschieden; nach Abtragung des Filzes kann man an Höckern unterscheiden: Je einen am Hinterrand und auf der Kardialregion; einen auf der Regio mesogastrica, epigastrica und je einen auf beiden protogastrischen Regionen. Zwischen demjenigen auf der Regio mesogastrica und demjenigen auf der R. cardiaca lieg't ein etwas in die Breite gezogener Höcker. Nach außen und oben steht von der Regio branchialis ein scharfer Stachel ab; auf der Linie zwischen ihm und dem Kardialhöcker stehen zwei kleine Höckerchen. Vor ihm, an der Grenze gegen die Regio hepatica, erhebt sich ein kuppelförmiger großer Höcker (Taf. XXVII, Fig. I3). Ueber den unteren Rand der Branchialregion zieht sich eine Leiste mit mehreren Höckern hin.

Die Rostralhörner sind, wie erwähnt, kurz und divergieren in einem kleinen Winkel (ca. $\left.25^{\circ}\right)$. Der Supraorbitalstachel ist stark, ebenso der spitze Postorbitalstachel. Sehr stark entwickelt ist der Hepatikalstachel. Die Leiste auf der unteren Branchialregion setzt sich unter dem Hepatikalstachel gegen die Pterygostomialregion fort und läuft zur vorderen Ecke des Mundfeldes.

Das Basalglied der äußeren Antennen ist breit, flach und ragt kielartig nach außen vor. Der Rand ist ziemlich glatt; bei der Antenne der rechten Seite zeigt er einen Einschnitt, der aber wohl auf eine Verletzung zurückzuführen ist. - Die Augen sind klein und blaß pigmentiert.

Die Beine sind sämtlich reichlich bedeckt mit kolbenförmigen Haaren. Sie sind relativ kurz, prismatisch und die Kolbenhaare sitzen vorwiegend auf den Kanten. Das 2. Beinpaar (r. Schreitbein) ist das längste, doch ist auch es nicht sehr lang.

Die Scherenfüße (\$) sind kurz und schlank (Taf. XXVII, Fig. I3). Der Meropodit ist prismatisch, mit gekielten Kanten; die Kiele sind wellenförmig ausgerandet. Der Carpopodit ist kurz, mit Kanten an der Oberseite, die Schere selbst ist schlank, seitlich komprimiert, oben scharf gekielt, unten proximal wenig gerundet, distal ebenfalls sehr scharf gekielt. Die Palma ist fast 2 mal so lang, als die Finger, filzig, während die dünnen, etwas nach innen gekrümmten Finger kahl sind; die Schneiden schließen zusammen und sind in der ganzen Ausdehnung mit feinen wellenförmigen Zähnen bedeckt.

Das breite, platte Abdomen des $q$ ist 7 -gliedrig (vgl. Taf. XXVII, Fig. 14); unter demselben sitzt ein Phryxus-ähnlicher Parasit.

I + Station I 85, Südwestküste von Sumatra (zwischen Benkulen und Padang), $3^{0} 4$ I, $3^{\prime}$ S. L., $100^{\circ} 59,5^{\circ} \mathrm{O}$. L., in einer Tiefe von $614 \mathrm{~m}$. 


\title{
Cyclometopa.
}

\author{
Familie Parthenopidae. \\ Gattung Lambris Leach.
}

Lambrus macrocheles (HERBST).

'Taf. XXXII, IFig. 5 .

1790 Cancer macrocheles Herbst, Krabben u. Krebse, Bd. I, Taf. XIX, Fig. I07.

1803 Limbins mediterinens Roux, in: Heller, Crust. südl. Europa, S. 58 (daselbst Litteratur u. Synnnyma).

1882 Lambrus meditcraneus Studer, Abh. Ak. Wiss. Berlin, S. 9 (der Abhandlung).

r894 Lambrus macrocheles Herisst, Orturann, Zool. Jahrb. Syst., Bd. VII, S. 4 I4.

Obwohl diese Art nicht selten ist, kenne ich in der Litteratur keine Abbildung von ihr. Das Werk von Roux ist mir leider nicht zugänglich. Ich habe daher dieser Arbeit eine Abbildung hinzugefügt, um die Identifizierung meiner Stücke bei einer Revision der Gattung, welche sehr erwünscht wäre, zu ermöglichen (Taf. XXXII, Fig. 5).

Exemplare, welche mir zu L. macrochcles zu gehören scheinen, enthält die Sammlung der deutschen Tiefsee-Expedition von zwei Fundorten: von der Seinebank und von der Kongomündung. Das Exemplar von der Seinebank, dessen Rostrum abgebrochen ist, hat auffallend kürzere Scheren mit dunkel-rotbraunen Fingerenden. Die Exemplare von der Kongomündung, woher auch das abgebildete ơ stammt, scheinen mir jedoch mit den Beschreibungen von $L$. macrocheles recht gut übereinzustimmen.

Der letztere Fundort ist bei weitem der südlichste, an dem die Art bisher gefunden wurde; die Verbreitung stimmt aber gut überein mit derjenigen einer ganzen Anzahl von bisher nur in nördlicheren Regionen gefundenen Formen, welche die Expedition in der gleichen Gegend auffand.

I o zerbrochen Station 25, Seinebank, $33^{\circ} 43,8^{\prime} \mathrm{N}$. Br., $14^{0} 20^{\prime}$ O. L., in einer Tiefe von ca. $150 \mathrm{~m}$.

I $\delta$, 3 i Station 71 , Kongomündung, $6^{0}$ 18, $7^{\prime} \mathrm{S}$. Br., $12^{0} 2,1^{\star}$ O. L., in einer Tiefe von $44 \mathrm{~m}$.

Verbreitung: Mittelmeer und mittlerer Ostatlantik: Mittelmeer (Heller, Carus); Nizza, Toulon (Roux, Risso); Genua (Verany); Neapel (Costa,); afrikanische und griechiche Küste (Lucas); Sicilien (HaLler); Morea: Metana (GuÉrtn); Westafrika: Liberia, $90 \mathrm{~m}$ Tiefe („Gazelle“: STUDER).

Familie Hymenosomidae. Gattung Halicarcinus WHITE.

\section{Halicarcinus planatus (FABRICIUS).}

I793 Cancer planalus Fabricius, Entom. Syst., Bd. II, S. 446.

I798 Lcucosia planata Fabricius, Entom. Syst., Suppl., S. 350.

I828 IIymenosoma Leachii GứRis, Icon., Taf. X, Fìg. 2; Voyage Coquille, Vol. II, p. 22. 
I 846 Halicarcines planatus (FABr.) WhITE, Ann. Mag. N. Hist., Vol. XVIII, p. i78, Taf. II, Fig. I.

I852 Halicarcinus planatus (FABr.) DANA, U. St. Expl. Exp., p. 385, Taf. XXIV, Fig. 7.

I853 Halicarcinus planatus (FABr.) Milne-Edwards, Ann. Sc. Nat., (3) Zool., Vol. XX, p. 222.

I 882 IIymenosoma planatum (FABR.) HASwell, Catal. Austr. Crust., p. I I4.

I 886 Halicarcinus planatus Miers, Challenger Brachyura, p. $28 \mathrm{I}$.

I 893 Halicarcinus planahus Ortanin, Zool. Jahrb. Syst., Bd. VII, I894, S. 31.

Io of und $q$ verschiedenen Alters Station I60, Gazelle-Hafen, Kerguelen.

3 junge Exemplare Foundery-Bucht, Kerguelen.

Verbreitung. Antarktisch-cirkumpolar: Falkland-Inseln (White, ebenda in 4 Faden Tiefe Miers: „Challenger"); Feuerland: Nassau Bay (Dana); Magellanstraße (Miers, Cunninghan, OrTmans); Auckland-Inseln (Jagurnot u. Lucas, Thallivitz); Neuseeland: Auckland (Heller); Cap Camplell (Miers: „Challenger"); Australien: Port Jackson, Port Western (Haswelt); Kerguelen (Mirers: „Challenger", Ortannv: „Gazelle"); Marion-Inseln („Challenger"); Prinz-Edward-Inseln (,Challenger").

\section{Gattung Hymenosoma LEACH.}

\section{Hymenosoma orbiculare DESMAREST.}

I825 IIymenosome orbiculare Desnarest, Considérations sur les Crustacés, p. I63, Taf. XXVI, Fig. I.

1837 Hymenosoma orbiculare MIrene-Enwards, Hist. Nat. Crust., Vol. II, p. 36.

1849 Lcachinm orbiculare Mac LEAY, Invertebrates, in: Saitn Zool. South Africa, p. 68.

I 849 Hy'menosoma orbiculare Milne-Edwards, Atlas Cuvier Règne Animal, Ed. 3, Taf. XXXV, Fig. I.

1858 IIymenosoma orbiculare Leach, Stimpson, in: Proc. Ac. N. Sci. Philad., p. Io8.

1858 Hymenosoma geometricum Stinipsox; Ebenda, p. 108 (var. ?).

I 886 Hy'menosoma orbiculare Desn., Miers, Challenger Brachyura, p. 280.

8 to $^{*}$ u. $q$ Station Ioo, Francisbai, $34^{0} 8,9^{\prime} \mathrm{S} . \mathrm{Br}, 24^{0} 59,3$ O. L.

2 Station 96, Cap Agulhas, $35^{\circ} 2,5^{\prime} \mathrm{S} . \mathrm{Br}$., $19^{\circ} 58,5^{\circ} \mathrm{O}$. L., in einer Tiefe von $80 \mathrm{~m}$.

7 o u. o Station Ior, Algoabai, $33^{0} 50,5^{\prime}$ S. Br., $25^{\circ} 48,8^{\prime}$ O. L.

Verbreitung: Capregion (Milne-Edwards, M. Leay): Simonsbai (Stimpson, Miers: „Challenger"), Tafelbai (Krauss).

\section{Familie Atelecyclidae.}

\section{Gattung Trichopeltarium M.-EDw.}

i880 Trichopeltarim. A. Milne-Edwards, in: Bull. Mus. Comp. Zool., Vol. VIII, p. ig.

I 896 Trichopcltarium Anderson, Journ. As. Soc. Bengal, Vol. LXV, 2, p. I03.

I899 Trichopeltarium ALcock, Ebenda, Vol. LXX, 2, p. 99

\section{Trichopeltarium Alcocki DOFLEIN.}

Taf. XXVIII, Fig. 4 u. 5 .

Trichopeltarium Alcocki Doflein, Abbildung in: CHun, Aus den Tiefen des Weltmeers, 2, Aufl., I903, S. 53 I.

Die vorliegende Form steht dem Trichopeltarium ovale ANDERson offenbar sehr nahe, ja ich würde das Exemplar für das junge o dieser Art gehalten haben, wenn es nicht die starken Stacheln des Vorderseitenrandes und der Gesamthabitus von dem einzigen bisher beschriebenen o 
der obigen Art ziemlich unterschieden. Trotzdem bin ich gencigt, anzunehmen, daß das Auffinden einer größeren Serie von Exemplaren verschiedenen Alters unsere Form nur als cin junges $q$ der ANdersov'schen Art erscheinen lassen wird. Da wir aber vorläufig keine sicheren Anhaltspunkte für eine solche Verschiedenheit der Altersstarlien haben, so hielt ich es für besser, die Form zunächst mit einem eigenen Namen zu belegen.

Der Cephalothorax ist oval, vorn spitzer zulaufend, hinten durch einen in der Nitte etwas konkaven Rand ziemlich gerade abgreschnitten. Die Oberfläche ist vorn und in der Mitte mit selbst wieder gekörnelten Höckern besetzt, auf den Branchialregionen und nach hinten und unten stehen spitze Stacheln; auf den Höckern stehen hie und da Borsten, auch auf der sonst glatten Fläche des Cephalothorax sind solche zerstreut.

Furchen, welche die Regionen abteilen, sind deutlich vorhanden; während Gastrikal- und Kardialregion ebenso abgeteilt sind, wie wie bei Tr. ovale, sind auf der vorderen Branchialregion außer dem halbmondförmigen Abschnitt, nach vorn und außen noch je ein breites Feld abgetrennt, auch Protogastrikal- und Hepatikalregionen sind deutlich.

Die Stirn trägt drei lange, scharfe (im Querschnitt kreisförmige) Stacheln, von denen die äußeren um ein wenig länger sind als der mittlere.

Die Orbita ist unvollkommen ausgebildet; der Schutz des Auges wird von 4 Stacheln gebildet, einem Prä-, Supra- und Postokularstachel, nebst einem verzweigten Subokularstachel. Einen weiteren Verschluß bildet das basale Glied der äußeren Antenne. Der Postokularstachel steht etwas tiefer als der Prä- und Supraokularstachel; in der gleichen Ebene mit diesen folgt am Vorderscitenrand eine Reihe von 3 scharfen, langen spitzen Stacheln, von denen der mittlere der kleinste, der letzte, größte, doppelt so groß ist als die anderen. In der Fortsetzung dieser Reihe findet sich auf der Branchialregion oben noch ein mäßiger Stachel, welchor zwischen der feineren Stachelbedeckung der Oberfläche hervorragt (Taf. XXVIII, Fig. 4).

Die inneren Antennen sind klein, der Länge nach grefaltet. Die äußeren Antennen sind ziemlich lang und behaart, der basale Teil ist fast so lang wie die Geißel. Die Augen sind lang, schlank, pigmentlos und etwas rückgrebildet. Vergl. Abschnitt II.

Das Epistom ist breit und deutlich, die äußeren Gnathopoden greifen über dasselbo hinweg; der Ischiopodit ist viel breiter als der Meropodit, seine inncre vordere Ecke greift weit vor, der Meropodit ist schlank oval, die Ränder des Gnathopoden sind sehr dicht mit dicken, gefiederten Haaren bedeckt.

Die Scherenfüße sind bei dem jungen $q$ vollkommen gleich ausgebildet, sie sind schr schlank; der Meropodit ist auf der Oberseite stachlig, der Carpopodit tritigt auf der Außenseite mehrere Reihen scharfer Stacheln, an der vorderen inneren Ecke einen lïngeren scharfen Stachel.

Die Schreitbeinpaare sind ebenfalls schlank, sie sind an den Rïndern ziemlich stark behaart, Meropodit und Carpopodit sind an der vorderen und zum 'Teil auch an der hinteren Kante mit Stacheln bedeckt. Die Daktylopoditen sind spitz und ganz gerade, pfriemenförmig.

Das Abdomen des jungen $q$ besteht aus 7 getrennten Gliedern, von denen das 6. das breiteste und längste ist. Zwischen je zwei Gliedern zeigt der Rand eine Einkerbung. Das I. Glied trägt auf der Mitte einen Stachel, das 2. und 3. je 3-4 Stacheh, die folgenden nur Granulationen (vgl. Taf. XXVIII, Fig. 5).

I q jur. Station r9I, Nähe der Siberutinseln (Westen ron Sumatra), o" 39,2' S. Br., $98^{\circ} 52,3^{\prime} \mathrm{O}$. L., in einer Tiefe von $750 \mathrm{~m}$. 
Trichopeltarium ovale AND. war an der Westküste von Ceylon in einer Tiefe von ca. $350 \mathrm{~m}$ gefangen worden. Ueber die Pigmentierung der Augen bemerkt ALcock nichts.

\section{Gattung Atelecyclus LEACH. \\ Atelecyclus septemdentatus MoNTAGU.}

I798 Cancer hippa, seplemdentatus MIoxtagu, Trans. Linn. Soc., Vol. II, Taf. I.

I8I. Atelecyclus septemdentatus LeAcri, Artikel Crustaceology in BREwster's Edinburgh Encyclopedia, 7 vols. $8^{0}$, I 8 I $3-18$ I 4 .

I 815 Atelecyclus heterodon Leach, Malacostraca podophthalmica Britanniae, Fasc. 6, Taf. II.

I 837 Atelecyclus heterodon Leach, Milne-Edwards, Hist. nat. Crust., Vol. II, p. 143.

I89t Atelecyclus septemdentatus (Mont.) Ortunan, Zool. Jahrb. Syst., Bd. VII, S. 422 (daselbst Litteratur).

I80+ Ateleyclus helerodon (Mont.) Milne-Edwards \& Bouvier, Crustacés MIonaco, Vol. VII, p. 50, Taf. V, Fig. 6 bis II (daselbst Litteratur).

Mitne-Edwards und Bouvter haben in der letztcitierten Schrift die bis dahin stets ungenau gebliebenen Beschreibungen der beiden europäischen Atelecychis-Arten revidiert und haben auch neue Abbildungen gegeben.

$2 \delta^{5}$, I + , Station 3 auf der Höhe von Aberdeen, $57^{\circ} 26^{\circ}$ N. Br., I $^{0} 28^{\prime}$ IV. L., in einer Tiefe von $79 \mathrm{~m}$.

Verbreitung: Nordostatlantik und Nittelmeer: südliches Norwegen (G. O. SArs); Nordsee (Möbius, Ortaldnn); England (Milne-Enwards, Beld); Golf von Biscaya („Hirondelle“: Milne-Edwards und Bouvier); Mittelmeer (Carus, Heller); Marseille (Marion, Guurret); Adria: Quarnero, Ragusa (Heller).

\section{Familie Portunidae.}

\section{Gattung Benthochascon Alcock.}

\section{Benthochascon Hemingi Alcock u. Anderson.}

Taf. XXIX, Fig. I u. 2; Taf. XLI, Fig. I u. 2 ,

I899 Benthochascon Hemingi Alcock d Anderson, Ann. Mag. N. H., I899, Jan., p. io.

1899 Benthochascon Memingi Alcock, Investigator Brachyura, p. 69, Taf. III, Fig. 2, q.

I 899 Benthochascon Hemingz Alcock, Journ. Asiat. Soc. Bengal, Vol. LXVIII, Pt. 2, p. I5.

Von dieser Art fand die deutsche Tiefsee-Expedition das bisher noch unbekannte o, welches in einigen enwähnenswerten Punkten vom q verschieden ist.

Die Oberfläche des Cephalothorax ist fein granuliert; am oberen Orbitalrand wird dadurch eine Einfassung aus feinen Körnern gebildet. Die Unebenheiten des Cephalothorax scheinen gröber zu sein als bei dem o (vergl. Taf. XXIX, Fig. I).

Stirn und Seitenränder sind lamellös vorgezogen; am Seitenrand ist zwischen dem 3. und 4. Seitenrandzahn eine leichte Kerbe erkennbar, welche durch die Furche, welche Branchial- und Hepaticalregion voneinander trennt, hervorgerufen wird.

Am oberen Orbitalrand finden sich die deutlichen Spuren von 2 Fissuren, der untere Orbitalrand ist fein gekörnelt. Die Augen sind sehr groß, die Cornea ausgedehnt, besonders 
nach unten und vorn; das Auge ist dunkelbraun pigmentiert, die Comeafacetten sind schr zahlreich und relativ klein.

Die Scherenfüße zeigen den bemerkenswertesten Unterschied yegrenüber dem weiblichen Tier in einer Struktur, von deren Vorhandensein bei letzterem wenigstens Au:ock keinerlei Andeutung macht.

Die Meropoditen und Carpopoditen zeigen keine wesentlichen Unterschiede. Die Scheren sind fast gleich, doch ist die rechte cin wenig größer. Auch ist die Bezahnung der Scherenfingrer bei der rechten Schere etwas massiver, ohne daß jedoch Zahl und Charakter der Zïhne bei beiden erheblich differierte.

Die Finger sind an beiden Scheren kleiner als die Palma; letztere ist stark aufgetrieben, abgerundet, oben und unten von einer stumpfen Káante begrenzt. Auf der Außenseite zeigen sich Spuren von Längslinien. Die Finger dagegen sind von den Seiten stark abgeplattet, der bewegliche, oben mit einer breiten flachen Kante, der unbewegliche unten mit einer scharfen Kante; beide sind, besonders der bewegliche, nach innen gekrümmt, die scharfen gebogenen Spitzen greifen übereinander. Die Zühne greifen an der kleineren Schere besser ineinander, als an der größeren.

Die auffälligste Bildung findet sich an der Basis des nicht beweglichen Fingers. Hier ist nämlich in die ganz gleichmäßig fein grekörnelte Oberfläche eine glatte Scheibe cincr porzellanglatten Substanz eingefügt, welche durch ihren spiegelnden Glanz und matt rötliche Farbe sich von der matt schimmernden, gelblichen Umgebung scharf abhebt. Einer solchen Scheibe auf der Außenseite des Fingers entspricht eine ganz ähnliche an der Innenseite. Beide sind umgekehrt eiförmig; das spitzere Ende steht gegen die lïngerspitze (Taf. XLI, Fig. 2, O).

Das Gewebe, welches zwischen beiden Platten den Finger durchsetzt, scheint in ihrem Bereich sehr dicht und fest zu sein. Wir haben offenbar besondere Organe in diesen Gebilden vor uns, über deren Bedeutung ich aber vorläufig keine Meinung äußern kann.

Das Abdomen des of ist breit dreieckig; die Grenzen sämtlicher 7 Glieder sind deutlich, doch bewegen sich das 3. und 4. gemeinsam; das 6. Glied ist das längste (Taf. XXIX, Fig. 2).

Die Geschlechtsfüße sind ähnlich ausgebildet, wie bei Geryon. Der vordere ist groß, stark, breit hakenförmig; er stellt fast einen regrelrechten Penis dar, indem sein distaler Teil zu einer Rinne zusammengefaltet ist, deren Ränder gut zusammenschließen. Die Röhre ist an der Basis offen; hier tritt in sie die weit über die Basis des 5. Pereiopoden hinaus verlängerte Samenröhre ein, und hier kann auch der fadendünne zweite Geschlechtsfuß eingeschoben werden (s. Taf. XLI, Figr. I, $g$ u. $g^{\circ}$ ). Die Größe des Cephalothorax ist $45 \mathrm{~mm}$ Länge und $5 \mathrm{r} \mathrm{mm}$ größte Breite; etwa grenau die Verhältnisse des größten bisher gefundenen $q$ (48:51).

I of Station 208, Sw. von Groß-Nikobar, $6^{\circ} 54^{\prime} \mathrm{N} . \mathrm{Br}$, $93^{\circ} 28,8^{\circ} \mathrm{O}$. L., in einer Tiefe von $296 \mathrm{~m}$.

Verbreitung: Andamansee, 338-738 m Tiefe (Alcock: „Investigator").

\section{Gattung Ovalipes Rathbun.}

I825 Platonychus LAtreille, Règne animal, 2 me édition, T. IV, p. 36 (pro parte, nec Platyonychus Latreilie, I818, Encykl., Vol. X, p. I51).

1808 Oralipes Rathuun, Proc. U. S. Nat. Mus., Vol. XXI, i899, p. $59 \%$.

1902 Ozalipes Ratinus, Stembing, South African Crustacea, Pt. 2, p. I 2 (daselbst Synonymic). 


\title{
Ooalipes trimaculatus DE HAAN.
}

\author{
Taf. XXXII, Fig. 6
}

I833 Anisopus trimaculata DE $\mathrm{HAAN}$, Fauna japonica, Crustacea decas I, p. I3.

I $83+$ Plntyonvchus bipustulatus MInxi-Enwards, Hist. Nat. Crustacés, Vol, I, p. 437, Taf. XVII, Fig. 7 - IO.

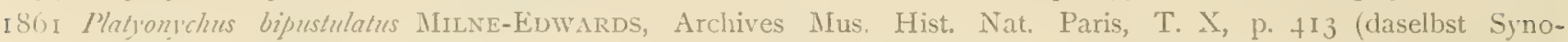
nymie u. ältere Litteratur).

I86 I Platyonjchus africanus MILnE-EDwARDS, ebenda, S. 4I3, Taf. XXXIV, Fig. 2.

I 803 Platyonjchus bipustulatus OrTuANe, Zool. Jahrb. Syst., Bd. VII, I804, S. 65 (daselbst Litteratur).

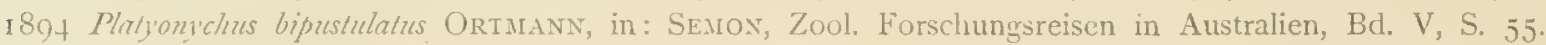

ISo8 Oralipes bipustulatus (MI.E.) Ritmbux, Proc. U. S. Nat. Mus., Vol. NXI, No. 7, p. 597.

1000 Inizre bipustulata Berg, Communic. Mus. Nac. Buenos-Ayres, Vol, I, I899.

IoO I Ożalipes bipustulatus (MI.-E.) Nobili, Boll. Mus. Zool. ed Anat. comp. Torino, Vol. XVI, No. 402, p. 7.

I 902 Oralipes trimaculahs (D. H.) Stebixis, South African Crustacea, Pt. 2, p. I3 (daselbst Litteratur u. Erörterung der Synonymie).

Von dieser im Indopacifik weit verbreiteten Art fing die Expedition an der Südspitze von Afrika eine Anzahl o und $q$ von verschiedener Größe.

Ich bemerke bei meinen Exemplaren, of und $q$, besonders aber bei den großen $\delta$, eine Struktur, welche, soweit ich sehen kann, den früheren Untersuchern entgangen ist, mit Ausnahme von Woon-MLson, welcher sie nach OrTadann untersucht hat (Woon-Mason, Nature, Vol. X, 1878, p. 53. Ortarann in: Bronn's Klass. u. Ordn. des Tierreiches, Malacostraca, $\therefore$ I $2+(1)$.

Der Unterrand der Palma ist nämlich an beiden Scheren mit quer zur Längsrichtung gestalteten Leistchen dicht bedeckt, welche an die Leistchenbildungen gewisser OcyporleArten erinnern. Am Meropoditen des 2. Pereiopoden, also I. Schreitbeines, findet sich am distalen Gelenk, am oberen Rand eine quergestellte Hornleiste. Beide Gebilde zusammen stellen offenbar ein Stimmorgan dar, welches Töne dadurch hervorbringen kann, daß die Hornleiste gregen die Leistenreihe gerieben wird.

Möglicherweise kann auch ein Bestandteil des Daktylopoden des 2. Pereiopoden durch Reiben an der Leistenreihe Töne hervorbringen. Während nämlich bei dèn 3 hinteren Pereiopodempaaren die Daktylopoditen abgeplattet sind und nach hinten eine einfache scharfe Kante besitzen, ist bei diesem durch Bildung einer tiefen Rinne die Kante verdoppelt; beide Kanten sind kielartig vorgezogen, besonders die obere; sie ist auch so angebracht, daß sie eventuell an der Leistenreihe gerieben werden kann.

Junge Exemplare sehen ziemlich abweichend von den alten aus und wurden von MruneEDWards als besondere Art, P\% africamis, beschrieben.

Von dieser zierlichen Form, welche ich seit der Originalbeschreibung in der Litteratur nicht mehr erwähnt finde, brachte die Expedition 3 Exemplare mit, welche größer sind als diejenigen, welche MLNE-EDwards in Händen hatte, und daher eine Ergänzung seiner Beschreibung erlauben. Während MrLne-EDwards in seiner Beschreibung erwähnt, daß die Art nur wenige Millimeter groß sei, ist das größere Exemplar, welches mir vorliegt, I $2 \mathrm{~mm}$ lang und I $3,5 \mathrm{~mm}$ breit. Ich habe durch das Studium der verschiedenen Stadien die Ueberzeugung gewonnen, daß es sich nur um die Jugendstadien von Ovalipes trimaculatus handelt.

Der Cephalothorax ist in die Länge gezogren; dies tritt aber bei jüngeren Exemplaren mehr hervor als bei älteren. Während das größte Exemplar, wie oben erwähnt, breiter als lang 
ist, haben die kleinen Stücke $7 \mathrm{mm:} 7 \mathrm{~mm}$. Die Oberfläche ist cluen und mit feinen Körnem bedeckt, welche mit dem Alter gröber werden (Taf. XXXII, Fig. 6).

Die Stirn ist in + Zïhne geteilt, welche bei dem großen Exemplar mehr vorragen als bei den kleinen. Die beiden mittleren Zähne sind kleiner und ragen weiter vor als die äußeren. Sie sind von letzteren durch einen bogenförmigen Ausschnitt getrennt, welcher bei dem älteren Exemplar tiefer ist als bei den jüngeren. Die Orbiten sind nicht ganz so breit als die Stirn; der obere Rand zeigt zwei Kerben, von denen die mittlere weniger tief ist, die äußere tiefere den äußeren Orbitalzahn stärker hervortreten macht.

Einschließlich des letzteren ist der Vorderseitenrand in 5 scharfe, spitze Sägezähne greteilt, von clenen der erste der größte ist, während die übrigen untereinander fast gleich sind (Taf. XXXII, lïg. 6). Die Ränder sind fein gekörnelt und mit feinen Härchen besetzt. Die Hinterseitenränder konvergieren sanft nach hinten. Der Hinterrand ist gewellt, indem in der Mitte und an beiden Seiten je eine seichte, nach vorn konvexe Einbuchtung vorhanden ist.

Die Augen sind groß und dunkel pigmentiert, die Geißeln der äußeren Antennen kurz und reichen seitlich geschlagen nicht cinmal bis zur äußeren Orbitalecke.

Die Scherenfüße sind fast gleich; der rechte kaum merklich größer. Der Meropodit ist prismatisch, am oberen distalen Ende mit einem behaarten Höcker versehen, der Carpopodit mit einem langen spitzen Stachel.

Die Schere ist schlank; die Finger nur $2 / 3$ so lang als clie Palma. Die Palma ist außen und oben gekielt: zwei der fein gekörnelten Kiele verlaufen auf der Oberseite, zwei auf der Außenseite. Auch die Unterseite ist scharf gekantet. Dic Daktyloporliten des 2. Pereiopodenpaares sind etwas breiter, die des 3. und 4. Paares etwas schmäler, lanzettlich.

Die Daktylopoditen des 5. Paares sind schlank elliptisch und am Ende fein zugespitzt. Die Spitze ist bei den jüngeren Exemplaren deutlicher als bei den älteren.

Alle 3 Exemplare haben ein schmales Abdomen mit weiblichen Pleopoden.

2 juv. Station 96, Cap Agulhas, $35^{\circ} 2,5^{\prime}$ S. Br., $19^{\circ} 58,5^{\prime}$ O. L., in ciner Ticfe von $80 \mathrm{~m}$.

I juv. Station Ior, Algoabucht, $33^{\circ} 50,5^{\circ} \mathrm{S} . \mathrm{Br}$, $25^{\circ} 48,8^{\circ} \mathrm{O}$. L., in einer Tiefe von $40 \mathrm{~m}$.

$6 \delta, 2 q$ Port Elizabeth, Natal, in der Reuse gefangen.

Verbreitung: Im ganzen Indopacifischen Gebiet; besonders aus den südlichen und nörcllichen gemäßigten Teilen des Gebiets; Südafrika und Südamerika (VVest- und Ostküste); Chile (Milie-Edwards, Ormans); Valparaiso (Gay); Coquimbo- und Lucobai (Cundinginait); Suidpatagonien (Mliers); La Plata (Berg, Nomilt); Neuseeland (Haswel., Ortmsnx); Süd-Australien

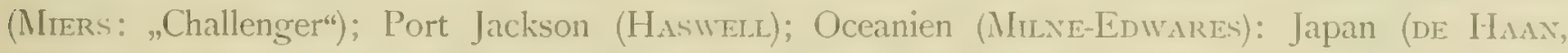
Ortmanx); Indien (Mhre-Enwards); Cap der guten Hoffnung (de Hadn, Herizlots); Port Elizabeth (Ortannm); Tafelloai (Ḱrauss, Thallitiz); Falsebai (Stebbingi); Simonsbai (MilnneEDIVARDS).

\section{Gattung Elliptodactylus n. 9 .}

Awei Exemplare einer kleinen Art von der westafrikanischen Küste vermag ich in keine der bekannten Gattungen einzureihen und begründe für sie daher die neue Gattung Elliptodacty'us. Sie ist am nächsten verwandt mit Oralifes Ruthisus und erinnert in manchen Punkten auch an Lupocyches Ad. \& Wnite. Dic Schreitbeine sind ungefähr so lang wie die Scherenfüße, das 
letzte Fußpaar ist mit typischen Schwimmfußdaktylopoditen ausgestattet, welche in der Form zwischen denen von Ovalipes und Portummus stehen, ihre Form ist breit lancettlich, das Ende zugespitzt. Der Cephalothorax ist breiter als lang, die Vorderseitenränder 5-zähnig. Das Basalglied der äußeren Antennen ist schmal und beweglich.

Die Stirn ist 3-zähnig. Die 2. Gnathopoden sind breit, der Merognathit vor der Insertion des Carpognathiten in einen breiten, viereckigen Lappen vorgezogren, welcher parallel dem Mundrand abgestutzt ist. Am Gaumen zieht eine sehr ausgeprägte Leiste bis zum Mundrand.

Das Abdomen des $\delta$ ist dreieckig mit breiter Basis, zur Spitze allmählich verlaufend; das letzte Glied hat die Form einer Lanzenspitze. Durch Vereinigung des 3.-5. Segmentes ist das Abdomen 5-gliedrig.

\section{Elliptodactylus rugosus n. sp.}

Taf. XXx, Fig. I-3; Taf. XXXII, Fig. 7. Textfig. 7 u. 8.

Der Cephalothorax ist auf der Oberfläche sehr rauh, indem auf jeder Region ein oder mehrere Höcker stehen, zudem ist die ganze Oberfläche fein gekörnelt. Auf dem größeren Exemplar erkennt man 2 Postfrontalhöcker, welche auf dem kleineren nicht sichtbar sind. Auf beiden sind erkennbar: ein Halbkreis von 4 Höckern auf den Metagastrikalregionen, 2 Höcker auf der Regio mesogastrica, zwei vordere und ein hinterer medianer auf der Regio cardiaca, eine Art von Leiste auf der Regio branchialis, der sich von der Regio cardiaca gegen den 3. Seitenrandzahn hinzieht (Taf. XXX, Fig. I u. 2). Die Stirn ist in 3 Zähne geteilt, von denen der mittlere schmäler und etwas länger ist als die äußeren. Der Rand dieser Zähne, der Orbita, und der Seitenrand ist ganz gleichmäßig fein gezähnelt. Die Orbiten sind so breit als die Stirn; auf den äußeren Stirnzahn folgt am oberen Rand der Orbita zunächst ein feines Zähnchen, darauf eine nicht ganz deutliche Fissur; in der Mitte des Supraorbitalrandes jedoch und weiter gegen die äußere Ecke folgen noch je ein deutlicher, tiefer Spalt. Der Vorderseitenrand verläuft als gleichmäßiger Bogen, auf welchem die 5 Zähne stachelartig aufgesetzt erscheinen. Der erste, zugleich äußerer Orbitalzahn, ist der größte, die anderen untereinander ziemlich gleich groß. Sämtliche Zähne sind scharf und spitz.

Der Hinterrand ist mäßig gebogen, er verläuft in dem unteren

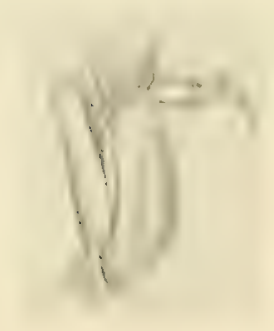

Fig. 7. Zweiter Gnathopod von Elliptodactylus rugasies DOFL. Seitenrand des Cephalothorax, der sich im Bogen nach vorn unter dem Hinterseitenrand hinzieht, welcher von der Hinterseite des 5. Seitenrandzahnes nach hinten bald verstreicht.

Der untere Orbitalrand ist tief bogig ausgeschnitten, der Ausschnitt greht auf beiden Seiten nach Bildung eines Vorsprungs in den entsprechenden Stachel über; außen in den Extraorbitalstachel, innen in den Suborbitalstachel, welcher so weit vorragt, wie der mittlere Stirnzahn (Taf. XXXII, Fig. 7).

Die Pterygostomialregionen sind glatt. Der Ischiognathit der

2 Gnathopoden ist breit, in der Mitte gefurcht; der Merognathit ist zu einem viereckigen Lappen über die Ursprungsstelle des Carpognathiten hinaus vorgezogen (Textfig. 7).

Die Scherenfüße sind schlank; der Meropodit ist prismatisch, die Innenkante fein gezähnelt; der Carpopodit ist kurz, auf der oberen Fläche rauh von Körnchen, mit einem kleinen scharfen 
Stachel an der Hinterecke und einem viel längeren, sehr spitzen Stachel an der Vorderecke. Die Schere selbst ist schlank, die Finger kïrzer als die Palma. Sie ist oben und unten scharf gekantet, beide Kanten sind fein gezähnelt, die obere endet über der Insertion des beweglichen Fingers mit einem spitzen Stachel. Auf der Außenfliiche der Palma unterscheidet man 3 mit Zühnnchen bedeckte Lüngsleisten, ebenso eine Höckerreihe lïngs des unbereglichen, zwei Linien feinerer Körner längs des beweglichen Fingers (vgl. Taf. XXX, Fig. 3). Letzterer hat oben eine scharfe,

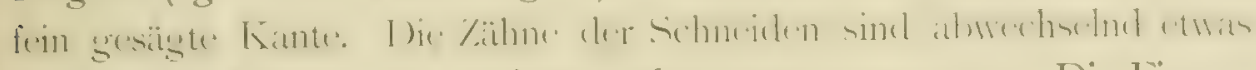
größer und kleiner und schließen sehr genau zusammen. Die Finger-

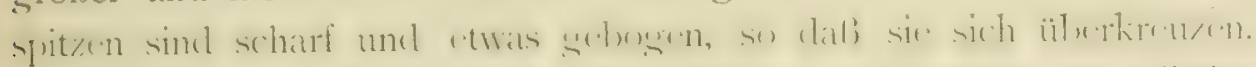

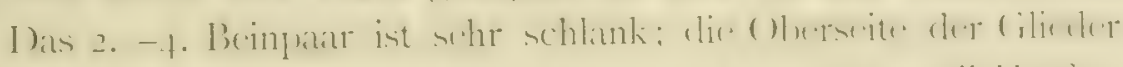

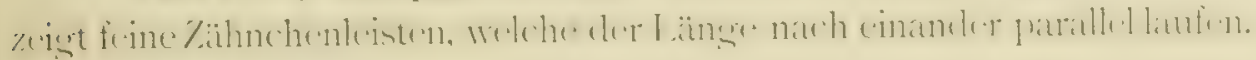

Das 5. Beinpaar ist durch die schlanke Schwimmplatte ausgezeichnet, welche zugespitzt ist.

Das Abdomen des $\delta$ ist oben in der Gattungsdiagnose be-

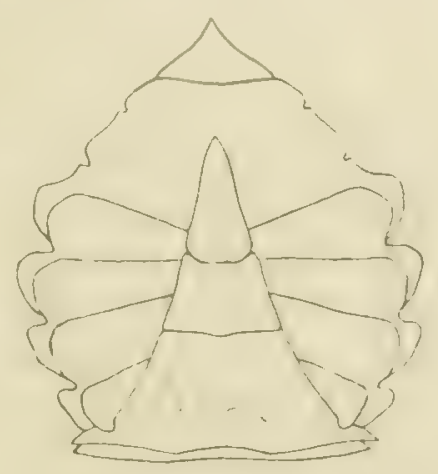

Fig. 8. Sternum von Elliptodactylus rugosus DorL. schrieben (s. Textfig. 8).

Die Sternalsutur erstreckt sich über die 2 hinteren Thorakalsegmente.

Die Farbe ist im Spiritus oben rötlich, unten gelblich; doch ist überall ein rot-grünes leichtes Irisieren bemerkbar.

$2 \delta$ Station 71. Vor der Kongomündung in einer Tiefe von $44 \mathrm{~m}$.

\section{Gattung Portunus Fabricius.}

\section{Portunus holsalus FABRICIUS.}

I798 Portunus holsatus Fabricius, Entomol. System. Suppl., p. 366.

I86 I Portunus holsatus Ninde-Edwards, Arch. Mus. Hist. nat. Paris, Vol. X, p. 393 (daselbst altere Litteratur und Synonymie).

1863 Portunus holsatus Heller, Krustaceen südl. Europa, p. 85.

1893 Portunus holsatus Ortananv, Zool. Jahrb. System, Bd. VII, I804, S. 69 (daselbst Litteratur).

I $\delta$, Station 3 bei Aberdeen, in einer Tiefe von $79 \mathrm{~m}$.

Verbreitung: Nordsee und Mittelmeer: Norwegen (G. O. SARs); Dänemark: IVestküste (Merneris); Nordsee (Metzgrer); Holland (Herklors); Belgien (van Beneden); England (Bell); Frankreich (Minne-Edwards); Mittelmeer (Heller, Carus); Schwarzes Meer (Czfrnilawsky).

\section{Gattung Caphyra Guérin.}

1832 Caphyra Guérin, Ann. Sci. Nat., Sér. I, T. X̃XV, p. 283.

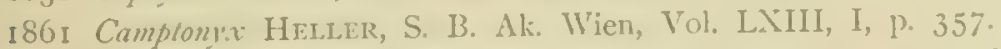

1860 Camplony: Mince-Enwarids, Nour. Arch. Mus. Paris, Vol. V, p. I56.

1873 Camplony: Milate-Eumards, ebenda, Vol. IX, p. I72.

I880 Caphyra Ricimeis, in: MIörius, Mecresfauna von Mauritius und den Seychellen, S. 154.

\section{Caphyra rolundifrons MILNE-EDIVARDS.}

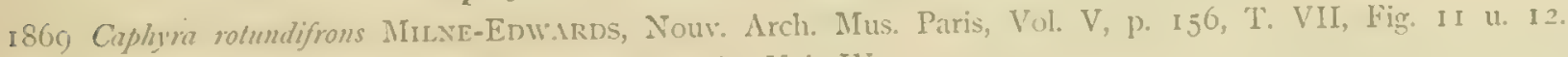

1873 Caphyra rohndifions MiLxe-Euwarns, ebenda, Vol. IX, p. 174.

1880 Caphya rohndifrons MI.-E. var. trilcns Ricntwes u. Mömus, Mecresfauna von Mauritius und den Scychellen, S. 154 . 
Von dieser seltenen Art wurden 3 f gesammelt; sie stimmen gut mit der Beschreibung von Milne-Edwars (I869) überein; Richters vermißte bei seinem Exemplar die zweite Fissur im oberen Orbitalrand. Sie ist bei den kleinen Stïcken, die mir vorliegen, ebenfalls nicht erkennbar, bei dem dritten, größeren ( $8 \mathrm{~mm}$ Thoraxlänge) ist sie jedoch deutlich. Alle 3 Exemplare haben 4 Seitenrandzähne. Vielleicht ist die Dreizähnigkeit des Vorderseitenrandes, welche Richters bei seinem männlichen Exemplar konstatierte, eine Geschlechtsverschiedenheit. Nach dem Befund von Milne-Edwards, welcher bei C. lacvis auf der einen Seite 6, auf der anderen nur 5 Zähne konstatierte, scheint aber Variabilität der Zahnzahl bei dieser Gattung vorzukommen, so daß sich die var. tridens auch auf diese zurückführen ließe.

Die Exemplare der deutschen Expedition wurden aus Korallen herausgeklopft; der Aufenthaltsort der Tiere wirft ein Licht auf die Bedeutung der Form ihres 5. Beinpaares. Wir haben in ihnen wohl an die festsitzende Lebensweise sich anpassende Lupinen zu erkennen.

3 q Mahé, Seychellen, in Korallen.

Verbreitung: Indopacifik: Neu-Caledonien, Samoa (Milne-Edivards); Mauritius (Richters).

\section{Gattung Charybdis DE HAan.}

I850 Chambdis-Occanns DE HAAN, Fauna japonica, Crust., p. 9 u. Io.

I860 Goniosoma A. Milne-Edwards, Ann. Sci. nat. Zool., (4), Vol. XIV, p. 263.

186 I Goniosoma A. Milne-Edwards, Arch. Mus. H. nat., Paris, Vol. X, p. 307.

I886 Goniosoma Mirers, Challenger Brachyura, p. I89.

I 897 Charybdis Rathbun, Proc. Biol. Soc. Washington, Vol. XI, p. I6I.

I809 Charydis Alcock, Joum. As. Soc. Bengal, Vol. LXVIII, Pt. 2, p. 47.

\section{Charybdis (Goniosoma) quadrimaculata A. MiLnE-EDwards.}

I86 I Goniosoma quadrimaculatum MiLne-EDwnrds, Arch. Mus. H. nat., Vol. X, p. 375, 585, Taf. XXXIV, Fig. 3. I 893 Goniosoma quadrimaculatum OrTunan, Zuol. Jahrb. Syst., Bd. VII, S. 82.

I 893 Goniosoma luciferim J. R. Henderson, Trans. Linn. Soc. London, Zool., (2) Vol. V, p. 374.

1899 Charybdis (Goniosoma) quadrimaculata Alcock, Journ. As. Soc. Bengal, Vol. LXVIII, Pt. 2, p. 54.

I $q$ Colombo, Ceylon,

Verbreitung: Ostindien: Malabar (MrLne-EDw.); alle Küsten von Vorderindien (Alcock); Ceylon (Henderson); Java (Milne-Eidw.).

Ein $\delta$ aus dem Emmahafen bei Penang, Westsumatra, möchte ich ebenfalls hierherrechnen, obwohl der stumpfe Lappen am äußeren Ende des unteren Orbitalrandes eher für Charybdis (Goniosoma) anmulata (FABRicıus) spräche. Auch sind die weißen Flecken auf dem Cephalothorax nicht deutlich. Doch steht das Exemplar in den meisten anderen Punkten $C$. quadrimaculata M.-E. sehr nahe, besonders der Durchmesser der Orbita verhält sich zur Breite der Stirn $=1: 3,2$.

\section{Charybdis (Goniosoma) natalor (HERBST).}

I799 Cancer natator Hesdst, Krabben, Bd. II, S. I56, Taf. XL, Fig. I.

I861 Goniosoma nalator Milwe-Edwards, Arch. Mis. H. nat. Paris, Vol. X, p. 370, 385 (das. iiltere Litt.).

I 899 Charybdis (Goniosoma) natator (HbSt.) Alcock, Journ. As. Soc. Bengal, Vol. LAVIII, Pt. I, p. 6r (das. Litt. u. Synonymie). 
I o juv. Colombo (Ceylon).

Verbreitung: Indopacifik: Südafrika: Natalbai (KRaUss); Ostindien: Ceylon: Trincomali (MÜller); Madras (Alcock, Henderrson); Pondicherry (Arcock); Rameswaram (Hevderson); Singapore (Alcock); Mayotte (M.-E); Java (M.-E); Celebes: Parepare (DF MLAN); Philippinen (MI.-E.); Molukken (M.-E.); Amboina (DE MAN); Hongkong (STtarpson, M.-E.); China (MI.-E.); Japan (DE HAAN, M.E.).

\section{Charyludis (Goniohellenus) hoplites WOOD-MASON.}

1877 Goniosoma hoplites WVod-MLAson, Ann. Mag. N. Hist., Ser. 4, Vol. XIX, p. 422.

1894 Goniosomiz hoplites Alcock \& Anderson, Journ. As. Soc. Bengal, Vol. LXIII, Pt. 2, p. I84.

1896 Goniosoma hoplites Axcock \& Anderson, Illustr. Zool. Investigator, Crust., Taf. XXIII, Fig. 6.

1899 Goniosoma hoplites AIcock, Investigator Deep Sea Brachyura, p. 67.

I899 Charybdis (Gonioluellenus) hoplites WiLt. Alcock, Journ. As. Soc. Bengal, Vol. LXVIII, Pt. 2, p. 66, var. vadom ALC. u. var. pusilla ALC, p. 67.

Bei dem einzigen Exemplar dieser Art ist der Hinterrand des Propoditen des 5. Fußpaares nur bei dem linken mit Dörnchen besetzt, beim rechten fast glatt. Auf der Kardialregion verläuft quer ein Feld von feinen Körnern, die aber nicht ganz so dicht stehen wie bei den Querleisten der Gastrikal- und Branchialregion.

I o Station 244, bei Dar-es-Salaam, $5^{\circ} 55,8^{\prime} \mathrm{S} . \mathrm{Br}, 39^{\circ} \mathrm{r}, 2^{\prime} \mathrm{O}$. L., in $50 \mathrm{~m}$ Tiefe.

Verbreitung: Indien: Coromandelküste, Indusdelta (Wood-MLson, Alcock); Orissaküste, Persischer Golf, Konkanküste (ALcock).

\section{Gattung Neptunus DE HAAN.}

? I8 3 Lupa Liscin, Edinburgh Encyclopaedia, Vol. VII, p. 380, Art. Crustaceology.

? 825 Lupa Desmarest, Consid. gén. Crustacés, p. 97.

I833 Nephunus dE HAan, Crustacea japonica, decas I, p. 7.

1834 Lupea Millne-Edwards, Hist. nat. Crust., Vol. I, p. 445.

1836 Lupa Milne-Enwards, Règne animal Cuvier, Crustacés, p. 46.

1886 Neptumus Miers, Challenger Brachyura, p. I72.

1897 Portumes Rathiun, Proc. Biol. Soc. Washington, Vol. XI, p. I55.

I900 Portumes Rathibun, American Naturalist, Vol. XXXIV, p. I40.

I902 Lupa Stebbing, South African Crustacea, Pt. 2, p. II.

Da mir die Schriften von Miß Rutibun nicht zugänglich sind, so kann ich mich für keine der vorgeschlagenen Nomenklaturänderungen entscheiden.

\section{Neplunus (Neplunus) sanguinolentus (HERBST).}

I783 Cancer sanguinolenhus HERBst, Krabben, Bd. I, Teil 2-5, p. I6I, Taf. VIII, Fig. 56-57.

180 I Nephun sanguinolentus Milne-Edwards, Arch. Mus. H. N. Paris, Vol. X, p. 310.

1899 Nephuns sanguinolentus Nobili, Ann. MIus. Civico Stor. Nat. Genova, Ser. 2, Vol. XXII (40), p. 25.

I899 Neptunus sanguinolentus Alcocr, Journ. As. Soc. Bengal, Vol. LXVIII, Pt. 2, p. 32 (das. Litteratur vollständig). Igor Nephunes sanguinolentus NobizI, Ann. Mus. Zool. Napoli, N. S. Vol. I, p. 9.

I902 Lupa sanguinolenta (HBSt) Stebing, South African Crustacea, Pt. 2, p. I I (das. Litteratur und Synonymic).

ot und o Padang, West-Sumatra.

5 juv. Station 200, bei Nias an der Oberfläche an Sargasso.

Verbreitung: Indopacifik. Cap der guten Hoffnung (Heller); Cap St. Blaize (SterBING); Rotes Meer: Erythraea (Nomid); Dar-es-Salaam (Ortmann); Réunion (HofmalanN): Indien: 
Bombay (Milne-Edwards, Henderson); Karachi, beide Küsten Vorderindiens (Alcock); Sind, Madras (Henderson); Ceylon (Heller, Henderson, Alcock); Trincomali (Müller); Penang (Alcocis); Nikobaren (Heller, Alcock); Singapore (Dana, Milne-Edivards); Java (Herklots): Samarang (M.-E。); Ins. Nordwachter (DE MAN); Bali (Miters); Borneo (Miers); Neu-Guinea: Geelvinkbai, Upuli (NoBili); Celebes (Thallwitz); Makassar (DE Man); Molukken: Amboina (De Man, Nobili, Ortmann); Ternate (Miers; „Challenger"); China (Milne-Edwards); Hongkong (Stmipson); Formosa: Takao [Südformosa], Tamsui [Nordformosa] (Münchner Museum); Japan (DE Hanin): Tokiobai, Kochi (Ormanni); Yokohama (Dofletn); Ost-Australien: Moretonbai und Port Jackson (Hasweli); Süd-Australien („Challenger"); Neu-Seeland: Auckland (Heller); Campbell-Ins. (Filhot); Sandwich-Ins. (Randalt, Dana, Milne-Edw.: „Challenger"): Molokai (Lenz).

\section{Neptunus (Hellenus) tuberculosus M.-E.}

i86 i Neptunus tuberculosus A. Mitne-Edwardo, Arch. Mus. H. N. Vol. X, p. 333, 339, Taf. XXXi, Fig. 5.

I 886 Neptunus tuberculosus Mrers, Challenger Brachyura, p. I76.

I893 Neptunus tuberculosus Henderson, Trans. Linn. Soc. Zool. (2), Vol. V. p. 369.

I899 Neptumus tuberculosus Alcock, Journ. As. Soc. Bengal, Vol. LXVIII, Pt. 2, p. 42.

I $q$ ohne Scheren, Station 244, bei Dar-es-Salaam, $50 \mathrm{~m}$ Tiefe.

Verbreitung: Indopacifik: Persischer Golf (Alcock); Golf von Martaban (Henderson); Ceylon (Alcocis); Andamanen (Aıсоск); Aru-Ins. (Mrers: „Challenger"); Sandwich-Ins. (M.-E.).

\section{Neptunus pelagicus L.}

Cancer pelagicus LInné, Mus. Lud. Ulr, p. 434, u. Syst. Nat., XIIma ed., p. IO42.

Litteratur s. Alcock, Journ. As. Soc. Bengal, Vol. LXVIII, Pt. 2, I899, p. 34.

I $\delta$ juv., welches der Beschreibung des $N$. armatus (Milne-Edwards, Arch. Mus. H. Nat. Paris, Vol. X, I86r, p. 322, Taf. XXXIII, Fig. 2) entspricht. Ebenso wie Orturann u. Alcock bin ich der Ansicht, daß $N$. armatus nur für junge Exemplare von $N$. pelagicus aufgestellt worden ist; S. Ortmann, Zool. Jahrb. Syst., Bd. VII, I894, p. 75.

I $\delta$ juv. Padang, West-Sumatra.

Verbreitung: Indopacifik: s. Ortanann a. a. O.

\section{Neptunus (Achelous) pubescens DANA.}

I 852 Lupa pubescens Danı, U. S. Expl. Exp. Crustacea, Vol. I, p. 274, Taf. XVI, Fig. 9. I86 I Achelous prbescens Milne-Edwards, Arch. Mus. H. Nat. Paris, Vol. X, p. 342.

Von dieser Art liegen mir 4 sehr kleine zerbrochene Exemplare vor; ich kann wegen der Jugendlichkeit der Exemplare ihre Zugehörigkeit zu der Art nicht mit Bestimmtheit nachweisen, auch kann ich infolgedessen die Giltigkeit der Art nicht untersuchen.

4 juv. Station 244 bei Dar-es-Salaam, $50 \mathrm{~m}$ Tiefe.

Verbreitung: Sandwich-Inseln (DANA).

\section{Gattung Seylla DE HAAN.}

\section{Scylla serrala (FORSKÅ).}

I755 Cancer serratus ForsKo․ Descriptio animalium etc., p. 90.

I850 Scylla serrata DE HAAN, Fauna japonica Crust., p. 44. 
I861 Scylla scrrati Minne-Edwards, Arch. Mius. H. N., Vol. X, p. 349.

I893 Scylla servala Ortaraxi, Zool. Jahrb. Syst., Bd. VII, I894, S. 78 (dasclbst Littcratur)

I899 Scylla serrala Alcock, Joum. As. Soc. Bengal, Vol. LXVIII, Pt. 2, p. 27 (daselbst Litteratur und Synunymie)

I $\delta$ klein, Dar-es-Salaam.

Verbreitung: Indopacifik (vergl. OrtaranN a. a. O.).

\section{Gattung Thalamita LATREILle. Thalamita danae STIMPSON.}

1852 Thalamita crenata DANA, U. S. Expl. Exped. Crust., Pt. I, p. 282, Taf. XVII, Fig. 7a-b.

I858 Thalamita danae Stimpsox, Proc. Ac. N. Science, Philadelphia I859, p. 39.

1861 Thalamila danae Milne-Edwards, Arch. Mius. H. N. Paris, Vol. X, p. 366, 367, Taf. XXXVI, Fig. I.

1899 Thalamita danae Alcock, Journ. As. Soc. Bengal, Vol. LXVIII, Pt. 2, p. 77.

I902 Thalamita prymna var. danae Srm., Borradaile, in: Fauna and Geography of the Maledive and Laccadive Archipelagoes, Vol. I, Pt. 2.

I ơ juv., ohne Scheren, Padang IVest-Sumatra.

Verbreitung: Indopacifik. Mozambique (Hnlgendorf); Mauritius (Richrers); Minikoi, Malediven (Borradaile); Malakka (DE MaN); Mergui-Ins. (dE MaN); Sumatra: Atjeh, Padang (DE MAN); Java, Samarang (M.E.); Ins. Enkhuisen bei Batavia (DE MAN); Pulo Edam, Nord wachter, Amboina, Waigeou, Timor, Ceram, Celebes (DE MLAN); Hongkong (Srrmpsov); NeuSeeland (Filhol); Auckland (Heller); Fidschi-Inseln (DANA).

\section{Gattung Thalamitoides A. Milne-Edivards. Thalamiloides quadridens MILNE-EDWARDS.}

I869 Thalamitoides quadridens Milne-Edwards, Nouv. Arch. Mus. H. Nat. Paris, Vol. V, p. I47, Taf. VI, Fig. 8-15.

Von dieser offenbar nicht håufigen Art liegen mir 2 Exemplare vor, welche sich in einigen Punkten voneinander unterscheiden. Beide unterscheiden sich von der Beschreibung von Minne-Edvards dadurch, daß der zweite Seitenrandzahn ziemlich klein ist. Während ferner bei dem einen die Stirn mit der Beschreibung von MrLne-Edwards übereinstimmt, sogar fast noch gerader ist, findet sich bei dem anderen Exemplar eine deutlich gelappte Stirn, die Kerben sind wohlmarkiert und es findet sich sogar je eine mehr, als bei den typischen Exemplaren, so daß die Stirn 8-lappig erscheint. Die accessorischen Kerben halbieren die großen medianen Stirnlappen. 2 kleine o Mahé (Seychellen) aus Korallen.

Verbreitung: Indopacifik: Tullear (S.-IV.-Küste von Madagashar); Upolu [Samoa] (MILNE-EDWARDS).

\section{Gattung Callinectes Stimipson.}

I860 Callinectes Strursox, in: Ann. Lyc. Nat. Hist. New York, Vol. VII, p. 220.

1895 Callinectes Rithibun, in: Proc. U. S. Nat. Museum, Vol. XVIII, p. 349 (MIonographic mit allen Litteratur-etc.Angaben).

\section{Callinecles larvatus ORDWAY.}

I 863 Callinecles larialus ORDWAY, Boston Journ. Nat. Hist., Vol. VII, p. 573.

1869 Callinecles lanatus Ordway, Sumtr, Trans. Connect. Acad. Science, Vol. II, p. 9.

I 879 Callinectes diacanthus var. lanatus MrLxe-Edwards, Miss. Scientif. au Mexique Crustacés, p. 225.

1893 Callinectes lavahis var. africanus? Benedict, Proc. U. S. Nat. Mus, Vol. XVI, p. 537.

1895 Callinecles laratus Ratribun, ibid., Vol. XVIII, p. $35^{8 .}$ 
Von meinen Exemplaren weichen die jüngeren von den RathBun'schen Angaben darin $\mathrm{ab}$, daß die innere Fissur des oberen Orbitalrandes weit offen ist, bei erwachsenen Exemplaren ist sie geschlossen.

2 , ad. I $q$ juv., $2 \delta$ juv., Victoria, Kamerun, in Reusen gefangen.

4 juv., Victoria, Kamerun, in Reusen gefangen.

Verbreitung: Tropischer Atlantik: Mexiko, Veracruz (Mrlne-Edwards); Florida, Bahamas. Große Antillen: St. Domingo, Jamaika. St. Thomas, Curaçao; Columbien: Sabanilla; Brasilien. Cap Verdische Inseln: St. Vincent. Westafrika: Bayafluß, Elmina, Aschantiland; Loanda (Rathbun).

\section{Familie Xanthidae.}

\section{Gattung Pilumnus LEACH.}

Pilummus hirtellus var. inermis Milne-Edv. u. Bouv.

I894 A. Milnne-Edwards u. Bouvier, in: Résult. scientif. Monaco, Vol. VII, p. 38.

4 o juv., I $\delta$ ad., I + mit Eiern.

Station 28, Cap Bojador, $26^{\circ}$ I $7^{\prime} \mathrm{N} . \mathrm{Br}$, $14^{\circ} 43,3^{\circ} \mathrm{W}$. L., in einer Tiefe von $146 \mathrm{~m}$.

Verbreitung: Azoren (Milne-Edwards u. Bouvier, Barrois? Miers: „Challenger" $[P$. spinifer?]).

\section{Pilumnus verrucosipes STIMPSON.}

Taf. XXXII, Fig. 3 u 4.

I 858 Pilumn vernucosipes Strmpson, Proc. Ac. N. S. Philadelphia, p. 36.

I88 I Pilummus vernucosipes Miers, Ann. Mag. Nat. Hist., Ser. 5, Vol. VIII, p. 2I6, Taf. XIII, Fig. 5.

I886 Pilumnus verncosipes MreRs, Challenger Brachyura, p. I 46.

Von dieser charakteristischen Form existierte bisher keine Abbildung. Ich habe daher auf Taf. XXXII, Fig. 3 u. 4 zwei Photographien eines jungen $q$ gegeben, welche sich bei der notwendigen Revision der Gattung Pihımmıs als nützlich erweisen dürften.

2 \& Station 99, Plettenbergbucht, Kapland, Flachwasser.

Verbreitung: Südafrika: Simonsbucht, $20 \mathrm{~m}$ (Smmpson); Westafrika: Goree-Ins., Senegambien (MIERS).

\section{Gattung Cymo dE HAAN. \\ Cymo Andrenssyi (Audouin).}

I809 Pilumnes Andreossyi Audouin, in: Savigny, Descr. de l'Egypte, p. 86, Taf. V, Fig. 5.

1850 Cymo Andreossyi DE HAAN, Fauna japonica, p. 22.

1852 Cymo Andreossyi Dana, U. S. Expl. Exp., Crust., p. 225, Taf. XIII, Fig. 2a-b.

I 894 Cymo Andreossyi Ortmann, Zool. Jahrb. Syst., Bd. VII, S. 443 (daselbst Litteratur).

i 898 Cy'mo Andreossy' Alcock, Journ. As. Soc. Bengal, Vol. LXVII, Pt. 2, p. 173 (daselbst Litteratur).

o und o Mahe, Seychellen, in Korallen.

Verbreitung: Indopacifik: Rotes Meer (Helter, SAvigny); Indien: Mekranküste, Ceylon, Andamanen, Nikobaren (Atcock); Mergui-Inseln (DE MAN); Java: Pulo Edam u. Insel Nordwachter (DE Man); Bonin-Insel (Strumson); Samoa-Inseln (Daña); Tahiti (Dana, Heller). 


\section{Gattung Xantho LEACH.}

\section{Xanlho exaratus (M.-EDw.) var. sanguinea (M.-EDw.).}

I834 Chlorodius sanguincus Milne-Enwards, Hist. nat. Crust., Vol. I, p. 402.

1894 Tantho evaratus (M.-E.) var. sangrinea ORTMANN, Zool. Jahrb. Syst., Bd. VII, S. 447 (daselbst Litteratur und Synonymic).

1898 Tantho (Leptodius) sanguineus (Evw.) ALcock, Journ. As. Soc. Bengal, Vol. LXVII, Pt. 2, p. II9 (Litteratur)

2 † Diego Garcia.

I $q$ Padang.

I $₫$, I $q$ Mahe, Seychellen, aus Korallen.

Verbreitung: Indopacifik: Rotes Meer: Massaua (Kossmann); Mauritius (M.-EDw., Richters); Réunion (M.-Edw.); Andamanen, Laccadiven (Alcock); Persischer Golf (Alcock); Ceylon (Heller, Müller, Alcock); Nikobaren (Heller, Alcock); Java (Mrers); Celebes (Thallwтrz); Neu-Guinea: Kaiser-IVilhelmsland (OrtusnN); Liu-Kiu-Insel (OrtasnN); Carolinen: Ponapé (Ortmann); Neu-Caledonien (M.-Edw.); Australien (Haswell); Fiji-Inseln (Ortmann); Neu-Seeland (M.-EDw.); Samoa, Rarotonga (ORTu.); Paumotu (DANA); Sandwich-Inseln (DANA).

\section{Xantho Lamarcki MiLne-EdwardS.}

Litteratur s. ORTMANN, Zool. Jahrb. Syst., Bd. VII, I894, S. 448.

I §, I q, Diego Garcia.

Verbreitung: Indopacifik.

\section{Xantho sp.}

Zwei jugendliche Exemplare einer Xantho-Art wurden im Agulhasstrom an bemerkenswert südlichen Fundorten gedredscht. Da ich nicht genug Vergleichsmaterial habe, vor allem keine jungen Tiere, so konnte ich die Art nicht mit Sicherheit feststellen. Sie gehört wohl in die nächste Verwandtschaft von $X$. exaratus (MI.-E.), doch ist der Stimrand gerader als bei dieser Art, die Oberfläche ist ziemlich granuliert und die Breite des Cephalothorax verhält sich zur Länge ungefähr wie $3: 2$.

I q Station 10.4, Agulhasstrom, $35^{\circ}$ I $6^{\prime} \mathrm{S} . \mathrm{Br}, 22^{\circ} 26,7^{\prime} \mathrm{O}$. L., in einer Tiefe von I $55 \mathrm{~m}$.

I o Station 105b, Agulhasstrom, $35^{\circ} 29^{\prime} \mathrm{S} . \mathrm{Br}, 2 \mathrm{I}^{0} 2,5^{\prime} \mathrm{O}$. L., in einer Tiefe von $102 \mathrm{~m}$.

\section{Gattung Liomera DANA. Liomera sp.}

Eine junge Liomera, welche auf der Agulhasbank gefunden wurde, gehört vielleicht zu ciner neuen Art. Doch kann man auf ein einzelnes junges Exemplar keine Diagnose begründen.

Der Cephalothorax ist in die Breite gezogen, die Oberfläche glatt, mattglänzend. Die Regionen sind deutlich, aber durch seichte Furchen getrennt. Die Stirn ist undeutlich gelappt. Der Seitenrand zeigt 4 undeutliche Vorsprünge (einschließlich der äußeren Orbitalecke. Die Scheren sind mäßig, beide ungefähr gleich groß. Der Carpopodit ist groß und zeigt vorn einen kräftigen Zahnlappen. Die Hände zeigen auf der Außenseite nach hinten hin 3-4 erhabene 
Längslinien. Der obere Rand ist breit gerundet, der untere ist scharfkantig. Die Finger sind längsgefurcht; die Zähne sind unregelmäßig. Die Finger sind spitzig und schließen an der Basis nicht zusammen.

Die übrigen Pereiopoden sind komprimiert, oben und unten scharfkantig, aber nicht gekielt. Die Farbe des jungen Tieres ist im Spiritus blaß violett, die Oberfläche opalesciert lebhaft. I $q$ juv., Station 105 auf der Agulhasbank, $35^{\circ} 29^{\prime} \mathrm{S} . \mathrm{Br}, 21^{\circ} 2,5^{\prime} \mathrm{O}$. L., in einer Tiefe von $102 \mathrm{~m}$.

\section{Gattung Actaea DE HAAN. Aclaea parvula (DE HAAN).}

I 850 Menippe parmulus DE HAAN, Fauna japonica, Crust., p. $2 \mathrm{I}$.

I 843 Menippe parvulus DE H., KRAUSS, Südafrikanische Krustaceen, S. 3.7, Taf. II, Fig. 2.

I 888 Actaea parula (DE H.) DE MAN, Joum. Linn. Soc. Zool., Vol. XX, p. 27.

I898 Actaea parvula (DE H.) ALcock, Journ. As. Soc. Bengal, Vol. LXVII, II, p. I46.

Meine Exemplare von dieser Art stehen zwischen den erwachsenen typischen und dem vermutlichen Jugendstadium bei DE MAN, S. 29. Die Finger sind hell, wie bei dem Exemplar von Krauss, auch ist die Behaarung sehr gering.

(Es ist übrigens die Art auch zu vergleichen mit Actaea setigera Mmne-Edwards, Arch. Mus. H. Nat. Paris, I 865 , p. 27 I.

2 o juv., Diego Garcia.

Verbreitung: Capland (DE HaAn); Natal (Krauss); Mergui-Inseln (DE Man); Andamanen (ALCOCK).

\section{Actaea hirsutissima (RÜPPEL).}

Taf. XXXII, Fig. I u. z.

1830 Xantho hirsutissimus RüPPEL, 24 Arten Krabben des Roten Meeres, S. 26, Taf. V, Fig. 6.

I 834 Xantho hirsutissimus Milne-Edwards, Hist. nat. Crust., Vol. I, p. 389.

1850 Actaea hirsutissima DE HAAN, Fauna jap., Crust., p. I8.

1852 Actaea hirsutissima DANA, U. S. Expl. Exped. Crust., p. I64.

1894 Actaed hirsutissima Ortmans, Zool. Jahrb. Syst., Bd. VII, S. 453 (das. Litteratur).

1898 Actaea hirsutissima Alcock, Journ. As. Soc. Bengal, Vol. LXVII, 2, p. 4 I.

Da von dieser charakteristischen Form noch keine wirklich gute Abbildung existrert, wie sie doch nur die Photographie zu geben vermag, so bilde ich sie auf Taf. XXXII, Fig. I u. 2 ab.

I $\delta$, I q Mahé, Seychellen auf Korallen.

Verbreitung: Rotes Meer (Rüppel, Heller, Kossitann): Djiddah (DE Man); Seychellen (Milne-Edivards); Mauritius (Milne-Edwards, Richters); Andamanen (Alcock); Neu-Kaledonien (Milne-Edwards); Samoa (Alcock, Ortmann, Dana); Tahiti (Heller).

\section{Gattung Phymodius A. Milne-Edwards. \\ Phymodius ungulatus (MILNE-EDWARDS).}

I 834 Chlorodine ungulahes Minne-Edwards, Hist. Nat. u. Crust., Vol. I, p, 400, Taf, XVI, Fig. 6-8.

Die reichliche Litteratur und Synonymie findet sich: 
I 894 Phymodius angulalus Ortainax, Zool. Jahrb. Syst., Bd. VII, S. 464.

I808 I\%modius mevlatus und monticulosus ALcock, Joum. As. Soc. Bengal, Vol. LXVII, 2, p). I62 u. I63.

1002 Phlmodus unsulalus BOrRsDAILE, in: GARDIXER, Geography and Biology of the Maledive Islands, Vol. I, p. 250.

2 ơ juv., I q juv. Mahé, Seychellen.

2 q juv., Diego Garcia.

Verbreitung: Indopacifik: Rotes Necr (Heller, Hilgendorf, Kossmane): Djiddah (DE MAN); Erythraea (Nobili); Ostafrika: Ibo (Hilgexdorf); Natal (Krauss); Madagaskar: Nossi Faly (Hoffmann); Manritius (Richters, Alcock, Ortmann); Malediven (Borradaile); Ceylon (Alcock): Trincomali (Mlülter); Andamanen, Nikobaren (Alcock); Liu Kiu-Ins. (Stmpson); Bonin-Ins. (Stumpson); Philippinen: Samboagan („Challenger": Miers); Australien: Port Denison (Haswell); Neu-Kaledonien (M.-Edw.); Samoa-Ins. (Jaguinot \& Lucas, Ortamann, Alcock); Tahiti (Stmpson, Heller).

\section{Gattung Chlorodius Leach em., A. Milne-Edivards.}

\section{Chlorodius niger (FORSKÅL).}

I755 Cancer niger Forskal, Descript. Anim., p. 80. Litteratur bei :

I894 Chlorodius niger Orturane, Zool. Jahrb. Syst., Vol. VII, p. 465.

1898 Chlorodius niger ALCock, Journ. As. Soc. Bengal, Vol. LXXII, 2, p. I60.

I902 Chlorodins niger Borradarle \& Gardiner, Geogr. and Biol. of the Maldive Islands, Vol. I, p. 259

ro $\delta$, $q$ bes. juv. Mahe, Seychellen aus Korallen.

Indopacifik vom Roten Meer und Madagaskar bis zu den Sandwich-Inseln, vergl. OrTMANN a. ล. O.

\section{Gattung Etisus Milne-Edwards. \\ Etisus dentatus (HERBST).}

I 790 Cancer dentatus HerbeT, Krabben, Bd. I, 2, S. I86, Taf. II, Fig. $60^{\circ}$

I834 Etisus dentatus Milne-Edwards, Hist. Nat. Crust., Vol. I, p. 4 II.

1852 Etisus dentahus DaxA, U. S. Expl. Exped., p. I85, Taf. XX, Fig. 2.

1873 Etisus dentahus A. Mrlne-Edwards, Nouv. Arch. Mus. H. N. Paris, Vol. IX, p. 233.

I877 Etisus dentatus Miers, Proc. Zool. Soc., p. I34.

r880 Etisus dentatus Richters, in: Mömus, Meeresfauna Mauritius etc.

I88I Elisus dentatus Lexz u. Ricriter, Abh. Senckenberg. Ges., Bd. XII, S. 42 I.

1882 Etisus dentatus Hasweil, Catal. Austral. Crust., p. 53.

I 885 Etisus dentahus MIERS, Challenger Brachyura, p. 132.

I804 Etisodes dentatus Ortmann, Zool. Jahrb., Syst., Bd. VII, S. 472.

I 898 Eisus dentatus Alcock, Journ. As. Soc. Bengal, Vol. LXVII, 2, p. I30.

I ơ juv., Diego Garcia.

Die Hand zeigt auf der Außenseite zwei parallele Längsreihen von stachclartigen Höckern.

Der Vorderseitenrand hat 4 Hauptzähne, von denen der erste stumpf ist und I Höcker auf seinem Hinterrand besitzt, der zweite, mit scharfer, hakenförmiger Spitze versehen, hat auf dem Hinterrande zwei accessorische Zühnchen, ebenso der dritte. Außerdem ist noch Körnelung des Randes zu erkennen. 
Die Farbe ist in Spiritus hellorange mit feiner, weißer Punktierung, die seitlichen Teile der Stirn sind beiderseits von einem großen, weißen Fleck mit bogiger Umgrenzung eingenommen.

Die Abweichungen von der Beschreibung der früheren Funde sind wohl durch die Jugendlichkeit des Exemplares bedingt.

Verbreitung: Indopacifik: Natal (Mirers); Madagaskar: Nossi Bé (Lenz u. Richters); Mauritus (Hoffmann, Richters); Andamanen (Alcock); Bomeo: Balabac-Str. (Dana); Australien: Torres-Str. (Hasweld); Neu-Kaledonien (Mrnne-Edw.); Fidji-Ins. (Dana); Samoa-Ins. (Ortanann).

\section{Gattung Daira DE HAAN. \\ Daira perlata (HERBST).}

1790 Cancer perlatus Herbst, Krabben, Bd, I, II, S. 265, Taf. XXI, Fig. 122.

I796 Cancer daira HeRBST, Krabben, Bd. III, II, S. 6, Taf. LIII, Fig. 2.

I 798 Cancer variolosus FABRicius, Ent. Syst. Suppl., p. 338.

I852 Daira perlata DE HAAN, Fauna japonica Crust., p. I8.

I834 Lagosioma perlata (Herist) MILne-Edwards, Hist. Nat. Crust., Vol. I, p. 387.

I894 Daira perlata (Herbst) Ortuann, Zool. Jahrb. Syst., Bd. VII, S. 474 (daselbst Litteratur).

I878 Daira perlata (Herbst) Alcock, Journ. As. Soc. Bengal, Vol. LXVII, Pt. 2, p. I55 (daselbst Litteratur).

IgO2 Daira perlata (Herbst) Borradaile, Gardiner, in: Fauna and Geogr. of the Maldive and Lacc. Archipelogoes, Vol. I, p. 258.

2 o, Diego Garcia.

Verbreitung: Indopacifik: Mauritus (Rtchters, Ortannn, Alcock); Laccadiven (Alcock) Malediven (Borrada几le); Liu-Kiu-Inseln (Stmipson); Amami Oshima (Ortanan); Flores (Thallwvitz); Timor (Thallwitz); Neu-Guinea (Herkiots); Neu-Kaledonien (Mulne-Edwards); Neuseeland (Miters, Filhol); Auckland (Hetmer); Fidji-Insel (Ortmann); Funafuti (Borradalle); Samoa-Inseln (Dana, Orimann, Alcock).

\section{Gattung Trapezia Latreille.}

I897 Ortmann, Zool. Jahrb. Syst., Bd. X, S. 201 (Monographie).

\section{Trapezia cymodoce (HERBST).}

I796 Cancer cymodoce Herbst, Krabben, Bd. III, S. 22, Taf. LI, Fig. 5.

1897 Trapezia cymodoce OrTmann, Zool. Jahrb. Syst:, Bd. X, S. 203 (Litteratur).

I q Mahe, Seychellen, aus Korallen.

Verbreitung: Indopacifik s. ORTMANN a. a. O.

\section{Trapezia ferruginea gutlata RÜPPEL.}

I830 Trape zin guttata RÜPPEL, 24 Arten, Krabben a. d. Roten Meer, p. 27 (unten). I897 ORturani, Zool. Jahrb. Syst., Bd. X, S. 205 (Litteratur).

I os, I juv., Mahé, Seychellen, aus Korallen.

Verbreitung: Indopacifik, s. OrTmann a. a. O. 


\section{Gattung Tetralia DanA. \\ Tetralia glaberrima (HERBST).}

1790 Cancer glabcrimus Hernst, Krabben, Bd. I, Pt. 2, S. 262, Taf. XX, Fig. II5.

1897 Tetralia glabemina Ortansw, Zool. Jahrb. Syst., Bd. X, S. 209.

I o Mahé, Seychellen, aus Korallen.

Verbreitung: S. Ortumn a. a. O.

\section{Familie Potamonidae. Gattung Potamon Savigny. Untergattung Potamonautes Macleay. Potamon (Potamonautes) Aubryi (Milne-Edvards).}

185 I Thelphusa aurantin Herklots, Addit. faun. carcin. Afric. occid., p. 5, Taf. I, Fig. 2 (nec Cancer aurantius HERBST). I861 Thelphusa Pelii Herklots, Études sur la classe des crustacés, Lexde, p. I 3.

I853 Thilphusa Aubri A. Milde-Edwards, in: Ann. Sci. nat. (3) Zool., Vol. XX, p. 210.

I869 Thelphusa Aubri A. Mirne-Edwards, in: Nouv. Arch. Mus. H. N. Paris, Vol. V, p. I86.

I860 Thelphusa africana A. Milne-Edwards, ibid., p. I86, Taf. XI, Fig. 2.

ISo7 Polamon (Polamonautes) Aubryi (A. Milne-Edwards), Orturann, Zool. Jahrb. Syst., Bd. X, S. 309.

Von westafrikanischen Süßwasserkrabben steht mir ein so geringes Material zur Ver fügung, daß ich die Verwandtschaftsverhältnisse der mir vorliegenden Exemplare nicht näher untersuchen kann. Ich hoffe bei Gelegenheit der von mir' längst geplanten Monographie der Süßwasserkrabben, zu welcher ich seit längerer Zeit Material sammele, darauf zurückkommen zu können.

I enwachsenes o, I q juv., Viktoria, Kamerun.

Verbreitung: VVestafrika: Goldküste: St. George d'Elmina (Herklots); Gabun (MrrneEDWARDS).

\section{Potamon (Potamonautes) perlatum (Milne-Edwards).}

1837 Thelphusa perlata MrLne-Edwards, Hist. nat. Crust., Vol. II, p. I3.

187 I Thelphusca anchietae Brito-Capello, in: J. Sc. Math. Phys. Nat. Lisboa, Vol. III, p. ז32, Taf. IIa, Fig. Ir.

I897 Potamon (Potamonautes) perlatum (MILne-Edwaros), OrTMAas, Zool. Jahrb. Syst., Bd. X, S. 307 (daselbst ausfülnliche Litteraturangabe).

I $\delta$ juv., Port Elizabeth (Natal), Bach in der Nähe des Kaffernkrals.

Sansibar, Sansibarküste (PFEFFER); südl. Deutsch-Ostafrika (Museum München); Natal (Krauss, Ortannns); Cap-Kolonie (Milne-Edwards, Krauss, Heller); Capstadt (Miers); Wellington (Miers); Constantia (Strurson); Chalkbai (Sruder); Deutsch-Südwestafrika: Windhoek (Museum München); Angola (Brito Capello).

\section{Gattung Geryon KRöYER.}

1837 Geryon Krörer, in: Naturhist. Tidsskrift, Vol. I, Kjubenhavn, p. 20.

1856 Chalcepres Gerstä̈kir, in: Arch. Nat., Vol. XXII, p. IIg.

Von der Gattung Geryon sind bisher 6 Arten beschrieben worden.

Geryon trispinosus (Herbst), DE MaN, Notes from the Leyden Museum, Vol. XII, I890, p. 69, Ortanan, Zool. Jahrb., Bd. VII, ı 894, S. 685, Indien, Japan. 
Geryon tridens Kröyer, in: Naturhist. Tidsskrift, Vol. I, 1837, p. 20, Nordostatlantik. Geryon quinquedens S. Sirrer, in: Trans. Connecticut Ac. of arts and science, Vol. V, I879, p. 35, Taf. IX, Fig. I-2, Nordwestatlantik.

Geryon incertus Miers, Challenger Brachyura, i 886, p. 224 (Taf. XVI, Fig. 3), Bermudas.

Geryon longipes Milne-Edwards, Compt. Rend. Ac, Sci. Paris, Vol. XCIII, i881, p. 879, Talisman Crustacea, I900, p. I03, Golf v. Biscaya, Mittelmeer.

Geryon affinis Milne-Edwards u. Bouvier, in Resultats Monaco, Vol. VII, p. 4I, Taf. I, Fig. I. Alcock, Investigator Brachyura, 1899, p. 85, Azoren, Südatlantik, Indische Westküste, Ostafrika (s. unten).

Dazu kommt noch der von mir unten neu beschriebene G. Paulensis. G. incertus Miers ist nach einem zerbrochenen Stück beschrieben und gehört wahrscheinlich nicht in diese Gattung. Betrachten wir die sämtlichen übrigen Formen, so kann es uns nicht entgehen, daß sie sich untereinander sehr nahestehen. Minde-Edwards vermutet in C. longipes eine Varietät von $G$. tridens Kröyer, ebenso hebt S. SiItH bei seinem G. quinquedens die sehr nahe Verwandtschaft mit der gleichen Art hervor; auch ich muß dies für G. Paulensis thun. So muß auch DE MAN in seiner genauen Beschreibung des G. trispinoszis HBst. auf die große Aehnlichkeit vieler Teile mit den entsprechenden bei G. tridens und longipes hinweisen.

Alle diese Formen erscheinen dadurch noch enger verbunden, daß bei einer genügend großen Anzahl von Exemplaren von einem Fundort sich nachweisen läßt, daß gewisse Eigenschaften während des Wachstums der Individuen sich kontinuierlich ändern, andere selbst bei Individuen von gleicher Größe variieren. Auf die Zahl und Größe der Seitenrandzähne brauchen wir aus diesem Grund kein allzu großes Gewicht zu legen, ebensowenig auf die Stirnform; selbst die relative Länge der Beine variiert und erscheint selbst beim gleichen Individuum auf beiden Seiten verschieden.

Auch G. affinis steht nach Mune-Edwards und Bouvier dem G. quinquedens sehr nahe, nur sind sie konstant durch die Form und Struktur der Daktylopoditen der Schreitbeine unterschieden. Ich muß gestehen, daß mir alle diese Unterschiede sehr geringfügig erscheinen. Bei hinreichend großem Untersuchungsmaterial würde man wohl zu dem Resultat kommen, daß man es mit einer einzigen, in der Tiefsee kosmopolitisch verbreiteten Species zu thu hat. Von ihr sind bisher nur einzelne Altersstadien, dazu vielleicht einige Standortsvarietäten oder wohl auch Subspecies gefunden worden. Doch habe ich vorläufig die Speciesbezeichnungen noch beibehalten, bis andere, denen reiches Material zur Verfügung steht, die Frage geprüft haben.

Ueber die geographische Verbreitung siehe Abschnitt IV.

\section{Geryon affinis MiLne-EdWARds u. BOUVIER.}

Taf. III, IV, XXXIII, XXXIV; Taf. XXXVIII, Fig. I-6; Taf. XLI, Fig. 3-7; Tai. XLIII, Fig. 2 u. 8. I894 Gerjon affinis Milne-Edwards u. Bouvier, Resultats Monaco, Vol. VII, p. 4I, Taf. I, Fig. I. I899 Geryon affinis AlCock, Investigator Brachyura, p. 85 (Addenda).

Diese Art wurde vom Fürsten von Monaco bei den Azoren erbeutet und in einem Exemplar von dem „Investigator“ an der Travancoreküste wieder gefunden. Die deutsche TiefseeExpedition fing Exemplare dieser Art sowohl im atlantischen als auch im indischen Ocean.

Aus dem Indischen Ocean stammt ein großes Exemplar von der ostafrikanischen Küste. Ich hatte nach der nach dem Leben gemalten Farbenskizze schon eine farbige Abbildung 
anfertigen lassen, als ich durch den Vergleich größeren Materials und die vorziigliche Abbildung und Beschreibung von Mrine-EDivards und Bouvier in den Stand gesetzt wurcle, mein Exomplar mit der atlantischen Art zu identifizieren.

Zwar weicht mein Exemplar in einer Reihe von Punkten vom Typus ab. Der obere Orbitalrand ist nicht gekörnelt, die in der Mitte derselben befindliche Fissur ist lang und deutlich. Außerdem ist das Aussehen der Spitzen der Daktylopoditen ein anderes. Die Fürbung weicht ebenfalls erheblich von derjenigen des Milne-Edwards und Bouvier'schen Originals ab (Taf. IV). - Alle diese Abweichungen betreffen aber variable Merkmale und ein ziemlich reiches Material von Geryon affunis aus dem südlichen Atlantischen Ocean brachte mich zu der Ueberzeugung, daß es sich um eine und dieselbe Art handelt.

Die Expedition fing nämlich auf der Valdiviabank im südatlandischen Ocean ca. 40 Stïck der gleichen Species, welche sich aber alle durch einige Merkmale ebenfalls unterscheiden lassen.

Die Stirn- und Seitenrandzähne sind spitzer als bei den bisher beschriebenen resp. abgebildeten Exemplaren von $G$. affniis. Auch sind die Abstände der Seitenrandzähne nicht genau der Beschreibung entsprechend. Meine zahlreichen Exemplare zeigen aber verschiedenartige Verhältnisse; bald ist dieser, bald jener Zahn etwas spitzer und etwas größer (vgl. z. B. Taf. XXXIII, Fig. I u. Taf. XXXIV, Fig. I). Am meisten neigen zur Verkleinerung der 2. und 4. Zahn; der vierte ist manchmal fast ganz verstrichen. Der Abstand zwischen dem 2. und 3. Seitenrandzahn ist variierend, aber bei keinem Exemplar ist er so groß wie in der Abbildung von Milne-Edwards und Bouvier.

Der obere Orbitalrand ist bei den meisten Exemplaren glatt, bei einigen zeigt er leichte Körnelung. Bei einigen jüngeren Exemplaren sind zwei Fissuren erkennbar: eine etwa in der Mitte des oberen Orbitalrandes, eine in der Mitte zwischen ihr und der äußeren Orbitalecke. Bei älteren Exemplaren ist die letztere meist nicht mehr erkennbar, und bei manchen ist auch die mittlere fast ganz verschwunden. Der Infraorbitalzahn ist bei den südatlantischen Exemplaren meist deutlich nach unten gerichtet, während er bei dem Stück von der ostafrikanischen Küste wie bei dem typischen affinis gerade nach vorn gerichtet ist.

Die Augen sind groß und dunkel pigmentiert (Taf. XLIX, Fig. I). Die Antennen beider Paare kräftig entwickelt. Näheres über die Sinnesorgane findet sich im Abschnitt II; s. auch Taf. XLIII, Fig. 2 u. 8.

Die Gestalt des Cephalothorax ist ebenfalls von der Abbildung bei MrLne-Edwards und Bouvier abweichend. Bei den meisten Exemplaren erscheint der Cephalothorax nach hinten mehr zusammengezogen: die Hinterseitenränder konvergieren deutlich. Die Verschmälerung des Cephalothorax nach hinten ist bei den jungen Individuen und besonders bei den $\delta$ viel auffallender als bei den Alten und den f. Vgl. Taf. XXXIII, Fig. I mil Taf. XXXIV, Fig. I. Der Hinterrand ist geschwungen, in der Mitte nach hinten konkav, während er in der citierten Abbildung ganz gerade ist; bei dem größten südatlantischen of ist er aber auffallender WVeise ebenfalls ganz schnurgerade. Die Wölbung des Cephalothorax ist bei ơ und of verschieden stark. Zieht man zwischen den hintersten Seitenrandzähnen eine Linie über den Cephalothorax, so erhält man eine hintere, mehr nach den Seiten abfallend gewölbte Hälfte und eine vordere auffallend steil zur Stirnregion abfallende Hälfte. Dieser Abfall ist bei den $q$ ein viel auffallender als bei den ð. Die Rauhigkeiten der Oberfliichenskulptur variieren stark; junge Exemplare sind fast 
glatt, ältere zeigen (bei den südatlantischen Stücken) meist zunehmende Rauhigkeit. Das ostafrikanische Exemplar ist auf den Branchialgegenden sehr rauh.

Die 2. Gnathopoden stimmen wohl vollkommen mit der Beschreibung überein; was die Form derselben im einzelnen und die übrigen Mundgliedmaßen anlangt, so sei auf die Abbildungen Taf. XXXVIII, Fig. $1-6$ hingewiesen. Die Kiemen sind ziemlich groß, gut ausgebildet, starr und kräftig und nach folgender Formel angeordnet:

\begin{tabular}{l|c|c|c|c}
\hline & Podobranchien & Arthrobranchien & Pleurobranchien & \\
\hline I. Gnathopod & I + Ep. & I & 0 & $2+$ Ep. \\
2. Gnathopod & I rud. + Ep. & 2 & 0 & $3+$ Ep. \\
I. & 0 & 0 & 2 & 2 \\
2. & 0 & 0 & I & I \\
3. Pereiopod & 0 & 0 & I & 0 \\
4. & 0 & 0 & 0 & 0 \\
5. & 0 & 0 & 0 & $9+2$ Ep.
\end{tabular}

Hervorzuheben ist, daß die 2 Arthrobranchien, welche dem 2. Gnathopoden zugezählt sind, deutlich an dem Segment des Cephalothorax sitzen, an welchem auch der 2. Gnathopod befestigt ist. Die Podobranchie des 2. Gnathopoden ist klein, rudimentär, während diejenige des I. Gnathopoden wohlentwickelt und größer als die zugehörige Arthrobranchie ist.

Was nun die Form und relative Länge der Pereiopoden anlangt, so ergeben sich hier Verschiedenheiten. Während bei dem großen Exemplar aus dem Indischen Ocean die 4. Pereiopoden in Uebereinstimmung mit der Originalbeschreibung von G. affniis die längsten sind, übertreffen bei den südatlantischen Exemplaren, welche viel kleiner sind, die 3. Pereiopoden die übrigen an Länge.

In der Form und Skulptur sind die Pereiopoden an den Exemplaren von beiden Fundorten sehr ähnlich; nur ist alles bei dem großen Stück entsprechend gröber und stärker. Je jünger die atlantischen Exemplare sind, um so schärfer und spitzer sind alle Stachel- und Körnerbildungen.

Die Spitzen der Daktylopoditen stimmen recht gut mit der Abbildung, welche MinNeEDWARds und Bouvier a. a. O. S. 43 von G. affmis gegeben haben, überein, wenigstens in den äußeren Umrissen. Außerdem zeigen aber das indopacifische Exemplar und einige von den südatlantischen eine eigenartige, offenbar durch Abnutzung entstandene Struktur der Spitze, welche auf der einheitlichen Spitze die Zeichnung von 3 scharfen Spitzen entstehen läßt (Taf. XLI, Fig. 5). Die Scherenfüße sind bei dem großen ostafrikanischen Exemplar ( 8 ) relativ groß und ungleich ausgebildet; die rechte ist größer und hat auch stärkere, größere Zähne mit breiterer Oberfläche. Die Granulationen auf sämtlichen Teilen der Scherenfüße sind recht grob, die Stacheln am distalen oberen Ende des Meropoditen und an der oberen inneren Ecke des Carpopoditen sind stark und spitz (Taf. IV).

Aehnlich verhält es sich bei den südatlantischen Stücken; je kleiner sie sind, um so schwächer sind die Granulationen, um so schlanker und schärfer jedoch jene beiden Stacheln. Der Gegensatz zwischen beiden Scheren ist auch bei den $q$ ausgesprochen. Wie erwähnt, sind aber die Zähne auf beiden Scheren nicht so verschieden, daß man eine Körner- und Zahnschere, resp. Freß- und Kampfschere unterscheiden könnte. Nur bei einem $q$ mittlerer Größe ist die linke Schere auffallend kleiner als die rechte und dabei mit Körnern auf den Schneiden der Finger versehen, anstatt mit richtigen Zähnen. Die Kleinheit des Gebildes und auch das häufige 
Vorkommen von Regeneraten an den Pereiopoden anderer Exemplare lïßt es wahrscheinlich erscheinen, daß es sich um ein Exemplar handelt, welches diese Schere durch Regeneration neugrebildet hat. Denn auch die jüngsten Exemplare, auch das offenbar recht junge, unten beschriebene Exemplar von Goryon Paulensis, zeigen schon mit gleichartigen Zühnen versehene Scheren beiderseits.

Die Geschlechtsfüße der $\delta$ von beiden Fundorten sind gleichartig ausgebildet. Der erste ist sehr stark und kräftig, das Endglied besteht aus einem sichelförmig gekrümmten Stück mit horniger Spitze. Der zweite hat ein pfriemenartig dünnes Endglied von einer dem Endglied des ersten entsprechender Form, mit ebenfalls horniger Spitze (Taf. XLI, Fig. 6). - Aus der Geschlechtsöffnung an der Basis des 5. Pereiopoden ragt eine lange Samenröhre hervor.

Das Abdomen des o entspricht ebenfalls in beiden Fällen dem von MrLne-Edwards und Bouvier s. a. O. S. 44, Fig. c abgebildeten. Doch sind bei den südatlantischen Stücken die Furchen, welche auf dem 3. und 4. Glied einen Mittelteil einschließen, deutlicher (Iaf. XXXII, Fig. 2). Die 7 Segmente sind deutlich frei.

Beim $q$ ist das Abdomen breit, besteht ebenfalls auf 7 freien Segmenten, von denen das 6. und 7. die längsten sind (Taf. XXXIV, Fig. 2). Doch genügt die Breite des Abdomens nicht, um die Fülle von Eiern, welche das $q$ produziert, zu bergen. Die stark verbreiterten äußeren Pleopodenäste bilden in der Lücke einen Korb um die Eiermasse.

Die Eier sind klein und dunkel gefärbt. Aus ihnen schlüpfen die Jungen im Zoëastadium aus; sie haben schon deutlich pigmentierte Augen (Taf. XLI, Fig. 3). Näheres hierüber s. Abschnitt II.

Was nun schließlich die Färbung anlangt, so zeigen uns schon die beiden Tafeln III und IV, daß die Tiere von den 2 verschiedenen Fundorten verschieden gefürbt waren, als sie vom Naler der Expedition skizziert wurden.

Das läßt sich in verschiedener WVeise erklären:

I) Entweder handelt es. sich um 2 verschieden gefärbte Formen;

2) oder das jüngere Stadium trägt eine andere, weniger specialisierte Färbung als das ältere;

3) oder endlich im Falle der Taf. III sind alle jene Chromatophoren im Zustande der Ausdehnung, welche im Falle der Taf. IV kontrahiert sind.

Mir erscheint die letztere Annahme als die wahrscheinlichere.

Erörtern wir nun die gegenseitige Stellung der vorliegenden Stücke, so spielen neben der Färbung vor allen Dingen die Form der Stirn- und Seitenrandzähne, die Form des Cephalothorax und die Größe der Individuen eine Rolle. Von diesen sämtlichen Merkmalen konnten wir jedoch feststellen, daß sie variabel sind, vor allem konnten wir auch sehen, daß eine graduelle Veränderung mit zunehmender Größe sich konstatieren ließ.

Der Größenunterschied ist allerdings ein auffallender. Während der Cephalothorax des ostafrikanischen Exemplars $12 \mathrm{~cm}$ in der Länge und in der Breite $14,5 \mathrm{~cm}$ mißt, sind die entsprechenden Maße bei allen südatlantischen, geschlechtsreifen Individuen $\mathrm{ca} .9 \mathrm{~cm}$ und I I cm. Dabei sehen wir die viel kleineren $q$ aus dem südatlantischen Ocean mit zahlreichen Eiern beladen. Definitiv läßt es sich also nicht entscheiden, ob wir es nicht mit einer Subspecies zu thun haben, da kein Exemplar der Serie auch nur annähernd die Maße des ostafrikanischen oder des großen Exemplars von MiLne-Edwards und Bouvier erreichte. Daß aber die Stücke ihre definitive Größe nicht erreicht hatten, ging daraus hervor, daß eines der größten eiertragenden 
$q$ bei anatomischer Untersuchung ein in voller Entwickelung neuer Eier begriffenes stattliches Ovar besaß. Wie wir schon mehrfach ervähnt haben, kommen ja viele Krabben lange vor Erreichung ihrer definitiven Größe zur Geschlechtsreife.

Somit fasse ich die verschiedenen Exemplare als verschiedene Altersstadien der gleichen Art auf.

Zahlreiche $\delta$ und o Station $83(?)$, Untiefe mitten im südatlantischen Ocean, $25^{\circ} 27^{\prime} \mathrm{S} . \mathrm{Br}$, $6^{0} 8,2^{\prime}$ O. L., 2000 m Vertikalnetz.

$3 \delta^{\prime}$, I 2 q Station 84 , Untiefe mitten im südatlantischen Ocean, $25^{0} 27^{\prime} \mathrm{S}$. Br., $6^{0} 8,2^{\prime}$ O. L., $936 \mathrm{~m}$ Tiefe.

I gr. o Station 258, ostafrikanische Küste, $2^{0} 58,5^{\circ}$ N. Br., $46^{\circ} 50,8^{\circ} \mathrm{O}$. L., in einer Tiefe von $1362 \mathrm{~m}$.

\section{Zur Anatomie von Geryon affinis Milne-Edw. u. Bouv.}

An einem o mittlerer Größe aus dem südatlantischen Ocean von Station 84 konnte ich die Anatomie untersuchen und einige Befunde machen, welche der Mitteilung wert sind.

Das Herz ist groß und sehr kräftig, seine Gestalt ist aus Taf. XLI, Fig. 4 zu entnehmen. Besonders fielen an den Ostien die sehr schön ausgebildeten, sehr kräftigen Semilunarklappen auf. Ebenso sind die vom Herzen abgehenden Blutgefäße sehr kräftig. Dies gilt auch für die Hauptgefäße in den sehr stark entwickelten Kiemen.

Der Oesophagus ist ziemlich eng, der Magen groß und mit kräftigen Hornplatten versehen. Eine Bürste von Haaren und Hornstacheln dient zum Abschluß des Pylorusabschnittes. An der Stelle, wo ventral der Magen in den Mitteldarm übergeht, münden in seine dorsale Wand zwei symmetrisch angeordnete langschlauchförmige Drüsen. Aehnliche Bildungen sind nach Gerstäcker (Bronn's Klassen und Ordn. Malacostraca, p. 967) schon von Milne-Edviards für Maja squinado und Carcinus maenas, von Duvernoy für Portumus puber, von Frenzel für Pachygrapsus und Dromia nachgewiesen worden. Sie werden in der Regel als paarige Blinddärme bezeichnet. Ich möchte sie vorläufig als Pylorusanhänge indifferent bezeichnen (Taf. XLI, Fig. 4, P). Siebold, welcher in ihnen eine weißliche Flüssigkeit nachwies, warf die Frage auf, ob nicht in ihnen Harnorgane zu erkennen seien. Dies erscheint mir unwahrscheinlich. Ich bin eher geneigt, in ihnen Drüsen zu erblicken, welche ein für bestimmte Verdauungsvorgånge notwendiges, fermenthaltiges Sekret absondern. Abgesehen von der physiologischen Untersuchung wäre es von Wichtigkeit, festzustellen, bei welchen Formen diese Pylorusanhänge vorhanden sind und bei welchen sie fehlen, um durch Vergleich der Ernährungsweise der betreffenden Formen die Bedeutung dieser Drüsen zu eruieren.

Ventral am Anfang des Mitteldarmes münden die sehr weiten Ausführungsgänge der Leber. Dieselbe ist, wie in der Regel bei den Dekapoden, sehr mächtig entwickelt (Taf. XLI, Fig. 4, L); sie erstreckt sich bis an den Vorderrand, bis zur Seitenecke, grenzt nach außen überall an die Kiemenhöhle an, nach innen an den Magen, unter welchem hin sich noch Teile von ihr bis fast zur Medianlinie hin erstrecken. Ferner legt sie sich an den Mitteldarm an und reicht unter dem Ovar hinziehend bis zur hinteren Grenze des Cephalothorax. 
Die Grenze des Mitteldarmes und Enddarmes zu bestimmen war bei dem Erhaltungszustand des Materials nicht mit Exaktheit möglich. Der gesamte hintere Abschnitt des Darmes erstreckt sich in geradem Verlauf bis zum Anus. Vor dem Uebertritt des Darmes in das Abdomen ist seine Wand durch einen ringförmigen Wulst verdickt, wie er ja bei anderen Arten auch schon nachgewiesen worden ist. Dorsal kurz vor diesem Ringwulst mündet eine unpare lange schlauchförmige Drüse (Taf. XLI, Fig. 4, Eg) in den Darm ein. Für sie gilt dasselbe, was ich oben von der Pylorusanhängen gesagt habe; ich möchte daher den früheren Autoren, deren Angaben über das Vorkommen dieses Organes zum Teil bezweifelt werden, in der Terminologie nicht folgen; statt von einem Blinddarm zu sprechen, möchte ich auch dieses Organ indifferent als Enddarmanhang bezeichnen.

Das Ovarium des untersuchten $q$ war sehr wohl entwickelt und mit zahlreichen jungen Eiern der verschiedensten Wachstumsstadien erfüllt (Taf. XLI, Fig.4, Ov); und dies, obwohl das Exemplar zur gleichen Zeit an den Pleopoden zahlreiche weitentwickelte Eier resp. Embryonen trug. — Der Eileiter ist vor seinem Eintritt in die Basis des 3. Thorakalbeines ein relativ sehr weites Rohr.

Das Nervensystem ist ausgezeichnet durch ein sehr einheitliches Thorakalcentrum; letzteres ist fast kreisförmig nur ganz wenig in die Länge gestreckt und zeigt in der Mitte eine kreisrunde Durchbohrung (s. Textfig. 9). Sehr stark entwickelt ist der Nervus opticus.

Näheres über die Sinnesorgane findet sich im Abschnitt II dieses Buches.

Im Magen des Exemplares fanden sich große Klumpen halbverdauter Substanz. Bei genauerer Untersuchung ließen sich noch färbbare Kerne nachweisen, ferner

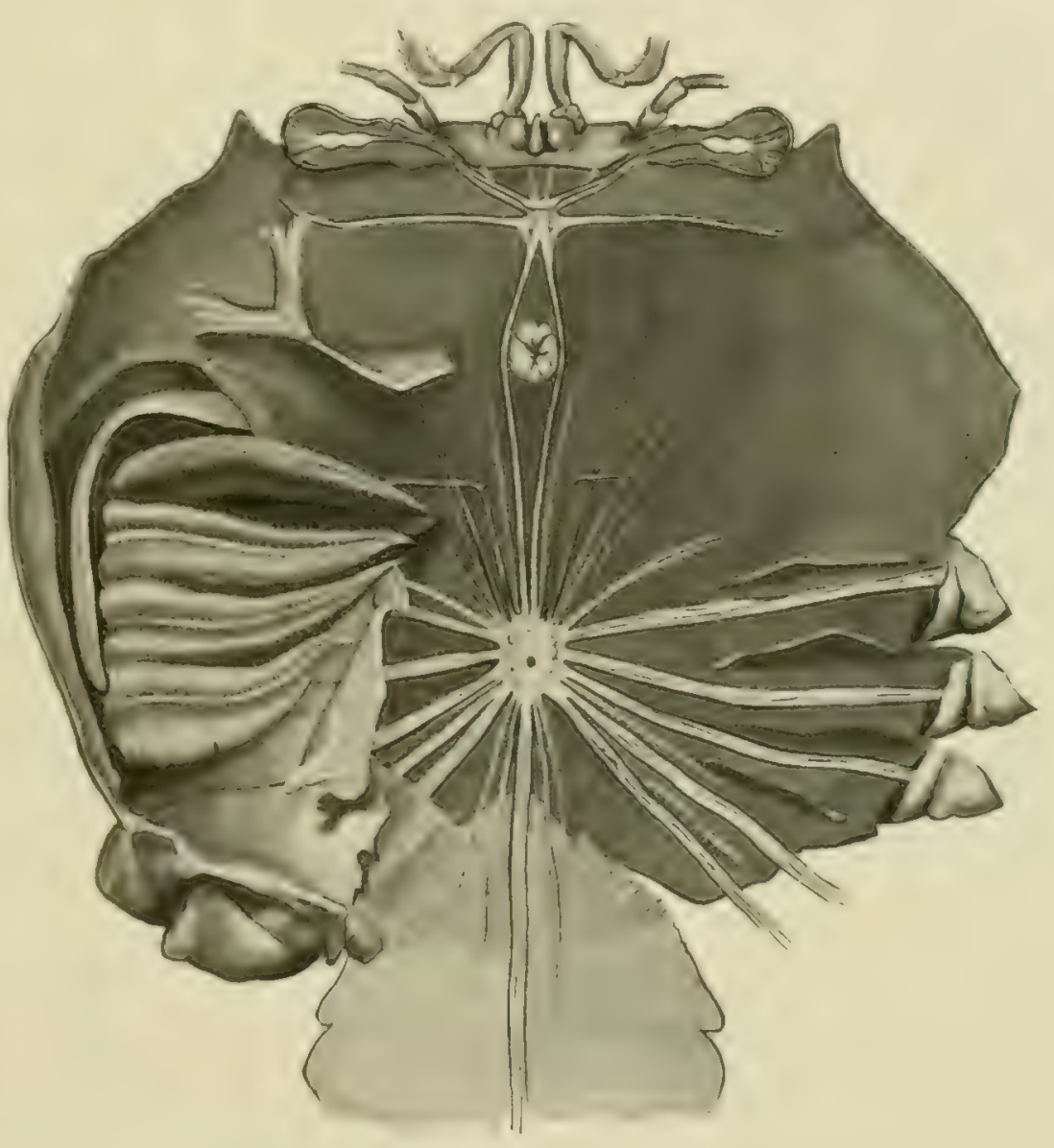

Fig. 9. Kiemenanordnung und Centralnervensystem von Geryon affinis. Stränge, die von Nerven oder glatter Muskulatur herrühren konnten. Jedenfalls ist anzunehmen, daß die Stücke von einem größeren, höheren Tier herrührten, vielleicht von einer großen Schnecke oder einem Cephalopoden.

Wir können daraus schließen, daß Geryon affinis ein Räuber oder Aasfresser ist. Auf letzteres weist auch der Umstand hin, daß der Fürst von Monaco Exemplare in Reusen durch Aas zu küdern vermochte. 


\section{Geryon Paulensis Doflein.}

Taf. XXXI, Fig. I u. 2.

1903 Geryon Paulensis Doflein, in: Chun, Aus den Tiefen des Weltmeers, 2. Aufl., S. 53I, Abbildung.

Nur mit Zögern habe ich dem an der oben citierten Stelle abgebildeten Krebs einen besonderen Speciesnamen gegeben und, wie aus der Darstellung auf S. Io6 hervorgeht, bin ich heute noch zweifelhafter geworden, ob wir es nicht mit einem Jugendstadium einer schon bekannten Art zu thun haben. Immerhin müssen wir die Form im Detail beschreiben, denn das Aussehen derselben und der Fundort lassen es immerhin möglich erscheinen, daß es sich um eine besondere Species handelt.

Von den bisher beschriebenen Formẻn von Geryon steht die neue aus dem Südindik dem G. quinquedens S. Simtr und dem G. Tongipes M.-EDw. am nächsten. Besonders dem ersteren steht er außerordentlich nahe, doch unterscheidet er sich durch die längeren Stacheln des Seitenrandes, durch die Stirn, welche breiter ist als die Orbiten, durch die spitzen, glatten Daktylen der Schreitbeine, durch die 7 freien Glieder des Abdomens.

Von G. Tongipes ist er durch das Vorhandensein des 2. und 4. Seitenrandstachels und dadurch unterschieden, daß bei ihm der 4, nicht der 3. Pereiopod der längste ist.

Der Cephalothorax ist breiter als-lang, auch ohne daß man die Seitenrandstacheln mitmißt. Nach hinten verschmälert er sich ziemlich erheblich. Im allgemeinen ist die Oberfläche ziemlich glatt und eben, von der Regio gastrica fällt die Oberfläche gegen die Stirn stark ab. Auf der Regio cardiaca, den Branchial- und protogastrischen Regionen ist je eine leichte Wölbung erkennbar (Taf. XXXI, Fig. I). Deutliche Granulationen bedecken die centralen Partien der Oberfläche; auf den Branchialregionen und in den Randgegenden ist die Körnelung sehr fein Die Regionen sind nicht durch Furchen voneinander abgegrenzt, aber trotzdem recht deutlich zu unterscheiden, da die Organe durch den Panzer durchschimmern. - Von der Regio epigastrica zieht sich eine feine Furche zur Mitte der Stirn.

Von den Seitenecken erstreckt sich je eine Querrölbung gegen die Regio mesogastrica. Von der Basis der 5. Pereiopoden ausgehend erstreckt sich ein WVulst schief nach vorn, etwa parallel zum Hinterseitenrand, um nach vorn auf der Branchialregion zu verstreichen.

Die Stirn ist lamellös, in der Mitte etwas nach unten vorgezogen, um mit dem Epistom in Verbindung zu treten. Sie ist mit vier Zähnen versehen, von denen die mittleren kleiner sind als die äußeren. Sie sind fein, spitz und nur durch einen engen Zwischenraum getrennt. Sie stehen etwas mehr nach unten als die äußeren Zähne, von denen sie durch einen weiteren Zwischenraum getrennt sind als der ist, welcher sie voneinander scheidet. Der Rand der Stirn ist in diesen Zwischenräumen nach innen konkav gekrümmt.

Die Orbiten sind weit, der obere Rand dünn, ohne deutliche Fissur; nur etwa in der Mitte sieht man eine undeutliche Spur einer solchen. Der untere Rand ist mit feinen Höckern bedeckt, der Orbitalzahn scharf und ziemlich groß.

Der Vorderseitenrand ist dünn vorgezogen, schwach bogenförmig und mit 5 Zähnen geschmückt, von denen der I., 3. und 5. in dieser Reihenfolge von wachsender Größe sind, während der 2. und 4. verschwindend klein sind (Taf. XXXI, Fig. I). Der I. bildet die äußere Orbitalecke, er ist dreieckig, spitz, abgeplattet, nach vorn und ein wenig nach außen gerichtet, der 2. ist 
rechts stumpfer und kïrzer als links, der 3 . ist beiderseits spitz, lang und stachelförmig; der 4. ganz kleine, folgt als spitzes Dörnchen in kurzem Abstand auf den 3. Ihn trennt ein crößerer Zwischenraum von dem 5. Dieser ist der größte von allen, steht stark nach vorn und außen, ist sehr spitz stachelförmig und sein Hinterrand geht mit einem sehr stumpfen Winkel in den Hinterseitenrand des Cephalothorax über. Der Hinterrand ist breit, in der Mitte leicht nach vorn konkav geschwungen. Die Pterygostomialregionen sind, mit bloßem Auge betrachtet, glatt, mit der Lupe erkennt man eine feine Granulierung. Das Basalglied der äußeren Antennen erreicht kaum die halbe Länge des Suborbitalstachels; es ist prismatisch und mit feinen Haaren bedeckt. Die Geißel ist rund, relativ dick und erreicht, zurückgeschlagen, etwa die Gegend des 4. Seitenrandzahnes. Das Basalglied der inneren Antennen ist sehr groß, ebenso die übrigen Teile derselben. Die äußeren Glieder können in einem schmalen Raume unter der lamellösen Stirn zurïckgeschlagen werden (vgl. Taf. XXXI, Fig. 2).

Die Augen sind groß, die Stiele dick, die Cornearegion ist mit zahlreichen kleinen Facetten bedeckt; die Färbung ist kräftig braun. Die Augen sind durch die 3 Stacheln an den Ecken der Orbita wohl geschützt. Das Mundfeld ist groß, der Rand vorn leistenartig mit einer deutlichen Fissur in der Nähe der vorderen Außenecke. Auf dem Gaumen verläuft eine Leiste bis zum Mundrand.

Die 2. Gnathopoden sind groß, die Haare am inneren Rand des Ischiognathen sind gelb und relativ kurz, der Merognath ist etwa fünfeckig, und unterhalb der Insertion des Carpognathen leicht vorgezogen (Taf. XXXI, Fig. 2). Der Exognath ist breit und an seiner vorderen Innenseite mit einem dreieckigen Vorsprung ausgestattet.

Die Scherenfüße sind mäßig groß und derjenige der rechten Seite nur um wenig größer, als derjenige der linken Seite (Taf. XXXI, Fig. I). Der Meropodit ist dreieckig prismatisch, kurz vor dem vorderen Ende der oberen Kante trägt er einen spitzen Zahn, der Carpopodit ist auf der oberen Fläche rauh von regelmäßigen Höckern; eine regelmäßige Reihe von solchen führt vom Hinterrand $z u$ der vorderen Innenecke; diese ist durch einen sehr langen, spitzen Stachel ausgezeichnet. Auch auf der äußeren Vorderecke sitzt ein Stachel, der aber kürzer und stumpfer ist. Die Schere ist ziemlich schwach; die Finger sind etwa ebensolang als die Palma. Obere und untere Kante sind stumpf. $\mathrm{Zu}$ der Mitte der Außenfläche der Palma zieht sich eine feine Kante hin. Die Schneiden sind mit breit dreieckigen, scharfen, abwechselnd größeren und kleineren Zähnen besetzt, welche sehr exakt zusammenschließen.

Die Schreitbeine sind lang, schlank und leicht komprimiert. Die 2. Pereiopoden sind die kürzesten, dann folgen die 5., dann die 3., während die 4 die längsten sind. Die Meropoditen zeigen am distalen Ende einen ganz undeutlichen Dorn (Taf. XXXI, Fig. I).

Die Daktylopoditen sind schlank, schmal, schwach, sensenförmig gekrümmt und ohne auffallende Skulptur. Sie sind seitlich komprimiert und enden in einer gelben, hornigen, scharfen Kralle.

Das mir vorliegende Exemplar ist ein junges o, dessen Abdomen noch nicht sehr verbreitert ist; die Pleopoden sind aber schon wohl entwickelt.

I $q$ juv., Station I 72 , nördlich von St. Paul und Neu-Amsterdam, 30 6,7 S. Br., $87^{\circ} 50,4^{\prime}$ O. L., in einer Tiefe von $2068 \mathrm{~m}$.

Deutsche Tiefsee-Lixpedition $1898-1899$. Bd. VI. 


\section{Catometopa.}

\section{Gattung Carcinoplax Milne-Edwards.}

I 850 Curtonotus de HAAN, Fauna japonica, Crust,, p. 20 (nomen praeoccup.).

1837 Carcinoplax Milne-Edwards, Hist. Nat. Crust., Vol. II, p. 60.

\section{Carcinoplax longimanus (DE HAAN).}

Taf. XXXV, Fig. I u. 2, Taf. XXXVI.

I850 Cancer (Curtonotus) longimanus DE HAAN, Fauna japonica, Crust., p. 50, Taf. VI, Fig. I.

I852 Carcinopla. longimanus (DE HAAN) MIrLNe-Edwards, Ann. Sci. nat. Zool. (3), Vol. XVIII, p. I64.

1894 Carcinoplax longimanus Ortaraxn, Zool. Jahrb. Syst., Vol. VII, p. 688.

I 900 Carcinoplax longimamis ALCock, Journ. As. Soc. Bengal, Vol. LXIX, Pt. 2, p. 303.

Trotzdem Alcock ausdrücklich das auffallende Wachstum der Scheren bei den ơ dieser Art auch für Exemplare aus indischen Gewåssern hervorhebt, konnte ich mich lange nicht entschließen, die mir vorliegenden Exemplare der „Valdivia“-Ausbeute für Angehörige dieser Art zu halten. Nachdem ich durch den genauen Vergleich mit einer ganzen Serie japanischer Exemplare, welche unser Münchner Museum besitzt, mich von der weitgehenden Uebereinstimmung in vielen wesentlichen Punkten überzeugt habe, halte ich es für angebracht, die Art genau zu beschreiben und vor allen Dingen die intereressanten Veränderungen der Formen und Proportionen während des Wachstums eingehend zu schildern. Denn die Veränderungen in den Proportionen des Cephalothorax, im Bau der Orbiten und in der Bildung der Scherenfüße des o sind so groß, daß man ohne weiteres darauf eine neue Species begründen würde, zumal die Dimensionen der jungen Tiere schon recht beträchtliche sind. Um ganz vorsichtig zu sein, unterscheide ich beide Formen als Subspecies der gleichen Art.

\section{Carcinoplax longimanus indicus n. sbsp. \\ Taf. XXXV, Fig. I u. 2.}

Die 4 von der "Valdivia“-Expedition mitgebrachten Exemplare sind etwa in gleichem Entwickelungsstadium, sie sind sämtlich junge Männchen. Das kleinste Exemplar hat einen querovalen Cephalothorax, dessen Länge sich zur Breite fast wie 4:5 verhält $(38 \mathrm{~mm}$ lang, $46 \mathrm{~mm}$ breit). Die Stirn ragt über die Peripherie des Cephalothorax und über die äußeren Orbitalecken weit vor (Taf. XXXV, Fig. I). Regio cardiaca, gastrica, hepatica und branchialis sind ziemlich deutlich erkennbar, obwohl nicht durch tiefe Furchen getrennt. Sonst ist die Oberfläche des Cephalothorax ziemlich glatt, abgesehen von einer ganz feinen Granulierung. Nur auf der Regio hepatica finden sich zwei Andeutungen von Höckern mit glatter Oberfläche.

Der Hauptunterschied gegenüber dem erwachsenen Tier zeigt sich am Cephalothorax in der Orbitalregion. Die Breite der Stirn ist I $2 \mathrm{~mm}$, das Verhältnis zur Breite des Cephalothorax ist $=2: 7,7$. Eine Einkerbung in der Mitte der Stirn ist kaum angedeutet.

Die Orbiten sind relativ klein, ihr Querdurchmesser ist $6,5 \mathrm{~mm}$. Breite der Stirn verhält sich also zur Breite der Orbita ungefähr $=2: \mathrm{I}$, beim erwachsenen Tier $=\mathrm{I}: \mathrm{I}$. Die Orbita ist nach hinten etwas schief nach unten gerichtet. Sie ist von einem erhabenen Rand, der fein gekörnelt ist, eingefaßt; Stacheln und Zähne sind jedoch keine vorhanden. Der Vorder- 
scitenrand ist (in der Sehne gemessen) fast ebenso lang wie der Hinterseitenrand. Er ist fein grekantet und zeigt drei Andeutungen von Zähnen oder besser Knoten, von denen der erste ctwa um den Durchmesser der Orbita von der äußeren Orbitaccke ent. fernt ist (Taf. XXXV, Fig. I).

Die Scherenfüße sind ungefähr ${ }_{2}^{1} / 2$ mal so lang wie der Cephalothorax. Sie sind etwas ungleich, indem der rechte etwas größere offenbar die Kampfschere darstellt, der linke kleinere die Freßschere.

Der rechte Scherenfuß mißt ca. Ioo $\mathrm{mm}$, und zwar entfallen davon auf die basalen Glieder einschließlich des Meropoditen $42 \mathrm{~mm}$, auf die Schere selbst $55 \mathrm{~mm}$ (am Unterrand gemessen). Der Meropodit ist prismatisch und hat an der oberen Kante, in $1 / 3$ der Lïnge Abstand vom distalen Ende, einen spitzen, aufrecht stehenden Stachel. Der Carpopodit hat am Innenrand 2 Zïhne, am Außenrand einen solchen. Auf den Innenflächen sind alle Glieder glatt, auf den Außenflächen mit Runzeln und feinen Körnern bedeckt; die Palma nur im oberen und proximalen Teil. Der Carpopodit mißt außen in der größten Ausdehnung 19 mm. Die Schere selbst ist kräftig, gedrungen, die Palma aufgetrieben; Ober- und Unterrand sind abgerundet. Die Finger sind kräftig, etwas abgeplattet und nach innen gebogen. Der bewegliche ist mit einigen kräftigen Zähnen versehen, zwischen denen kleinere stehen. Der unbewegliche Finger hat im distalen Teil 2 große Zähne; die Spitzen der beiden Finger sind scharf und bogig gekrümmt. Die Schneiden der Finger schließen nicht zusammen. Die linke Schere ist im allgemeinen ebenso grebaut, doch schlanker, die Palma weniger aufgetrieben. Die Finger sind weniger gekrümmt und am unbeweglichen besteht die Bezahnung aus kleineren gleichmäßigeren Zähnen, die Schneiden schließen daher gut zusammen. - Die Finger sind bei beiden Scheren tief schwarzbraun, die Spitzen sind gelblich-weiß und greifen übereinander. An der Innenseite der Palma ist zwar die Gegend an der Basis der Finger stark aufgetrieben, aber spiegelglatt und ohne Andeutung eines Höckers oder Zahnes.

Ich bemerke, daß von den 4 Exemplaren nur 2 die Verschiedenheit der Scheren zeigen; zwei haben ziemlich gleich gebaute Scheren, vom Typus der Freßschere.

Die Vasa deferentia sind als Samenröhren weit über die Basopoditen der 5. Pereiopoden hinaus verlängert; sie gehen durch eine Kerbe des Sternalrandes hindurch, diese Kerbe ist jedoch nach der Seite und hinten weit offen.

Das Abdomen ist im Bereich des 3. Segments am breitesten; letzteres berührt die Basopoditen der 5. Pereiopden. Es verschmälert sich im Bereich des 4. und 5., um im Bereich des 6. Segments wieder etwas breiter zu werden. Das 7. Segment ist gleichseitig dreieckig, mit gerundeter Spitze und konvexem proximialen Rand (Taf. XXXV, Fig. 2).

\section{Carcinoplax longimanus japonicus (DE H.).} Taf. XXXVI.

Die japanischen Exemplare der Münchener Sammlung sind alle älter und die Unterschicde gregenüber den indischen sind z. T. so groß, daß ich sie wenigstens zu einer besonderen Subspecies rechnen muß.

Das von DE HAAN abgebildete junge Männchen ist schon größer als unsere indischen Exemplare Die Schere zeigt schon den Typus der enwachsenen Form, wenn auch in viel 
kleineren Dimensionen. Vor allem sind dort die Leiste und der Höcker an der Innenseite der Schere schon deutlich ausgebildet; auch scheint der Vorderseitenrand des Cephalothorax schon dem des Erwachsenen zu entsprechen.

Bei dem größten $\delta$ des Münchener Museums ist der Cephalothorax stark in die Breite gezogen (Länge : Breite $=1: 1,4$ ). Die Oberfläche ist sehr stark gewölbt, vor allen Dingen sind die Hepatikalregionen aufgetrieben (vgl. Taf. XXXVI).

Die Stirn ist an den beiden Ecken in Zähne ausgezogen, zwischen diesen konkav kontouriert, mit einer kleinen Vorragung in der Mitte. Der Orbitaldurchmesser ist der Stirnbreite ungefähr gleich. Die Orbiten haben sich nämlich bis zu dem ersten Vorderrandzahn hin ausgedehnt; letzterer ist $z u$ einem ganz stattlichen Extraorbitalzahn geworden, welcher nicht sehr weit hinter dem Niveau der Stirn zurückbleibt. Die Augenstiele sind jedoch nicht dementsprechend gewachsen; auch die Höhlung, in welche sie eingelagert sind, reicht nicht ganz bis zu dem Extraorbitalzahn hin (vgl. Taf. XXXVI).

Die Hauptveränderungen haben die Scherenfüße erfahren. Sie sind zwar etwas ungleich, doch fällt das in Anbetracht ihrer Größe nicht sehr auf. Der rechte ist größer und hat eine schwach keulenförmige Kampfschere, die linke, Freßschere, ist schlanker, mehr prismatisch.

Der ganze rechte Scherenfuß mißt $260 \mathrm{~mm}$; er ist also fast 5 mal so lang als der Cephalothorax. Mehr als die Hälfte davon entfällt auf die Schere.

Der ganze Scherenfuß ist an der Basis des Meropoditen am dünnsten; von da an nimmt er bis zur Basis der Scherenfinger kontinuierlich an Dicke zu.

Der Meropodit ist dreikantig prismatisch; er zeigt eine leichte spiralige Drehung seiner Kanten, was offenbar zur Festigung des an sich zu dünnen Gebildes beiträgt. Der Stachel am oberen Rande steht nur mehr in einem Abstande von ca. 1/5 der Länge des Meropoditen von dessen distalem Ende entfernt. Der Carpopodit ist kräftig, er zeigt am äußeren Rande einen kleinen, höckerartigen, am inneren Rande einen etwas größeren, hakenförmig gebogenen Stachel.

Die rechte Hand hat eine dicke Palma von $100 \mathrm{~mm}$ Länge, die Finger messen $40 \mathrm{~mm}$ und sind seitlich abgeplattet. Die Palma ist oben und unten breit gerundet; auf der Mitte der Innenfläche läuft eine Kante, welche in einem kräftigen Zahn I 5 mm vor der Basis der Finger endet.

Der untere Kontur der Schere verläuft nicht ganz gerade, sondern im distalen Teil wellenförmig, indem im basalen Teil des unbeweglichen Fingers sich eine Ausbuchtung nach unten zeigt und die Spitze hakenförmig gebogen ist. Die Zähne der rechten Schere sind grob und die Schneiden schließen nicht vollkommen zusammen.

Die linke Schere ist viel schlanker; sie ist am Ober- und Unterrand kantiger; auch sind Kante und Zahn auf der Innenfläche viel kräftiger. Die Zähne auf den gut schließenden Schneiden sind kleiner und es wechselt regelmäßig ein etwas größerer mit einem etwas kleineren ab. Die hakenförmigen Fingerspitzen greifen den beiden Scheren übereinander, aber nicht mehr sehr stark. Die Farbe der Finger ist a uffallenderweise hellrosa.

Die Farbe der ganzen Tiere ist rosarot, mit bläulichem Schimmer, wie sie DE HAAN für das lebende Tier beschreibt.

Das einzige o unserer Sammlung zeigt, wie auch DE HAAN es abbildet einen viel mehr viereckigen Cephalothorax als die ơ. Die Scheren erinnern an den Typus der jungen Exemplare, doch sind sie schon viel weiter ausgebildet. Sie zeigen eine Kante auf der Innenseite der 
Palma und eine kräftige Höckerbildung an deren distalem Ende. Auch sind sie viel reicher skulpturiert.

Bei dem Exemplar ist die linke Schere die kräftigere, die rechte die schwächere; letzterc ist nach dem Typus einer Freßschere, erstere wie eine Kampfschere bezahnt. Bei beiden greifen die Fingerspitzen nicht übereinander. Die Finger sind rosa gefärbt. - Die weibliche Geschlechtsöfnung ist sehr groß und von weicher Haut umgeben, was nicht unbedingt auf eine bedeutende Größe der Eier schließen läßt, wie man aus dem Verhalten bei Geryion entnehmen kann.

Ich lasse die Maße einer Anzahl von Exemplaren folgen:

\begin{tabular}{|c|c|c|c|c|c|c|c|c|c|c|}
\hline & Cephalothoraxlänge & Breite & Stirn & Orbita & Scherenfuß total & Bas. his Meropodit. & Carp. & Schere & Palma & Finger \\
\hline x. $ð$ juv., Nicobaren & $38 \mathrm{~mm}$ & 46 & 12 & 6,5 & r. 100 & 42 & 19 & 59 & 32 & 27 \\
\hline 2. ठౌ Japan & $49 \quad 1$ & 65 & 14 & 12,5 & r. 218 & 92 & 29 & 120 & 80 & 40 \\
\hline 3. gr. ठे Japan & 55 " & 74 & 15 & 14,5 & r. 260 & 115 & 27 & 140 & 100 & 40 \\
\hline 4. 7 Japan & $4^{8} \quad$, & 62 & 12,5 & $\mathrm{I} 2,5$ & 1. Ino & $3^{8}$ & 21 & 59 & $4 r$ & 20 \\
\hline
\end{tabular}

$4 \delta^{\circ}$ juv., Station $208 \mathrm{im} \mathrm{S.} \mathrm{W.} \mathrm{von} \mathrm{Groß-Nicobar,} 6^{\circ} 54^{\circ} \mathrm{N} . \mathrm{Br}$., $93^{\circ} 28,8^{\prime} \mathrm{O}$. L., in einer Tiefe von $226 \mathrm{~m}$.

Verbreitung: Japan (DE HaAn): Sagamibai, Nagasaki (Ortannn), Fukuura (Museum München); Andamanen I $10 \mathrm{~m}$ (Alcock); Birma: Golf von Martaban roo m (Atcock).

\section{Carcinoplax longipes (WOOD-MASON).}

I88I Nectopanope longipes Woon-Masox, Ann. Mag. Nat. Hist., Ser. 6, Vol. VII, p. 262.

I 895 Nectopanope longipes ALOCK and Axdersox, Illust. Zool. Investigator Crust., Taf. XIV, Fig. 7.

1899 Carcinoplax longipes ALCock, Investigator Deep Sea Brachyura, p. 7r.

1900 Carcinoplax longipes Alcock, Journ. As. Soc. Bengal, Vol. LXIX, Pt. 2, p. 3.

Von dieser kleinen, zierlichen Form hat die „Valdivia"-Expedition ebenfalls in der Gegend der Nicobaren ein junges $q$ erbeutet. Der Beschreibung von Alcock habe ich nur wenig hinzuzufügen: Der Körper ist bei meinem Exemplar vollkommen fein filzig behaart, besonders die Unterseite und die Extremitäten. Die Scherenfüße sind nicht viel länger als der Cephalothorax. - Mein Exemplar mißt nur $7 \mathrm{~mm}$ in der Länge. Da auch das größte Exemplar Alcocks nicht mehr als $14 \mathrm{~mm}$ maß, so wäre es nicht ausgeschlossen, daß wir es mit einer Jugendform zu thun hätten, die sich bis zum Erwachsensein noch bedeutend verändern könnte; doch wage ich vorläufig nicht, sie mit $C$. longimana in engere Beziehung zu bringen.

I $q$ juv., Station 2 I0, im Süden von Groß-Nicobar, $6^{\circ} 53, I^{\circ} \mathrm{N} . \mathrm{Br}, 93^{\circ} 33,5^{\circ}$ O. I., in einer Tiefe von $752 \mathrm{~m}$.

Verbreitung: Andamanen 400-530 m, Travancoreküste $785 \mathrm{~m}$ (Alcock).

\section{Gattung Goneplax LeACH.}

1813-14 Goneplax Lexici, Edinb. Encycl., Vol. VII, p. 430. Art. Crustaceology.

I9O2 Goneplax Stebisis, in: South African Crustacea, Pt. 2, p. I5 (daselbst ausführlich Litteratur und Synonymic).

\section{Goneplax angulata (PENNANT).}

I777 Cancer angulatus Pexxanr, Brit. Zoology", Vol. IV, p. 7, Taf. V, Fig. 10.

18i3-It Goneplax angulata Leacir, a. a. O., S. 430. Ausführliche Litteraturangabe bei Stebisis am oben angeführten Ort, S. I6- I6. 
Ortatann hat für diese Gattung und Ommatocarcinus White eine eigene Familie Goncplacidae aufgestellt, Atcock betrachtet sie als Vertreter einer Unterfamilie. Maßgebend ist beiden Autoren die Vergrößerung der Augenstiele und die dadurch bedingte Verbreiterung des Cephalothorax in seinem vorderen Teil. Ich vermag dieser Erscheinung keine solche Bedeutung zuzuschreiben, halte vielmehr die Gattung für nächstverwandt mit Carcinoplax. Die Aehnlichkeit in der Bildung der Stirn und ihren Veränderungen während des Wachstums, in der großen Verschiedenheit der Scherenfüße bei $q$ und jungen $\delta$ einerseits und alten $\delta$ andererseits, die bis in kleine Details ähnliche Bildung der Scheren, der Bau des Abdomens u. s. w. sind so auffallend, daß die weite Trennung der Gattungen nicht angebracht ist. Formen wie Psopheticus verbinden die beiden Gruppen aufs engste.

Was weiter die Frage anlangt, ob Goneplax angulatus und G. rhomboides (FABricius) zu vereinigen sind oder ob sie zwei verschiedene Arten darstellen, so kann ich mich aus Mangel an Material darüber nicht aussprechen. Die Exemplare des Münchener Museums von G. Tromboides sind aber kaum von angulata zu unterscheiden. Es ist mir nicht bekannt, ob man auch junge Exemplare mit mangelndem hinteren Seitenrandstachel kennt; sonst wäre es wohl möglich, daß es sich um eine Alterserscheinung handelt, wie ja auch sonst häufig bei Krabben Stachelbildungen mit dem Alter verschwinden. Ich bin jedenfalls geneigt, beide Formen zu einer Art zu vereinigen, wie dies schon zahlreiche Autoren vorgeschlagen haben.

Zahlreiche juv., Station Ioo, Francisbucht, $34^{\circ} 8,9^{\prime} \mathrm{S} . \mathrm{Br}, 24^{0} 59,3^{\prime}$ O. L.

2 juv., Station IOI, Algoabucht, $33^{\circ} 50,5^{\prime} \mathrm{S}$. Br., $25^{\circ} 4^{8}, 8^{\circ} \mathrm{O}$. L., in einer Tiefe von $40 \mathrm{~cm}$.

Zahlreiche juv., Station 107, Agulhasbank, $35^{\circ} 21^{\prime} \mathrm{S} . \mathrm{Br}, 20^{\circ} 22,4^{\prime} \mathrm{O}$. L., in einer Tiefe von II $7 \mathrm{~m}$.

Verbreitung: Atlantischer Ocean bis $618 \mathrm{~m}$ Tiefe (Milne-Edwards und Bouvier): Englische Küste (BELL): Kanal, Golf von Biskaya (Milne-Edwards); Golf von Cadix (M.-Edw. und Bouv.) bis zur afrikanischen Küste; Mittelmeer (M.-Edw., Heller, Carus); Adria (Heller).

Südafrika: Cap St. Blaize (Stebbrng).

Indischer Ocean: Persischer Golf (?) (ALcock).

\section{Gattung Psopheticus WoOd-Mason.}

I890-9I Wood-Mason, Admin. Rep. Marine Survey India, p. 20 (nur der Name).

1899 ALcock, Investigator Deep Sea Brachyura, p. 72.

I900 Alcock, Journ. As. Soc. Bengal, Vol. LXIX, 2, p. 308.

\section{Psopheticus stridulans WOOD-MASON.} Taf. XXX, Fig. 4.

I 892 Psopheticus stridulans Wood-Mason, Illustrations of the Zoology of the Investigator Crustacea, Taf. V, Fig. I. I894 Psopheticus stridulans Alcock, Ann. Mag. Nat. Hist., Ser. 6, Vol. XIII, p. 402.

I899 Psopheticus stridulans ALcock, Investigator Deep Sea Brachyura, p. 73.

1900 Psopheticus stridulans ALCock, Joum. As. Soc. Bengal, Vol. LXIX, 2, p. 309.

Alcock hat schon hervorgehoben, daß diese Form Carcinopiax sehr nahe steht. Ich habe den Eindruck, als bestehe die Familie Goneplacidae DANA (wie Alcock sie definiert) zur Zeit aus viel zu vielen artenarmen Gattungen; eine Revision an der Hand genügenden Materials würde wohl die Zahl der Gattungen mindestens auf die Hälfte heruntersetzen. 
Vielleicht ist bisher das alte of von Ps. stridulans noch unbekannt; die Scheren sind auffallend ähnlich denjenigen der jungen of von Carcinoplax und Goneplax. Vielleicht werden sic im Alter auch bedeutend verlängert.

Bemerkenswert ist, daß sie auch hier, wie bei den meisten Carcinoplacidae, dimorph sind. Die rechte (Kampfschere) ist größer; die Finger klaffen an der Basis weit auseinander, da der bewegliche stark gekrümmt ist. Beide Finger zeigen nur kurz vor dem distalen Ende einige Zühne.

Die männliche Geschlechtsöffnung befindet sich in einer Kerbe des hinteren Sternalrandes, ganz analog dem Verhalten bei den verwandten Formen.

Das größere ơ ist viel größer als Alcock’s größtes Exemplar; ich füge daher die Maße bei:

$\begin{array}{lc}\text { Länge des Cephalothorax } & 62 \mathrm{~mm} \\ \text { Breite des Cephalothorax } & 29 " \\ \text { Breite der Stirn } & 8,5 " \\ \text { Breite der Orbiten } & 8, \\ \text { Länge des rechten Scherenfußes } & 62 " \\ \text { Länge der rechten Schere } & 34 " \\ \text { Länge der rechten Palma } & 22 " \\ \text { Länge der Finger } & 12,\end{array}$

$2 \delta^{\circ}$, Station 208, im SIV. von Groß-Nicobar, $6^{\circ} 54^{\prime} \mathrm{N} . \mathrm{Br}, 93^{\circ} 38,8^{\prime} \mathrm{O}$. L., in einer Tiefe von $296 \mathrm{~m}$.

Verbreitung: Bisher ausschließlich im Andamanenmeer 315-785 $\mathrm{m}$ Tiefe (WoodMLSON, ALCOCK).

\section{Gattung Pilumnoplax StinPson.}

I 858 Pilumnoplax Stimpson, Proc. Ac. Nat. Sci., Philadelphia, p. 93.

\section{Pilumnoplax heterochir (STUDER).}

I882 Pilummes heterochir StUder, Abhandl. K. Ak. Wissensch. Berlin, Abh. II, S. I I, Taf. I, Fig. 3.

I880 Pseudorhombila (Pihmnoplax) normanni MIIERS, Narrat. Chall. Exped., Vol. I, I't. 2, p. 587.

1886 Pilumnoplax heterochir (ST.) MIIERS, Challenger Brachyura, p. 227, Taf. XIX, Fig. I.

Die Funde der „Valdivia“-Expedition zeigen, daß diese interessante Form eine ziemlich ausgedehnte subantarktische Verbreitung besitzt. - Auch die ganz kleinen jungen Exemplare sind deutlich als zu der Art gehörig zu identifizieren; sie weichen nur darin $a b$, daß sie länger sind im Verhältnis zur Breite, daß die Meropoditen der Scherenfüße relativ etwas länger sind, dagegen die Oberflächenskulptur des Cephalothorax kaum erkennbar ist.

Ein großes o von Station 103 zeigt statt der sonst regelmäßig ganz dunkelbraunen Finger solche, welche weißlich, heller als die übrige Hand sind.

I o Station $103 \mathrm{im}$ Agulhasstrom, $35^{\circ}$ 10,5 $5^{\prime} \mathrm{S}$. Br., $23^{\circ} 2^{\prime} \mathrm{O}$. L., in einer Tiefe von $500 \mathrm{~m}$.

I großes $\delta$ ohne Extremitäten, Station I04, Agulhasbank.

I q juv., Station 104, Agulhasbank, $35^{\circ} 16,5^{\prime} \mathrm{S} . \mathrm{Br}, 22^{\circ} 26,7^{\prime}$ O. L., in einer Tiefe von $155 \mathrm{~m}$. 
I $\delta^{*} 4$ juv., Station II 3 , Cap der guten Hoffnung, $34^{\circ} 33,3^{\prime} \mathrm{S} . \mathrm{Br}$, I $8^{\circ} 21,2^{\prime} \mathrm{O}$. L., in einer Tiefe von 3 I $8 \mathrm{~m}$.

J 2 juv., Station I65, St. Paul, $38^{\circ} 40^{\prime} \mathrm{S}$. Br., $77^{\circ} 38,6^{\prime} \mathrm{O}$. L., in einer Tiefe von $672 \mathrm{~m}$.

Io juv., Station 167 , Neu-Amsterdam, $37^{\circ} 47^{\circ} \mathrm{S}$. Br., $77^{\circ} 33,7^{\circ} \mathrm{O}$. L., in einer Tiefe von $496 \mathrm{~m}$.

Verbreitung: Nightingale Ins. (Tristan da Cunha, I 85 m Tiefe (Mrers: „Challenger"), Cap der guten Hoffnung, Agulhasbank (Studer: Gazelle; Miers: „Challenger").

\section{Pilumnoplax americana RATHBUN.}

Taf. XXYV, Fig. 3 u. 4.

I898 Pilumnoplax americanus Mary J. Rathbun, Bull. Lab. Nat. Hist. Iowa, p. 283, Taf, VII, Fig. I u. 2.

1899 Pilunnoplax sinclairi Alcock, Investigator Deep Sea Brachyura, p. 74, Taf. III, Fig. I.

I900 Pilimnoplax americana Rathbun, Alcock, Journ. As. Soc. Bengal, Vol. LXIX, Pt. 2, p. 3 I I.

Nachdem ALCock die Uebereinstimmung der indischen Form mit der ostamerikanischen nachgewiesen hat, ist auch für Pilumnoplax in Erwägung zu ziehen, ob nicht eine Anzahl bisher scharf unterschiedener Arten sich als Varietäten einer weit verbreiteten Form betrachten lassen. Wie Alcock schon hervorgehoben hat, steht $P$. americana dem $P$. heterochir SIUdER sehr nahe und es sind auch sehr enge Beziehungen zu $P$. abyssicola Miers vorhanden.

Das mir vorliegende Exemplar fasse ich als das nach Aicock bisher unbekannte of von Pihmmoplax americana auf (die Arbeit von Miss Rathbun war mir leider nicht zugänglich). Es weicht allerdings in einigen Punkten von der Beschreibung Arcocks ab. Der Cephalothorax ist I $1,5 \mathrm{~mm}$ lang und $15 \mathrm{~mm}$ breit, nach Alcock beim o $13 \mathrm{~mm}$ lang und $16 \mathrm{~mm}$ breit. Der Stirnrand ist nicht so auffallend viereckig abgeschnitten.

Nur die linke Schere ist am oberen Rand stark granuliert. Die rechte größere Schere ist glatt. Das 4. Pereiopodenpaar ist $35 \mathrm{~mm}$ lang, also mehr als $21 / 2 \mathrm{mal}$ so lang als der Cephalothorax, sogar mehr als 3 mal so lang. Die Farbe ist im Spiritus blaß orange, die Finger sind lebhaft hellbraun.

Es muß aber hervorgehoben werden, daß das Tier trotz seines männlichen Abdomens weibliche Pleopoden besitzt. Es ist also nicht ganz ausgeschlossen, daß es auch im sonstigen Bau nicht ganz normal ist.

Von $P$. heterochir ist es unterschieden:

I) durch die zweilappige Form des I. Vorderseitenrandzahnes;

2) durch das Vorhandensein des Hinterseitenrandzähnchens; allerdings findet sich dasselbe bei vielen Exemplaren von $P$. heterochir angedeutet, bei manchen sogar ziemlich deutlich;

3) durch die glatte Oberfläche des Cephalothorax;

4) durch die zarteren Scherenfüße;

5) durch den an den Seiten weniger eckig abgeschnittenen Stirnrand;

6) durch die Länge der Beine.

Trotzdem ist die Aehnlichkeit eine unverkennbare.

I o Station 202, südlich von Bangkam im Nias-Nordkanal, Westküste von Sumatra, $\mathrm{I}^{0} 48, \mathrm{I}^{\circ} \mathrm{N} . \mathrm{Br} ., 97^{\circ} 6^{\circ} \mathrm{O}$. L., in einer Tiefe von $14 \mathrm{I} \mathrm{m}$. 
Verbreitung: Längs der $A$ tlantischen Küste von Nordamerika (Florida und Geormia) ca. 370-800 m Tiefe (Ritnisux); Ostindische Westküste: Travancorekiuste, in einer Tiefe von $775 \mathrm{~m}$.

Bemerkenswert ist demgegenüber die geringe 'Tiefe, in welcher das Exemplar der "Valdivia“Expedition grefunden wurde.

\section{Gattung Litocheira KINAHAN.}

1858 Lifocheira Kinaman, Journ. Roy: Dublin Soc., Vol. I, p. I2 I.

1886 Litochcira Mrers, Challenger Brachyura, p. 231.

\section{Lilocheira Kingslevi (Miers).}

1880 Braclignapsus Kimgsleyi Miras, Narrat. Challenger Exped., Vol. I, Pt. 2, p. 587

1886 Lilocheira Kingsleyi Miners, Challenger Brachyura, p. 532.

Kaum einen halben Breitengrad von der Stelle entfernt, an welcher diese Art von der „Challenger"-Expedition entdeckt worden war, wurde sie von der "Valdivia"-Expedition wieder aufgefunden. Der genauen Beschreibung und guten Abbildung von Mrers habe ich an dieser Stelle nichts Wesentliches hinzuzufügen.

Im Gegrensatz zu den Exemplaren von MIERs sind die meinigen im Spiritus vollkommen blaß gelblich-weiß geworden.

7 Exemplare ( 4 \%, 2 q mit Eiern, I q juv.) Station I 3 , bei dem Kap der guten Hoffnung, $34^{\circ} 33,8^{\prime} \mathrm{S}$. Br., I $8^{\circ} 21,2^{\prime} \mathrm{O}$. L., in einer Tiefe von $318 \mathrm{~m}$.

Verbreitung: Kapregion („Challenger“" $35^{\circ} 4^{\prime} \mathrm{S} . \mathrm{Br}, 18^{0} 37^{\prime}$ O. L., in einer 'Tiefe von $275 \mathrm{~m})$.

\section{Gattung Camatopsis Alcock.}

1899 Camalopsis, Investigator Deep Sea Brachyura, p. 75.

\section{Camalopsis rubida Alcock \& Anderson.}

1899 Camatopsis mbida Alcock \& Avdersox, Ann. Mag. N. Hist., Ser. 7, Vol. III, Jan. 1809, I. I3.

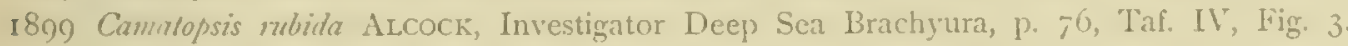

1900 Camatopsis mbida ALCOCK, Journ. As. Soc. Bengal, Vol. LXIX, Pt. 2, p. 320.

Die "Valdivia"-Expedition erbeutete von dieser interessanten Form leider nur ein verletztes $q$ etwas südlich von der Regrion, in welcher der "Investigator" sie aufgefunden hatte. Das junge o zeigt den Umriß des Cephalothorax etwas mehr eingeschnitten, als die Abbildung des alten \& bei Alcock (1899) es erkennen läßt. Es ist die Stirn durch leichte Kerben in 4 Lappen eingeteilt, der obere Orbitalrand ist nach hinten ausgreschnitten, und der an ihn angrenzende, in den Seitenrand übergehende Teil des Vorderrandes ist noch einmal nach vorn vorgezogen. Der Seitenrand ist kantig.

I $\delta$ juv. Station 203, südlich von Bangkam (TVestkiiste von Sumatra), I" 47, I" N. Br., $96^{\circ} 58,7^{\circ}$ O. L. in einer Tiefe von $660 \mathrm{~m}$.

Verbreit ung: Andamanensce, $355 \mathrm{~m}$ (Alcock).

Deutsche Tiefsce-Expedition 1898-1899. Bd. V1. 


\section{Gattung Hexaplax n. g.}

Diese neue Gattung, welche mit ihren meisten Charakteren recht gut in die Unterfamilie Hexapodinae der Gonoplacidae DANA paßt, ist durch sehr große Augen ausgezeichnet. Infolgedessen muß in der Diagnose der Unterfamilie, welche bisher nur Arten mit kleinen Augen und kleinen Orbiten enthält (vgl. die Diagnose bei Alcocr, Journ. As. Soc. Bengal, Vol. LXIX, Pt. 2, I900, p. 287), der Passus über die Augen verändert werden. Er muß lauten: Augen und Orbiten klein oder sehr groß. Sonst wäre man genötigt, für die eine Art und Gattung eine neue Unterfamilie aufzustellen.

In der äußeren Erscheinung erinnert die Gattung an Hexapus DE HAAN, doch bilden Stirn und Seitenrand eine ziemlich regelmäßige Kreisbogenlinie, zu welcher der vollkommen gerade Hinterrand die Sehne darstellt. Auch sind die Schreitbeine schlanker und länger; es sind nur 3 Paare vorhanden.

Der Cephalothorax ist viel breiter als lang; die Seitenränder verlaufen im hinteren Teil fast parallel; die Stirn ist ziemlich schmal und nur wenig nach unten geneigt.

Die Orbiten sind sehr groß, in der Form den keulen- oder hammerförmigen Augenstielen entsprechend. Sie kommunizieren nicht mit den Höhlen der inneren Antennen, vielmehr ist die Orbitalspalte durch das 2. Glied der äußeren Antennen geschlossen. Die Augen sind sehr groß, hammerförmig.

Das Epistom ist deutlich; die Mundöfnung hat stark nach vorn konvergierende Seiten. Die Ischiopoditen der 2. Gnathopoden sind groß, deutlich vom Meropoditen getrennt; letztere sind viereckig, der Palpus an ihrer vorderen Innenecke inseriert. Der Palpus ist mäßig lang und füllt die Mundspalte nur im Bereich der Meropoditen aus, während sie zwischen den Ischiopoditen weit klafft. Der Exognath ist nicht verborgen; er ist schlank und mit langer Geißel versehen.

Die Scherenfüße sind kräftig, bei dem $\delta$ etwas ungleich.

A $u$ Ber ihnen sind nur 3 Paare von Pereiopoden vorhanden; das 4. Paar (5. Pereiopodenpar) fehlt vollkommen. Ebenso fehlt das 5. Segment des Sternums vollkommen.

Das Sternum ist außerordentlich breit, das Abdomen ist sehr schmal und bedeckt eine schmale Rinne in der Mitte des Sternums; an deren Seitentvänden münden auf dem 4. Sternalsegment die märnlichen Geschlechtsöffnungen. Mit diesen hängen die Geschlechtsfüße des I. Paares innig zusammen, so daß sie beim Ablösen des Abdomens am Sternum hängen bleiben.

\section{Hexaplax megalops n. sp.}

Taf. XXXI, Fig. 3 u. 4; Taf. L, Fig 7 .

Aehnelt offenbar in der äußeren Erscheinung dem Lambdophalhus sexpes ALcock sehr (Alcock, Journ. As. Soc. Bengal, Vol. LXIX, Pt. 2, I900, p. 330), doch ist er von diesem durch die Orbitalregion in auffallender Weise unterschieden. Auch ist die Form des I. Geschlechtsfußpaares eine andere.

Die Form des Cephalothorax erinnert etwas an ein Rechteck, dessen Vorderecken stark abgerundet sind. Die Länge des Cephalothorax beträgt $10 \mathrm{~mm}$, die Breite $15 \mathrm{~mm}$, also das 
Verhältnis $2: 3$. Die Oberfläche ist nach vorn etwas mehr gewölbt als nach hinten, nach den Seiten hin jedoch fast ganz flach.

Regionen lassen sich keine unterscheiden; die Oberfläche ist fast ganz glath, kaum sind mit der Lupe feinste Granulationen erkennbar. An den Seiten des Cephalothorax und auf der Innenseite der Scherenfüße findet sich lange, dünne Behaarung. Der Vorderseitenrand verläuft von den Orbiten zunächst bogrenförmig nach außen, dann biegt er plötzlich nach hinten um, und die Seitenränder verlaufen fast parallel, nur leicht konvergierend zum ganz gerade alogeschnittenen Hinterrand (Taf. XXXI, Fig. 3). Die Kante ist ganz fein gesägt.

Die Stirn ist mittelmäßig; sie ist durch die Orbiten von den seiten stark cingreengt, so daß ihr Umriß etwa amboßförmig erscheint. In der Mitte des fast geraden Vorderrandes ist sie ein wenig eingekerbt.

Die Orbiten sind sehr groß; ihr Durchmesser ist größer als die Breite der Stirn. Ihr Unterrand ist glatt bogenförmig, der obere ist entsprechend der Form der Augenstiele in der Mitte mit einem in die Orbita weit vorragenden Lappen versehen. Zähne und Stacheln fehlen, nur eine feine Körnelung faßt den Rand ein, und einwärts von diesem steht eine Reihe wimperartiger Haare. Nähere Beschreibung der Augen S. Abschnitt II, vgl. auch Taf. L, Fig. 7.

Die Höhle der inneren Antennen ist mit der Orbita durch eine schmale Orbitaspalte im Zusammenhang; diese Spalte ist aber durch das 2. Glied der äußeren Antennen geschlossen. Die Höhlen der inneren Antennen sind voneinander durch ein ganz schmales Septum getrennt. Die inneren Antennen selbst haben ein sehr großes, aufgetriebenes Basalglied und lange und diüne 2. und 3. Glieder. Die äußeren Antennen haben 3 dünne, cylindrische Grundglieder und eine relativ dicke und lange Geißel, wie viele andere Carcinoplaciden.

Das Epistom ist schmal, aber vollkommen ausgebildet; die Seiten der Mundöffnung konvergieren nach vorn ziemlich stark bogenförmig (Taf. XXXI, Fig. 4).

Die vordere Mundkante setzt sich jederseits in eine Bildung fort, welche aus zahlreichen schiefgestellten, kleinen Leistchen besteht und schief bis über die Basis des Scherenfußes hinzieht; sie gleicht vollkommen den Stimmorganen bei zahlreichen Krabben, z. B. den Ocypoden. Sie scheint auch als Stimmorgan funktionieren zu können; denn an der Innenseite der Palma der Hand entspricht ihr jederseits eine dünne Leiste, welche, über die Leistchen gerieben, ein schnarrendes Geräusch hervorbringt.

Von der hinteren Mundecke zieht sich über der Basis des ScherenfuRes bis zum I. Schreitbeinpaar bogenförmig die Eingangsöffnung in die Kiemenhöhle hin.

Die Scherenfüße sind bei dem of etwas ungleich und werden es wohl bei ganz erwachsenen $\delta$ noch mehr sein. Der Meropodit des massiveren rechten Scherenfußes ist dreikantig, spiralig gredreht; die Kanten sind fein gresägt.

Die Schere ist gedrungen gebaut, die Höhe beträgt \%/5 der Länge; auf der Aul3enseite ist die Palma fein granuliert, in der Mitte ist eine Längslinie erkennbar. Die Finger sind so lang, wie die Schere hoch; die obere Seite des beweglichen Fingers ist zweikantig abgeplattet. Die Schneiden an der rechten Hand klaffen an der Basis und sind mit groben Zähnen bestanden, an der linken Hand sind feinere Zühne vorhanden, und die Schneiden passen gut zusammen. Die Finger sind längsgefurcht und weiß gefärbt. 
Die Beine sind lang und schlank; das längste 3. Pereiopodenpaar ist 3 mal so lang wie der Cephalothorax (Taf. XXXI, Fig. 4). Sämtliche 3 Paare sind dorsoventral abgeplattet. Die Oberfläche ist fein gekörnelt, die vordere Kante der Meropoditen ist mit Sägezähnen versehen, diejenige der Carpopoditen ebenfalls, aber mit viel feineren. Die Daktylopoditen sind lang, sehr spitz und nur ganz wenig nach innen gekrümmt.

Das Sternum ist sehr breit und ganz glatt. Das männliche Abdomen ist sehr schmal; es ist schmal-dreieckig mit gewelltem Rand, das letzte Segment hat ein abgestumpftes Ende (Taf. XXXI, Fig. 4 unten). Es sind 7 Segmente erkennbar; doch bewegen sich das 3., 4 . und 5 . gemeinsam, und ist ihre Trennung etwas undeutlich.

Die I. Geschlechtsfüße reichen bis in die Mitte des I. Sternalsegmentes und sind einfach griffelförmig gestaltet. Die $\delta$ Genitalöffnungen münden in der schmalen Rinne, welche das Abdomen bedeckt, an den Innenwänden nahe dem Hinterrand; mit ihrer Umgebung hängt die Basis der 2. Geschlechtsfüße eng zusammen, so daß letztere bei der Ablösung des Abdomens am Sternum hängen bleiben und die Geschlechtsöffnung selbst schwer mit Sicherheit zu erkennen ist. I of Station I99, Nias-Südkanal, $0^{0}$ I 5, $5^{\prime}$ N. Br., $98^{\circ} 4^{\prime}$ O. L., in einer Tiefe von $470 \mathrm{~m}$.

\section{Gattung Pinnotheres Latreille.}

Die Gattung Pinnotheres ist in den letzten Jahrzehnten zu einer der sehr artenreichen Gattungen herangewachsen. Dabei ist es schwer zu entscheiden, ob nur unvollkommene Kenntnis der Formen und ihrer Variabilität diesen Artenreichtum vortäuscht oder ob er in der Natur thatsächlich begründet ist; es wäre dies an sich nicht unwahrscheinlich, wenn wir bedenken, daß Parasiten und Commensalen aus Gattungen, welche bei vielen Wirten vorkommen, diesen entsprechend sehr häufig auch viele Arten aufweisen. Nach meiner Ansicht spielt letzterer Umstand wohl eine wichtige Rolle, aber noch mehr mag mitwirken, daß viele der aufgestellten Arten nur auf ein oder wenige Exemplare begründet sind. Wenn ich daher in nachfolgendem ein Exemplar wohl beschreibe, ihm aber keinen Namen gebe, so hat dies seinen Grund darin, daß ich es vermeiden will, die Synonymie in dieser Gattung unnötig zu vermehren. Ich hoffe, daß auf Grund der Beschreibung und Abbildung jemand, dem ausreichendes Material von anderen Arten vorliegrt, sie leicht wird identifizieren können. Sollte es dann notwendig sein, so ist ein Name leicht gegeben.

\section{Pinnotheres sp. \\ Taf. XXXVII, Fig. 3 u. 4. Textfig. Io.}

In der Algoabai wurde von der "Valdivia"-Expedition ein $f$ einer Pinnotheres-Art gefunden, welche von der einzigen, bisher für die Region angegebenen Art $P$. tridacnae Rüpp. in wesentlichen Punkten abweicht.

Der Cephalothorax ist breiter als lang ( $3,5 \mathrm{~mm}$ breit, I I,5 lang), statt länger als breit; die Oberseite geht nicht ganz glatt und rund in die Seitenwände über, sondern es ist eine ziemlich deutliche Kante vorhanden, welche die Cephalothoraxoberfläche einfaßt. Die Stirn, welche nur circa $2 \mathrm{~mm}$ breit ist, ist etwas vorgezogen und in der Nitte leicht eingekerbt. 
Die Schere ist kräftig, $8 \mathrm{~mm}$ lang, $3 \mathrm{~mm}$ hoch, der bewegliche Finger $3 \mathrm{~mm}$ lang, der unbewegliche $2 \mathrm{~mm}$. Auf den Schneiden der Finger findet sich nur je ein Zahn.

Die Pereiopoden sind ebenfalls ziemlich kräftig; sie zeigen an den Propoditen unten nur einen ganz schwachen Haarsaum.

Der Daktylopodit des 2. Gnathopoden ist nicht einmal hall) so breit als der Propodit; er überragt letzteren um ein geringres (s. Textfigr. 10).

Das Abdomen des $q$ besteht aus 7 Segmenten, welche alle ziemlich lang sind. Die Eier sind sehr klein.

I \& Station Iorb, Algoabai, ca. $40 \mathrm{~m}$ Tiefe (?). Wirt unbekannt.

\section{Pinnolheres villosissimus n. $\mathrm{sp}$. Taf. xxxvil, Fig. 6 u. 7 . Textfig. II,}

Obwohl von dieser Art mir ebenfalls nur ein cinziges q vorliegt, glaube ich doch die Art als neu beschreiben zu können, da das Aussehen von allen mir bekannten Formen erheblich abweicht und zudem Fundort und Wirt genau festgrestellt sind.

Die Art ist auffallend durch die lange, zottige Behat arung des Cephalothorax und der Beine, welche ihr eine grewisse Aehnlichkeit mit manchen Arten der Gattung Pilum-

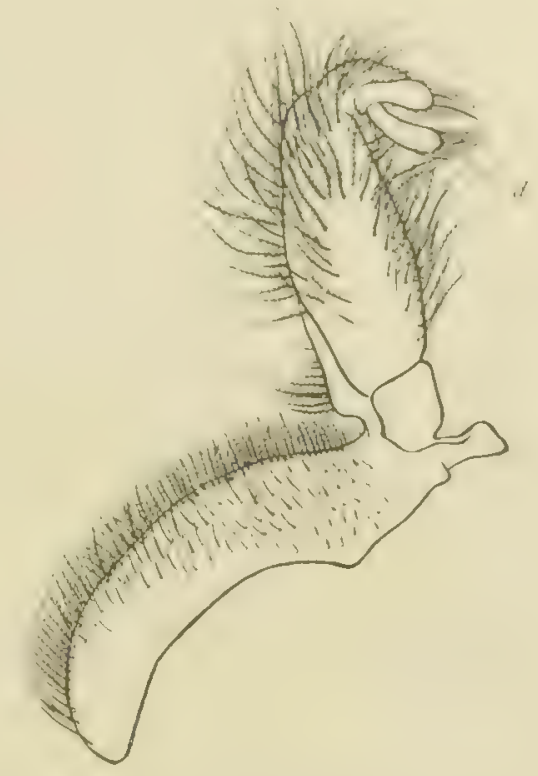

liig. 10. Zweiter Gnathopod der linken Seite von Pthnotheres sp. d Daktylopodit. mus verleiht. Der Cephalothorax ist queroval, indem die Länge

$7 \mathrm{~mm}$, die Breite $8 \mathrm{~mm}$ beträgt. Die Stirn ist nur $2 \mathrm{~mm}$ breit, ein wenig vorgezogen und nach unten geneigt.

Die zottige Behaaruug bedeckt vor allem den vorderen Teil der Cephalothoraxoberfläche die Seitenwände sind fast frei von den langren gefiederten Haaren und nur mit kurzem sammetartigen Haarkleid bedeckt. An den Seitenkanten entlang ziehen zwei nach hinten konvergierende, besonders auffallende Streifen der langen Haare.

Furchen oder Unebenheiten der Oberfläche sind keine zı erkennen. Der Vorderrand ist bogenförmig, die Seitenränder nach hinten etwas konvergierend, der Hinterrand ziemlich geradlinigy (Taf. XXXVII, Figg 6).

Die Augen sind wohlausgebildet, mit relativ großer, halbkugeliger, dunkelbraun pigmentierter Cornea. Die 2. Gnathopoden sind ganz mit den langen Fiederhaaren bedeckt; der verwachsene Ischio- und Meropodit sind nach innen mit einer lamellenartigen Verbreiterung versehen. Der Carpopodit ist kleiner als der Propodit; letzterer ist mehr als doppelt so breit als der an seiner Basis inserierte, schmale, parallelrandige Daktylopodit, dessen stumpf abgerundete Spitze die seinige ïberragt (s. 'lextfig. I I).

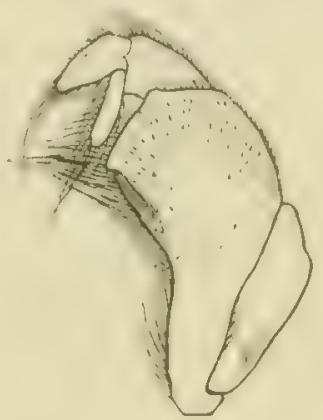

liig. II. Pimnotheres zillosissimus n. sp. Zweiter Gnathopod der linken Seite von hinten gesehen.

Die Scherenfüße sind mäßig groß (Lüinge der rechten Schere $4,5 \mathrm{~mm}$,

Höhe ca. I,5 mm Länge der Finger $1,5 \mathrm{~mm}$ ); sie sind gäinzlich mit zottigen Haaren bedeckt. Die Schneiden der Finger sind vollständig glatt, schließen vollstïndig zusammen und sind 
scharf messerschneidenförmig. Die Innenseite der Scherenfüße ist weniger lang behaart als die Außenseite.

Die Schreitbeine sind sämtlich kurz, dick, gedrungen und mit den langen zottigen Haaren mit Ausnahme der Daktylopoditen bedeckt; das 2. und 5. Pereiopodenpaar ist kürzer als die beiden mittleren, welche etwa gleich lang sind. Die Daktylopoditen sind kurz, dick, etwas gekrümmt und mit haarscharfer Endklaue versehen.

Das Abdomen des $q$ ist dünn, durchscheinend, besteht aus 7 freien Gliedern. Es ist auf der Oberfläche nur mit ganz kurzem Filz bedeckt, an den Rändern zottig behaart.

Die Eier des kleinen Tieres sind auffallend groß, ca. I mm Durchmesser.

I $q$ frei in der Kloake der Holothurie Muelleria lecanora JäGER von Prof. LuDwIG gefunden; Herkunft der letzteren: Emmahafen bei Padang.

\section{Gattung Ocypoda Fabricius.}

Litteratur s. Ortanan, Carcinologische Studien, in: Zool. Jahrb., Syst., Bd. X, I897, S. 359.

\section{Ocypoda Kuhli DE HAAN.}

I835 Ocypoda Kuhli de HAAn, Fauna japonica, Crust., Dec. 2, p. 58.

I880 Ocypoda Ryderi Kingsley, Proc. Acad. Philadelphia, I880, p. I 53.

I 897 Weitere Litteratur siehe Ortmann, a. a. O. S. 364.

Die Art, welche von DE MAN schon für das benachbarte Atjeh angegeben ist, wurde von der "Valdivia"-Expedition in 3 jugendlichen Exemplaren auf $\mathrm{Pulo}$ Weh, einem Inselchen an der NW.-Küste von Sumatra gefunden.

Verbreitung: Kapland: Port Elizabeth (Ortmann), Natal (Kingslev); Kilwa (Ortmann); Dar-es-Salaam (Ortmann); Sansibar (Pfeffer); Atjeh (de Man); Marlagaskar (Miers); Java (de MAN); Westaustralien: Sharkbucht (Miers); Thursday Island (Mifers); Neue Hebriden (Miers); Japan (Mitrs); Sandwich-Inseln (MIERs).

\section{Ocypoda ceratophthalma (PALLAS).}

I772 Cancer ceratophthalmus Paldas, Specilegia, p. 83. Taf. V, Pig. 17.

1790 Cancer cursor Herbst, Krabben und Krebse, Bd. I, Taf. I, Fig. 8 u. 9.

1798 Ocypoda ceratophthalna Fabricius, Suppl. Entom. Syst., p. 347

I835 O. cordimana DE HAan (nec Desmarest), in: Fauna japonica, Crust., Dec. 2, p. 87, Taf. XV, Fig. 4.

I 837 O. brericomis Milne-Edwards, Hist. Nat. Crust., Vol. II, p. 48.

I852 O. Unillei Milne-Edivards (nec Guérin), in: Ann. Sci. Nat., Zool., Ser. 3, Vol. XVIII, p. IfI.

I 865 O. macleayana Hess, Decapodenkrebse Ost-Australiens, p. i7, Taf. VI, Fig. 8.

1880 O. Fabricii Kingsley, in: Proc. Ac. N. Sci. Philadelphia, p. I 82.

I 897 O. ceratophthalma (Palt.) Ortmann, Zool. Jahrb. Syst., Bd. X, S. $36+$ (daselbst noch zahlr. ältere Litteratur).

1900 O. ceralophthalma (P.) ALcock, Journ. As. Soc. Bengal, Vol. LXIX, Pt. 2, p. 345.

IgOI O. ceratophthalma (P.) BorRADAile, in: Gardiner, Fauna and geography of the Maledive and Laccadive Archipelagoes, Vol. I, p. 97 (Biologie).

I + , I $q$ Groß-Nikobar, im Sand eingewühlt.

I of Diegro Garcia.

Verbreitung: Häufig an sandigen Küsten der ganzen indopacifischen Region: vom Roten Meer und Natal im Westen bis Tokio im Norden, Neu-Südwales im Süden, Tahiti, Sandwich- und Fanning-Inseln im Osten. 


\section{Ocypoda africana DE MAN.}

1881 O. africana de $M$ LAx, in: Not. Lcyden MLus., Vol. III, p. 253.

1882 O. africana Miners, in: Ann. Mag. N. Hist., Ser. 5, Vol. X, p. 386.

1882 O. hevagonura HrlagxdorF, in: S.-B. Naturf. Frounde Berlin, S. 23.

1883 O. africana DE MAx, in: Not. Leyden Mus., Vol. V, p. 155

1890 O. Eidicarlsi Ozorio, in: J. Sc. Math. Phys. Nat. Lisbor (2), Vol. II, No. 5.

I 896 O. Edradsi Ozorio, DE Max, in: Jahrb. Hamburg. wiss. Anst., Bd. XIII, S. go.

1807 O. africana de Mlan, Ortanan, Zool. Jahrb. Syst., Bd. X, S. 365.

I d, verletztes juv., Victoria, Kamerun.

Außerdem liegen mir Exemplare von Akkra, August 1872, und von Gabun vor, gesammelt von Prof. Buchiolz, welche dem Zoologischen Museum der Universität Greifswald gehüren.

Verbreitung: Westküste von Afrika: Congoküste (DE MAN); Loango (InLrendorf); lle du Prince (Ozorio); Liberia (de Man, Hilgendori); Senegambien (Hilgendorf).

\section{Ocypoda cursor (L.).}

1766 Cancer cursor Linvé, Syst. nat. 12. edit., 1). 1039.

1804 Ocipoda ippeus Olivier, Voy. dans l'empire Othoman, Vol. II, p. 235, Taf. XXX, Fig. I.

I 852 O. cursor Mrlce-Edwards, Ann. Sci. Nat. (3), Zool., Vol. XVIII, p. I 42 . Weitere Litteratur bei:

1897 O. hippens Orturanx, Zool. Jahrb. Syst., Bd. X, S. 368.

1900 O. cursor L. Milne-Edwards u. Bouvier, Talisman Crustacen, p. 107.

I q, Große Fischbai, Tiger-Halbinsel. Es ist dies bei weitem der südlichste bisher festgestellte Fundort der Art; ihre Verbreitung in die gemäßigteren Teile des Mittelmeergebietes läßt aber vermuten, daß sie sich noch viel weiter nach Süden an der Küste von Deutsch-Südwestafrika entlang erstrecken wird. - Außerdem liegen mir Exemplare von Dongila, Gabun vor, gesammelt im August 1875 von Prof. Buchnolz (Museum Greifswald).

Verbreitung: Küsten des Mittelmeers im Osten und Süden: Griechenland: Astros und Nisea bei Megara (Guḱkis); Syrien (Olivier); Aegypten (Lamarck); Afrikanische Küste des Mittelmeers (Desilarest); Cap Verdische Inseln (Stumpson, Miers, Studer, Milne-Edwards u. Bouvier); Senegal (Kngsley, Hilgendorf); Liberia (Studer); Acra d'Elmina (de Man); Congoküste (de M Man, Studer); St. Paul de Loanda (Studer, Benedicr).

\section{Gattung Uca LEACH.}

18 I 5 Ua Leach, in: Trans. Linn. Soc. London, Vol. XI, p. 309 u. 323.

1817 Gelasimus Latreille, in; Nouv. Diction. Hist. Nat., Vol. XII, p. 5 I7. Litteratur siehe:

I8gi Gelasimus de MLA, in: Not. Leyden Mus., Vol. XIII, p. 20 ff.

1894 Gelasimus Ortuans, in: Zool. Jahrb. Syst., Bd. VII, S. 749.

1897 Uca Ortмaxi, in: Zool. Jahrb. Systo, Bd. X. S. 346.

1900 Gelasimus A.cock, in: Journ. As. Soc. Bengal, Vol. LXIX, Pt. 2, p. 350.

\section{Uca tangieri (EYDOUX).}

1835 Gelasimus tangieri Erdoux, Mag. Zool. il. 7, Taf. XVII.

185 I G. perlalus Hezkiots, Addit. faun. Carcin. Afric. Occid,, p. 6, Taf. I, Fig. 3. Litteratur siehe:

I897 Uca tangieri (Eyo.) Ortarani, Zool. Jahrb. Syst., Bd. X, S. 356. 
I §, Victoria Kamerun, an der Mündung eines Baches.

3 б, 2 o, Banana, Congomündung.

I $\delta$, Creek des Congo bei Banana, von Fischern am Ufer gefangen.

Ferner liegen mir von Prof. Buchнolz gesammelte Exemplare vor von Victoria, Kamerun, September 1873 und von Dongila, Gabun i 875 (Museum Greifswald).

Das oben erwähnte, von Fischern gefangene Stück hat eine sehr eigentümlich gestaltete Schere. Während sonst meistens die rechte Schere die größere ist, finden wir hier eine stark vergrößerte linke Schere, die rechte ist kleiner und annähernd nach dem Typus sonst links befindlichen kleinen Schere gebaut. Es handelt sich also wohl um eine Regeneration. Auffallend dabei ist nur, daß die regenerierte große Schere nicht nach dem Typus der gewöhnlichen großen Schere gebaut ist, sondern die Palma ist dick, stark gekömelt, besonders am Oberrand und Unterrand mit einer körnigen Kante abgegrenzt. In der unteren Region der Palma verläuft eine Körnerreihe parallel dem Unterrande bis auf den beweglichen Finger, die Finger sind kürzer als die Palma, der unbewegliche ist kurz, dreieckig; der bewegliche gekrümmt. Die Schneiden sind ohne Zähne; die Spitzen abgestutzt.

Verbreitung: Vom sůdlichen Portugal längs der Westküste Afrikas bis Angola. Algarve (Brito Capelio); Cadiz (Milne-Edwards); Narokko: Tanger (Exdoux, affirm. Ortmanx); Senegambien (Miers, Hilgiendorf); Sierra Leone (Mitrs); Liberia (Hilgendorf, Ortmany); Boutry (Herklots); Guinea (Kingsley, de Man); Beyah river, Aschanti (Benedict); Lagos (Studer); Chinchoxo (Studer); Congomündung (Studer); S. Paolo de Loanda (Hilgendorf, BENEDICT).

\section{Uca annulipes MiLnE-EDWARDS.}

1837 Gelasimus annulipes Milne-Edwards, Hist. nat. Crust., Vol. II, p. 55, Taf. XVIII, Fïg. Io-I3.

1837 G. marionis Milne-Edwards (nec DesMarest), ibid., p. 53.

1839 G. minor Owen, Zool. Beecheys Voyage Blossom, p. 79, Taf. XXIV, Fig. 2.

1852 G. perplevins Milne-Edwards, in: Ann. Sci. nat., (3) Zool., Vol. XVIII, p. 150, Taf. IV, Fig. 18.

I 858 G. pulchellus Stimpsox, in: Proc. Ac. Nat. Sci., Philadelphia, p. Ioo. Litteratur bei

I897 Uca ammlipes (M.-E.) Ortarana, in: Zool. Jahrb. Syst., Bd. X, S. 354.

I o Dar-es-Salaam, bei welchem die Ringelung der Beine deutlich ist, aber der Oberrand der Schere ist nicht ganz stumpfkantig zu nennen. Mit der Abbildung bei Kingster (Proc. Ac. Nat. Sc., Philadelphia i 880, Taf. X, Fig. 22) stimmt sie aber gut überein.

Verbreitung: Ganze Indopacifische Region vom Roten Meer und Ostafrika im Westen, Madagaskar und Australien im Süden, bis zu den Sandwich-Inseln und Tahiti im Osten; OrtManN bezweifelt die Richtigkeit der Angaben für die Westküste von Amerika (Vancouver: Bate, Nieder-Californien: Lockington und Valparaiso: Milne-Edwards und Lucas, Gay).

\section{Gattung Dotilla STimpson. Dotilla fenestrata HiLgENDORF.}

I 843 Doto sulcatus Krauss, Südafrik. Crustac., S. 39 .

I869 Dotilla fenestrata Hilgendorf, in: v. D. Deckens Reisen, Bd. III, I, S. 85, Taf. III, Fig. 5.

I878 Dotilla fenestrata Hilgexdorf, in: Monatsber. Ak. Wissensch. Berlin, S. 806. 
1884 Dotilla fenestrata Misers, Zool. Alert., S. $5+3$.

1804 Dotilla fenestrata OrTm.nN, in: Smox, Zool. Forschungsreisen, IBd. V, I't. x, S. 58 u. 66.

rgor Dotilla fencstrata ORtamax, in: Brows, Klassen u. Ordnungen, Malacostraca, p. I 22 I.

Viele $\delta$ und $q$, Dar-es-Salaam.

Verbreitung: Sansibar (Premfer); Kilwa, Dar-es-Salaam (Ortmann); Ibo (Hilgmdorfa); Mozambique (Hingiexdorf, Mifrs); Jnhambane (Hrlgendorif); Natalbai (KraUss); Cap der guten Hoffnung (ORTMANN).

\section{Gattung Macrophthalmus LATREILLE. IIacrophthalmus dilatalus DE HAAN.}

1835 DE HAAN, Fauna japonica, Crust., Dec. 2, p. 55, Taf. XV. Fig. 3.

1897 ORTminn, Zool. Jahrb. Syst., Bd. X, S. 345 (das. Litteratur).

Ich kann nicht mit aller Sicherheit nachweisen, ob das mir vorliegende Exemplar zu obiger Art gehört, da es ein junges $q$ ist und ich von ähnlichen Arten nicht genug Material habe, um es zu bestimmen.

I $q$ juv. Padang, Emmahafen.

Verbreitung: Japan (DE HaAx): Tokiobai (Ortmann); Yokohama (Doflein); Südostkïste von Japan (OrTMANN).

\section{Gattung Geograpsus Stmipson. \\ Geograpsus Grayi Milne-Edwards.}

1853 Geograpsus Grayi Mrlne-Edwards, Ann. Sci. nat, Ser: 3, Vol. XX, p. 170.

I 858 Geograpsus mbidus Stimpson, Proc. Ac. N. Sci. Philadelphia, p. IO3. Litteratur siehe:

1880 Geograpsus Grayi M.-EDw., Kingsley, Proc. Ac. Soc. N. Sci. Philadelphia, p. Ig6.

$189+$ Gcograpsus Graji Orturdxx, Zool, Jahrb. Syst., Bd. VII, S. 707.

1900 Geograpsus Grayi Alcock, Journ. Ac. Soc. Bengal, Vol. LXIX, Pt. 2, p. 395.

I $q$ ohne Scherenfüße Diego Garcia.

Verbreitung: Indopacifik: Rotes Meer (Miers); Sansibar (Miers); Mauritius (Rtcriters, OrTManN); Amiranten (Mters); Seychellen (Richters); Andamanen, Nicobaren, Laccadiven (Alcock); Ceylon (MIers); Bonin-Inseln (Strmipson); Neu-Guinea: Greelvinkbucht (NobiLi); Australien (Mulne-Edwards); Fidschi-Inseln („Challenger“: Miers); Tahiti (Krngstey, Ortaiand).

\section{Gattung Pachygrapsus RandalL. Pachygrapsus simplex (Herkiots).}

1857 Grapsus simplev Hierfiots, Addim. ad fann. carcin. Afr. occid., p. 9. Taf. I, Fig. 8.

1880 Pachygrapsus simplex Herklots, Kingslex, Proc. Ac. N. Sci. Philadelphia, p. 201.

Diese Art scheint mir dem P. gracilis (SAUssure) aus Westindien sehr nahe zu stehen, wenn sie nicht sogar mit ihr identisch ist. $P$. simplex würde sich, im Falle meine Vermutung zutrifft, der ganzen Reihe von Strand- und Landformen anschließen, welche auf beiden Seiten des Atlantischen Oceans vorkommen.

I o Banana, Creek des Congro, auf den Mangroven kletternd (Dr. Braeur leg.).

2 juv. ebenda, auf im Wasser treibendem Holz.

Verbreitung: Westafrika: Boutry (Herkiors). (Für P. gracilis: Westindien, Florida.) 


\section{Pachygrapsus aethiopicus HilgendoRF.}

1869 Pachygrapsus aethiopicus Hrlgendorf, in: v. D. Deckens Reisen, Bd. III, 2, S. 88, Taf. IV, Fig. 2. I880 Pachygrapsus aethiopicus Hilgendorf, Kingslet, Proc. Ac. N. Sci. Philadelphia, p. 200.

Bei den Pachygrapszs-Arten zieht sich über den Cephalothorax eine nach vorn offene halbkreisförmige Furche dahin, welche bei den Formen mit bezahntem Seitenrand zwischen dem Orbitalzahn und dem I. Seitenrandzahn in den Seitenrand mündet. Diese Furche wäre wohl bei einer Revision der Grapsiden systematisch zu ververten. - Bei den vorliegenden Exemplaren von $P$. acthiopicus ist ein solcher 1 . Seitenrandzahn wenigstens angedeutet, besonders bei dem offenbar erwachsenen, Eier tragenden 옹

I $\delta$, I $q$ Dar-es-Salaam: Hafen.

Verbreitung: Ostafrika: Ugurunga (HILGENDORF).

\section{Gattung Planes LeAch-BelL. Planes minutus (LinNÉ).}

I766 Cancer minutus Linné, Syst. Nat., Ed. XIIma, p. 1048.

Litteratur siehe:

I880 Nautilograpsus minutus (L.) Kingsler, Proc. Ac. Nat. Sci. Philadelphia, p. 202.

I894 Nautilograpsus minutus Ortmann, Zool. Jahrb. Syst., Bd. VII, S. 7 IO.

I $q$ Station I 72, südlicher Indischer Ocean, $30^{\circ} 6,7^{\prime} \mathrm{S} . \mathrm{Br} ., 87^{\circ} 50,4^{\circ} \mathrm{O}$. L., an der Oberfläche.

Verbreitung: Circumtropisch, bewohnt die schwimmenden Tangwiesen und greht in manchen Meeren ziemlich weit nach Norden und Süden über die Wendekreise hinaus. S. auch OrTMIANN a. a. O. S. 7 I I.

\section{Gattung Sesarma SAY.}

\section{Sesarma lleinerti DE MAN.}

1837 Sesargna tetragona MiLNe-EDwards, H. nat. Crust., Vol. II, p. 73

1887 Sescrma Meinerti DE MIAN, in: Zool. Jahrb., Bd. II, S. 648 u. 668.

Litteratur s.

1894 Sesarma Meinerti DE MAN, Ortmann, in: Zool. Jahrb., Bd. VII, S. $72 \mathrm{I}$.

1804 Sesarma Meinerti DE MIAN, Orturand, in: Senox Forschungsreisel, Jena, Bd. V, S. 56.

I 900 Sesama Meinerti DE MAN, ALcock, in: Journ. As. Soc. Bengal, Vol. LXIX, Pt. 2, p. 4 I7.

I + Dar-es-Salaam.

Verbreitung: Indopacifik: Sansibar (HILgendorf); Bagamoyo, Kingani (PFeffer) Dar-es-Salaam, Salzwassersümpfe des Upangathals (Ortmann); Mozambique (Hilgendorf); Natalbai (Krauss); Madagaskar (A. M.-EDw.); Nossi Faly, Nossi Bé, Sakatia (Horimaxn); Mauritius (M.-Enw., Richters, Ortwans); Ost-Indien: Madras (Alcock); Andamanen (Alcock); Philippinen: Bohol (Bürger); Südsee (Ormunn); Neu-Caledonien (M.-Edv.).

\section{Sesarma sp.}

2 ganz junge unbestimmbare Exemplare im Creek des Congo bei Banana auf im Wasser schwimmendem Holz.

\section{Sesarma sp.}

I junges o Naukari, Nikobaren aus einer hohlen Frucht von Nipa fruticans. 


\section{Gattung Leiolophus Miers.}

S. Miers, Revision of the Plagusiinae, in: Ann. Mag. Nat., (5) Vol. I, 1878, p. 147.

\section{Leiolophus plamissimus (HERBST).}

I88 4 Cancer planissimus Herizst, Krebse und Krabben. Bd. III, Heft 4, p. 3, Taf. LIX, Fig. 3

1850 Acanthopus planissimus DE HAגN, Fauna Jap. Crust., p. 30.

1853 Acanthopus Giblesi H. Mil.st-Enwards, Ann. Sci. Nat. \%ool., Ser. 3, Vol. XX, p. I8o.

18-6 Lciolophus planissimus Mrers, Catal. New Zealand Crust., p. 46.

Litteratur s. ferner: Miers, Ann. Mag. nat. Hist., Ser. 5, Vol. I, I878, p. I83; OrtaAx, Zool. Jahrb. Syst., Bd. VII, 1894, P. 731.

I q juv., Diego Garcia.

Verbreitung: Kosmopolitisch, mit Ausnahme der kảlteren Meere.

\section{Gattung Gecarcinus Latreille. \\ Gecarcinus lagostoma MiLne-EDw.}

1837 (iecarcinus lagostoma MIr.⿲e-Edwaros, Hist. Nat. Crust., Vol. II, p. 27

1876 G. muricola Drew, in: Proc. Zool. Soc. London, p. 464.

I 897 G. lagostoma M.-E. Ortmans, in: Zool. Jahrb. Syst., Bd. X, S. 337 (daselbst Litteratur).

I $\delta$ Victoria, Kamerun.

Es ist dies das erste mit Sicherheit für IVestafrika nachgewiesene Exemplar der Art (s. Ortmann, a. a. O., S. 338). Am selben Fundort hat auch Buchholz im September I873 einige typische Exemplare dieser Art gesammelt, welche mir vorliegen.

Verbreitung: Ascension (Drew, Miers, Ortalann, Benedict); IVestafrika?? (Ortanan).

\section{Gattung Cardisoma LATReille. Cardisoma guanhumi LATREILLE.}

Litteratur s. Ortmaxi, Zool. Jahrb. Syst., Bd. VII, I 894, S. 735.

Ich kann keinen Unterschied zwischen Cardisomen der Atlantischen Küsten und solchen der Indopacifischen Region erkennen. Das vorliegende $\delta$ z. B. zeigt die weit klaffenden Scherenfinger, welche nach ORTMANx nur seine amerikanischen alten Stücke zeigten.

I ¿, I q groß. Chagos-Insel, Kokoswälder.

Verbreitung: Cirkumtropisch.

\section{Gattung Retropluma GiLL.}

$189+$ Archaeoplax Arcock und Axdersox, Journ. As. Soc. Bengal, Vol. LXIII, Pt. 2, p. 180 (nom. praeocc.).

1894 Retropluma Gilu, in: Americ. Naturalist, I894, p. 1044.

1895 Plenoplax Al.cock und Axdersox, Illustr. Zool. Investigator Crustacea, Taf. XV.

1899 IMenoplax Arcock, Investigator Brachyura, p. 78.

1900 Prenoplax Ar.cock, Joum. As. Soc. Bengal, Vol. LXIX, Pt. 2, p. 455.

\section{Retropluma Chuni n. sp.}

Taf. XXXVII, Fig. I น. 2.

1002 Retropluma notopus Alcock, Dofi.eix, Abbildung in: Chux, Aus den Ticfen des Weltmeeres, 2. Aufl., Jena, $\therefore 53 \mathrm{r}$ 
Bei der ersten Untersuchung hielt ich das von der „Valdivia“-Expedition erbeutete Exemplar für einen Vertreter der gleichen Species, auf welche ALcock und Anderson diese interessante Gattung begründet haben. Eine genauere Vergleichung zeigte mir jedoch, daß die Verschiedenheiten kaum auf Altersunterschiede und dergl. begründet sein können, daß also eine besondere Form vorliegt, wenn anders die Beschreibung und Abbildung von R. notopus (Alc. und AND.) genau sind, was ich anzunehmen allen Grund habe. Auffallend ist immerhin, daß die neue Form in geringer Entfernung von dem Fundort der früheren Art entdeckt wurde. Aber bei dem gegenwärtigen Stand unseres Wissens können wir unmöglich zwei Formen für identisch halten, deren gleich große Exemplare in so wesentlichen Punkten differieren. Vgl. hierzu auch Trichopeltarium Alcocki, S. 88.

Der Cephalothorax von Retrophuma Chuni ist fast hexagonal; er ist auf der oberen Fläche vollkommen glatt, nur gegen die Stirn ein wenig, aber sehr gering, abfallend; nach allen Seiten ist er von einer scharfen Kante begrenzt.

Außer dem Extraorbitalstachel finden sich am Seitenrand des Cephalothorax noch jederseits 3 spitze Stachel, der erste davon steht an der vorderen Ecke des Cephalothorax.

Die Stirn, oder besser gesagt: das Rostrum, ist lang, sehr schmal - noch schmäler als bei $R$. notopus - und scharf zugespitzt, nicht wie bei diesem ausgerandet.

Ehe ich mich den weniger auffallenden Einzelheiten zuwende, hebe ich von unterscheidenden Merkmalen noch hervor: die nicht aufgetriebenen, vielmehr ganz glatten Branchialregionen, den Mangel an Suturen quer über den Cephalothorax, die Dünnheit der Augenstiele. und Kleinheit und Schmalheit der Cornea.

Der Cephalothorax ist hexagonal, oben abgeplattet; obwohl die Oberfäche uneben ist, sind die gewöhnlichen Regionen nicht scharf umgrenzt. Die Panzeroberfläche ist glatt und weißlich, aber mit gelbroten, filzartigen Härchen bedeckt, welche am Vorderrand, an der Unterseite, sowie an den Rändern der Beine in längere Behaarung übergehen. An den Erhabenheiten des Cephalothorax ist die Behaarung offenbar abgerieben, wodurch eine etwa doppelkreuzförmige Zeichnung entsteht (Taf. XXXVII, Ftg. I). Die Regio cardiaca ist durch einige tiefe, schmale Furchen einigermaßen abgegrenzt, nach vorn durch einen nach vorn offenen Bogen, auf den Seiten durch gerade, nach vorn divergierende Linien. Von der Regio gastrica läuft eine gerade Reihe von Höckern zum 3. Seitenrandzahn. Ferner sieht man über die vordere Gastrikal- und Hepatikalregionen eine erhabene Kante ungefähr parallel der allgemeinen Richtung des Vorderrandes bogenförmig verlaufen. Sie verschwindet vor dem Seitenrand kurz vor dem 2. Seitenrandzahn. Der Vorderrand sieht ziemlich verschieden von dem des $R$. notopus aus. Im allgemeinen ist er tief konkav ausgeschnitten. Die Mitte der Stirn ragt als schmales, lanzenförmiges Rostrum weit vor. Von unten ist dieses zwischen den inneren Antennen vorragend deutlich zu sehen.

Die Orbiten nehmen zusammen nur etwa die Hälfte des Vorderrandes des Cephalothorax ein. $Z u$ beiden Seiten des Rostrums ragen in zurückgezogenem Zustand die Augenstiele schief nach außen vor; sie sind kürzer als das Rostrum. Die Augen werden nach außen durch einen Extraorbitalstachel geschützt, welcher gerade nach vorn vorragt, sehr scharf und spitz ist, aber nur halb so lang als das Rostrum. Er wird auch von dem an der Vorderecke des Seitenrandes stehenden, etwas nach außen gerichteten scharfen Stachel überragt. Beide sind durch eine sehr tiefe Einkerbung voneinander getrennt. 
Von dem Stachel an der Vorderecke zieht der Seitenrand zunächst geradlinig schicf nach außen und hinten zu einem Seitcnrandstachel, welcher dem ersten ungefähr an Größe glcichkommt. Vom 2. zum 3. Stachel verlaufen die Seitenrïnder in der Cicsamtrichtung fast parallel der Längsachse, aber nach innen konkav ausgeschnitten. Der 3. Stachel ist nur halb so groß als die beiden vorderen. Hinter ihm konvergieren die fast geradlinigen Ränder bis zum Hinterrand etwas, in den sie mit scharfer Ecke übergehen. Kurz hinter dem 3. Zahn zeigt der scharfkantige Rand eine leichte Kierbe. Der Hinterrand ist glatt, nach hinten konvex gebogen und zeigt in der Mitte eine Einbuchtung nach vorn.

Die Seitenwände des Cephalothorax stoßen in der scharfen Kante in rechtem oder spitzem Winkel mit der Oberseite zusammen. Die Pterygostomialregionen sind vorn halbkugelförmig aufgebläht, mit glatter Oberfläche. Nach hinten wird dieser aufgeblähte Teil von einer tiefen Furche begrenzt, welche von der vorderen Mundecke nach hinten und außen zicht. Vor den Basen der Scherenfüße ist eine tiefe rinnenartige Grube, deren Längsachse schief nach vorn und außen gerichtet ist. Im Hintergrund der Grube öfnet sich in Form eines Halbmondes der Eingang in die Kiemenhöhle.

Die Orbiten sind nach unten sehr unvollstïndig begrenzt, indem unter dem Auge das mïchtig aufgeblähte Basalglied der inneren Antennen liegt. Diese selbst sind nach unten gar nicht geschützt. Die zwei folgenden Glieder der inneren Antennen sind untereinander und mit dem Durchmesser des Basalgliedes etwa gleich lang. Die Geißel ist kurz. Sie falten sich horizontal zusammen.

Außerhalb von den inneren Antennen sind die äußeren inseriert, so daß die basalen Glieder beider sich berïhren. Erst außerhalb von diesen findet sich unter und etwas außerhalb des Extraorbitalzahnes der von ALсосK auch erwähnte Zahn, welcher nach ihm bei $R$. notopus die Orbita von unten begrenzen soll. Zwischen ihm und dem Extraorbitalzahn ist das 2. Glied der äußeren Antennen nach außen vorgestreckt. Die Grube zwischen diesen Zähnen und dem von mir als I. Seitenrandzahn bezeichneten Stachel wird man wohl nicht zur Orbita hinzurechnen dürfen.

Die basalen Glieder der äußeren Antennen sind cylindrisch, das I. ist kürzer, das 2. und 3. etwas länger. Sie sind mit langen Haaren bewachsen, die Geißel proximal mit etwas kürzeren, distal ist sie kahl.

Die Augenstiele sind relativ klein, dünn, an der Basis verdickt und mit kleinen, schmalen länglichen Corneen von dunkelbrauner Farbe versehen.

Die Mundöffnung ist vorn breiter als hinten; die Ischiopoditen der 2. Gnathopoden sind zwar nach innen durch eine Lamelle verbreitert, trotzdem klaffen die 2. Gnathopoden weit und lassen die Mandibeln unbedeckt (s. Taf. XXXVII, Fig. 2).

Die Scherenfüße (nur der rechte ist erhalten) sind klein. Der Meropodit ist dreikantig mit abgerundeten Kanten, schlank, distal etwas verdickt. Er und der Carpopodit sind an den Rändern mit langen Haaren in einfacher Reihe bestanden. Die Schere ist glatt und unbehaart. Sie ist schlank gebaut, nur $1 / 3$ so hoch als lang und seitlich komprimiert. Die Palma ist etwas kürzer als die Finger. Letztere sind dünn, spitz, etwas gemeinsam nach unten gebogen. Sie schließen gut zusammen, indem sie nur proximal eine kleine Lücke zwischen sich lassen. Ihre Schneiden sind mit wenigen wellenförmigen Zähnen versehen. Die Schreitbeine sind lang, schlank, von oben nach unten komprimiert, mit glatten Rändern. Das 3. Pereiopodenpaar ist das längste. 
Die Beine sind behaart, die Haare sind an der vorderen und hinteren (schmalen) Kante länger, besonders am Carpopoditen und Propoditen; an diesen Gliedern am 2. und 3. Pereiopodenpaar nur an der Vorderseite, am 4. Pereiopodenpaar auch an der Hinterseite. - Der Basopodit des 2. Pereiopodenpaares trägt an der Vorderseite einen nach vorn gerichteten spitzen Stachel.

Die Daktylopoditen sind schlank lanzettförmig mit 4 scharfen Kanten; sie sind von vorn nach hinten komprimiert, und in der gleichen Richtung etwas gebogen. Sie sind kaum behaart. Kanten und Spitze sind sehr scharf.

Die 5. Pereiopoden haben die eigenartige, für die Gattung charakteristische Form, indem sich auf dem Coxopoditen ein kurzer cylindrischer Basopodit und auf diesem eine Kette von 5 gleichartig ausgebildeten, etwa cylindrischen, und gleichlangen Gliedern erheben, welche vorn und hinten eine Reihe langer Haare tragen, wodurch sie ein federartiges Aussehen erhalten. Das letzte Glied ist zugespitzt.

Das Abdomen des noch nicht geschlechtsreifen $q$ besteht aus 7 freien Gliedern; von denen das letzte lang und schmal ist und in eine Grube des Sternums paßt.

I \& Station 194, im Süden von P. Nias (West-Sumatranisches Meer), $0^{0}$ I 5,2 ${ }^{`}$ N. Br., $98^{\circ} 8,8^{\prime}$ O. L., in einer Tiefe von 6 I $4_{4} \mathrm{~m}$.

Retrophma notopus (ALC. u. AND.) wurde an der Coromandelküste in Tiefen von I80 bis $450 \mathrm{~m}$ und in der Andamanensee in Tiefen von $340 \mathrm{~m}$ gefunden.

\section{Litteraturverzeichnis zum I. Teil.}

Das nachfolgende Verzeichnis enthält die genauen Titel der im systematischen und fauuistischen Teil citierten Schriften, soweit ich derselben habhaft werden konnte. Diejenigen Arbeiten, welche mir unzugänglich blieben, sind mit einem * versehen.

Adaus and White in: White, Short descriptions of new or little know Decapod Crustacea, in: Ann. Mag. of Nat. Hist., Ser. 2, Vol. II, I 848 , p. 282.

- Crustacea, in: Zoology of the voyage of H. M. S. „Samarang6, London 1848.

Alcock, in: Ann. Mag. of Nat. Hist., Ser. 6, Vol. XIII, I894.

- in: Ann. Mag. of Nat. Hist., Ser. 7, Vol. XIII, I894, p. 402.

- Materials for a carcinological fauna of India. No. I: The Brachyura oxyrhyncha, "in: Journal of the Asiatic Society of Bengal, Vol. LXIV, Pt. 2, I895. No. 2: The Brachyura oxystoma, Vol. LXV, Pt. 2, I806. No. 3: The Brachyura Cyclometopa I, Vol. LXVII, Pt. 2, I898. No. 4: The Cyclometopa II, Vol. LXVIII, Pt. 2, I899. No. 5: The Brachyura primigenia or Dromiacea, Vol. LXVIII, Pt. 2, I899. No. 6: The Brachyura Catometopa, Vol. LXIX, Pt. 2, I900.

- An Account of the deep sea Brachyura collected by the R. Indian Marine Survey Ship "Investigator", Calcutta I 899.

- Crustacea, in: Illustrations of the Zoology of the Royal Indian Marine Surveying Steamer "Investigator“. Herausgegeben zuerst ohne Angabe eines wissenschaftlichen Redakteurs, dann unter dem Namen von Alcock und ANDERSON, schließlich von ALCOCK allein. Die Hefte enthalten Abbildungen aus verschiedenen Abteilungen des Tierreiches. Darunter (separat numeriert) Crustacea, Taf. I-XLV (sämtlich Dekapoden), I892-1899.

- and Anderson, Natural History Notes from the "Investigator", Ser. 2. An Account on a recent collection of deep sea Crustacea from the Bay of Bengal and Laccadive Sea, in: Journal of the Asiatic Society of Bengal, Vol. LXIII, Pt. 2, I894, p. I4I.

- Natural History Notes from the ,Investigator", Ser. 3, No. 2. An Account of the deep sea Crustacea dredged I 897 - I898, in: Ann. Mag. of Nat. Hist., I899, p. I.

ANDERSON, siehe auch AlCOCK.

- Natural History Notes from the „Investigator", Ser. 2, No. 2I. An Account on the deep sea Crustacea collected I894-I895, in: Journal Asiatic Society of Bengal, Vol. LXV, Pt. 2, I896, p. 88. 
Audouis, V., Crustacés, in: SAvignt, Description de l'Égypte. Histoire naturelle, T. I (Explication sommaire cics planches de Crustacés de l'Égypte et de la Syrie), I8on.

BeLl, Horae carcinologicae I. A Monograph of the Leucosiadac, in: Transactions of the Linnean Society, London, Vol. XXI, $1852-1855$, p. 227.

- A History of the British stalk-eyed Crustacea, 1853.

*Berg, Carlos, in: Communicaciones Mus. Nacional Buenos Ayres, Vol, I, I809.

BORRADAIL, Marine Crustaceans, Taf. I-VII, in: Garotner, Fauna and geography of the Maledive and Laccadive Archipclagoes, Vol. I, I900-1903.

Bosc, Histoire naturelle des Crustacés (Suites à Buffon), An X, I802,

Bouvier, siehe auch unter MILNE-EDwards, A.

Bouvier, E. L., Sur l'origine homarienne des crabes, in: Bulletin de la Société Philomathique de Paris, Sér. 8, T. VIII, I 897 , p. 34 .

- Sur la classification, les origines et la distribution de la famille des Dorippiclés, ebenda, Sér. 8, T. IX, I897, p. 54.

Brito-Capelio, F., Algunas especies novas de generos Calappa e Telphusa, in: Jomal de Sciencias math. phys. e nat., Lisboa, Vol. III, I87I, p. I 28.

CAso, Crostacei brachiuri ed anomuri letti nel viaggio della R. Corvetta "Vettor Pisani", in: Bolletino della Società Nat., Napoli, Vol. III, I880.

Crun, C., Aus den Tiefen des Weltmeeres, Schilderungen von der deutschen Tiefsee-Expedition ("Valdivia"Expedition), I. Aufl., Jena I900, 2. Aufl., Jena I902.

Cuvier, G., Règne animal, éd. 2, Crustacés par Latrenlle, I 829.

DANs, Crustacea, in: U. S. Exploring Expedition, Vol. XIII u. XIV, mit Atlas, 1852.

Desmarest, Considérations sur les Crustacés, 1825.

Doriein, F., Die Dekapodenkrebse der arktischen Neere, in: Roexer u. Schaudinn, Fauna arctica, Bd. I, S. 3I5, Jena 1900 ,

- Ostasiatische Dekapoden, in: Abhandlungen der Königl. bayr. Akademic der Wissenschafteu, II. Klasse, Bd. AXI, III. Abt., S. 6I3.

*Erdoux, Magasin de Zoologie, T. V, I835, Notice I7, Taf. XVII.

FABricius, Entomologia systematica emendata et aucta, Vol. II, Hafnia I 793.

- Entomologiae systematicae Supplementum, 1798.

FAxon, Report on a cruise of the "Albatross" on the west coast of Mexico, Panama to the Galapagos: Crustacea, in: Memoirs of the Museum of Comparative Zoology, Cambridge, Mass., Vol. XVII, I895.

Forski̊, Descriptiones animalium, quae in itinere orientali observavit, ed. Nimiunir, 1775.

Gerstäcker, Carcinologische Beiträge, in: Archiv für Naturgeschichte, Bd. XXII, Heft I, r856.

Gill, A new Bassalian Type of Crabs, in: American Naturalist, I894, p. 1044.

GúkriN-MÉNeville, Iconographie du règne animal de Cuvier. VI. Annélides, Crustacés et Arachnides, 1828 ( $1829-1844)$.

Gú́ris, Voyage de „la Coquille“, T. II, 1828, p. 22.

- Notices sur quelques modifications à introduire dans les Notopodes de M. LATREILLE, in: Annales des Sciences naturelles, Sér. I, T. XXV, I832, p. 283 .

DE HaAn, Crustacea, in: Siebold, Fauna jatonica. Datum des Titels 1850 . Erschienen in Dekaden (Decas $\mathrm{I}-\mathrm{V}, \mathrm{I} 833-\mathrm{I} 842)$.

Haswert, A. W., Catalogue of the Australian stalk- and sessile-cyed Crustacea, Sydney 1882.

HELLER, CAMr, in: Sitzungsberichte der Akademie der Wissenschaften in Wien, Bd. LXII, I, I861, p. 357.

- Die Crustaceen des südlichen Europa, Wien I863.

Hrinderson, Anomura, in: Reports on the scient. results of the "Challenger", London 1888.

- A Contribution to Indian Carcinology, in: Transactions of the Linnean Society London, Zoology, Ser. 2, Vol. V, 1892, p. 325.

HERbST, J. F. W., Versuch einer Naturgeschichte der Krabben und Krebse, Bd. I-III, I790-I796, Berlin und Stralsund.

HERkLots, Addimenta ad faunam carcinologicam Africae occidentalis, Lugduni Batavorum 1851.

* Études sur la classe des Crustacés, Leyden i86r,

Hess, E, Beiträge zur Kenntnis der Dekapodenkrebse Ostaustralicns, I 865.

Hilgendorf, Crustacea, in: vor DER DeCrex's Reisen in Ostafrika, Bd. III, I 869.

- Carineologische Mitteilungen, in: Sitzungsberichte cler Gesellschaft Naturforschender Freunde, Berlin, I882, S. 23. 
Kinaman, Remarks on the habits and the distribution of marine Crustacea on the eastern shores of Port Philipp. Victoria, in: Journal of the Royal Society of Dublin, Vol. I, I858, p. I I I.

Kingsley, Carcinological Notes. No. 2. Revision of the Gelasimi, in: Proceedings of the Academy of Natural Science Philadelphia, 1880 , p. I 35 .

- Carcinological Notes. No. 3. Revision of the Genus Ocypoda, in: Proceedings of the Academy of Nat. Science Philadelphia, I 880 , p. I 79 .

- Carcinological Notes. No. 4. Synopsis of the Grapsidae, ebenda, p. I87.

Krauss, F., Die südafrikanischen Crustaceen, Stuttgart 1843.

Kroyer, Geryon tridens, en ny Krabbe, in: Naturhist. Tidsskrift, Vol. I, I837, Kjobenhavn, p. IO, Taf. I.

LAMARCK, J. J., Histoire naturelle des animaux sans vertébres, T. V, I8I5.

*Latreille, Artikel Insectes, in: Encyclopédie méthodique, T. X, I818.

- Crustacés, in: Règne animal de Cuvier, 2 me édition, T. IV, I825.

LEACH, Artikel Crustaceology, in: BREwSTER's Edinburgh Encyclopaedia, 7 vols. 80, I8I3-I8I4.

* - Malacostraca podophthalmia Britanniae, London 1817-1821.

- A tabular view of the external characters of four classes of animals, which Linse arranged under Insecta, in: Transactions of the Linnean Society of London, Vol. XI, 1815, p. 306.

- Zoological Miscellanea, Vol. IV, I8I5.

LENz u. Richters, Beitrag zur Crustaceenfauna von Madagaskar, in: Abhandlungen der Senckenbergischen Gesellschaft Frankfurt a. M., Bd. XII, I88I, S. 42 I.

Lisné, C., Fauna suecica, I 76 I.

- Museum S:ae R:ae M:tis Ludovicae Ulricae Reginae I764.

- Systema naturae, éditio I2., I766.

Lucas, M. H., Observations sur un nouveau genre de Crustacés de l'ordre des Décapodes brachyures, in: Annales de la Societé Entomologique de la France, Sér. I, T. VIII, p. 573.

MAC LEAY, On the brachyurous Decapods of the Cape; Invertebrates, in: Suith, Illustrations of the Zoology of South Africa, Vol.: Reptiles and Invertebrates, I849, p. 53.

DE MAN, Carcinological Studies in the Leyden Museum, in: Notes from the Leyden Museum, Vol. III, I88 r, No. I, p. I 2 I, No. 2, p. 245.

- Carcinological Studies in the Leyden Museum, in: Notes from the Leyden Museum, Vol. V, I883, p. I50.

- Uebersicht der indopacifischen Arten der Gattung Sesarma, in: Zoologische Jahrbücher, Abt. für Systematil u. Biologie, Bd. II, I887, S. 639.

- Report on the Podophthalmous Crustacea of the Mergui Archipelago, in: Journal of the Linnean Society of London, Zoology', Vol. XXII, I888, p. I.

- Carcinological studies in the Leyden Museum, No. 5, in: Notes from the Leyden Miseum, Vol. XIII, I89I, p. I. Milne-Edwards, A., Observations sur les affinités zoologiques et la classification naturelle des Crustacés, in: Annales des Sciences naturelles, Zool., Sér. 3, T. XVIII, I852, I, p. I08, II, p. I28, Mémoire sur la famille des Ocypodiens.

- III. Fortsetzung von II, ebenda, Sér. 3, T. XX, I853, p. I63.

- Etudes zoologiques sur les Crustacés récents de la famille des Portuniens, in: Archives du Musée d'Histoire naturelle, Paris, T. X, I86i, p. 309.

- Description de quelques Crustacés nouveaux provenant du voyage de M. A. Bouvier aux îles du cap Vert, in: Revue et Magasin de Zoologie, Sér. 2, T. XXI, 1869, p. 374.

- Description de quelques Crustacés nouveaux de la famille des Portuniens, in: Nouvelles Archives du Musée d'Histoire naturelle, Paris, T. V, I869, p. 145.

- Recherches sur la faune carcinologique de la Nouvelle-Calédonie, in: Nouvelles Archives du Musée d'Histoire naturelle, Paris, T. IX, I873, p. 155 .

- Crustacés, in: Mission scientifịque du Mexique, I880.

- Étude préliminaire sur les Crustacés, in: Bulletin of the Museum of Comparative Zoology, Harvard College, Cambridge Mass., Vol. VIII, I88I.

- Considérations générales sur la faune carcinologique des grandes profondeurs de la mer des Antilles et du Golfe de Mexique, in: Comptes rendues de l'Académie des Sciences, T. XCII, Paris I881, p. 384.

- et Bouvier, in: Bulletin du Musée d'Histoire naturelle, Paris, T. IV, I 898.

- Crustacés dérapodes, in: Résultats des campagnes scientifiques du prince de Monaco, T. VII, 1894, u. T. XIII, I899. 
Mrrane-Edwards et Bouvier, Crustacés décapodes, in: Expéditions scientifiques du "Travailleur" et du, "Talisman" P’aris 1900 .

- Reports on the results of dredging in the Gulf of Mexico in the Carribean Sea and along the $\lambda$ tlantic Cnast of the United States by the U. S. Steamer "Blake“ XXXIX. Les Dromiacés et Oxystomes, in Memoirs of the Museum of Comparative Zoology, Cambridge, Vol. XXVII.

Mincte-Em Wrins, Henri, Histoire naturelle des Crustacés, T. I-III, Paris 1835-1839.

- Atlas zu Cuvier, Règne animal, éd. 3. Crustacés, 1836.

Mlars, Enwarn J., Catalogue of the stalk- and scssile-eyed Crustacea of New Zealand, London 1876 .

- Revision of the Plagusinae, in: Ann. Mag. Nat. Hist., Ser. 5, Vol. 1, 1878, p. I47.

- Descriptions of new or little known species of Maioid Crustacea (Oxyrhyncha) in the Collection of the British Muscum, in: Annals and Mag. Nat. Hist., Ser. 5, Vol. IV, I879.

- On a collection of Crustacea made by Captain H. C. ST. JonN in the Corean and Japanese Seas, in: Proceclings \%oolog. Socicty London, 1879 , p. 18.

- On the classification of the Maioid Crustacea or Oxyrhyncha, in: Journal of the Linnean Society London, Zoology, Vol. XIV, 1879, p. 634.

- On a collection of Crustacea made by Baron Hermand Madtzas (sic!) at Goréc Island, Scnegambia, in: Ann. Mag. Nat. Hist., Ser. 5, Vol. VIII, I88I, p. $20 \%$.

*- Crustacea, in: Report on the zoological collections of H. MI. S. "Nlert", I88+ (I885).

- Brachyura, in: Reports of the Scientific Results of H. M. S. "Challenger", I886.

Montage, Description of several marine animals found on the South Coast of Devonshire, Transact. Linn. Society Lundon, Vol. VII, 1804 .

Nonili, Note intorno ad una collezione di Crostacei di Sarawak (Bomeo), in: Bolletino dei Musei di Zoologia ed Anatomia comparata di Torino, Vol. XVI, Igor.

- Decapodi e Stomatopodi Éritrei del Museo Zoologico dell'Università di Napoli, in: Annuario del Museo Zoologico Napoli, N. S. Vol. I, No. 3, Igor.

- Contribuzioni alla conoscenza della fauna carcinologica della Papuasia, delle Molucche e dell'Australia, in: Annali del Museo Civico di Storia naturale Genova, Ser. 2, Vol. XX, I899, p. 230.

ORDwAY, Monograph of the genus Callinectes, in: Boston Journal of Natural History, Vol. VII, 1863, p. 567.

Ortalan,, A. E., Die Dekapodenkrebse des Straßburger Museums, 8 Teile, in: Zoolog. Jahrbücher, Abt. für Systematik und Biologie der Tiere. I. Teil, Natantia, Bd. V, I89I (90); II. Teil, Gattung Palacmon, Bd. V, 189I; III. Teil, Homaridea etc., Bd. VI, I892 (9I); IV. Teil, Galatheidea et Paguridea, Bd. VI, I892; V. Teil, Hippidea, Dromiidea u. Oxystomata, Bd. VI, I892; VI. Teil, Majoidea u. Cancroidea, I., Bd. VII, I894 (93); VII. Teil, Cancroidea, II. Cyclometopa, Bd. VII, I894; VIII. Teil, Cancroidea, III. Catometopa, Bd. Vol. V1I, I894.

- Dekapoden, in: Semon, Forschungsreisen in Australien und im Malayischen Archipel, Bd. V, Jena i 894, S. I.

- Decapoda u. Schizopoda, in: Ergebnisse der Plankion-Expedition, Bd. II, G. b., Kiel u. Leipzig I898.

- Carcinologische Studien, in: Zoologische Jahrbücher, Abteilung für Systematik u. Biologie, Bd. X, 1897, S. 258.

- Geographische Verbreitung der Dekapodenfamilie Trapeziidac, in: Zoologische Jahrbücher, Abteilung für Systematik u. Biologie, Bd. X, I897, S. 201 .

- Malacostraca, in: Bronn, Klassen u. Ordnungen des Tierreichs, Bd. V, Arthropoda, II. Crustacea. (Begonnen von Gerstäcker, fortgesetzt und abgeschlossen von OrTManN.)

Owen, Crustacea, in: Zoology of BeEciey"s Voyage on H. M. S. „Blossom", I830.

*Ozorio, Nouvelle contribution pour la connaissance de la faune carcinologique des îles St. Thomé et du Prince, in: Journal de Sciencias mathematicas, physicas y naturaes, Acad. Lisboa, (2) Vol. I, 189o, p. I 29.

Pallas, Spicilegia zoologica, Fasc. IX, Berolini 1772.

Pexwant, British Zoology, Vol. IV, 1777.

Pocock, Report of a deep-sea trawling off the South West Coast of Ircland, Crustacea, in: Ann. Mag. Nat. Hist, Ser. 6, Vol. IV, I889, p. 425.

Ratirbun, Mary, Scientific results of explorations by the U. S. Fish Commission Steamer "Albatross". No. XXIV. Descriptions of new genera and species of crabs from the West Coast of North America and the SandwichIlds, in: Proceedings of the U. S. National Museum of Natural History, Vol. XVI, I893, p. 223.

- Notes on the crabs of the family Inachidae in the U. S. National Museum, ebenda, Vol. XVII, I894, p. 43. 
Rathbun, Mary, The genus Callinectes, ebenda, Vol. XVIII, I895, p. 349.

*_ in: Proceedings of the Biological Society Washington, Vol. XI, r897.

* - Brachyura of the Florida Keys, in: Bulletin of Laboratory of Natural History of Iowa, I898, p. 250.

- The Brachyura collected by the U.S. Fish Comm. Steamer "Albatross" on a voyage from Norfolk, Virginia, to

S. Francisco, California, in: Proceed. U. S. Nat. Mus., Vol. XXI, I899 (1898), p. 567.

- in: Synopses of North American Invertebrates, VII; The Cyclometopous or Cancroid Crabs of North America, American Naturalist, Vol. XXXIV, Igoo, p. I40.

Richters, Crustaceen, in: MIömius, Meeresfauna von Mauritius und den Seychellen, r880.

RoEMer, Genera Insectorum, 1782.

Roux, Crustacés de la Mediterranée, I 828.

RÜPPEL, 24 Arten Krabben des Roten Meeres, I830.

Sars, Crustacea, in: Norske Nordhavs Expedition (Norwegian North Atlantic Expedition), Zoology, Vol. VI, I885.

Sirrm. S. J., Notes of North american Crustacea No. I, Ocypodoidea, in: Transactions Connecticut Academy of Science, Vol. II, I870, p. II3.

- Report on the Decapod Crustacea of the Albatross dredgings off the East coast of the United States in 1883 , in: Annual Report of the Commissioner of Fish and Fisheries for 1882 (1883).

- in: Report U. S. Commission of Fish and Fisheries for I885 (1887), p. 625.

Stebbing, TH., An History of Crustacea, in: International Scientific Series, Vol. LXXIV, I 893.

- South African Crustacea, in: Department of Agriculture, Cape of Good Hope, Marine Investigations in South Africa, Pt. I, I900, Pt. 2, I902.

Stimpson, in: Journal of the Boston Society of Natural History, Vol. VI, I857, p. 4I 2.

- Prodromus descriptionis animalium evertebratorum, quae in expeditioni ad Oceanum Pacificum Septentrionalem etc., Crustacea, in: Proceedings of the Academy of Natural Science, Philadelphia, Pars III, Crustacea Maioidea, Jahrg. 1897, p. 216; Pars IV, Crustacea Cancroidea et Corystoidea, Jahrg. I858, p. 3 I ; Pars V, Crustacea Ocypodoidea, Jahrg. 1858, p. 93; Pars VI, Crustacea Oxystomata, Jahrg. I858, p. 159; Pars VII, Crustacea anomoura, Jahrg. I 858 , p. 225.

- Notes on North American Crustacea, II, in: Annals of the Lyceum of Nat. Hist. New York, Vol. VII, I860, p. 176.

Studer, Th., Verzeichnis der Crustaceen, welche während der Reise der „Gazelle“ an der Westküste von Afrika, Ascension und am Cap der guten Hoffnung gesammelt wurden, in: Abhandlungen der $\mathbf{K}$. pr. Akademie der Wissenschaften, Berlin I882 (1883), Abhandlungen der Nichtmitglieder (separat paginiert).

Thonson, Wyville, The depths of the sea. An account on the general results of the dredging cruises of $\mathrm{H}$. M. SS. "Porcupine" and "Lightning" during the summers of 1866, I 869 and 1870, London 1873

WHITE, siehe auch ADAMS.

- Notes on four new genera of Crustacea, in: Ann. Mag. Nat. Hist., Vol. XVIII, I846, p. I 76.

- Short Description of some new species of Crustacea, in: Proceed. Zoological Society London, I8.7, p. 84.

Wood-Mason, Description of a new species of Portunidae from the Bay of Bengal, in: Ann. Mag. Nat. Hist., Ser. $4, \mathrm{~V}, \mathrm{XIX}, \mathrm{I} 877, \mathrm{p} .422$.

- Administrative Report of Imp. Marine Survey of India, I890-I891.

- and Alcock, Natural History Notes from H. M. S. „Investigator“, Crustacea, in: Ann. Mag. Nat. Hist., Ser. 6, V(1). VII, I $8(1) 1$, I. 18 ; u. 258 .

- - ebenda, Ser. 6, Vol. XIII, I894, p. 401. 


\section{Biologischer Teil.}

A. Beschreibung von Sinnesorganen einiger Tiefseekrabben. 



\section{Beschreibung ron Sinnesorganen einiger Tiefseekrabben.}

Der biologische Teil meiner Darstellung muß sich vielfach auf eine genaue Schilderung des Baues einiger durch das Leben in der Tiefsee besonders stark beeinflußte Sinnesorgane stützen. Um das bisher von der Biologie der Tiefseekrabben Bekannte in lesbarer Form einheitlich darstellen zu können, ist es daher zweckmäßig, die Detailbeschreibung in einem besonderen Abschnitt vorausgehen zu lassen, um später auf dieselbe zurückverweisen zu können.

Im großen und ganzen sind daher in dem nachfolgenden Abschnitt nur Beschreilungen enthalten, während in dem sich dann anschließenden Abschnitt über die "Biologie der Tiefseekrabben" die allgemeinen Folgerungen aus den festgestellten Thatsachen zusammengefaßt sind.

\section{Bau der Augen einer Anzahl von Krabben aus verschiedenen Tiefen.}

Die Facettenaugen der Arthropoden sind schon von sehr zahlreichen Forschern untersucht worden und daher hat sich eine Menge von Bezeichnungen für die einzelnen Teile eingebürgert, welche oft von verschiedenen Autoren in verschiedenem Sinne angewandt werden. Um bei meiner Darstellung keine Mißverständnisse aufkommen zu lassen, habe ich schematische Abbildungen angefertigt (Textfigur I 2 u. I 3 ) und in denselben alle wesentlichen Bezeichnungen eingetragen, welche in dieser Arbeit von mir gebraucht worden sind.

Die Untersuchungstechnik, welche ich anwandte, war eine sehr einfache. Ich untersuchte die abgretrennten Augen in Alkohol bei auffallendem und durchfallendem Licht; damn hellte ich sie auf und untersuchte sie nochmals in durchsichtigem Zustand. Schließlich fertigte ich Schnitte durch eine Anzahl von Augen an, ohne sie zu entkalken. Nachdem ich eine gute Entkalkungsmethode gefunden hatte, habe ich Schnitte durch nichtentkalkte Augen nur noch zur Kontrolle angefertigt, um festzustellen, ob nicht durch die Entkalkungsmethode Pigment oder Tapetum aufgrelöst werde. In den meisten Fällen trat eine solche Auflösung nicht ein.

\section{Allgemein in diesem Werk angewandte Bezeichnungen.}

Proximal und distal sind bei dem Augensticl für Richtungen in dessen Längsachse angewandt, jedoch bei den einzclnen Augenkeilen für Kichtungen in der Längsachse des einzelnen Augenkeiles.

Die Ausdehnung in der Achse $A B$ (Fig. 13) ist stets als Länge, die Ausdehnung in der Achse $Y Y$ stets als Breite der betreffenden Augenbestandteile in Text angegeben. 
$A B$ optische Achse

$X Y$ Richtung senkrecht zur optischen Achse.

$C$ Corneafacette, Cornealinse.

$C u$ Cuticula des Augenstieles.

$\mathrm{Cz}$ Corneagenzelle, Corneazelle.

F Facettenregion.

$H$ dorsales Augenhorn, zapfenförmiger Fortsatz des Auges.

Ip Irispigment (Ipz Irispigmentzelle).

$K$ Krystallkegel.

Kz Krystallkegelzelle, Krystallzelle.

L Lamina fenestrata, Grenzmembran des Auges.

Iff Nevenfasern, Neurofibrillenbündel.
No Nervus opticus.

Om stäbchenartige Bildungen im I. Ganglion opticum.

$P$ Pigment, Pigmentanhäufungen als seitlicher Lichtschutz für das Auge Rp Retinapigment.

$S$ Stäbchen, Rhabdom.

$S / 2$ Sinneshaare.

Sz Stäbchenzellen, Rhabdomzellen, Sehzellen.

$Z=\mathrm{L}$ verdruckt in Fig. I 2 für $\mathrm{L}=$ Lamina fenestrata.

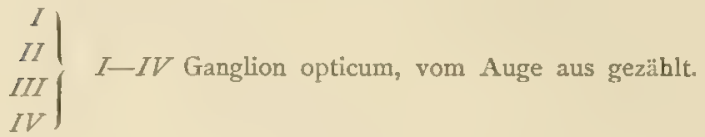

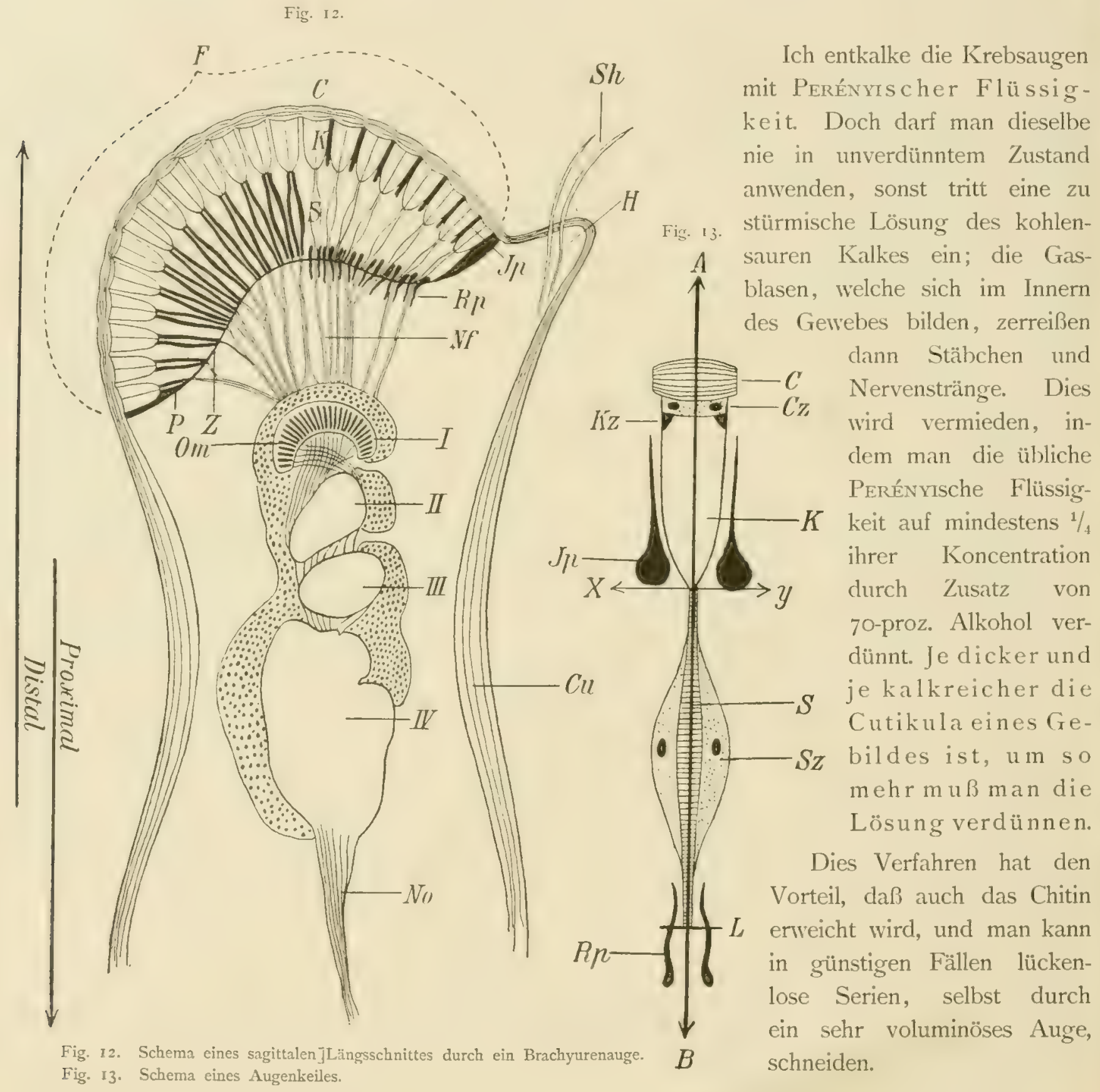


Die durch Verdunstung von destilliertem Wasser angeklebten Schnitte habe ich mit verschiedenen Methoden gefïrbt: Hämatoxylin mit Eosin, Orange, Pikrinsäure in verschiedenen Kombinationen, Pikrokarmin, Bismarckbraun, Methylgrün, Safranin etc. wurden zu verschiedenen Zwecken angewandt. Doch hatte ich die besten Resultate mit Boraxkarmin, wobei ich cine verdünnte Lösung von Anilinblau oder Bleu de Lyon als Gegenfärbung sehr nützlich fand. Für feine Strukturen that, wie immer, Heideninarss Eisenhämatoxylin vortreffliche Dienste.

Schließlich möchte ich noch hevorheben, daß die Konservierung in reinem, starkem Alkohol (von ca. 95 Proz.) wie sie von den Teilnehmern der "Valdivia"-Expedition zur Anwendung gebracht wurde, da man eine Benutzung des Materiales zu histologischer Untersuchung nicht ins Auge gefaßt hatte, meist gute Resultate ergab. Man konnte an so konservierten kleineren Objekten selbst sehr feine histologische Details studieren. Vielfach waren sogar Objekte, die mit kunstreicheren Methoden konserviert waren, weniger gut erhalten. Alkohol hat eben den großen Vorteil, ein schnell ins Innere der Gewebe vordringendes Konservierungsmittel zu sein. Allerdings zur Erhaltung so feiner Strukturen, wie sie in den Stäbchen des Augres sich zeigen, scheint es nicht auszureichen. Um da gute Resultate zu erzielen, wird man ohnehin das Objekt bei der Konservierung zerstückeln müssen.

Um das Auffinden zu erleichtern sind im Nachfolgenden die einzelnen Augen in der Reihenfolge angeführt, wie sie durch die systematische Anordnung ihrer Träger im I. Teil dieses Werkes vorgezeichnet ist. Wir werden aber später sehen, daß die Augen selber einer ganz anderen Systematik folgen, als ihre Träger.

\section{Homolodromia Bouvieri DofL.}

Taf. XLVI, Fig. I u. 2 ; Taf. XLVII, Fig. I-5.

Das Ange dieser Art gehört zu den reduzierten und pigmentlosen Augen. Sämtliche Elemente sind vorhanden, aber in besonderer Ausbildung. Zudem fehit das Pigment vollkommen.

Der nicht sehr bewegliche Augenstiel hat, wie der ganze Körper des Tieres, nur ein dünnes Chitinskelett: seine Oberfläche ist mit Borsten bedeckt, ein Kranz von gefiederten Borsten umgiebt die Cornearegion (Taf. XLVI, Fig. 2). Der Augenstiel ist etwa cylindrisch, kurz, am vorderen Ende einfach abgerundet, die Cornearegion ist also nicht besonders erweitert. Sie nimmt den vorderen Teil des Augenstieles ein und ist nach vorn und unten gerichtet. Die Corneafacetten sind groß und viereckig. Ihrer Größe entspricht die geringe Anzahl von Augenkeilen ${ }^{2}$. Man zählt deren auf einem sagittalen Durchschnitt nur etwa 35-45. Merkwürdigerweise sind die einzelnen Corneafacetten in der Richtung des Lichteinfalles sehr dünn, ihre Breite beträgt etwa das Io-fache ihrer Dicke. Sie sind nur ganz wenig gewölbt, so daß sie für die Lichtbrechung kaum eine besondere Bedeutung haben werden. Auf Querschnitten erkennt man die 2 großen Kerne, welche zu jeder Facette grehören (Taf. XLVII, Fig. I).

x) Ich verwende den althergebrachten Ausdruck "Augenkeil" für den cinzelnen Komponenten des Facettenauges, da cr klar ist ohne mit der theoretischen Auffassung der Entstehung des liacettenauges verknüpft zu sein. Das letztere ist der Fall bei dem von HESSE gebrauchten "Omma", welches aucls einen weiteren Begriff bedeutet und der von ExxER und Crus angewandte susdruck „F acettenglied" ist leicht mißzuverstehen und eine unklare Wortbildung. 
Die Krystallkegel sind sehr groß; sie sind etwa pyramidenförmig, ihre Länge in der Richtung zur optischen Ache verhält sich zum Breitendurchmesser etwa wie $3:$ I. Sie stoßen sehr dicht aneinander, so daß kaum Zwischenräume hie und da zwischen ihnen erkennbar sind. Die Kerne der Corneazellen, sowie diejenigen der Krystallkegelzellen sind sehr groß (s. Taf. LXVII, Fig. I u. 2). In jedem Krystallkegel lassen sich auf Querschnitten 4 Kerne nachweisen. Auf solchen erkennt man auch die unregelmäßig sechseckige Gestalt der Krystallkegel (Taf. XLVII, Fig. 3 u. 4). Die Krystallkegel gehen mit einer kelchförmigen Verschmälerung direkt in die spindelförmigem Stäbchen über. Die Region dieses Ueberganges ist durch das ganze Auge hin durch zahlreiche Kerne ausgezeichnet. Diese Kerne sind ebenfalls sehr groß und da man im allgemeinen ihrer 7 zählen kann, so sind es offenbar die Kerne der Stäbchenzellen (Taf. XLVII, Fig. 2 Rk.). Zwischen den Krystallkegeln finden sich regelmäßig noch Kerne eingekeilt, und zwar je ein Kern zwischen je zwei Krystallkegreln, es sind offenbar die Kerne von Pigmentzellen (Taf. XLVII, Fig. 2 Ipk). Es ist aber in dem Auge von Homolodromia Bouvieri keine Spur von Irispigment vorhanden. Die Stäbchenzellkerne umgeben im Kreis, aber in unregelmäßigen Zonen angeordnet das obere Ende des Stäbchens (Taf. XLVII, Fig. 2 u. 5). Die innere Struktur der Stäbchen ist schlecht erhalten. Die Stäbchen, welche an ihrer dicksten Stelle nur halb so breit sind als die Krystallkegrel, lassen meist einen ziemlichen Zwischenraum zwischeneinander. Dieser war beim lebenden Tier offenbar von durchsichtigen, sehr locker gebauten Zellen eingenommen, deren große Kerne am Präparate hie und da erkennbar sind. Auch bei diesem Auge, wie bei zahlreichen der später zu beschreibenden verlaufen nicht alle Stäbchen gerade in der Richtung des Lichtstrahles, sondern die randständigen sind in verschiedener Weise verbogen. Das Gleiche gilt übrigens auch für die Krystallkegel.

Die Membrana fenestrata ist sehr dünn, zieht sich aber als deutliche, scharfe Grenze auf den Schnitten fast wie ein bogenförmiger Strich durch das Auge (Taf. XLVI, Fig. I). In der Umgebung der Lamina fenestrata und hinter derselben finden sich an den Nerven Spuren eines ganz fein verteilten hellen Pigmentes. Es sind nur ganz feine, ziemlich locker angeordnete Partikelchen, und ihre Quantität ist so gering, daß ich nicht mit Sicherheit entscheiden kann, ob es sich um abblendendes Pigment oder reflektierendes Tapetum handelt; doch scheint mir wahrscheinlicher, daß es sich um letzte Spuren von Pigment handelt, da die Substanz bei abgesperrtem Spiegellicht im mikroskopischen Bild nicht glänzt.

Am auffallendsten weicht der nervöse Teil des Auges von dem typischen Bau des Dekapodenauges ab. Man kann deutlich erkennen, daß dies mit der geringen Anzahl der Augenkeile zusammenhängt. Man kann bei diesem Auge die Bildung von Neurofibrillen ${ }^{1}$ ) erkennen, welche aus jedem Stäbchen durch die Membrana fenestrata hindurchtreten. Dieselben vereinigen sich, indem die von den dorsalen Augenkeilen ziemlich ventral ziehen, die von den vorderen in einem Winkel ventralwärts umbiegen und die von den ventralen dorsalwärts heransteigen zu einem einzigen Nervenstrange, welcher als langes, dünnes Gebilde zu dem entfernten I. Ganglion opticum zieht (Taf. XLVI, Fig. I). Dieses, sowie die übrigen Bestandteile des Ganglienapparates sind relativ sehr klein. Die Kerne sind auch im Nervensystem relativ groß.

I) Ich nenne Neurofibrillen in der nachfolgenden Darstellung feine Fasern, welche in den Präparaten sich in ähnlichen Bildern zeigten, wie sie in den speciellen Arbeiten über die Neurofibrillen gegeben sind, ohne mich jedoch dadurch mit den theoretischen Anschauungen APATHYS oder BETHEs einverstanden zu erklären. Ich hatte bisher zu wenig Gelegenheit, denselben näher zu treteg. 
Ich kann an meinen Prïparaten nicht mit Sicherheit feststellen, ob sämtliche \& Augenganglien vorhanden sind. Doch scheint es mir der Fall zu sein. Sie sind allerdings rückgrebildet und auf einen minimalen Umfang beschränkt.

Eine Frage möchte ich noch erörtern; nämlich ob nicht das Auge infolge der Beschaffenheit seiner Krystallkegelzellen deren große Kerne weit in das Gebilde hineinreichen, als ,akones" Auge zu bezeichnen ist. Es scheint mir dies nicht im eigentlichen Sinn des IVortes zuzutreffen. Die große Ausdehnung der Prismen, sowie ihren durchaus den typischen Krystallkegeln gleichende regrelmäßige Form spricht dafür, daß es sich um diesen homologe Gebilde handelt. Allerdings müssen sie sehr weich gewesen sein, wie daraus hervorgeht, daß ihre 4 Bestandteile gegeneinander nicht, wie dies sonst der Fall zu sein pflegt, durch regelmäßige Flächen abgegrenzt sind, sondern daß sie vielfach einen deformierten Eindruck machen (Taf. XLVII, Fig. 2).

Länge des gesamten Augenstiels $2 \mathrm{~mm}$.

Maße der einzelnen Augenteile:

\begin{tabular}{|c|c|c|c|}
\hline & Länge & Breite & $\left.\begin{array}{l}\text { Längsdurchmesser: } \\
\text { Querdurchmesser }\end{array}\right\} \begin{array}{c}\text { der zugehörigen } \\
\text { Kerne }\end{array}$ \\
\hline Corneafacelte & $7 \mu$ & $47 \mu$ & \\
\hline Kern der corneagenen Zellen & & & $7 \mu: 21 \mu$ \\
\hline Krystallkegel, gemessen am Querschnitt & & $28-3 I \mu$ & I $3 \mu: 8,5 \mu$ \\
\hline$" \quad \quad$ " $\quad$ Längsschnitt & $127 \mu$ & $47-5^{6} \mu$ & $17 \mu: 8,5 \mu$ \\
\hline $\begin{array}{l}\text { Stäbchen } \\
\text { oberes Ende } \\
\text { unteres ", }\end{array}$ & $99-14 I \mu$ & $\begin{array}{l}35 \mu \\
6-7 \mu\end{array}$ & \\
\hline Stäbchenzellkerne & & & I4 $\mu:$ Io $\mu$ \\
\hline
\end{tabular}

\section{Hypsophrys longipes Alc. u. And.}

Taf. L, Fig. 4; Taf. LI, Fig. I; Taf. LII, Fig. I-5.

Diese Art hat als Homolide ein langgestieltes, sehr bewegliches Auge. Die Form desselben ist ungefähr klöppelförmig (Taf. L, Fig. 4). An den dünnen Anfangsstiel schließt sich ein cylinderförmiger Teil an, welcher schließlich in den stark verdickten, halbkugelförmigen Endteil übergeht. Die von Facetten bedeckte Oberfläche ist eine sehr große, indem sowohl das distale Ende als auch die proximal davon gelegenen Regionen der kugelförmigen Endverdickung des Auges vollkommen mit Facetten bedeckt sind (Taf. L, Fig. 4). Das Auge zeigt, von außen betrachtet, zwar eine blasse Färbung, aber man sieht doch Pigment deutlich durchschimmern. Die Einzelfacetten waren rundlich, bei genauer Untersuchung sechseckig und, verglichen mit den Augen von Oberflächenformen, groß. Am größten waren diejenigen der centralen Cornea. Nach innen ist eine Wachstumszone ausgebildet, in welcher die einzelnen Augenkeile viel kleiner sind. Sie sind stark gebogen, besonders im Stäbchenteil, und ihre Krystallkegel sind nicht fertig ausgebildet (Taf. LII, Fig. I). Im sagittalen Längsschnitt waren 50-60 Augrenkeile angeschnitten. Die Cornealinsen waren in der Richtung des Lichtstrahles sehr flach. Ihr Durchmesser in dieser Richtung betrug nur etwa ${ }^{3} / 3$ der Breite. Jede stellt eine konvex-konkave Linse dar, indem be- 
merkenswerterweise die äußere Fläche deutlich konvex gewölbt war, während die innere annähernd der Wölbung des Auges folgte, nur ein wenig konkaver war. Die Schichtung war sehr wenig deutlich, nur nahm die äußere Schicht etwas stärker die Farbe an als die innere. Die centralen Krystallkegel sind annähernd prismatisch geformt (Taf. LII, Fig. 2), nach der Peripherie zu wird ihre Form immer mehr pyramidenförmig, ja selbst birnförmig; besonders gilt dies für die Wachstumszone (Taf. LII, Fig. 1). Auch bei ihnen ist die Kleinheit der peripheren gegenüber den centralen auffallend. Sie sind etwa $2 \frac{1}{2}-3$ mal so lang wie breit und sind ziemlich dicht aneinander gelagert. Im Querschnitt sind sie etwas unregelmäßig, und man erkennt ihre Zusammensetzung aus 4 Stücken. Während das an die Cornea anstoßende Drittel frei von Pigment ist, sind die beiden proximalen Drittel von einem dichten Nantel dunkelbraunen Irispigmentes umgeben. Dasselbe ist in deutlich nachweisbare Pigmentzellen eingeschlossen, deren verdickter Zellkörper in den Zwickeln an der Basis der Krystallkegel gelegen ist. Von diesen Zellkörpern aus ziehen sich in Form ganz dünner Lamellen Fortsätze dieser Pigmentzellen in die engen Zwischenräume zwischen die Krystallkegel hinein. Diese Lamellen umgeben den Krystallkegel mit regelmäßigen sechseckigen Gehäusen, wie der Querschnitt, Taf. LII, Fig. 3, zeigt. Am proximalen Ende der Pigmentzellen ist das Pigment in Kugeln zusammengeballt, wie der Längsschnitt, Taf. LII, Fig. 2, und der Querschnitt durch diese Region. Fig. 5, zeigt. In der Wachstumszone, wo die Krystallkegel nicht so eng gedrängt stehen, sind auch Pigmentzellen mehr ausgebreitet, das Pigment ist in ihnen lockerer verteilt und läßt in der Mitte der Zelle stets den Kern deutlich erkennen (Längsschnitt, Taf. LII, Fig. I, und Querschnitt, Fig. 4). Die Krystallkegel gehen mit einer kelchartigen Verschmälerung in die Stäbchen über. Während die centralen Krystallkegel und Stäbchen regelmäßig in der Richtung des Lichtstrahles eingestellte Systeme darstellen, sind die peripheren Krystallkegel oft sehr schief gestellt, und die dazu gehörigen Stäbchen sind oft sehr stark, manchmal sogar S-förmig gekrümmt (Taf. LII, Fig. I). Die Stäbchen haben größere Zwischenräume zwischen einander als die Krystallkegel. Der distale Rhabdomteil ist zunächst etwas verdickt, verschmälert sich dann sehr stark, der proximale Teil stellt eine etwas dickere, spindelförmige Bildung dar. In der Mitte des dünnen distalen Teiles erkennt man in Ausbauchungen liegende Zellkerne, welche zu den Stäbchenzellen gehören. Es war in einzelnen Stäbchen möglich, 7 Stück zu zählen. Daher bin ich im Zweifel, wohin ich die in den Zwischenräumen zwischen den Stäbchen auftretenden Zellkerne zu rechnen habe (s. Taf. LII, Fig. I u. 3). Vielleicht gehören sie zu Blutzellen. Im distalen Teil des Stäbchens ist eine feine Längsfaserung erkennbar. An der Stelle, wo sich das Stäbchen wieder spindelförmig verdickt, zieht durch das Auge eine Art von Scheidewand, welche allerdings nicht überall deutlich vorhanden ist. Wahrscheinlich ist diese Bildung nur ein Kunstprodukt, entstanden bei der Konservierung. Ich möchte sie nicht als eine Schaltmembran ansehen. In dem spindelförmigen Teil des Stäbchens ist die Blättchenstruktur sehr deutlich, jedoch hat man den Eindruck einer spiraligen Anordnung der feinen Strukturelemente. Die Struktur hört eine Strecke vor dem proximalen Ende des Stäbchens auf, so daß in dem letzteren, verschmälerten Ende nur noch eine Längsfaserung erkennbar ist. In der Nachbarschaft des unten Endes sind Kerne sichtbar, etwas weiter distal liegen große Zellen mit sehr feinkörnigem Protoplasma dem Rhabdom an. Deren Kerne sind mittelgroß und bläschenförmig, die Grenzmembran des Auges ist sehr kräftig, hinter ihr liegen in vereinzelten Brocken gesondert dunkelbraune Pigmentmassen, welche 
hie und da auch die Nervenstränge eine kurze Strecke begleiten. Es macht den Eindruck, als lïgen die Pigmentanhäufungen zum Teil in lakunenartigen Hohlräumen (s. Taf. LII, Fig. 2 L). Die aus je einer Gruppe von Stäbchen hervorgehenden Neurofibrillen vereinigen sich zu schwachen Strängen, deren eine große Anzahl das Auge mit dem nahegelegenen I. Ganglion opticum verbinden. Diese Nervenfasern durchsetzen eine sehr lockere Gewebsschicht, welche aus Zellen und einem dichten Geflechte bindegewebeartiger Fasern besteht. Das I. Ganglion opticum ist ungrefähr in der Form einer Schüssel mit nach innen umgebogrenen Rändern und flachem Boden über das 2. optische Ganglion gestiilpt. Die in das r. Ganglion opticum eintretenden Nervenfasern haben zuerst die Rindenschicht zu passieren, um sodann in die aus zahlreichen, stübchenartigen Bildungen zusammengesetzte Markschicht einzudringen. Aus diesen Stäbchen gehen wiederum Fasern hervor, welche die Verbindung mit dem 2. Ganglion vermitteln und zunächst auf ihrem Wege sich kreuzen. Sonst will ich an dieser Stelle nicht weiter auf die Details des Baues eingrehen, ich bemerke nur, daß das 2. und 3. Ganglion sehr klein, das 4. dagegren sehr groß und mit gehirnartigen Windungen versehen ist. Der ganze Ganglienkomplex nimmt mehr als die Hälfte des ganzen Augenstielraumes ein, und an der Basis des 4. Ganglions geht aus demselben ein sehr dicker Nervenstrang hervor (s. Taf. LI, Fig. 2).

\section{Na $B$ e des Auges und seiner Teile.}

\begin{tabular}{l|r|r}
\hline & Länge & Breite \\
\hline Augenstiel & $3.5 \mu$ & \\
Corneafacetten & I0 $\mu$ & $56 \mu$ \\
Krystallkegel & I0 $\mu$ & $35 \mu$ \\
Stäbchen & $282 \mu$ & \\
Distaler Teil 134 $\mu$, & & \\
proximaler Teil (Spin- & & \\
del) I48 $\mu$; Breite & & \\
distal II $\mu$, proximal & & \\
I7 $\mu$. & &
\end{tabular}

\section{Homolochunia Valdiviae DofL.}

Taf. XLIX, Fig. 3; Taf. LI, Fig. 2.

Homolochunia besitzt, wie alle Homoliden, ein sehr langgestieltes, freiberregliches Auge. Der Augenstiel ist mit einem doppelten Gelenk versehen, der proximale Teil zwischen dem I. und 2. Gelenk ist cylindrisch, der distale Teil ist sehr viel breiter, keulenförmig enveitert und besitzt an der vorderen Fläche eine weit ausgebreitete Cornea, welche so angeordnet ist, daß sie einen sehr großen Gesichtswinkel umfaßt (ca. 250 in der horizontalen Durchschnittsebene). Der distale Teil des Augenstieles ist von oben nach unten stark abgeplattet, so daß der Querschnitt durch das Auge etwa einem Rechteck mit abgerundeten Schmalseiten glcicht. Die Facettenregion erscheint deutlich pigmentiert, die einzelnen Facetten sind ziemlich klein. Auf dem horizontalen Durchschnitt zeigt sich, daß der ganze Stiel eine sehr dicke Cuticula besitzt, welche sich in dem Gebiet der Cornea sehr stark verdünnt (Taf. LI, Fig. 2). In dem ganzen dicken Teil ist die Cuticula des Stieles mit eigentümlichen, schuppenförmigen Haaren bedeckt (Taf. LI, 
Figr. 2 H). Diese Haare sind mit einem kleinen Kugelgelenk der obersten, stark färbbaren Cuticulaschicht eingefügt. Die ganze übrige Dicke der Cuticula wird von einem feinen Kanal durchsetzt, an dessen unterem Ende eine Zelle sitzt. Letztere entsendet durch den Kanal hindurch einen Fortsatz zur Basis des Schuppenhaares. An manchen Stellen sieht es aus, als befänden sich zahlreiche Zellkerne in dem Kanal. Das Schuppenhaar selbst hat einen eigenartigen Bau, welcher bei den Brachyuren nicht selten vorkommt, und welcher bisher, glaube ich, niemals eingehender beschrieben worden ist.

Die äußere Form des Haares entspricht etwa dem eines großen Aroideenblattes, doch ist es nicht lang gestielt, sondern sitzt mit dem kurzen Gelenkstielchen fest in der Gelenkpfanne und erhebt seine Spreite nur wenig über die Oberfläche des Augenstieles. Es ist nicht vollkommen glatt, sondern besitzt eine gewisse Dicke, es ist aber nicht massiv gebaut, sondern weist eine eigenartige, sehr zarte Struktur auf. Im Durchschnitt erkennt man zahlreiche feine Stränge, welche von der unteren Fläche zur oberen ziehen und sich gegen die Oberfläche hin fein verästeln. Diese Stränge sind der Ausdruck einer fast schaumartigen Struktur. Es handelt sich aber nicht um vakuolenartige Gebilde, sondern um viele feine Stränge und Lamellen, welche alle ihren Stützpunkt in einem starken Balken finden, welcher, dem Mittelnerv eines Blattes vergleichbar, vom Gelenk ausgeht und das ganze Schuppenblatt durchzieht. Derartige Schuppen kommen bei zahlreichen Dromiiden und Oxyrhynchen vor. Indem sich ihre Ränder fest über- und aneinander lagern, erzeugen sie eine feste filzartige Bedeckung der Oberfläche des Tieres. Weitere Angaben findet man im 2. Abschnitt dieses Teils.

Es liegt in der Natur der Sache, daß ein so kompliziertes großes Auge auch einen starken Muskelapparat zu seiner Bewregung braucht, mancherlei Stützgewebe besitzt und mit besonders wohlausgebildeten Organen zur Ernährung und zum Schutz der einzelnen Teile versorgt ist. Ich will hier nicht im Detail auf die interessanten Befunde eingehen, welche sich in dieser Hinsicht machen lassen, ich will nur auf einige Beobachtungen hinweisen, die sich sofort bei der Durchsicht der Präparate aufdrängen. Zunächst fällt auf, daß der ganze Innenraum des Augrenstieles von der Grenzmembran des Auges bis zum Austritt des Augennerven zwischen den einzelnen Organteilen eine dichte Füllsubstanz aufweist. Es ist mir nicht ganz klar geworden, ob es sich in ihr nicht um geronnene Blutflüssigkeit handelt. Der ganz enorm entwickelte Ganglionapparat ist in eine Art von bindegewvebiger Tasche eingeschlossen, deren Wandungen dick und grobfaserig sind. Aehnliche Bildungen umschließen zwar auch bei anderen Augenformen den Ganglienkomplex, aber bei keinem anderen Auge habe ich sie so stark entwickelt vorgefunden.

Schreiten wir nun zur Betrachtung des eigentlichen optischen Apparates, so ist zunächst zu erwähnen, daß die zu jedem Augenkeil gehörige Corneafacette sehr dünn ist. Im Durchschnitt ist sie etwa $2^{1} / 2$ mal so breit als dick. Die Schichtung in ihr ist sehr undeutlich. Sie ist nur ganz schwach bikonvex gewölbt.

Corneafacetten und Krystallkegel sind im Querschnitt viereckig. Die Krystallkegel sind etwa 4 mal so lang als breit, sie sind fast ganz prismatisch gebaut, ihr vorderes Ende ist ziemlich gerade abgestutzt, ihr hinteres Ende ist halbkugelförmig abgerundet. Sie sind fast in ihrer ganzen Ausdehnung von einem deutlichen dunkelbraunen Pigmentmantel umhüllt. Der Pigment- 
mantel beginnt etwas nach dem distalen Ende und erstreckt sich auf etwa $2 / 3$ der Ausdehnung der Krystallkegel proximalwärts. Da sie schr eng aneinanderliegen, ist das l'igment in ganz dünnen Blättern zwischen sie eingrekeilt. Die Krystallkegel sind bei dieser Art besonders hart und sind - vielleicht durch Lösung von Pigment - gelblich gefürbt. Die Details des Baues des Stäbchens sind an meinen Präparaten nicht schr klar zu erkennen, da durch Quellung große Klumpen einer bräunlichen Substanz ausgeschieden sind und an manchen Stellen die Lagerung der Teile zueinander vollkommen verschoben haben. Doch waren einzelne Regionen der geschnittenen Augen für die Untersuchung etwas günstiger. Neine Untersuchung gilt daher hauptsächlich für die randständigen Stäbchen. In der Nähe des proximalen Endes der Krystallkegel befinden sich einige Kerne, welche wohl auf die Pigmentzellen zu bezichen sind. Die Stäbchen sind in zwei verschieden strukturierte Hälften geteilt; die distale Hälfte ist, an den Krystallkegel anschließend, zunächst etwa so dick wie dessen Basis, verschmälert sich aber dann rasch in einen dünnen Strang, welcher etwa die Hälfte der ganzen Länge des Stäbchens erreicht. Die proximale Hälfte ist dünn spindelförmig. Während der an den Krystallkegel anstoßende kurze, verdickte Teil Querstrichelung zeigt, ist der daran anschließende Teil fein längsstreifig. Der untere spindelförmige Teil zeigt die übliche Blättchenstruktur mit spiraliger Anordnung. Der ganze Zwischenraum zwischen den Stäbchen, welche, entsprechend deren Form, oben weit und unten enger ist, ist mit einer feinkörnig niedergeschlagenen Substanz (vielleicht geronnene Blutflüssigkeit?) erfüllt, Die äußeren Seiten des ganzen Augenapparates bekleidet eine dichte Pigmentmasse, welche an der Membrana fenestrata mit dem unterhalb derselben gelegenen Retinapigment (Taf. LI, Fig. $2 R p$ ) in Verbindung tritt. Dieses ist viel feiner verteilt als das Irispigment. Es begleitet meistens die Nervenstränge bis in eine geringe Entfernung von ihrem Ursprungsort.

Die aus den Stäbchen hervorgehenden Neurofibrillen erreichen nämlich, in einer großen Anzahl von Nervensträngen vereinigt das mäßig weit entfernte 1. Ganglion opticum. Diese Nervenstränge befinden sich nicht etwa frei in dem Zwischenraum zwischen Auge und Ganglion, wie das bei manchen anderen Augen der Fall ist, sondern sind vollkommen in jene feine, granulierte Substanz eingebettet, welche ich vorher als Ausfüllung des Zwischenraumes zwischen dem Stäbchen beschrieben habe, und welche auch sonst alle freien Räume des Augenstieles ausfüllt (Blutflüssigkeit?). Das I. Ganglion opticum hat ungefähr die Form eines Hutpilzes, dessen Stiel etwa das 2. Augenganglion darstellen würde. Die Rindenschicht ist relativ nicht sehr dick, die Markschicht zeigt, entsprechend der großen Anzahl von Augenkeilen, eine große Anzahl von Stäbchenbildungen, welche einander vollkommen parallel angeordnet sind. Von den übrigen Ganglien wäre hervorzuheben, daß sie, besonders das 4. mit seinen gehirnartigen Windungen, sehr groß sind. Aus dem 4. geht der sehr starke Sehnerv (Taf. LI, Fig. 2 No) in mehreren Portionen hervor. Nachdem er aus dem Sack, welcher die Ganglien umschließt, hervorgetreten ist, durchtritt er die ziemlich engre Gelenköffnung zwischen den beiden Teilen des Augenstieles.

Als besonders auffallend am Bau dieses Auges wäre hervorzuheben, daß die Stäbchen in dem nach außen grelegenen Augenabschnitt viel größer sind, als in der Hälfte, welche der Mittellinie des Krabbenkörpers zugewandt ist. Im letzteren Abschnitt erreichen sie nur $1 / 3-1 / 2$ der Länge, welche sie im äußeren Teil besitzen (s. u. Tabelle). Ein so auffallender Unterschied lïßt sich für die Krystallkegel nicht feststellen, wenn sie auch im äußeren Teil etwas größer sind. Die Corneafacetten scheinen im ganzen Auge übereinstimmende Dimensionen zu haben. 
Maße des Auges und seiner Teile:

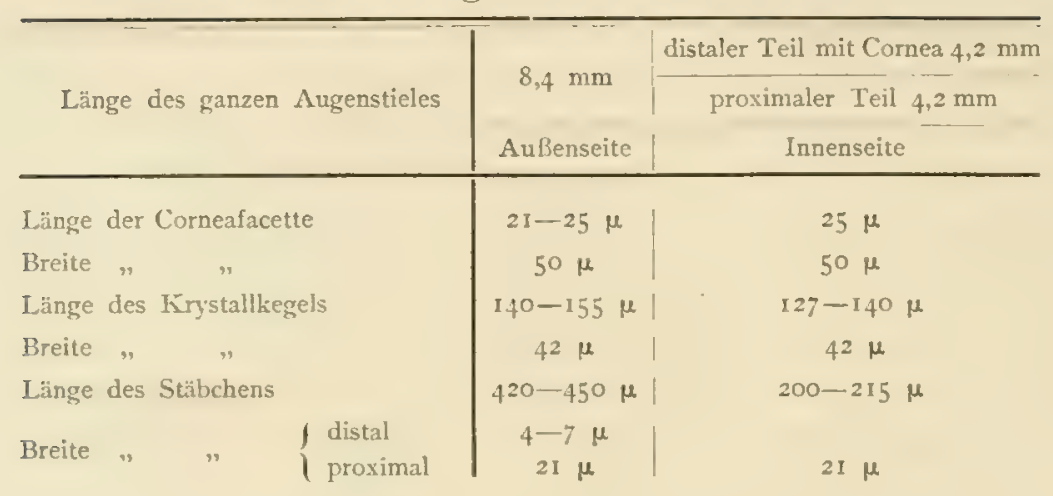

\section{Ethusina abyssicola S. J. SMITH.}

Taf. XLIV, Fig. $1-3,8$ u. 9 .

Die Augen der Gattung oder Untergattung Ethusina unterscheiden sich von denen der verwandten Formen, besonders von den eigentlichen Ethusa-Arten durch ihre Kleinheit, die Kürze ihrer Stiele, sowie durch den Umstand, daß die Augenstiele, statt beweglich zu sein, mit den umgebenden Partien des Cephalothorax verwachsen sind. Im Zusammenhang damit ist es sehr bemerkenswert, daß ich im Augenstiel keine Muskeln oder Ansätze von solchen nachweisen konnte. Es wäre ja auch möglich, daß dies auf einen Präparationsfehler zurückzuführen wäre; nach dem gesamten Aussehen der Schnitte halte ich dies aber nicht für wahrscheinlich. Doch ist schon von außen zu erkennen, daß die Cornea in Facetten eingreteilt ist, sowie daß ein dunkles Pigment vorhanden ist. Das letztere ist besonders weiter rückwärts im Auge in dichter Masse angehäuft. Der von der Cornea eingenommene Bezirk ist relativ klein, er nimmt nur einen geringen Teil des distalen Endes des Augenstieles ein und ist aufallend viereckig konturiert (vergl. Taf. XLIV, Fig. I U. 2).

Untersuchen wir das Auge auf Schnitten, so können wir feststellen, daß es aus einer relativ geringen Anzahl von Augenkeilen zusammengesetzt ist. Diese Augenkeile sind ziemlich normal gebaut. Wir erkennen zunächst eine dicke, sehr fein geschichtete Cornea, welche entsprechend den Augenkeilen in kleine Facetten abgeteilt ist. Es ist hervorzuheben, daß die Einteilung der Cornea an der Außenseite kaum oder gar nicht erkennbar ist, während sie nach innen vollkommen deutlich ist (Taf. XLIV, Fig. 3). Im centralen Teile des Auges ist die Cornea dünner als peripher. Die Form der Corneafacetten ist eine etwa quadratische. Die Wölbung nach innen ist deutlich konvex. Auch in den mittleren Teilen, wo die Cornea am dünnsten ist, ist ihre Ausdehnung in der Richtung der optischen Achse eine größ̧ere als in der Breite. Maße sind unten angeführt.

An die Corneafacetten stoßen die kurzen Krystallkegel, deren Länge die Breite kaum übertrifft. Sie sind dicht in ein dunkelbraunes Pigment eingehüllt. Das Pigment reicht vom distalen Ende der Krystallkegel bis zu der Stelle, wo sie sich kelchförmig verjüngen, um in die Stäbchen überzugehen (Taf. XLIV, Fig. 3 u. 8). Das Pigment ist sehr feinkörnig, in Zellen eingeschlossen. Doch scheinen die großen Zellen mit den dichten Kernen, welche sich in dieser Region als gleichmäßige Schicht durch das Auge ziehen, nicht mit ihnen in Zusammenhang zu stehen (Taf. XLIV, Fig. $8 R$ ). 
Die Stïbchen selbst sind dünn, schlank, etwa doppelt so lang wie die Krystallkegel und verjüngen sich in ihrem Verlaufe von diesen bis zur Membrana fenestrata allmählich. Zwischen ihnen befindet sich ein dichtes Füllgewebe, welches aber in meinen Präparaten schlecht erhalten ist. Es ist aber zwischen den Stäbchen keine Spur von Pigment vorhanden.

Dagegen findet sich eine mächtige Anhäufung von Pigment unmittelbar hinter der Membrana fenestrata. Die aus den Stäbchen hervorgehenden Nervenfasern ziehen in mehreren dicken Strïngen von der Membrana fenestrata zu dem etivas entfernt gelegenen I. Ganglion opticum (Taf. XLV, Fig. 3 Nf). Diese Stränge sind im distalen Teil, also in dem Teil, in welchem sich die Nervenfasern erst bündelweise vereinen, von dichtem, dunkelbraunem Pigment umgeben, welches dicke, klumpenartige Anhäufungen. bildet und die Nervenfasern vollkommen verhüllt. Proximal wird das Pigment allmählich feinkörniger, schließlich verliert es sich, und man sieht die Nerven nicht weit von ihrem Eintritt in das Ganglion frei hinzichen (Taf. XLIV, Fig. 9).

Im I. Ganglion opticum kann ich von den stäbchenförmigen Bildungen nichts Deutliches erkennen.

Die 4 Augenganglien mit ihren Verbindungssträngen bilden nur einen ganz dünnen, im Centrum des Augenstiels verlaufenden Strang. Im übrigen sind augenscheinlich alle Teile wohl ausgebildet, aber sie erreichen nur eine geringe Größe, und die Zahl der sie zusammensetzenden Elemente ist nur eine geringe. Histologische Details über den Bau des Ganglions führe ich nicht an, da zu diesem Zwecke mein Material nicht gut genug erhalten ist.

Auf die Gesamtanordnung des Pigmentes werde ich sogleich zu sprechen kommen, wenn ich den Bau des Auges von Ethusa somalica geschildert haben werde.

Der ganze Augenstiel mißt I,3 $\mathrm{mm}$ in der Länge.

Maße der Augenteile:

\begin{tabular}{l|c|c|c}
\hline & Länge & Breite \\
\hline Corneafacetten & Augenmitte & $19 \mu$ & ca. $30 \mu$ \\
Rristallkegel & peripher & $50-75 \mu$ & ca. $30(27-33) \mu$ \\
& $23 \mu$ & ca. $30 \mu$
\end{tabular}

\section{Ethusa somalica DofL.}

Taf. XLIV, Fig. 4 น. 5

Das Auge von Ethusa somalica unterscheidet sich in einigen Punkten schon bei ïußerlicher Prüfung von demjenigen von Ethnsina abyssicola. Es hat eine Länge von ca. I $\mathrm{mm}$ mit dem Stiel.

Der Augenstiel zeigt eine, wenn auch nicht sehr beträchtliche, so doch unzweifelhaft feststellbare Beweglichkeit. In seinem äußeren Aufbau weicht er dadurch ab, daß die spiralige Wulstung fehlt. Auch hier kann ich auf den Schnitten Muskeln nicht nachweisen.

Die Facettenregion umfaßt einen relativ viel größeren Teil der Endpartie des Augenstieles und ist nicht viereckig, sondern durch eine bogenförmige Kontur abgegrenzt (Taf. XLIV, Fig. 4). 
Auf Schnitten zeigt das leider nicht sehr gut erhaltene Objekt eine Reihe von interessanten Abweichungen vom Bau des Ethusina abyssicola-Auges.

Die Cornea ist relativ dick und deutlich geschichtet. Doch wird sie auch in den peripheren Teilen bei weitem nicht so dick, wie bei Ethusina abyssicola; auch ist die gesamte Cuticula des Augenstieles viel dünner. Auch der Breitendurchmesser der Corneafacette ist ein geringerer.

Ein gleicher Unterschied findet sich bei den Krystallkegeln.

Von den Stäbchen und dem Gangliensystem kann ich nichts bestimmtes sagen, da sie nicht gut erhalten sind. Doch kann man sehen, daß jenseits der Membrana fenestrata eine ganze Anzahl von Nervensträngen zum I. Ganglion opticum hinzogen. Die ganze Nervenmasse und ihre Pigmenthülle ist so merkwürdig in Reihen angeordnet, daß ich mir keine bestimmte Vorstellung darüber machen kann, bis zu welchem Grade dies ein Kunstprodukt ist. Jedenfalls ist ein größerer Teil des Augenstieles im Innern von der Nervenmasse ausgefüllt als bei Ethusina abyssicola.

Vor allem fällt auch hier die mächtige Pigmentmasse auf, welche eine Strecke hinter der Membrana fenestrata beginnt und von der einen Seite her wie eine Schale die Nervenmasse umfaßt. Es ist dunkelbraunes Pigment, in runden Klumpen angehäuft, und diese Klumpen erscheinen zum Teil in Reihen angeordnet (s. Taf. XLIV, Fig. 5 Rp). Merkwürdig ist die Menge und die Lage dieses Pigments. Aehnlich ist es ja auch bei E. abyssicola angeordnet, und auch dort überrascht es durch seine Masse und dunkle Färbung.

Fragt man sich nach dem Zweck einer solchen Anhäufung, so ist man unwillkürlich versucht, eine hinter dem Auge gelegene Lichtquelle zu vermuten, deren Licht von den empfindlichen Nervenfasern abgehalten werden soll. Doch habe ich vergeblich nach einer solchen Lichtquelle, etwa einem am Augenstiel befindlichen Leuchtorgan gesucht. Auch an den umgebenden Partien des Cephalothorax konnte ich bei äußerlicher Untersuchung nichts Derartiges finden. Allerdings war mein Material zu kostbar — je I Stück von jeder Art — um eine genaue Untersuchung zu ermöglichen. Hier, wie in so vielen Fällen, mangelt uns leider jegliche Beobachtung am Lebenden.

\section{Cymonomus granulatus NoRM.}

Taf. XLIV, Fig. 6 u. 7.

Schon seit der Expedition der "Porcupine“ spielen die Augen dieser Art in der Litteratur über Tiefseetiere eine besondere Rolle. Norman und Wrville Thomson hatten zuerst die merkwürdigen Bildungen, welche wir bei Exemplaren dieser Art an der Stelle von Augenstielen treffen, untersucht, allerdings nicht histologisch, und hatten festgestellt, daß bei gewissen Exemplaren die Augen so sehr umgewandelt sind, daß sie von einer Umwandlung derselben in antennenartige Gebilde sprachen. Dabei glaubten sie einen gesetzmäßigen Zusammenhang zwischen der Tiefenverbreitung und der Reduktion der Augen feststellen zu können. Sie hatten nämlich gefunden, daß Exemplare aus 200-670 $\mathrm{m}$ in dem südlichen Teil des von ihnen festgestellten Verbreitungsbezirkes der Art zwar blind zu sein schienen, aber immerhin rudimentäre Augen an den Augenstielen zeigten. Die Augenstiele waren nämlich vorne abgerundet, von Pigment 
haben sie nichts nachgewiesen. Die Augenstiele waren beweglich und standen zu beiden Seiten eines ziemlich langen Rostrums. Bei Exemplaren jedoch, welche im Norden in einer Tiefe von $1000-1300 \mathrm{~m}$ gefangen worden waren, waren dic Augenstiele unbeweglich. Sie waren viel größer als bei der südlichen Form, waren an der Basis einander sehr genähert und sogar verwachsen; ferner waren sie an der Spitze nicht abgerundet, sondern endeten mit einer Art von spitzem Stachel. Sic hatten nicht mehr nach der Ansicht Norman's die Funktion von Augen, sondern sie dienten als Rostrum, während das eigentliche Rostrum, welches bei den südlichen Exemplaren so kräftig entwickelt war, überraschenderweise verschwunden war.

Dieses Beispicl von Abhängigkeit der Augrenausbildung von der Tiefenverbreitung der gleichen Art hat seither in der theoretischen Litteratur immer eine Rolle gespielt, ohne dal\} eine genaue Nachuntersuchung in den fast 40 Jahren, die seit der ersten Angalse verflossen sincl, vorgenommen worden wäre. Eirst Bouvier ist in seiner mit A. MiLne-Euwardos verfaßten Bearbeitung der dekapoden Krustaceen der "Talisman“-Expedition ( I g00) auf die Frage an cler Hand von neuem Material zu sprechen gekommen. Er fand, daß bei den zahlreichen Exemplaren, welche er untersuchte, ein deutliches Rostrum vorhanden war, und daß dic Augenstiele beweglich waren. Auch zeigten sie eine glatte und manchmal selbst ein wenig gefürbte Corneaoberfläche. Da seine Exemplare aus dem südlichen Teil des Verbreitungsbezirkes stammten, so vermutet er, daß die geographische Verbreitung, nicht die Tiefenverbreitung, im Zusammenhang stünde mit der Umwandlung der Augenstiele. Er gründet dies darauf, daß seine Exemplare aus verschiedenen Tiefen stammten und trotzdem alle gleichmäßig ausgebildete Augen besaßen.

Ich kann durch genauere Untersuchung eines allerdings geringen Materials einige Beiträge zur Lösung dieser Frage liefern, indem ich die Augen eines Exemplares von der ostafrikanischen Küste aus der Tiefe von ca. I000 m, welches die Valdiviaexpedition gefangen hatte, und ein Exemplar von Gibraltar aus der Tiefe von nur $440 \mathrm{~m}$, welches mir Herr Professor E. L. BouVIER aus dem Material des Talisman in liebenswürdigster TVeise zur Verfügung gestellt hatte, untersuchen konnte. Ich erhielt dabei Resultate, wolche zwar mit denen von Noruns nicht absolut übereinstimmen, aber ihnen doch analog sind. Schon das Auge aus einer Tiefe von $440 \mathrm{~m}$ zeigte deutlich die Charaktere eines rückgebildeten Auges. Es enthielt keine Spur von Pigment, der Augenstiel war genau der Beschreibung von Bouvier entsprechend, schlank, mit Stacheln besetzt, aber am vorderen Ende abgerundet und mit einer durchsichtigen Cornearegion versehen, welche nach hinten deutlich abgegrenzt ist (Taf. XLIV, Fig. 6). Am durchsichtig gemachten Präparat sah man Spuren von Augenkeilen durchschimmern, aber auf Längsschnitten stellte sich heraus, daß die Verhältnisse ganz ähnlich lagen wie bei der Tiefenform glaucomma von Cyclodorippe uncifora. Es war nämlich eine dicke Cuticula vorhanden, welche auch in der Cornearegion sehr dick war. Eine Einteilung in einzelne Facetten war nicht nachweisbar, auch war die Wölbung der Cuticula eine vollkommen gleichmäßige.

Krystallkegel waren auch keine nachweisbar und die Stäbchen setzten direkt an der Cuticula an. Wie wir sehen, also Verhältnisse, welche denen von Cjelodorifpe uncifera glaucomma entsprechen.

Ganz anders sah das Auge der Tiefenform von der ostafrikanischen Küste aus. Das Rostrum dieser Form war, wie schon in der Beschreibung S. 33 hervorgehoben, sehr klein und wurde von den Augenstielen überragt. Die Augenstiele selbst waren mit einer kräftigen Spitze 
versehen, die Stacheln waren viel mehr dornenartig ausgebildet, als bei dem Auge der Exemplare aus dem mittleren Atlantik. Der ganze Augenstiel lief viel spitzer zu als bei jener Form und der ohnehin viel kleinere Raum an der Spitze trug keine Andeutung einer Cornearegion (Taf. XLIV, Fig. 7).

Auf Schnitten erkannte man eine über das ganze Gebilde sich ausdehnende, sehr dicke Cuticula. Die Stacheln erschienen als eine Verdickung dieser Cuticula, indem keine Hohlräume sich in sie hineinerstreckten. Soweit der Erhaltungszustand des Auges es zuläßt, und der ist für die Entscheidung dieser Fragen vollkommen genügend, ist weder eine Spur von Facetten noch von Krystellkegeln noch von Stäbchen vorhanden (Taf. XLIV, Fig. 7). Jedoch ist im Innern des Auges noch deutlich ein starker Nervenstrang zu erkennen. Wo allerdings dessen Fasern sich hinerstrecken, das war nicht zu entscheiden. Andere Nervenfasern im Auge zogen zu den Sinneshaaren hin, welche sich besonders in den Nischen zwischen den Stacheln auf kleinen Kugelgelenken erhoben. Ob allerdings diese Nervenfasern mit dem starken Nervenstrang in $\mathrm{Zu}$ sammenhang standen, das konnte ich nicht entscheiden. Ein schwacher, bräunlicher Ton, welcher durch die Cuticula durchschimmerte, rührte nicht von Pigment her, sondern von einer leichten Bräunung der Muskelfasern. Es waren nämlich solche in dem Augenstiele noch erkennbar, wie denn das ganze Gebilde noch beweglich war.

Wir haben es hierin also mit einem Organ zu tun, welches, soweit unsere Kenntnisse etwas derartiges zu beurteilen erlauben, sicherlich als Sehorgan untauglich war. Allerdings hatte es statt dessen eine andere Funktion übernommen, und es scheint mir keinem Zweifel zu unterliegen, daß Norman bis zu einem gewissen Grade recht hatte, wenn er sagte, daß die Augenstiele die Funktion von Rostren übernommen hätten. Denn wie solche oder wie Antennen müssen die Augenstiele dem Tiere als Wahrnehmungsorgane für Druck oder Stoß resp. als Tastorgan dienen. Der Augenstiel hat damit aber durchaus keine Funktion übernommen, welche ihm von vornherein fremd gewesen wäre; denn wie der ganze Körper der Crustaceen an verschiedenen Stellen mit Sinneshaaren besät ist, so pflegen sie auch auf dem Augrenstiel vorhanden zu sein. Ich habe sie besonders an den dorsalen Hörnern der Augenstiele gefunden, welche zwischen die Cornea eingekeilt zu sein pflegen und sich oft als Fortsätze über dieselben erheben. Ich habe dieselben und die Sinneshaare z. B. bei Cyrtomaia eingehender beschrieben und abgebildet (s. unten). Es ist also ein Organ des Gesichtssinnes in ein solches des Tastsinnes umgewandelt worden, indem während des Schwindens der Endigungen des einen Sinnes die des anderen erstarkten und sich vermehrten.

Eine neue Arbeit von Ray LANkester erschien erst während des Druckes dieses Werkes und ich habe sie unten in der zusammenfassenden Uebersicht über die Augen der Tiefseekrabben noch berücksichtigen können.

\section{Cyclodorippe uncifera ORTMANn.}

\section{7a. Cyclodorippe uncifera melanomma DoFL.}

Taf. XLVI, Fig. 3, 4, 5; Taf. XLVII, Fig. 7.

Das Auge dieser Form entspricht in seinem Bau mehr den lichtbewohnenden als den Dunkelformen. 
Der Augenstiel ist schlank und dünn, die Cornearegion umfaßt das ganze vordere Ende und dehnt sich ziemlich weit auf der ventralen Seite nach hinten aus. Die Facetten sind klein, viereckig, ihre Zahl eine relativ große. Auf dem sagittalen Querschnitt zählt man 40-50 Augrenkeile, was bei der Kleinheit des Auges eine ziemlich große Zahl ist. Schon von außen schimmert ein dunkelbraunes Pigment durch. Die Cuticula des Augenstieles ist ziemlich dünn, auch die Corneafacetten sind in der Richtung der optischen Achse nicht stark entwickelt, sondern nur ebenso lang als breit. Jede einzelne Facette stellt eine bikonvexe Linse dar. Gegenüber der später zu schildernden Form glancomma ist hervorzuheben, daß die Cornea eine starke, deutliche Schichtung in ca. ro Lagen zeigt (Taf. XLVII, Fig. 7). An sie schließt sich ein Krystallkegel an, welcher etwa $2 \frac{1}{2} \mathrm{mal}$ so lang als breit ist, dabei nicht ganz so breit, als das untere Ende der Corneafacetten. Der Krystallkörper ist kegelförmig gestaltet und läuft in eine feine Spitze aus. Der Erhaltungszustand des Objektes erlaubt kein sicheres Urteil über die Stelle, an welcher Krystallkegel und Stäbchen ineinander übergehen. Die Krystallkegel sind untereinander durch ziemlich erhebliche Zwischenräume getrennt. In diese Zwischenräume erstrecken sich die pseudopodienartigen Fortsätze der Irispigmentzellen. Durch ein feines Halsstück verbindet sich der Krystallkegel mit den langen, regelmäßig spindelförmigen Stäbchen. Dieselben sind etwa romal so lang als breit und sind durch regelmäßige Abstände von einer WVeite, welche ihrer eigenen Breite gleichkommt, voneinander geschieden. Sie sind vollkommen auf allen Seiten von einem braunen Pigmentmantel umhüllt. Das Pigment ist wohl als teilweise vom Irispigment, und teilweise vom Retinapigment herrührend, zu betrachten. Es ist also ein Auge mit Lichtstellung des Pigments.

Die Membrana fenestrata wird von den zahlreichen Neurofibrillen durchsetzt, welche sich nicht sehr bald zu einem Nervenstrang vereinigen, sondern die weite Strecke zwischen der Membrana fenestrata und dem I. Ganglion opticum mit einem dichten Geflecht von Fasern erfüllen.

Der Ganglienapparat ist in meinen Schnitten nicht gut genug erhalten, um eine genaue Beschreibung desselben liefern zu können. Es ist aber deutlich erkennbar, daß sämtliche Bestandteile in guter Ausbildung vorhanden waren. Die Kerne in sämtlichen Teilen des Auges sind klein.

Die ganze Ausbildung des Auges weist darauf hin, daß wir es weder mit dem Auge eines ausgesprochenen Lichttieres, noch mit dem einer Dunkelform zu tun haben. Die Zahl und die Form der Elemente, die braune Farbe des Pigments und die Beschaffenheit des optischen Apparates weisen darauf hin, daß das Auge nicht sehr geeignet sein kann zur Wahrnehmung von Bildern. Immerhin ist es ein vollfunktionierendes Organ, welches sich in ausgesprochener Weise von der sogleich zu beschreibenden Tiefseeform derselben Art unterscheidet. Es sei bemerkt, daß das Tier in der Sagamibai in Japan in einer Tiefe von etwa $30-50 \mathrm{~m}$ gefangen worden ist.

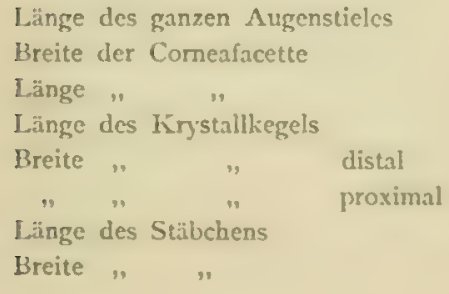

Maße der Augenteile:

\begin{tabular}{|c|c|c|c|}
\hline $1,5 \mathrm{~mm}$ & Kerndurchmesser & der Stäbchenzellen & $4 \mu$ \\
\hline $28 \mu$ & , & $\therefore$ Corneagenzellen & 1,5 \\
\hline $28 \mu$ & " & ", Ganglienzellen & $3 \mu$ \\
\hline $21 \mu(28 \mu)$ & ," & " Epithelzellen & $4 \mu$ \\
\hline $8,5 \mu$ & $"$ & "Riesenzellen im & \\
\hline $\begin{array}{c}2 \mu \\
60-70 \mu\end{array}$ & & Ganglion & $4 \mu$ \\
\hline $\begin{array}{l}60-70 \mu \\
11-12 \mu\end{array}$ & Gesamtdurchmesser & $r$ der letzteren & I5 $\mu$ \\
\hline
\end{tabular}




\section{7b. Cyclodorippe uncifera glaucomma ALC.}

Taf. XLVI, Fig. 6 u. 7; Taf. XLVII, Fig. 6.

In allen Charakteren, in welchen das soeben besprochene Auge demjenigen eines Lichttieres glich, unterscheidet sich das Auge der Tiefseeform von ihm.

Der Stiel ist ziemlich kurz, plump keulenförmig; seine Gesamtlänge ist 0,9 mm. Die Cornearegion überzieht das vordere Ende gleichmäßig, ohne sich oben oder unten weiter nach hinten zu erstrecken. Schon bei der Betrachtung von außen erkennt man, daß die Cornea nicht in Facetten eingeteilt ist, vielmehr ist sie vollkommen gleichmäßig ausgebildet (Taf. XLVI, Fig. 6). Es schimmern allerdings Andeutungen von Augenkeilen durch, aber die sonst so regelmäßige Einteilung der Cornea in kleine Partien fehlt vollkommen. Auch schimmert keine Spur von Pigment durch, vielmehr ist das Auge vollkommen blaß und hat einen milchigen, opalescenten Glanz. Auf Schnitten erkennt man zunächst, daß die Cuticula des ganzen Augenstiels eine außerordentlich dicke ist. Sie ist vor allen Dingen viel dicker als bei der forma melanomma.

In der Cornearegion erkennt man kaum eine Spur von der sonst so regelmäßigen und deutlichen Einteilung in kleine Lichtbrechungsapparate. Nicht nur, daß die äußere Oberfläche in ganz gleichmäßiger Wölbung verläuft, auch an der Innenseite erkennt man nur schwache Vorwölbungen, welche den einzelnen Augenkeilen entsprechen. Nur auf sehr feinen Schnitten erkennt man bei starken Vergrößerungen feine Andeutungen einer Einteilung der Cornea (Taf. XLVII, Fig. 6).

Ferner kann man von Schichtungen in der Cuticula nur schwache Spuren wahrnehmen. Diese Andeutung von Schichtung ist aber nicht wie sonst durch deutliche Lamellen gebildet, sondern man unterscheidet nur proximal in der Cuticula zwei Regionen, die sich etwas intensiver färben. Nur diese am meisten proximal gelegenen Schichten zeigen auch schwache Spuren eines wellenförmigen Verlaufes. Auffallend ist dagregen eine feine radiäre Streifung der Cuticula, welche an den Corneafacetten anderer Formen nicht nachzuweisen ist (Taf. XLVII, Fig. 6).

Direkt an die Cornea stoßen nun die Stäbchen an. Allerdings sind noch Fortsätze der Zellen zwischen sie und die Cornea eingekeilt, aber von Krystallkegeln ist keine Spur vorhanden, und es ist auch kaum mit Sicherheit zu sagen, welche von den Zellen als Corneazellen, und welche als Krystallkegelzellen aufzufassen sind. Es lassen sich auf den Schnitten in der Nachbarschaft des oberen Stäbchenendes immer eine ganze Anzahl von Zellkernen unterscheiden, deren Zugehörigkeit aber schwer zu bestimmen ist. Im ganzen Auge sind auch auf Schnitten nicht die geringsten Spuren von Pigment zu entdecken. Die Stäbchen selbst sind plump gestaltet, ihre Länge ist $3-3^{1} / 2$ mal so groß als ihre Breite (im Längsschnitt). Sie sind durch etivas unregelmäßige Zwischenräume voneinander getrennt. Ihre Zahl ist entsprechend ihrer Größe viel geringer als bei der forma melanomma, I 5-20 in einem sagittalen Schnitt. Auch die Länge der Stäbchen ist keine ganz regelmäßige, und ich kann auf meinen Schnitten auch eine Lamina fenestrata nicht mit Deutlichkeit nachweisen. Doch mag dies an der Konservierung liegen. Die Neurofibrillen bilden auch hier. ein dichtes Geflecht, vereinigen sich aber auch bald zu dem ventral verlaufenden Nervenstrange, welcher zum I. Ganglion opticum zieht.

Dieses liegt, entsprechend der Kürze des Augenstiels, nicht sehr weit von der Basis der Stäbchen entfernt. Der Ganglienapparat ist wohl ausgebildet. Er füllt proximal den größten Teil des Augenstieles aus. Die Kerne sind im ganzen Auge mittelgroß, die Kreuzungen der 
Fasern zwischen den einzelnen Ganglien sind deutlich erkennbar. Aus dem 4, schr massigen Fanglion entspringt der Nervus opticus als sehr kräftiger Strang. Wir haben also hier ein Aurge vor uns, welches gegenüber demjenigen der forma melanomma sehr rudimentïr ist. Der Mangel an Corneafacetten und Krystallkegeln bedeutet den Mangel fast jeden optischen Apparates, was die Abwesenheit von Pigment eigentlich als selbstverständlich erscheinen läßt. All dies im Verein mit der geringen Zahl von Augenkeilen führt uns zu der Annahme, daß dies Auge sicher zum Wahrnehmen von Bildern ungeeignet ist, ebenso zum Wahrnchmen von Berregungen, ja sogar zum Wahrnehmen der Lichtrichtung wird es kaum tauglich sein. Es wird vielleicht nur zur Wahrnehmung von Lichtintensitätsunterschieden dienen. Darauf, daß es aber immerhin cin funktionierendes Organ ist, weist die starke Entwickelung der nervösen Teile hin,

Ungefähr der gleiche Grad von Rückbildung ließ sich an Augren von Exemplaren aus Ostafrika aus 500-700 $\mathrm{m}$ Tiefe und an solchen aus der Sagamibai in Japan aus $150-200 \mathrm{~m}$ Tiefe nachweisen, welch letztere ich der bewährten Freundschaft Herrn Professor Döderierss in Straßburg verdanke.

Maße der Augenteile:

Der ganze Augrenstiel mißt in der Länge $0,9 \mathrm{~mm}$.

\begin{tabular}{|c|c|c|c|}
\hline Dicke der Cuticula & $3 t \mu$ & Durchmesser einer Ganglienzelle & \\
\hline Breite eines Corneaabschnittes & $17-21 \mu$ & 1) gewölunlichen & $5-7 \mu$ \\
\hline Länge eines Stäbchens & $50 \mu$ & 2) Riesen- & $10-12 \mu$ \\
\hline $\begin{array}{l}\text { Breite " " } \\
\text { Kerndurchmesser der Stübchenzelle }\end{array}$ & $17 \mu$ & Durchmesser von Epithelzellen & $7-I+\mu$ \\
\hline
\end{tabular}

\section{Cyclodorippe dromioides OrTn.}

Taf. XLVII, Fig. 8.

Ich habe, um für gewisse Punkte einen Vergleich zu ermöglichen, ein aus Japan stammendes Exemplar dieser Art aus ca. I $80 \mathrm{~m}$ Tiefe, welches mir Herr Professor DüDERLEIN in liebenswürdiger Weise aus den von $\mathrm{ihm}$ selbst gesammelten Schätzen zur Verfügung gestelit hatte, untersucht. Der Augenstiel war mäßig lang, dünn und in der Facettenregion kaum verdickt. Die Cornea zeigte sich deutlich in Facetten eingeteilt, welche von mittlerer Größe waren. Das Auge war vollkommen weiß.

Auf Schnitten zeigte der Augenstiel eine ziemlich dicke Cuticula, welche in der Cornearegrion etwas verschmälert war. Die Corneafacetten waren in Form von bikonvexen Linsen ausgebildet, deren äußere WV̈̈lbungen schwach, deren innere Wölbung jedoch sehr stark, fast halbkugelförmig war (Taf. XLVII, Fig. 8). Die Schichtung des Chitins war eine sehr deutliche. Der Durchmesser der einzelnen Corneafacetten in der Richtung der optischen Achse war größer als der Querdurchmesser. An sie schlossen sich sehr kleine Krystallkegel an, welche ungefähr die Form einer stark gekrümmten, konkav-konvexen Linse besaßen. Die Konkavität schloß sich dicht der proximalen Wölbung der Cornealinsen an, während die konvexe Seite an die Stäbchen stieß. Der Durchmesser dieser Bildungen in der Richtung der optischen Achse war nur hall, so groß als der Qucrdurchmesser und nur $\% / 3$ so groß als derjenige der Cornealinsen. Bei den 
meisten Krystallkegeln war deutlich in der Mitte die Trennungslinie zu erkennen, welche die übliche Zusammensetzung aus 4 Stücken verriet.

Die Stäbchen schließen sich mit breitem distalen Ende an die Krystallkegel an, deren Konvexität sie umfassen. Sie sind spindelförmig und relativ kurz. In ihrem Inneren läßt sich eine deutliche spiralige Streifung erkennen. Sie sind ziemlich dicht aneinander gelagert, immerhin sind Zwischenräume zwischen ihnen verhanden, während die Krystallkegel dicht aneinander stoßen. Die Zwischenräume sind durch zarte, durchsichtige Zellen ausgefüllt. Es ist weder von Irisnoch von Retinapigment eine Spur erkennbar. Aus jedem der Stäbchen geht ein Bündelchen von Neurofibrillen hervor. Diese Bündel konvergieren und vereinigen sich zu einem dicken, einheitlichen Strang, welche zu dem I. Ganglion opticum zieht. Dieses ist etwas distal von der Mitte des Augenstiels grelegen. Der ganze Ganglienapparat stellt einen Strang dar, welcher an seiner dicksten Stelle kaum doppelt so breit wird, wie der die Stäbchen mit dem Ganglion opticum verbindende Nervenstrang.

\begin{tabular}{|c|c|c|c|c|c|}
\hline Ganzer Augenstiel: & Länge & I,5 mm & Krystallkegel & Breite & $28-3 \mathrm{I} \mu$ \\
\hline Corneafacetter & Länge & $25-28 \mu$ & Stäbchen & Länge & $85 \mu$ \\
\hline " & Breite & $28-3$ I $\mu$ & , & Breite & $\{$ distal $17 \mu$ \\
\hline Krystallkegel & Länge & $17-21 \mu$ & 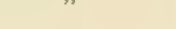 & & proximal $6 \mu$ \\
\hline
\end{tabular}

\section{Cyrtomaia Suhmi Miers.}

Taf. XLV, Fig. I-5; Taf. LII, Fig. 6.

Das Auge von Cyrtomaia ist zwar ein für Dunkelheit eingerichtetes Auge, aber es ist nicht etwa das Auge eines Tiefseetieres. Es ist das typische Beispiel eines in nicht besonders weitgehender Weise an das Leben in der Dämmerung angepaßten Brachyurenauges.

Der Stiel ist mäßig lang, in der Mitte etwas zusammengezogen, distal wieder verbreitert und ungefähr eiförmig aufgeblasen (Taf. XLV, Fig. I). Diese verdickte Region entspricht der Cornearegion, welche sich vorn und ventral ausdehnt, während an der dorsalen Seite eine von Facetten freie Region sich weit nach vorn erstreckt und über die Cornearegion hinaus in Form einer zipfelförmigen kleineren Spitze vorgezogen ist. Diese von Facetten freie Region beschränkt sich aber auf den medianen Teil der dorsalen Oberfläche. $\mathrm{Zu}$ beiden Seiten von ihr reichen die Facetten auch auf die Dorsalseite herüber.

Die Facetten sind mittelgroß, sie sind viereckig. Die Zahl der Facetten ist keine sehr große. Im sagittalen Längsschnitt zählt man deren 50. Das Auge erscheint durch das durchschimmernde Pigment leicht bräunlich gefärbt (Taf. XLV, Fig. 2).

Untersuchen wir das Auge auf Schnitten, so zeigt es sich von einer mäßig dicken Cuticula überzogen, welche in der Cornearegion sehr viel dünner ist. Jede einzelne der Corneafacetten ist in der optischen Achse nur halb so lang wie in der darauf senkrechten Richtung. Die Form der Facette entspricht einer bikonvexen Linse; in ihrer optischen Funktion wird sie allerdings einer konkav-konvexen Linse entsprechen. Die äußerste, sehr durchsichtige Schicht des Chitins zieht sich in ganz gleichmäßiger Krümmung über das ganze Auge hin, so daß die äußere Begrenzung einer jeden Corneafacette eine konvexe ist. Die darauf folgenden Lagen des Chitins 
sind viel dichter und deutlich konkav nach innen gekrümmt (Taf. XLV, Fig. 3 u. 4). Denselben parallel verlaufen sämtliche übrigen Schichten bis zu der innersten, so daß die Facette nach innen von einer stark konvexen Fläche begrenzt ist. Der Zwischenraum zwischen dieser Fläche und der ebenfalls leicht konvexen Fläche des Krystallkegels ist durch die Corneagenzellen und den kleinen Protoplasmakörper der Krystallkegelzellen ausgefüllt. Die Corneagrenzellen haben kleine, im Durchschnitt kreisrunde Kerne, während die Kerne der Krystallkegelzellen viel größer und etwa dreieckig erscheinen (Taf. XLV, Fig. 4).

Die Krystallkegel sind auf dem Längsschnitt fast eiförmig. Sie liegen aber ziemlich dicht aneinander, so daß die Seiten meist abgeplattet sind. Distal und proximal ist zwischen ihnen immer eine kleine, dreieckige Lücke vorhanden. Bei den central getroffenen sieht man in der Mitte deutlich die Linie, in welcher die einzelnen Bestandteile zusammenstoßen. Die 4 Teile stoßen so zusammen, daß auf dem Querschnitt etwa die Figur eines $\mathrm{H}$ entsteht. Der Pigmentmantel umgiebt die Krystallkegel so, daß sie auf dem Querschnitt fast kreisrund erscheinen (s. Taf. LII, Fig. 6). Jeder Krystallkegel ist nämlich von einem dichten Mantel dunkellsraunen Pigments umhüllt. Derselbe reicht in dünner Schicht bis zu den Krystallkegelzellen nach vorn, proximal ist die Pigmentmasse verdickt. In dieser Verdickung der Pigmentzellen liegen die Kerne (Taf. XLV, Fig. 4). Die Pigmenthülle, welche die Außenseite des äußersten Krystallkegels sowohl dorsal wie ventral in jedem Sagittalschnitt bekleidet, ist eine ziemliche Strecke weit proximal fortgesetzt, so daß auch die Region der Stäbchen von außen her vor Lichtstrahlen geschützt ist. In der Umgebung des unteren Endes der Krystallkegel lassen sich eine Anzahl von Kernen nachweisen.

Zwischen den Pigmentmassen tritt an das untere Ende der Krystallkegel das Stäbchen heran. Es ist an seinem oberen Ende schon sehr schmal, verschmälert sich aber dann noch mehr zu einem ganz dünnen Strang, um sich dann in der zweiten Hälfte seines Verlaufes zu einer mäßig dicken Spindel zu erweitern. Am unteren Ende ist diese Spindel wieder zugespitzt, und man sieht aus jeder derselben ein gesondertes Bündel von Neurofibrillen hervorgehen. Im oberen Teile des Stäbchens ist deutlich Querstrichelung erkennbar, der mittlere, sehr dünne Teil scheint nur aus dem Rhabdom zu bestehen, während in dem unteren Teil das ebenfalls verdickte Rhabdom wieder von gestrichelten Seitenteilen umgeben ist.

Die Lamina fenestrata ist sehr deutlich, hinter ihr sind die aus jedem Stäbchen hervorgehenden Neurofibrillenbündel je von einer sehr deutlichen, aber nicht sehr dichten, hellbraunen Pigmenthülle umgeben. Diese Neurofibrillenbündel vereinigen sich zu einer größeren Anzahl von Nervensträngen, welche zu dem nicht sehr weit entfernten I. Ganglion opticum ziehen. Der Umfang des Ganglienapparates ist ein mittelgroßer. Das ganze, in allen seinen Teilen wohlausgebildete Ganglion füllt etwa die Hälfte des ganzen inneren Hohlraumes des Augenstieles aus. Da das Objekt recht gut erhalten war, so gebe ich eine etwas ausführlichere Beschreibung der Struktur. Das I. Ganglion opticum hat etwa die Form einer dickwandigen, über das zweite Ganglion gestülpten Schüssel. Es besteht deutlich aus zwei Schichten. Ich bezeichne in der nachfolgenden Schilderung stets die zellkernreiche Schicht als Rindenschicht, die zellkernarme und faserreiche als Markschicht. Beim I. Ganglion opticum hat man den Eindruck, als seien Rindenschicht und Markschicht ursprünglich die zwei Hälften einer dickwandigen Hohlkugel gewesen, und als sei dann die Markschicht wie das Entoderm ciner Gastrula in dieselbe eingestülpt worden. 
Die Markschicht zeigt radiär angeordnet die charakteristischen stäbchenartigen Bildungen, welche entsprechend der Zahl der Augenkeile relativ zahlreich sind. Aus ihr gehen Nervenfasern hervor, welche sich kreuzen und in die Markschicht des 2. Ganglions eintreten,

Es folgt das 2. Augenganglion, welches ähnlich gebaut ist, nur ist die Markschicht fast vollständig homogen, sie weist nur wenige Ganglienzellkerne in ihrem Inneren auf. Aus ihr treten die Nervenfasern hervor, welche, nachdem sie sich gekreuzt haben, direkt in die Narkschicht des 3. Ganglions eintreten. Die Rindenschicht des 3. Ganglions hängt mit derjenigen des 2. Ganglions kontinuierlich zusammen. Die Nervenfasern, welche die Markschicht des 3. und 4. Ganglions bilden, kreuzen sich ebenfalls in ihrem Verlauf.

Das 4. Augenganglion ist bei weitem das größte, seine Marksubstanz überwiegt bei weitem die Rindensubstanz, welch letztere das Ganglion nicht allseitig umschließt, sondern in einigen inselartigen Anhäufungen der Oberfläche desselben aufsitzt. Die Marksubstanz ist sehr eigenartig ausgebildet, indem sie durch eine Menge von Windungen ihrer Substanz in der Struktur an ein Gehirn erinnert. Der an ihrer Basis entspringende Nervus opticus ist sehr kräftig.

Der am distalen, dorsalen Ende des Augenstieles befindliche Fortsatz trug an seinem Ende 3 Sinneshaare, welche zur Untersuchung der Struktur dieser Organe sehr geeignet waren. Es waren dies schlanke, im Querschnitt runde Borsten, welche mit einem Kugelgelenk in einer kleinen Grube in der äußersten Chitinlage saßen (vgl. Taf. XLV, Fig. 4). Von ihrer Basis aus durchbohrt ein feiner Kanal die ganze Cuticula. In diesen Kanal reichte der Fortsatz einer Sinneszelle hinein, welche mit dem größten Teil ihres Körpers nach innen von der innersten Chitinlage sich befand. An sie schloß sich eine feine Nervenfaser an, welche sich eine ziemlich weite Strecke proximalwärts verfolgen ließ, von welcher ich aber nicht nachweisen konnte, mit welchem Hauptnerven sie sich vereinigte.

Maße des Auges und seiner Teile:

\begin{tabular}{|c|c|c|}
\hline Ganzer $\Lambda$ uge & stiel & 2,5 \\
\hline Corneafacette & Breite & $42-50$ \\
\hline & Länge & $2 \mathrm{I} \mu$ \\
\hline Krystallkegel & Breite & $42-56 \mu$ \\
\hline 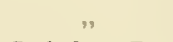 & Länge & $92-$ \\
\hline äbchen Bre & & I \\
\hline Län & & \\
\hline
\end{tabular}

$\begin{array}{ccc}\text { Kerndurchmesser Corneagene Zelle } & 4 \mu \\ \text { " } & \text { Krystallzelle } & \text { I } \mu \text { lang, } 3 \mu \text { breit } \\ \text { " } & \text { Stäbchenzelle } & 6 \mu \\ , & \text { Ganglienzelle } & \text { \% } \mu \\ \text { " } & \text { Epithelzelle } & \text { I I } \mu \text { lang, } 4 \mu \text { breit } \\ \text { " } & \text { Muskelzelle } & \text { ca. } 35 \mu \text { lang, } 4 \mu \text { breit. }\end{array}$

\section{Platymaia Wyville-Thomsoni Miers.}

Taf. XlIX u. L, Fig. 2, 5 u. 6; Taf. LI, Fig. 3, u. Taf. LIII, Fig. I, 2 u. $3 \mathrm{~A}-\mathrm{E}$; Taf. LIV, Fig. I-7.

Stadium I. Das Auge dieser Form konnte ich auf 3 verschiedenen Entwickelungsstadien untersuchen, und es stellten sich dabei sehr interessante Beziehungen zwischen Form und Lebensweise heraus. Das jüngste Stadium war nämlich noch im Uebergang zwischen der Anpassung an das pelagische Leben und derjenigen auf dem Meeresboden begriffen. Die Augen waren aber ausgesprochen diejenigen eines pelagischen Tieres. Sie waren nämlich mäßig lang gestielt und kugelig aufgetrieben (Taf. XI.IX, Fig. 2). Die Cornearegion erstreckte sich über einen großen Teil dieser kugeligen Oberfläche, so daß das Tier einen Gesichtswinkel von über $270^{\circ}$ in allen 3 Ebenen umfassen konnte; dabei sah es wesentlich nach vorn, oben, unten und den Seiten, 
nach hinten war das Gesichtsfeld etwas eingeschränkt. Es ist ferner noch hervorzuheben, daß das Auge ziemlich große Facetten besitzt, deren Form sechseckig war, und daß es zu gleicher Zeit sehr blaß erschien; doch zeigte es schon in diesem Stadium einen leichten Goldglanz, eine Erscheinung, die später an Intensität zunimmt. Auf Schnitten zeigte sich ein dementsprechendes Bild (Taf. LIII, lïg. I). Entsprechend dem jugendlichen Stadium des Ticres ficl zuniichst die relative Menge großer Kerne auf. Die Corneafacetten sind schwach bihonvex, außen öfter plan oder fast konvex. Ihnen liegen nach innen die beiden wurstförmigr gekrümmten Kerne der Corneagenzellen an. Der Krystallkegel erscheint auf dem Längsschnitt immer in 3 Teile geteilt (Taf. LIII, Fig I k $)$. Dies hat seinen Grund in der eigenartigen Ineinanderschiebung seiner 4 Bestandteile, welche auf dem Querschnitt erkennbar ist (Taf. LIII, Iig. 3 E). Die Kerne und der sie umschließende Teil des Zellkörpers befinden sich am oberen Ende und sind noch kaum zur Seite gedrüngt (Taf. LIII, Fig. I ks). Sie sind in der Mittellinie ziemlich dicht aneinander gelagert, sodaß das Licht, um in die tieferen Augenschichten zu dringren, durch sie hindurchfallen muß (Taf. LIII, Fig. $3 \mathrm{C}$ krs). Im übrigen entspricht die Form des Krystallkegels ungeführ einem Prisma, dessen proximaler Teil sich allmählich verjüngt. Die cinzelnen Krystallkegel sind doppelt so lang wie breit und sehr eng zusammengedrängt.

An der Stelle, wo die Zellen des Irispigmentes sichtbar zu sein pflegren, erkennt man hier deutliche Kerne, doch sind die Zellen pigmentlos; ich kann nur minimale Spuren einer gelben, tapetumartigen Substanz erkennen.

Die Stäbchen sind lang-kegelförmig, ehe sie sich in ihrem Verlauf zur Membrana fenestrata etwas zuspitzen (Taf. LIII, Fig. I). Nit ihrem oberen Ende sitzen sie direkt dem mittleren Teile des Krystallkegels an, während sie von den Seitenteilen seitlich etwas umfaßt werden. Die Rhabdomzellen sind deutlich sichtbar — ich konnte in wiederholten Fällen 7 zählen — ihre Kerne liegen in einer Zone durch das ganze Auge etwa an der Grenze des I. und 2. Drittels des ganzen Stäbchens (Taf. LIII, Fig. I S:).

Die Stäbchen lassen in ihrem ganzen Verlauf eine deutliche Querstrichelung erkennen, welche sehr an die Bilder erinnert, welche Hesse von den Stiftchensäumen in Arthropodenaugen gegeben hat. Zwischen den unteren Enden der Stäbchen befinden sich große Zellen mit zartem Plasma; deren Kerne sind auffallend groß. Sie zeigen ein ganz fein alveolär angeordnetes Gerüst, auf welchem sehr fein verteilte Chromatinkörnchen verteilt sind (Taf. LIII, Fig. I $I n k$ ). Im Umriß sind sie sehr regelmäßig oval oder kreisrund. Sie unterscheiden sich auffallend von den Kernen der Krystallkegelzellen, welche ein viel gröberes Netzwerk besitzen, sowie von denjenigen der Irispigmentzellen und der Sehzellen, welche eine ganz dichte Struktur besitzen. Die ziemlich großen Kerne der Krystallkegelzellen haben im Längsschnitt einen breitgelappten Umriß, diejenigen der Pigmentzellen sind klein und kreisrund, diejenigen der Sehzellen sind unregelmäßig gestaltet und zum Teil in ganz feine Zipfel ausgezogen. Die Membrana fenestrata ist eine auffallend dicke Schicht, die sich aus Zellen von verschiedener Beschaffenheit zusammensetzt (Taf. LIII, Fig. I MIf). Einmal sind im Durchschnitt langgestreckte, ungefähr spindelförmige Zellen mit rundlichem, dicht gebautem Kern vorhanden, manche davon sind auch mit feinen, pseudopodienartigen Fortsätzen versehen; es ist dies das stützende Bindegewebe. Dazwischen finden sich ovale Zellen mit blïschenförmigem Kern. Im Innern zeigt der letztere eine fein granulierte Struktur und ein fein verteiltes Chromatin. Aehnliche Kerne zeigen Zellen, 
welche zwischen der Grenzmembran und dem I. Ganglion opticum verstreut liegen, und welche zum Teil einen verästelten Zellkörper haben. Vielleicht sind sie als Blutzellen anzusehen. Hier und da finden sich auch bindegewebige Stränge in dem von den Nervensträngen durchzogenen Zwischenraum zwischen Auge und Ganglion opticum. Die zahlreichen Nervenstränge, welche aus den Neurofibrillen, die aus den Stäbchen austreten, sich bilden, haben selbst große, sehr dicht strukturierte und sehr stark sich färbende Kerne. Der Ganglienkomplex ist relativ groß, es fällt auf, daß das 4. Augenganglion allein etwa so groß ist wie die 3 übrigen zusammen. Das I. Ganglion ist wieder pilzhutförmig und zeigt in der Markschicht zahlreiche Stäbchenbildungen. Das 4. Ganglion ist wieder gehirnartig mit Windungen versehen. Die Rindenschichten sind sehr kernreich und haben embryonalen Typus. Im ganzen Auge ist kein Pigment erkennbar, unter der Grenzmembran und überhaupt in deren Umgebung kann ich weder eine Spur von Pigment, noch von Tapetum erkennen. Dorsal befindet sich eine weit ausgedehnte Wachstumszone, aus welcher sich die Augenelemente allmählich herausdifferenzieren (Taf. LIII, Fig. I $W$ ). Sie besteht aus dichtgedrängten Zellen von embryonalem Typus, aus welchem sich zunächst spindelförmige Zellen herausdifferenzieren.

Stadium II-IV. Schon das nächste Stadium (Stadium II vergl. S. 62), welches an Größe und im sonstigen Habitus sich noch kaum von dem erstbeschriebenen Stadium unterscheidet, zeigt einen stark abweichenden Augentypus. Das Auge ist nicht mehr kugelig, sondern ungefähr citronenförmig gestaltet, wobei aber der Stiel ungefähr an dem stumpfen Ende dieses Gebildes und im rechten Winkel zu dessen Längsachse angebracht ist (vergl. Taf. L, Fig. 5 u. 6). Die Corneafläche ist nicht mehr nach fast allen Richtungen gewendet, sondern schaut im wesentlichen nur mehr nach vorn und unten. Im horizontalen Längsschnitt umfaßt der Gesichtswinkel nur mehr ungefähr $100^{\circ}$. Zur Untersuchung der histologischen Details wollen wir ein etwas älteres Stadium benutzen, welches im systematischen Teil als Stadium IV (vergl. S. 6.3) bezeichnet ist.

Hier erkennen wir, daß Unterschiede in fast allen wesentlichen Teilen des Auges aufgetreten sind.

Die Corneafacetten sind nicht sehr deutlich voneinander geschieden. Immerhin kann man erkennen, daß sie schwach konvex gewölbt sind, sie sind aber gegen das frühere Stadium viel dicker geworden, indem sie besonders in der dorsalen Region ebenso dick wie breit geworden sind. Sie sind deutlich geschichtet; die Krystallkegel haben eine ausgesprochen birnförmige Gestalt angenommen. Sie sind am oberen Ende ziemlich scharf zugewölbt, die dadurch zwischen ihnen und den Corneafacetten entstehenden zwickelförmigen Zwischenräume sind immer noch durch die Corneagen- und Krystallkegelzellen eingenommen (s. Taf. LIII, Fig. 2 Cz u. $K r$ ). Die Krystallkegel selbst sind relativ kurz, sie sind am unteren Ende ziemlich stark zugespitzt und ragren mit diesem Ende wie in eine Hülse zwischen den Pigmentzellen hindurch in das Bündel der Rhabdomzellen hinein (Taf. LIV, Fig. I). Die Stäbchen sind ziemlich lang, und infolge der stark in die Breite gezogenen Form des Auges stehen ihrer eine große Anzahl wie Palissaden nebeneinander (Taf. LIII, Fig. 2). Am oberen Ende, etwa in einem Drittel der Gesamtentfernung zwischen Krystallkegel und Grenzmembran, findet sich ein Kranz von 7 sehr dicht strukturierten, kleinen, ovalen Kernen. Sie sind in eine feine, sich ganz hell färbende Schicht eingeschlossen, 
welche auch das gesamte Rhabdom umhüllt (Taf. LIV, Fig. I). Es sind dies die Sehzellen, wie auch aus dem Querschnitt Taf. LIV, Fig. 7 zu ersehen ist. In der distalen Hälfte sind die Sehzellen mit einem feinen, braunen Pigment erfült, welches aber nicht dicht genug ist, um dic Kerne zu verdecken. Zwischen den Krystallkegeln liegen Zellen, welche sonst das Pigment zu enthalten pflegen; in ihnen ist aber keine Spur von solchem nachweisbar (vgl. Taf. LIII, Fig. 2; Taf. LIV, Fig. I). In der unteren Hälfte erkennt man zwischen den einzelnen Rhabdomen Zellen mit ovalen Kernen. Diese haben ein zartes Gerüst und färben sich sehr schwach. Innerhalb der oben geschilderten Schicht zeigt nun das Rhabdom eine eigenartige Anordnung. Es ist nämlich in Form eines dünnen Stranges ausgebildet, welcher eine deutliche Querstrichelung oder, besser gesagt, Zickzackstrichelung zeigt (Taf. LIV, Fig. I). Dabei ist das ganze Rhabdom wohl durch den Einfluß der Konservierungsflüssigkeit innerhalb der umhüllenden Scheide spiralig aufgerollt. Die großen Kerne von embryonalem Typus, welche im Stadium I zwischen den Stäbchen so sehr auffielen, sind jetzt kaum mehr nachweisbar, da sie viel kleiner sind und kaum mehr Farbe annehmen. Oberhalb der Lamina fenestrata zieht sich durch das Auge ein Band, welches eine gelblich-bräunliche Farbe aufweist. Es besteht aus einer sehr feinen Substanz, welche nicht in den Sehzellen enthalten zu sein scheint, und stellt wohl die Tapetumsubstanz in ihrem ersten Auftreten dar (Taf. LIII, Fig. 2 Tap). Die Lamina fenestrata ist relativ bei weitem nicht mehr so dick wie bei dem Jugendstadium. Ich kann in ihr hauptsächlich nur bindegewebige Zellen erkennen; großkernige Zellen, welche sich sehr stark färben, sind hier und da dazwischen sichtbar. Die auffallendsten Verschiedenheiten zeigen sich nun aber am Ganglienapparat, und zwar am I. Ganglion. Dasselbe ist breit, flach, schirmförmig. Es zeigt zunächst distal eine Schicht von dichtgedrängten Zellen mit großen, chromatinreichen Kernen. Auf diese folgt die Region der stäbchenartigen Bildungen, welche sehr kurz sind, und aus denen, wie gewöhnlich, Fasern hervorgehen, zwischen denen zahlreiche Kerne erkennbar sind. Diese Fasern erscheinen nun in Gruppen gesondert, welche auf dem Schnitt durch ebenfalls streifenförmige Inseln aus kernreicher Rindensubstanz geschieden sind. Dadurch entsteht ein höchst auffallendes Bild, welches aber wohl in einfacher Weise zu erklären ist, wenn wir annehmen, daß jene Inseln von Rindensubstanz der Rindensubstanz des 2. optischen Ganglions angehören, und daß sie zum Teil bis in das Gebiet des I. Ganglions vorgeschoben sind. An den oberflächlichen Schnitten kann man nämlich erkennen, daß sie thatsächlich kontinuierlich in die Rindensubstanz des 2. Ganglions übergehen, aus der sie auf dem Schnitt in Form von verdickten Zapfen, denen in Wirklichkeit Lamellen entsprechen, vorragen. Es steht diese Bildung vielleicht im Zusammenhang mit der außerordentlichen Breitenentwickelung des Auges und der dadurch bedingten Breitenausdehnung des I. Ganglion opticum. Die Marksubstanz des 2. Ganglions, sowie die des 3. zeigen ebenfalls eine ungefähr napfförmige Gestalt, wobei die Dicke vom 3. Ganglion bis zum I. Ganglion distalwärts immer mehr zunimmt. Das 4. Ganglion ist, wie gewöhnlich, wieder das größte. Es zeigt gehirnartige Windungen und hat eine relativ gering entwickelte Rindensubstanz. Aus ihm entspringt ein sehr kräftiger Nervus opticus.

Stadium VII. An dem dritten untersuchten Stadium, dem Auge des erwachsenen Tieres, können wir eine weitere Reihe von Umbildungen erkennen, welche zum Teil sehr auffallend sind. Sie erstrecken sich auf die Form und die Größenverhälltnisse der einzelnen Augenelemente, auf das Pigment und das Tapetum. 
Die Corneafacetten sind kaum etwas mehr als halb so breit wie lang; ihre Wölbung ist schwach bikonvex, ihre Schichtung ist eine sehr starke und deutliche (Taf. LI, Fig. 3; Taf. LIV, Fig. 2). Die Corneagen- und Krystallkegelzellen haben nun eine relativ viel geringere Ausdehnung. Die von ihnen erzeugten Teile sind wohl als ausgewachsen zu betrachten. Der Krystallkegel ist nicht mehr birnförmig, sondern in seiner mittleren größten Partie cylindrisch. Distal läuft er zwar noch spitz zu und proximal ist er in eine lange feine Spitze ausgezogen, welche sich weit zwischen die oberen Enden der Sehzellen hineinzieht. Die einzelnen Krystallkegel sind sehr stattlich (s. unten die Tabelle). - Zwischen den Krystallkegeln, welche nahe bei einander stehen, sind ganz glatte, lamellenartige Zellen eingeschaltet, deren Kern in einer kleinen Verdickung der Zelle an der Stelle liegt, wo die Krystallkegel mit ihren verschmälerten unteren Enden auseinanderweichen (Taf. LIV, Fig. 2). Die fadenförmige Verlängerung des Krystallkegels tritt zuerst scheinbar frei in den Retinalraum; thatsächlich ist sie wohl von einer feinen Plasmaschicht umhüllt, welche zu den Sehzellen gehört. Der Retinalraum erscheint dadurch in zwei Teile geteilt, daß er im proximalen Teil ganz mit Tapetumsubstanz erfüllt ist, welche bei auffallendem Lichte stark silberig glänzt (Taf. LII, Fig. 3 Ta). In dem von dieser Masse freien Raum erscheinen die Stäbchen ausgesprochen spindelförmig, während sie das Tapetum als feine Fasern durchsetzen.

Die Stäbchenzellen umhüllen das Rhabdom, wobei sie durch ihre stark emporgewölbte Form den Eindruck eines Bündels von 7 langen Fasern machen (vgl. hierzu den Querschnitt von Stadium IV, Taf. LIV, Fig. 4 u. 5). Aber sie umhüllen das Rhabdom als dickere Schicht nur in seinem mittleren Teil (Taf. LI, Fig. 3; Taf. LIV, Fig. 2 II). In diesem mittleren Teil befinden sich auch ihre Kerne, welche im Stadium IV weit mehr distal lagen.

Das Auffallendste in dem mittleren Teil ist aber, daß die 7 Zellen hier mit einer dichten Masse dunkelbraunen Pigmentes erfüllt sind. Dasselbe ist nur in der mittleren Partie in größerer Menge vorhanden, distal und proximal nimmt es rasch ab, obwohl die Zellen ihre feinen Ausläufer noch weiter erstrecken.

Proximal wird das Stäbchen bald zu einem sehr feinen und dünnen Gebilde, welches dann die Tapetumschicht durchsetzt (Taf. LIV, Fig. 3). An jedem Stäbchen erstreckt sich das Tapetum noch eine Strecke weit distalwärts. Mit der Lamina fenestrata schneidet proximal die Tapetumsubstanz gerade ab.

Sie besteht aus großen, ovalen oder kugeligen Schollen und feinen Granulationen einer Substanz, welche im auffallenden Licht sehr stark reflektiert, im durchfallenden Licht in Wasser, Glycerin und Alkohol gelblich durchscheinend ist.

Die Plättchenstruktur in den Rhabdomen ist innerhalb der ganzen von Pigment und von Tapetum umschlossenen Strecke erkennbar.

Feine Granulationen hinter der Lamina fenestrata sind wohl Gerinnsel, ich halte sie nicht für Tapetumsubstanz. Die Lamina fenestrata selbt ist frei und deutlich.

Der Bau des Ganglienapparates ist noch komplizierter geworden als im Stadium IV, stellt aber nur eine weitere Entwickelung der dort erreichten Stufe dar. Ich kann mich auf eine detaillierte Schilderung der zum Teil in ihrer funktionellen Bedeutung vorläufig unverständlichen Einzelheiten nicht einlassen. 
Maße des Auges und seiner Teile.

\begin{tabular}{|c|c|c|c|}
\hline & Stadium I & Stadium IV & Stadium VII \\
\hline 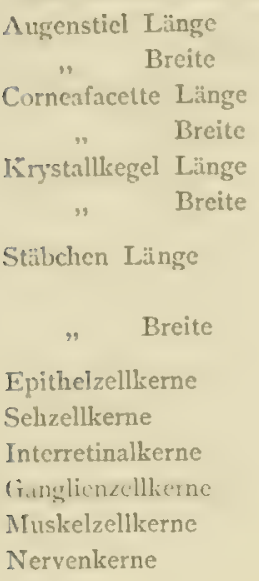 & $\begin{array}{c}1,9 \mathrm{~mm} \\
1 \mathrm{~mm} \\
17-20 \mu \\
35 \mu \\
50-56 \mu \\
35 \mu \\
155-170 \mu \\
1 \text { distal I7 } \mu \\
\text { proximal } 3 \mu \\
6: 6 \text { bis } 9: 9 \mu \\
11: 7: 7 \mu \\
17: 17 \mu, 14: 21 ! \\
11: 11 \mu, 17: 11: \\
21: 4 \mu, 14: 7 \mu \\
6: 14 \mu\end{array}$ & 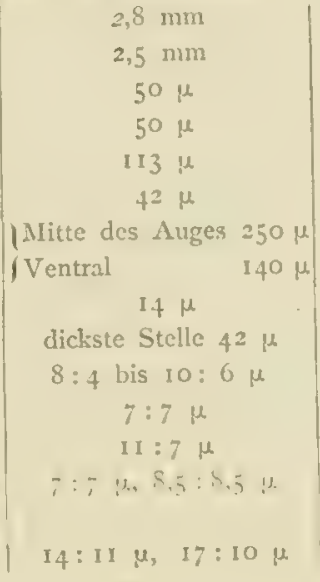 & $\begin{array}{l}7 \mathrm{~mm} \\
7.5 \mathrm{~mm} \\
140 \mu \\
85 \mu \\
200 \mu \\
70 \mu \\
450 \mu \\
600 \mu \\
28-35 \mu \\
8: 5 \mu\end{array}$ \\
\hline
\end{tabular}

\section{Physachaeus etenurus AlC. \\ Taf. XLVIII, Fig. I-II.}

In dem Auge dieser Art haben wir das von dem Durchschnittstypus der Dekapoden augen am meisten abweichende funktionsfähige Auge, welches ich bei Brachyuren kennen grelernt habe. Die Gattung Phy'sachaens ist ja überhaupt eine der an das Leben in der Tiefsee am meisten angepaßten Brachyurengattungen. Schon von außen betrachtet bietet das Auge einen auffallenden Anblick (Taf. XLVIII, Fig. I). Es ist klein, der Augenstiel cylindrisch, die Comeafläche ist gleichmäßig halbkugelförmig gerundet und bedeckt gleichmäßig das distale Ende des Augenstiels. Der proximale Teil des Augenstiels ist wie der übrige Körper des Tieres mit einem feinen Filz bedeckt. Außerdem erkennt man in der Nähe der Facettenregion einigc längere Borsten. Dieselben sind Sinneshaare. Ein ganz besonders auffallendes befindet sich dorsal auf jenem kleinen Höcker, welcher bei den Brachyuren sich regelmäßig an dieser exponiertesten Stelle des Auges befindet. Dieser Höcker trägt fast immer Sinneshaare und hat offenbar den Zweck, mechanische Reize, welche das Auge etwa treffen könnten, vorher aufzufangen; dadurch wird es dem Auge ermöglicht, bei Gefahren seine empfindlichen Teile rasch in den Schutz der Orbiten zu bringen.

Die Comearegion selbst ist von einer auffallenden Durchsichtigkeit. Aus der Tiefe schimmert durch sie hindurch ein leichter, goldbrauner Ton. Das auffallendste an dem Auge bei äußerlicher Betrachtung ist, daß die Cornearegion in eine relativ geringe Anzahl sehr großer, regrelmäßig sechseckiger Facetten eingeteilt ist. Die Zahl derselben dürfte nicht viel größer als 50 sein.

Untersuchen wir das Auge auf sagittalen Durchschnitten, so ist der Anblick ein ebenso auffallender. IVas zunächst überrascht, ist nicht nur die Größe der einzelnen Organteile, sondern auch der Zellen und Zellkerne (Taf. XLVIII, Fig. 2).

Das Chitin des Augenstiels ist besonders auf der dorsalen Zeite schr dick. Die Cornearegion ist ziemlich gleichmäßig gewölbt, doch lassen sich die cinzelnen Facetten recht gut 
unterscheiden. Ja, es macht sogar den Eindruck, als seien sie ein wenig konkav (Taf. XLVIII, Fig. 2 u. 4). Nach innen sind sie jedoch deutlich konvex gewölbt. Die Dicke der Facetten ist eine geringe, ihre Breite eine etwa doppelt so große. An sie stößt der auffallend kleine, etwa polsterförmige Krystallkörper. Er ist nur etwa ${ }^{1 / 4}$ so dick als breit und hat im allgemeinen die Form einer bikonkaven Linse. Seine vordere Konkavität schmiegt sich eng der Konvexität der Corneafacette an. Seine hintere, proximale Konkavität ist nicht ganz so regelmäßig, indem das Zentrum in Form eines kleinen Zäpfchens in das Innere des Stäbchens vorzuragen scheint (Taf. XLVIII, Fig. 4 rechts). Ganz klar ist mir übrigens das Wesen dieser Bildung nicht geworden. Ich konnte sie durchaus nicht in jedem Krystalkegel nachweisen. Die Krystallkegelzellen, oder vielmehr ihre Kerne, erscheinen in Form von kleinen Dreieckchen, ganz in die vordere, äußere Ecke des Gebildes verschoben. Auf Querschnitten erkennt man deutlich die Zusammensetzung aus 4 Zellen (Taf. XLVIII, Fig. 8), im unteren Teile die Art und Weise, wie das obere Ende des Stäbchens umfaßt wird (Fig. 9). Zwischen den einzelnen Krystallkegeln befindet sich nur ein enger Zwischenraum. Derselbe ist mit einer goldbraunen Masse ausgefüllt, einer pigmentartigen Substanz. Diese Substanz ist nicht in feinen Körnchen verteilt, sondern besteht aus ziemlich großen Körpern von tetraëdrischer bis spindelförmiger Gestalt (Taf. XLVIII, Fig. 4, 5, 6, 7). Sie scheint mir nicht in Zellen eingeschlossen zu sein, vor allem nicht zu den Zellen zu gehören, welche sonst das Irispigment enthalten. Es scheint also zunächst keine Möglichkeit einer Verschiebung des Tapetums vorzuliegen. Bei genauer Untersuchung findet man jedoch, daß hie und da einige wenige dieser Körper zwischen den Stäbchen liegen (Taf. XLVIII, Fig. 4). Die Form der Stäbchen ist eine auffallend breitkegelförmige. Sie sitzen so in der hinteren Konkavität der Krystallkörper, daß sie von deren Seiten noch breit umgriffen werden. Nach hinten laufen sie ziemlich rasch spitz zu, sind am dünnsten nach dem 2. Drittel ihres Verlaufes und sind am Grunde wieder etwas breiter (Taf. XLVIII, Fig. 2 u. 4). Im Innern lassen sie eine deutliche Querstreifung erkennen, welche sehr fein ist und ebenfalls den Eindruck eines spiralen Verlaufes hervorruft. An den Seitenrändern des Längsschnittes erkennt man stärker lichtbrechende Gebilde in gleichmäßiger Reihe angeordnet, welche je nach der Richtung des Schnittes verschieden getroffen sein oder eventuell fehlen können (Taf. XLVIII, Fig. 4). Ueber ihre Deutung findet sich näheres in der histologischen Uebersicht über den Augenbau. Die einzelnen Stäbchen haben einen ziemlich weiten Abstand voneinander. Die Zwischenräume sind von einem durchsichtigen Gewebe ausgefüllt, welches aus wenigen, sehr großen Zellen besteht, deren Kerne ebenfalls eine ganz auffallende Größe besitzen. Auf Querschnitten durch diese Region kann man gar keine Zellgrenze erkennen (Taf. XLVIII, Fig. IO); auf Längsschnitten nur an Stellen, wo starke Schrumpfung beim Konservieren eingetreten ist (Taf. XLVIII, Fig. 4). Die Stäbchen konvergieren zur Lamina fenestrata sehr stark. Besonders die am Rand gelegenen Stäbchen sind stark gebogen, manchmal sogar S-förmig gekrümmt. Hinter der Lamina fenestrata treten die Neurofibrillen in ein von sehr großen Zellkernen erfülltes Gewebe. Sie vereinigen sich sehr bald zu einem einheitlichen Nervenstrang, welcher mit ihnen zusammen etwa das Bild der Wassergarbe einer Fontäne darbietet (Taf. XLVIII, Fig. 2). Die Fasern dieses Nervenstranges sind ziemlich grob, die in ihm enthaltenen Zellkerne sehr groß (са. 2 I $\mu$ ). Noch eigenartiger ist aber das Gewebe, welches diesen Nervenstrang umschließt. Es ist dies eine ganz lockere, im Leben offenbar ganz durchsichtig gewesene Gallerte, deren Zellen den Anblick von echten Gallertzellen darbieten, indem sie 
mit langen Ausläufern untereinander zusammenhängen und 'mit diesen große Partien der homogenen Gallerte umschließen. Ihre Kerne sind von einer auffallenden Größe, und zu bemerken wäre auch, daß ihre Anzahl im Verhältnis zu dem von ihnen ausgefüllten Raum eine schr geringe ist (Taf. XLVIII, Figr. 2). Manche der Zellkörper haben offenbar unter dem Einfluß der Konservierungsflüssigkeit ihr Plasma zusammengezogren und sich zu runden Körpern zusammengekugelt. Dann erkennt man in ihrer Nachbarschaft Lücken im Gewebe, in welche offenbar dic Fortsätze hineingereicht hatten. Auch solche Zellen, deren Ausläufer erhalten sind, haben eine kugelige Gestalt (Taf. XLVIII, Fig. I r). Bemerkenswert ist übrigens, daß sich dem Kernverhalten nach scheinbar zweierlei Zellen im Gallertgewebe finden (Taf. XLVIII, Fig. I I):

I) Die Kugelzellen mit ihren Ausläufern, welche einen rundlichen Kern mit sehr homogener Substanz und ein ganz gleichmäßiges Zellplasma besitzen. Sie sind meist einzeln, selten sind zwei sehr nahe beieinander. Ganz selten findet man solche mit 2 Kernen. Sie messen $13: 13$ "s bis I $8:$ I $8 \mu$. Im letzteren Fall ist der Durchmesser des Kernes ca. Io $\mu$.

2) Etwas größere ovale Zellen mit relativ größeren Kernen. Letztere sind viel lockerer grebaut. Das Chromatin ist in groben Körnern auf dem Netzwerk verteilt. Aehnliche stark färbbare Körner finden sich in der Umgebung des Kerns im Zellplasma. Solche Zellen liegen in der Regel zu mehreren in der Umgebung von Kugelzellen (Taf. XLVIII, Fig. I I).

Was den Ganglionkomplex des Augenstiels anlangt, so ist hervorzuheben, daß er vollständig ausgebildet ist, d. h. es sind sämtliche 4 Ganglienknoten vorhanden (Taf. XLVIII, Fig. 3), auch ist er im hinteren Teile des Augenstiels so ausgedehnt, daß er in der Region des 4. Ganglions den ganzen Hohlraum des Augenstiels, soweit er nicht von Muskeln und Bindegewebe eingenommen wird, ausfüllt (Taf. XLVIII, Fig. 2). Aber entsprechend dem optischen Teil des Auges ist auch im nervösen Teil die Zahl der Elemente eine geringe, die Elemente selbst aber um so größer. Die Kerne sowie die Ganglienzellen sind in geringer Anzahl vorhanden - verglichen mit den entsprechenden Teilen der Flachseeformen, - aber sie sind sehr groß. Im I. Ganglion opticum sind stäbchenartige Bildungen zu erkennen, aber ebenfalls in geringer Anzahl, offenbar entsprechend den Zahlen der Augenkeile (Taf. XLVIII, Fig. 3). Im Durchschnitt messen die Ganglienzellen IO: $15 \mu$, IO: IO $\mu$, I4:I4 $\mu, I_{2}: 17 \mu$. Doch finden sich in der Zellmasse distal

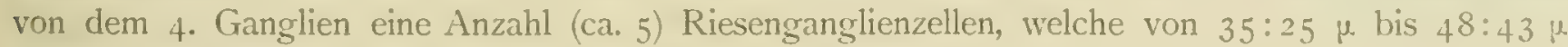
messen. Im letzteren Fall betrug die Größe des Kerns r 7:I $7 \mu$.

Ich bemerke noch, daß Epithelzellen des Augenstieles ca. I7:17 ${ }^{3}$. (Kern I4:14 $\mu$ ) oder $2 \mathrm{r}: 6 \mu$ je nach der Form maßen.

Die Länge des ganzen Auges ist $0,8-0,9 \mathrm{~mm}$.

Die Maße der einzelnen Bestandteile des optischen Apparatessind folgende:

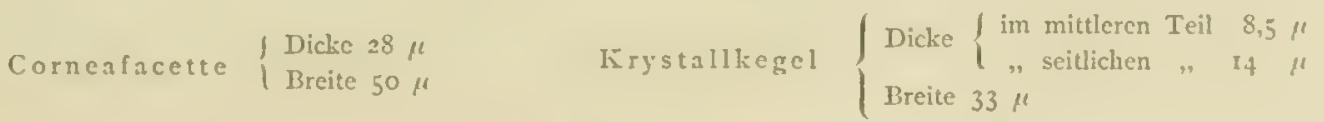




\title{
Lispognathus Thomsoni NoRM.
}

\author{
Taf. XLV, Fig. 6 u. 7 .
}

Von dieser weit verbreiteten Form habe ich ein Exemplar aus dem Nordatlantic untersucht, welches mir zeigte, daß es sich offenbar um einen Bewohner des tieferen Wassers handelt, jedenfalls um ein Dämmerungstier. Die Cuticula des Augenstieles ist sehr dick, auch die Corneafacetten sind in der Richtung des Lichteinfalles ungefähr ebenso ausgedehnt als in der Breite. Die äußere Fläche der Corneafacetten ist flach bis schwach konkav, die innere Fläche ist sehr stark konvex. Die Zahl der Augenkeile ist eine ziemlich geringe, 20-30 im sagittalen Schnitt. Die Krystallkegel sind lang und dünn, ihre Basis und der obere Teil der an sie anstoßenden Stäbchen ist von gelbraunem Irispigment umhüllt. Die schlanken Stäbchen sind frei von Pigment und zeigen deutlich die spiralige Streifung. Es scheint auch ein hellbraunes Retinapigment vorhanden gewesen zu sein. Der Ganglienapparat ist stark entwickelt und füllt den größten Teil des Augenstiels aus. Mehr Details anzugeben, gestattet mir der Erhaltungszustand des Objektes nicht.

Maße des Auges und seiner Teile:

\begin{tabular}{|c|c|c|c|c|c|}
\hline Ganzer Auger & nstiel & $\mathrm{r}, 5 \mu$ & Irrystallkegel & Länge & $140-170 \mu$ \\
\hline Corneafacette & Breite & $42 \mu$ & Stäbchen & Breite & $14 \mu$ \\
\hline 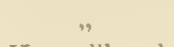 & Länge & $50 \mu$ & $"$ & Länge & $180-210 \mu$ \\
\hline Krystallkegel & Breite & & & & \\
\hline
\end{tabular}

\section{Pleistacantha Moseleyi Miers.}

Taf. LV, Fig. 4 u. 5; Taf. LIV, Fig. 8-i4.

I. Jugendstadium.

Der Augenstiel ist länglich, dabei ziemlich dick, die vordere Partie stark kuglig aufgetrieben, so daß die Facettenregion nach vorn und allen Seiten und sogar ein wenig rückwärts schaut. In der Aufsicht ist das Auge vollkommen blaß. Die Corneafacetten sind von mittlerer Größe und etwa sechseckig. Auf dem sagittalen Schnitt fällt zunächst der große Gesichtswinkel des Gesamtauges auf, er umfaßt gut $270^{\circ}$. Die am meisten peripher gelegenen Augenteile sind viel kleiner als die zentral gelegenen. Es ist unverkennbar, daß sich an der Peripherie noch eine Wachstumszone des Auges befindet, was sich auch durch den embryonalen Zustand der Augenkeilanlagen in dieser Region kund giebt.

Die centralen Augenkeile haben folgenden Bau. Die Corneafacetten sind bikonvex und sehr dünn, in der optischen Achse kaum ein viertel so lang als im Breitendurchmesser. An sie anschließend, finden wir die ungefähr dreieckigen Corneagenzellen, deren Form dadurch bestimmt wird, daß die Krystallkegel etwa birnförmig sind. Die 4 Stücke des Krystallkegels liegen auf dem Querschnitt nicht etwa so aneinander, wie die 4 Quadranten eines Kreises, sondern sind in komplizierterer Weise aneinander geschoben, wie dies der Querschnitt auf Taf. LIV, Fig. I3 erkennen läßt. Infolgedessen erscheinen sie auf dem Längsschnitt meist dreiteilig. Die Krystallkegel liegen ziemlich dicht aneinander. Dadurch, daß sie aber an den proximalen Enden erheblich verschmälert sind, entstehen in dieser Region breite Zwischenräume. In diese Lücken reichen große Zellen hinein, welche in dieser Region des Auges eine breite Schicht durch dessen 
ganze Ausdehnung bilden. Sie bilden eine so sehr zusammenhängende Schicht, daß man dic Zellgrenzen kaum erkennen kann; diese Schicht wird siebartig durchlöchert, inclem durch runcle Oeffnungen die Krystallkegel hindurchtreten (Taf. LIV, Fig. 14). In der Regel erkennt man auf dem sagittalen Schnitt zwischen je zwei Krystallkegeln je zwei zu diesen Zellen gehörige Kerne (Taf. LIV, Fig. 9). Im centralen Teil des Auges kann man die Grenzen zwischen den Stäbchenzellen und diesen Irispigmentzellen schwer erkennen (Taf. LV, Fig. 5). Diese Zellen sind unzweifelhaft die Repräsentanten der Irispigmentzellen. Von Pigment enthalten dieselben aber keine Spur. Ebensowenig ist eine Andeutung von einer Masse zu erkennen, welche als Iristapetum hütte dienen können. Es ist natürlich nicht ganz ausgreschlossen, daß\} eine solche Masse vorhanden war, aber bei der Konservierung des Tieres aufgelöst worden ist.

Anordnung und Form der Stäbchen erinnert durchaus an die von Criun für die Dämmerungsaugen von pelagischen Ticfsce-Schizopoden beschriebene Anordnung (Taf. LV, Fig. 5). Die Stäbchen beginnen mit einer etwas verdickten Partie, welcher seitlich dic Sehzellkerne ansitzen, und welche deutlich eine Querstrichelung erkennen läßt. Die Sehzellen sind besonders an den peripheren Augenkeilen gut zu erkennen; sie liegen in einem Kreis, ganz am peripheren Ende des Stäbchens. Von der verdickten Partie des Zellleibes, welche den Kern in dieser Region umgiebt, erstrecken sich feine Ausläufer über das Stäbchen in proximaler Richtung (Taf. LIV, Fig. 9). Der Umstand, daß die Kerne der Sehzellen fast genau in derselben Zone liegen, läßt auf Querschnitten die Siebenzahl der Sehzellen besonders schön hervortreten (Taf. LIV, Fig. I I). In diese distale Region wandern übrigens die Sehzellen erst im Laufe der Entwickelung des Stäbchens, wie ein Blick auf ein embryonales Stäbchen aus der Wachstumszone lehrt (Taf. LIV, Fig. 8). Auf die verdickte distale Partie (Taf. LV, Fig. 5 sd) folgt ein außerordentlich feiner Strang, welcher ca. die Hälfte der Länge des ganzen Stäbchens ausmacht. An ihn schließt sich eine schlanke Spindel an. Diese Spindel zeigt ein verschiedenes Bild, je nachdem sie central durchschnitten oder nur im Anschnitt getroffen ist. Wenn sie central durchschnitten ist, so kann man einen centralen Raum erkennen, welcher mit einer scheinbar homogenen Substanz erfüllt ist. Die Ränder zeigen sich aus sehr feinen, alternierend schwächer und stärker lichtbrechenden Schichten gebildet. Ist das Stäbchen nur angeschnitten, so daß wir auf seine äußere Oberfläche sehen, so erkennen wir eine Art von spiraliger Streifung.

Der spindelförmig enveiterte Teil des Stäbchens umfaßt übrigens nicht ganz dessen proximale Hälfte, sondern endigt kurz vor der Grenzmembran, in einem Abstande, der etwa $1 / 10$ der Gesamtfläche des Stäbchens beträgt. Das proximalste Ende zeigrt dann eine abermalige Verbreiterung. Dieser letzte Teil des Stäbchens ist nicht quergestrichelt, sondern man erkennt in ihm Längsstreifung, welche sich auch über die Grenzmembran hinaus fortsetzt. Die Streifung ist verursacht durch die Neurofibrillen, welche sich zu Bündeln vereinigen und in einer ziemlich großen Anzahl von Strïngen dem nahe gelegenen I. Ganglion opticum zustreben. Zwischen den unteren Enden der Stäbchen erkennt man eine Zone schwach färbbarer Kerne, die schon öfter erwähnten Interretinalkerne. Der ganze Ganglienkomplex ist dicht zusammengedrängt, so daß Nark- und Rindenschicht der einzelnen Teile kontinuierlich zusammenhängen. Der Ganglienkomplex ist mittelgroß, er füllt nicht ganz die Hälfte des inneren Hohlraumes des Augrenstieles aus. Das I. Ganglion ist pilzhutförmig und zeigt in seiner Markschicht zahlreiche Stäbchenbildungen. 


\section{Erwachsenes Tier.}

Das Auge des erwachsenen Tieres ist entsprechend viel größer. Schon von außen zeigt es deutlich einen bräunlichen Farbton. Die Corneafacetten sind ziemlich erheblich dicker als bei dem jungen Tier, sie sind fast ebenso dick wie breit (Taf. LV, Fig. 4). Die Krystallkegel sind sehr eng aneinander gedrängt und infolgedessen viel mehr prismatisch gebildet als bei dem jungen Tier. Die Irispigmentzellen sind mit einem dichten, braunen Pigment erfüllt, sie stellen eine kontinuierliche, durch das ganze Auge reichende Lage von mäßiger Dicke dar (Taf. LV, Fig. 4, Querschnitt Taf. LIV, Fig. 15). Sie entsenden dabei weder distal nach proximal Fortsätze, so daß sie eine ganz gleichmäßige Wand bilden, welche nur von den Stäbchen durchbrochen wird. Sie umschließen dieselben gerade in der Partie, wo sie die obere, quergestrichelte Verdickung bilden. Hier sind auch deutlich die Kerne der Sehzellen sichtbar, welche in einem Kranz das verdickte Ende der Stäbchen umschließen (Taf. LIV, Fig. I 5). Während bei den Stäbchen im Auge des jungen Tieres die peripheren noch nicht die Teilung in den strangförmigen und spindelförmigen Teil erkennen ließen, zeigen bei den Augen des erwachsenen Tieres sämtliche Stäbchen diese Beschaffenheit. Man kann daraus schließen, daß die Stäbchen während des Wachstumes zuerst eine Gestalt besitzen, welche gedrungen ist, sowie daß sie dann durchweg quergestrichelt sind (Taf. LIV, Fig. 9), und daß erst allmählich die Dreiteilung im Lichtempfindungsorgan vor sich geht. Zum Unterschied vom jungen Tier zeigt das erwachsene ein, wenn auch schwaches, Retinapigment. Die aus der Grenzmembran hervortretenden feinen Nervenfasern sind nämlich von einem ganz feinen Staub von Pigment umhüllt, welcher an einzelnen Stellen auch ein wenig über die Grenzmembran vordringt und die basalen Teile der Sehzellen umhüllt (Taf. LIV, Fig. I 2).

Es wäre ferner noch hervorzuheben, daß im Auge des erwachsenen Tieres der Ganglienapparat nicht entsprechend der Gesamtgröße des Auges gewachsen ist. Vor allen Dingen fällt die relative Kleinheit des 1. Ganglions auf, doch steht das Verhältnis ganz gut damit im Linklang, daß vielmehr ein Wachstum als eine Vermehrung im optischen Apparat des Auges stattgefunden hat. Sämtliche Teile des Ganglienapparates liegen in gerader Linie hintereinander und bilden einen ziemlich dünnen Strang, der kaum ein Achtel des inneren Raumes des Augenstieles ausfüllt. Bemerkenswert ist auch die Form der einzelnen Ganglien, von denen das I. - 3. etwa napfförmig gestaltet sind, das 4. mit seinen Windungren ist etwa nierenförmig. Die Rindenschicht liegt bei dem I. und 2. distal, bei dem 3. und 4. proximal und ventral. Auch der Nervus opticus selbst ist ein im Verhältnis zur Mächtigkeit des ganzen Organes nicht sehr starker Strang.

Maße des Auges und seiner Teile.

\begin{tabular}{|c|c|c|c|c|c|}
\hline & Stadium I & Stadium II & & Stadium I & Stadium II \\
\hline $\begin{array}{l}\text { Ganzes Auge } \\
\text { Corneafacette, Länge } \\
\text { ", Breite } \\
\text { Krystallkegel, Länge } \\
\text { ", } \quad \text { Breite }\end{array}$ & $\begin{array}{c}2 \mathrm{~mm} \\
\text { II } \mu \\
35 \mu \\
100-1 \mathrm{I} 2 \mu \\
42 \mu\end{array}$ & $\begin{array}{c}8,5 \mathrm{~mm} \\
56 \mu \\
70 \mu \\
183 \mu \\
70-85 \mu\end{array}$ & $\begin{array}{l}\text { Stäbchen, Länge } \\
\qquad, \quad \text { Breite } \\
\text { Stäbchenzellkern } \\
\text { Irispigmentzellkern } \\
\text { Ganglienzellkern }\end{array}$ & $\begin{array}{c}280-350 \mu \\
15-17 \mu \\
5-7 \mu \\
5-7 \mu \\
8-10 \mu\end{array}$ & $\begin{array}{c}420-500 \mu \\
25 \mu\end{array}$ \\
\hline
\end{tabular}




\section{I4. Scyramathia Hertwigi DowL.}

Das Auge dieser Form ist mäßig groß, die Corneafläche klein, nach vorn und unten gerichtet. Die Zahl der Augenkeile ist eine relativ kleine, in einem sagittalen Durchschnitt beträgt sic $30-40$.

Die einzelnen Elemente sind ziemlich groß, doch erinnern sie in ihren Verhältnissen mehr an littorale als an Tiefseeformen.

Besonders hervorzuheben ist, daß das Auge vollkommen pigmentlos ist. Es fehlt sowohl Iris- als Retinapigment.

Die Corneafacetten sind viereckig; ihre Ausdehnung in der Richtung des Lichteinfalles ist eine geringe, was um so auffallender ist, als clie übrige Chitinhülle des Augenstieles eine schr dicke ist, ungefähr ro mal so dick wie die Cornea. Die Corneafacetten sind jecle für sich nach außen schwach, nach innen stark konvex gewölbt.

Die Krystallkegel sind lang und schlank, ihr Durchmesser in der Richtung des Lichtstrahles ist etwa 3 mal so lang wie derjenige der Corneafacette, in der Breite erreichen sie nicht cinmal ein Viertel der Länge. Thre Gestalt ist spitz-kegelförmig, im Querschnitt sechseckig. Am Grunde der kelchförmigen Verschmälerung, mit welcher sie in die Stäbchen übergehen, findet sich eine Lage von Zellen, welche durch zahlreiche kleine Kerne auffällt, indem sie jich als einheitliche dünne Lage durch diese ganze Region des Auges hinzieht. Von diesen Zellen sieht man amöboide Fortsätze sich zwischen die Krystallkegrel erstrecken. Doch ist auf den verschiedenen Präparaten in den Zellen keine Spur von Pigment zu entdecken. Möglicherwreise enthielten sie einen in Alkohol löslichen Farbstoff, der vielleicht die Funktion eines Tapetums übernahm.

Der Krystallkegel geht in ein langes, spindelförmiges, dünnes Stäbchen über, dasselbe ist etwa $1 \frac{1}{2}$ mal so lang wie der Krystallkegel. Innerhalb des durchsichtigen Protoplasmas der Zellen, welche es zusammensetzen, erkennt man deutlich eine spiralige Streifung, zwischen welcher ovale, stark lichtbrechende Körperchen (?) sichtbar werden. Aus der stark verschmälerten Basis des Stäbchens gehen mehrere Neurofibrillen hervor, welche die Membrana fenestrata durchsetzen. Der \%wischenraum zwischen den einzelnen Stäbchen war offenbar von einem sehr lockeren, durchsichtigen Füllgewebe eingenommen, welches nur unvollkommen erhalten ist.

Die Membrana fenestrata ist ziemlich stark, das Neurofibrillengewirre, welches sich an dieselbe anschließt, wird bald $z u$ einigen stärkeren Strängen vereinigt, welche $z u$ dem entfernt liegenden I. Ganglion opticum ziehen. Das r. Ganglion opticum ist stattlich, hutpilzförmig, die Zahl der stäbchenförmigen Elemente in demselben ist eine mittelgroße.

Die Kerne im Auge selbst sind klein, dagegen sind sie in den Augenganglien, besonders im 3. und 4. Ganglion recht groß.

Die Ausbildung der Augrenganglien ist entsprechend dem Entwickelungsgrade des Auges eine ziemlich hohe; sämtliche Teile sind wohlausgebildet und groß, so daß der gesamte Ganglienapparat mehr als die Hälfte des Hohlraumes im Augenstiel ausfüllt.

Der Nervus opticus ist ein recht dicker Strang.

Länge des ganzen Auges $3,5 \mathrm{~mm}$. 
Maße der Augenteile.

\begin{tabular}{|c|c|c|c|c|c|}
\hline & Dicke & Breite & & Länge & Breite \\
\hline $\begin{array}{l}\text { I) Corneafacetten } \\
\text { Mitte des Auges } \\
\text { Peripherie des Auges }\end{array}$ & $\begin{array}{l}47-54 \mu \\
70-85 \mu\end{array}$ & $\begin{array}{c}57 \mu \\
57-64 \mu\end{array}$ & $\begin{array}{l}\text { 2) Krystallkegel } \\
\text { Mitte des Auges } \\
\text { Peripherie des Auges }\end{array}$ & $\begin{array}{l}170 \mu \\
170 \mu\end{array}$ & $\begin{array}{l}42 \mu \text { oben } \\
27 \mu \text { unten }\end{array}$ \\
\hline
\end{tabular}

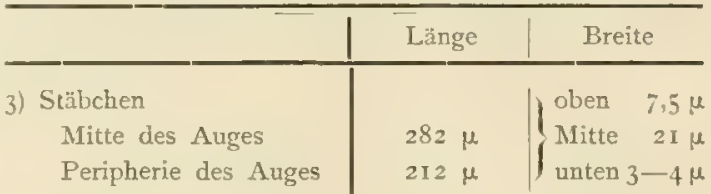

Maße von Zellen des Augenstieles.

$\begin{array}{lcc}\text { Epithelzellen } & 4-6 \mu \text { Längsdurchmesser } \\ \text { Bindegewebszellen } & 6-7,5 \mu \\ \text { Ganglienzellen } & \text { 10-12 } \mu \\ \text { Ganglienriesenzellen } & \begin{array}{c}75-90 \mu \\ 30-60 \mu\end{array}\end{array}$

\section{Seyramathia Rivers-andersoni Alc.}

Taf. LV, Fig. I u. 2.

Das Auge von Scyramathia Rivers-andersoni ist im allgemeinen nach demselben Prinzip gebaut wie dasjenige von S. Hertwigi, doch zeigt es in allen jenen Punkten, in denen die Augen von Tiefenbewohnern von jenen der Oberflächenformen abweichen, eine fortgeschrittenere Anpassung als erstere Form.

Die Cornea ist von einer ziemlich erheblichen Ausdehnung in der Richtung des Lichteinfalles. Die einzehnen Corneafacetten sind in dieser Richtung etwa doppelt so lang wie in der Breitenausdehnung (Taf. LV, Fig. 2). Jede Corneafacette ist nach außen und innen deutlich konvex gewölbt. Sie sind auch durch dichtere Partien der Cuticula wie durch senkrechte Scheidewände voneinander getrennt. Auf Querschnitten erkennt man im distalen Teil der Krystallkegel zunächst die 4 Kerne der corneagenen Zellen; die Krystallkegelzellkerne sind erst in der Mitte der Krystallkegel ziemlich gleichmäßig angeordnet zu erkennen.

Die dicht aneinanderschließenden Krystallkegel sind in der optischen Achse mäßig lang, sie sind etwa $2 \frac{1}{2} \mathrm{mal}$ so lang wie breit. An ihrer Basis zieht sich durch das ganze Auge jene Lage von Zellkernen, welche für die Region des Irispigmentes charakteristisch ist, aber die Zellen selbst sind sehr klein, und es ist keine Spur von Pigment in ihnen enthalten.

Mit einer kuppelförmigen scharfen Abgrenzung ist das obere Ende der Stäbchen in das untere Ende der Krystallkörper, welches sie umgreift, eingelagert. Die Stäbchen selbst sind ziemlich plump kegelförmig und dicht aneinander gelagert. An solchen, welche central durchschnitten sind, erkennt man an beiden Seiten einen feinen "Stiftchensaum", diesem entsprechen auf den Anschnitten der Stäbchen eng aneinander liegrende spiralige Reihen von solchen Stiftchen.

Die Membrana fenestrata ist nicht sehr dick, stößt aber selbst an ein sehr dichtes Gewebe. Dieses Gerrebe besteht zum Teil aus gallertartiger Substanz, zum Teil, mehr gegen das Ganglion hin, aus einem zellenreichen Gewebe. Es ist von den zahlreichen, mäßig starken Strängen der Nerven durchzogen, welche die Stäbchenenden mit dem 1. Ganglion opticum verbinden. Die großen 
Kerne der Zellen des Füllgewebes in der Nachbarschaft des 1. Ganglion opticum lassen bei dem einen Exemplar im Inneren deutlich einige Chromatinelemente erkonnen; manche scheinen sich im Knäuelstadium zu befinden, bei anderen sind die Chromosomen deutlich gesondert. Diesc Zellen haben einen Durchmesser von 6-8 «. Die Größenverhältnisse des Auges weisen auch darauf hin, daß es sich um ein noch im Wachstum begriffenes Organ handelt. Das Tier, welchem das Präparat entstammt, war auch noch nicht ausgewachsen. Der Ganglienapparat des Auges ist groß und wohlentwickelt. Im I. Ganglion opticum sind die Stäbchenbildungen deutlich erkennbar. Die anderen Ganglienabschnitte sind groß und zellenreich, die Kreuzungen der Opticusfasern zwischen den einzelnen Ganglienabschnitten sind deutlich erkennbar.

\begin{tabular}{|c|c|c|}
\hline$M a B e$ & No. I & No. 2 \\
\hline Länge des ganzen Auges & $1,2 \mathrm{~mm}$ & $2 \mathrm{~mm}$ \\
\hline Breite der Corneafacette & $33 \mu$ & $50 \mu$ \\
\hline Dicke $" \quad$, & $33 \mu$ & $54-83 \mu$ \\
\hline Breite des Krystallizegels, distal & $37 \mu$ & $47 \mu$ \\
\hline$" \quad, \quad, \quad$ Mitte & $30 \mu$ & $33 \mu$ \\
\hline $\begin{array}{l}\text { Länge " } \\
\text { Breite des Stabchens oben } \\
\text { Länge " " }\end{array}$ & $100 \mu$ & $\begin{array}{c}110-125 \mu \\
10-15 \mu \\
130 \mu\end{array}$ \\
\hline
\end{tabular}

\section{Trichopeltarium Alcocki DofL.}

Taf. XLVII, Fig. 9, Io u. I I.

Das Auge dieser Art erinnert in den Grundzügen des Baues an dasjenige von Cyclodorippe dromioides, doch ist der ganze Augenstiel bedeutend länger und schlanker; an der Basis verdickt, verläuft er nach vorn fast ganz gleichmäßig cylinderförmig. Nur am vorderen Ende befindet sich die im wesentlichen nach vorn gerichtete Cornearegion, auf dem Stiel befinden sich an der Dorsalseite einige kleine Stachel, ferner ist die Oberfläche mit einer Anzahl langer, befiederter Haare bedeckt (Taf. XLVII, Fig. 9). Die Corneafacetten sind in auffallend geringer Anzahl vorhanden und dementsprechend ziemlich groß. Im sagittalen Schnitt zählt man ihrer nur etwa I5 (Taf. XLVII, Fig. Io); in den feineren Details des Baues ist eine große Aehnlichkeit mit dem Auge von Phy'sachaenes ctemum vorhanden, vgl. S. 165. Die einzelne Comeafacette besitzt die Form einer plan-konvexen oder konkav-konvexen Linse. Es ist nämlich die Außenseite jeder Linse fast ganz flach, zum Teil konkav gewölbt, während die innere Fläche stark konvex vorgewölbt ist (Taf. XLVII, Fig. ro u. Ir). Der Durchmesser der Linse in der optischen Achse ist bei den ventralen Facetten so groß oder größer als der Querdurchmesser, bei den vorderen und dorsalen Facetten dagegen ist er nur zwei Drittel mal so groß. Die Cuticula zeigt sehr ausgeprägt die Schichtung, wobei zu bemerken ist, daß von außen nach innen fortschreitend sämtliche Lagen konkav gekrümmt sind, wobei die Konkavität immer mehr zunimmt. Die Grenze zwischen den einzelnen Facetten ist durch eine starke Faltung der sämtlichen Schichten, an der Außenfläche durch eine entsprechende Kerbe bezeichnet (Taf. XLVII, Fig. I I). An die Corneafacetten schließt sich eine größere Anzahl von Kernen an, deren Zugehörigkeit bei der Erhaltung des Objektes nicht ganz leicht zu entscheiden ist. Zwei dieser auf den dünneren Durchschnitten regelmäßig getroffenen Kerne gehören offenbar dem Krystallkegel an. Die Kerne in den äußersten distalen Zipfeln der Krystallkegelbildungen gehören wohl den Corneagenzellen an. Die außen 
an den Krystallkegeln anliegenden Kerne sind wohl als die Kerne der pigmentlosen Irispigmentzellen zu betrachten. Der Krystallkegel ist sehr kurz und sehr stark bikonkav. Während er in seinen Randpartien fast der Cornealinse an Längenausdehnung gleichkommt, ist er im Centrum kaum ein Viertel so lang (= dick). Die Breite entspricht derjenigen der Cornealinse, so daß die einzelnen Krystallkegel aneinanderstoßen, oder nur ganz schmale Lücken zwischen sich lassen. In die hintere Konkavität des Krystallkegrels ist das vordere Ende des Stäbchens tief eingelassen (Taf. XLVII, Fig. II). Die Stäbchen sind mittellang, ihre Seitenwand ist von deutlichen Zellen gebildet, deren Plasma offenbar sehr durchsichtig war, sehr große Kerne enthält, und welche auf dem Längsschnitt zu langen, sehr dünnen Gebilden ausgezogren sind. Der Rhabdomteil des Stäbchens selbst ist deutlich quergestrichelt. Das Stäbchen verschmälert sich nach hinten erheblich, ist aber noch an der Lamina fenestrata relativ dick. Zwischen den einzelnen Stäbchen sind Zwischenräume vorhanden, welche offenbar durch die Schrumpfungen der Stäbchenzellen entstanden sind. Hier und da sieht man in diesen Zwischenräumen die Reste langer, geschrumpfter Zellen (Taf. XLVII, Fig. I I i). Von Irispigment ist im Auge keine Spur nachweisbar, dagegen findet sich, allerdings nur auf wenigen Schnitten und nur in der dorsalen Region im Hintergrund von etwa 5 Augenkeilen, ein wenig braunes Pigment hinter der Grenzmembran und an den Nervenfasern (Taf. XLVII, Figg. Io). Die aus den Stäbchen hervortretenden Neurofibrillen vereinigen sich fächerförmig konvergierend zu einem ganz dünnen Nerven, welcher zu dem etwas distal von der Mitte des Augenstieles gelegenen I. Ganglion opticum läuft (Taaf. XLVII, livig. in $/$ ).

Die Anordnung der einzelnen Bestandteile des Ganglienapparates ist überhaupt bei dieser Art eine eigentümliche und offenbar von der Länge des Augenstieles beeinflußt. Das 1. Ganglion opticum ist nämlich mit den 3 übrigen Ganglien durch einen langen, dünnen Nerven verbunden. Es hat selbst eine stark ausgebildete Rindenschicht und eine viel geringere Markschicht. Auch kann ich Spuren von stäbchenförmigen Bildungen in demselben erkennen, allerdings nur wenige, entsprechend der geringen Zahl der Augenkeile. Ob in dem verbindenden Strang eine Kreuzung der Nervenfasern stattfindet, konnte ich nicht mit Sicherheit feststellen. Das 2. Ganglion, welches also von dem I. ziemlich weit entfernt liegt, hat eine sehr stark entwickelte, kernreiche Rindenschicht, von der aus ein langer Strang ebensolchen kernreichen Gewebes sich an dem Nervenstrang entlang nach vorn erstreckt. Die Markschicht ist bei diesem 2. Ganglion verhältnismäßig gering ausgebildet. Bei dem 3. Ganglion ist sie viel ausgedehnter, auch die Rindenschicht des letzteren ist ziemlich umfangreich. Das 4. Ganglion ist, wie gewöhnlich, das größte und zeigt in der Marksubstanz Windungen, auch die Rindensubstanz wohlentwickelt. Zwischen dem 2. und 3., 3. und 4. Ganglion sind die Kreuzungen der Nervenfasern deutlich. Im proximalen Teile füllt der Ganglienapparat ungefähr die Hälfte des Augenstieles aus. In einzelnen Schnitten sind zahlreiche, zum Teil ziemlich starke Blutgefäße erkennbar. Die Kerne in sämtlichen Teilen des Auges sind relativ klein.

Maße des Auges und seiner Teile:

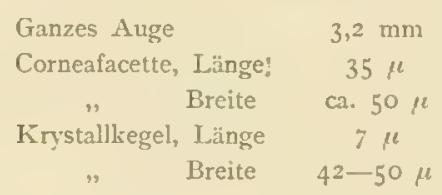

$\begin{array}{cl}\text { Krystallkegelkern, Länge } \\ \text { Stäbchen, } & \text { Breite } \\ \text {." } & \text { Länge } \\ \text { " } & \text { Breite, distal } \\ & \text { " proximal }\end{array}$




\section{Geryon affinis Milne-Edw. u. Bouvier.}

Taf. XLIX, Fig. I; Taf. LII, Fig. 7; Taf. LV, Fig. 6; Textig. I4.

\section{Auge des erwachsenen Tieres.}

Das Auge von Geryon ist sehr groß; es hat einen sehr kräftigen beweglichen Stiel. Die Facettenregion ist vorn in die Breite gezogen, so daß das Auge, ähnlich wie dasjenige von Plaly'maia, einen relativ großen Raum nach vorn und unten überschauen kann (Taf. XLIX, Fig. I). Doch ist die vordere Region nicht so stark gegen den Stiel abgreknickt, wie bei Platymair.

Die mit zahlreichen wohlausgebildeten Facetten bedeckte Cornearegion erscheint durch im Innern des Auges gelegenes Pigment tiefbraun.

Die histologische Untersuchung dieses großen und harten Auges war mit besonderen Schwierigkeiten verknüpft, welche ich nicht alle überwinden konnte. Daher ist es mir nicht gelungen, so weit in die Einzelheiten des Baues einzudringen, wie es bei diesem interessanten Objekt wünschenswert grewesen wäre.

Untersuchung auf Schnitten zeigt uns, daß es sich um ein iridopigmentäres Auge handelt (Taf. LV, Fig. 6),

Wir erkennen, daß in dem Auge die Dimensionen der einzelnen Augenkeile in der Mitte am größten sind, während die peripher gelegenen viel kleinere Krystallkegrel und Stäbchen besitzen.

Die derbe Cuticula des Augenstieles ist in zwei Schichten geteilt, von denen die äußere noch derber ist als die innere. Letztere hat etwa die vierfache Dicke der ersteren. Die äußere Schicht ist an den Stellen, wo Sinneshaare sie durchbohren, von einer weiten Oeffnung durchsetzt, welche das basale Ende des Haares wie eine Gelenkpfanne aufnimmt. Die innere Schicht der Cuticula ist an solchen Stellen nur von dem feinen Kanal für die Nervenendigungen durchbohrt.

Die Teilung in zwei Schichten ist auch in der Facettenregion besonders bei gewissen Färbungen zu erkennen.

Im übrigen sind die Corneafacetten ziemlich gleichmäßig geschichtet; sie sind ebenso lang wie breit, zum Teil sogar etwas länger.

Die Krystallkegel sind recht auffallend, und zwar durch ihre Dimensionen, ihre Struktur und ihre Farbe. Sie sind sehr lang, 2-3mal so lang wie loreit. Ihre Struktur muß auch eine ganz andere gewesen sein als bei den meisten anderen Formen, welche ich untersuchte. Durch die Konservierung waren nämlich eine Unmenge feiner Granula in ihnen niedergeschlagen worden, welche durch faserige Züge und Wüinde zusammengehalten wurden. Die Substanz der Kegrel scheint also eine viel weichere gewesen zu sein als bei den meisten anderen Formen, welche ich untersuchen konnte. Ihre Farbe war in den konservierten Objekten eine gelbliche oder brïunliche. Das wird wohl kaum ihre ursprüngliche Färbung gewesen sein. Vielleicht ist sie eine Folge der Konservicrung, indem der Niederschlag in clieser Farbe abgeschieden wurde, oder es mag aus ciner Substanz, die als Tapetum oder sonstwie im Auge vorhanden war, sich gelöst und die Kegel gefärbt haben. Immerhin ist es auffallend, daß nur sie diese Fürbung zeigen.

Die unteren Enden der Krystallkegel sind von einer Hülse dunkelbraunen Pigmentes umgeben. Das Pigment ist in feinen Platten und Fasern angeordnet, und diese werden wohl aus der protoplasmatischen Leibessubstanz der Irispigmentstellen bestehen. Doch grelang es mir nicht, 
mit Sicherheit letztere nachzuweisen. Mit Sicherheit läßt sich jedoch feststellen, daß das Pigment $\mathrm{n}$ icht in den Stäbchenzellen liegt. Das Irispigment ist auf das untere Drittel der Krystallkegel beschränkt und umschließt dasselbe ziemlich vollständig.

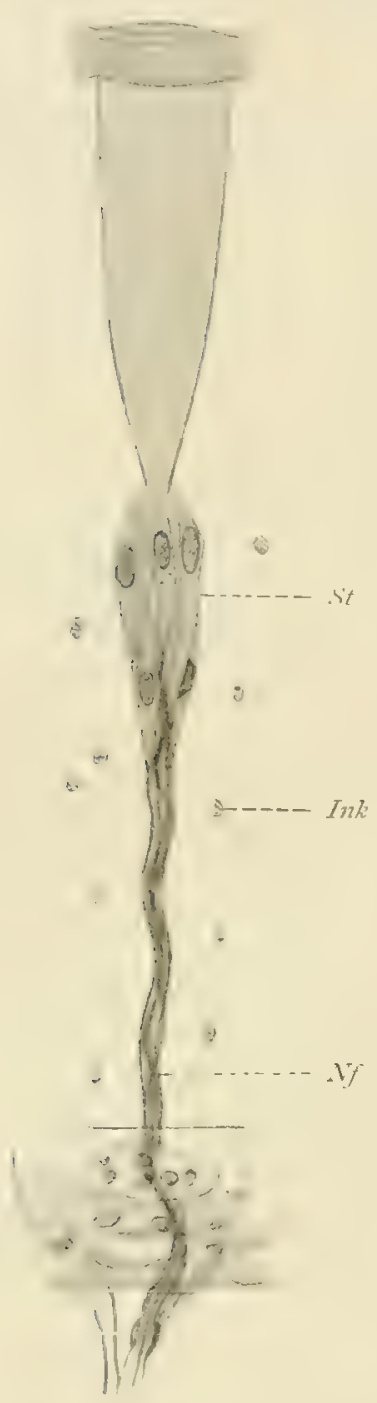

Fig. I4. Augenkeil von Geryon affinis M-E. u. Bouv. St Stäbcbenzellen, $N f$ Neurofibrillenbündel, Ink Interretinalkerne.

Die Stäbchenregion des Auges zeigt eine Anzahl von Eigentümlichkeiten. Wie Taf. LV, Fig. 3 zeigt, ist das Stäbchen schlank-keulenförmig, im proximalen Teil wird es sehr dünn. Im distalen Teil ist es von den verdickten Zellkörpern der 7 Stäbchenzellen umgeben, welche im dicken Schnitt als lockeres Bündel sichtbar sind; sie umschließen in charakteristischer Weise das distale Ende des Stäbchens (s. Textfig. 14). Auf dünneren Schnitten erkennt man die von dem eigentlichen Stäbchen deutlich abgesetzten Zellkörper mit ihren Kernen (Taf. LV, Fig. 3). Auffallend ist, daß hier umgekehrt wie z. B. bei Plcistacantha der quergestreifte Teil, welcher die übliche Stäbchenstruktur aufweist, der distale ist, während die proximale Hälfte des Stäbchens der Plättchenstruktur entbehrt. Im proximalen Teil erkennt man eine Anzahl starker Stränge, welche bei genauerem Studium sich als Ausläufer der quergestreiften Partie der Stäbchenzellen erkennen lassen. Soviel ich feststellen konnte, sind es ihrer auch sieben. Sie sind bis zur Lamina fenestrata gesondert nebeneinander sichtbar und treten auch gesondert durch dieselbe hindurch. Sie sind die Nervenfibrillenbündel, welche sich zu den Nervensträngen vereinigen, um in das I. Ganglion opticum zu münden (s. Textfig. 14). Die Fig. 3 der Taf. LV ist nach einem nicht sehr gut konservierten Exemplar angefertigt; infolgedessen ist dort bis zur Lamina fenestrata hin eine Plättchenstruktur angegeben. Erst später erhielt ich von Herrn Prof. Chun während der Expedition abgeschnittene und gut konservierte Augen des Tieres, welche klare Bilder ergaben; nach solchen ist Textfig. I4 angefertigt.

Außer den erwähnten Dingen fällt der Reichtum an kleinen Kernen in der Retinalregion auf (Taf. LV, Fig. 3 Ink; Textfig. I $4 \mathrm{In}$ k).

Die zahlreichen Nervenstränge, welche zum 1. Ganglion opticum laufen, durchziehen einen fast ganz von Gewebe freien Raum. Das I. Ganglion ist flach ausgebreitet, es stellt eine etwa tellerförmig gewölbte Lamelle dar. In ihm sind die stäbchenförmigen Bildungen nicht sehr deutlich zu erkennen; nur in den Randpartien ist zum Teil eine merkwürdig regelmäßige Anordnung zu erkennen, indem je 1 o Zellen in gerader Reihe hintereinander liegen, und diese Längsreihen durch schmale Faserstränge ganz regelmäßig voneinander getrennt sind. Von ihm ziehen die Nervenfasern in sehr geradlinigen Strängen zum 2. Ganglion. Die Bündel von Nervenfasern sind durch Zellanhäufungen voneinander getrennt, ähnlich wie wir dies früher bei dem Auge von Platymaia kennen lernten. Doch ist die Kreuzung der Fasern ganz deutlich sichtbar. 2. und 3. Ganglion sind relativ klein, zwischen ihnen und zwischen dem 3. und 4. ist die Kreuzung der Fasern sehr deutlich. Das 4. zeigt wieder die gehirnartigen Windungen und ein unentwirrbares Geflecht von Fasern. Aus ihm geht der sehr starke Nervus opticus hervor. 
Der ganze Ganglienapparat ist wie gewöhnlich in einen bindegewebigen Sack eingehüilt, der hier aber auffallend stark ist.

Das Auge ist ein iridopigmentäres Auge; denn wie wir sahen, ist das Irispigment mächtig entwickelt, während von Retinapigment im Gewebe nichts nachzuweisen ist. Die Kerne der abführenden Nervenstrünge zeigen sich in der Nähe der Lamina fenestrata, von einer dunkeln granulierten Masse umgeben, doch bin ich zweifelhaft, ob es überhaupt Pigment ist. Auch könnten die kleinen Quantitäten kaum von Einfluß auf den Sehvorgang sein.

\section{Auge der Larve.}

IVie später ausgeführt werden wird, ist in den Eihüllen von Geryon affinis das junge Tier im Zoëastadium zum Ausschlüpfen fertig. Es war daher von besonderem Interesse, dessen Augen auch zu untersuchen. Eine Abbildung eines Schnittes zeigt Taf. LII, Fig. 7.

Es sind schwache Cornealinsen vorhanden, gut entwickelte lange Krystallkegel und lange Stäbchen. Zahlreiche große Kerne erfüllen die Stäbchenregrion, doch habe ich den Jindruck, als handle es sich ausschließlich um Stäbchenzellkerne. Als wesentlich ist hervorzuheben, da $\beta$ ein gut entwickeltes Irispigment und, in den Randpartien des Auges wenigstens, ein starkes Retinapigment vorhanden ist.

Maße des Auges und seiner Teile.

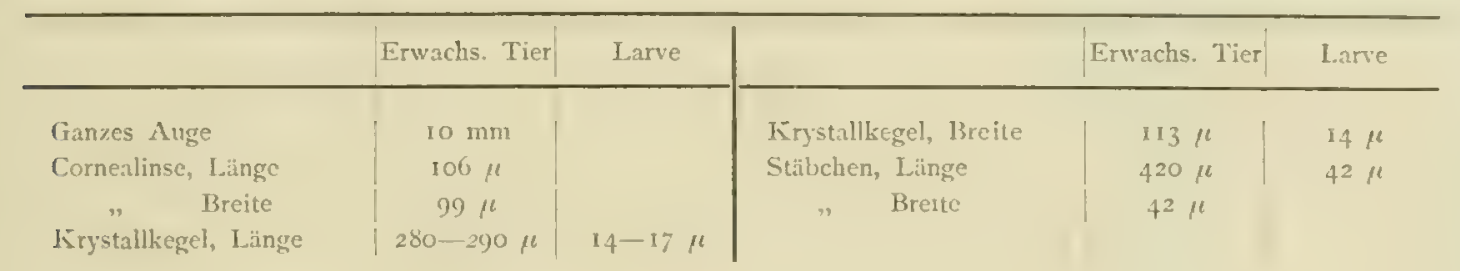

\section{Hexaplax megalops DofL.}

Taf. L, Fig. 7; Textfig. I5 и. г6.

Das Auge von Hexaplax megalops erschien bei der ersten Untersuchung viel auffallender, als es sich später bei der Untersuchung auf Schnitten herausstellte. Doch ist es immerhin sehr bemerkenswert.

\%unächst fällt es durch seine gewaltige Größe auf. Das Verhältnis der Augengröße zur Größe des ganzen Körpers wird von keiner Brachyure des tieferen Wassers übertroffen und erinnert an die Größenverhältnisse der Augen von grewissen Galatheiden (s. Taf. XXXI, Fìg. 3).

Auch die Corneafacetten sind recht groß (vergl. Taf. L, Fig. 7). Im Aufsichtsbild zeigt das Aurge zwei dunkel gefärbte Centren, in denen scheinbar dunkles l'igment aus dem Innern des Auges durchschimmerte. Ich vermutete ein irgendwie geartetes Doppelauge und ließ die umständliche Abbildung auf Taf. L, Fig 7 anfertigen. Doch enttäuschten die Schnittpräparate sehr. Dic ganzen inneren Gewebe waren infolge von schlechter Konservierung greschrumpft, und infolge dessen waren zwei Klumpen entstanden, an denen man kaum Spuren radiërer Streifung und nicht einmal das Vorhandensein von Pigment nachweisen konnte. 
Die zahlreichen großen Facetten des Auges sind besonders auf der Vorder- und Unterseite verteilt. Auf der Oberseite mündet der Stiel ein, und zwar ist die Wölbung so eigenartig,

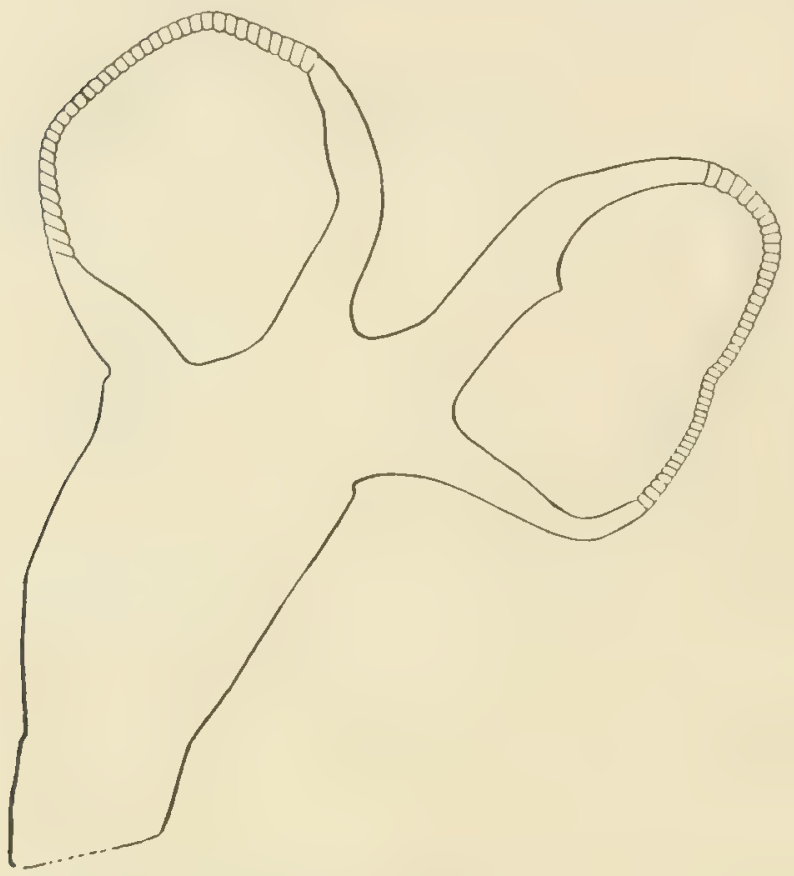

Fig. 15. Frontaler Schnitt durch den dorsalen Teil des rechten Auges von Hexaplax megalops DoFL. daß auf Schnitten Bilder entstehen, als ob am gleichen Stiel 2 Augen säßen, wie sie nebenstehende Textfigur i 5 zeigt.

Die Schnitte ließen nur die Form der Corneafacetten studieren. Dieselben sind sehr lang und schwanken in dem Verhältnis der Länge zur Breite von I: I bis 2:3. Die Schichtung ist eine sehr deutliche. Die Wölbung eine bikonvexe, wobei die nach innen gerichtete Wölbung sehr stark, fast kegelförmig ist (Textfig. I6).

Sonst kann ich leider über die Struktur des Auges nichts Sicheres an den Präparaten erkennen.

Maße des Auges und seiner Teile:

Ganzes Aurge Länge: $4,5 \mathrm{~mm}$

" $\quad$ Breite (breiteste Stelle der Fiacettenregion): $3,5 \mathrm{~mm}$

Länge der Corneafacette: $50-65 \mu$ (im peripheren Teil des Auges)

Breite " $\quad 50 \mu(35-50 \mathrm{im}$ peripheren Teil des Auges).

\section{Ueber den Bau der Geruchsorgane einiger Tiefseekrabben.}

Wie mit fast sämtlichen Organen des Arthropodenkörpers, verhält es sich auch mit den Antennen: die Angaben über den Bau derselben bei den verschiedenen Formen sind ganz fragmentarisch, die Histologie ist nur bei einigen wenigen Formen, die immer wieder als klassische Untersuchungsobjekte herangezogen wurden, erforscht; über die Beziehungen des Baues dieser Organe zur Lebensweise ihrer Träger sind zwar hier und da allgemeine Andeutungen gemacht worden, diese beziehen sich aber meist nur auf die Größenverhältnisse, und wo sie etivas eingehender sind, handeln sie von niederen Formen und nicht von den Brachyuren, welche uns hier speciell beschäftigen. So existieren sehr wertvolle Angaben von Weismann über Entomostraken, von Chun über Euphausien, Mysideen und Sergestiden etc.

Aber auch bei den Brachyuren zeigt fast jede Form, deren Lebensweise wir kennen, und deren Antennen wir untersuchen, deutliche Beziehungen zwischen deren Bau und den Lebensverhältnissen. Ich werde in dem allgemeinen Teil dieses Abschnittes Belege dafür bringen. Bis jetzt fehlt aber jede Vorarbeit. Wenn ich also in der allgemeinen Darstellung der Biologie der 
Tiefseekrabben versuche, aus dem Bau der von mir untersuchten Antennen Bezichungen zur Lebensweise zu konstruicren, so kann ich leicht Trugschlüsse begehen, da ich nur eine beschränkte Zahl von Krabben anderer Lebensbezirke untersuchen konnte. So erscheint es denn zweckmäßig, Fig. 17 hier zunïhst die exakte Beschreibung, wie bei den Augen, vorausgehen zulassen, um die Verwertung ag $g^{\prime \prime}$ meiner Befunde auch dann zu ermöglichen, wenn meine Schlüsse sich als trügrerisch herausstellen sollten. Bekanntlich befinclen sich bei den Decapoden die als Träger des Geruchssinnes gedeuteten Organe auf den inneren Antennen. Und zwar finden sich die Enclapparate auf der Außengreißel derselben. Bei den Brachyuren nun pflegen die Geißeln der inneren Antenne gregenüber dem Verhalten der Cariden und Macruren sehr kurz zu sein. Die Aulsengeißel speciell ist in der Recrel in ihrem basalen Teil ver. dickt, und dieser basale Teil ist meist von der Endgeißel scharf abgesetzt (s. Textfig. 1 $7 A g^{\prime}$ u. $A g^{\prime \prime}$ ). Nur auf dem basalen Teil sitzen mun die „R iech ha are“. Ich ziehe diese Bezeichnung als die prägnantere und mehr aussagende den sonst noch in der L.itteratur angrewandten (Geruchscylinder, Ge-
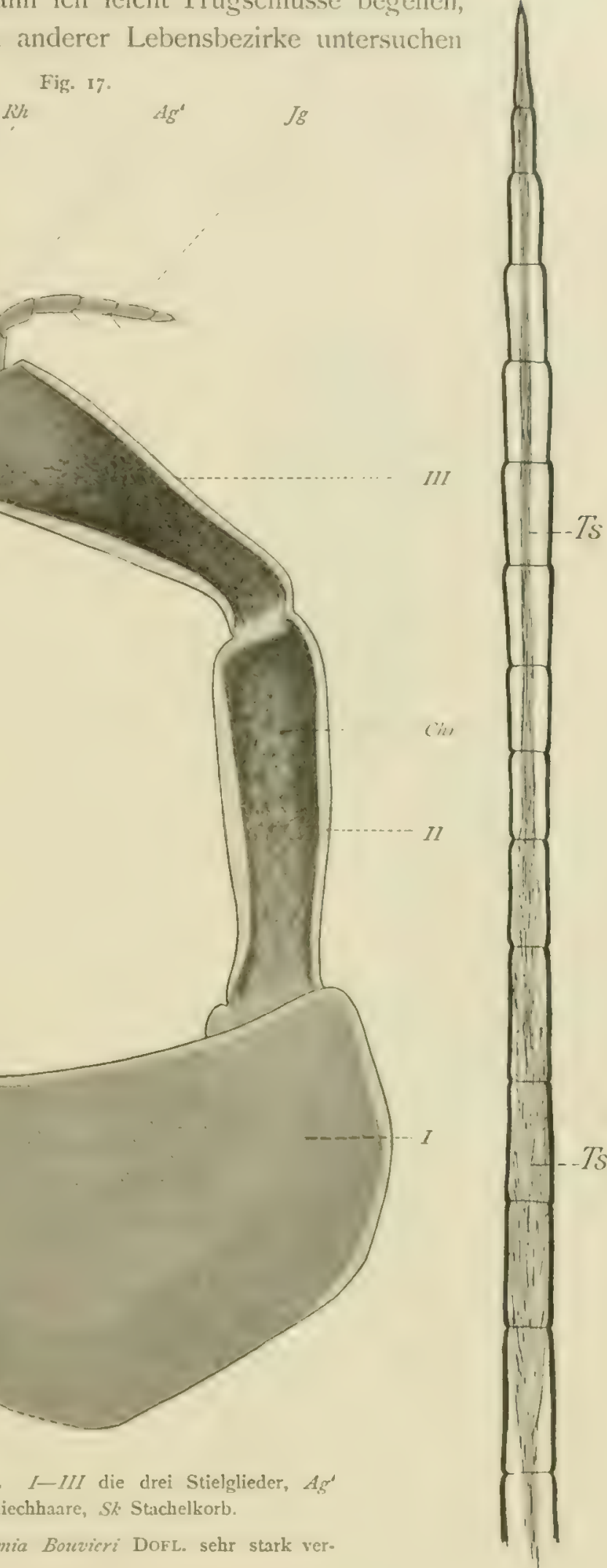
größert. Ts Terminalstrang.

Fig. 17. Innere Antenne von Chlorodius niger (Fonsk.). I-III die drei Stielglieder, $A g^{\circ}$ proximaler, $A g^{\prime \prime}$ distaler Teil der Außengeißel, $J g$ Innengeißel, $R h$ Riechhare, $S k$ Stachelkorb.

Fig. 18. Distales Ende eines Riechhaares von Homolodromia Bonvicri DoFL. sehr stark ver- 
ruchszapfen) vor. Diese Haare sind hohl und sehr dünnwandig. In basalen Teil des einzelnen Haares ist die Wand viel dicker als im distalen Teil desselben; die Haare erscheinen im durchfallenclen Licht sehr zart konturiert.

Bei manchen Formen fand ich im proximalen Teil der Haare Versteifungseinrichtungen (Gi) yon affinis Taf. LIX, Fig. 2), bei anderen fand ich die Haare im distalen Teil gegliedert

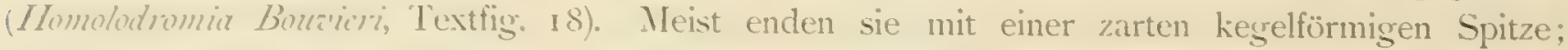
ich habe bei Brachyuren keine offenen Haare gefunden. Solcher Riechhaare finden sich auf

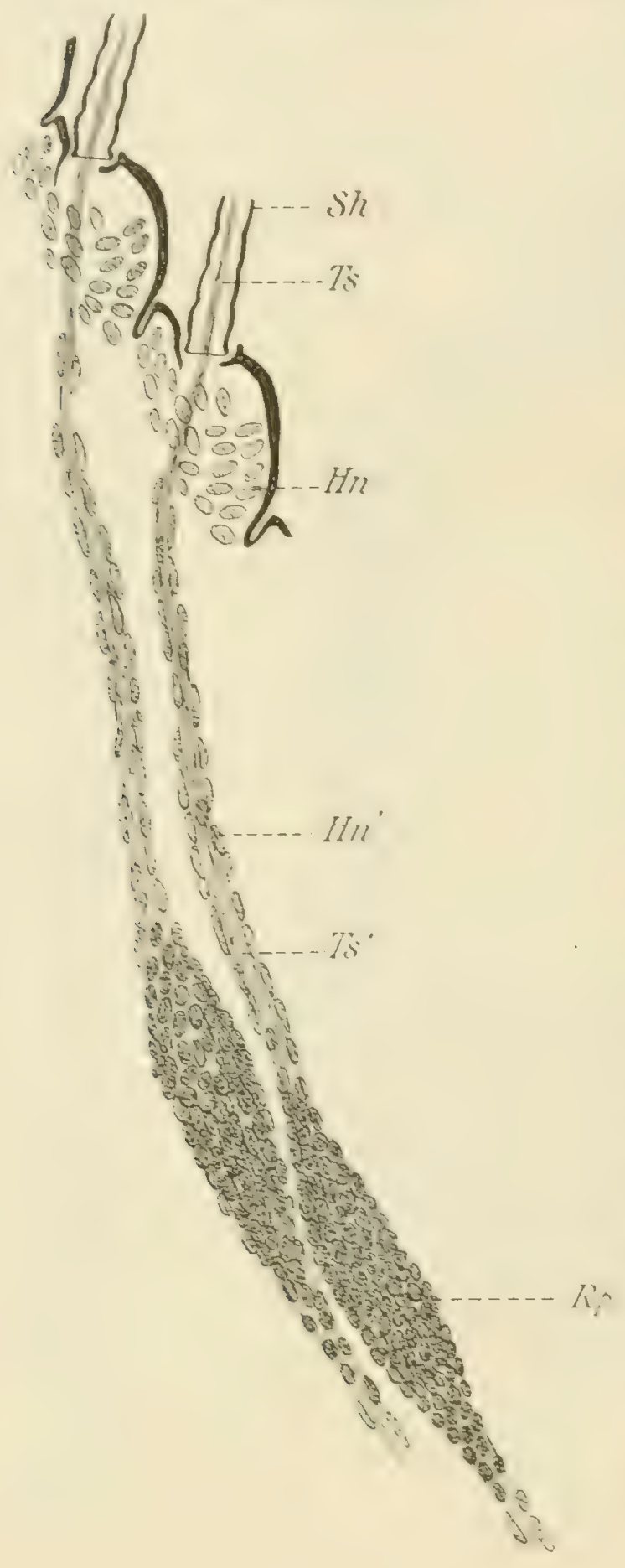

den basalen Segmenten der Außengeißel meist mehrere auf jedem Segment. Sie sind dann in Gruppen oder in Reihen angeordnet (vergl. Taf. XLIII, Fig. 6 u. 9; Taf. LVI, Fig. 5).

IVas nun die Innervation des Sinnesorganes anlangt, so fand ich sie durchaus den Angaben entsprechend, welche vox Ratri z. B. für Astacus (= Polumobius) fluriatilis Roxd., den Flußhrebs, gemacht hat.

Der Geruchsnerv spaltet sich in dem 3. Basalwied oder in der Außengeißel der inneren Antenne in zahlreiche Aestchen, ron denen je einer mit einer Gruppe ron Sinneszellen, Nervenzellen rom Charakter einer bipolaren Ganglienzelle, in Verbindung tritt. Diese Gruppen von Sinneszellen stellen sich als sehr kompakte, geschlossene Einheiten dar, und jede derselben versorgt ein Riechhaar mit Nervenendigungen. Diese Nervenendigungen treten in Form feinster Fasern - aus je einer Simneszelle je eine Faser hervor, und die aus je einem Sinneszellennest hervortretenden Fasern vereinigen sich zu einem Strang, welcher in ein Riechhaar eintritt und dort den Terminalstrang darstellt. Ein solcher Terminalstrang erstreckt sich in jedem Riechhaar bis in die (iegend der Spitze. Die Fasern liegen dicht zusammengelagert, doch findet man nicht selten Stellen - meist eine in einem Haar - wo die Fasern aufgelockert sind und sich durcheinanderflechten (s. Textfig. Is TS unten).

Die Simneszellennester werden in der Regrel als Ganglien bezeichnet; ich vermeide diesen Aus-

Fig. 10. Zwei Riechspindeln mit Terminalnerven von Homols.

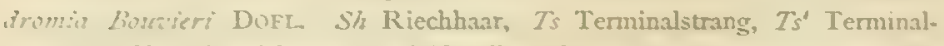
ner: $H n$ Hyphlermiskerne, $H n^{\circ}$ Neurilemmkerne des Terminalnerven, $R_{f}$ Riechspindel. 
druck, da or nicht exakt genugy ist, und nenne diese als histologische Einheiten sich darstellenden zum Geruchsorgan gehörigen Gruppen von Sinneszellen „Riechspindeln“.

Bei den meisten niederen Decapoden und auch bei viclen Brachyuren sind dieselben spindelförmig gestaltet und in einer Reihe hintereinander angeordnet. So stehen sie beim Flußkrebs entsprechend der Gestalt der Antennengeißel eng gedrängt in einer Lïngsseihe, wobei jede Riechspindel einem kurzen Iïbrillenbündel den Ursprung giebt, welches unmittelbar hinter ihr in den lïngsverlaufenden Hauptstrang des Riechnerven einmündet (s. Textfig. 20).

Nit der höheren Komplikation des Geruchsorganes jedoch schen wir, wie die Riechspindeln in der Geißel der Antenne keinen Platz mehr finden und in das 3. Basalglied der Antenne allmählich hineingedrängt werden. Wir können bei verschiedenen Arten alle Stufen dieser Erscheinung verfolgen.

Dabei vereinigen sich die einzelnen Riechspindeln zu einer mehr und mehr einheitlichen Masse, welche ganz den Eindruck cines großen peripheren Ganglions macht. Aber man kann in ihr die wohlgesonderten einzelnen - zu je cinem Riechhaar gehörigen - Riechspindeln unterscheiden, und wir vermissen auch die für periphere Ganglien charakteristische Fasersubstanz. Ob eine Bezichung der einzelnen Sinneszellen untereinander besteht, oder ob weitere Nervenzellen in den Riechspindeln, besonders der komplizierteren Formen, eine Rolle spielen, kann ich nicht entscheiden, da hierzu mein Material nicht grenügrend groß und gut konserviert war. Die ganze Masse besteht, soviel wir bis jetzt

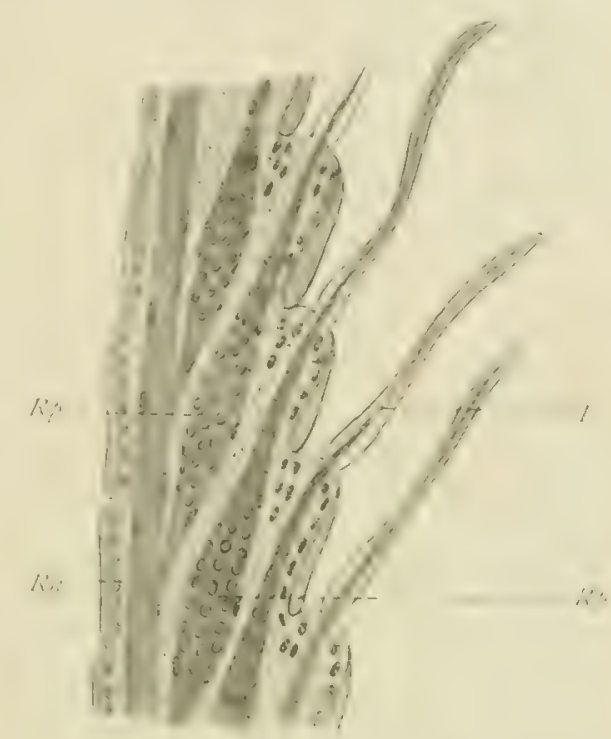

Fig. 20. Iunervation des Geruchsorganes bei den Flulikrebs ('Potamobius thutiatilis [RONI).]). Nach $\because$ RAтr. Ru Riechnerv, Rp Riechspindel, Ts Terminalstrang. wissen, aus Sinneszellen und den sie zum Teil umhuillenden resp. in Portionen, die Riechspindeln, abteilenden Bindegrewebszellen; dazu kommen, außer dendritenartigen Fortsätzen der Sinneszellen, die von der einen Seite cintretenden Nervenfasern und die peripher hervortretenden Endigungen des Terminalstrangses; auch letztere können, und zwar um so mehr, je größer die Entfernung zwischen Riechhaar und Riechspindel ist, von Bindegewebsellen umhüllt sein, so daß sie einen regelrechten, von Neurilemm eingehüllten Nerven darstellen. In solchen Fällen ist es oft praktisch, sie mit. einem unterscheidenden Namen zu bezeichnen, ich nenne sie Terminalnerven (Textfig. I9 $T s^{\prime}$ ).

Wo eine solche Vereinigung zahlreicher oder sämtlicher Riechspindeln zu cinem einheitlichen Gebilde, wie es z. B. Taf. LVI, Fig. 3 darstellt, eingetreten ist, spreche ich von einem Riechlappen oder Lobus osphradicus. Ich bemerke, daß bei zahlreichen Formen eine Trennung in zwei größere Lappen erkennbar ist, von denen der eine der inneren, der andere der iußeren Wand des 3. Stielgliedes der inneren Antenne innerlich anliegt. Oft geht aus jedem derselben ein besonderer Nervenstrang hervor, welcher sich mit seinem Partner meist an der Crenze des 2. und 3. Stielgliedes vereinigt. Zwischen beiden Lappen verläuft dann meist der Muskel, welcher die Außengeißel der Antenne bewegt. Fig. 3, Taf. LVI, zeigt uns die beiden Lappen mit den Nerven von der Flåche, Fig. 5 zeigt sie uns von der Seite. 
Hervorheben möchte ich noch, daß die Riechspindeln als histologische Einheiten etwa den Stäbchen im Auge der Decapoden entsprechen, die Riechzellen den Sehzellen, und der ganze Lobus osphradicus etwa der Gesamtretina des Facettenauges, nicht etwa dem Ganglion opticum.

Wir haben also am peripheren Teile des Geruchsorgans eine ähnliche Konstruktion aus einzelnen Elementen zu konstatieren, wie man sie heutzutage beim Facettenauge annimmt. Doch besteht ein wesentlicher Unterschied: das Ganglion opticum des Auges hat am Geruchsorgan kein Analogon im peripheren Teil. Ob im Gehirn dem konzentrierteren Organ eine kompliziertere Bildung entspricht, kann ich nicht sagen. Auch um diese Frage zu verfolgen, war mein Material weder reich genug noch hinreichend sorgfältig konserviert.

Ich schließe nun wieder in systematischer Reihenfolge die Beschreibung des Baues der wichtigsten Formen an.

\section{Homolodromia Bouvieri DofL.}

Taf. LVI, Fig. I u. 2; Taf. LVII, Fig. 2.

Die inneren Antennen dieser Form sind relativ groß (Taf. LVI, Fig. I). Die Außengeißel ist sehr lang (Taf. LVI, Fig. $2 A g$ ) und schlank, distaler und proximaler Teil sind nicht voneinander abgesetzt. Doch tragen die letzten $6-7$ Glieder der Außengeißel keine Riechhaare mehr, sondern nur mehr Tasthaare.

Die Riechhaare sind sehr lang; im proximalen Teil mit dickerer Chitinhülle versehen als im distalen Teil. Sie sind im proximalen Teil in ähnlicher Weise versteift, wie wir es unten bei Geryon kennen lernen werden, im distalen Teil deutlich gegliedert. Textfig. I 8 stellt nur den distalen Teil eines solchen Haares dar. Der Terminalstrang ist gut bis ans Ende des Haares zu verfolgen; ungefähr am Anfang des distalen Drittels der Haarlänge ist der Terminalstrang pinselartig aufgelockert (Textfig. I 8 Ts unten).

Auf jedem der basalen I6-i 8 Glieder der Außengeißel steht eine Reihe von solchen Riechhaaren nebeneinander. Die Menge dieser Haare bedingt eine Menge von Riechspindeln, und der Mächtigkeit des Terminalstranges entspricht in jeder Spindel eine große Anzahl von Riechzellen. Infolgedessen haben die einzelnen Riechspindeln in der Außengeißel keinen Platz, und sie sind zum größten Teil im Innern des 3. Basalgliedes angehäuft (s. Taf. LVII, Fig. 2). Man kann trotz des großen Gewirres, welches im Gesamtbild zu Tage tritt, bei der Untersuchung auf Schnitten jeden Terminalstrang zu seiner Riechspindel verfolgen. Ebenso sind letztere als wohlisolierte Zellgruppen erkennbar, und die aus ihnen hervorgehenden centripetalen Nervenstränge sind ebenfalls mit überraschender Deutlichkeit zu verfolgen.

Wir haben hier also einen noch nicht ganz vollkommen ausgebildeten Lobus osphradicus vor uns.

Bemerkenswert sind noch folgende Einzelheiten des Baues der Antenne: die von den distalen Glierlern der Geißel stammenden Nerven, welche von den Sinneshaaren (Tasthaaren, nicht Geruchshaaren) derselben herkommen (Taf. LVII, Fig. 2 Tan), vereinigen sich ebenfalls mit dem Geruchsnerven, aber ohne mit einer ähnlichen Bildung, wie einer Riechspindel, in Verbindung getreten zu sein. 
Ebenso vereinigt sich der aus der Innengeißel (Taf. LVII, Fig I $I g$ ) kommende Nervenstrang, welcher Sinneshaare vom Typus von Tasthaaren innerviert, mit den Riechnerven, aber erst hinter dem Lobus osphradicus.

Bemerkenswert ist ferner, daß der Terminalstrang von Bindegewebszellen umhüllt ist, so daß er vollkommen den Eindruck eines Nerven macht (Taf, LVII, Fig. 2 Tn). Die Einhüllung der sensiblen Endfasern in eine bindegewebige Hülle, die Bildung eines Terminalnerven, ist wohl durch die große Entfernung zwischen Endapparat und Sinneszellen bedingt.

Die Vereinigung der centripetalen Nervenfasern zum Riechnerven erfolgt innerhalb des 3. Gliedes des Antennenstieles.

Die zahlreichen Muskelstränge, welche in diesem 3. Glied ansetzen und die Antenne zu einem sehr beweglichen Organ machen, sind in Fig. 2 der Taf. LVI zum Teil cingezeichnet; in Fig. I der Taf. LVII sind sie weggelassen.

\section{Homolochunia Valdiviae DofI.}

Taf. XLIII, Fig. I.

Die Geißeln der inneren Antenne sind bei dieser Form sehr kräftig entwickelt, bemerkenswerterweise auch die Innengeißel, welche mit zahlreichen langen Tasthaaren besetzt ist. Die Außengeißel ist sehr breit, die Riechhaare sind lang, in größerer Anzahl auf jedem Segment vorhanden; die Zahl der mit ihnen versehenen Segmente ist sehr groß, nur wenige Endsegmente tragen Tasthaare.

Die Histologie dagegen zeigt einen primitiven Typus. Die lange und breite Außengeißel bietet im Innern weitaus genug Raum für die ziemlich regelmäßig angeordneten Riechspindeln. Dieselben liegen dicht hinter der Basis je des Riechhaares, zu dem sie gehören. Sie sind birnförmig bis spindelförmig gestaltet und bestehen aus einer relativ geringen Zahl von Sinneszellen. Die Verhältnisse erinnern sehr an den Bau bei dem Flußkrebs (s. Textfig. 20) und bei Platymaia (s. unten).

Die Nervenstränge, welche aus den Riechspindeln proximal hervorgehen, vereinigen sich zu einem starken Strang, welcher an der Außenseite der Außengeißel hinzieht. Kaum einige Riechspindeln ragen in das 3. Glied des Antennenstieles hinein.

Es ist also bei dieser Form kein Lobus osphradicus gebildet.

\section{Cymonomus granulatus (Noris.).}

\section{Taf. LVI, Fig. 5 .}

Die schlanke innere Antenne dieser Art zeigt eine lange, dünne Außengeißel und eine recht kurze Innengrißel. Die Aủßengeißel ist mit Reihen kräftiger Riechhaare bestanden, welche zu je 4-5 auf jedem Segment sitzen. Nur die letzten 5 Segmente tragen statt der Riechhaare Tasthaare (Taf. LVI, Fig. 5).

Die Riechspindeln sind auch hier in das 3. Stielglied verlagert und zu einem Lobus osphradicus vereinigt. Derselbe besteht wieder aus 2 deutlichen Lappen, von denen je einer den Breitseiten des Gliedes anliegt. Während die übrigen Figuren der Tafel LVI dies Glied von der Breitseite zeigen, ist es in Fig. 5 bei Cymonomus granulatus um $90^{\circ}$ gedreht gezeichnet, 
so daß man deutlich die beiden Lappen erkennen kann, zwischen welchen der Muskel sich distalwärts erstreckt. Die Lobi erstrecken sich fast durch das ganze Stielglied bis an dessen proximales Ende.

Sie lassen die Grenzen zwischen den einzelnen Riechspindeln nicht erkennen, sondern erscheinen auch auf den Schnitten als je eine Masse; die Sinneszellen sind sehr groß, locker angeordnet und lassen zwischen einander zahlreiche Fasern erkennen.

Ganz dieselbe Form und dieselbe Anordnung der Teile zeigen auch die Antennen der Exemplare von Gibraltar, welche ich untersucht habe und von denen unten noch die Rede sein wird.

\section{Cyclodorippe uncifera glaueomma ALC. Taf. LVI, Fig. 4; Taf. LVII, Fig. 3 .}

Die innere Antenne ist lang und schlank, die Geißeln sind klein und dünn, die innere Geißel ist erheblich kürzer als die äußere (Taf. LVI, Fig. 4).

Die Riechhaare sind lang, aber nicht in auffallend großer Zahl vorhanden; es sitzen ihrer ca. je 5 auf jedem Segment.

Die Terminalstränge sind — wie auch die Riechhaare - sehr dünn und setzen sich in lange dünne Terminalnerven fort. Deren Zahl ist immerhin eine so große, daß in der dünnen Außengeißel kein Platz für die Riechspindeln bleibt. Dieselben sind in das 3. Stielglied verdrängt. Hier bilden sie einen Lobus osphradicus (Taf. LVI, Fig. $4 L O$ ); die einzelnen Riechspindeln sind da so eng zusammengedrängt, daß man keine Grenzen zwischen ihnen erkennen kann, sondern nur einen einheitlichen Lobus. Derselbe ist länglich-eiförmig und auf das distale Drittel des 3. Stielgliedes der Antenne beschränkt. Sein Bau ist - verglichen z. B. mit dem von Physachachs -- ein sehr lockerer. Die Zellen stehen nicht sehr nahe aneinander, und das ganze Gebilde ist sehr reich an Fasern. Zum Teil liegt es auch an dem Erhaltungszustand des Präparates, daß alle Fibrillen besonders deutlich hervortreten.

\section{Cyrtomaia Suhmi platyceros DofL.}

Taf. LVI, Fig. 6 u. 6 a.

Bei dieser Art sind die Geißeln im Verhältnis zur Gesamtlänge der inneren Antenne klein, doch ist die Ausstattung mit Riechhaaren eine ziemlich reichliche (Taf. LVI, Fig. 6). Bei einem der untersuchten Exemplare fand sich eine bemerkenswerte Besonderheit am drittletzten Glied der äußeren Geißel. Die letzten 3-4 Glieder sind normalerweise cylindrisch gebaut und sind mit Tasthaaren besetzt. Während die eine der Antennen dieses normale Bild (Taf. LVI, Fig. 6) zeigte, machte bei der anderen Antenne des gleichen Tieres das drittletzte Glied den Eindruck, als sei es aus 2 Gliedern verwachsen, außerdem zeigte es nach der Außenseite zwei spitz-kegelförmige Auswüchse, welche an ihrem Gipfel mit einem ganzen Büschel von Tasthaaren besetzt waren (Taf. LVI, Fig. 6a). Die Ursache und eventuelle Bedeutung dieser Bildung habe ich nicht auffinden können.

Bei Cyytomaia ist ein Lobus osphradicus vorhanden. Er ist allerdings klein und im distalsten Teil des 3. Basalgliedes gelegen, also nicht anders, als er sich auch bei zahlreichen Flachwasserformen nachweisen läßt (Taf. LVI, Fig. 6 LO). 
Kaum einige Riechspindeln liegen in der Geißel oder auf der Frrenze von 3. Basalglied und Außengeißel, die übrigen sind alle zu einem recht kompakten Gebilde zusammengedrängt.

Der Lobus osphradicus ist auch hier in zwei den Seitenwänden des 3. Basalgliedes anliegende platte Lappen eingeteilt, zwischen welche der Muskel hineinreicht.

Der Riechnerv ist sehr stattlich und läßt sich wie gewöhnlich sehr klar durch den ganzen Antennenstiel, an der Statocyte vorbei, verfolgen.

\section{Platymaia Wyville-Thomsoni Mrs.}

Taf. XLIII, Fig. 6; Taf. LVII, Fig. I.

Die innere Antenne von Platymaia gleicht im äußeren Bau in ihren distalen Teilen schr derjenigen von Homolochunia. Auch hier sind beide Geißeln sehr krüftig entwickelt; die innere ist mäßig mit Sinneshaaren versehen; die äußere ist sehr stark, seitlich abgeplattet, aber immerhin schlank gebaut. Jedes der recht schmalen Glieder trägt eine ganze Reihe ron Riechhaaren, mit Ausnahme der 3-4 letzten, welche mit Tasthaaren bestanden sind. Die einzelnen Riechhare sind sehr lang (s. Taf. XLIII, Fig. 6); ihre Gesamtheit stellt einen ansehnlichen Büschel dar.

Der Aehnlichkeit im äußeren Bau entspricht auch Uebereinstimmung mit Homolochunia in den Verhältnissen des inneren Baues. Auch hier sehen wir die Riechspindeln in einfachen Längsreihen angeordnet. Entsprechend der Länge der Haare und der Mächtigkeit des Terminalstranges sind die Riechspindeln proximal viel größer als distal, d. h. sie bestehen da aus viel mehr Zellen und stellen dementsprechend viel umfangreichere Gebilde dar (s. Taf. LVII, Fig. I).

Die einzelnen Riechspindeln stehen mit ihrer Längsachse fast senkrecht zur Längsausdehnung der Außengeißel. Nur ein ganz kurzer Strang verbindet ihr distales Ende mit dem Fuß des Riechhaares, in welches sie eintreten. Ebenso entspringt an ihrem proximalen Ende nur ein kurzer Nerv, der sich dicht hinter seinem Ursprungsort mit dem Hauptstrang des Riechnerven vereinigt. Letzterer tritt als ziemlich mächtiger Strang in den proximalen Anfangsteil der Außengeißel ein und zieht, indem er die Einzelnerven an die Riechspindeln abgiebt, sich rasch verdünnend, stets in der Mitte des Innenraumes der Geißel dahin (Taf. LVII, Fig. $1 R n^{\circ}$ ).

Es ist sehr zu beachten, daß fast der ganze äußere Teil des Innenraumes der Außengeißel frei von Geweben ist. Wir sehen also hier, in dem Falle, wo Platz genug vorhanden ist, die primitive Anordnung der Riechspindeln beibehalten; hier wäre sogar noch Platz für eine weit stärkere Ausbildung des Riechorganes. Ein Blick auf Taf. LVIII zeigt uns, daß z. B. bei Plyysachaeus in der Geißel bei weitem nicht Platz genug auch nur für die Hälfte der Riechspindeln gewesen wäre; dort wird der ganze Raum von den zahlreichen Terminalnerven in Anspruch genommen.

\section{Physachaeus ctenurus Alc. u. And.}

Taf. XLIII, Fig. 9; Taf. LVI, Fig. 3; Taf. LVIII.

Das Geruchsorgan von Physachaens ist von sämtlichen untersuchten Formen das am stärksten entwickelte. Schon die äußerliche Untersuchung zeigt uns die außerordentlich langen Riechhaare, welche in mehreren Exemplaren nebeneinander auf jedem Glied der Außengeißel stehen (Taf. XLIII, Fig. 9), sowie den durchschimmernden mächtigen Lobus osphradicus.

Dessen Mächtigkeit überrascht noch mehr an den Längsschnitten. Wie Fig. 3 auf Taf. LVI und Taf. LVIII zeigen, füllt der Lobus osphradicus zwei Drittel des Innenraumes des 3. Basalgliedes aus. 
Der große Umfang des Organes hat in verschiedenen Dingen seine Ursache, und zwar in der Menge von Riechhaaren, der Stärke der Terminalstränge und schließlich in der Großzelligkeit der Gewebe des Tieres, welche sich auch an den Sinnes- und Bindegewebszellen dokumentiert. Der Lobus osphradicus ist in 2 große Hauptlappen geteilt, von denen jeder einer Breitseite des 3. Antennenstielgliedes anliegt (Taf. LVI, Fig. 3, LO' u. LO"). Zivischen ihnen beiden erstreckt sich der Hauptlängsmuskel nach vorn (Taf. LVI, Fig. $3 M$ ). Trotz der Größe des 3. Stielgliedes sind die einzelnen Riechspindeln sehr eng zusammengedrängt, so daß ihre Form dadurch sehr beeinflußt wird. Auf dem Schnitt Taf. LVIII sieht man, wie manche derselben zu langen, dünnen Strängen ausgezogen sind. - Die Länge, welche der Terminalstrang erreicht, ist zum Teil eine ganz außerordentliche. Die bindegewebige Hülle, welche den in der Antenne selbst verlaufenden Teil des Terminalstranges umschließt, besteht aus sehr großen Zellen (Taf. LVIII $N m$ ).

Die Großzelligkeit ist eine auffallende Eigentümlichkeit auch der übrigen Gewebe der inneren Antennen. Die Muskeln sind aus einer geringen Anzahl großer Zellen zusammengesetzt, welche in dem reichlichen Protoplasma nur wenige große Kerne und eine geringe Anzahl voneinander isoliert verlaufender quergestreifter Stränge aufweisen. Die Riechnerven, welche aus den centripetalen, aus den Riechspindeln hervorgehenden Nervensträngen sich bilden, sind zum Teil nach dem Typus gebaut, den schon Lexdig im Centralnervensystem des Flußkrebses nach gewiesen hatte; er hatte die eigentümlichen dicken, röhrenartigen Bildungen, welche aus einer gelatinösen Masse zu bestehen scheinen, und in denen man fibrilläre Strukturen erst spät nachzuweisen vermochte, Kolossalfasern genannt.

\section{Geryon affinis Milne-Edwards u. Bouv.}

Taf. XLIII, Fig. 8; Taf. LIX, Fig. I-3.

Während die Außengeißel der inneren Antenne von Geryon mit dicht gedrängten Riechhaaren besetzt ist, stehen auf cler Innengeißel nur wenige kurze Tasthaare. Beide Geißeln sind kräftig gebaut; die äußere zeigt die Andeutung einer Zweiteilung, indem der basale Teil dicker ist und der distale sich stark verdünnt. Der erstere trägt die Riechhaare, während der letztere nur mit Tasthaaren bedeckt ist.

Die Riechhaare fallen auf durch eine Eigentümlichkeit ihres Basalteiles; durch abwechselnde Verdickung und Verdünnung haben sie nämlich in diesem Teil ein geringeltes Aussehen. Auf Schnitten erkennt man, daß nicht eine Verdickung des Chitins die Ausladungen bedingt, sondern der Längsschnitt durch die Wand zeigt eine gleichmäßige Dicke, aber geschlängelte Form (Taf. L_IX, Fig. I $R h^{\prime}$ u. Fig. 2). Offenbar dient diese Anordnung dazu, das Haar steif zu halten, dabei ihm aber seine Elasticität zu belassen. Im distalen Teil ist das Haar einfach röhrenförmig, doch entbehrt es auch hier nicht einer Versteifungsvorrichtung. Die Innenwand der Röhre ragt in kurzen Intervallen in Form von Leisten vor, welche gegen die Spitze hin deutlich eine spiralige Anordnung annehmen. Die Spitze selbst ist fein kegelförmig, am äußersten Ende aber abgestutzt; die erwähnte spiralige Verdickung zieht sich bis in die äußerste Spitze (Taf. LIX, Fig. 3) und erscheint bei abgebrochenen Haaren zum Teil isoliert.

Der Terminalstrang geht in einen kurzen Terminalnerven über, welcher in die langgestreckte Riechspindel mündet. Die Riechspindeln sind sehr groß, bestehen aus zahlreichen Zellen, und man kann verschiedene Zelltypen in ihnen unterscheiden: I) peripher gelegene spindelförmige 
Zellen und 2) central gelegrene Zellen mit großem Kern, zartem Protoplasma mit sehr feinen pseudopodienartigen Auslïufern. Ich bin nicht ganz sicher, ob ich die Verhältnisse richtig deute wenn ich erstere für bindegewebige Hüllzellen und letztere für bipolare Sinneszellen halte. Gerade bei dieser Art sind mir die Beziehungen der einzelnen Zellen zu einander nicht vollkommen klar geworden, und ich halte eine genaue Untersuchung mit guten Methoden an zu histologischen Zwecken eigens konserviertem Material für sehr lohnend.

Aus jeder Riechspindel geht ein relativ sehr dünner Nervenstrang hervor. Die von den distalen Spindeln kommenden vereinigen sich meist bald zu dünnen Nerven. Die von den proximalen Spindeln jedoch bleiben lange isoliert und vereinigen sich erst am Grunde der Geißel.

Die Histologie des ganzen Gebildes wird noch dadurch kompliziert, daß in die Geißel ein ziemlich starkes Blutgefäß eintritt, welches zu jeder Riechspindel eine Kapillare entsendet, welche in enger Berührung mit dem Nervenstrang und der Riechspindel verläuft und noch in der Nähe der Basis des Riechhaares nachweisbar ist.

\section{Die Statocysten einiger Tiefseekrabben.}

Ich habe bei einer Anzahl von Arten auch die in dem 1. Stielglied der inneren Antennen gelegenen Statocysten einer Untersuchung unterzogen. Dabei leitete mich folgende Ueberlegung: Wenn thatsächlich die Statocysten Organe des Orientierungssinnes und nicht Organe des Gehörsinnes sind, so muß man bei den beweglicheren Formen, welche leicht verschiedenen Druckverhältnissen ausgesetzt sind, eine besondere Ausbildung erwarten. Sind dagegen die betreffenden Organe in den Dienst des Gehörs gestellt, so wäre es nicht unwahrscheinlich, bei den Formen mit rückgebildeten Augen besonders gut entwickelte Gehörorgane vorzufinden. Leider erlaubte der Erhaltungszustand und die geringe Anzahl der Exemplare bei einigen der interessantesten Formen keine Untersuchung; aber immerhin haben sich einige Beobachtungen machen lassen, welche ich im Nachfolgenden zusammenstelle und aus denen ich erst in den Abschnitt „Biologie der Tiefseekrabben“ Schlußfolgerungen ziehe.

Vorausschicken möchte ich einige Bemerkungen über den gegenwärtigen Stand unserer Kenntnisse vom Bau der "Gehörbläschen" bei den Brachyuren. Das Wesentliche unserer Kenntnisse von ihnen verdanken wir HENSEx (1863), welcher in seiner berühmt grewordenen, sehr exakten Abhandlung über das Hören wirbelloser Wassertiere eine Fülle wichtiger morphologischer Beobachtungen niedergelegt hat.

Was die Brachyuren anlangt, so wäre von seinen Beobachtungen hervorzuheben, daß er nur geschlossene Bläschen, denen Otolithen fehlten, bei dieser Abteilung der Decapoden fand. Seither sind weitere Befunde über diese Punkte in der Litteratur nicht verzeichnet worden, und noch 1899 hebt HeNsen hervor, daß seines Wissens alle Brachyuren der „Otolithen“ entbehrten. Seine Angaben kann ich, wie man unten sehen wird, zum Teil berichtigen, dagegen kann ich seinen wichtigen und zahlreichen Untersuchungen über die Form und Anordnung der Sinneshaare in den Bläschen kaum etwas hinzufügen. Die mangelnde Uebung im Präparieren dieser Gebilde ließ mich bei der Untersuchung des spärlichen Spiritusmaterials nicht recht zum Ziel kommen. Die Resultate, welche ich gewonnen habe, verdanke ich der Anfertigung von Schnittserien, welche besonders bei den kleinen Formen leicht herzustellen waren. 
Die Innervation hat neuerdings PRENrISS (1899) einer genauen Untersuchung bei einigen Decapoden unterzogen. Seinen Befunden kann ich natürlich erst recht nichts hinzufügen, da mein Naterial eine derartige Untersuchung gar nicht erlaubte. Ich hebe jedoch hervor, daß ich viele seiner sorgfältigen und wertvollen Untersuchungen anderer Bauverhältnisse bestätigen kann. Uebrigrens hebt auch er noch hervor, daß bei sämtlichen Brachyuren der geschlossene otolithenlose Typus vorherrsche.

\section{Homolodromia Bouvieri DofL.}

Taf. LVI, Fig. 2: Textfig. zI.

Bouvier hat in einer interessanten Abhandlung (I897) nachgewiesen, daß die Gattung Homolodromia durch viele Merkmale als die niederste recente bekannte Brachyurenform charakterisiert sei. Ich kann den zahlreichen Eigentümlichkeiten, durch welche sie den Homariden sich nähert, eine weitere Macrureneigenschaft hinzufügen: die Statocyste ist in Gestalt eines offenen Bläschens auscrebildet. Es scheint mir zwar der gegenwärtige Stand unseres Wissens nicht auszuschließen, daß auch bei höheren Brachyurenformen sich dauernd offene Statocysten häufiger werden nachweisen lassen; für einige Formen werde ich ja unten diesen Nachweis liefern. Aber im Verein

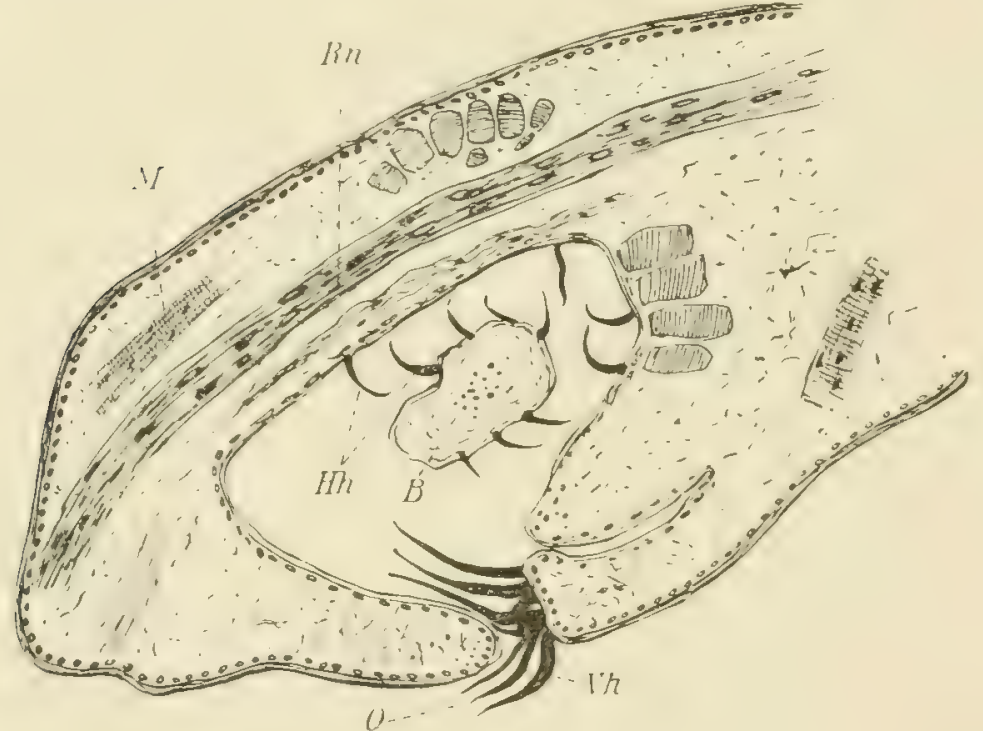

Fig. 2I. Schnitt durch das Basalglied der inneren Antenne von IIomolodromia Bouvieri DOFL. O Oeffnung der Statocyste, Vh Verschlußhaare, $H h$ Sinneshaare, $R n$ Riechnerv, II Muskel, $B$ Anschnitt der Statocysteneinstülpung. mit den übrigen Merkmalen spricht mein Befund jedenfalls zu Gunsten der Bouvierschen Auffassung von der systematischen Stellung der Gattung.

Das Basalglied der inneren Antenne ist mäßig dick (Taf. LVI, Fig. 2) und enthält im Innern ein Bläschen, dessen Wandung nicht glatt ist, sondern einige tiefe Einfaltungren zeigt, die ins Innere des Bläschens vorragende Beulen darstellen.

Auf der Seite des Basalgliedes konnte man schon von außen eine durch einen Büschel von Haaren markierte Stelle erkennen, welche die offene Kommunikation ins Innere des Bläschens darstellte. Auf Schnitten sind die Verhältnisse sehr klar zu übersehen (Textfig. 2 I). Man sieht eine weite Oeffnung ins Innere der Statocyste führen und die eine Lippe dieser Oeffnung mit einer Gruppe sehr kräftiger Haare, welche nach innen umgebogen sind, bestanden (Textfig. 2 I $O$ u. $V / h$ ).

Im Innern erkennt man an verschiedenen Stellen der Oberfläche Gruppen von hakenförmigen Haaren, auch an den Wänden der ins Innere ragenden Vorwölbungen (Textfig. 2 I Hh). Indem diese letzteren zum Teil getroffen sind, stellen sie sich auf den Schnitten wie im Innern des Bläschens gelegene Körper dar. Bemerkenswert ist, daß an solchen Stellen die Haare in einem engen Kanal einander direkt gegenüberstehen. Ich konnte nur kräftige Hakenha are finden. 


\section{Dromia atlantica DofL.}

Dromia allantica besitzt ebenfalls eine offene Statocyste, deren Eingang durch ein dichtes Haarbüschel fast undurchdringlich verstopft ist. Noch auffälliger ist, daß sich bei letzterer Art auch mehrere statolithenartige Gebilde im Innern des Blïschens fanden. Und zwar ficlen sie besonders dadurch auf, daß sie aus organischem Naterial, oder wenigstens auf organischer Grundlage aufgebaut zu sein scheinen, obwohl wir es mit einer Art mit offenem Bläschen zu thun haben. Im Inneren des Bläschens konnte ich in der Schnittserie keine Haarbildungen nachweisen, obwohl das Objekt sonst einen sehr gut konservierten Eindruck machte. Doch ist es bei der Anfertigung von Schnitten durch Objekte, welche in Paraffin eingebettet waren, mir öfter begegnet, daß Haare der verschiedensten Art, die am ganzen Objekt noch zu sehen waren, bei den Manipulationen des Schneidens, Aufklebens, Färbens u. S. w. verloren gingen.

\section{Homolochunia Valdiviae DofL.}

Das Organ in dem I. Stielglied der inneren Antenne ist nicht ganz einfach gebaut, und da ich nur ein Exemplar untersuchen konnte, weiß ich nicht, ob ich alles richtig erkannt und gedeutet habe. Außer einer großen Blase können wir nämlich einen zweiten, mehr schlitzartigen Hohlraum erkennen, der den Eindruck eines Vorhofes der eigentlichen Statocyste macht, ohne daß ich allerdings mit Sicherheit angeben könnte, ob zwischen beiden eine offene Kommunikation besteht. Die eigentliche Statocyste ist sehr groß, ihre Wandung ist bis auf eine starke distale Einstülpung ziemlich der Form einer Kugelschale genähert. An den Wänden, besonders der ventralen und den Seitenwänden, erkennt man nicht sehr dicht stehende feine Haare, welche mit Kugelgelenken in den Chitinüberzug des Blaseninneren eingelassen sind. Sie sind kurz und spitz und ragen in das Lumen der Statocyste in der Richtung auf eine Statolithenansammlung vor. Es findet sich da ein Haufen von Detritus, welcher teils organische Bestandteile, die sich gefärbt hatten, meist aber kleine Splitter unorganischer Art, dazu Stücke von Diatomeenschalen und Schwammnadeln umschloß. Die Lage dieser Objekte läßt es unzweifelhaft erscheinen, daß es sich um Statolithen handelte.

Der enwähnte vorhofartige Raum liegt in dem seitlichen stark vorgewölbten Teil des Basalgliedes der Antenne, der in Taf. XLIII, Fig. I nach oben gerichtet ist. Er besteht aus einem schmalen, schlitzartigen Raum, der mit der Außenwelt durch eine feine Spalte in Verbindung steht. Die nach innen (in Bezug auf das ganze Basalglied gesprochen) gerichtete Wand dieses Raumes ist stark gewölbt und nach dem Lumen des Vorraumes ragen von ihr 60-70 bewegliche Haare empor. Die Haare sind sehr kräftig, mit einem Kugelgelenk ihrer Unterlage eingefügt; sie sind relativ kurz und sehr gedrungen; ihr distales Ende ist im rechten Winkel abgrebogen und ist stumpf. In diesem Raum ist von Statolithen keine Spur.

Ich vermutete, daß eine Verbindung zwischen diesem Vorraum und der eigentlichen Statocyste besteht, daß er jedoch durch Verlust des entscheidenden Schnittes in der Schnittseric mir entgangen ist.

Das Chitin in der Umgebung des Vorraumes ist stark verdickt, außen von ihm sind cinige Anhäufungen dunkelbraunen Pigmentes erkennbar. 


\section{Cymonomus granulatus Norm.}

Das ostafrikanische Exemplar von Cymonom granulatus hat ein sehr schlankes i. Stielglied der inneren Antenne und dementsprechend eine kleine Statocyste. Bei der Untersuchung auf Schnitten ist der offene, nur durch ein Haarbüschel versperrte Eingang in dieselbe mit aller Deutlichkeit zu erkennen. Im Inneren der Statocyste erkannte man ferner eine Anzahl kleiner stark lichtbrechender Körper, welche sicherlich von außen eingeführte Fremdkörper waren und vielleicht als Statolithen gedient haben.

\section{Cyclodorippe uneifera glaucomma ALC.}

Die Form aus der Tiefe an der ostafrikanischen Küste zeigte ebenfalls eine kleine Statocyste im schlanken I. Glied des Antennenstieles. Auch bei dieser ist wahrscheinlich eine dauernd offene Kommunikation mit der Außenwelt vorhanden. Ganz sicher ließ es sich nicht erweisen, da gerade die kritischen Schnitte verletzt waren. Im Innern der Statocyste fand ich der einen Wand anliegend ein kugeliges Gebilde offenbar organischer Natur, welches wohl die Grundlage des Statolithenkörpers darstellte. Doch ist der Befund nicht ganz einwandfrei, da ich das Gebilde nur in einem Schnitt auffand.

\section{Cyrtomaia Suhmi platyceros DofL. Taf. LVI, Fig. 6.}

Die Statocyste von Cyytomaia ist relativ groß, ihr Lumen ist durch zahlreiche Einfaltungen verengt. Eine Oeffnung nach außen konnte ich nicht nachweisen, ebensowenig Statolithen. An der Innenwandung fanden sich nur wenige große und plumpe Haare.

\section{Physachaeus ctenurus AlC.}

Hier läßt sich ein sehr enger, aber offener Eingang in die Statocyste mit aller Deutlichkeit nachweisen. Die Statocyste ist mäßig groß, in der Hauptsache einmal stark abgeknickt, so daß man auf Schnitten meist zwei durch eine dünne Wand voneinander getrennte Lumina nebeneinander sieht. In den beiden Abteilungen, sowohl dem distalen, der mit der Oeffnung nach außen mündet, als auch in dem proximalen Teil finden sich Haare an den Wandungen. Dieselben sind relativ dick und plump gebaut, aber sie sind dabei sehr zartwandig.

Nur in der hinteren Abteilung findet sich eine Anhäufung von Detritus, in welchem organische Materie mit feinen Splittern anorganischen Ursprungs vermengt ist; dieselbe dient jedenfalls als Statolith.

\section{Geryon affinis M.-E. u. Bouv. Tat. XLIII, Fig. 8 .}

Das sehr große Basalglied der inneren Antenne enthält bei dieser Form ein mächtiges Bläschen, offenbar ohne Kommunikation mit der Außenwelt. Es ist ziemlich hartwandig; in der Gestalt ungefähr nierenförmig, mit einigen tiefen Einstülpungen ins Innere. So entstehen einige Kanäle. wie es scheint, 3, welche vielleicht den drei Dimensionen des Raumes entsprechend, rechtwinklig zueinander verlaufen. Ihre Wandungen sind mit sehr zahlreichen Haaren von verschiedener Feinheit und Form bestanden. 


\section{Biologiseher Teil.}

B. Biologie der Tiefseekrabben. 



\section{Biologie der Tiefseekrabben.}

Die Krabben sind mit wenigen Ausnahmen bodenbewohnende Tiere; unter Tiefseekrabben sind demgemäß diejenigen Formen zu verstehen, welche den Necresboden der lichtlosen und - wie wir gleich hinzufügen wollen - der lichtarmen Regionen bewohnen. Untersuchen wir das Vorkommen der Tiefseekrabben genauer, so können wir weiter feststellen, dal3 die Existenz derselben auch von einer gewissen, ziemlich tiefen Temperatur abhängig ist, während der Druck, soweit wir bis jetzt wissen, keinen besonderen Einfluß ausübt und keine Eigentümlichkeiten in der Organisation bedingt.

Danach ist es klar, daß wir Tiefseekrabben in den verschiedenen Abschnitten der Oceane in ganz verschiedenen Tiefen antreffen. Je nach der Klarheit des Wassers dringt das Licht in verschieden große Tiefen: wenn wir daher als obere Grenze des Vorkommens im Mittel $400 \mathrm{~m}$ annehmen, so ist damit nicht ausgeschlossen, daß in manchen Meeresgebieten Tiefseetiere auch in bedeutend geringere Tiefen vordringen können. In anderen Teilen des Meeres, in denen zwar keine Spur von Licht mehr vorhanden ist, finden wir keine Tiefseekrabben mehr, wenn dort die Temperatur eine zu große Höhe erreicht. So fehlen der Tiefe des Roten Meeres alle charakteristischen Tiefseeformen. Dagegen finden wir z. B. an der Küste von Senegambien und Portugal, bei der Philippineninsel Cebu, im Karaibischen Meer und ganz besonders an der Ostküste von Japan in ganz geringen Tiefen günstige Lebensbedingungen für Formen, die wir als Tiefseetiere zu bezeichnen gewohnt sind.

Nicht alle Krabben, welche wir in den so charakterisierten Tiefenregionen vorfinden, sind jedoch als Tiefseekrabben zu bezeichnen. Vergleichen wir die statistischen Tabellen, welche ich weiter unten gebe, und in denen die sümtlichen in größeren Tiefen bisher gefangenen Krabben eingetragen sind, so ersehen wir, daß alle Expeditionen grelegentlich in größeren Tiefen selbst Formen gefunden haben, welche wir sonst in der Strandzone zu suchen gewohnt sind, z. B. Arten der Gattung Calappa u. a.

Dies kann einmal darin seine Ursache haben, daß diese Exemplare beim Aufziehen der liangapparate in geringeren Tiefen in das Netz gerieten. In anderen Fïllen aber handelt es sich um Formen, welche an den Boden gelyunden sind und welche aus größeren Tiefen hervorgeholt wurden, ohne daß das Netz in geringerer Tiefe noch den Boden berührte. Es kann also keinem Zweifel unterliegen, daß solche Exemplare als gelegentliche Vorkommnisse, als "Irrlinge* in der Tiefsee aufzufassen sind. Es sind dies Tiere, deren eigentliche Heimat wir in anderen Lebensbezirken des Meeres suchen müssen oder in den meisten Fällen schon längst kennen. 
Teilen doch eine ganze Anzahl von Lebensbezirken mit der Tiefsee einzelne der wesentlichen Bedingungen.

I) gehören dahin die polaren Meeresgebiete, welche zum Teil in noch belichteten Tiefen konstante Temperaturen des Wassers aufweisen, welche mit denjenigen der Tiefseebezirke übereinstimmen. So finden wir in der Arktis und Antarktis Gebiete mit einer Fauna, welche gewisse Eigenschaften mit der Tiefseefauna teilt, in relativ geringen Tiefen. Doch wollen wir hierauf an dieser Stelle noch nicht näher eingehen, da gerade die Brachyuren in der Arktis und Antarktis nur durch sehr wenige Formen vertreten sind. Es sei nur hervorgehoben, daß Formen, welche in diesen Bezirken des Meeres ihre Heimat haben, in der Tiefsee ähnliche Lebensbedingungen vorfinden können und daher, wo die Möglichkeit dazu durch die Konfiguration des Meeresbodens gegeben ist, in die Tiefsee einwandern oder sich in derselben gelegentlich aufhalten können. Aehnliche Bedingungen bieten ferner Strömungs- und Auftriebgebiete, in denen das Meerwasser entweder durch Strömungen von den polaren Gegenden oder durch aufsteigendes kaltes Tiefenwasser in der Temperatur dem Wasser der Tiefsee entspricht.

2) giebt es eine große Anzahl von Brachyurengattungen, deren Lebensweise sie ebenso in Dunkelheit bannt, wie die Tiefseekrabben. Es sind dies Formen mit wühlender Lebensweise, Schlammbewohner, Kommensalen und andere Formen mit besonderen Lebensgewohnheiten, z. B. Nachttiere, welche sich bei Tag verkriechen und in der Dunkelheit ihre eigentliche Lebensthätigkeit entfalten. IVir können sie alle bezeichnen als Bewohner lichtloser oder lichtarmer Lebensbezirke. Bei ihnen zeigen sich eine Anzahl der nämlichen Anpassungen, welche wir bei Tiefseetieren und Höhlenbewohnern wiederfinden, und welche offenbar durch den Aufenthalt an lichtlosen Orten bedingt sind. Es ist leicht einzusehen, daß solche Formen, sofern ihnen nicht die Temperaturverhältnisse Schranken entgegensetzen, leicht in die Tiefsee eindringen können. So sehen wir denn z. B. Pinnotheriden, welche mit Formen der oberflächlichen Regionen verwandt sind, bisweilen in sehr große Tiefen eindringen, ohne daß an ihnen weitergehende Anpassungen festzustellen wären, z. B. Pinnotheres aby'ssicola Alc. u. And. aus $786 \mathrm{~m}$ Tiefe, Pinnixa occidentalis Ratнв., weche von $35-435 \mathrm{~m}$ vorkommt. Schließlich könnten wir auch darauf rechnen, in tiefen Höhlen, in welche sich das Meer hineinerstreckt, Formen mit gewissen Eigenschaften der Tiefseeformen zu finden. Für Brachyuren ist diese theoretische Möglichkeit bisher nicht erfüllt, aber für andere wirbellose Tiere, z. B. Mytilus nach LisI.

3) Die dritte Hauptbedingung der Tiefseeregionen, nämlich die Unbewegtheit des Wassers, ist in mehr oder minder hohem Grade in sehr weiten Gebieten des Meeres verwirklicht; in Tiefen zwischen 30 und etwa $100 \mathrm{~m}$ zieht sich eine Region hin, welche etwa mit der Korallinenregion von FORBES gleichzusetzen wäre. Dieses Gebiet ist durch zahlreiche charakteristische Formen, speciell unter den Brachyuren, ausgezeichnet, welche durch ihren zarten Bau sich von den massiven Formen der Brandungszone unterscheiden und an Formen der Tiefsee im Habitus erinnern. Auch aus dieser Region können bei geeigneten Temperaturverhältnissen manche Formen, unter ihnen besonders die Nachttiere, in ziemlich große Tiefen eindringen. Und je nach den Licht- und Temperaturverhältnissen können auch Tiefseetiere weit in diese Region des stillen Wassers aufwärts vordringen. So können wir denn auch aus dem bisher vorliegenden Material erschließen, daß sich zwischen der belichteten Region des Wassers und der eigentlichen Tiefsee eine Dämmerungszone ausbreiten muß, deren Grenzen nach beiden 
Richtungen hin keine scharfen sind, und welche durch eine Fülle von organischen Formen charahterisiert ist.

Somit ist es nicht zu verwundern, hängt vielmehr mit den natïrlichen Bedingungen aufs engste zusammen, wenn es nicht möglich ist, die Tiefseebewohner aus einer Abteilung des Tierreiches in ähnlicher IVeise scharf zu definieren, wie dies z. B. bei Planktontieren oder bei Parasiten möglich ist. Wir müssen also mit großer Vorsicht und Exaktheit vorgehen, wenn wir es unternehmen, über Biologie von Tiefseetieren Untersuchungen anzustellen. Ist ja doch auch dic Biologie der meisten Litoralformen des Meeres nur sehr mangelhaft erforscht. Wir setzen uns daher immer der Gefahr aus, in unseren Schlüssen ziemlich schwere Irrtümer zu begrehen. Trotzdem muß der Versuch, aus dem vorliegrenden Material allgemeine Ergebnisse zu gewinnen, von dem Untersucher von Tiefseematerial ebensowohl unternommen werden, wie etwa von dem Paläontologen an seinem noch lückenhafteren Material; denn zum mindesten grewinnen wir dadurch die Gesichtspunkte für fernere Untersuchungen und sind nicht mehr grenötigt, bei späteren Tiefseeforschungen blindlings zu verfahren. So haben wir denn auch bei den neueren Tiefsee-Expeditionen immer präcisere Fragestellungen und dadurch immer neuc und für die Wissenschaft wichtigere Ergebnisse hervorgehen sehen.

Bei Tiefsee-Untersuchungen befinden wir uns immerhin in einer besseren Lage als der Palïontologe bei Untersuchungen ausgestorbener Formen, denn einmal haben wir in der Regel die Möglichkeit zum Vergleich mit vervandten Strandformen, ferner hat man es neuerdings möglich gemacht, lebend erbeutete Tiefseetiere eine Zeitlang lebend zu erhalten, und dadurch die Möglichkeit gewonnen, ihre Bewegungen, Anwendung von Sinnesorganen u. s. w. am lebenden Tier zu beobachten; schließlich sind aber auch die Tiefseetiere speciell aus der uns hier interessierenden Gruppe in der Regel beim Heraufkommen noch gut erhalten und lassen, wenn sie gut konserviert sind, eine genaue Untersuchung des Baues und der Struktur zu.

So soll es denn im nachfolgenden Abschnitt unsere Aufgabe sein, durch Untersuchung und Vergleichung der einzelnen Bauverhältnisse bei Krabben aus der Tiefsee uns ein Bild von den Funktionen ihrer Organe zu machen; dann können wir durch sorgfältiges Studium der Organisation und der Lebensverhältnisse der Tiere deren Lebensweise erschließen. Das Erschlossene wird der Wahrheit um so näher kommen, je genauer die physikalischen, chemischen und biologischen Bedingungen, unter denen das Tier lebt, bekannt sind, und je genauer die entsprechenden Strukturen bei verwandten Formen, welche unter anderen, bekannten Lebensbedingungen existieren, erforscht worden sind.

IVir werden sehen, daß da noch sehr viel zu thun ist, und daß wir infolgedessen an vielen Punkten nicht über die Stellung von Fragen und die Formulierung von Hypothesen hinauskommen.

Ich habe es bei meinen bisherigen Untersuchungen stets praktisch gefunden, die Biologie von Tieren nach folgenden Gesichtspunkten zu betrachten:

r) Bewegung und Habitus;

2) Ernährung und Athmung;

3) Angriffs- und Schutzvorrichtungen;

4) Sinnesorgane;

5) Fortpflanzung. 
Diese Kategorien stehen einander zwar logisch nicht gleichberechtigt gegenüber, aber bei genauerer Betrachtung erkennt man, daß sie innerlich zusammenhängen, und sie lassen eine übersichtliche Gruppierung der Befunde zu, ohne uns zu allzu vielen Wiederholungen zu zwingen.

\section{Bewegung und Habitus.}

Derjenige äußere biologische Faktor, von dem wir den Habitus eines Organismus am meisten abhängen sehen, ist seine Bewregungsweise. Viele Krabben der Tiefsee sind ausgezeichnet durch zarten Bau, einen relativ kleinen, dreieckigen, viereckigen oder runden Cephalothorax, der meist auch dorsoventral abgeplattet ist, und übermäßig lange, cylindrische, schlanke Beine. Es ist dies der Habitus, welcher zu dem populären Namen der "Seespinnen“ geführt hat. Wir finden Formen mit diesem Habitus in den verschiedensten Gruppen der Brachyuren. Ich nenne als Beispiele die Homoliden, die Cyclodorippen, zahlreiche Oxyrhynchen, ferner Cyclometopen (Trichopeltarium) und Katometopen (Retrophuma). Solche Formen bewegen sich mit eigentümlich schaukelndem, hüpfend-schwebendem Gang auf den Spitzen der Daktylopoditen in einer Weise, die thatsächlich an clie Bewegung mancher Spinnen, besonders auch der Opilioniden, erinnert. Jedem, der einmal lebend derartige Formen im Aquarium beobachtet hat, wird diese eigentümliche Bewegungsweise aufgefallen sein. Es ist ja dieser Habitus nicht ausschließlich charakteristisch für die Formen der Tiefsee, sondern für diejenigen des ruhigen Wassers von ca. $30 \mathrm{~m}$ Tiefe an. Der bloße Anblick solcher Formen lehrt uns auch, daß sie nicht geeignet sind für den Aufenthalt in dem stark bewegten Wasser der Gezeitenregion. Eine Form, wie die japanische Riesenkrabbe, Kacmpfferia Kaempfferi, wäre bei der Unbeholfenheit, welche sie nach Doederlein außerhalb des Wassers zeigt, in der Brandungszone unmöglich. Hier halten sich nur wenige der eigentlichen Seespinnen auf, und zwar sind dies ausschließlich Formen, welche die Tangwiesen bewohnen, an den Algen angeklammert leben und so vor der Gewalt des Wellenschlages geschützt sind, indem sie jede Bewegung der Wellen mitmachen. Nach einem Sturm hat man am Strande oft Gelegenheit, zu beobachten, wie die Formen der etwas tieferen Region in Mengen zerschmettert ans Land getrieben worden sind, während die robusten Formen der Brandungszone in diesen Leichenhaufen fast vollkommen fehlen.

Daß die Formen mit den langen, zarten Beinen durchaus nicht geeignet sind, diejenigen Regionen zu bewohnen, in denen der Wasserstand erheblich wechselt und in denen sie der Gefahr, aufs Trockene gesetzt zu werden, ausgesetzt sind, zeigt uns ihr Benehmen, wenn wir sie fangen. Die langbeinigen Sten o r y y chen, Maia-Arten, Kacmpfferia und andere sind außerhalb des Wassers mehr oder weniger hilflos und können von ihren schlanken Beinen und ihren oft gefährlich aussehenden Scheren gar keinen Gebrauch machen. Ihre Körperform und Schwere steht eben in einem so festen Verhältnis zum specifischen Gewicht des Meerwassers, daß sie nur in ihrem natürlichen Element ihre Gewandtheit entfalten können. Auch in den Aquarien sehen wir solche Formen nicht selten durch die Gervalt des einströmenden Wassers zerbrechen.

Wie ganz anders nehmen sie sich dagegen aus, wenn wir sie in der Tiefe der Aquarien, z. B. der Neapler Station, herumklettern sehen, oder wenn wir sie vom Boote aus an sehr klaren Stellen des Meeres über den Grund hinhuschen sehen. Da werden uns alle Vorteile ihres Baues begreiflich. Mit unglaublicher Gewandtheit können sie über die unebensten Stellen des Meeres- 
bodens hinturnen, sie schweben gyleichsam über den Becten von Florideen, Hydroidpolypen, Spongien, Röhrenwürmern u. s. W. dahin, welche den Meeresboden bedecken. Der geringste Stützpunkt genügt bei der Form ihrer Beine und ihrem geringen specifischen frewicht, um sie zu tragen. Es ist hier nicht der Ort, um auf alle Modifikationen ihrer Bewegungsweise und die sich hieraus ergebenden Vorteile einzugehen. Einen Punkt möchte ich jedoch hervorheben, der es speciell begreiflich erscheinen laßt, wieso es manchen dieser „Seespinnenformen“ leicht möglich war, in die Tiefsee einzuwandern.

Wir wissen, daß weite Gebiete des Bodens der Oceane mit weichem schleimigen Tiefseeschlamm bedeckt sind. An manchen Stellen erreicht dieser Schlamm in vollkommen weicher Beschaffenheit eine ziemlich große Miichtigkeit. Es muß also für viele Tiefseeformen vorteilhaft sein, Einrichtungen zu besitzen, um über diesem Tiefseeschlamm sich gleichsam schwebend zu crhalten. Es ist also nicht verwunderlich, wenn wir die zu diesem Zwecke jedenfalls vorteilhafte Spinnenform bei einer ganzen Reihe von Tiefseearten finden. Ich erwähne nur Platymaia, Cyytonaia, Homola, Latreillia, Echinoplax u. a. Ist es also richtig, daß es für viele Formen nützlich ist, eine relativ geringe "Sinkgeschwindigkeit" zu haben, so begreifen wir teleologisch die Bedeutung vieler anderer Einrichtungen der Krabben der tiefen Regionen, welche uns zum Teil an die Einrichtungen zum Schweben bei den pelagischen Tieren erinnern.

I) Die dorsoventrale Abplattung des Cephalothorax. Vergleichen wir die Form des Cephalothorax bei gewissen Bewohnern der Tiefe mit derjenigen bei ihren litoralen Verwandten, so fällt uns auf, daß die Höhe im Vergleich zu Länge und Breite bei den Tiefenbewohnern oft eine auffallend geringe ist, z. B. bei Platymaia und einer ganzen Anzahl von Lithodiden. Auch ist nicht selten die untere Fläche fast vollkommen flach ${ }^{1}$. Dieses Formverhältnis erhöht ohne Zweifel den Formwiderstand, welcher für die Schwebfähigkeit eines Körpers von größter Bedeutung ist.

2) Ausladende Stellung der Beine. Die Beine sind bei solchen Formen vielfach in der Weise mit dem Cephalothorax verbunden, daß die 3 ersten Glieder fast wagrecht vom Körper abstehend gehalten werden. Die distalen Glieder werden dann bei der Bewegung fast senkrecht grehalten. Durch diese Anordnung wird ein eigentümlich federndes Tragen des Körpers erzielt, wodurch offenbar cine Kraftersparnis ermöglicht ist. Die Länge, Form und Anordnung der Beine erhöhen noch weiterhin den Formwiderstand. Es sind nämlich bei zahlreichen der oben erwähnten Formen Meropodit, Carpopodit und Daktylopodit sehr stark verlängert. Auch finden sich statt drehrunder Beinglieder bei einer Anzahl von Formen solche mit dorsoventraler Abplattung, so daß die Beine z. B. bei Platymaia flach wie eine Messerklinge sind. Die Oberflächenvergrößerung in wagrechter Richtung wird bei manchen Formen, so Platymaia, Cyrtomaia, Pleistacantha, noch durch Haarfransen an den Kanten der Beinglieder oder durch wagrecht abstehende Reihen mehr oder weniger langer Stacheln gesteigert.

3) Allgemeine Oberflächenvergrößerung. Bei zahlreichen Formen, z. B. Platymaia, Pleistacantha. Acanthodes, Trichopeitarinn, Dynomene u. a., finden wir Cephalothorax und Beine über und über mit einem förmlichen IVald von Stacheln bedeckt. Es fällt diese Stachelbedeckung der Formen des tieferen Wassers um so mehr auf, wenn wir

I) Die Auftreibung der Branchialregionen und Größenentwickelung der Kiemenhöhle, wclche offenbar besondere Ursachen hat. wird weiter unten in dem Kapitel über Ernährung und Atmung behandelt werden. 
sie mit dem glatten Cephalothorax der ausgesprochenen Strand- und Litoralformen vergleichen, z. B. Portunus, Cancer, Grapsus etc. Hier handelt es sich offenbar ebenfalls um eine Oberflächenvergrößerung durch die Stachelbildungen, wobei es vorläufig noch dahingestellt bleiben muß, ob die Oberflächenvergrößerung als physiologisches Moment oder die Erhöhung des Formwiderstandes der wesentliche Faktor ist. Dabei wäre noch folgende Beobachtung hervorzuheben: ich konnte bei einer ganzen Reihe von Arten feststellen, daß die Jugendstadien von stachel-

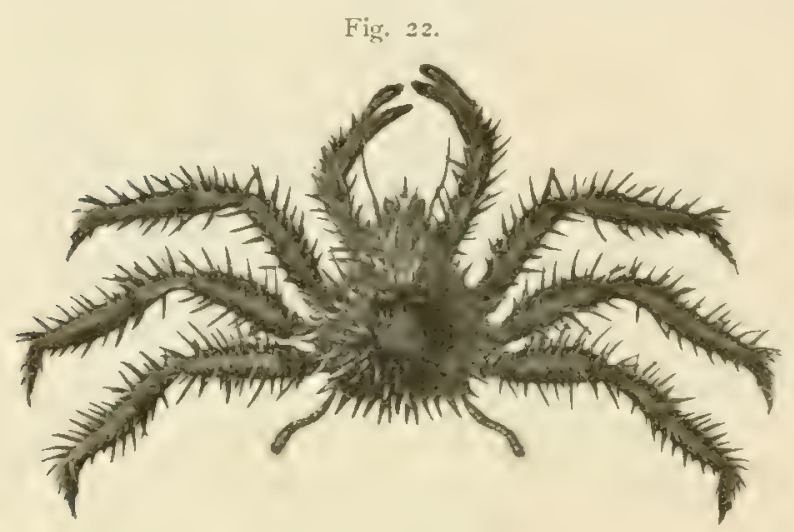
armen oder stachellosen Formen außerordentlich stachelig sind, z. B. bei Platymaia, Pleistacantha, Acanthodes und anderen Brachyuren, denen sich aus anderen Gruppen weitere Formen in Fülle anreihen ließen, z. B. Lithodes antarcticus (Textfig. 22 u. 23) etc. Bei diesen Formen sind die jungen Tiere zierlich gebaut und mit einem ganzen Wald von langen, dünnen Stacheln bedeckt; im Verlauf der Entwickelung werden die Stacheln kürzer, plumper und kräftiger, nehmen Firig. 23 .

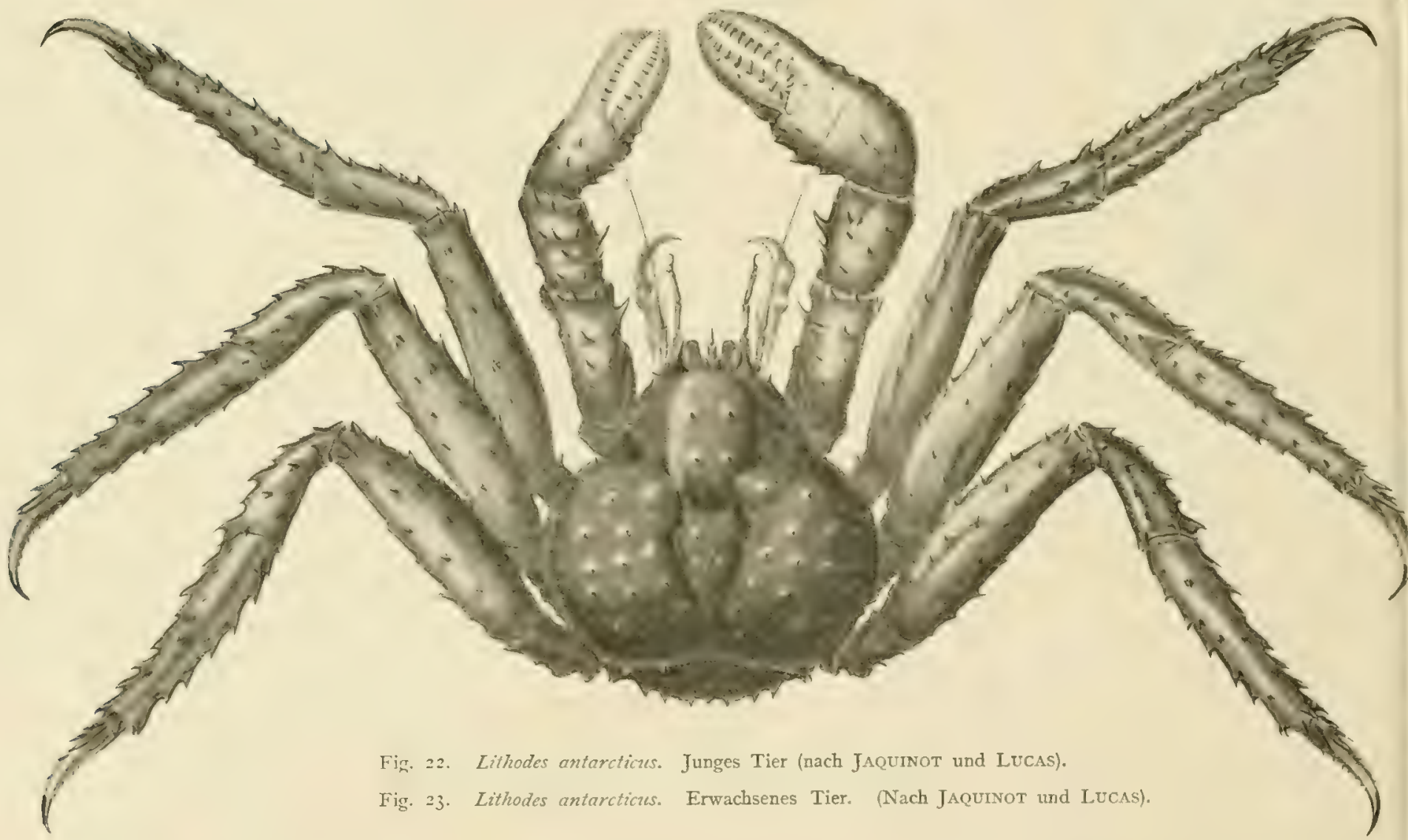

an Zahl ab, und schließlich sind bei einigen Formen Cephalothorax und Beine ganz glatt und stachelfrei. Wir können uns diese Umwandlung durch zwei verschiedene Gedankengänge zu erklären suchen. Wir können einmal uns das Stachelkleid als ein Ueberbleibsel aus der Larven- 
zeit vorstellen. Alle diese Formen haben pelagische Larven, deren Schwebfähigkeit, wie ja immer bei Decapodenlarven, durch Ausbildung von Stacheln erhöht ist. Nun können wir uns vorstellen, daß bei der Umwandlung in die definitive Form zu gleicher Zeit ein allmählicher Uebergang zur bodenbewohnenden Lebensweise erfolgt, und daß infolgedessen auch der Körper des jungen Tieres noch Schwebeeinrichtungen braucht. Auch ist es bekannt, daß die Ausbildung von Stacheln den Verlauf der Häutungen erleichtert.

Näherliegend scheint es mir, die allmähliche Umwandlung der Körperoberfläche in eine direkte Beziehung $z u$ irgend einer Funktion der Körperoberfläche zu setzen. Bei dieser Annahme wäre es verständlich, daß die allmähliche Zunahme der glatten Körperoberfläche und der Lïnge und des Umfanges der Gliedmaßen nach und nach dic bei den Jugendstadien durch die Ausbildung der Stacheln gelieferte Oberfläche ersetzt.

4) Bildung der Daktylopoditen. Die Daktylopoditen sind bei den verschiedenen Decapodenformen je nach der Lebensweise außerordentlich verschieden gebildet, und allein unter den Krabben lassen sich so viele Unterschiede aufweisen, daß die Betrachtung derselben ein ganzes interessantes Kapitel füllen könnte. Ich erinnere nur an die Ruderplatten bei den schwimmenden Formen, an die noch so wenig erforschten Gestaltungen, welche wir bei denjenigen Formen finden, die in den Aesten der Korallenriffe klettern u. s. w.

In der Tiefsee finden wir ebenfalls besonders angepaßte Daktylopoditen; ich habe z. B. oben bei Hypsoplurys darauf hingewiesen daß die Form derselben den schwebenden Gang unterstïtzen muß. An dieser Stelle möchte ich noch die starke Borstenbedeckung bei manchen Formen hervorheben, welche z. B. den Daktylopoditen der Schreitbeine von Plcistacantha Moscleyi (Taf. XXVI, Fïg. I) wie eine Bürste erscheinen läßt. Es ist wohl kein Zweifel, daß diese Ausbildung sehr greeignet sein muß, um das Einsinken im weichen Schlamm zu verhindern und eine rasche Bewegung auf dem unsicheren Untergrund zu fördern.

\section{Körpergrösse.}

Bei einigen höhlenbewohnenden Crustaceen ist es aufgefallen, daß die Körpergröße der Individuen eine relativ große ist. Auch hat z. B. R. Schnemer (I 885 u. I 887) bei Gammamus und Asellus in Bergwerken beobachtet, daß sie dort eine bedeutendere Körpergröße erreichen als im Freien. Zum Teil mit Recht hat er wohl diese Tatsache auf den verminderten Kampf ums Dasein zurückgeführt; denn bei dem Mangel an Feinden dürften die Individuen dort durchschnittlich eine höhere Lebensdauer erreichen.

Auch unter den Tiefsectieren ist die Größe einzelner Formen immer sehr aufgefallen. Nach den Ergebnissen des „Challenger" nimmt die Größe der Isopoden nach der Tiefe und nach den Polen hin zu. Riesenformen wie Bathynomns kommen nur in der Tiefe vor. Nach BATE nehmen auch die WVillemoesien nach der Tiefe an Größe zu. Vergleichen wir die Ergebnisse der „Valdivia“-Expedition damit, so fällt uns auf, daß auch diese aus einer Reihe von Gruppen riesenhafte Vertreter in der Tiefe fand: die größten bisher bekannten Sagitten, A ppendicularien, Ostracoden etc.

Was die Brachyuren speciell anlangt, so ist es sicherlich auffallend, daß die Formen, die am weitesten nach Norden grehen, sehr groß sind: Chionocctes und Lithodes. Auch in der 
Tiefsee sind sehr große Exemplare von einzelnen Arten gefunden worden. Kaempfferia ist ja eine Form des tiefen Wassers, ihr schließen sich Geryon und Lithodiden an. SмIтн (1886) hat eine ganze Anzahl weiterer Dekapoden angeführt, die in der Tiefsee auffallend groß werden.

Wir dürfen in diesen Erfahrungen wohl kaum die Wirkung des Zufalls erblicken. Jedenfalls ist man aber kaum berechtigt, die Erscheinung auf einen allzu großen Frieden in der Tiefsee zurückzuführen. Niemand nimmt heute mehr mit Gwrn Jefrreys an, daß es in der Tiefsee keinen Kampf ums Dasein gäbe. Vielleicht ist es die Einwirkung der Kälte auf die Zellthätigkeit, welche das starke Körperwachstum bei diesen Formen herbeiführt.

An diesem Ort möchte ich nicht unterlassen auf eine Thatsache hinzuweisen, welche bei den Decapoden wie bei allen anderen Tiergruppen sich mit mehr oder minder großer Deutlichkeit nachweisen läßt und deren theoretische Bedeutung nicht hinreichend gewürdigt wird. Viele Formen treten in die Fortpflanzungsthätigkeit ein, ehe sie die definitive Größe erreicht haben und ehe die specifischen Merkmale zur vollkommenen Ausbildung gelangt sind. Wir konnten bei Echinoplax, Platymaia, Geryon auf diesen Umstand hinweisen.

Damit im Zusammenhang wird wohl auch die Erscheinung stehen, daß an manchen Orten sich sämtliche Exemplare einer Art, trotzdem sie in voller Fortpflanzungsthätigkeit sind, erheblich unter dem normalen Durchschnitt der Körpergröße befinden. Ob Temperatur-, Ernährungs- oder andere Verhältnisse zur Bildung solcher lokaler Zwergrassen führen, ist ohne genauere Untersuchungen nicht $\mathrm{zu}$ entscheiden. Wir konnten oben für Inachus dorsettensis (Penn.) und Inachus leptochimes Leach (S. 72-73) auf dies eigenartige Verhalten hinweisen und ich hoffe später über mehr Arten nach genauer Untersuchung detaillierte Angaben machen zu können.

\section{Ernährung und Atmung.}

Seit den ersten Tiefsee-Untersuchungen, welche uns in den Tiefen des Oceans eine Fülle von organischen Wesen kennen gelehrt haben, deren Existenz von dem Vorhandensein selbständig assimilierender Organismen, also von Pflanzen, unabhängig oder vielmehr in sehr indirekter Weise abhängig ist, hat die Ernährung der Tiefsee-Organismen eines der interessantesten Probleme gebildet. Auch heute noch ist über diese Frage noch wenig bekannt. Zwar wissen wir, daß durch das herabrieselnde organische Material, den „Nahrungsregen“, wie man ihn nach dem Vorgang von Wrville-Thoגison bezeichnet hat, eine Menge von Nahrungsstoffen den Tiefseetieren zur Verfügung steht; ob und in welcher Weise dieselben von ihnen ausgenutzt werden. über diese Frage liegt noch sehr wenig statistisches Material vor. Ich habe es daher für nützlich gehalten, das Material der deutschen Tiefsee-Expedition auch in dieser Richtung auszunutzen, und konnte über die Ernährung der Tiefseekrabben einiges feststellen. Die Detailangaben hierüber findet man im systematischen Teil bei den einzelnen Arten.

Wie zu erwarten war, hat sich herausgestellt, daß eine große Anzahl der Formen offenbar eine räuberische Lebensweise führen oder Aasfresser sind. Bei Geryon affinis z. B. fanden sich im Magen Stücke von Crustaceen, Cephalopoden und Schwammreste.

Bei vielen anderen Formen, z. B. bei Platymaia, bei Scyramathia Hertwigi u. a., waren Magen und Darm gänzlich mit Schlamm erfüllt. Dieser Schlamm war hauptsächlich reich an 
Foraminiferen. Es liegt nun der Schluß nahe, daß diese Formen Schlammfresser sind, und daß sie den an Organismen so reichen Tiefseeschlamm zu ihrer Ernährung ausnutzen. Ich möchte aber noch weitere Untersuchungen abwarten, ehe ich diesen Schlu\} ziehe, denn einerseits vermisse ich bei den betreffenden Formen specielle Anpassungen an das Schlammfressen, wie wir sie bei Schlamm- und Sandbewohnern des Flachwassers kennen; weder die Mundwerkzeuge sind auffallend verbreitert, noch ist der Darm in bemerkenswerter Weise verlängert. Andererseits lassen sich die Befunde auch in anderer WVeise erklären. Es können nämlich die betreffenden Tiere, während sie in dem Trawl heraufgezogen wurden, in der Todesangst den Schlamm verschluckt haben.

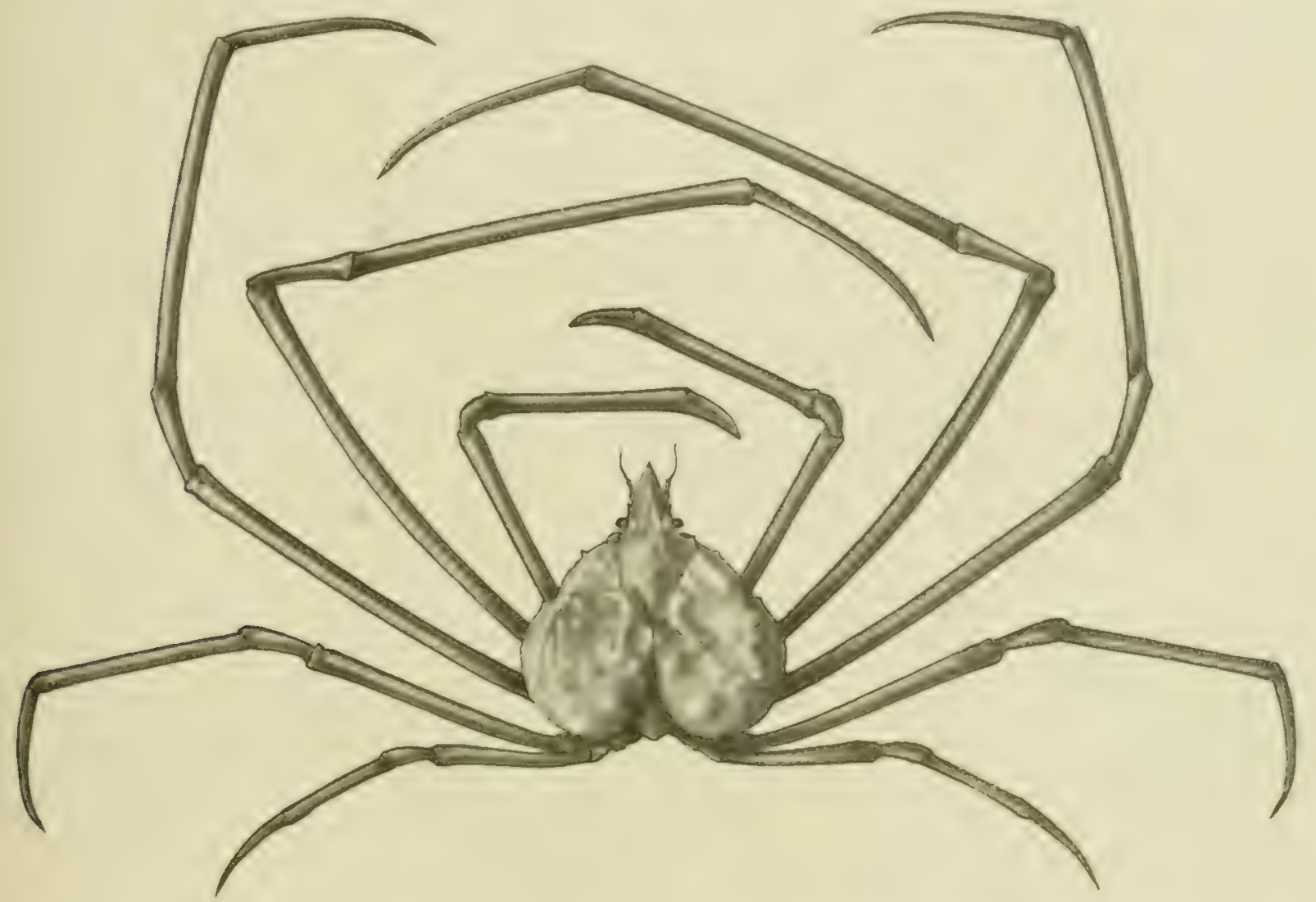

Fig. 24. Encephaloides Armstrongi ALc. Mit den aufgetriebenen Branchialregionen. (Nach ALcock.)

Es ist sehr gut möglich, daß die A tmung bei den Tiefseetieren in etwas anderer Weise vor sich greht als bei Flachwassertieren. Direkte Beobachtungen konnten vorläufig darüber noch nicht gemacht werden. Wir müssen uns damit begnügen, Indicienbeweise zu sammeln. Wie schon Alcock, so konnte auch ich beobachten, daß bei einer Reihe von Tiefseeformen die Atemhöhlen stark aufgetrieben sind, so bei Physachacus, Platymaia, Pleistacantha (Taf. XXV, Fig. I). Bei Encephaloides sind sie so stark entwickelt, daß die Branchialregionen beider Seiten sich in der Mitte berühren und nur einen schmalen Schlitz zwischen sich lassen (Textfig. 24). Der Anblick des Cephalothorax ähnelt dadurch dem eines Vorderhirns mit 2 Großhirnhemisphüren und gab Alcock Anlaß zur Wahl des Gattungsnamens. 
Diesen Formen schließen sich Arten von Chionoecetes und Hyastemus an, wenn ich die Beschreibungen von Miß Rathbun (1893) in richtiger Weise auslege. Diese Autorin hat nämlich gefunden, daß Chionoecetes Tamneri RAthв., welcher Ch.opilio (FABr.) in tieferem Wasser an der Nordwestküste von Amerika ersetzt, durch aufgetriebene Branchialregionen sich von letzterem, der Form des flacheren Wassers unterscheidet. Und bei Hyastenus longipes (Dana) konstatiert sie 2 Formen, von denen die eine, breitere, mit geschwollenen Branchialregionen in südlicheren Fundorten in größerer Tiefe sich fand.

Nach meinen Beobachtungen sind die Branchialregionen bei jungen Exemplaren der von mir untersuchten Arten noch gering entwickelt und erreichen erst während des Wachstums des Tieres die extreme Ausbildung. Nun existieren Untersuchungen von WeLdox an Carcimus maenas, aus denen, wenn auch der Autor sie etwas anders auslegt, nach meiner Ansicht hervorgeht, daß durch Sauerstoffarmut des Wassers eine Vergrößerung der Kiemenhöhle herbeigeführt wird. Ich bin daher geneigt, in den aufgetriebenen Kiemenhöhlen von Tiefseeformen eine funktionelle Anpassung zu erblicken, welche durch die Sauerstoffarmut des tiefen Wassers bedingt ist. Jedenfalls haben wir in diesem Befunde ein der experimentellen Untersuchung zugängliches, sehr interessantes Problem vor uns.

Wie ich nachträglich sehe, hat H. Przibrair (1902) Gelegenheit gehabt, nachzuweisen, daß starke Veränderungen der Proportionen des Cephalothorax bei dem gleichen Individuum nach der Häutung sich einstellen können. Seine Experimente zeigen deutlich, daß äußere Verhältnisse - bei seinen Versuchen an Carcinus maenas war es die „Domestikation“, d. h. die Zucht im Aquarium -- von bestimmendem Einfluß sein können. Jedenfalls sind seine Resultate der oben von mir gemachten Annahme günstig.

\section{Angriffs- und Schutzvorrichtungen.}

Fast in jeder größeren Tiergruppe sehen wir, daß, wie die übrigen höheren Anpassungen, auch die Instinkte und intelligenzartigen Fähigkeiten von neuem selbständig sich aufbauen. Da sehen wir stets zwei Hauptgruppen sich bilden, die allerdings untereinander nicht schärfer abgegrenzt sind, als wir es auch sonst bei Gruppen, die wir aus der Natur herauskonstruieren, zu finden gewohnt sind. Wir finden nämlich:

I. Träge, langsame Formen mit reflexartigen Instinkten, welche in ihrem Habitus an die Umgebung in irgend einer Weise angepaßt sind, Schutzfärbung, Schutzformen, eventuell auch Warnfarben besitzen [Chamacleon, Mantiden, Bacillus, Pleuronectiden, Garneelen $\left.{ }^{1}\right)$.

II. Flinke, bewegliche Formen mit modifizierteren Instinkten, welche meist kräftig sind und keine beträchtliche Schutzanpassung an die Umgebung zeigen. Es sind dies Raubtiere, dann jene Formen, welche gewöhnlich als das Beispiel für Vorkommen von Intelligenz im Tierreiche angeführt werden.

1) Unter letzteren ist z. B. der mit einer so außerordentlichen Fähigkeit, seine Färbung nach der Umgebung zu verändern, begabte Virbius z'arians ein Tier, welches an Algen festgeklammert lebt und sich von der Ebbe eher aufs Trockne setzen läßt, als daß es seinen Sitz InsläRt (G.AMBte u. KEebte 1900). 
Während die Formen der ersten Gruppe, wenn sie angecrriffen werden, durch ruhiges Verhalten ihre Schutzanpassungen instinktiv ausnützen, eventuell auch sich tot stellen, suchen die Vertreter der 2. Gruppe ihr Heil in der Flucht oder aktiver Verteidigung oder wenden sogar Listen an.

Dies Gebiet der Biologie ist natürlich bei der Untersuchung von Tiefseeformen fast unzugäinglich, während die Flachseebewohner, gerade unter den Brachyuren, ein unerschöpfliches Material für derartige Betrachtungen darstellen. Immerhin können wir durch den Vergrleich mit den letzteren für die Tiefseekrabben eine Reihe von allgemeinen Gesichtspunkten feststellen. Es fällt zunächst auf, daß die überwiegende Mehrzahl von Tiefseearten aus der Gruppe der Brachyuren Vertreter des ersten der oben aufgestellten Typen stellt. Wir finden unter ihnen eine sehr große Anzahl von maskierten Formen: i) solche, welche die ganze Oberfläche des Cephalothorax mit festsitzenden Tieren bepflanzt haben. Es sind dies besonders Formen der mittleren Tiefen, und unter ihnen besonders Oxyrhynchen. Wie die Umstände des Fangres zeigren, bewohnen sie die unterseeischen Gärten von festsitzenden Tieren, welche in jenen Regionen die Plätze der Pflanzenwelt einnehmen. Wir können kaum eine Kaempfferia, Philyra, Inachus, Stenorhyuchus fangen, ohne ihren Cephalothorax gänzlich mit Hydroidpolypen, Schwämmen, Actinien, Röhrenwürmern, Bryozoen, Cirripedien, Ascidien u. s. w. bedeckt zu finden. Das Benehmen der gefangenen Tiere, welche sich, in ein Aquarium gesetzt, sofort zwischen die gleichen Tierformen, mit denen sie bewachsen sind, flüchten und dort sich ganz ruhig verhalten, beweist, daß die Tiere tatsächlich in jene erste Kategorie gehören. 2) finden wir besonders unter den Dromiiden und Oxystomen der größeren Tiefen Arten, welche sich dadurch schützen, daß sie mit dem hintersten Fußpaar Schwämme, Ascidien, Echinodermen oder Muscheln als Schild über ihren Rücken halten. Manche von ihnen werden von diesen ihren Schildern, wenn es sich um Kolonien von festsitzenden Tieren handelt, mit der Zeit gänzlich umwachsen.

Ferner ist eine Einrichtung, welche bei vielen grundbewohnenden Formen, besonders unter den Dromiiden und Oxyrhynchen wiederkehrt, anzuführen. Bei solchen, z. B. bei Homolochunia und Hyastemus-Arten ist die ganze Ober-
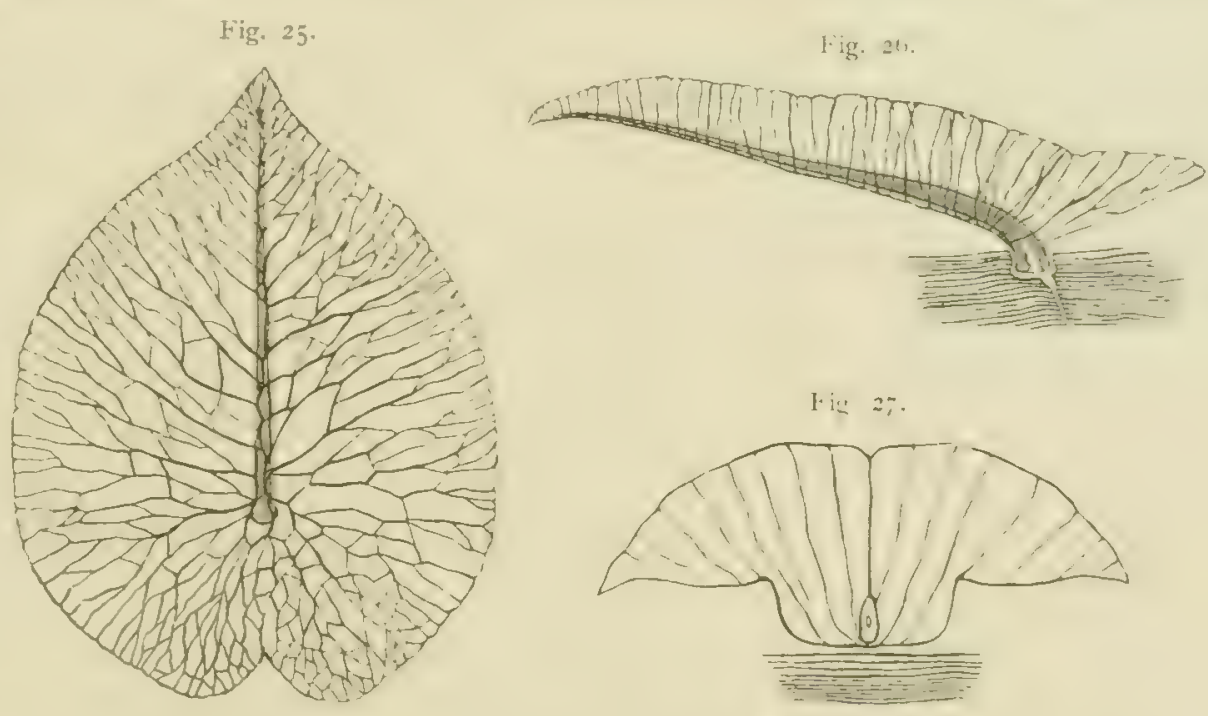

Fig. 25. Flächenansicht eines Blatthaares von Homolochunia Valdiziae DofL.

Fig. 26. Längsschnitt

Fig. 27. Querschnitt

fläche des Körpers und der Extremitäten mit einem zarten Filz bedeckt. Bei genauerer Untersuchung enveist sich derselbe als zusammengesetzt aus einer Unzahl in eigentümlicher Weise umgebildeter Haare.

Bei Homolochunia z. B. sind sie breit blattförmig gestaltet; die Fläche des Blattes liegrt der Oberfläche des Chitinpanzers des Tieres ungefähr parallel. Von dieser oberen Fläche be- 
trachtet, erscheint das Blatthaar ungrefähr herzförmig. Man erkennt eine Art von Mittelrippe und zahlreiche feine Stränge, welche sich wie Adern eines Blattes ausnehmen (Fig. 25). Ein Längsschnitt zeigt uns, daß der Stiel von der unteren Fläche des Blattes entspringt und daß von ihm aus die als Mittelrippe erscheinende Röhre ausgeht (Fig. 26). Die feinen Adern der Flächenansicht stellen sich als die Querschnitte feiner Lamellen und Stränge heraus, welche von der unteren Wand des ziemlich dicken Blattes zur oberen ziehen (Fig. 26 u. 27). Das ganze Gewebe ist locker und offenbar durchlässig.

Ein relativ sehr feiner Porenkanal durchsetzt die Cuticula am Grunde des Stieles; durch ihn treten die Fortsätze von Matrixzellen in das proximale Ende des Stieles ein. Von sensiblen Zellen konnte ich nichts mit Sicherheit erkennen.

Die Bedeutung dieser Blatthaare, welche mit ihren Rändern so dicht zusammenhängen, daß sie wie verklebt erscheinen, ist nicht leicht festzustellen. Es ist nicht auszuschließen, daß sie im Leben des Tieres eine wichtige physiologische Funktion besitzen; aber daneben haben sie auch ihre biologische Bedeutung. Aehnlich wie die Angelhaare, die auf dem Panzer zahlreicher Formen sich finden (vergl. z. B. Physachacus ctemumes ALc., Taf. XLII, Fig. I), zur Maskierung durch Befestigung von Hydroidpolypen, Algen u. s. w. dienen, so halten diese Blatthaare auf dem Panzer ihrer Träger den Schlamm der Umgebung in einer dünnen, gleichmäßigen Lage fest. Dadurch wird das Tier, ohne in seiner Beweglichkeit behindert zu werden, der Umgebung außerordentlich ähnlich; und dazu hat es den Vorteil, bei einem Wechsel des Aufenthaltsortes ohne Schwierigkeit auch sein Kleid wechseln zu können.

Alles dies sind Anpassungen, welche nicht speciell für die Tiefsee charakteristisch sind, auf deren Vorkommen in der Tiefsee, besonders auf deren Häufigkeit, aber hingewiesen werden muß. An dieser Stelle mag auch darauf aufmerksam gemacht sein, daß die Stachelbedeckung mancher Formen, für welche wir weiter oben eine andere Erklärung zu finden suchten, sicherlich gleichzeitig einen Schutz für ihre Träger darstellt.

Schwieriger als Vertreter der I. Gruppe sind solche der 2. Gruppe in der Tiefsee nachzuweisen. Doch können wir aus der Analogie schließen, daß Formen wie Geryon und die Carcinoplaciden hierher gehören. Ihr ganzer Habitus weist auf Kraft, Beweglichkeit und Schnelligkeit hin. Auch sind sie meist nur vereinzelt gefangen worden, während die Vertreter der I. Gruppe meist in großen Mengen gleichzeitig gefangen werden.

Was ich beobachten konnte, weist jedenfalls darauf hin, daß auch in der Tiefsee ein sehr intensiver Kampf ums Dasein herrscht. Von den Arten, die in größerer Individuenzahl erbeutet wurden, zeigt stets eine große Anzahl der Stücke Spuren von in der Natur erlittenen Beschädigungen. Vorstehende Teile des Cephalothorax waren gebrochen und wieder verheilt, Extremitäten waren abgebrochen und entweder teilweise oder schon ganz, aber in verkleinertem Maßstabe, regeneriert. Bei anderen waren kaum die ersten Schritte zur Regeneration geschehen. Dies weist darauf hin, daß für die Tiere das Bedürfnis eines ausgiebigen Schutzes vorliegt, und es ist daher sicherlich nicht voreilig, wenn wir den naheliegenden Analogieschluß ziehen und die Einrichtungen, welche denen von geschützten Flachseeformen ähneln, als Schutzvorrichtungen erklären.

Hier wäre auch eine Bemerkung über die Farbe der Tiefseekrabben anzufügen. Auch der Färbung nach sehen wir die Tiefseekrabben in zwei Gruppen zerfallen: blasse, gelblich 
oder weißlich, manchmal auch blaßrosa grefürbte Formen stehen solchen von sehr lebhafter Farbe gegenüber. Von blassen Formen wären hervorzuheben: Arten von Dicranodromia, Cyclodorippe, Cy'monomus etc.

Es sind dies meist die Formen, welche in der Litteratur als „blinde Formen" bezeichnet werden, also jene mit rudimentären Augen.

Dagegen ist von einer großen Anzahl von Formen, wie aus den Tabellen am Schluß dieses Bandes zu ersehen ist, eine lebhaft rote Farbe nachgewiesen. Es ist das eine Tatsache, welche bei sämtlichen Tiefsee-Expeditionen sehr auffiel, von Willenoes-Sumir schon betont wurde, und in den Crustaceenbänden der "Albatross"- und "Talisman"-Expedition herrschen auf den bunten Tafeln die roten Färbungen vor. Auch die farbigen Tafeln dieses Bandes, welche nach unterwegs von F. WINTER gefertigten Skizzen ausgeführt wurden, zeigen ausschließlich Nuancen von Rot. (Siehe Tafel I-IV.) Diese Erscheinung ist nicht etwa auf die Klasse der Crustaceen beschränkt, sondern auch in den anderen Tierabteilungen finden sich zahlreiche rot gefärbte Tiefseebewohner, besonders unter den Fischen.

In den Jahren, in denen so viel über die Bedeutung der Farben für die Tierwelt philosophiert wurde, konnte es nicht ausbleiben, daß eine Menge von Theorien über die rote Farben der Tiefseetiere aufgestellt wurden. So hat Verrill (I 884) die Vermutung ausgesprochen, daß in der roten oder purpurnen Färbung der Tiefseetiere eine Anpassung zu erblicken sei. Er nimmt an, daß selbst in großen Tiefen ein sanftes grünes Licht herrsche, da nur die Strahlen von dieser Farbe vom Wasser hindurchgelassen würden. So müsse es für die Bewohner jener Tiefen von Vorteil sein, in die Komplementärfarbe von Grün: Rot gekleidet zu sein. Dann müßten die Tiere grau oder schwärzlich erscheinen und wie Schatten dahinschweben. Abgesehen davon, daß Grau von Grün immerhin stark absticht und man nicht einsehen kann, warum dann die Tiere nicht grün gefärbt sind, was doch ohne Zweifel noch vorteilhafter sein müßte, haben neuere Untersuchungen solche Annahmen zu sehr unwahrscheinlichen gemacht.

Schon FAxon (I 895) hat die bis zu jenem Jahr bekannten Daten zusammengestellt, welche alle die gleiche Auslegung zulassen, die auch ich sogleich auseinandersetzen werde. Auch er macht darauf aufmerksam, daß bei den Formen der Tiefe blaue und grüne Farben fast vollkommen fehlen und sich nur bisweilen an der Eiern von Tiefseeformen nachweisen lassen. Auch er findet die blassen Farben auf jene benthonischen Formen beschränkt, welche im Schlamm und sonstwie dem Lichte gånzlich entzogen leben, dagegen bei den freibeweglichen und besonders den pelagischen Tiefenbewohnern findet er stets das leuchtende charakteristische Krebsrot.

Nun hatte schon Pouchet (1872) gefunden, daß Decapoden in dunklen Gefäßen oder bei Exstirpation der Augen rote Färbung am ganzen Körper annehmen. JourdarN (I 878 ) und MALARD (1892) haben bei einzelnen Arten gefunden, daß lïngerer Aufenthalt im Dunkeln die gleiche Reaktion zur Folge hat; Przibram (1902 B) hat auch bei Carcinus maenas festgestellt, daß Blendung zu konstanter Rotfärbung führt.

Gaxble und KeEble (1900) haben die Farbenveränderungen bei der Garneele Hippolyte varians studiert und gefunden, daß die Tiere eine starke Bl a u färbung regelmäßig nachts, und auch wenn sie längere Zeit im Dunkeln gehalten werden, annehmen. Sie fanden auch, daß plötzliche 
Reize zu Veränderungen der Farbe führen. Die Ergebnisse, welche sie in Bezug auf die Periodicität der Verfärbungen hatten, die sich im Laufe von 24 Stunden regrelmäßig einstellen, mahnen ebenfalls sehr zur Vorsicht bei der Deutung der Farben von Tieren, deren Lebensverhältnisse wir nicht sehr genau kennen.

Wir können also die rote Farbe der Tiefseekrebse eventuell als eine Farbenreaktion auf den Shock hin, den die kombinierten Reize beim Heraufziehen des Netzes ausüben, erklären. Wir können einige Fälle, welche von FAxOx und Cxasble und KEEBLE angeführt worden sind, heranziehen, um wahrscheinlich zu machen, daß während des Heraufziehens der Netze Farbenveränderungen eintreten. Es sprechen dafür manche der rot auf transparentem Grund gefleckten Formen, welche der „Talisman“ erbeutete; auch die verschiedenen Färbungen der auf Taf. III und Taf. IV abgebildeten Exemplare von Geryon affinis M.-E. u. Bouv. kann ich hinzufügen. Schließlich hat schon FAxON ungewöhnliche blaue und gelbe Flecke an Tieren als Anzeichen eines Uebergangsstadiums der physiologischen Verfärbung angesprochen.

Einige der oben besprochenen Experimente lassen für die rote Farbe der Tiefseekrebse auch die Deutung zu, daß sie als Folge einer Art von Starrheit der Chromatophoren unter dem Einfluß der Funktionslosigkeit der Augen zu betrachten ist.

Ehe man ein definitives Urteil über die Färbung der Tiefseekrebse und deren biologische Bedeutung abgeben kann, müssen viel exaktere Untersuchungen vorliegen. Der Fürst voN Monaco hat bewiesen, daß man in abgrekühltem Seewasser Formen aus größeren Tiefen eine Zeitlang am Leben erhalten kann. Gelingt es, solche Formen am Licht einige Zeit $z u$ halten, so werden wohl nach kurzer Zeit Reaktionen sich einstellen, welche uns gestatten werden, die Färbung viel sicherer $z u$ beurteilen. Jedenfalls scheint mir aber bei dem gegenwärtigen Stand unseres Wissens ein so weitgehender Schluß auf die Nützlichkeit der Färbung, wie ihn VerRulL gemacht hat und wie ihn seither fast alle populären Schriftsteller übernommen haben, unstatthaft zu sein.

\section{Sinnesorgane.}

Die meisten und - wie ich hoffe - die besten und brauchbarsten Befunde habe ich durch die Untersuchung der Sinnesorgane der Brachyuren gewonnen. Die rein empirischen Ergebnisse habe ich oben schon niedergelegt. An dieser Stelle will ich nun die Bedeutung der verschiedenen Bautypen für ihre Träger zu erörtern suchen und beginne mit den Augen.

\section{A. Biologische Bedeutung des Augenbaues bei den Krabben.}

Bei den Brachyuren als Decapoden-Krebsen findet sich nur eine Art von Augen, und zwar sind dies die auf beweglichen Stielen in der Zahl von zweien vorhandenen Facettenaugen. Während man früher geneigt war, die Facettenaugen der Crustaceen für relativ gleichartige Gebilde zu halten, haben uns zuerst die Untersuchungen von CHun (I 896) darauf aufmerksam gemacht, wie große Verschiedenheiten im Bau bei Formen, welche unter verschiedenen Lebensbedingungen leben, vorkommen. Doch war ich nicht darauf gefaßt, in den Facettenaugen so überaus plastische Organe kennen zu lernen, welche auf jede Aenderung der Lebensbedingungen 
reagiert zu haben scheinen. Die Untersuchung lenrt uns allein bei den Decapoden cine überraschende Fülle von Typen kennen, und wenn wir unter den Decapoden nur die Brachyuren ins Auge fassen, so bleibt uns noch eine unübersehbare Formenmannigfaligkeit zur Betrachtungr übrig. Wir ich schon in meiner vorläufigen Mitteilung (DofLEIN 1903) hervorhob, kommen Brachyuren unter den verschiedenartigsten Lebensbedingungen vor, ja wir können sagen, daß sie unter den Tieren mit Facettenaugen den allerverschiedenartigsten Lebensbedingungen ausgesetzt sind.

Wenn man einen bestimmten Augentypus als Normalauge bezeichnen will, so muß man wohl eine weder nach der einen, noch nach der andern Seite extrem ausgebildete Form wählen. Solche Augen besitzen die Krabben, welche in geringen Tiefen, in dem noch hell durchleuchteten Wasser von ca. Io-20 $\mathrm{m}$ Tiefe, leben und ihren Lebensgewohnheiten nach als Tagtiere bezeichnet werden können.

Sie besitzen ein mäßig großes Auge, welches auf leicht beweglichem, mäßig langem Stiel sitzt. Die Augenkeile sind zahlreich und ziemlich klein, von ihren Bestandteilen ist die Cornealinse etwas breiter als $\operatorname{lang}^{1}$ ), der Krystallkegel ist prismatisch, schlank, doppelt so lang wie breit und stark lichtbrechend. Die Stäbchen sind meist etwa doppelt so lang wie die Krystallkegel und meist etwa kegelförmig gestaltet, indem sie distal etwas breiter sind als proximal. Das Pigment ist in großen Mengen vorhanden und tiefschwarz gefärbt. Dieses umgiebt, solange das Tier kräftigem Licht ausgesetzt ist, die ganzen Stäbchen, die unteren Enden der Krystallkegel und die Austrittsstellen der Nervenfibrillen an der Lamina fenestrata. Es ist im stande, Bewegungen auszuführen, und zwar geht in der Dunkelheit eine derartige Verschiebung des Pigments vor sich, daß nur zwischen den Krystallkegeln eine Lage von Pigment sich befindet, das Irispigment, und eine weitere am unteren Ende der Stäbchen an der Lamina fenestrata, das Retinapigment. Die Stäbchenregion ist dabei ganz frei von Pigment.

Was nun die Funktionsweise solcher Normalangen anlangt, so ist sie nach den Forschungen von ExNer (I89I) eine verschiedenartige, je nach der Stellung des Pigments. Hüllt das Pigment die Stäbchen vollständig ein, also bei dem "T a ga uge“ (Textfigur 28 links), so entsteht ein aufrechtes Bild, entsprechend den Forderungen der JoHannes MÜLLER'schen Theorie des musivischen Sehens. Dabei ist jeder dem Mosaiksteinchen vergleichbare, von einem Augenkeil gelieferte Anteil des Bildes von seinem Nachbarn vollkommen durch die Pigmentscheide abgetrennt. ExxER nennt ein so zustande kommendes Bild ein A p p ositionsbild.

Ist jedoch das Pigment in Nachtstellung (Textfigur 28 rechts), so können Lichtstrahlen, welche unter größerem Winkel in die Cornealinse einfallen, von dem Krystallkegrel weitergeleitet werden und nicht nur das zum zugehörigen Augenkeil gehörige Stäbchen, sondern auch diejenigen benachbarter Augrenkeile treffen. Da nun die Stäbchen der Ort der Lichtperception sind, so muß um jeden Bildbestandteil, den je ein Augenkeil liefert, ein Zerstreuungskreis entstehen. Es entsteht nach Exier ein „Superpositionsbild“, welches zwar nicht sehr scharf, dafür aber viel lichtstärker ist und daher für das Tier bei schwacher Beleuchtung der Umgebung einen biologischen Vorteil bringt. Es ist dies Superpositionsbild ganz besonders geeignet zum Wahrnehmen von Bewegungen. 


\section{Allgemein in diesem Werk angewandte Bezeichnungen.}

Proximal und distal sind bei dem Augenstiel für Richtungen in dessen Längsachse angewandt, jedoch bei den einzelnen Augenkeilen für Richtungen in der Längsachse des einzelnen Augenkeiles.

Die Ausdebnung in der Achse $A B$ (Fig. 29) ist stets als Längc, die Ausdehnung in der Achse $X Y$ stets als Breite der be. treffenden Augenbestandteile im Text angegeben.

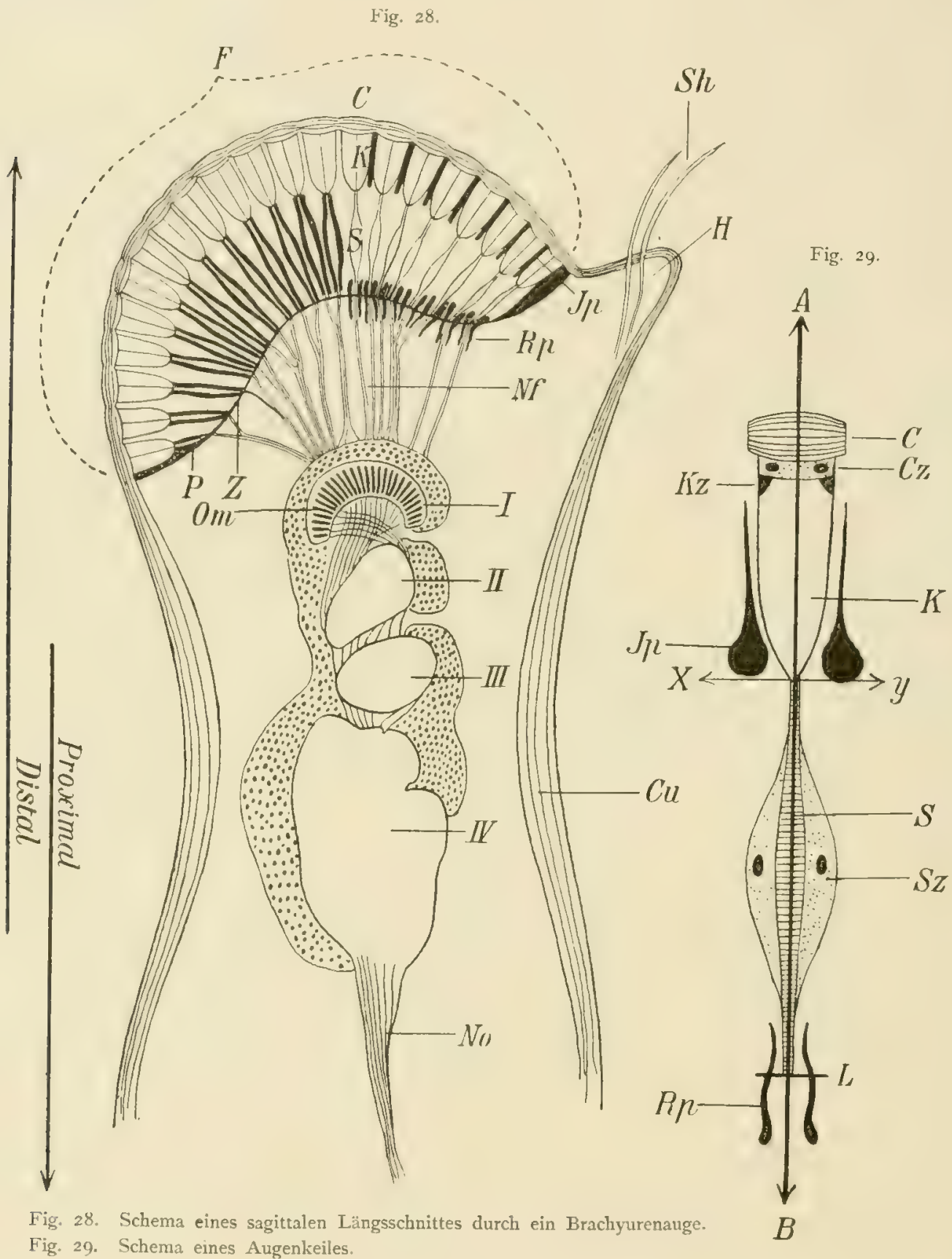

$A B$ optische Achse

$X Y$ Richtung senkrecht zur optischen Achse

$C$ Corneafacette, Cornealinse

$C u$ Cuticula des Augenstieles

Cz Corneagenzelle, Corneazelle

$F$ Facettenregion
$I I$ dorsales Augenhorn, zapfenförmiger Fortsatz des Auges Is Irispigment (Ipz Irispigmentzelle)

K Krystallkegel

Kz Krystallkegelzelle, Krystallzelle

$L$ Lamina fenestrata, Grenzmembran des Auges

Nf Nervenfasern, Neurofibrillenbünde] 


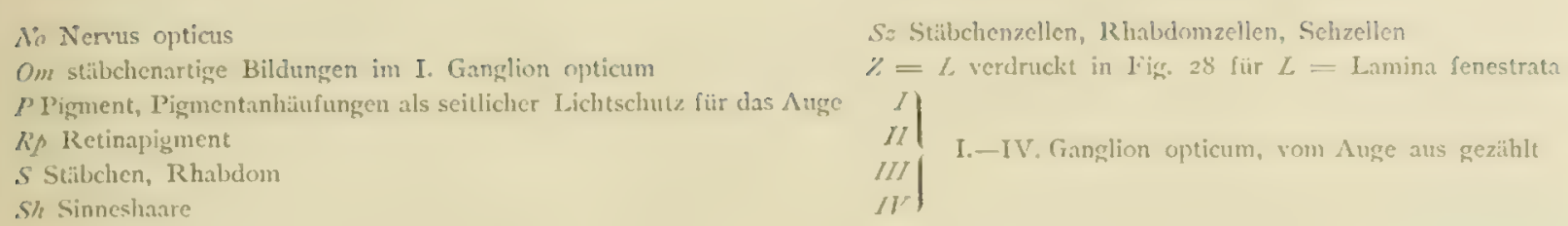

In allen jenen Verhältnissen, welche ich als typisch für das Normalauge bezeichnete, können wir bei Augen von Tiefseekrabben Verschiedenheiten feststellen, die in sehr verschiedenartiger, aber gesetzmäBiger Weise auf die einzelnen Arten verteilt erscheinen. Bei manchen $\lambda$ rten sind die Augen enorm vergröbert, so bei Platymaia Wyille-Thomsoni Mrs., bei Geryon affnis M.-E. und Bouv, bei Hexaplax megalops Dor.. Dabei sind die Augen so gebaut, daß sie einen möglichst großen Bezi-k nach vorn und unten bestreichen, während der Ausblick nach hinten und oben, welcher für den Bodenbewohner von geringerer Wichtigkeit ist, behindert ist. Bei anderen sind sie dagegen in auffallender Weise verkleinert, z. B. Cymonomus gramulatus Nork., Cyclodorippe uncifera OrTan., Ethusina aby'ssicola S. Sar., Trichopeltarium Alcocki Dori. Ebenso können wir ein gegensätzliches Verhalten bei den Augenstielen feststellen: Die Augen von Homolochmia Valdiviae Dofl., Latreillopsis bispinosa Henderson, Hypsophry's longipes Alc. besitzen durch ein 2. Gelenk des stark verlängerten Stieles eine erhöhte Beweglichkeit, während die kurzgrestielten Augen von Ethusina abyssicola S. Sir. und der übrigen Arten dieser Gattung wie E. Challengeri und E. Investigatoris U. S. W. die Augen von Cy'monomus, Physachacus, ganz oder fast ganz unbeweglich sind.

Viel bedeutender als die bisher verzeichneten Unterschiede sind diejenigen, welche sich bei den verschiedenen Arten in der Form, Größe und Anzahl der Bauelemente feststellen lassen. Was zunächst die Zahl der Augenkeile anlangt, so fand ich sie bei den großen Augen, also bei IJyposophry's, Homolochmia, Platymaia, Goryon, Hexaplax u. s. w. stets in großer Anzahl vorhanden.

An sie schlossen sich Formen mit mäßig großen Augen an, bei denen die Menge der Augenkeile ebenfalls eine mäßige war, ohne daß direkt auffallend geringe Anzahlen zu konstatieren waren; es sind dies Formen, wie Cy'vomaia, Lispognallus, Scyramathia.

Eine dritte Gruppe wird von Formen gebildet, deren Augen äußerlich nicht so sehr verkleinert erscheinen, bei denen aber die Anzahl der Augenkeile recht klein war: Ethusa, Ethusina, Cyclodoritpe uncifera melanomma DorL. und Physachaens, welch letzterer aber durch die sehr geringre Anzahl der Augenkeile eine besondere Stellung einnimmt.

Eine vierte Gruppe bilden Formen mit auffallend kleinen Augen, deren Augenkeile nur in ganz geringer Zahl vorhanden sind: Cy'clodorippe dromioides ORTM., Trichopeltarizm Alcocki Dofl. Ihnen ist, wie wir nachher sehen werden, von Flachwasserformen z. B. Pinnotheres anzuschließen.

Und $\mathrm{fünftens}$ wären schließlich Formen mit kleinen oder sehr kleinen Augensticlen zu enwähnen, bei denen die Augenkeile gar nicht mehr ausgebildet sind. Von Brachyuren dieser Gruppe habe ich nur Cymonomus granulatus (Norkr.) untersucht, doch wären noch eine ganze Reihe bodenbewohnender Formen aus den Gruppen der Macruren und Galatheiden hierher zu rechnen.

Die Beurteilung nach der Größe der Bauelemente führt nicht ganz zu derselben Gruppierung der Formen. 
Die absolut größten Naße von Augenkeilen finden wir bei den Formen mit den größten Augen; so erreicht die Corneafacette bei Geryon eine Breite von ca. ıоo $\mu$, bei Platymaia eine solche von $85 \mu$ Ganz andere Resultate erhalten wir jedoch, wenn wir die relativen Größen vergleichen. So ist die Länge des Augenstieles bei Homolochnnia ungefähr $8 \mathrm{~mm}$, bei Physachaens $0,8 \mathrm{~mm}$, also bei ersterem finden wir den zehnfachen Betrag des letzteren, trotzdem ist die Breite der Corneafacetten die gleiche $(50 \mu)$. Die Zahl von $50 \mu$ bedeutet überhaupt für die Mehrzahl der untersuchten Formen aus einiger Tiefe die Minimalbreite der Corneafacetten.

Zusammenfassend sei hervorgehoben, daß ich bei keiner einzigen Form aus einiger Tiefe - wenn auch nur aus Ioo m - so kleine und so zahlreiche A ugenkeile fand wie bei den typischen Tagformen der Strandregion.

Größe und Form sind bei Corneafacetten und Krystallkegeln sehr verschiedenartig ausgebildet, wir finden aber stets, daß die beiden optischen Bestandteile des Augenkeiles voneinander abhängig sind, sich gegenseitig bedingen: Ist die Linse der Corneafacette in ihrer Länge mittelgroß, so ist es auch der Krystallkegel, und beide sind im Längenmaß ungefähr gleich groß. Ist die Cornealinse auffallend kurz, so ist der Krystallkegel auffallend lang; ist die Cornealinse sehr groß, so ist der Krystallkegel sehr klein, oft minimal ausgebildet.

Das gegenseitige Verhältnis ist auch bedingt durch den feineren Bau der Bestandteile. Wo der Krystallkegel sehr lang ist, finden wir eine kaum geschichtete Cornealinse, wo die Linse stark geschichtet und gewölbt ist, meist einen sehr verkürzten Krystallkegel. Die Krystallkegel selbst sind bei den meisten Formen weich; so harte und stark lichtbrechende Krystallkegel, wie sie bei Insekten vorkommen und wie sie auch bei pelagischen Decapoden häufig sind, fand ich bei keiner einzigen Art.

Nach den erwähnten Gesichtspunkten kann man die Augen wieder in 5 Gruppen teilen, welche mit den oben erwähnten aber nicht ganz übereinstimmen:

I. Corneafacette etwa ebenso lang wie der Krystallkegel; beide messen 20-30 $\mu$ : Ethusina abyssicola S. Surth, Cy'dodorippe uncifera melanomma DofI. Ethusa somalica DofL.,

II. Corneafacetten kürzer als die Krystallkegel; Maße sehr verschieden:

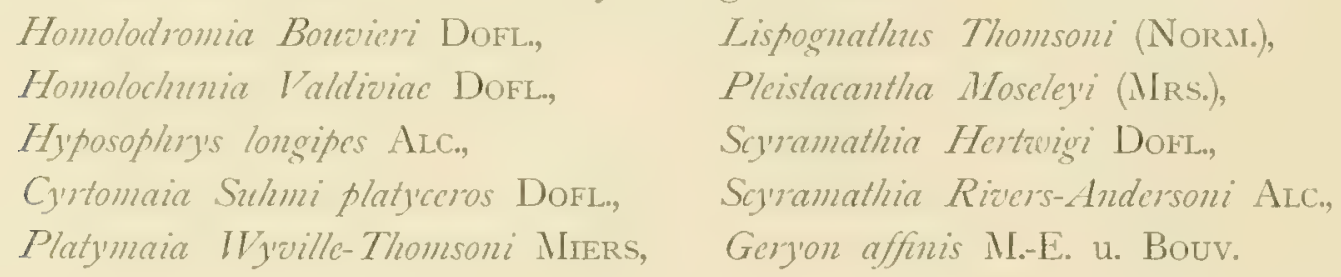

III. Corneafacette größer als der Krystallkegel; man kann bei den betreffenden Formen fast ron akonen Augen sprechen:
Cyclodorippe dromioides OrTir., Phy'sachacus ctenurus Alc.,
Trichopeltarium Alcocki DofL, Pimnotheres tridacnae RÜPP.

IV. Corneafacette sehr wenig geschichtet und undeutlich abgegrenzt, flach, so daß man vermuten kann, daß sie optisch unwirksam ist:
Homolodromia Bouvicri DoFL,
Hypsophrys longipes Arc.,
Cyclodorippe uncifera glancomma ALc.,
Homolochunia Valdiviae DofL. 
V. Krystallkegel fehlend oder so strukturiert, daß man annehmen kann, daß er optisch unwirksam ist:

\section{Cyclodoriphe uncilera glancomma ALC.}

Hierher gehören vielleicht einige Arten der Fruppe III. Ferner einige Flachwasser- und Strandformen, bei denen die Krystallkegel aus so lockerer Substanz aufgebaut sind, daß man die Augren als pseudokone Augen bezeichnen mul:

\section{Menacthius monoceros (LaTr.), Ocypode ceratophthalma (F.air.).}

Wenden wir uns zu den Stähchen, welche in der Regrel, und wohl mit Recht, als dic lichtempfindenden Elemente des Auges angesehen werden, so können wir konstaticren, daß auch hier die größten Stäbchen in den größten Augen sich finden; aber durchweg ist auch zu konstatieren, daß die relative Größe abhängrt von der Größe und guten Ausbildung der optischen Teile des Augenkeils. Nach der Lünge der Stäbchen können wir die untersuchten Formen in 3 Gruppen einteilen:

I. Stäbchen $50-\mathrm{r} 50 \mu$.

Homolodromia Bouvieri DofL. (99-I4 I $\mu)$,

Ethusina aby'ssicola S. Sir.,

Ethusa somalica DorL.,

Cy'clodoritpe uncifera glaucomma Alc. $(50 \mu)$,

Cydodoritpe uncifera melanomma Dort. $(60-70 \mu)$,

Cyclodoritpe dromioides OrTa. (85 p.),

Scyramathia Rizers-Andersoni Alc. ( $130 \mu$ ),

Ply'sachacus ctenumes Alc. (106 p),

Trichopeltarium Alcocki Dort. $(50-85 \mu)$.

II. Stäbchen I $50-400 \mu$.

Hypsophry's longipes ALc. $(282 \mu)$,

Scyramathia Hertwigi DofL. $(282 \mu)$,

Cy'tomaia Sulhimi platyceros DofL. $(280 \mu)$,

Platymaia Wyzille-7homsoni Mrs. juv. (155-250

Pleistacantha Moseleyi Mrs. juv. $(250-350 \mu)$,

Lispognathus Thomsoni [Noris.] (180-2 го $\mu$ ).

III. Stäbchen $400-600 \mu$.

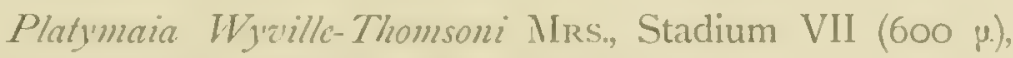

Pleistacantha Moseleyi Mrs., Stadium II (420-500 $\mu$ ),

Geryon affinis M.-E. u. Bouv. $(420 \mu)$,

Homolochnnia Valdiviae DofL. $(420-450 \mu)$.

Die Form der Stäbchen ist bei den kürzeren ungrefähr cylindrisch, in anderen laällen mehr oder weniger schlank kegelförmig, bei den längeren meist spindelförmig, wobei oft noch Verdickungen in der dem Krystallkegel benachbarten distalen Partie vorkommen. Stets aber sehen wir auch die Form der Stäbchen in einer Abhängigkeit von der Konfiguration des optischen Apparates, d. h. von Corneafacette und Krystallkegel. So sind wir denn genötigt, 
an eine Abhängigkeit von der optischen Leistungsfähigkeit dieser Teile zu denken, und so wollen wir jene Frage im Zusammenhang mit dieser unten behandeln.

Vorher müssen wir aber noch die Pigment- und Tapetumsubstanzen des Auges besprechen, da sie von entscheidender Bedeutung für den optischen Nutzwert des Auges sind. Dabei zeigen sie in Vorkommen, Menge und Anordnung die allergrößten Verschiedenheiten bei den verschiedenen Augen.

Zunächst muß ich hervorheben, daß sich in der Farbe der Pigmente bedeutende Unterschiede zeigen. Ueber das Vorhandensein von farbigen, löslichen Pigmenten (oder Lasurfarben?), wie sie bei manchen Formen vorkommen müssen, kann ich auf Grund meines Materials nichts Bestimmtes aussagen. Diejenigen Formen, welche während der Expedition in farbigen Skizzen festgehalten worden waren, hatten zufällig alle dunkelbraunes Pigment in den Augen. Sidney Surrm (I 886) giebt an, daß bei einer Reihe der von ihm (nur äußerlich) untersuchten Formen sich farbige Augenpigmente fanden. Auch den Abbildungen und Beschreibungen von FAXON (1895) kann man entnehmen, daß bei manchen Formen bunte (meist rote und gelbe) Pigmente im Auge sich finden. Sie müssen in Alkohol sich lösen oder auch unter dem Einfluß des Lichtes beim toten Tier verblassen, denn an den konservierten Exemplaren sind sie äußerlich nicht mehr wahrnehmbar. Ob das Vorkommen von wohlausgebildeten Irispigmentzellen bei manchen der von mir histologisch untersuchten Formen, bei denen aber keine Spur eines Pigmentes sich nachweisen ließ, auf das Vorkommen eines solchen bei der Konservierung zerstörten bunten Pigmentes zu beziehen ist, kann ich nicht entscheiden.

Mir erscheint es sogar wahrscheinlicher, daß die Farbigkeit der betreffenden Augen nicht auf farbigem Pigment, sondern auf der Imprägnierung der optischen Bestandteile, eventuell auch der Sehelemente, mit einem durchsichtigen Farbstoff beruhte. Bei Geryon affinis M.-E. u. Bouv. fand ich auch am konservierten Auge die Krystallkegel stark gelblich gefärbt.

Eine solche Imprägnierung könnte in zweierlei Richtungen nützlich sein:

I) sie könnte die Ausnützung der in die Tiefe dringenden Strahlen des Spektrums erhöhen, oder

2) sie könnte das Auge speciell für von Leuchtorganen ausgehendes farbiges Licht sensibel machen.

Ein Nutzen von echtem Pigment von bunter Farbe wäre allerdings auch einzusehen. Denn wenn in gewissen Tiefen thatsächlich annähernd monochromatisches Licht herrscht, so wird eine Blende oder Schutzhülle in der Komplementärfarbe dieselben Dienste tun, wie im weißen Lichte das schwarze Pigment.

Vorausgesetzt nun, daß sich aus gewissen Gründen unter Ausschluß von starkem Licht schwarzes oder dunkles Pigment nicht entwickeln könnte, so wäre es teleologisch verständlich, bei Formen aus einer gewissen mittleren Tiefe buntes Pigment zu finden. Tatsächlich finden wir denn auch bei Formen aus 600-800 m Tiefe gelb oder rot gefärbte Augen.

Jedenfalls fand ich bei keiner einzigen der von mir untersuchten Formen, wenn sie auch nur aus I00-I50 m Tiefe stammten, das charakteristische tiefschwarze Pigment der Strandformen. Und doch findet sich ein solches auch bei stark rückgebildeten Augen, wenn der Träger nur der stark belichteten Litoralregion angehört, so bei Pinnotheres tridacnac RüPP. Die Formen aus dem tieferen Wasser haben ein dunkelbraunes bis hellbraunes, ja selbst gelbbraunes Pigment. 
Auch ist es in viel geringeren Mengen vorhanden als in den Augen der Litoralkrabben. Ferner ist es meist, aber nicht immer, in gröberen Brocken angrehäuft, nicht in solchem fein pulverförmigen Zustand, wie bei den Litoralformen, bei denen dieser Zustand jedenfalls zur Erhöhung der Beweglichkeit beitrïgt.

Bei sämtlichen Formen, bei denen vollständige Pigmentierung (s. S. 207) konstatiert wurde, fand es sich ferner in der „Nachtstellung“", d. h. als Iris- und Retinapigment angeordnet; Krystallkegrel und Lamina fenestrata waren dann mit Pigment von außen überzogen, während die Stäbchen von Pigment frei waren. Nur 2 Formen machen Ausnahmen, aber bei diesen liegen ganz besondere Verhältnisse vor (Cyclodorippe uncilera melanomma Dorto und Platymaia IVy'villeThomsoni Mrs.).

Nach dem Vorhandensein und der Anordnung des Pigmentes kann man die von mir untersuchten Augen der Formen aus tieferem Wasser in folgende 6 Gruppen anordnen:

I. Augen mit mäßigem Iris- und Retinapigment in Nachtstellung:

a) Cy'romaia Suhmi platyceros Dorin, Lispognathus Thomsoni (Norm.),

b) mit sehr geringem Retinapigment: Hypsoplurys longipes Alc., Homolochunia Valdiviae DOFL.

II. Augen mit mäßigem Irispigment, jedoch einem mächtigen Klumpen von Pigment hinter der Lamina fenestrata; Nachtstellung des Pigments:
Ethusa somalica DofL,
Ethusina abyssicola S. Smitr.

III. Iridopigmentäre Augen:
Physachaenes ctemumes Alc.,
Geryon affinis M.-E. u. Bouv.

Pleistacantha Moseleyi Mrs.

Hier wären auch die I b erwähnten beiclen Formen mit sehr schwachem Retinapigment eventuell anzuführen.

IV. Retinopigmentäre Augen:

\section{Trichopellarium Alcocki DorL.}

V. Augen mit Tagstellung des Pigmentes:

Cyclodoritpe uncifera mclanomma Dofu, Platymaia Wyrille-Thomsoni Mrs.

VI. Pigmentlose Augen:
Homolodromia Bouvieri DofL., Cymonomus gramulatus (Norms.),
Cyclodorippe dromioides OnTMr, Cyclodoripte uncifera slaucomma ALC,
Scyramathic Hertavigi Dori..,
Scyramathia Rivers-Andersoni Atc.

Schließlich hätten wir in dieser Uebersicht noch der Ganglien zu gredenken. Außer bet dem ganz reduzierten Auge von Cymonomus gramulatus (Norм.) grelang es mir stets bei guten Präparaten, sämtliche vier Teile des Augenganglions nachzuweisen. Bei Homolodromia Bonaien Dort. konnte ich sie zwar nicht mit Sicherheit nachweisen, aber ich bin nach dem allgemeinen Aussehen der erhaltenen Teile nicht im Zweifel, daß sie vorhanden sind.

Dagegen läßt sich eine schr große Verschiedenheit in Bezug auf den Umfang des Ganglienkomplexes nachweisen. Während er bei Ethusina aby'ssicoli S. Sur, Homolodromia 
Bouvieri Dofu., Trichopeltarinm Alcocki Dofl., Syrramathia Rivers-Andersoni Alc. recht klein ist, und bei Phy'sachacus ctonums Alc. seine relative Größe nur der Größe der ihn zusammensetzenden Zellen verdankt, ist er bei Cyrtomaia Sulmi platyccros DofL. von normaler Größe; bei Itypsophrys longipes ALc. und Homolochunia Valdiziae DofL. erreicht er schon eine ganz ansehnliche Größe. Bei Geryon affnis M.-EDw. u. Bouv. und gar bei Platy'naia Wy'ville-Thomsoni Mrs. ist er geradezu monströs ausgebildet, wie ein Blick auf die Tafel LIII, Fig. = lehrt.

Dahei sind besonders die 1. Ganglien in ihrem Umfang in auffallender Weise von der Zahl der Augenkeile abhängig. Es hat den Anschein, als entspräche je einem Augenkeil eine jener stäbchenartigen, von PARKER Om matidien genannten Bildungen im I. Augenganglion. Da dieselben in einer Lage angeordnet sind, so bildet das I. Ganglion bei Augen mit vielen Augenkeilen eine mächtige gewölbte Schale (Taf. LIII, Fig. 2 I), während bei Augen mit wenigen Augenkeilen das I. Ganglion wie ein kümmerliches Rudiment wirkt (Taf. XLVI, Fig. 7).

Die Unterschiede sind an den übrigen Ganglien ebenso ersichtlich, besonders an dem 4, welches bei facettenreichen Augen starke, an Gehirne erinnernde Windungen entwickelt; ebenso steht die Dicke des Augennerven in einem direkten Verhältnis zur Zahl der Augenkeile.

\section{Der Sehvorgang im Auge der Tiefseekrabben.}

Wenn ich nun versuchen will, die optische und physiologische Wirksamkeit der. verschiedenen beschriebenen Strukturen zu deuten, um ihren Zusammenhang mit der Lebensweise der Tiere zu beurteilen, so bin ich mir wohl bewußt, daß unserer Erkenntnis der Sinnesfunktionen bei niederen Tieren enge Schranken gesteckt sind. WVenn ich also trotz aller Ueberlegung der erkenntnistheoretischen Schwierigkeiten mich an Deutungen heranwage, so muß ich dies mit einigen Worten begründen.

ExNer hat bei einer ganzen Anzahl von Arthropoden die optischen Leistungen der lichtbrechenden Bestandteile des Facettenauges zu analysieren vermocht. So besteht auch für die von mir beschriebenen Formen die Möglichkeit, die aus dem anatomischen Befund abgreleiteten Schlüsse durch sorgfältige Präparation oder durch Herstellung von Modellen zu prüfen; vorausgesetzt natürlich, daß jemand von den geeigneten Arten einmal genügend Naterial zur Verfügung hat. Daher brauche ich wohl diesen Teil meiner Betrachtungen nicht als fundamentlose Spekulationen anzusehen.

Die physiologische Bedeutung der Stäbchen ist in den Details immer noch eine umstrittene Frage, und es dürfte wohl für alle Zeiten unmöglich sein, sie, soweit das subjektive Empfinden des Tieres in Betracht kommt, zu enträtseln. Ihre Bedeutung im allgemeinen jedoch, als Vermittler der Lichtwahrnehmung, ist heutzutage nicht mehr bestritten. Unsere Kenntnis vom Bau der peripheren Endapparate der Sehnerven hat bei allen Tiergruppen zu so übereinstimmenden Resultaten, die wir hauptsächlich den Arbeiten HESSE's verdanken, geführt, daß wir wohl allen Grund haben, bei den Arthropoden in den Stäbchen den Sitz der Lichtperzeption zu erblicken. In biologischen Betrachtungen, wie ich sie unten anschließe, kommt es nun auf die specielle Auffassung des Vorganges der Lichtperzeption gar nicht an, es handelt sich nur um Vergleichung der räumlichen Anordnung, Form und Dimensionen der Lichtperzeptionsorgane einerseits und der Lebensbedingungen der einzelnen Tierformen andererseits, um festzustellen, 
ob die eine Gruppe von Erscheinungen eine Abhängigkeit von der anderen zeigt. Solche Betrachtungen können uns immer einen tieferen Einblick in die physiologrische Anatomie eines Organes bringen; sind sie mit hinreichender Vorsicht angestellt und bleibt sich der Bearbeiter der erkenntnistheoretischen Vorbehalte berrußt, so sind sie die Grundlage für die experimentelle Erforschung der Fragen, welche durch sie erst aufgeworfen oder scharf präcisiert werden.

Wir haben oben (S. 210) gesehen, daß Corneafacette und Krystallkegel in ihrer Größe sich gegenseitig bedingen. Wo kleine Cornealinsen vorhanden sind, finden wir sehr große Krystallkegel, wo erstere sich einem mittleren Maß nähern, thun das auch letztere, so daß dann beide optischen Bestandteile beinahe oder vollkommen gleich groß werden; wo die Cornealinsen sehr dick und stark grewölbt sind, finden wir minimale Krystallkegel: jene annähernd akonen Augen, welche wir in der III. Gruppe auf S. 2 ro zusammenstellten. Wo schließlich die Krystallkegel ganz fehlen, haben wir es mit sehr rückgebildeten Augen zu thun.

Aehnlich verhält es sich mit der Lichtbrechung: je stärker die Lichtbrechung der Cornealinsen ist, um so geringer ist diejenige der Krystallkegrel, soweit es sich wenigstens am konservierten Objekt feststellen ließ.

An dicser Stelle möchte ich auch eine Bemerkung über den Bau der Cornealinsen einschalten. Bei vielen Formen des tieferen Wassers zeigte es sich, daß dieselben, wenn sic auch im äußeren Umriß bikonvex $z u$ sein schienen, doch in ihrer optischen Wirkung sich anders verhalten müssen als bikonvexe Linsen. Die äußersten Schichten, 2. B. bei Lispognathus (Taf. XLV, Fig. 7) oder Cy'tomaia (Taf. XLV, Fig. 4), sind oft ganz zart, und die auf sie folgenden stïrker lichtbrechenden Schichten sind alle nach innen konvex gewölbt, so daß sie aussehen wie cin Satz aufeinander gestellter Uhrgläser. Es scheint mir also wahrscheinlich, daß die Lichtbrechung in ihnen in einer Weise erfolgt, welche in der Mitte steht zwischen derjenigen in echten Linsen und derjenigen in Linsencylindern, etwa nach Art der Etagenlupen.

Die Arten der Gruppe I (S. 2 Io) besaßen etwa gleich stark oder vielmehr gleich schwach lichtbrechende Cornealinsen und Krystallkegel, die Formen der Gruppe II verhielten sich sehr verschieden, diejenigen der Gruppe III hatten sehr stark lichtbrechende Cornealinsen, sehr schwach lichtbrechende Krystallkegel, von denjenigen der Gruppe IV hatten Hypsophorys und Homolochmia schwach lichtbrechende Cornealinsen und ziemlich stark lichtbrechende Krystallkegel, während schließlich von Gruppe V Menacthius und Ocypoda stark lichtbrechende Cornealinsen und an Stelle der Krystallkegel Gebilde von so zarter, spongröser Struktur besaßen, daß in ihnen das Licht wohl ungebrochen fortgeleitet wurde.

Mit Nachdruck verdient hervorgehoben zu werden, daß ich bei keiner Form so stark lichtbrechende Krystallkegel fand, wie sie bei pelagischen Schizopoden und Cariden vorkommen.

Was nun die Form der optischen Bestandteile anlangt, so habe ich oben in der exakten Beschreibung meiner Befunde oft die Cornealinsen als auf der distalen Seite konkar beschrieben. So fand ich sie bei einer Anzahl von Formen in meinen Priparaten; ich bin aber nicht ganz sicher, ob es sich dabei un das ursprüngliche Verhalten oder um ein bei der Konservierung aufgetretenes Kunstprodukt handelt. Bei der Nehrzahl der gut konservierten Exemplare fand ich die Linsen nach außen konvex grewölltst. Nach innen fand ich sie stets, und zwar meist sehr stark konvex grewölbt; eine Ausnahme machen nur Arten der Gruppe IV (Homolodromia, 
Hypsophrys, Homolochunia), deren sehr dünne, schwach lichtbrechende Linsen nach innen schwach konvex gewölbt waren.

Die Krystallkegel sind in der Form sehr variabel: in ihrem Hauptteil bald ausgesprochen cylindrisch, bald sechseckig-prismatisch, bald - und zwar besonders bei jüngeren Tieren birnförmig; stets laufen sie in eine mehr oder minder feine Spitze aus, welche sich zwischen die distalen Teile der Stäbchenzellen hineinerstreckt. Meist ist es schwer zu sagen, wo der Krystallkegel aufhört und das Stäbchen anfängt.

Bei den Formen der Gruppe III finden wir ganz kurze, schwach lichtbrechende Krystallkegel, welche auffallenderweise die Form einer bikonkaven oder konkav-konvexen Linse besitzen.

Wenden wir uns nunmehr der Wirkung zu, welche diese verschiedenartigen optischen Apparate auf die einfallenden Lichtstrahlen ausüben! Leider fehlen mir die physikalischen Kenntnisse und der Scharfsinn eines ExxER, um in die Tiefe der zahlreichen und interessanten Probleme eindringen zu können, die sich hier aufdrängen. Ich kann nur andeuten, daß die Vielheit der Modifikationen weniger konstanter Elemente, wie sie zu so verschiedenartigem Aussehen führt, so auch zu einer Vielheit in der Funktionsweise führen muß - und dies bei Tierarten, welche wir ihren sonstigen Bauverhältnissen nach für nahe Verwandte halten müssen.

\section{Einfache Dämmerungsaugen.}

Bei einigen Tiefseekrabben finden wir Augen, welche zwar eine sehr kleine Facettenregion aufweisen, die nur wenige Corneafacetten umfaßt, aber es findet sich reichliches dunkelbraunes Pigment, und zwar in typischer Nachtstellung (s. S. 207). Die Stäbchen in diesem Auge sind mäßig lang, und ich kann keine Anzeichen dafür erkennen, daß irgend welche Anpassungen seine Brauchbarkeit erhöhen. Die Lichtbrechung dürfte in diesen Augen, deren Cornealinse ungefähr ebenso lang ist wie der Krystallkegel, nach dem von Exxer für das Sehen von Superpositionsbildern aufgestellten Schema vor sich gehen.

Augen solcher Art kommen bei den Gattungen Ethusa und Ethusina vor. Sie sind vor allem durch die geringe Anzahl der Augenkeile ausgezeichnet. Auffallend ist ferner speciell bei Ethusina abyssicola S. Sir. die Kürze der Stäbchen, durch welche die Vorteile des Superpositionsbildes nicht voll ausgenutzt $z$ u sein scheinen. Suchen wir uns eine Vorstellung von der Wirksamkeit eines solchen Auges zu machen, so müssen wir feststellen, daß einerseits die Wirksamkeit der Krystallkegel als Linsencylinder, andererseits die Nachtstellung des Pigmentes Zerstreuungskreise um die einzelnen Bildpunkte zur Folge haben werden. Infolge der Kürze der Stäbchen werden diese wohl nicht sehr breit sein. Außerdem wird die geringe Anzahl von Facetten, welche dazu auf einer relativ stark konvexen Fläche ausgebreitet sind, dem Zustandekommen eines scharfen Bildes von ausgedehnteren Gegenständen hinderlich sein. Allerdings ist es unmöglich, eine Grenze der Leistungsfähigkeit nach oben hin ohne experimentelle Untersuchung festzustellen; ein größeres Recht haben wir, diese Grenze nach unten zu bestimmen. Und da können wir wohl annehmen, wie ich schon in meiner vorläufigen Mitteilung (DorLein 1903) hervorgehoben habe, daß das Auge sicherlich im stạnde ist, kleine in Bewregung begriffene, leuchtende Objekte, z. B. Leuchtorgane von Tiefseeorganismen, wahrzunehmen. 
Bei dieser Erklärung habe ich mir, wie ich schon oben (S. I 52) hervorgehoben habe, keine Vorstellung von der Bedeutung der großen Pigmentansammlung hinter der Lamina fenestrata, wie sie bei diesen Augen vorkommt, gremacht. Neuerdings hatte Herr Retnhard Domr.y die Güte, mir Prïparate von Augen pelagischer Decapoden zu zeigen, bei denen der Augenstiel eine noch auffallendere Ansammlung von Pigment aufweist. Wie er mir sagte, findet er diese Erscheinung bei zahlreichen Arten. So ist denn zu hoffen, daß die Untersuchung dieser Formen Licht auch auf die Verhältnisse bei Ethusa und Ethusina wirft.

Prinzipiell ähnlich muß der Sehvorgang bei einigen anderen Arten mit weit vollkommeneren Augen verlaufen, welche ich daher auch bei dieser I. Gruppe bespreche. Bei Cyrtomaia Sulhmi platyceros DofL. (Taf. XLV, Fig. I-4) z. B. finden wir mäßig große Augen, bei denen auch die Zahl der Augenkeile unbeträchtlich ist, jedenfalls viel geringer als bei Strandformen von entsprechender Größe. Auch bei Lispognathus Thomsoni (Norm.) [Taf. XLV, Fig. 6 u. 7] liegren die Verhältnisse ähnlich. Einen wesentlichen Unterschied zeigen bei diesen Formen gregrenüber Ethusina die Stäbchen: sie sind relativ viel länger, das Auge kann infolgedessen noch ziemlich schief einfallende Strahlen ausnützen, und es wird ein relativ helles Superpositionsbild entstehen; bei Cy'tomaia ein relativ viel helleres, da bei dieser die Krystallkegel viel kürzer sind als bei Lispognathus. Letztere Form hat auch ein viel mehr verschiebbares Irispigment, was ihrer weiten bathymetrischen Verbreitung entspricht.

Die beiden zuletzt besprochenen Arten geben uns auch zu einer Ueberlegung über die Form der Stäbchen Anlaß; während wir bei Cyrtomaia (Taf. XLV, Fig. 4) schlanke, spindelförmige Stäbchen finden, sind letztere bei Lispognathus (Taf. XLV, Fig. 7) plump und am oberen Ende am breitesten. Fast stets finden wir spindelförmige Stäbchen mit der Anschwellung, in welcher wir die lichtempfindlichen Nervenendigungen suchen, am proximalen Ende bei solchen Augen, von denen wir aus ihren übrigen Bauverhältnissen und aus dem Aufenthalt ihrer Träger schließen können, daß sie am meisten das Superpositionsbild ausnützen. Die mit breitem distalen Ende dem Krystallkegel ansitzenden Stäbchen jedoch finden wir meist in Augen, welche auch zur Wahrnehmung eines irgendwie gearteten Appositionsbildes eingerichtet sind. So auch bei Lispognathus. Suchen wir uns eine Vorstellung von dem Strahlengang bei den Augenkeilen dieser Form zu machen, so ist es nicht unwahrscheinlich, daß durch die breite untere Fläche des Krystallkegels parallele Strahlen austreten. Die Stellung des Pigmentes kann so geregelt werden, daß das Austreten sehr schiefer Strahlen unmöglich wird, und daß die ganze Menge des Lichtes im Stäbchen weitergeleitet wird, welches aber nur von senkrecht auf die Cornea auffallenden Strahlen herrühren kann: wir haben also die Bedingungen eines Appositionsbildes gegeben, für dessen Auffangung die breiten distalen Enden der Stäbchen besonders geeignet sind. Dagegen sind bei Cy'tomaia die kurzen Krystallkegel mit der starken Wölbung der Grenzflïchen sehr geeignet, um außer den der Achse parallelen Strahlen auch schief einfallende weiterzuleiten; diese werden ituch von der Achse divergierend aus dem unteren Ende des Krystallkegels austreten. Die untere Grenzfläche ist aber stark sewölbt und von Pigment frei. So sind alle Bedingungen zu einem lichtstarken Superpositionsbild mit großen Zerstreuungskreisen gegeben. Und wiederum finden wir in den Stäbchen die geeignetsten Rezeptoren für dies Bild, indem sie sehr lang sind und ihre lichtempfindliche Partie weit proximal verlagert ist. Die beistehenden 
Textfiguren (30 u. $3 \mathrm{I}$ ) suchen in einer allerdings willkürlichen und schematischen, aber, wie ich hoffe, anschaulichen Weise der Vorstellung zu Hilfe zu kommen.

Wir können dem Bau dieser beiden Augentypen entnehmen, daß Cyytomaia ein in höherem Grade an das.Leben im tieferen Wasser angepaßtes Tier ist als Lispognathus. Thatsächlich weisen uns die Verbreitungsverhältnisse von Lispognathus Thomsoni (NORM.) auch darauf hin, daß wir in ihm eine polare Form zu erblicken haben, welche in der Tiefe das kalte Wasser aufsucht. Näheres hierüber findet man im tiergeographischen Abschnitt dieses Bandes.
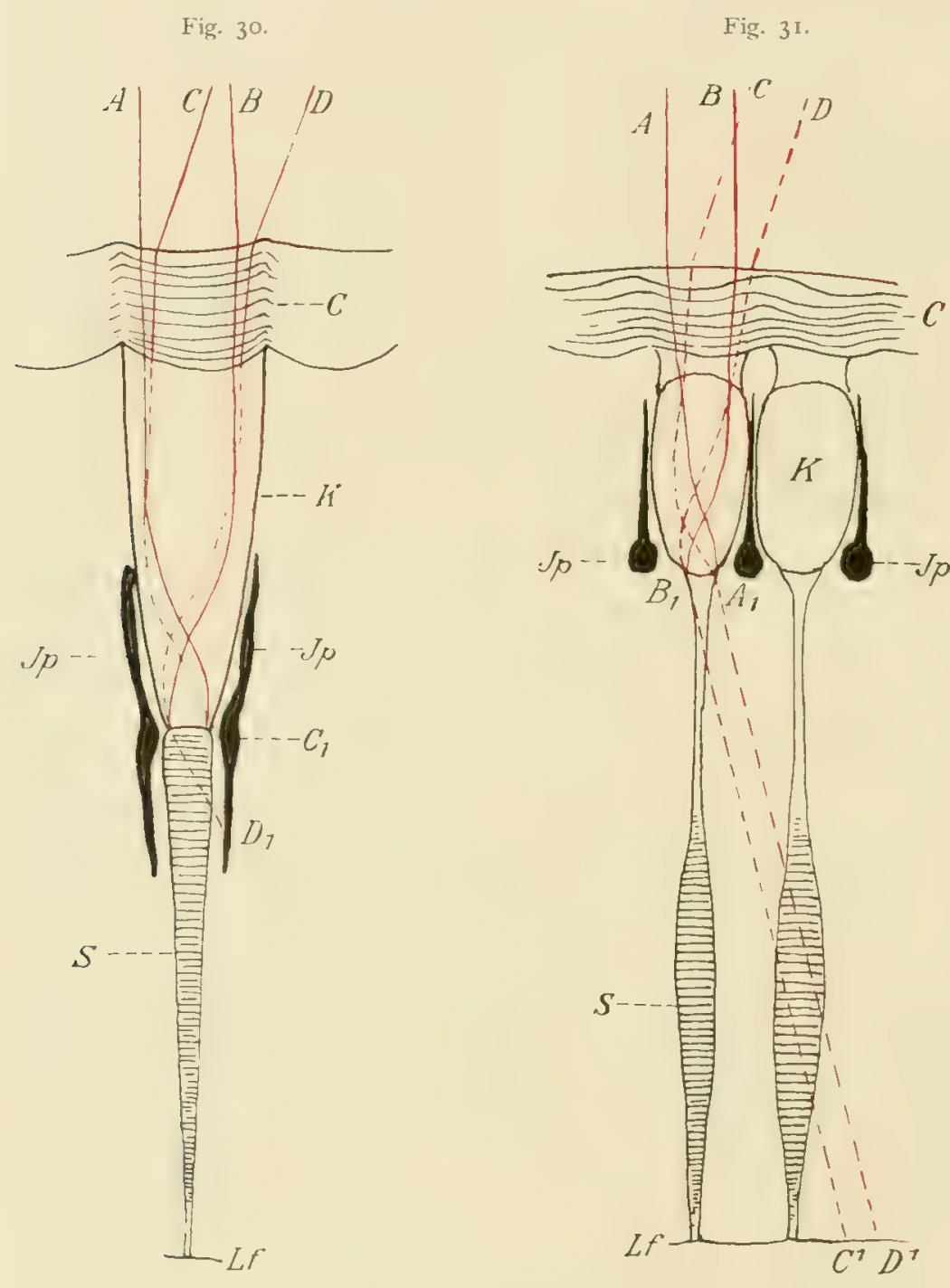

Fig. 30. Schematische Darstellung des Strahlenganges in einem Augenkeil eines Appositionsauges. $C$ Corneafacette, $K$ Krystallkegel, $S$ Stäbchen, $J P$ Irispigment, Lf Lamina fenestrata.

Fig. 31. Schematische Darstellung des Strahlenganges in einem Augenkeil eines Superpositionsauges. C Corneafacette, $I T$ Krystallkegel, $S$ Stäbchen, JP Irispigment, If Lamina fenestrata.
Noch typischere Dunkelaugen sind diejenigen der beiden letzten Formen, welche ich von den untersuchten Arten dieser ersten Gruppe zuerteile. Es sind dies die auf Taf. LI, Fig. I u. 2 nebeneinander abgebildeten Augen von Hypsophrys longipes ALc. und Homolochunia Valdiviae Dofl. Die Anpassung liegt vornehmlich in der bedeutenden Größe der Stäbchen, welche bei Homolochunia fast die Länge von $1 / 2 \mathrm{~mm}(450 \mu)$ erreichen, und deren lichtempfindliche Spindel weit proximal von den Krystallkegeln entfernt liegt (Taf. LII, Fig. 2). Dabei haben die Augen ein deutliches Irispigment und ein sehr schwaches Retinapigment, welch letzteres vollkommen hinter der Lamina fenestrata liegt. Hervorzuheben ist ferner die Dünne und sehr geringe Krümmung der Cornealinsen. Die Folge dieser letzteren Eigentümlichkeit wird sein, daß in den Linsencylinder sehr schwach konvergierende Strahlen eintreten, ferner wird die Cornealinse nicht sehr schiefe Strahlen auffangen. Die bedeutende Länge der Stäbchen läßt dies nicht notwendig erscheinen; zudem ist nicht nur die Cornealinse, sondern auch der Krystallkegel sehr kurz, ferner die Breite der Corneafacette eine relativ sehr große (ca. $50 \mu$ ). IVenn wir uns ins Gedächtnis zurückrufen, daß es sich um sehr große Augen mit großen Mengen von Augenkeilen handelt, 
so können wir uns vorstellen, daß das Augge unter ungünstigen Verhältnissen ein relativ lichtstarkes und relativ deutliches Bild hervorbringen kann.

Die auffallende Erscheinung, daß die Stäbchen auf der Außenseite des Auges, besonders bei Homolochunia, ungefähr doppelt so lang sind wie auf der Innenseite (420-450 $\mu: 200-2$ I $5 \mu$ ), legt es nahe, zu untersuchen, ob darin wohl ein ähnlicher Vorteil gregeben sei wie bei den in Front- und Seitenaugen geteilten Augen pelagischer Tiefsee-Schizopoden und Sercestiden, welche Cuun (1896) beschrieben hat. Ein großer Unterschied gegenüber letzteren ist ja darin gregeben, daß die optischen Bestandteile der langstäbigen Augenkeile ke in e größeren Dimensionen haben als diejenigen der kurzstäbigen. Stets finden wir eine Breite der Corneafacetten von ca. $50 \mu$, und auch die Länge und Breite der Krystallkegrel bleibt sich annähernd gleich. So wird der Vorteil wohl darin liegen, daß die langstäbigen Augenkeile hellere Bilder infolge größerer Zerstreuungskreise erhalten.

\section{Iridopigmentäre Augen.}

Die bisher betrachteten Augen waren im Effekt eigentlich alle schon iridopigmentäre Augen, da bei ihnen das Retinapigment vollständig hinter der Lamina fenestrata angehäuft war. Bei der letztbesprochenen Form war es zudem in auffallend geringer Menge vorhanden. Immerhin könnte man annehmen, daß diese Formen, wenn sie dauernd in stärker belichteten Regionen lebten, imstande sein würden, die Zerstreuungskreise ganz oder teilweise abzublenden. Es grelang mir aber auch bei den Krabben, echte iridopigmentäre Augen nachzuweisen, bei denen das Retinapigment vollkommen fehlt und welche sich den von CHun beschriebenen iridopigmentären Augen der Schizopoden anschließen. Ich fand solche bei Echinoplax Moseleyi Mrs. und bei Geryon affinis M.-E. u. Bouv. In beiden Fällen waren es sehr große Augen, bei Echinoplax ein mehr kugeliges, bei Geryon ein in die Quere verbreitertes Auge. Beide zeichneten sich durch sehr breite Corneafacetten aus: während wir bei den bisher betrachteten Formen höchstens eine Breite von ca. $50 \mu$ fanden, weisen die Corneafacetten von Pleistacantha eine Breite von $70 \mu$, diejenigen von Geryon eine solche von $99 \mu$ auf. Auch die Länge der Corneafacetten ist eine ansehnliche; in Bezug auf die Krystallkegel und Stäbchen jedoch verhalten sich beide Gattungen verschieden. Bei Plcistacantha finden wir mäßig große, birnförmige Krystallkegel und um deren untere Enden das Irispigment gehäuft. Wir können annehmen, daß dies Auge nach dem Typus der iridopigmentären Augen ein Superpositionsbild von relativ großer Lichtstärke erzengt. Die Stäbchen sind lang und schlank-spindelförmig, wie es für "Superpositionsaugen" charakteristisch ist

Eine Beobachtung, welche ich an diesen und an einigen Augen der ersten Gruppe zu machen glaubte, möchte ich trotz ihrer Unsicherheit nicht unerwähnt lassen, da sie - wenn bestätigt - ein größeres Interesse beansprucht. Ich glaubte eine Struktur der Stäbchen zu erkennen von der Art, wie sie in Fig. 5 auf Tafel LV abgebildet ist. Auf den Krystallkegel folgt ein etwas verdickter, ganz kurzer Teil des Stäbchens, in dem Plättchenstruktur erkennbar ist (sd), dann folgt ein langer, stabförmiger, homogener Teil (ss), und proximal befindet sich schließlich eine kleine Spindel, abermals mit Plättchenstruktur (sp). Ich bin geneigt, in dieser Einrichtung eine Verteilung der Lichtempfindungsfähigkeit auf zwei Teile der Retina zu sehen. Proximal wird das Superpositionsbild von den Spindeln in der üblichen Weise wahrgenommen. 
Der distale Retinaabschnitt dagegren ist seiner ganzen Lage und seiner Beziehung zum Pigment nach geeignet, bei senkrechtem Strahleneinfall auf die Corneafacette ein Appositionsbild zu liefern. Ein Blick auf die Textfigur 3 I und auf Fig. 5 der Tafel LV lehrt dies ohne weiteres. Es fragt sich nun, ob beide Bilder getrennt vorkommen können, ob das Appositionsbild des distalen Retinaabschnittes nicht dennoch mit Zerstreuungskreisen gesehen wird, weil gleichzeitig

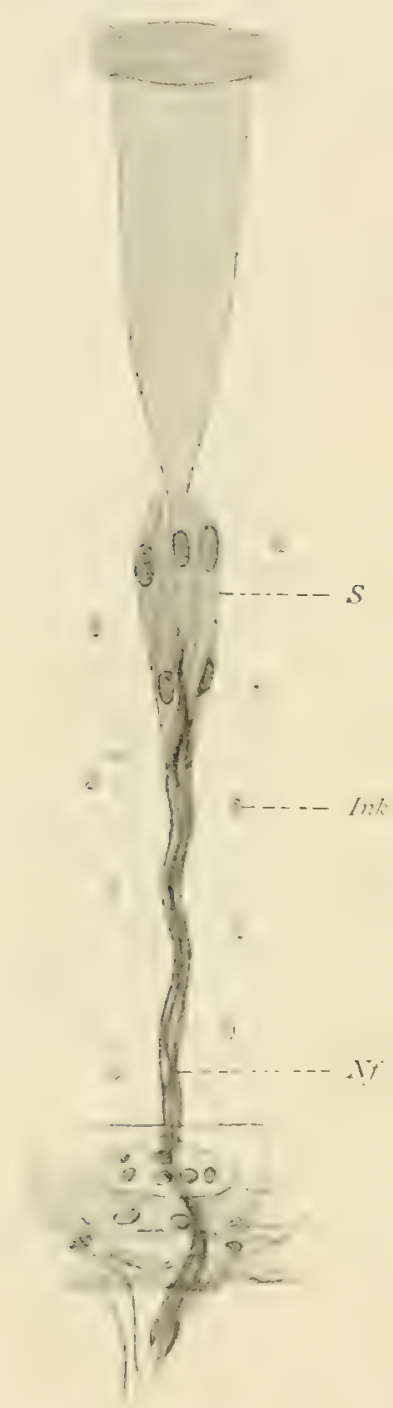

Fig. 32. Augenkeil von Geryon affinis MI-E. u. Bouv. $S$ Stäbchen, Ink Interretinalkerne, $\lambda$ lf Nervenfasern. im proximalen Teil ein Superpositionsbild entsteht. Es ist nicht unmöglich, daß eine geringe Berieglichkeit des Pigmentes je nach dem Bedürfnis das Auftreten der beiden Abbildungsformen reguliert. Wahrscheinlicher scheint mir jedoch die Annahme, daß das Pigment unbeweglich ist, und daß eine verschiedene Einstellung für nahe und ferne Objekte hier im Auge präformiert ist.

Geryon affmis M.E. u. Bouv. hat sehr breite Corneafacetten (99 $\mu$ ), die aber auch recht lang sind ( I06 p); dabei sind die Krystallkegel die

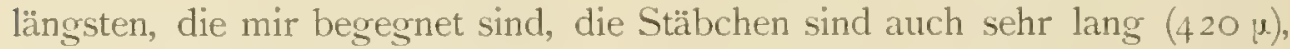
wie denn das ganze Auge sehr große Dimensionen aufweist (Taf. XLIX, Fig. I). Dabei fallen in dem iridopiermentären Auge zwei Umstände sehr auf: 1) ist das Irispigment um das distale Ende der Krystallkegel dicht gehäuft, so daß schiefe Strahlen kaum austreten können; 2) haben die Stäbchen die für Appositionsaugen charakteristische Kegelform, und dazu findet sich nur im distalen Teil jene für den Ort der Lichtempfindung charakteristische Plättchenstruktur oder Querstrichelung, während der proximale Teil von deutlichen Strängen, die wohl aus Bündeln von Neurofibrillen bestehen, durchzogen wird (Textfig. 32; wegren der Pigmentanordnung s. Taf. LV, Fig. 6).

Ich glaube, ein solches Auge kann nur durch Vermittlung des Appositionsbildes Gegenstände wahrnehmen. Es ist allerdings nicht ganz ausgeschlossen, daß bei einer bestimmten Stellung des Irispigmentes Lichtstrahlen, die schief auf die Linse gefallen sind, schief in den Retinalraum einfallen und andere Stäbchen, als das des zugehörigen Augenkeils, in Erregungszustand versetzen. Für eine solche Verschiebung des Pigmentes und damit zusammenhängende Entstehung eines Superpositionsbildes habe ich allerdings keine Anhaltspunkte. Dagegen glaube ich fast aus der Struktur des Gewebes zwischen den Stäbchen und hinter der Lamina fenestrata schließen zu sollen, daß ein reflektierendes Tapetum vorhanden war, welches aber bei der Konservierung und Präparation gelöst wurde.

III. Reflektoraugen.

Merkwürdigerweise konnte ich nur bei einer einzigen der untersuchten Brachyuren Augen mit reflektierendem Tapetum nachweisen. Ein solches ist ja nach ExNER's Untersuchungen bei Decapoden mit nächtlicher Lebensweise auch in seichterem Wasser nicht selten, und CHUN hat es ebenfalls bei bodenbewohnenden Tiefseeformen nachgewiesen. So ist es nicht unmöglich, 
daß bei manchen der untersuchten Formen ein solches Tapetum vorhanden war, durch eine der vielfachen Behandlungsmethoden, denen es bis zur Fertigstellung des Präparates ausgesetzt war, jedoch gelöst wurde.

Die Form, bei welcher ich es mit Sicherheit nachweisen konnte, war Platymaia IryvilleThomsoni Mrs. Aber auch bei dieser Form finde ich es nur im Auge des erwachsenen Tieres. Bei den jüngeren Stadien fehlt es; bei der halblarvalen Form (Taf. LIII, Fig. I) konnte ich keine Spur von Tapetum oder Pigment nachweisen und bei dem mittelgroßen Tier (Taf. LIII, Figg. 2) von beiden auch nur Spuren. $\mathrm{Ob}$ dies eine normale und regelmäßßige Eirscheinung ist. daß diese Substanzen sich erst im Laufe der Entwickelung einstellen, kann ich nicht mit Sicherheit entscheiden, da mir hierzu das Material fehlt. Nir scheint es aber richtiger, in einer anderen Gruppe von Einflüssen, die Ursache dieser auffälligen Erscheinung zu suchen. Es stammt nämlich Stadium I mit den pigment- und tapetumlosen Augen aus einer Tiefe von $748 \mathrm{~m}$, Stadium IV mit schwach pigmentierten Augen aus einer Tỉefe von 404 m, während das erwachsene Stück des Stadiums VII aus einer Tiefe von nur $296 \mathrm{~m}$ stammt (vergl. die Zusammenstellung der Stadien auf S. 68 u. 69). So können wir denn einen Linfluß des Lichtmangels vermuten, auf den ich weiter unten bei der Erörterung der Standortsvarietäten noch zurückkommen werde. Hier wollen wir bloß diese Verhältnisse verzeichnen, die einzelnen Stadien als gesonderte Formen von Sehapparaten betrachten und uns nur mit ihrer Leistungsfähigkeit beschäftigen. Stadium I ist daher unten mit den pigmentlosen Augen anderer Formen zu behandeln, und vor dem zwischen I und VII in der Mitte stehenden Stadium IV wollen wir zunächst das ausgeprägtere Stadium VII besprechen.

Die Abbildungen Taf. L, Fig. 5 u. 6, und Taf. LI, Fig. 3 rufen uns den Bau dieses stattlichen Auges ins Gedächtnis zurück. Schon die Größe weist uns darauf hin, daß es sich um ein Organ handeln muß, welches für das Sehen in dem speciellen Lebensbezirk des Tieres angepaßt ist. Die Cornealinsen haben eine sehr große Oeffnung ( 85 i.), Cornealinse und Krystallkegel sind ungefähr gleich lang. Nach außen sind die Cornealinsen kaum gewölbt. Die ganze hintere Region des Auges ist mit dem stark reflektierenden Tapetum erfüllt.

Je mehr ich mir die optische und physiologische Leistungsfähigheit dieses Augentypus überlege, um so mehr drängt sich mir die Ueberzeugung auf, daß wir es mit einem geradezu wunderbar zweckmäßig gebauten Organ zu tun haben. Die Größe des Auges und sein Facettenreichtum erlaubten es ihm wohl, ein ziemlich deutliches Bild zu sehen, welches nach Art eines Appositionsbildes zu stande kommen muß. Zur Wahrnehmung werden wohl nur parallel der Achse einfallende Strahlen gelangen, eventuell solche schiefe Strahlen, welche nahe der Achse und nicht zu schief $z u$ dieser einfallen (Textfigur 33 ist entworfen, um die hier gegebenen Auseinandersetzungen zu veranschaulichen). Die dichte Pigmenthülle, welche den gesamten lichtempfindlichen Teil des Stäbchens umhüllt, verhütet das Eintreten von Strahlen, welche das Bild durch Zerstreuungskreise weniger scharf machen könnten. Ein Superpositionsbild ist somit ausgeschlossen, wenn nicht unter bestimmten Verhältnissen eine Verschiebung des Pigmentes eintritt, wofür ich keine Anhaltspunkte habe. Dieses Appositionsbild kann aber relativ lichtstark sein; denn die Cornealinsen sind sehr breit, der Krystallkegel ist kurz, und schließlich kann auch die Tapetumschicht zur Erhellung des Bildes beitragen, indem die Strahlen, welche das Stäbchen passiert haben, ron ihr reflektiert, zum zweiten Male durch dasselbe hindurchereschickt werden 
(vergl. Textfig. $33 A A_{1}, B B_{1}$ rechter Augenkeil). Es wäre also möglich, daß die gleichen Nervenendigungen durch diese Einrichtungen einen verdoppelten, aber unveränderten Lichtreiz empfingen.

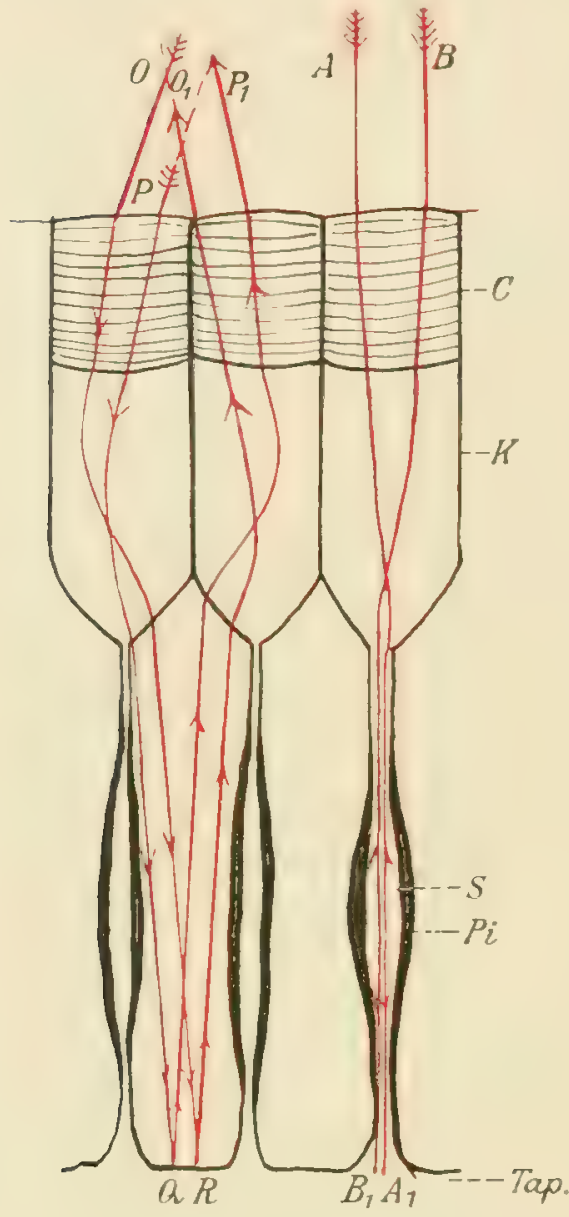

Fig. 33. Schema des Einfalles und der Weiterleitung der Lichtstrablen in den Augenbeilen von Platymaia II yrille-Thomsori MRS. $C$ Cornealinse, $K$ Krystallkegel, $S$ Stäbchen, Pi Pigment, Tap. Tapetum, $A A_{1}, B B_{1}$ Parallel zur optischen Achse einfallende Lichtstrahlen und $O R, P Q$ Schief einfallende Strablen, $R O_{1}, Q P_{1}$ dieselben reflektiert.
Damit ist aber die Bedeutung des Tapetums nicht erschöpft. Die in die Cornealinse schief zum Hauptstrahl einfallenden Strahlen werden in dem Linsencylindersystem so gebrochen werden, daß sie, seitlich austretend, den Retinalraum durchdringen und, vom Tapetum reflektiert, durch einen je nach ihrer Richtung mehr oder weniger nahe henachbarten Linsencylinder wieder austreten; sie werden das Auge, bei der von mir aufgefundenen Pigmentstellung, verlassen, ohne einen physiologischen Effekt zu erzielen. Biologisch kann aber ihre Wirkung eine wesentliche sein. Aehnlich wie bei manchen Nachtschmetterlingen wird in der Dämmerung das Auge stark leuchten und somit dem Tier den gleichen Nutzen gewähren können wie ein mit Eigenlicht leuchtendes Leuchtorgan. In Textfigur $33 O R-R O^{\prime}, P Q-Q P^{\prime}$ ist an dem linken Augenkeil in schematischer Weise der Strahlengang für diesen Effekt angedeutet.

Sollte sich bei dem Auge von Platymaia noch eine Verschiebung des Pigmentes nachweisen lassen, so würden dieselben Ueberlegungen angeben, daß es ein in hohem Grade für das Zustandekommen eines sehr hellen, aber unscharfen Superpositionsbildes geeignetes Sehorgan ist. Es würden dann nicht nur viele der direkt schief einfallenden Strahlen, sondern auch die reflektierten Strahlen zum Zustandekommen des Superpositionsbildes beitragen.

Ein solches muß wohl ohne weiteres in den jüngeren Stadien mit geringer Pigmententwickelung wie Stadium IV (Taf. LIII, Fig. 2) zu stande kommen.

\section{Pigmentlose Augen.}

In der Litteratur über Tiefseeorganismen findet man stets die pigmentlosen Augen als rückgebildete Augen bezeichnet, und ein Auge, welches bei dem konservierten Exemplar weiß aussieht, wird - auch wenn es groß und wohlgebildet ist - meist als ein Organ aufgefaßt, welches mangelhaft funktionieren müsse. Auch ich war zuerst zu einer solchen Auffassung geneigt; aber die ExNeR'schen Beobachtungen an Phronima und eine Ueberlegung, die ein befreundeter Physiologe bei mir anregte, haben mich. von einer extremen Auffassung abgebracht.

Zweierlei Vorgänge können es sein, welche im pigmentlosen (und zugleich tapetumlosen) Auge das Zustandekommen eines Bildes ermöglichen. 
Erstens es kann, wie dies ExNer für das Auge von Phronima nachgerviesen hat, durch totale Reflexion ein katoptrisches Appositionsbild entstehen.

Zweitens können in dem Auge gewisse. Substanzen vorhanden gewesen sein, welche für bestimmte, in der Tiefe wichtigere Strahlen die Blendenwirkung des Pigmentes ersetzten. So würde, um durch ein Beispiel, was ich hier im Sinn habe, zu erläutern, eine Lösung von Chininsulfat eine sehr geeignete Blende für ultraviolette Strahlen darstellen. Diese letztere Idee meines Freundes Dr. Walter Straub, welche im Prinzip mit der von mir schon früher ausgesprochenen Annahme, daß bunte Pigmente für Strahlen von bestimmter Färbung als Pupillen dienen könnten, im Prinzip übereinstimmt und sich nur dadurch unterscheidet, daß sie auch für unser Auge durchsichtige Pupillarsubstanzen in den Kreis der Betrachtungen zieht, diese Idee ist natürlich am konservierten Material nicht $z u$ prüfen. Auf sie sei hier als auf eine zu ervägende Möglichkeit hingrewiesen.

Eher könnte man prüfen, ob eine katoptrische Wirkung in den Krystallkegeln der betreffenden Formen sich nachweisen läßt. Von einer der in Betracht kommenden Arten habe ich auch genug Material, um einen Versuch wagen zu können.

Wenn ich auch persönlich die pigmentlosen Augen, welche ich bei Brachyuren kennen gelernt habe, für rückgebildete Organe halte, so halte ich doch aus Gründen der Theorie eine Ueberlegung über ihre Funktionsfähigkeit für sehr wichtig. Ich werde daher bei der Besprechung der Augentypen hervorheben, was bei ihnen auf Herkunft von einem vollkommneren Organ hinweist, von welchem Augentypus man sie ableiten kann, und was an ihnen eventuell zweckmäßig zur Erzielung einer Funktion scheint.

Die Formen, um welche es sich handelt, sind folgende:

Homolodromia Bonvieri DofL.,

Platymaia W'yille-Thomsoni Mrs., Stadium I,

Scyramathia Hertuigi DoFL,

Scyramathia Rivers-Andersoni Alc.

Ihnen schließen sich als Formen mit pigmentlosen, noch weiter rückgebildeten Augen an:

Cyclodorippe uncifera glaucomma ALc.,

Cy'monomus granulatus (NORMr.).

Viele der Formen mit pigmentlosen Augen, die ich nicht genauer untersuchen konnte, gehören sicherlich auch hierher.

Die Augen der Scyvamathia-Arten und die der larvenartigen Jugendform von Platymaia sind im Prinzip gleichartig gebaut, nur haben letztere viel mehr Augenkeile und dünne, nach außen leicht konkave Cornealinsen. Bei den 3 Formen jedoch sind mäßig lange Krystallkegel vorhanden, an denen mit breitem distalen Ende schlank-kegrelförmige Stäbchen ansitzen. Es fällt ferner bei ihnen auf, daß die Krystallkegel so dicht aneinander stehen, daß kaum ein Zwischenraum, der etwa ron einem Pigment hätte ausgefüllt gewesen sein können, zwischen ihnen bleibt; doch sind die Kerne der Irispigmentzellen erkennbar. Die Scyramathia-Augen scheinen von augenkeilreicheren Augen herzuleiten zu sein, welche mit reichlichem, die Stäbchen umhüllendem Pigment zur Erzeugung von Appositionsbildern eingerichtet waren. Auf letzteres weist die Form der Stäbchen und ihr Anschluß an die Krystallkegrel hin. Wir können uns nun eine 
Funktion des Auges wohl nach Art eines Superpositionsauges vorstellen, dafür scheint aber die Form der Stäbchen ungeeignet, welche viel eher dafür spricht, daß durch katoptrische Wirkung ein lichtschwaches Appositionsbild, ähnlich wie im Auge von Phronima, entsteht.

Das Auge von Homolodronia Bouvieri Doft. mit seinen breiten und dünnen Corneafacetten, seinen langen Krystallkegeln und langen spindelförmigen Stäbchen ist wohl von einem iridopigmentåren Auge abzuleiten, welches ein Superpositionsbild erzeugte. Die geringe Lichtbrechung der optischen Bestandteile, die Lücken zwischen den Krystallkegeln und die Länge der spindelförmigen Stäbchen weist darauf hin, daß hier vielleicht trotz katoptrischer Wirkung der Krystallkegel ein Superpositionsbild mit so großen Zerstreuungskreisen entsteht, daß man von einem Bild wohl gar nicht mehr wird sprechen können; doch wird wohl Wechsel der Lichtintensität, Richtung des Lichteinfalles und Bewregung des hellen Gegenstandes wahrgenommen werden.

Wie steht es nun aber mit der Lichtempfindung bei Cyclodorippe uncifera glancomma (ALC.) und bei der noch nicht ganz rudimentären Form von Cymonomus gramulatus (NoRMr.)? In beiden Fällen haben wir Stäbchen in geringer Anzahl, welche an eine kaum gegliederte Cornea anstoßen, ohne daß Krystallkegel oder irgend ein Ersatz für solche vorhanden wären. IVir können uns kaum vorstellen, daß solche Augen auch nur über die Richtung des Lichteinfalles orientieren können; doch mag dies innerhalb gewisser Grenzen durch die Struktur der Cuticula noch ermöglicht werden. Vom Erkennen eines Bildes kann nicht mehr die Rede sein.

Bei Cy'monomus gramulatus (NORM.) in der typischen Form vollends können wir wohl sagen, daß das ehemalige Auge oder vielmehr sein Stiel zu einem Organe umgewandelt ist, welches keine Gesichts-, sondern nur noch Tastempfindungen vermittelt.

Wir sehen also, daß, obwohl der Organismus aus dem Material, welches ihm zur Verfügung steht, immer noch irgend etwas Verwendbares zu machen vermag, doch Fälle in der Natur sich nachweisen lassen, wo ein Organ durchaus nicht eine für die Lebensverhältnisse seines Trägers vollkommene Beschaffenheit besitzt; wir können es wenigstens nicht nachweisen, wenn wir uns auch alle Mühe geben, jede Möglichkeit zu berücksichtigen und nachzuprüfen.

\section{Lins en a ugen.}

Linsenaugen möchte ich zum Unterschied von den meisten Decapoden-Augen, deren optische IVirksamkeit auf dem Bau der Krystallkegel beruht, welche als Linsencylinder funktionieren, einige Augenformen nennen, bei denen der Krystallkegel zu kurz und zu wenig lichtbrechend ist, um anders als eine Linse zu wirken. Dafür spricht auch seine Form bei den betreffenden Arten.

Die in Betracht kommenden Arten sind zunächst:

$$
\begin{aligned}
& \text { Cyclodorippe dromioides ORTM., } \\
& \text { Physachaeus ctemumes Alc. } \\
& \text { Trichopeltarizm Alcocki DorL., }
\end{aligned}
$$

Bei allen diesen Formen haben wir sehr kleine Facettenregionen, und da die Cornealinsen relativ sehr breit sind, so haben die Augen ziemlich wenig Augenkeile. Die Cornealinsen sind 
ziemlich lang, die Krystallkegel sehr kurz, und zwar bei Physachactes und Trichopeltarinu bikonkav, bei Cyclodorippe dromioides konkav-konvex gewölbt.

Bei den 3 Arten sind die Corncalinsen so stark geschichtet, daß sie wohl nicht direkt als Linsen, sondern eher nach Art einer Etagenlupe wirken. IVie dem auch sei, jedenfalls findet eine Konzentration der Strahlen statt, welche von dem Krystallkegel wahrscheinlich wieder parallel gerichtet oder vielleicht schwach divergent gemacht werden. Die Textfigur 34 giebt einen Begriff von diesem Vorgang. Man kann ihr ferner entnehmen, daß das Auge, obwohl es die Pigmentverhältnisse eines iridopigmentären Auges besitzt, dennoch ein Appositionsbild wahrnehmen muß; allzu schief einfallende Strahlen werden bei der Textfigur 34 entsprechenden Konstruktion nicht zur Wahmehmung gelangen, sondern von dem Irispigment absorbiert werden. Somit würde ein bei aller Lichtstärke relativ deutliches Appositionsbild resultieren, wenn innerhalb der Stäbchen eine Weiterleitung des Lichtes durch totale Reflexion stattfindet; auf eine solche weisen die vielfach verkrümmten Formen besonders der randständigen Stäbchen hin. Die punktierten roten Linien weisen uns darauf hin, in welcher TVeise die Cornealinse senkrecht treffende Strahlen in das Stäbchen gelangen würden, wenn der Krystallkegel überhaupt keine nennenswerte Brechungsfähigkeit besäße. Es würde dadurch ein recht undeutliches, verschwommenes Bild von sehr großer Lichtstärke entstehen.

In beiden Fällen sehen wir ohne weiteres den großen Nutzen der stäbchenform ein. Dieser breite Kexel muß alles durch die optischen Vorrichtungen einfallende Licht auffangen und nutzbar machen. Die Frage, ol ein aufrechtes oder ein verkehrtes Bild entsteht, kann ich natürlich ohne exakte Untersuchung nicht beantworten. Sie ist ja auch zunächst ohne biologische Bedeutung.

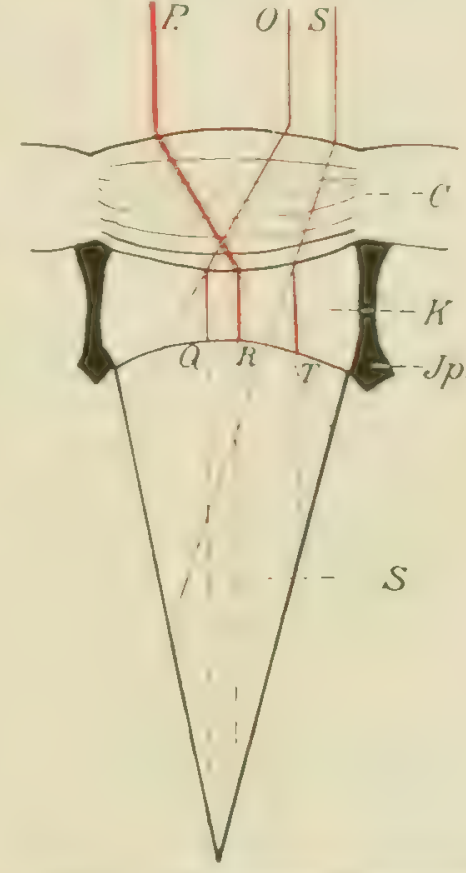

Fir. 34. Schematische I)arstellung des Strahlenganges in einem Augenkeil von Plyysachaeus. C Cornealinse, $K^{2}$ Frystallkegel, $J$. Irispigment, S Stibchen, $P R, O\langle$, $5 T$ juallel 2 ur utish Achse auffallende und gebrochene Strahlen.

Die beiden anderen Formen haben kein Irispigment. Bei der auch bei ihnen anzunehmenden katoptrischen Wirkung der Stäbchen hat dies keine so große Wichtigkeit. Jedenfalls ist auch hier, besonders bei Trichopeltarizm, hervorzuheben, daß sich die distalen Enden der Stäbchen den proximalen Flächen der Krystallkegel aufs engste anschmiegen.

Bei einigen Formen der Litoralregion finden sich Eigentümlichkeiten des Augenbaues welche den Sehvorgang sicher stark beeinflussen müssen. Bei Ocypode ceratophthalma (Forsk., und bei Menaethins monoceros (LATr.) z. B. finden wir pseudokone Augen (Textfig. 35 u. 36). An Stelle der Krystallkegel finden wir da eine schaumartige Substanz, kaum lichtbrechend, deren Anblick sehr absticht von allem, was wir bisher von Krystallkegeln kennen gelernt haben. Vielleicht war sie beim lebenden Tier vollkommen homogen, durchsichtig und von sehr geringer Lichtbrechung. Jedenfalls müssen wir sie als einen Pseudoconus bezeichnen, wie GrENACHER (1879) ihn bei zahlreichen Insekten fand. Wir müssen wohl annehmen, daß Strahlen, welche aus der Linse hervorkommen, in diesem Medium kaum gebrochen werden, sondern es 
annähernd geradlinig passieren. Bei Ocypode, welche meist auf dem trocknen Lande sich aufhält, wird wohl die konzentrierende WVirkung der Cornealinsen eine ziemlich beträchtliche sein,

Fig. 35.

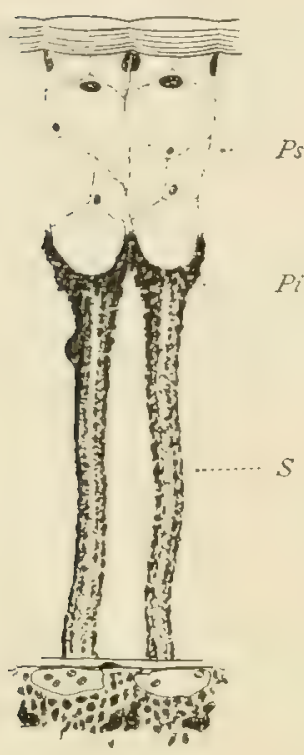

Fig. $3^{6 .}$

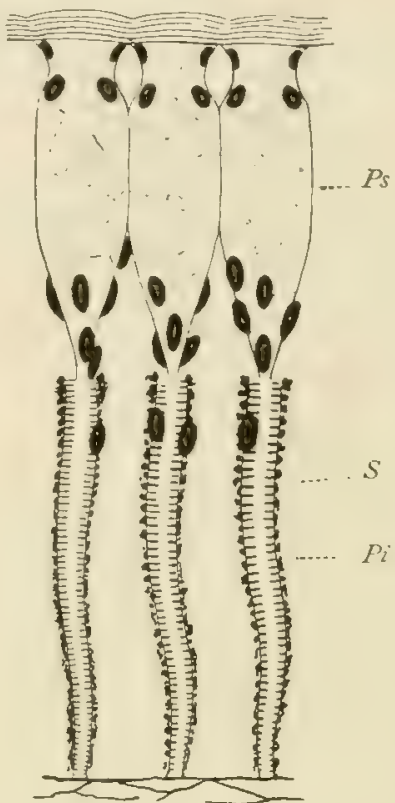

Fig. 35. Augenkeile von Ocypode ceratophthalma (FORSK.).

Fig. 36. Augenkeile von Menaethius monoceros (LATR.) Ps Pseudoconus. $S$ Stäbchen. $P_{i}$ Pigment.

so daß wir bei dem Abstand Ivon Cornealinse und Stäbchen wohl vermuten dürfen, daß der Brennpunkt in der Nähe des distalen Stäbchenendes liegt. Vielleicht dürfen wir für Menaethizes die gleiche Annahme machen.

Wenn nicht die Wirkung der Cornealinse oder diejenige des Pseudoconus derjenigen eines Linsencylinders gleicht, müssen hier verkehrte Netzhautbildchen entstehen. Noch eigenartiger ist das vollkommen akone Auge von Pinnotheres tridanae (Textfigur 37). Die wenigen Augenkeile des kleinen Auges besitzen eine mächtige Cornealinse, keinen Krystallkegel und ganz dicht von schwarzem Pigment eingehüllte kurze Stäbchen. Wie es ExNer für Limuhıs schildert, ist ein Zwischenraum zwischen dem proximalen Ende der Linse, welcher

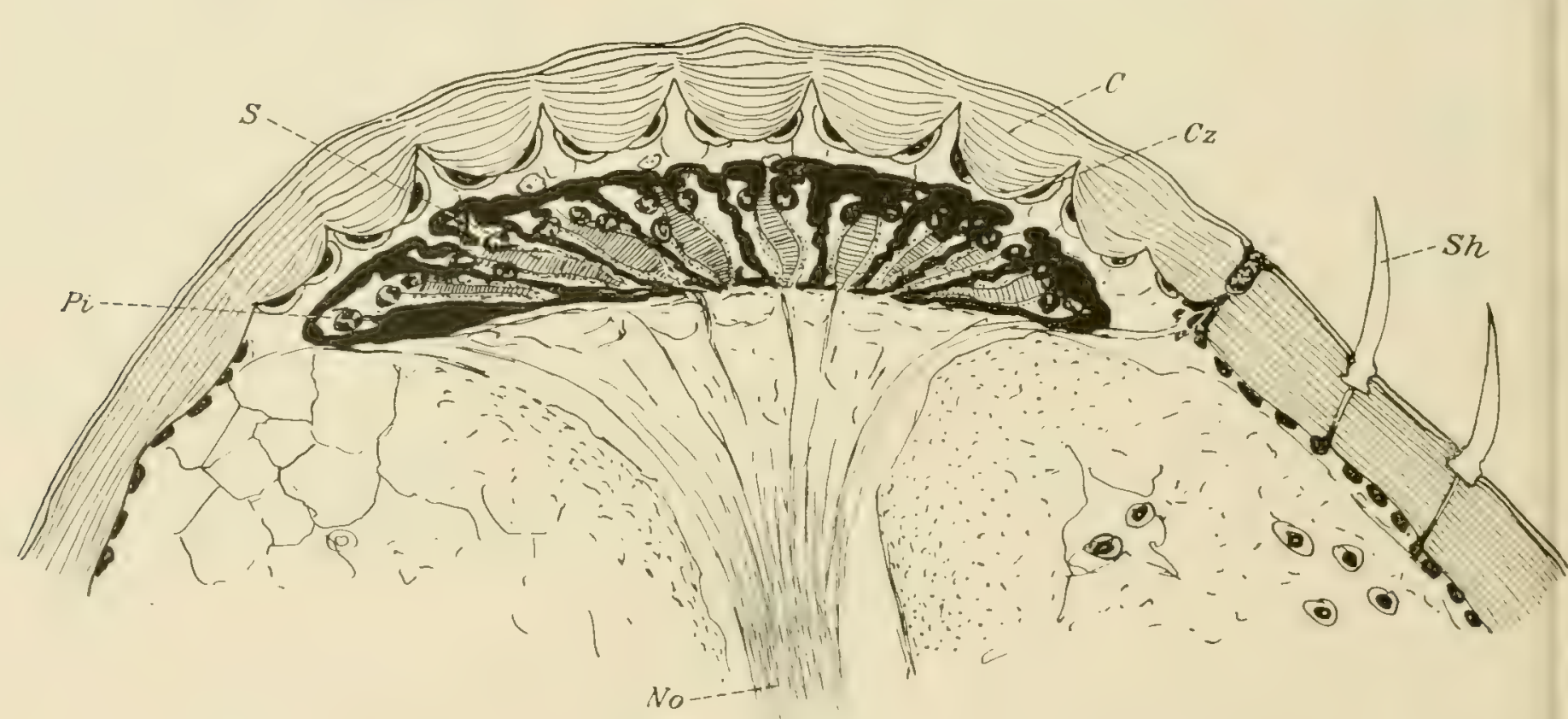

Fig. 37. Schnitt durch das Auge von Pinnotheres tridacnace RüPP. $C$ Cornealinse, $C z$ Corneagenzellen, $P i$ äußere Pigmentscheide, $S$ Stäbchen mit feiner innerer Pigmenthülle, $S h$ Sinneshaare.

wohl bei dem lebenden Tier von durchsichtigem Gewebe ausgefüllt war. Es ist nur dann möglich, daß die Cornealinse ein aufrechtes Bild entwirft, wenn sie nach Art eines Linsencylinders das Licht bricht. 
Ist dies nicht der Fall, so muß jeder Augenkeil ein verkehrtes Bildchen wahrnehmen (Textfig. 38). Wir hätten damit auf einmal unter den höchsten Decapoden einen Fall des Sehens nach dem Prinzip der Gotrsche'schen Theorie. Dafür könnte eventuell die außerordentlich starke Umhüllung jedes Augenkeiles mit Pigment sprechen; es ist außer einer speciellen feinen Pigmenthülle um das Stäbchen, die vielleicht beweglich ist, eine mächtige Pigmentscheide vorhanden, welche jeden Augenkeil von seinem Nachbarn trennt.

Immerhin scheint es mir vorläufig noch wahrscheinlicher, daß die dicke Cornealinse so wirkt, wie z. B. bei Limulnes Krystallkegel und Cornealinse zusammen, d. h. daß ein aufrechtes Appositionsbild zustande kommt.

Doch ist eine Entscheidung dieser gegensätzlichen Möglichkeiten nur durch direkte Untersuchung zu erreichen. Ich möchte auf dies interessante Problem ausdrücklich aufmerksam gemacht haben, da Pinnotheriden überall am Neere leicht zu haben sind und die Untersuchung keine so großen Schwierigkeiten bereiten wird, wie man zunächst annehmen sollte.

An den oben erwähnten pseudokonen Augen konnte ich eine Eigentümlichkeit beobachten, welche für die von EXNER angenommene katoptrische Wirkung der Krystallkegel bei normalen Augen (ExNer, 189I, S. 59) spricht. Bei diesen pseudokonen Augen mit nichtbrechenden Krystallkegeln ist nämlich zwischen denselben stets eine von dem

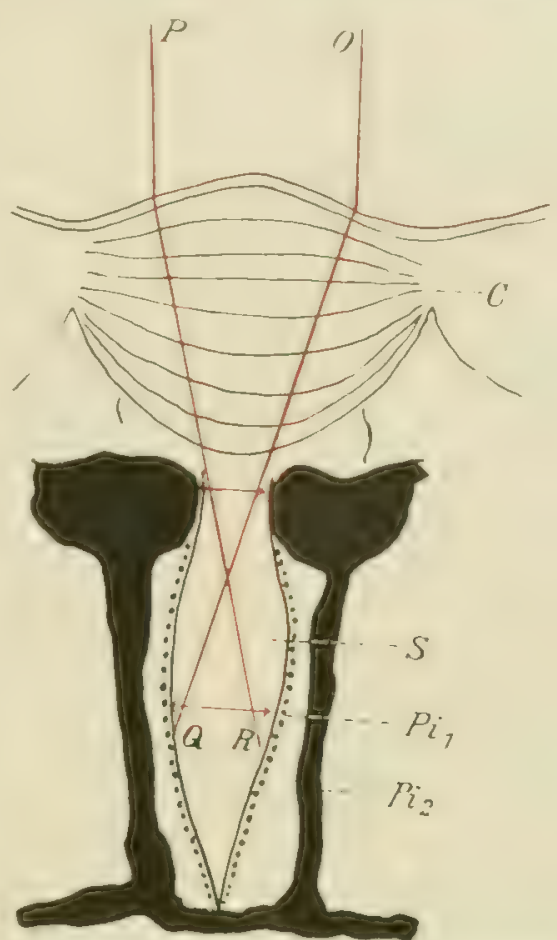

Fig. 38. Schema der Lichtbrechung im Augenkeil von Pinnotheres tridacnae RÜPP. $C$ Cornealinse, $S$ Stäbchen, $P_{i}$ innere feinere Pigmenthülle, $P_{i_{2}}$ äußere Pigmentscheide, $P R$ u. $O Q$ Weg 2 weier parallel einfallender Lichtstrahlen. stäbchenumhüllenden Pigment verschiedene Pigmentmasse von gelbbrauner Farbe $z u$ finden. Vielleicht ist es eine tapetumartige reflektierende Substanz, welche durch die Präparation ihre reflektierenden Eigenschaften verloren hat. Einerlei ob reflektierend oder absorbierend, trägt sie in demselben Sinne zur Leistung des Auges bei, wie bei den typischen Augen die Reflexion der Kegel.

\section{Vergleich des Augenbaues bei Tieren mit verschiedener Lebensweise.}

Die große Wichtigkeit, welche das Sehorgan für das Leben der Tiere hat, spiegelt sich in der Mannigfaltigkeit des Baues, welche in innigster Beziehung zur Lebensweise und den Existenzbedingungen der Arten steht. Während es nun leicht ist, diese Abhängigkeit in groben Zügen und im allgemeinen $z u$ erweisen und $z u$ beschreiben, ist es außerordentlich schwer, die Gesetzmäßigkeit im einzelnen zu erforschen.

Man kann wohl im allgemeinen sagen, Tiefseetiere haben entweder stark verkleinerte und rudimentäre oder sehr vergrößerte Augen. Aber es ist weder diese Regel allgemein giltig, noch besagt sie, daß nur Tiefseetiere mit diesen Eigentümlichkeiten ausgestattet sind.

Die umstehende Textfigur 39 zeigt das riesenhafte Auge von Ocypode ceratophthalma. Es ist dies eine Krabbenart, welche auf dem sonnendurchglühten Sandstrand tropischer Meere 
wohnt und, soviel mir bekannt geworden ist, ein Tagtier ist. Das Auge ist mit Tausenden von Augenkeilen versehen, lang-walzenförmig in die Quere gezogen und kann senkrecht in die Höhe gestreckt getragen werden. Dabei ist diese Art nur ein Repräsentant für viele Gattungen von gleicher Lebensweise, welche durch solche großen Augen ausgezeichnet sind.

Auf der anderen Seite finden wir auch ganz kleine Augen unter bestimmten Bedingungen bei Strandformen, wie wir gleich unten für Pinnotheres zu erörtern haben werden. Im einen wie im anderen Fall wird sich die Bedeutung der Augengröße für specielle Lebensverhältnisse erweisen lassen.

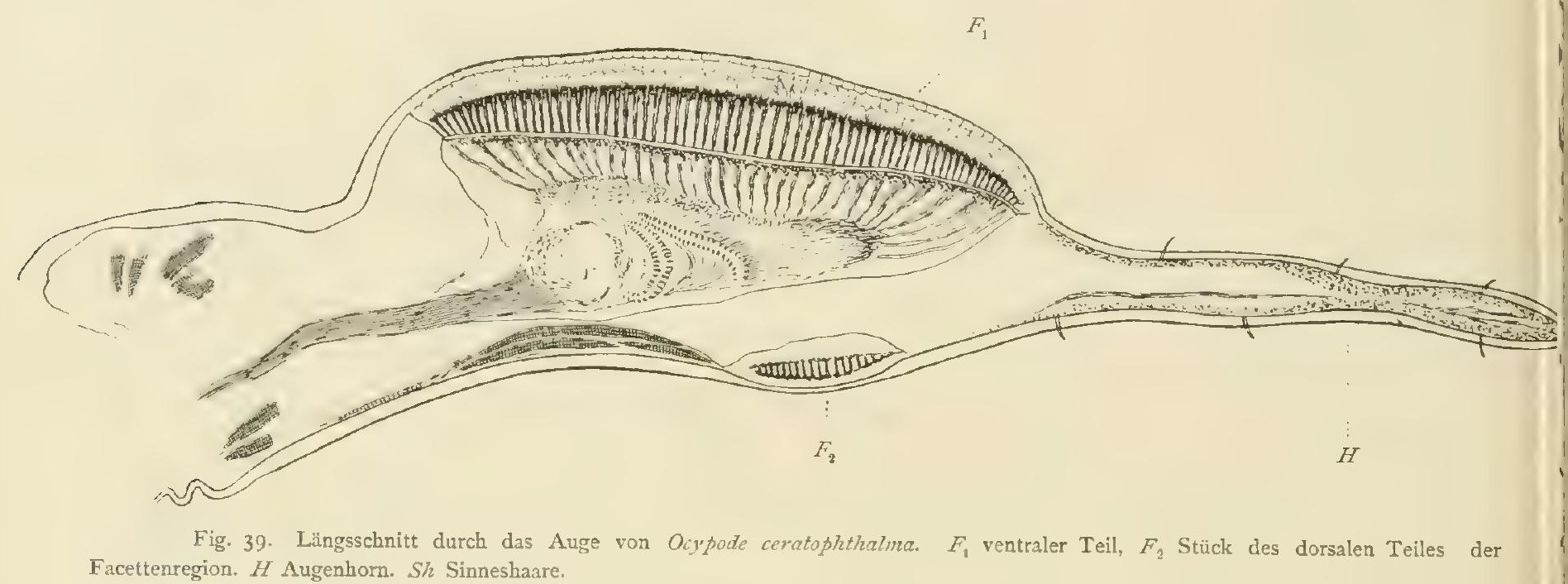

So ist auch das Leben in den lichtarmen oder lichtlosen Regionen der Tiefsee ein Specialfall unter den verschiedenartigen Existenzbedingungen, welche bei den Tieren die Entstehung großer Sehorgane begünstigen.

Daß solche bei den Tieren verschiedenster Abteilungen in der Tiefsee auftreten, dafür haben wir hinreichend Belege: Fische, Cephalopoden und vor allem Crustaceen zeigen diese Erscheinung. Bei den Brachyuren sind es vorwiegend die gut beweglichen flinken Formen, welche stark vergrößerte Augen haben: Geryon-Arten, Platymaia u. S. w. Das stimmt mit den Erfahrungen in den anderen Crustaceengruppen überein: die höchstentwickelten Augen von dem bedeutendsten Umfang, noch größer als bei den erwähnten Bodenbewohnern, haben pelagische Formen, also solche, denen die größte - wenn auch passive - Beweglichkeit zukommt.

Chun (1 894) hat in seiner Atlantis-Arbeit die riesigen Augen der pelagischen Schizopoden und Sergestiden beschrieben. Bei ihnen finden wir die Augen noch dazu in zwei Abschnitte, ein Front- und ein Seitenauge geteilt; das stellt nach seinen scharfsinnigen Darlegungen einen bedeutenden Vorteil für das in der lichtarmen Tiefe schwebende Tier dar. Stark vergrößerte Augen haben auch pelagische Amphipoden: die Plwonima-Arten schließen sich mit ihrem ebenfalls zweigeteilten Auge den Schizopoden an, und die höchste Ausbildung wird wohl bei dem seltsamen Cystisoma Neptıni Willex. erreicht, dessen ungeheure Augen fast ein Drittel der Oberfläche des Tieres bedecken.

Auch unter den Insekten sind die Formen mit den größten Augen, z. B. Libelluliden, die beweglichsten Formen, und auch die oben erwähnten Ocypoden gehören zu den raschesten 
Krabben. So müssen wir denn schließen, daß mehr Bewegungsbedürfnis als der Lichtmangel der Umgrebung die Größe der betreffenden Augen bedingt.

Ich habe in meiner vorläufigen Mitteilung Andeutungen gemacht über Erklärungsmöglichkeiten, welche diesen teleologisch verständlichen Zusammenhang einer hausalen Betrachtungsweise zugänglich machen sollen. Ich ging dabei von der Großäugigkeit bei Gammariden in halbdunklen unterirdischen Räumen und bei den sogenannten Kloakenaalen aus. Es ist unnütz, auf diese Erläuterungsmöglichkeiten einzugehen, ehe nicht die von mir begonnenen Experimente zn einem positiven oder negativen Resultat geführt haben.

Auch der feinere Bau des Auges zeigt allerorts Beziehungen zur Lebensweise.

Die Veränderungen des optischen Apparates bei Tiefseeformen bestehen meist in einer Vergrößerung des Querdurchmessers von Corneafacette und Krystallkegel. Die Folge davon ist eine gesteigerte Lichtstärke des Systems. Bei den Formen, deren Augen in ihrer Gesamtausdehnung nicht vergrößert sind, wie wir das bei Phy'sachacus, Trichopeltarium etc. sahen, führt die Größe der einzelnen Augenkeile dazu, daß das Auge nur eine geringe Anzahl von Augenkeilen umfaßt. Es ist das eine Erscheinung, welche wir bei zahlreichen Tieren mit Facettenaugen, welche lichtarme Regionen bewohnen, wiederfinden. CHUN hat die geringe Anzahl und Größe der Augenkeile bei den Frontaugen von pelagischen Tiefsee-Schizopoden, bei den monströsen Augen von Arachnomysis Leuckarti, Brutonysis Vogti und anderen Formen nachgewiesen. Längst ist schon die Größe und geringe Anzahl von großen Facetten bei den in Höhlen lebenden Käfern, z. B. der Gattungen Trechus und Bythimus, bei denjenigen Arten, deren Augen nicht vollkommen rudimentär sind, beobachtet worden. Bei ihnen wurden nur $60-80$ Facetten gezählt.

Auch bei Decapoden, welche nicht in der Tiefsee wohnen, kommen facettenarme Augen vor. Bei den meisten der in Betracht kommenden Arten sind sie noch nicht untersucht. Stets wird aber ein Zusammenhang mit der Lebensweise festzustellen sein. Pinnotheres tridacnae RüPP. z. B., dessen Auge in Textfigur 37 auf S. 226

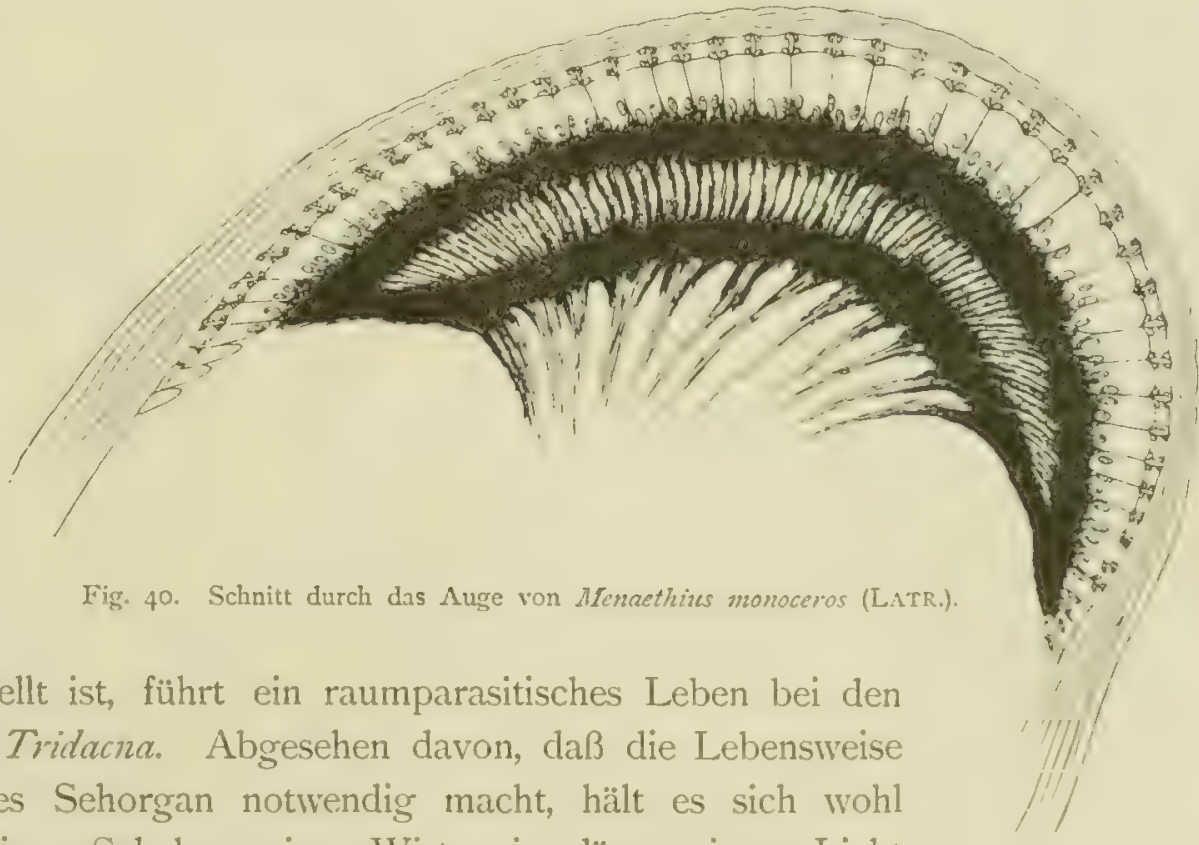
in einem Querschnitt dargestellt ist, führt ein raumparasitisches Leben bei den Riesenmuscheln der Gattung Tridacna. Abgesehen davon, daß die Lebensweise des Tieres kein kompliziertes Sehorgan notwendig macht, hält es sich wohl zumeist zwischen den gewaltigen Schalen seines Wirtes in dämmerigem Licht auf. Doch bei dessen Aufenthaltsort in der Region der Korallenriffe, wo starkes Sonnenlicht das IVasser durchflutet, bedarf das Auge einer sehr starken Pigmententwickelung, welche das Auge in auffälliger Weise von den übrigen betrachteten Augen mit wenig Facetten unterscheidet (Textfig. 37 u. 38). 
Was das Pigment in den Augen der Brachyuren anlangt, so muß ich wiederholen, daß ich bei keiner Form, aus einer Wassertiefe von ca. $50 \mathrm{~m}$ an, ein so tiefschwarzes und reichliches Pigment fand, wie es bei den litoralen Formen vorkommt. Die Textfigur 40 stellt einen Schnitt durch das Auge der auf Korallenriffen in geringer Tiefe häufigen Krabbe Menaethius monoceros Latr. dar; die Abbildung soll den Vergleich mit den pigmentarmen Formen des tieferen Wassers ermöglichen und giebt gleichzeitig ein Bild von der Anordnung des Pigmentes bei Tageslicht im Auge eines solchen Tagtieres.

Wir erinnern uns daran, daß wir bei den pigmentreichsten Augen von Tiefseekrabben das Pigment stets in Nachtstellung fanden. Diese Eigenschaft teilen also die Tiefseekrabben mit denjenigen Formen der Strandregion, welche darauf angewiesen sind, bei Nacht oder in der Dämmerung zu sehen. Nur sahen wir, daß bei den Formen des tiefen Wassers das Pigment in der Nachtstellung fixiert, unbeweglich geworden zu sein scheint. Es stimmt dies mit den Beobachtungen überein, welche CHUN bei Schizopoden gemacht hat.

Die für die Wahrnehmung von Appositionsbildern geeigneten Augen von Tagtieren werden abends durch Pigmentverschiebung in Augen verwandelt, welche geeignet sind zum Wahrnehmen von Superpositionsbildern. Bei vielen bodenbewohnenden Krabben der Tiefsee und bei den Dämmerungsschwebformen unter den Schizopoden und Decapoden finden wir das Auge dauernd zur Wahrnehmung von Superpositionsbildern eingerichtet ${ }^{1}$ ). Dem entsprechen weitere Anpassungen, besonders die Verlängerung der Stäbchen und die Verschiebung der lichtwahrnehmenden Teile in größere Entfernung von den bildentwerfenden Bestandteilen des Auges.

Aehnliche Verlängerung können wir auch an den spindelförmigen Stäbchen einer Anzahl von litoralen Formen, deren Pigment verschiebbar ist, nach den Abbildungen und Beschreibungen von Exner (189i) und Rosenstadt (1896), erkennen. Sie finden sich bei Arten von Pagumus, Galathea, Dromia, Portunzus, Pisa etc. etc. Von einer ganzen Reihe dieser Formen ist bekannt, daß sie eine vorwiegend nächtliche Lebensweise führen. Auch bei einer Anzahl von Nachtschmetterlingen sind ähnliche Einrichtungen bekannt geworden: bei Catocala mpta, Lasiocampa quercifolia u. a. Freilich sind bei all diesen Formen die Einrichtungen nicht von der gleichen Vollkommenheit, wie sie uns insbesondere bei den pelagischen Tiefseetieren entgegentreten.

Um gleich hier das Vorkommen von Tapetum zu behandeln, so sei hervorgehoben, daß dessen Besitz wiederum vielfach Tiefseeformen und Nachttieren des Flachwassers gemein ist. Unter letzteren finden wir es vielfach bei den gleichen Formen, von denen eben die Rede war. Auch bei Tieren aus ca. 50-100 m Tiefe, deren Gewohnheiten wir nicht kennen, ist es vielfach konstatiert. Das Vorkommen von Tapetum ist ja eine längst bekannte Erscheinung bei landbewohnenden Nachttieren, bei nächtlichen Raubtieren, bei Nachtvögeln ebenso wie bei Nachtschmetterlingen. Wir haben oben, auf S. 22 I u. 222, den Effekt des Tapetums ausführlich behandelt.

Wir haben schließlich bei einer Anzahl von Tiefseebrachyuren pigmentlose und rudimentäre Augen konstatiert, und haben gefunden, daß rudimentäre Augen stets pigmentlos oder sehr pigmentarm waren. Wir haben oben gesehen, daß Pigmentlosigkeit nicht ohne weiteres das Auge funktionslos machen muß, und wir kennen eine Anzahl von Fällen, in denen

I) Dasselbe gilt nach Beobachtungen, die ich neuerdings machen konnte, für die Augen von pelagischen Amphipoden aus verschiedenen Familien. 
die Augen zwar pigmentlos sind, aber sicherlich funktionieren. Ich erinnere nur an die Augen von Albinos. IVenn wir aber von Formen absehen, bei denen das Auge infolge der katoptrischen Bildentstehung keines nder eines sehr gering entwickelten l'igmentes bedarf, so finclen wir den Pigmentmangel nur bei Tieren unter solchen Lebensbedingungen, unter denen wir auch Tiere mit mehr oder minder vollkommen rudimentären Augen antreffen.

So hat R. Schneider (1885) in den Klausthaler Gruben eine Varietät von Gammamus pulex mit pigmentlosen Augen gefunden; in Höhlen vorkommende Arten von Cambarıs und Troglocaris Schmidti Dorm. haben pigmentlose Augen. Ihnen schließen sich die in Höhlen lebenden Käfer an, besonders die zahlreichen Trechus-Arten mit pigmentlosen Augen. Aehnliches gilt für Tiere, welche in der lichtlosen Region unserer tieferen Süßwasserseen vorkommen. So hat Hofer (1899) eine neue Varietät cacca von Cyclops viridis aus der Tiefe des Bodensees beschrieben.

Unter den Malacostraken der Tiefsee kennen wir aus allen Abteilungen Formen mit pigmentlosen Augen: Macruren, Cariden, Galatheiden sind schon durch die früheren Expeditionen bekannt geworden, und was ich bisher von den Galatheiden und Paguriden der deutschen Tiefsee-Expedition studieren konnte, bestïtigt diese Erfahrungen in ausgectehntem Mafie.

Alle die bis jetzt besprochenen Augenformen zeigten, von außen betrachtet, eine deutliche Facettierung der Cornea: ein äußerliches Anzeichen davon, daß die Augenkeile in voller Ausbildung erhalten waren und daß sich die Rückbildung nur auf das Pigment bezog. IVir haben aber bei den Brachyuren auch einige Formen kennen gelernt, bei denen keine Corneafacetten und keine Krystallkegel vorhanden waren, und konnten am nervösen Teil des ursprünglichen Auges verschiedene Stufen der Rückbildung erkennen: wir sahen derartiges bei Cyclodorippe uncifera glaucomma ALC. und bei Cymonomes granulatus (Norr.).

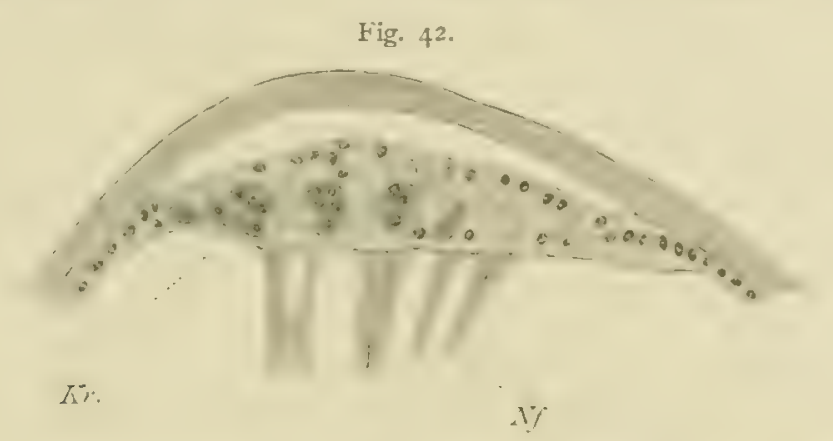

Fig. 4r. Schnitt durch das Auge von Cambarnes pellacidues Tellk. (Nach PARKER). G.o. Ganglion opticum.

Fig. 42. Distales Ende des Auges in Fig. 41. Stärker vergrößert. I Reste der Krystallkegel. Nf Nervenfasern. (Nach PARKER.)

Rudimentierung und Verlust der Sehorgane konstatieren wir bei verschiedenen Gruppen von Tieren: wir finden sie sehr ausgesprochen bei Parasiten, ebenso bei Tieren, welche unter

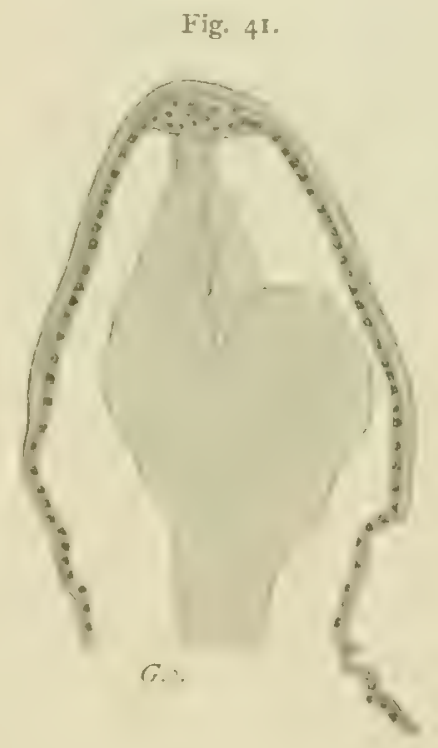
der Erde oder im Schlamm wühlen.

Die gleiche Erscheinung finden wir im ausgebildetsten Maße bei Höhlentieren. Vom $\mathrm{O} l \mathrm{~m}$ bis zu den Planarien finden wir hier die Einflüsse des Lichtmangels am Sehorgan ausgeprägt. Um nur die Formen mit Facettenaugen zu behandeln, so sind die zahlreichen Höhlen- 
käfer mit rudimentären oder fehlenden Augen schon wiederholt erwähnt worden: Trechus, Bathy'scia, Bythinus etc. etc.

Besonders bemerkenswerte Formen sind von Malacostraken Asellus cavaticus und Gammamus puteanus. Bei beiden Formen sind die Augen vollkommen rudimentär, bei Gammarus puteanus ist wohl das dem Gehirn ansitzende Ganglion opticum noch sichtbar, aber es fehlt jede Spur von Corneafacetten, Krystallkegeln, Stäbchen und Pigment.

Ebenso ist merkwürdigenweise das Ganglion opticum noch erhalten bei der blinden Cambarus-Art, welche PARKer (1890) untersucht hat. Wir ersehen dies aus den beistehenden Abbildungen, welche ich aus seiner Arbeit kopiert habe. Der mächtige Sack in Textfig. 4 I ist der Ganglienkomplex. In Textfig. 42 ist das distale Ende des Auges, zu dem noch einige Nervenfasern vom Ganglion opticum aus hinziehen, stärker vergrößert. PARKER hat die mehrere Kerne umfassenden Bildungen, welche in der Figur etwas dunkler getönt sind, für die Reste der Krystallkegel gehalten. Nach meinen Erfahrungen an Cyclodorippe uncifera sind es vielleicht eher die Reste der Stäbchen. Dies würde im Zusammenhang mit anderen Beobachtungen dafür sprechen, daß die Rückbildung von der Peripherie gegen das Centralorgan fortschreitet.

Für Tiefseeformen ist das Rudimentärwerden der Augen ebenfalls für Tiere der verschiedensten Abteilungen bekannt. Doch ist auch hier noch kaum untersucht, was eigentlich rudimentär wird, ob noch brauchbare Lichtperzeptionsorgane irgendwelcher Art vorliegen, und welche Stufen beim Rudimentärwerden durchzumachen sind.

Schon die ersten Untersucher von Tiefsee-Crustaceen sind auf die rudimentären Augen aufmerksam geworden, Sars, Wyville Thonson, Norman und andere erwähnen die Thatsache, und ihre zum Teil recht fragmentarischen Bemerkungen haben hundertfältige Verwertung bei Spekulationen gefunden, aber keine einzige exakte Untersuchung zur Folge gehabt. Ich kann daher nicht auf die vielen Litteraturstellen eingehen, an denen die Augen von Tiefseetieren citiert werden. Es würde für unseren Zweck auch gar keinen Wert haben.

So führe ich denn im Nachfolgenden nur diejenigen Autoren an, welche eine thatsächliche Bereicherung unserer Kenntnis rudimentärer Augen bei Tiefsee-Crustaceen bewirkt haben. Bei dem Umfang der durchzusehenden Litteratur und bei der Art und Weise, in der die gelegentlichen Notizen oft versteckt untergebracht sind, kann ich nicht dafür bürgen, auch nur annähernd alle Litteraturstellen, die hıer von Nutzen sein könnten, aufgefunden zu haben.

v. WrLEnoes-Sum hat in seinen Briefen von der "Challenger"-Expedition, sowie in den Arbeiten, welche er während der Reise vollenden konnte, besonders in derjenigen über die atlantischen Formen (1875) immer wieder seinem Erstaunen über die zahlreichen blinden Formen Ausdruck gegeben und von manchen Formen die äußere Beschaffenheit der Augenrudimente beschrieben.

In der Folge haben denn auch die Bearbeiter des „Challenger"-Materiales bei den einzelnen Arten die Rückbildungen, unter Hervorhebung der Tiefe, aus welcher die Tiere stammten, beschrieben, aber stets nur nach äußerlicher Untersuchung. Insbesondere haben BATE (I 888) und SARs (I885), ersterer für die Macruren besonders der Gattungen Thanmastocheles, Pentacheles, Polycheles, Willemoesia u. S. w., letzterer für gewisse bodenbewohnende Schizopoden, den Einfluß des Aufenthaltes in der lichtlosen Tiefsee auf die Rückbildung der Augen 
betont. Sie haben eine Reihe von interessanten Formen beschrieben, bei welchen sie rudimentïre Augren fanden; bei manchen Formen ist nur Pigmentlosigkeit konstatiert worden, bei anderen Fehlen der Cornea, Umgestaltung des Augenstieles und schließlich vollkommenes Fehlen des letzteren; so deuten z. B. bei Thaumastochcles zalumors WVir..Fm. nur 2 Gruben die Stellen an, wo das Auge bei anderen Formen sitzt.

Zur selben \%eit veröffentlichte S. Sirmi (г 886) im Anschluß an die Untersuchungen des „Albatross“ eine Studie über die Tiefsee-Decapoden des Nordatlantik. Außer vielen interessanten Daten über die Verbreitung und Biologie der vom "Albatross" gedredgten Arten giebt er auch einen Ueberblick über die an den Augen festgestellten Eigentümlichkeiten. Auch Surm betont die große Verschiedenheit im Aussehen der Augen bei den verschiedenen Formen; er fand alle Etappen von vergrößerten, gut entwickelten Augen bis zu vollkommen rudimentïren. Und zwar fand er die Formen mit gut entwickelten Augen in den großen Tiefen, während die Arten mit den am meisten rudimentären Augen in weniger als $1600 \mathrm{~m}$ Tiefe leben. Er ist nun der Ansicht, daß wahrscheinlich trotz der entgegengesetzten Meinung der Physiker Lichtschwingungen in Tiefen bis zu $3000 \mathrm{~m}$ vordringen. Die Unterschiede in der Beleuchtung des Meereshodens sind nach seiner Ansicht nicht nur durch die absolute Tiefe bedingt, sondern auch durch die Entfernung rom Festland. Er meint, in das reinere Wasser inmitten des Oceans möge ebensoviel Licht bis zu $3000 \mathrm{~m}$ Tiefe eindringen, wie in dem getrubten Wasser in der Nähe des Landes in Tiefen von 800 oder selbst $350 \mathrm{~m}$. So, meint er, sei es erklärlich, daß die Augen von Exemplaren des Parafagums pilosimamus in einer Tiefe ron $4000 \mathrm{~m}$ nicht merkbar verschieden seien von solchen aus $450 \mathrm{~m}$ Tiefe.

Die hauptsächlichen Veränderungen, welche er bei den Bewohnern der Tiefe auffindet, sind folgende:

1) Er findet, daß die verschiedenen Formen Stufen einer allmählichen Rückbildung darstellen, indem die Zahl der "Sehelemente" gradweise abnimmt; bei manchen Formen resultieren rudimentäre. Augen und in manchen Fällen fehlen die Augen sogar vollständig. So sieht er eine Reihe von Formen von Geryon quinquedens und Lithodes Agrssizii mit ihren stark vergrößerten, dunkel pigmentierten Augen bis zu Ethusina abyssicola mit ihren zwar pigmentierten, aber augenkeilarmen und unbeweglichen Augen. Am äußersten Ende seien dieser Reihe anzuschließen Formen wie Cymonomus, denen die Augenkeile vollkommen fehlen. Er hebt ferner hervor, daß bei nahe verwandten Formen aus verschiedenen Tiefen nicht selten diejenigen des tieferen Wassers die kleineren Augen besitzen; z. B.

$\begin{array}{lr}\text { |Sympagumes pichus } & 300-480 \mathrm{~m} \\ \text { |Parapagumes pilosimanus } & 468-4000 \mathrm{~m} \\ \text { |Pontophihus gracilis } & 400-825 \mathrm{~m} \\ \text { |Pontophihus aby'si } & 3500-4000 \mathrm{~m} \\ \text { |Nematocarcimus cursor } & 700-1500 \mathrm{~m} \\ \text { |Nematocarcinus cusiferus } & 1000-3700 \mathrm{~m}\end{array}$

2) Er findet bei viclen 'Tiefseeformen das Augenpigment statt schwarz dunkel purpurn, brïunlich, rötlich, hell purpurn, hell rötlich und selbst fast farblos, wobei die Zahl der Augenkeile („Sehelemente") groß oder klein sein kann. Als Beispiele großer buntpigmentierter Augen führt 
er an: Glyphocrangon und Benthonectes. Oft sind die blaßpigmentierten Augen auch arm an Augenkeilen, z. B. bei Parapasiphaë sulcatifrons. Parapasiphaë cristata, Acanthephyra microphthalma sowie bei den Arten von Hymenodora.

3) Er macht darauf aufmerksam, daß die Augen manchmal ziemlich groß sein können, dabei aber in der feineren Struktur (nach äußerlicher Prüfung!) die weitest gehenden Rückbildungen aufweisen können. So ist er der Ansicht, daß die Augen von Glyphocrangon, die zivar groß, aber sehr kurz gestielt sind, offenbar in Anpassung an das Sehen im tiefen Wasser, der Anfang einer Reihe von Rückbildungen sind, die darin gipfeln, daß der Augenstiel zum Träger eines ganz anderen Sinnes wird. Er hält Pontophilus aby'ssi für eine weitere Etappe: die Augen, die ebenso groß sind wie bei den verwandten Flachwasserformen, sind fast farblos, nicht sehr deutlich facettiert und haben wahrscheinlich an einem Teil der Oberfläche die normalen Augenkeile eingebüßt. Bei den Augen einiger Munidopsis-Arten sind die Augenkeile vollkommen verschwunden, und hinter der glatten durchsichtigen Cornea sieht man ein weißliches Pigment (Tapetum? Anm. des Verf.) und besonders geartete Nerven. Daß diese Organe nichts anderes seien als auf einem frühen embryonalen Stadium stehen gebliebene und funktionslose Augen, hält er nicht für wahrscheinlich, da bei manchen Arten dieselben ebenso groß seien wie die normalen Augen verwandter Flachwasserformen. Für noch unwahrscheinlicher hält er die Annahme der Funktionslosigkeit bei den Pentacheles-Arten, denn in dieser Gattung sind sie zwar unter die Stirn zurückgezogen, diese hat aber einen Ausschnitt, um sie hervorragen zu lassen.

Schließlich hebt er die interessante Thatsache hervor, daß die so sehr abgeänderten (angepaßten) Augen von Pentacheles sich in einer geschlossenen Gruppe finden, deren sämtliche Angehörige wohl seit langen geologischen Zeiten Tiefseebewohner seien. Dagegen seien die Formen, deren Augen weniger angepaßt oder rudimentär seien, Verwandte von Flachwasserformen und wohl erst in geologisch neuerer Zeit in die Tiefsee eingewandert.

Milne-Edwards und Bouvier (I892) haben bei den von ihnen untersuchten Paguriden zwar viele Formen mit sehr großen oder mit normalen Augen in der Tiefsee gefunden, aber nur eine Form mit rückgebildeten Augen: Catapaguroides microps, welche nicht zu Tiefen von weniger als $960 \mathrm{~m}$ aufsteigt. Sie sehen die Ursache dieser guten Ausbildung der Sehorgane bei den meisten Tiefseepaguriden in dem Vorhandensein von Phosphorescenzlicht in der Tiefe; ich entnehme ihren Darstellungen, daß ihnen die Idee eines diffusen Lichtes, das, von den Leuchtorganen zahlloser Organismen ausgehend, die Tiefe des Meeres ähnlich erleuchtet, wie das Meerleuchten die Oberfläche, plausibel erscheint.

In einer späteren Studie über die Galatheiden (I894) kommen dieselben Autoren auf diese Vorstellung zurück, um zu erklären, wie es kommt, daß in dieser formenreichen Abteilung neben den blinden Formen solche mit hoch entwickelten und sehr großen Augen in der Tiefsee vorkommen. Sie heben hervor, daß die Galathea-Arten normale, gut entwickelte Augen besitzen: sie bewohnen das seichte Wasser. Bei den Arten von Pleuroncodes und Mumida aus mittleren Tiefen finden wir sehr vergrößerte Augen. In den großen Tiefen (900-rgoo m und noch tiefer) finden wir in den Gattungen Galacantha, MInmidopsis, Galathodes, Elasmonotus und Orophorhynchus alle Beispiele von Augenrückbildung. Aber neben ihnen leben Diptychus-Arten mit wohlentwickelten Augen, welche damit sich den oben erwähnten Paguriden an die Seite stellen. 
Zur Erklïrung dieser Thatsache benutzen die Verfasser das, was wir von der Lebensweise der verschiedenen Formen bisher wissen. Die Galat thein en halten sich unter Steinen und in Felsenspalten auf; die Diptychinen dagregen, mit Ausnahme von Eumunidu, leben auf dem Boden, an den verzweigten Kolonien von Hydroidpolypen und Korallen angreklammert. Je nach der Lebensweise seien nun die verschiedenen Formen in verschiedener Weise dem Einfluß des Lichtes, sei dies nun das Sonnenlicht oder das Phosphorescenzlicht der Tiefsee, ausgesetzt. Die Galatheinen und Porcellaninen auf der cinen Seite, die Diptychinen auf der anderen Seite haben normal entwickelte Augen, weil sie beide eine genügende Lichtmenge erhalten; bei clen Galatheinen und Porcellaninen, welche die Litoral- und Sublitoralregion bewohnen, ist es das Sonnenlicht, welches abgeschwächt in ihre Löcher vordringt, bei den kletternden D ip ty ch i n e $n$ ist es das direkt von außen kommende Licht oder das ron den phosphorescierenden Tieren erzeugte. Die Mnnida- und Eumnuida-Arten haben mehr angepaßte Augen infolge ihres mehr rerborgenen Lebens, obwohl sie in denselben Tiefen vorkommen wie die letztgenannte Unterfamilie, Tiefen von ca. $400 \mathrm{~m}$. Geht man in noch größere Tiefen, so soll nach MruxEEdwards und Bouvier nur noch die Phosphorescenz als Lichtquelle dienen; sie nehmen an, daß das Licht ein ziemlich starkes ist in den mittleren Regionen, wo sehr viele Tiere zu seinem Zustandekommen beitragen. In größeren Tiefen nimmt es mit dem Reichtum der Formen ab, um in Tiefen von $4000 \mathrm{~m}$ nur mehr ganz schwache Wirkung zu iußern. Dies schwache Licht kann noch den vagabundierenden Paguriden und kletternden Diptychinen nützlich scin, nicht aber den verborgen lebenden Galatheinen, insbesondere der Gattungen Galacantha, Munidopsis, Galathodes, Elasmonohes, Orophorhynchus.

Diese zeigen entweder Verkleinerung des Augenstieles und der Facettenregion, oder eine Atrophie der Augenkeile, der erstere seltnere Fall zeigt sich schon bei Thunida microphthalma aus I600 m Tiefe, ganz kleine Facettenregion findet sich bei gewissen Mrunidopsis und Elasmonotus.

Bei Arten von Munidopsis zeigen sich nun auch Reduktionen der Sehelemente, die Augen verlieren mehr und mehr ihre Funktion, dabei werden die Augenstiele ganz kurz und unbereglich. Schließlich verwachsen sie mit dem Rostrum; dabei hat sich, ähnlich wie wir das bei Brachyuren sehen, bei einigen der Formen das dorsale Augenhorn mehr und mehr verlängert und trägt als spitzer Stachel nach Ansicht der Autoren zur WVehrhaftigkeit des Tieres bei. Verschiedene Stufen dieses Vorganges reprisentieren die Arten: Mnmidopsis robusta, Munidopsis spinoculata, Elasmonotus squamosus, MTunidopsis Antoni, Orophorynchus Marionis, O. Parfaiti, O. lividus. Ich verzichte darauf, diese interessanten Befunde von Mirne-EDWARds und Botvier hier durch Abbildungen aus ihren Werken zu erlåutern, da ich bei Bearbeitung der Gralatheiden der deutschen Tiefsee-Expedition doch darauf werde eingehen müssen.

Alcock, der verdienstvolle Naturforscher, welcher in Indien die Ergebnisse der Vermessungsfahrten des "Investigator" der Wissenschaft zugänglich machte, hat eine Unmengu von Notizen über die Lebensweise der von ihm beschriebenen Formen in seinen systematischen Publikationen niedergelegt (I894-I902, nachdem WOOD-MASOx schon I887 mit ähnlichen Publikationen begonnen hatte). Es ist unmöglich, alle Notizen, welche sich auf Augen von Tiefseeformen beziehen, an dieser Stelle zu erörtern. Doch hat er selbst (AI_cock 1902) eine populïre \%usammenfassung seiner Ergebnisse verfaßt, auf welche wir uns bezichen können. Er 
hat uns eine Unmenge neuer Illustrationen der schon bekannten Gesetze kennen gelehrt, ohne daß jedoch wesentlich neue Gesichtspunkte sich ergeben hätten. Auch er bestätigt, daß in den Tiefen von $500-700 \mathrm{~m}$, wo eine tiefe Dämmerung herrschen muß, Formen mit großen, dunkel pigmentierten Augen vorwiegen: Nephrops andamanica, Chlaenopagumis Andersoni, Pylocheles Miersii, Psopheticus stridulans, Mnunida andamanica. Doch fand er auch in den tieferen Regionen Formen mit riesigen, dunkel pigmentierten Augen und führt dies auf das Vorhandensein von Phosphorescenzlicht zurück. Besonders bei den Paguriden denkt er sich den Zusammenhang so, daß die auf den Schneckenschalen sitzenden Anthozoen Leuchttiere seien und so transportable Lichtquellen darstellen.

Ferner konnte er unter den Tiefseebewohnern auch eine große Anzahl von Formen mit rïckgebildeten Augen auffinden, und zwar sowohl unter den offenbar wühlenden Formen als auch unter den frei sich bewegenden. Sogar eine Paguride mit rückgebildeten Augen kann er anführen, Parapylocheles scorpio: es ist dies allerdings eine Form, welche wahrscheinlich im Schlamm wühlt; das Tier ist symmetrisch gebaut und benutzt keine Schneckenschalen.

Pigmentlose und rudimentäre Augen wurden bei 20 Proz. der vom "Investigator" gedredgten Malakostraken gefunden: Petalophthalmus amiger, Prionocrangon ommatosteres, Plastocrangon caeca, Phobemes caecus, Psalidopus, Pentacheles, Nephropsis, Phoberns sind Beispiele von mehr oder minder weitgehender Verkümmerung. Leider wurden gar keine Untersuchungen des feineren Baues angestellt.

Faxov (1895) macht in seiner Bearbeitung der "Albatross"-Ausbeute von der Westküste von Amerika darauf aufmerksam, daß die Formen mit rückgebildeten Augen wohl diejenigen sind, welche am Boden im Schlamm eingewühlt leben, während die freischwimmenden Formen, wie Penaeiden, Pasiphaeiden, Sergestiden, Gnathophausien, gut entwickelte Augen besitzen. Letztere sind auch mit kräftiger Färbung versehen, während erstere bleiche, blasse Farben aufweisen.

Chun (I896) war der erste, welcher mit modernen Methoden und biologischen Fragestellungen an die Untersuchung des feineren Baues der Augen von Tiefsee-Krustaceen heranging. Seine Untersuchungen erstrecken sich vorwiegend auf pelagische Formen, bei denen er eine Fülle von interessanten Einrichtungen vorfand. Er entdeckte bei diesen die Zweiteilung in Front- und Seitenauge und fand die Erklärung für diese Teilung in der pelagischen Lebensweise der Tiere und in der Art und Weise, wie sie die Lebensverhältnisse, den Besitz von Leuchtorganen u. s. w. ausnützen.

Er stellte fest, daß alle Einrichtungen, welche die Augen dieser Schizopoden und Sergestiden von denjenigen der Litoraltiere unterscheiden, die Erzielung eines möglichst hellen, wenn auch undeutlichen, Bildes zum Zweck haben; daß die Augen, seien sie nun iridopigmentär oder retinopigmentär, hauptsächlich geeignet sind, um Bewegungen wahrzunehmen. Seine Untersuchungen über die Bedeutung der verschieden gestalteten Augenteile für die unter so speciellen Lebensverhältnissen existierenden Tiere haben meiner Bearbeitung vielfach als Grundlage gredient, und ich hatte oben häufig Gelegenheit, auf sie zu verweisen.

Leider hat Chus nur kurze Bemerkungen über seine Untersuchungen an den Augen von bodenbewohnenden Formen veröffentlicht. Er fand bei einer Reihe von Formen ähnlich wie bei den pelagischen Tieren iridopigmentäre Augen, ferner fand er durchweg kugelig gestaltete 
Augen, nie jene teleskopartigen Fortsïtze, welche er an den Facettenaugen der pelagischen Formen kennen gelehrt hatte. Schließlich fand er bei einer Reihe von Formen Tapetum, zum Teil in mäßiger Ausbildung (bei Heterocarpus und Nematocarcinus), zum Teil auch in geradezu monströser Ausbildung (bei Glyphocrangon, Acanthephyra, Pontophilus u. a.).

Ich habe (DorLerN 1903) eine vorläufige Mitteilung veröfentlicht, in welcher ich die Befunde, welche ich hier ausführlich darlege, kurz skizziert habe. Ich zeigte, welche Rückbildungen und Anpassungen am feineren Bau der Brachyurenaugen sich nachweisen lassen, und suchte durch theoretische Erörterungen, auf welche wir unten zurückkommen werden, die Schwierigkeiten, die sich einer Erklïrung der 'Thatsachen entgegenstellen, zu vermindern, und zwar auf Grund der Biologie und Entwickelungsgeschichte der verschiedenen Tiefseeformen.

RAy LANKEster (1903) schließlich hat die verdienstrolle Arbeit unternommen, die viel mißverstandenen kurzen Mitteilungen von Norмax über Cy'monomus granulatus an der Hand des Materiales der "Porcupine“-Expedition zu ergänzen und dessen seit 35 Jahren daliegenden Abbildungen zu veröffentlichen. Eigentlich Neues enthält seine Arbeit nicht; nur ist hervorzuheben, daß er die verschiedenen Cy'monomus-Formen als distinkte Arten beschreibt und einige davon neu benennt. Wir werden im Abschnitt über die Herkunft der Tiefsee-Krabben auf diese Formen zurückkommen, daher will ich an dieser Stelle nicht näher darauf eingehen.

\section{Die Ursachen der Rückbildung der Augen.}

Ueber die Ursachen, welche bei den Augen von Tieren Pigmentlosigkeit und Rückbildung herbeiführen, wissen wir nichts Sicheres. Das Problem, welches diese Erscheinungen uns bieten, ist ein doppeltes: ein biologisches und ein physiologisches, man könnte auch sagen ein teleologisches und ein kausales. Das erstere können wir durch Beobachtung und Statistik lösen, das letztere nur durch experimentelle Forschung.

Zur Erforschung des biologischen Problems haben schon viele Zoologen Beobachtungen beigetragen: ich habe versucht, das WVesentliche aus den Arbeiten früherer Autoren gemeinsam samt den Resultaten meiner Forschungen in den vorhergehenden Abschnitten darzustellen. Und ich hoffe, durch ergänzende Beobachtungen und gewisse Gedankengänge so weit gekommen zu sein, daß man diese Seite des Problems einheitlich auffassen und als Grundlage zur experimentellen Erforschung des physiologischen Problems benützen kann.

Aus der Darstellung des Baues der Augen und seines Zusammenhanges mit der Lebensweise der Tiere ergab sich stets die Abhängigkeit der Ausbildungshöhe des Auges von Licht. Nichts scheint ja so naheliegend wie dieser Zusammenhang, und seit der Zeit Laxarkck's ist immer wieder auf ihn hingewiesen worden. Der Zusammenhang. scheint aber kein so ganz einfacher zu sein, sonst wären nicht so viele Theorien zu seiner Erklärung gemacht worden, von denen keine so einleuchtend war, daß man auf sie exakte Untersuchungen begründete.

Ueberblicken wir die Thatsachen, welche für die Abhängigkeit des Augenpigmentes vom Licht sprechen, so wären zunächst alle jene Tiere zu erwähnen, von denen wir im vorigen Abschnitt hervorhoben, daß sie mit ihren pigmentlosen Augren an dunkeln Orten leben. Ferner wäre anzuführen, daß viele Formen, welche an solchen dunkeln Orten leben, auch das Körperpigment verlieren, vollkommen blaß werden. Dabei ist es besonders interessant, daß die Augen solcher 
Formen manchmal die einzigen pigmentierten Teile am Körper sind, daß diese Organe also die Fähigkeit haben, das Pigment am zähesten zurückzuhalten. Diese Thatsachen gelten nicht nur für Tiere, welche die Tiefsee, Höhlen, tiefe Brunnen, unterirdische Wasserläufe und unsere tiefen Süßwasserseen bewohnen, sondern auch für Parasiten, für Tiere, welche in Holz, Früchten, Erde leben u. s. w:

Wir sehen also einen unzweifelhaften biologischen Zusammenhang zwischen Licht und Pigmentbildung. Ehe wir auf die Frage nach dem physiologischen Zusammenhang eingehen, müssen wir von den weitergehenden Rückbildungen der Augen sprechen; denn wir werden sehen, daß hier der nämliche Zusammenhang besteht.

Wir haben oben (S. 230-232) schon für eine Reihe von Formen diesen Zusammenhaing betont, müssen aber an dieser Stelle einige für unseren Gedankengang besonders wesentliche Formen hervorheben, bei denen repräsentative Formen mit höher ausgebildeten und mit rudimentären Augen bekannt geworden sind.

Wir haben von Cyclodorippe uncifera OrTu. zwei Formen kennen gelernt, welche sich durch fundamental verschiedene Augen voneinander trennen ließen. Während die eine, in geringer Tiefe gefangen, wohlausgebildete Augenkeile mit einer vollständigen Pigmenthülle besitzt, so daß sich bei dem untersuchten Exemplar sogar Tagstellung des Pigmentes nachweisen ließ, zeigen die Exemplare aus größerer Tiefe außer der Pigmentlosigkeit jene starke Rückbildung, welche auf S. I 56 beschrieben worden ist.

Die verschiedenen Formen der Gattung Cymonomns, deren gegenseitiges Verhältnis im Abschnitt über die Herkunft der Tiefseefauna weiter unten noch behandelt werden wird, zeigen ebenso eine Abhängigkeit ihrer Augenbildung vom Ort ihres Vorkommens. Die umstrittenen Darstellungen Normann's hat neuerdings Ray LANkester (I903) bestätigt und ergänzt. Alle Formen haben rudimentäre Augen, dabei sind aber diejenigen der südlichen Exemplare, welche in seichterem oder, wenn in tieferem, wie ich vermute, in durchsichtigerem Wasser vorkommen, weniger stark degeneriert als diejenigen der nördlichen Tiefseeform. Während bei den ersteren eine deutliche, allerdings nicht in Facetten geteilte Cornea, Reste von Stäbchen, ja eventuell noch mehr Reste eines wohlorganisierten Auges sich finden, sind bei der nördlichen Tiefseeform alle Reste von optischen und nervösen Augenteilen verschwunden. Die Augrenstiele sind zu knorrigen, stacheligen Gebilden geworden, welche an der Basis noch dazu miteinander verwachsen und unbeweglich sind. Sie ragen an der Stelle des bei dieser Form viel kleineren Rostrums vor. Einerlei nun, wie die Formen sich zu einander verhalten mögen, wir haben jedenfalls eine Form des helleren und warmen und eine Form des dunkleren und kalten Wassers. Ich werde unten darauf $z u$ sprechen kommen, da $\beta$ die niedere Temperatur des Wassers bei diesen Zusammenhängen wohl zu beachten ist.

Schließlich kennen wir noch eine dritte Brachyure, deren Augen je nach der Tiefe ihres Fundortes eine verschiedene Ausbildung besitzen. Bathyplax typhlus A. M.-E. hat im seichten Wasser auf dem kurzen Augenstiel eine kleine, aber deutliche und dunkel pigmentierte Facettenregion aufzuweisen. In Tiefen von $700-800 \mathrm{~m}$ jedoch findet man das Tier mit sehr kurzen Augenstielen ohne Entwickelung einer Cornea; jedenfalls ist kein Pigment zu erkennen.

In einigen anderen Fällen hat man bei Crustaceen beobachten können, daß von einer Gattung in den verschiedenen Tiefen einander vertretende Formen vorkommen, die man nicht 
zu einer Art rechnen kann, die immerhin einander nahe stehen. So lebt die Isopoden-Fattung Serolis in dem antarktischen Gebiet vom Seichtwasser bis zu großen Tiefen hinab (citiert nach W WLTER I 893):

"Serolis Schylei findet sich von 7-128 m. Sie besitzt große, wohlentwickelte Augen, welche stark aus dem Kopfschild hervortreten.

Serolis bromleyana lebt von $730-3600 \mathrm{~m}$, ihre Augen sind klein und rückgebildet.

Serolis gracilis wurde in $1230 \mathrm{~m}$ Tiefe in mehreren Exemplaren gefischt. Zwei Stücke glichen in ihrer Augenentwickelung der S. bromleyana, ein Exemplar hatte noch stïrker verkümmerte Augen, während ein drittes verschwindend kleine, degenerierte Augen besaß.

Serolis antartica lebt ron $7,30-2920$ m und ist vollkommen blind."

Diese Thatsachen, zusammengenommen mit der Erfahrung, daß man an lichtlosen Orten immer bei einigen der Tierformen rudimentäre Augen findet, weisen so klar auf eine direkte Abhängigkeit vom Licht hin, daß wohl niemand an ihr zweifeln würde, stände dem nicht die Erfahrung gegenüber, daß in der Tiefsee neben Formen mit rückgebildeten Augen fast noch mehr Formen mit normal aussehenden oder gar höher angepaßten Augen vorkommen.

Konsequente Darwinisten, wie besonders WrISMANw, erblicken in dieser zwiefältigen Entwickelung der Sehorgane ron Tiefseetieren, ein schwerwiegendes Argument für die Selektionstheorie. Die höher angepaßten Augen ließen ihre Entstehung nach dem üblichen Schema auf Variation und Auslese zurïckführen, während zur Erklärung der rudimentären Organe das Prinzip der Panmixie herangezogen wurde. Panmixie, d. h. Aufhören der Thätigkeit der Auslese, führt nach WEIswans zu einer stufenweisen Degeneration der Organe, welche nicht durch die stets wirkende Auslese auf ihrer Höhe erhalten werden. Später zog er noch die Theorie der Germinalselektion zur Erklärung mit heran, nach welcher die Determinanten funktionierender Organe als die besser ernährten im Kampf der Teilchen die Oberhand gewinnen; die Determinanten funktionsloser Organe sind benachteiligt, werden ausgemerzt, und so müssen die durch sie determinierten Organe verschwinden.

Abgesehen von den Einwänden, welche diese Theorien im allgemeinen treffen, ist für die hier behandelte Fragre hervorzuheben, daß durch sie nicht erklärt ist, warum gerade bei einer Form eine höhere Anpassung, bei der anderen Rückbildung eintrat.

Von den biologischen Verhältnissen ausgehend, haben Faxon (1895) und Milne-Edwards und Bouvier (1894) uns einen Einblick in diese Abänderungen zu verschaffen gesucht. Beide heben hervor, daß die Lebensweise einen entscheidenden Einfluß haben muß, indem die bewerlichen Formen angepaßte Augren brauchen, welche die im Schlamm wühlenden oder angeklammert lebenden Formen enthehren können. Mrixe-EDwarts und Bouvier heben ferner die Wirksamkeit des Phosphorescenzlichtes in der Tiefe hervor, wie wir oben S. $234-235$ sahen. Aber auch diese Anschauung kann nicht vollkommen befriedigen. Viele der Formen mit rudimentären Augen haben durchaus nicht das Aussehen von Tieren, welche im Schlamm wühlen. Ferner bleiben solche Fälle, wie wir sie soeben geschildert haben, in denen graduelle Verschiedenheiten je nach dem Vorkommen der Tiere sich konstatieren ließen, unerklärt. Ueberhaupt verweist uns diese biologische Erklärung für die kausale Begründung der Ėrscheinung vollkommen auf die Selektionstheorie. Ich bin zwar weit davon entfernt, die Wirksamkeit der Selektion rollkommen zu leugnen, aber ich wende sie nicht gern als Erklärungsprinzip an, ehe nicht alle 
anderen kontrollierbaren Erklärungsmöglichkeiten erschöpft sind; denn die Entstehung einer Tierform durch Selektion können wir experimentell oder durch sonstige naturwissenschaftliche Methoden nicht prüfen.

Für die Entstehung von Tiefseetieren, speciell Crustaceeen mit rudimentären Augren, glaube ich jedoch ein biologisches Erklärungsprinzip gefunden zu haben, dessen physiologische Ergänzung durch Experimente geprüft werden kann.

Vie ich schon in meiner vorläufigen Nitteilung dargestellt habe, sind die Brachyuren und sonstigen Crustaceen mit rudimentären Augen solche Formen, bei denen wir aus den untersuchten Embryonen oder aus den Dimensionen der Eier erschließen können, daß sie eine direkte Entwickelung ohne Metamorphose oder wenigstens mit abgekürzter Metamorphose durchmachen. WVeitere Belege hierfür sind unten im Abschnitt über die Fortpflanzung, sowie in den angehängten Tabellen am Schluß dieses Bandes gegeben.

Damit ist natürlich nicht gesagt, daß alle Formen mit abgekürzter Entwrickelung notwendigerweise rudimentäre Augen besitzen müssen. Denn wir wissen ja von zahlreichen arktischen litoralen Arten, daß sie die gleiche Eigentümlichkeit besitzen, ohne daß ihre Augen dadurch beeinflußt wären. Das Gleiche gilt von den Süßwasserbewohnern. Und ebenso können sich Formen in mittleren Tiefen finden, deren Augen volle Ausbildung besitzen, obwohl sie eine abgekürzte Netamorphose durchmachen. Wenn aber solche Formen in lichtlosen Regionen vorkommen, so wird ihre Brut dazu verurteilt sein, dauernd dem Licht entzogen zu leben, während die frei schwimmenden Larven von anderen bodenbewohnenden Formen in ihrer Jugend große Wanderungen unternehmen und in dieser Zeit wenigstens mit dem Licht in Berührung kommen können. Die einzelnen Beispiele sind unten im Abschnitt über die Fortpflanzung angeführt. Hier möchte ich nur hervorheben, daß die Formen mit kleinen Eiern, welche Zoëalarven produzieren, alle wohlentwickelte oder selbst hoch ausgebildete pigmentierte Augen besitzen.

So komme ich denn zu der Auffassung, daß die Pigmentierung der Augen direkt vom Licht abhängt. Bei den meisten Formen ist allerdings ein mehrere oder viele Generationen hindurch andauernder Aufenthalt im Dunkeln notwendig, um die Pigmentbildung zu unterdrücken; ein solcher wird gewährleistet durch die direkte Entwickelung ohne wanderfähige Larven, und natürlich ganz besonders begünstigt, wenn das erwachsene Tier ebenfalls wenig beweglich ist.

Ich habe oben die Augen von jungen Platymaia Wyzille. Thomsoni Mrs. (S. I6I) und jungen Pleistacantha Moseleyi (MRS.) [S. I 68] beschrieben, welche ebenfalls des Pigmentes entbehrten, obwohl die erwachsenen Tiere pigmentierte Augen besitzen. Vielleicht sprechen diese Befunde dafür, daß selbst bei Formen, die sonst regelmäßig pigmentierte Augen besitzen, unter ungünstigen Verhältnissen manche Individuen pigmentlose Augen besitzen.

In den untersuchten Fällen handelte es sich um junge Tiere, die zufällig in größerer Tiefe gefunden waren als die alten Stadien, und bei denen vielleicht Strömungsverhältnisse oder sonstige Ungunst es mit sich brachten, daß mehrere Generationen nicht ans Licht gekommen waren. So wåre die Möglichkeit gegeben, daß auch bei solchen Formen sich Standortsvarietäten mit rudimentären Augen bilden.

Pigmentverlust und Rudimentärwerden der Augen scheint ja eng zusammenzuhängen. Die nämlichen Entwickelungsverhältnisse, wie bei den Formen mit pigmentlosen Augen, finden wir bei denjenigen mit ganz rudimentären Sehorganen. 
Wie allerdings das Licht auf das Pigment und wie der Pigmentmangel auf die Entwickelung des Auges einwirkt, darüber fehlt es noch an den experimentellen Untersuchungen. Ich habe begonnen, solche durchzuführen, aber kann von denselben noch nichts Entscheidendes berichten, da sie natürlich lïngrere Zeit in Anspruch nehmen.

Eine Reihe von Erfahrungen sind der Annahme günstig, daß das Licht direkt die Pigmentvermehrung in den Zellen befördert. (Die Erörterungen, welche ich hier zusammenstelle, bezichen sich selbstverständlich zunächst nur auf melaninartige dunkle Pigmente.) Dic Bräunung, dic wir am eigenen Gesicht unter der Entwickelung des Sonnenlichtes wahrnehmen, spricht schon dafür. Tir. Lisr (1899) konnte an Miesmuscheln, die sich bei Neapel in einer Cxrotte finden, in deren Tiefe selbst bei Tag absolute Finsternis herrscht, feststellen, daß die im Hintergrund der Grotte wachsenden Individuen nahezu alle blaß und farblos sind; je mehr man sich dem Eingang der Grotte nähert, desto zahlreicher finden sich die Muscheln (Mytilus galloprovincialis und minimus) und desto dunkler pigmentiert sind sie; am Grotteneingang selbst zeigen sic den normalen Habitus. Aehnliche Erfahrungen wurden an Mytihus-Exemplaren gesammelt, die gelegentlich in den Wassserbecken der dunkeln Kellerräume und in den Seewasserleitungrsröhren der Neapeler Station wuchsen. Derselbe Autor konnte ferner bei Lithodomus dacty/us, der Meerdattel, welche im Gestein bohrt und, wenn sie aus der Tiefe hervorgeholt wird, ganz pigmentlos ist, dadurch, daß er sie dem Licht aussetzte, tiefe Bråunung herbeiführen.

Aehnliche Resultate hatte ZeLLer (I889), als er Olme (Protcus anguincus) am Licht hielt; er stellte fest, daß sie eine deutliche Bräunung annahmen.

Fig. 43 .

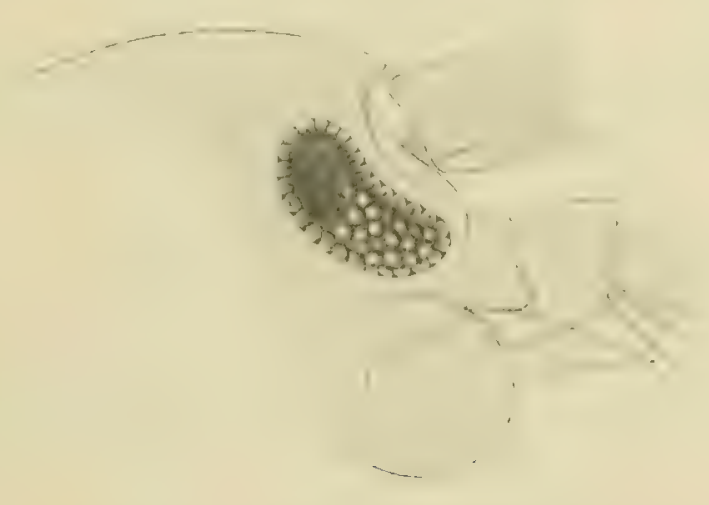

Fig. 44.

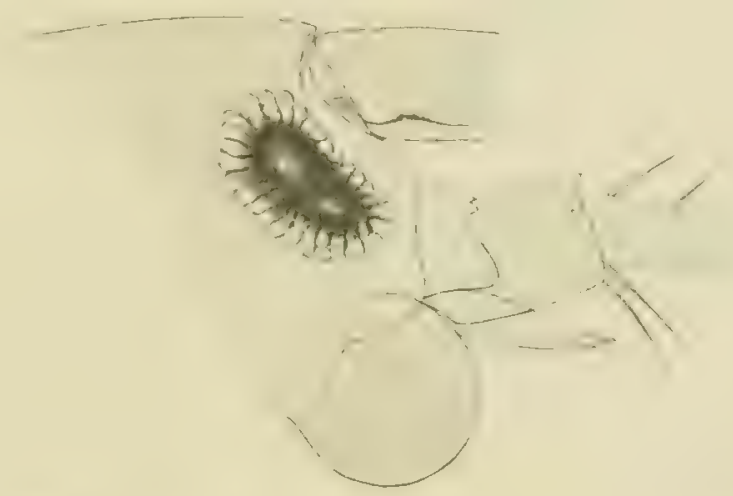

Fig. 43. Auge von Gammarus paler. Tagtier. (Nach R. Schnemer.)

Fig. 44. " " " Bergwerksform. (Nach R. Schneruer.)

FRIEs (1874), der als sehr zuverlässiger Beobachter bezeichnet wird, will an Gammanus und Aselhus, welche er im Dunkeln hielt, sehr bald eine Abnahme des Körper- und Augenpigmentes beobachtet haben. Doch ist hier der Verdacht zulässig, daß seinen Beobachtungen verschiedene Konzentrationszustände des Pigmentes zu Grunde lagen, daß die Körperpigmentzellen z. B. sich bei den Dunkeltieren in kontrahiertem Zustand befanden. Bei Gammarus putcamus will derselbe Beobachter ein schwaches Dunkeln bemerkt haben, wenn das Tier im diffusen Tageslicht gehalten wurde.

R. SCHnEIDER (1885) hat in Clausthaler Schächten verschieden stark pigmentierte Formen von Gammarus pulex gefunden; und zwar fand er in den alten, aus dem I6. und I\%. Jahrhundert stammenden Schächten ganz blasse, milchweiße, große Formen in sehr großer Menge, 
in den Schächten, deren Alter $1 / 2$ bis $3 / 4$ Jahrhundert betrug, Formen mit geringem, gelblichem oder bräunlichem Pigment und schließlich in Schächten von ca. 30 Jahren Formen, die sich von den oberirdisch lebenden nicht unterscheiden ließen.

An den Augen konnte Schneider bei der pigmentlosen Form ebenfalls bemerkenswerte Veränderungen konstatieren, welche er als eine beginnende Rückbildung auffaßt. Er findet das Auge etwas größer, die Krystallkegel in ihrem Verband gelockert, ein ärmlicheres, aber dunkleres Pigment als bei dem Tagtier, und dies Pigment ist mehr in Streifen angeordnet, weniger dicht als bei der oberirdischen Form (Textfig. 43 u. 44). Es will mir scheinen, als seien jene Veränderungen am Pigment auf die Thatsache der Verschiebbarkeit des Pigmentes zurückzuführen, welche erst seither genauer erforscht worden ist. Somit würde es sich vielleicht bei der bleichen Form hauptsächlich um eine Reduktion des Körperpigmentes handeln, während in den Augen das Pigment vielleicht eine fixierte Dunkelstellung angenommen hat; eventuell auch eine geringe Verminderung desselben eingetreten ist.

Fig. 45

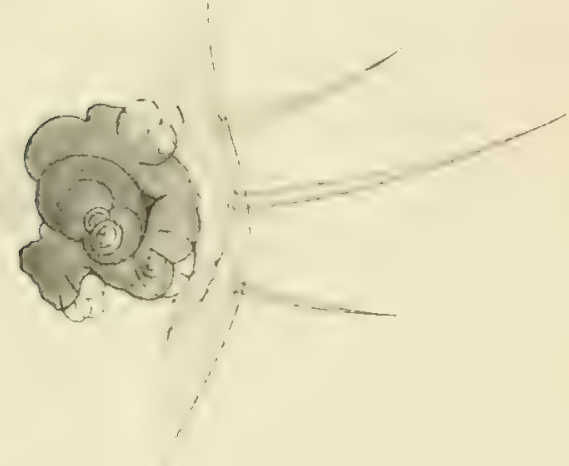

Fig. 46 .

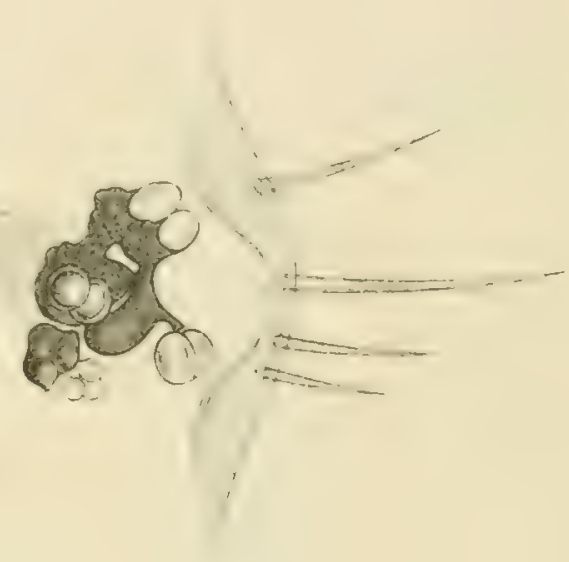

Fig. 45. Auge von Asellus aquaticzes. Tagtier. (Nach R. Schneider.)

Fig. 46. " " " $"$ var. friburgensis. (Nach R. Schineider.)

Derselbe R. SchnetDer (I 887 ) hat ferner in 400 Jahre alten Freiberger Schächten einen Aselhus gefunden, der zwischen aquaticus und cavaticus vermitteln soll, Asclhus aquaticus Var. fribergensis. Er fand in den ganz alten Schächten eine Form, welche vollkommen blaß war, ohne Hautpigment. Nur an den Augen fand er das Pigment noch vorhanden; was er als Zeichen einer Verminderung des Pigmentes in den Augen ansieht, ist vielleicht, ebenso wie ich es beim Clausthaler Gammanus vermute, der Effekt einer Nachtstellung desselben (vergl. Textfig. 45 u. 46). Auch bei dem Asellhs fand or in mutmaßlich weniger lange besiedelten Tümpeln des Grubenreviers Formen, welche weniger weitgehende Pigmentdegeneration aufwiesen. Daß er bei diesen Formen keine Veränderung des Augenpigmentes feststellen konnte, spricht entweder dafür, daß hier die Nachtstellung noch nicht fixiert ist und infolgedessen beim Transport im Tageslicht Verschiebung des Pigmentes stattfand, oder dafür, daß es sich wirklich um eine Pigmentverminderung handelt.

VIGIER hat ebenfalls an Asellus in Wasserleitungsröhren und anderen dem Licht entzogenen Orten verschiedene Rückbildungsstufen in der Pigmentierung konstatiert, je nach dem Lichtreichtum oder Lichtmangel der Fundorte. 
Bei den Wirbeltieren ist ebenfalls die Tendenz, das Pigment zurückzuhalten, im Auge am größten. So sind in der Haut der Larve von Amblyopsis nach EIGENManx (1 898) zwar zahlreiche Pigmentzellen vorhanden, auch beim erwachsenen fier nicht selten, enthalten aher nur äußerst wenig Pigment. Im Auge dagegen ist das Pigment normal.

Derselbe Autor hat in einer hochinteressanten zusammenfassenden Darstellung (EIrENMaNx r 899 ) berichtet, daß bei den gleichen Arten von blinden Fischen die Pigmentmengen großen Schwankungen ausgesetzt sind (bei Typhlichthy's allein findet sich kein Augenpigment). Ueberhaupt zeichnen sich die Formen mit degenerierten Augren durch eine große individuelle Variabilität im Entwickelungsgrad derselben aus.

Ueberblicken wir die Augenbeschaffenheit bei der ganzen Familie der $A \mathrm{mbly}$ opsiden, so können wir nach EigENMANix feststellen, daß 2 Species, die oberirdisch, aber unter Steinen und verborgen leben, zwar etwas rückgebildete, aber doch zum Sehen geeignete Augren besitzen (Chologaster comutus und papilliferns). Chologaster Agassizii lebt in Höhlen und hat viel kleinere Augen. Bei allen 3 Arten sind aber Linse, Glaskörper, Pigment etc. wohlausgrebildet. Die Augren von den ausschließlich höhlenbewohnenden Gattungen Amblyopsis, Troglichthy's und Typhlichlhy's sind sehr rückgebildet. Die Rückbildungen betreffen Linse, Glaskörper, Augenmuskeln, Retin a, Nervus opticus u. s. w. Es ist hervorzuheben, daß speciell die beim sehenden Tier funktionierenden, arbeitleistenden Teile der Rückbildung anheim fallen, und zwar äußert sich dic Degeneration zuerst an Retina und Sehnerv, zuletzt wird die Linse von ihr ergriffen.

Als sehr wichtig wäre von Eigenmann's Befunden noch hervorzuheben, daß Amblyopsis, die Io Monate am Licht gehalten wurden, keine Zunahme der Pigmentierung aufwiesen.

Ferner stellte sich heraus, daß Amblyopsis nicht, wie man annahm, lebendiggebärend ist sondern daß das Weibchen die Eier unter dem eigenen Kiemendeckel aufbewahrt; auch die jungen Tiere finden dort eine Zuflucht.

„Bei den jungen Tieren legt sich das Auge ganz normal an, später treten Verzögerungen in der Entwickelung ein, und manche Prozesse machen vorzeitig Halt, z. B. die Zellteilung und damit im Zusammenhang das Wachstum des Organes. Die Linse erscheint zur normalen Zeit, aber auch hier sistiert die Zellteilung bald, und die Zellen behalten ihren embryonalen Charakter. Bevor der Fisch $10 \mathrm{~mm}$ lang geworden ist, ist die Linse wieder ganz geschwunden. Der Opticus bleibt ein dünnes Faserbündel, das bald seine kompakte Struktur verliert und allmählich ganz schwindet; nur der intraokulare Teil erhält sich länger. Die Skleralknorpel wachsen langsam, aber lange und degenerieren nicht in dem Grade wie die anderen Teile des Auges."

Aus alledem folgt also, daß die Rückbildung des Augen- und Körperpigmentes stets auch eine Degeneration der Augenorganisation im Gefolge hat. Dic große Frage ist num, ob hier ein direkter /usammenhang besteht, der in zweifacher Hinsicht sich äußern könnte.

Erstens könnte der Pigmentmangel das Ausbleiben eines notwendigen Entwickelungsreizes im Gefolge haben, so daß gewisse Prozesse unterbleiben, die in der normalen Entwickelung gresetzmäßig eintreten.

Zweitens könnte der Pigmentmangel die Funktion des Auges illusorisch machen, und dadurch der notwendige Anstoß zur weiteren Entwickelung fehlen.

Es wäre aber auch möglich, daß kein direkter Zusammenhang besteht, sondern daß der Lichtmangel, wie auf den Pigmentbildungsprozeß, so auch auf die ontogenetischen Vorgänge bei der Bildung des Augres hemmend einwirkt. 
Schließlich können wir noch annehmen, daß der Mangel an gewissen Stoffen im Wasser der Tiefsee, oder daß die tiefe Temperatur, oder schließlich diese Bedingungen gemeinsam mit dem Lichtmangel auf die Augenentwickelung hindernd einwirken.

Zunächst möchte ich hervorheben, welche Anhaltspunkte dafür vorliegen, daß wir es mit einer experimentell prüfbaren entwickelungsphysiologischen Frage zu thun haben. Wir haben oben hervorgehoben, daß nach Eigenmann bei Amblyopsis die Augen ontogenetisch bis zu einer gewissen Stufe sich normal entwickeln, um dann eine Retardation in der Zellteilung zu erfahren, worauf schließlich Rückbildungsprozesse eintreten; unter den Wirbeltieren ist eine solche Veränderung des Auges während der Embryonalentwickelung auch noch bei Protens angzinueus und bei Typhlogobius festgestellt worden. In ähnlicher Weise ist für eine ganze Anzahl von Crustaceen mit rudimentären Augen festgestellt, daß die Augen beim jungen Tier relativ viel größer und besser entwickelt sind als beim erwachsenen Tier. So ist dies von PAckard für

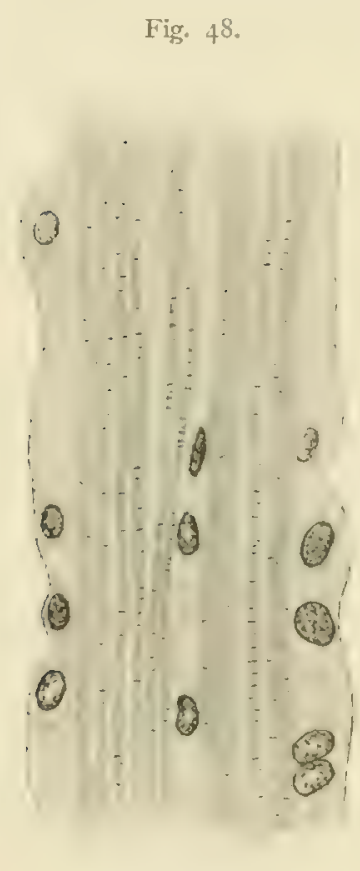

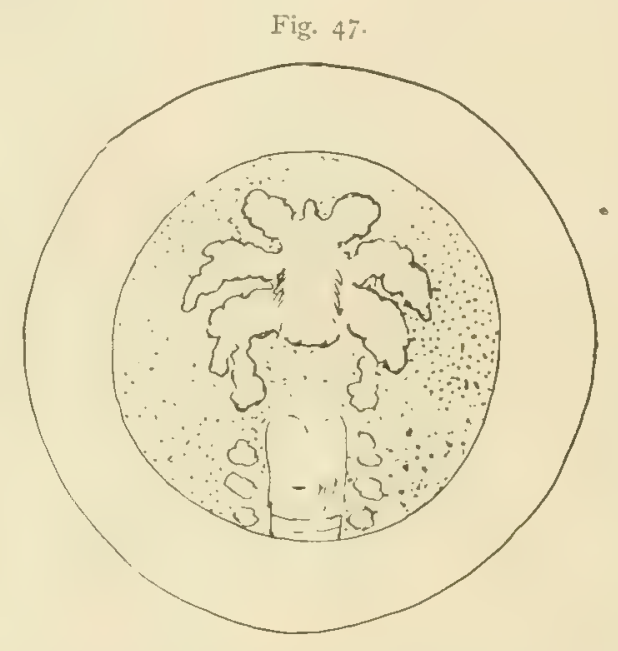

Fig. 47. Ei mit Megalopastadium des Embryos von IVillemocsia leptodactyla. (Nach BATE, Challenger Macrura.)

Fig. 48. Strick eines Muskels aus der inneren Antenne von Physachaeus ctenurus. Nach einem Schnitt von $5 \mu$ Dicke. Cambamus pellucidus aus den Höhlen Kentuckys gefunden worden, Bumpus (nach PAcKard I894) hat bei Callianassa Stimpsoni von Woodshall, einem im Schlamm wühlenden Tier, festgestellt, daß die Augen der Larve wohlentwickelt, diejenigen des erwachsenen Tieres stark rückgebildet sind. Ebenso soll nach SEMPER (1880) der in den Wasserlungen einer Holothurie lebende Pimotheres holothuriae als Larve sehr große wohlentwickelte Augen besitzen, welche während der weiteren Entwickelung rückgebildet werden. BATE hat Embryonen von Willemoesia leptodactyla, welches Tier ebenfalls abgekürzte Metamorphose und rudimentäre Augen vereinigt, untersucht und gefunden, daß der im Megalopastadium befindliche Embryo große, wohlentwickelte Augen besaß, die offenbar pigmentlos waren (Textfig. 47).

Ich habe oben an verschiedenen Orten darauf hinweisen können, daß sich die untersuchten Sinnesorgane bei gewissen Formen durch die Größe und geringe Anzahl von Zellen auszeichneten, welche die verschiedenen Gewebe zusammensetzen. Besonders war dies auffällig bei Physachaeus ctenums Alc. Bei dieser Form fiel im Augenstiel und in den Antennen, aber auch in anderen Körperteilen die Größe und geringe Zahl der Zellen im Nuskelgewebe, den Nerven, Ganglien, im Epithel u. s. w. auf. Textfigur 48 zeigt uns den eigenartigen Charakter eines solchen Muskels. Wenn es gelänge, festzustellen, warum diese Gewebe, warum auch die Gewebe des Auges selbst so zellenarm sind, so wäre für diese Form auch erklärt, warum nur so wenige und so große Augenkeile das Auge zusammensetzen. Ja, es mag dies derselbe kausale Zusammenhang sein, welcher auch die geringe Anzahl und die Größe der Eier bei diesen Formen bedingt. So sehen wir denn die Fragestellungen in ganz einheitlicher Weise sich zusammen- 
schließen: leider stellen sie bisher nur ein Arbeitsprogramm dar, und die Hoffnungen, die ich am Schluß meiner vorläufigen Mitteilung aussprach, bald über Resultate experimenteller Untersuchungen berichten zu können, haben sich bis jetzt noch nicht verwirklicht. Möglicherweise ist die Kälte des Tiefenwassers cin Faktor, welcher die Zellteilungsthätigkeit beeinflußt; wie ja R. HerTwir und seine Schüler gezeigt haben, daß bei einer Reihe von Ticren Kultur im kalten Wasser Größe der Zellen und geringe Anzahl der Zellteilungen in einem bestimmten Zeitraum bedingt. Dagegen haben wir oben gesehen, daß bei Pinnotheres Hidacnac aus dem Oberflächenwasser des heißesten aller Meere ebenfalls Großzelligkeit und Zellarmut der Gewebe sich findet. Es brauchte dies kein Einwand gegen die Annahme einer Temperatureinwirkung zu sein; denn in vielen Fällen wirken abnorm hohe und abnorm tiefe Temperaturen ganz gleichsinnig auf die lebenden Wesen ein.

Es sind eine ganze Menge von Fragen, die ich da aufgeworfen habe; aber ich glaube, es ist nützlich, sie aufzuwerfen, denn sie müssen erst erforscht werden, ehe wir mit irgend einem Grad von Bestimmtheit annehmen dürfen, daß Selektion, Germinalselektion, immanente Zweckmäßigkeit oder irgend ein anderes theoretisches Prinzip die nicht näher zu untersuchende Ursache aller dieser wunderbaren Umwandlungen ist, die wir am Auge dem Licht entzogener Tiere kennen lernen.

\section{B. Bedeutung des Baues der Geruchsorgane für die Lebensweise der Tiefsee- krabben.}

Wir haben einige Beweise, welche uns berechtigen, die hohlen Haare der Außengeißel der inneren Antennen bei den Decapoden mit ihren Terminalsträngen und zugehörigen Sinneszellen als chemoreceptorische Sinnesorgane zu betrachten. Aehnliche Wahrscheinlichkeitsgründe sprechen dafür, daß sich an den Mundwerkzeugen ebenfalls ein chemoreceptorisches Organ befindet. Wenn ich auch weiß, daß von vielen Physiologen die Ansicht vertreten wird, daß im flüssigen Medium die Funktion eines chemoreceptorischen Sinnesorganes nur nach Analogie des Schmeckens verstanden werde könne, und wenn ich mir auch wohlbewußt bin, daß hier ein sehr interessantes und wichtiges Problem der Untersuchung harrt, so spreche ich doch von einem Geruchsorgan an den inneren Antennen der Decapoden. Eine besondere Bezeichnung ist nötig, um den Unterschied von den an den Mundteilen befindlichen chemoreceptorischen Organen zu bezeichnen, und ich wähle die alte Bezeichnung, um es demjenigen, der die Physiologie dieser Organe einmal untersucht, zu überlassen, eine neue und zweckmäßige Terminologie zu schaffen. Zugleich möchte ich mit meiner Bezeichnung den Unterschied in dem biologischen Wert der beiden Organformen für das Tier hervorheben, indem ich unter Gernchsorgan ein chemoreceptorisches Organ für Fernwirkungen, unter Geschmacksorgan cin solches für Nahwirkungen (besonders bei der Nahrungsaufnahme) rerstehe.

Am Geruchsorgan der Tiefseekrabben fielen mir eine Reihe von Eigentümlichkeiten auf, welche diese ron den bisherigen Beschreibungen dieses Organes bei Decapoden unterschieden. Zu meiner Ueberraschung mußte ich aber wahrnehmen, daß in der Litteratur sich Angaben über die Bauverhältnisse der inneren Antenne von nur ganz wenigen Formen fanden. So war denn auch keine Untersuchung vorhanden, welche versucht häitte, den Bau der inneren Antennen verschiedener Strandformen auf die rerschiedene I_ebensweise ihrer Trïger zurückzuführen. 
$1 \therefore ;$

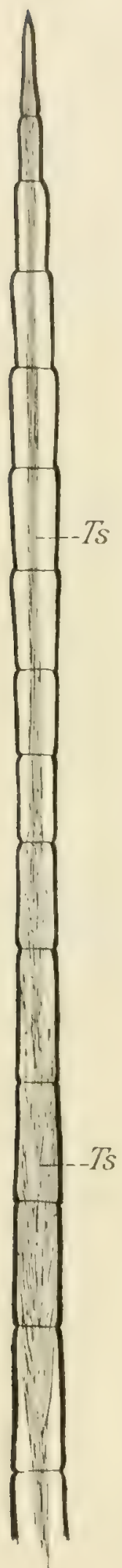

Als ich dann, im Anschlur an meine Untersuchung dieser Organe bei den Tiefseekrebsen eine Anzahl von Strandformen untersuchte, fand ich bald, daß ich gut daran gethan hatte, noch nichts ron den Vorstellungen, die ich mir über die bio-

$$
\text { Fig. 49. }
$$

The

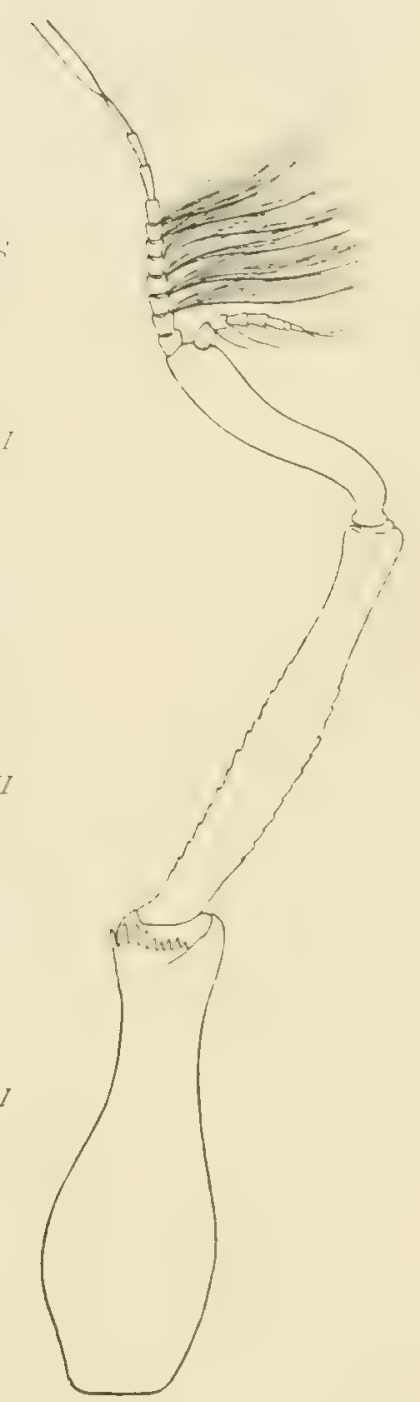

Fig. 49. Innere Antenne ron Cymonomus granzelatues (NORM.) Nach RAY LANKESTER. I-III Stielglieder, $A_{s}$ Außengeißel. Ig Innengeißel. $R / 2$ Riechhaare. $T h$ Tastbaare.

Fig. 50. Gegliedertes Ende eines Riechhares son Homolotromio Borzicr: DoFL., Ts Terminalstrang. logische Bedeutung der Bauverschiedenheiten gemacht hatte, zu veröffentlichen. Denn viele dieser Vorstellungen stellten sich als vollkommen irrig heraus. Trotzdem habe ich es gewagt, mir neue Vorstellungen an der Hand des größeren Thatsachenmateriales zu bilden. Ich trage diese in aller Bescheidenheit vor, im Bewußtsein, auch hier wieder in vielen Punkten zu irren, in der Hoffnung aber auch, durch den Irrtum die Erkenntnis auf diesem interessanten Gebiet um einiges zu fördern.

Die inneren Antennen einer Krabbe tragen auf dem 3. Stielglied 2 Geißeln, deren Cuticula in eine Anzahl von kurzen Gliedern eingeteilt ist, und welche bei allen Formen relativ sehr kurz sind und nie eine so beträchtliche Größe erreichen, wie wir sie von so vielen Macruren und Cariden kennen.

Die Verkürzung trifft vor allem die Innengeißel (Textfig. $49 \mathrm{Ig}$ ), welche nur mit Tasthaaren besetzt ist und welche bei den Krabben wohl hauptsächlich die Außengeißel mit ihren feinen Organen vor Fährnissen zu warnen hat. Demselben Zweck dienen auch die Endglieder der Außengeißel mit ihren Tasthaaren (vergl. Textfig. +9 Th).

Die Außengeißel ist auf ihrer Innenseite mit hohlen Haarbildungen bedeckt, welche bekanntlich als Riech- oder Schmeckhaare bezeichnet werden. Wir haben bei der speciellen Schilderung des Geruchsorganes z. B. von Homolodromia den Bau derselben kennen gelernt (S. I 8z). Sie stehen meist zu mehreren auf je einem Gliede der Außengeißel, und zwar sind sie dann in einer Reihe angeordnet, welche dem Hinterrand dieses Gliedes parallel läuft. Die Zahl der Glieder der Außengeißel ist bei den verschiedenen Arten eine schwankende, ebenso der Durchmesser dieses Gebildes, ferner auch die Zahl der Riechhaare sowie deren Weite und Länge. Auch in der Form der letzteren fand ich Verschiedenheiten, indem sie bei manchen Formen glatt waren, bei anderen gegliedert (Textfig. 50); diese Gliederung, welche nur bei sehr langen Riechhaaren gefunden wurde, hat sicherlich die Bedeutung, das Haar bei den lebhaften Bewegungen der Antenne vor dem Abbrechen zu bewahren, indem es dann nachgleitend sich biegt und so den 
Druck vermeidet. Bei derselben und bei anderen Formen, so bei Geryon affmis, dessen Riechhaare ebenfalls sehr lang sind, fand ich die hasalen Teile derselben mit ringförmigen Ausbauchungen der Chitinröhre versehen, welche wohl zur Versteifung des Grebildes dienten (Taf. LVIII, Fig. $4 \mathrm{R} / h^{\prime \prime}$ ).

Besprechen wir zunächst die biologrische Bedeutung der Verkürzung der Außengeißel. Dieselbe kann erstens in Beziehung stehen zu einer geringen Ausbildung des Feruchsorganes überhaupt. Diese finden wir bei einer Anzahl ron Küstenund Landformen, welche srut sehende Tagtiere sind und infolgedessen wenigrer auf ein hochentwickeltes Geruchsorgan angewiesen sind. Zweitens finden wir aber eine V'erkürzung der Außengreißel auch mit einer sehr starken Entwickelung der Riechhaare lombiniert. Aberesehen von allsemeinen Organisationstendenzen können auch hier biologische Momente in vielen Fällen zur Erklärung herangrezogen werden. Ich fand eine solche Verhürzung vielfach bei Formen der Brandungszone und bei Riffbewohnem. Bei diesen lebhaft herumkletternden Tieren, welche ich hier im Sinne habe, ist bei ihren Wanderungen zur Nahrungssuche, bei ihren Kümpfen mit Artgenossen und raubgierigen Vertolgern die Antenne mit ihren zarten Riechhaaren beständigg gefährdet. Ihre Verhürzung erleichtert das Zurüchziehen in eine sichernde Grube am Kopf ihres Trägers und ermöglicht außerdem eine weitere Form des Schutzes, die ich bei solchen Tieren entdeckte. In Textfig. 5 I ist die Antenne ron Chlorodius niger abgebildet, einer häufigren Riffkrabbe des Indopacifik. Hier sehen wir die Geißeln der inneren Antenne an ihrer Basis von einem Kranz hakenförmigrer Haare umgreben. Diese Haare sind nicht hohl wie

$R h=\quad A_{g}{ }^{\circ} \quad J g$ g 
In den Korb, den sie in ihrer Gesamtheit bilden, können die Geißeln, wie hinter einem Gitter geschützt, zurückgezogen werden.

Eine solche Einrichtung habe ich bei keiner Krabbe gefunden, welche in einer Tiefe von auch nur $20 \mathrm{~m}$ ihren regelmäßigen Aufenthalt hat, geschweige denn bei einer Tiefseekrabbe.

Bei denselben sind auch die Antennengeißeln durchweg nicht so stark verkürzt. Sie bedürfen eben in dem ruhigen Wasser der Tiefsee nicht des ausgiebigen Schutzes vor den Zufälligkeiten der Umgebung. Zwar haben Milne-Edwards und Bouvier (I 894 ) bei Galatheiden des tiefen Wassers eine ähnliche Einrichtung an der inneren Antenne beschrieben, wie ich sie oben bei Chlorodius niger als „Stachelkorb“ geschildert habe. Aber sie haben dieselbe in ganz anderer Weise gedeutet, indem sie den accessorischen. Haaren eine wichtige Sinnesfunktion, und zwar Tastfunktion zuschrieben. Da über den feineren Bau dieser Haare und ihre etwaige Verbindung mit Nerven nichts gesagt ist, so können wir nicht entscheiden, ob es sich wirkiich um Sinneshaare oder um Schutzstacheln handelt, wie in dem von mir beschriebenen Fall. Aber es scheint mir, als sei das letztere der Fall, und dies wäre bei der Lebensweise der betreffenden Galatheiden, welche in Felslöchern, in und an Tierstöcken leben und in Sand und Schlamm wühlen, nicht verwunderlich. Die erwähnten Autoren heben besonders hervor, daß die Erscheinung bei den Formen des flachen Wassers ebenso häufig ist und suchen sie bei diesen als ein Erbe von den Tiefseebewohnenden Vorfahren zu erklären. Ich hoffe, bald solche Formen untersuchen zu

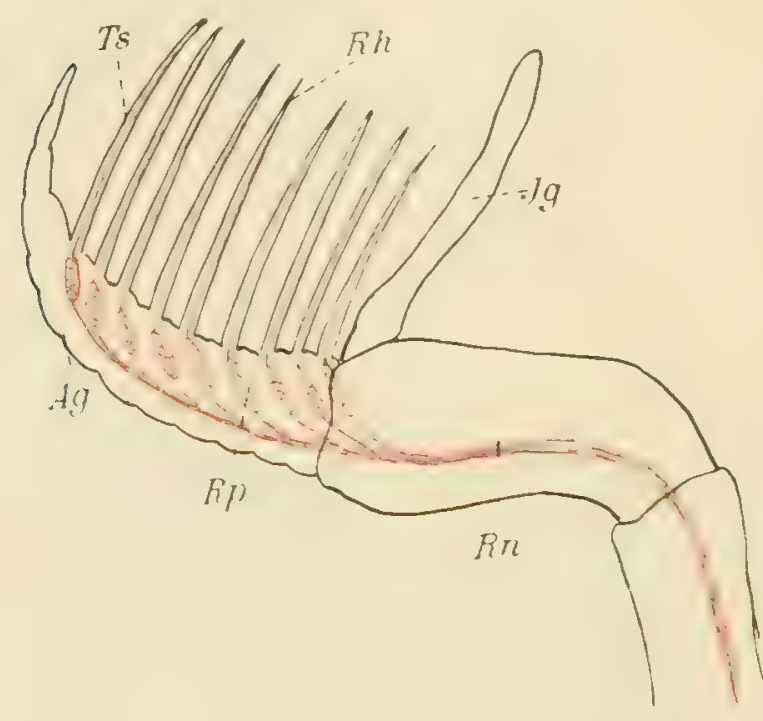

Fig. 52. Schema des Geruchsorganes der Brachyuren, I. Typus. Ag Außengeißel. $/ g$ Innengeißel. $R /$ Riechhaar. $R n$ Riechnerv. Rp Riechspindel. Ts Terminalstrang. können, und dann wird sich wohl durch den histologischen Befund entscheiden, welche Anschauung die wahrscheinlichere ist.

Am meisten fielen mir bei meinen Untersuchungen die bisher noch nicht beachteten Unterschiede im Bau der nervösen Endapparate des Geruchsorganes auf. Wie ich schon oben im Detail auseinandersetzen konnte (S. i 82 ff.), kann man im wesentlichen drei Typen für die Anordnung der Riechzellen und der aus ihnen gebildeten Riechspindeln unterscheiden, welche drei Typen allerdings durch vielfache Uebergänge miteinander verbunden sind.

Bei dem ersten Typus (Textfig. 52) sind die Riechspindeln in einfachen Reihen angeordnet, ähnlich dem schon voir RaTH geschilderten Verhalten beim Flußkrebs. Jede Riechpapille sitzt unmittelbar unter dem Riechhaar, zu welchem sie gehört, und der Terminalstrang hat nur einen ganz kurzen WVeg im Innern der Antennengeißel zurïckzulegen, ehe er in das Lumen seines Riechhaares eintritt. Die aus den Papillen austretenden Nervenfäden vereinigen sich zu einem kräftigen Nervenstrang, dem jeder einzelne Bestandteil unmittelbar hinter der zugehörigen Papille zufließt.

Der zweite Typus (Textfig. 53) stellt einen Uebergang zu dem sogleich zu schildernden dritten Typus dar. Die Geruchspindeln befinden sich zum größten Teil nicht mehr in der Außen- 
geißel, welche mäßig lang und mäßig dick ist, aber relativ viele und starke Riechhanre trïigt, sondern sind in das 3. Stielglied geriiclit. Die Terminalstrünge sind meist zu Terminalnerven verlïngert. Eine deutliche Gliederung in zwei Hauptmassen hat bei diesem von mir so benannten Lobus osphradicus noch nicht stattgefunden.

Bei dem dritten Typus (Textfig. 54) liegen sïmtliche Riechspindeln in dem 3. Stielglied der Antenne; die Außengeißel ist meist relativ kurz und dünn und trägt sehr zahlreiche starke Riechhare. Der aus den Riechspindeln entstandene Lobus osphradicus ist sehr groß, meist in zwei Portionen geteilt, welche den Außenwäinden des 3. Stielgliedes anliegen und zwischen welchen der Muskel hindurchzieht, welcher die Außengeißel bewegt. Die einzelnen Riechspindeln sind so dicht zusammengedrängt, daß man meist ihre Grenzen nicht mehr erkennt und jede der beiden Portionen des Lobus osphradicus eine mehr oder weniger einheitliche Masse bildet.

1.1. $5 i$

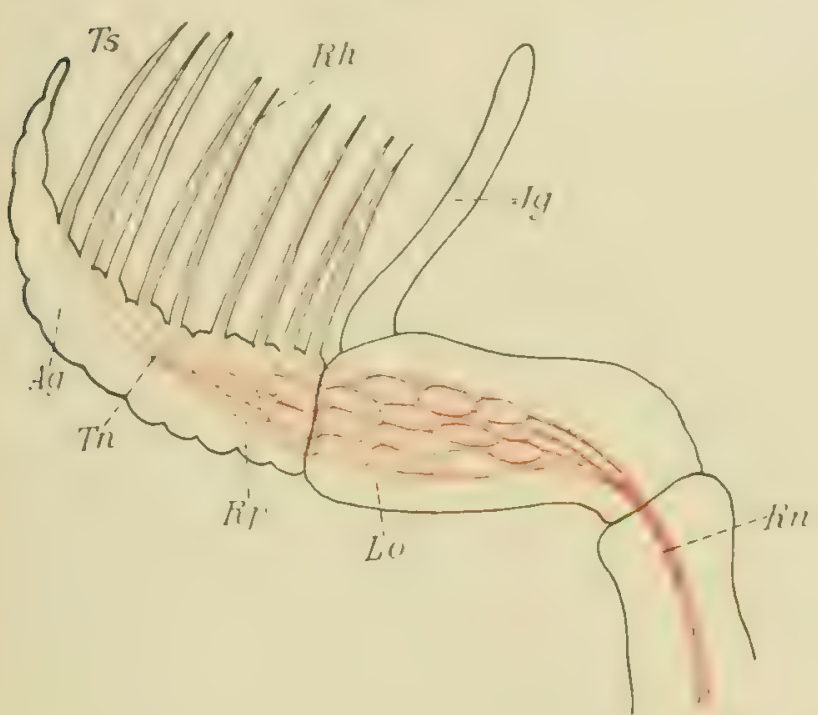

$1: \cdots ; 1$

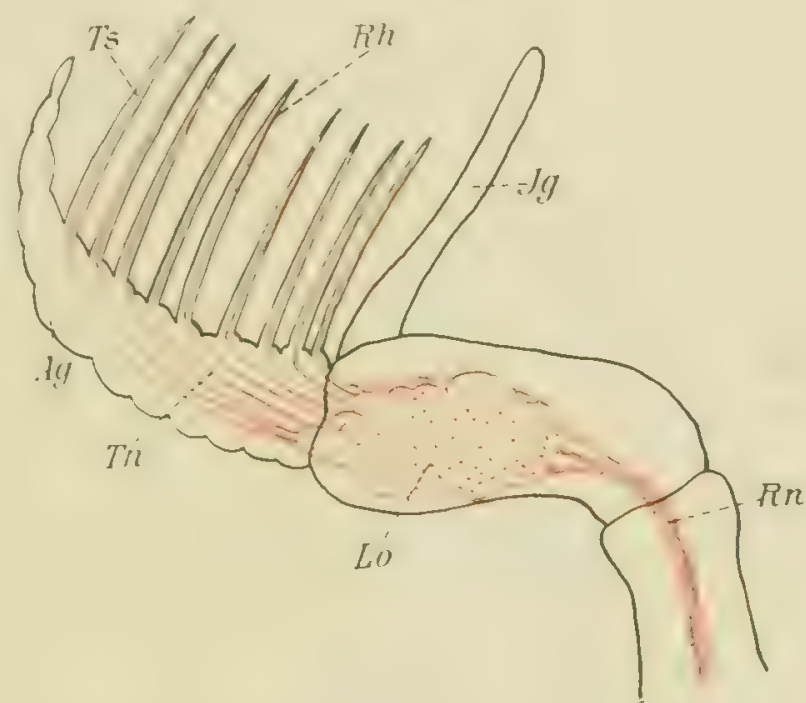

Fig. 53. Schema des Geruchsorganes der Brachyuren, II. Typus. Buchstabenbedeutung wie bei Fig. 52. Tn Terminalnerv

Fig. 54. Schema des Genuchsorganes der Brachyuren, 1Il. Typus. Buchstabenbedeutung wie Fig. 52 u. 53.

Was ist nun die biologische Bedeutung dieser verschiedenen Bautypen? Da ich die komplizierte Form mit großem Lobus osphradicus zuerst bei ausgesprochenen Tiefseeformen auffand, so lag es nahe, eine Anpassung an das Leben in der Tiefsee in ihr zu erblicken. So fasse ich sie denn auch auf, wenn auch die Verhältnisse nicht ganz so einfach sich herausstellten, wie es zuerst den Anschein hatte.

Wir müssen nämlich bis auf weiteres daran festhalten, daß die Verschiedenheit im Bau bei dem II. und III. Typus nicht etwa auf eine höhere oder kompliziertere Organisation des Riechorganes schließen läßt, sondern nur auf eine Vermehrung und eventuell eine Vergrößerung seiner Elemente. Fragen wir uns nach der Wirkung einer solchen Vermehrung der Elemente, so bleibt uns zur Beantwortung dieser Frage nur die vergleichende Betrachtung, da Experimente vorläufig nicht vorliegen und ich solche bis auf weiteres noch nicht anstellen kann.

Wir nehmen im allgemeinen an, daß Tiere, welche weniger gut ausgebildete Sinnesorgane der übrigen Sinne haben, oder welche in Verhältnissen leben, in denen sie diese Sinnes- 
organe nicht zur Anwendung bringen können, bessere Geruchsorgane haben müssen als ihre in den erwähnten Dingen begünstigteren Venwandten. So nehmen wir an, daß Nachttiere ein besseres Geruchsorgan besitzen müssen als die Tagtiere ihrer Verwandtschaft. Wir nehmen an, daß Höhlentiere und Bewohner der dunkeln Regionen unter der Erde und in der Tiefe der Gewässer sich ebenso von ihren am Licht lebenden Verwandten unterscheiden müssen. Schließlich nehmen wir an, daß die Männchen bei manchen Tieren, besonders bei weniger dicht verbreiteten, ein sehr gutes Riechvermögen haben müssen, um ihre Weibchen aufzusuchen und zu finden.

Für die Richtigkeit dieser Annahme sprechen erstens biologische Beobachtungen Wir wissen z. B., daß Nachtinsekten durch die starken Gerüche nächtlich sich öffnender Blumen angelockt werden. Ferner wissen wir, daß bei manchen Insekten die Weibchen einen auffallenden Geruch besitzen, welcher die Männchen herbeizieht, und man benutzt bei solchen Formen sogar die lebenden Weibchen als Köder, um die Männchen zu fangen.

Mit diesen biologischen Beobachtungen stehen morphologische Befunde in Uebereinstimmung. Wir finden bei nächtlichen Insekten vielfach eine starke Vergrößerung der Geruchsorgane, so z. B. bei zahlreichen Spinnern unter den Schmetterlingen: ich erinnere an die mächtigen Antennen von Attacus atlas u. s. w.

Ferner finden wir bei den Männchen vieler Tiere besser entwickelte Geruchsorgane als bei den Weibchen. Als bekanntestes Beispiel seien die Lamellicornier angeführt, bei denen

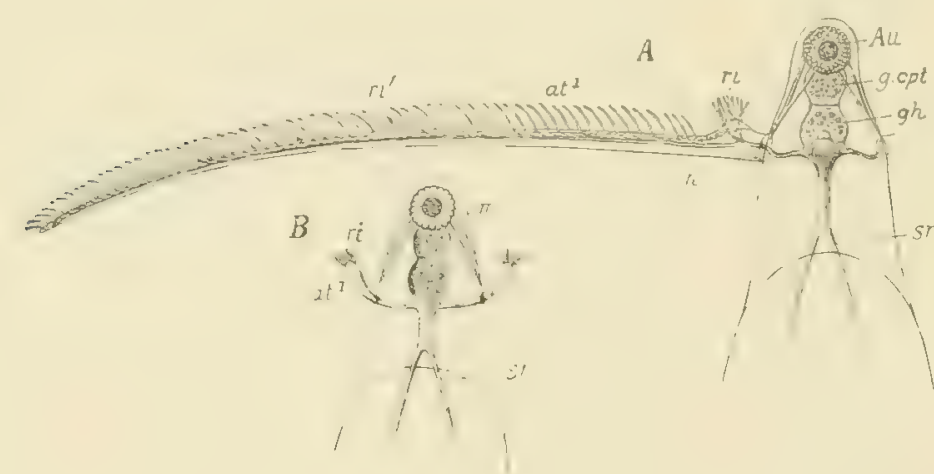

Fig. 55. Leptodora hyaline. A Kopf des Männchens, B Kopf des Weibchens. Au Auge. g. opt. Ganglion opticum. g/2 Gehim. at I. Antenne mit den Riechfäden $r i$ u, $r i^{*}$. $s r^{-}$Schlundring. die Männchen Fühler besitzen, welche mehr und größere Blätter tragen als diejenigen der Weibchen. Und, um ein Beispiel aus der Reihe der Crustaceen anzuführen, bei Leptodora hy'alina ist der Unterschied der Geruchsorgane bei $\delta$ und $q$ ein ganz enormer, wie WeIsMaxx hervorgehoben hat (s. Textfig. $55 \mathrm{~A} \mathrm{u.} \mathrm{B)}$.

Um unseren Vergleich unten im einzelnen durchführen zu können, müssen wir aber noch einige Fälle anführen. Eine ganze Reihe von Tieren verdanken die Steigerung ihrer Riechfähigkeit und

die damit zusammenhängende Vergrößerung ihrer Geruchsorgane bestimmten Gewohnheiten, so sind z. B. viele Aasfresser mit monströs entwickelten Geruchsorganen versehen: viele Haie unter den Fischen, viele andere Wirbeltiere und Wirbellose, und unter letzteren seien als den Brachyuren nächstverwandtes Beispiel die aasfressenden Paguriden genannt.

Wir haben also eine ganze Reihe von Momenten ins Auge zu fassen, wenn wir die biologische Bedeutung der verschiedenen Bautypen des Geruchsorganes bei den Brachyuren beurteilen wollen.

Um zunächst die Beziehungen zur Geschlechtsthätigkeit zu erwähnen, so muß ich hervorheben, daß ich keinen auffälligen Unterschied an den Antennen von $\delta$ und $q$ feststellen konnte. 
Allerdings war hierzu mein Material nicht reich genug. Bei den Mysideen der verschieclenen Tiefen besitzen nämlich nach G. O. Sars die $\delta$ einen Schopf von Spürhaaren, welcher den $q$ fehlt, und Cruv konnte bei Arachnomysis Lenckarti einen solchen sogar in ganz monströser Ausbildung beim of nachweisen. Ja, er fand bei dieser Form auch ein "Antennenganglion", welches an Umfang dem Gehirn nahezu gleichkommt und welches bei genauer Untersuchung sich wohl ebenfalls nicht als echtes peripheres Ganglion, sondern als Lobus osphradicus in dem von mir gebrauchten Sinne herausstellen wird (vergl. Textfig. 56).

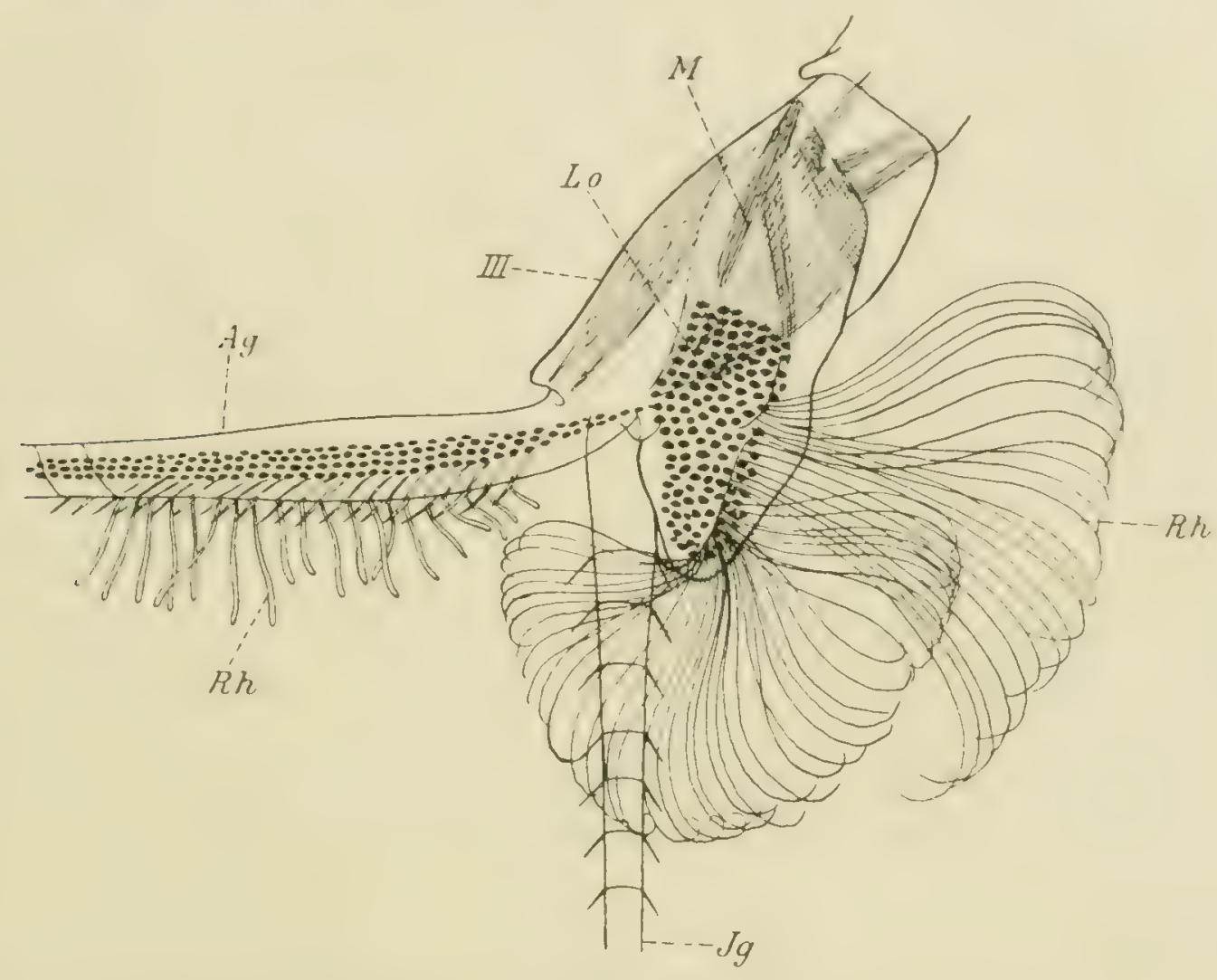

Fig. 56. Antennenbasis ron Arachurompsis Latckarti CH. (Nach CHuN.) III Drittes Basalglied der inneren Antenne. Ag Auliengeiliel. $J_{g}$ Innengeißel. $R / 2$ Riechhaare. Lo Lobus osphradicus. II Mfuskel.

Dagegen ließ sich eine deutliche Beziehung zum Leben in der Dunkelheit feststellen. Sämtliche Formen, bei denen ich trotz der Herkunft aus größerer Tiefe die einfache Anordnung der Riechspindeln feststellen konnte, waren Arten mit großen, facettenreichen Augen: Homolochunia Valdiziae Dofn., Platymaia IVyrille-Thomsoni Mrers und Geryon affinis M.-E. u. Bouv. WVic man sieht, sind dies zum Teil Arten mit Augen, welche für das Sehen bei schwachem Licht sogar besondere Anpassungen aufweisen.

Diejenigen Arten jedoch, welche mit einem Lobus osphradicus versehen sind, haben fast sämtlich mehr oder weniger reduzierte Augen: Cy'rtomaia Sulmi Mrs. mit seinen mäßig reduzierten Augen besitzt einen kleinen Lobus osphradicus, Homolodromia Boucieri Dofl. mit den sehr zurückgebildeten Augen hat einen mächtigen Lobus osphradicus, welcher allerdings noch nicht den ausgesprochenen Typus erreicht wie bei Cyclodorifpe, Cy'monomus und Physachactus. Bei diesen letzteren steht die Ausbildung des Riechorgans in nächster Beziehung zu den übrigen 
Baueigentümlichkeiten, welche alle auf einen dauernden Aufenthalt in der ewigen Dunkelheit der Tiefsee schließen lassen. In schönster Uebereinstimmung damit zeigt z. B. Pinnotheres tridacnac mit seinen stark rückgebildeten Augen, welche vollkommen an diejenigen eines Tiefseetieres erinnern, in seiner inneren Antenne einen Lobus osphradicus.

Dagegen fand ich auch bei einigen Formen des seichteren Wassers und selbst der Strandregion einen wohlausgebildeten Lobus osphradicus. Hier ist die Erklärung zum Teil nicht ganz einfach. Bei einigen Formen allerdings ergiebt sich die Deutung von selbst durch die Untersuchung der Augen; bei Scyramathia Hertwigi Dofl. z. B. finden wir die Augen schon in einem rückgebildeten Zustand, in der inneren Antenne einen wohlabgegrenzten, wenn auch kleinen Lobus osphradicus. Bei Dromia atlantica DofL., für welche Form ein etwa ebenso ausgebildeter Lobus festgestellt werden konnte, fanden sich die Augen mit zwar normalem Bau, aber Nachtstellung des Pigmentes; also handelt es sich schon um einen Bewohner der Dämmenungsregion. Und ich bin fest davon überzeugt, daß man bei genauem Nachforschen, auch bei Nachttieren der Oberfläche, resp. der Strandregion Aehnliches wird feststellen können.

In Fällen, wo aber bei Tagtieren sich eine ähnliche Bildung des Geruchsorganes findet wird man in anderen biologischen Verhältnissen eine Erklärung der Erscheinung finden können. In manchen Fällen wird eine besondere Form der Ernährung die Ursache sein, in anderen aber können wir eine Beobachtung, welche ich gemacht habe, zur Erklärung heranziehen. IVir sahen schon oben, daß z. B. bei Chlorodius niger (Forsk.) die Außengeißel der inneren Antenne besonders in ihrem basalen, die Riechhaare tragenden Teil sehr kurz ist, und brachten diese Verkürzung in Zusammenhang mit dem Schutzbedürfnis des zarten Riechorganes, welches auch durch die Ausbildung des Stachelkorbes (Textfig. 5I Sk) befriedigt erschien. Die Verkürzung der Geißel muß aber zur Folge haben, daß die Riechspindeln, welche zu der, zum Leben des Tieres notwendigen, Anzahl von Riechhaaren gehören, in dem Innern der Geißel keinen Raum finden. Thatsächlich finden wir auch einen mäßig großen, aber scharf abgegrenzten Lobus osphradicus im 3. Stielglied der Antenne.

So finden wir denn, wie wir es schon bei den Augen festgestellt haben, an den Riechorganen der Tiefseekrabben eine Anzahl von Einrichtungen, welche bei anderen Formen auch durch andere Lebensbedingungen veranlaßt worden sind. Wie wir sehen, spricht dieser Umstand aber nicht gegen unsere Deutung, daß eine - in diesem Fall wohl sicher indirekte - Wirkung des Lebens in der Tiefsee diese Bauverhältnisse herbeigeführt habe, er ist uns vielmehr ein Beweis für die Gesetzmäßigkeit, mit der die Vorgänge am Organismus sich abspielen. Wir entnehmen daraus, daß, durch verschiedene Ursachen hervorgerufen, das gleiche Mittel verschiedenen Zwecken dienen kann.

\section{Ueber die biologische Bedeutung der Statocysten bei den Tiefseekrabben.}

Noch schwieriger als bei den übrigen Sinnesorganen ist es bei den "Statocysten" oder "Otocysten", etwas über die biologische Bedeutung der verschiedenen Ausbildungsgrade, welche sich bei Tiefseeformen finden, auszusagen. Sind doch die Meinungen über die Bedeutung dieser Organe bei den Formen des flachen Wassers noch nicht geklärt. Ich habe oben (S. I 87 ) erwähnt, aus welchen Gründen ich mich veranlaßt sah, die Anatomie dieser Organe an meinem 
Material zu untersuchen. Thatsiichlich hat sich ein Resultat ergeben, und zwar spricht dasselbe durchaus für die Annahme, daß wir es in den Bläschen im I. Basalglied der inneren Antenne mit Gleichgewichtssinnesorganen zu thun haben; damit ist allerdings nicht ausgesagt, daß nicht zugleich Teile von ihnen dic Perception von Longitudinalwellen bestimmter Lïngen zu vermitteln vermöchten, mit anderen Worten, als Gehörorgane dienten. Darüber künnen nur Experimente und Beobachtungen am Lebenden entscheiden; die bisher angestellten Versuche sprechen ja gegren die Annahme einer Hörfähigkeit, dagegen geht aus ihnen hervor, daß dic Krabben Erschütterungen des Wassers durch einen hoch entwickelten Tastsinn wahrnehmen.

Bei den von mir untersuchten Formen konnte ich nun feststellen, daß offene Statocysten mit oder ohne nachweisbare Statolithen sich bei einer Anzahl von Brachyuren finden, so bei:

\section{Homolodromia Bouvicri DofL., \\ Dromia attantica DorL., \\ Cyclodorippe uncifera glaucomma ALc., \\ Physachacus ctemumes Alc.}

Dagegen fanden sich wohlentwickelte, geschlossene Bläschen, ohne Otolithen, bei:

Cy'tomaia Sulmi platyceros Dofu.,

Platymaia Wyville-Thomsoni Mrs.,

Geryon affinis M.-E. u. Bouv.

Durch die Untersuchung verschiedener Formen, die ich nicht zerstückeln konnte, ergab sich ferner, daß stets die Formen mit sehr großen Basalgliedern der inneren Antennen auch sehr große Statocysten in deren Innern bergen. Wir werden sogleich sehen, daß der Befund stets mit anderen Eigenschaften dieser Tiere vergesellschaftet erscheint. Die wichtigsten der untersuchten Formen, bei denen große Basalglieder der inneren Antennen sich feststellen ließen, sind folgende:

Homola barbata oricutalis HeND.,

Paromola profundormen Aic. u. AND.,

Homolochunia Valdiviae DoFL.,

Hypsoplury:s longipes Alc. U. AND.,

Homologenus Braneri Dofl.,

Elhusina, verschiedene Arten,

Eithusa,

Echinoplax Moseleyi Mrs.,

Benthochascon Hemingi ALC.,

Psopheticus stridulans ALc.,

Geryon Panlensis Dori.,

Carcinoplax longimanus indicus DorL,

$$
" \quad \text { " japonicus Doris }
$$


Dagegen wären als Arten mit auffallend kleinen Basalgliedern und dementsprechend kleinen Statocysten noch zu nennen:

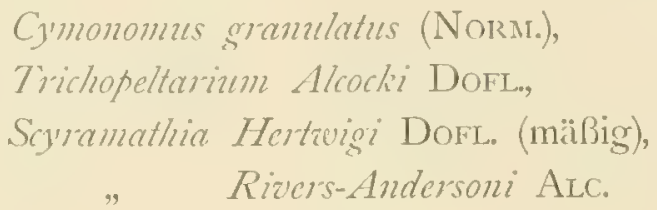

und andere Arten dieser Gattung.

Diesen Formen ließen sich aus der Litteratur noch ganze Reihen anschließen, und sie alle weisen uns auf die gleiche Gesetzmäßigkeit hin: die mit wohlentwickelten Augen versehenen Formen haben auch große, gut entwickelte Statocysten, die Formen mit rudimentären, vor allen Dingen die mit pigmentlosen Augen, haben kleine Basalglieder, also wohl auch kleine Statocysten.

Nun ist natürlich die Frage aufzuwerfen, ob wirklich die kleinen Statocysten auch in der Leistung hinter den großen zurückbleiben müssen. Ich nehme dies an und erschließe es aus ihrem primitiveren Bau. Sie sind meist einfach kugelig gebaut, die Anzahl der Sinneshaare in ihrem Innern ist eine geringe, und die in den untersuchten Fällen festgestellte Anwesenheit eines Statolithencentrums weist auch auf eine nicht sehr vielseitige Funktion hin.

Die großen Statocysten jedoch sind geschlossene Blasen mit einer sehr komplizierten Form. Die Hülle des Gebildes zeigt eine Anzahl von Falten, welche so in das Innere vorragen, daß dieses keinen einheitlichen Hohlraum bildet, sondern in einige Kanäle eingeteilt erscheint; diese Kanäle tragen an ihren Wänden die Sinneshaare, und es scheint mir nicht unwahrscheinlich, daß thatsïchlich Beziehungen in der Anordnung dieser Kanäle zu den drei Hauptebenen des Tierkörpers bestehen. Auch ist ja festgestellt, daß gerade in diesen großen, kompliziert gebauten Statocysten die großen Mengen von Sinneshaaren vorkommen, welche noch dazu nach verschiedenen Typen gebaut sind. Berücksichtigen wir dies alles und machen wir die Annahme, daß die Sinneshaare, was ja an sich wahrscheinlich ist, im specifischen Gervicht von der sie umgebenden Statocystenflüssigkeit abweichen, eine Annahme, der auch Prevrrss zuneigt, so ist sehr wohl zu verstehen, daß es sich um komplizierte Gleichgewichtssinnesorgane handelt.

Wie verhalten sich nun hierzu die sonstigen biologischen Verhältnisse bei den Decapoden? Bei den pelagischen Formen, wie Lucifer und Sergestes, finden wir kugelige Statocysten mit relativ geringen Mengen von Sinneshaaren. Das sind Verhältnisse, wie wir sie auch sonst bei pelagischen Tieren finden, bei Pteropoden und Heteropoden, bei Cölenteraten und anderen. Es ist wohl zu verstehen, daß diese Form der Statocysten in Zusammenhang stcht mit den einfachen Bewegungsbedingungen, welche für diese mehr oder minder passiv wandernden Tiere in Betracht kommen. In einem ansprechenden Vortrag hat A. LANG (I903) kürzlich auseinandergesetzt, wie man sich auf Grund der Forschungen von Chun, Verworn u. a. die Wirkung der Statocyste bei pelagischen Tieren erklären kann. Es wird sich meist für das Ticr nur um eine Unterscheiclung von oben und unten und um eventuelle Korrekturen der Körperstellung handeln. Die zu diesen Zwecken notwendige Orientierung kann ihm durch die kugelige Statocyste vermittelt werden.

Bei den nektonischen Formen finden wir mittelmäßig ausgebildete Statocysten, welche schon unregelmäßig gestaltet und vielfach noch offen, ferner in vielen Fällen mit Statolithen versehen sind. 
Endlich bei jenen Formen, welche entweder auf dem festen Land oder am Strand oder am Boden des Meeres zu den behenden Lïufern gehören, finden wir die größten Statocysten, welche gleichzeitig geschlossen und ohne Statolithen sind; sie haben die oben erwähnte komplizierte Form, welche mir an auffallendsten bei Geryon affinis M.-E. u. Bouv. entgegentrat.

Nun entsprechen die Gruppen, in welche wir nach der Beschaffenheit der Statocysten dic Tiefsecbrachyuren einteilen konnten, vollstïndig der Gruppierung, welche wir durch die Eintwickelungshöhe der Gesichts- und Geruchsorgane fanden; und zwar gruppieren sich unter Berücksichtigung der drei Sinnesorgane die Arten so, daß die Formen mit höher entwickelten Augen und den höher entwickelten Statocysten die weniger hoch entwickelten Geruchsorgane besitzen, während die Formen mit den höchstentwickelten Geruchsorganen rückgebildete Augen und wenig entwickelte Statocysten aufweisen.

Eine Erklïrung dieses Zusammenhanges scheint mir sehr nahe zu liegen und beleuchtet gleichzeitig die gesamten Lebensverhältnisse der Tiefseckrabben. Die Formen mit guten Augen sind -- wie auch der ganze Habitus beweist - die beweglichen, flinken Tiere, welche weite Wanderungen auf dem Boden des Meeres auszuführen vermögen. Sie sind hierfür mit guten Orientierungsorganen versehen: mit guten Augen, guten Gleichgewichtssinnesorganen, und ihr Geruchsorgan hat keine hypertrophische Ausbildung nötig gehabt. Die Formen mit rückgebildeten Augen jedoch sind halb sessil in ihrer Lebensweise; sie klammern sich an Schwämmen, Cölenteraten oder Tunicaten etc. des Bodens an, und wie sie ihrer Gesichtsorgane entbehren können, so vermissen sie auch ein hoch ausgebildetes Gleichgervichtssinnesorgan nicht; damit jedoch die Orientierung, besonders das gegenseitige Auffinden der Geschlechter, nicht ganz unmöglich werde, sind sie mit guten Geruchsorganen versehen, wie wir auch gleich sehen werden, daß sie mit guten Tastorganen ausgerüstet sind.

So kommen wir zu dem Ergebnis, daß die biologische Betrachtung der Tiefseebrachyuren gecignet ist, die Theorie von der statischen Sinnesfunktion der Bläschen im Basalglied der inneren Antennen zu stützen, während die Annahme, sie seien Hörorgane, keine Bekräftigung erfährt, allerdings auch keine Widerlegung. Auffallend ist es jedenfalls, daß bei Formen, deren Augen keine hohe Funktion mehr auszuüben vermögen, das Gehör, wenn es vorhanden und in den Blïschen lokalisiert ist, als Fernsinn nicht vikariierend zu Hilfe kommt.

\section{Die Entwickelung des Tastsinnes bei den Tiefseekrabben.}

Eingehende Untersuchungen über den Tastsinn, oder richtiger über die Tastorgane, bei den Tiefseekrabben habe ich nicht ausgeführt. Einige Beobachtungen drängen sich aber bei der systematischen Betrachtung der einzelnen Formen ohne weiteres auf.

Sinneshaare, welche das Getast vermitteln, sind ja bei den Brachyuren, wic bei den übrigen Decapoden in verschiedener Weise über den ganzen Körper verteilt und besonders auf den Extremitäten oft in Büscheln und Reihen vereinigt. Es ist mir aber bisher noch nicht gelungen, über die speciellen Beziehungen der Anordnung zur Lebensweise Klarheit zu erlangen. Infolgedessen will ich mich hier auf einige Bemerkungen über die äußeren Antennen beschrïinken. 
Auf den äußeren Antennen finden wir in der Regel mehr oder weniger lange Sinneshaare in großer Anzahl verteilt; eine Anzahl von Formen ist auf Taf. XLIII abgebildet. Diese Sinneshaare sind offenbar die Vermittler besonders feiner Tastempfindungen, und Experimente weisen darauf hin, daß sie nicht nur auf direkte Berührungen, sondern auch auf relativ geringe Erschütterungen des umgebenden Mediums Reaktionen veranlassen.

Eine Betrachtung der verschiedenen Typen zeigt uns in der Größe der inneren Antennen und dem Reichtum an Sinneshaaren, sowie deren Dimensionen vielfache Verschiedenheiten. So finden wir lange Antennen mit langen Sinneshaaren, welche in großer Anzahl vorhanden sind, bei folgenden Formen:

I. Homolodromia Bonvieri DofL.,

Cyrtomaia Suthii platyceros Dofin,

Pliysachacus ctemumes Alc,

Trichopeltarinm Alcocki DofL.,

Retrophuma Chuni DoFL.

Lange Antennen, bei denen die Sinneshaare nicht so auffallend lang sind, finden sich bei:

II. Homola barbata orientalis HEND.,

Dromia spinosa (STUDER),

Paromola profundom W.-M.,

Hypsophiry's longipes ALc. U. AND.,

Homologenus Braucri DofL.,

Ethussina-Arten,

Ethusa-Arten.

Schließlich finden sich relativ kurze Antennen, deren Sinneshare auffallend kurz sind, bei:

III. Homolochumia Valdiviac Dort.,

Cyclodorippe-Arten,

Platymaia Wy'ville-Thomsoni Mrs.,

Sitramuathict-irten,

Benthochascon Hemingi ALC.,

Psopheticus stridulans ALC.,

Hexaplax sexpes Dori.,

Geryon-Arten,

Carcinoplax longimanus etc.

Versucht man, die Ausbildung der äußeren Antennen in Beziehung zur Lebensweise zu setzen, so fällt es bald auf, daß die systematische Zugehörigkeit zur Form einen größeren Einfluß auf dieselbe zu haben scheint als bei den anderen betrachteten Sinnesorganen. Wir finden vorwiegend lange Antennen bei den Dromiaceen und Oxyrhynchen, während bei den Oxystomen, den Cyclometopen und Catometopen kurze Antennen vorherrschen. Doch kommen die Einflüsse der Lebensweise trotzdem in vielen Fällen zur Geltung. Es fällt auf, daß bei Tiefseebrachyuren aus sämtlichen Abteilungen lange Antennen vorkommen, wir finden sie sogar meistens. 
Ëne Bezichung zur Organisationshöhe der übrigen Sinnesorgane läßt sich nicht so klar nachweisen, wie etwa bei den Augen, Geruchsorganen und Statocysten untereinander. Immerhin zeigen die Formen mit rückgrebildeten Augen besonders lange und mit zahlreichen langen Sinneshaaren versehene ïußere Antennen. Sie bilden die erste der oben zusammengestellten Crruppen. lËne besonders große, sinneshaarreiche Antenne besitzt /lomolodromia (Taf. XLHI, Fïg. I).

In den übrigen Gruppen (II und III) zeigt sich eine buntere Nischung der Formen. Di zeigen Formen mit wohl ausgebildeten Augren, wie Homola barbata liaBr. in ihren verschiedenen Formen, Paromola, Hypsopluys, Homolegenus, mit ihren zum Teil schr großen Augen recht kräftig ausgebildete Antennen, Ethusa und Ethusina haben Antennen, deren Ausbildung im umgrekehrten Verhältnis zur geringren Entwickelung ihrer Augen steht; ebenso haben Homolochunia. Platymara und Goryon mit ihren hoch angepaßten Augen Antennen mit sehr wenigen und sehr kurzen Sinneshaaren; dagregen ist es sehr auffallend, bei den Arten von Cyclodorippe ebenfalls geringe Entwickelung der Antennen aufzufinden.

Berïcksichtigen wir aber die übrigen Verhältnisse des Körperbaues, so finden wir fast stets bei den Formen mit gering entwickelten Tastantennen lange Rostra (Scyramathica) oder weit ausladende Stachelbildungen (Homolochunia), oder weit vom Körper abstehende, zarte, stachelreiche Beine (Platy'maia, Cy'clodorippe), so daß man, besonders wenn man die vielen in der Litteratur angeführten Fälle hinzuzieht, wohl sagen kann, daß alle Tiefseekrabben hoch entwickelte, für den Aufenthalt im Dunkeln oder in der Dämmerung hesonders geeignete Tastsinnesorgane besitzen. Aehnliches ist ja auch für die Tiefseegarneelen und Macruren bekannt; nähere Angaben über einige Formen und Litteratur findet sich in einer neueren Arbeit von KoTTE (1903).

\section{Fortpflanzung.}

Für das \%ustandekommen der Fortpflanzung ist es sicherlich von großer Bedeutung, daß viele der Formen mittlerer und größerer Tiefen in srößeren Scharen beisammen sich aufhalten. Neben den Formen, welche die Expeditionen in geringen Nengen erbeutet haben, stehen solche, von denen große Mengen im gleichen Netzzug gefangen wurden. Bei der "Valdivia“Expedition war dies der Fall z. B. bei Dromia bicomis (Sturder), Dromia spinosa (Studer), Cy'tomaia Sumi Mrs., Platymaia Wyruille-Thomsoni Mrs., Scyramathia Hertaigi Dofu., Scyramathie Rizers-Andersoni ALC, Geryon affinis M. EDw. u. Bouv.

Stets fanden sich bei solchen größeren Fängen Männchen und Weibchen im gleichen Zug. Bei einigen Formen, von denen nur 2 Exemplare erbeutet wurden, kam es auch vor, daß diese beiden $\delta$ und $q$ waren (Mnursia armata curtispina Mrs. und Mursia cristimana Latr. u. a.). Aehnlich wie in den von Ortmaxx (Btrons's Klassen u. Ordn., Malacostraca, S. 124.j) zusammengestellten Fällen, deutet letzterer Befund auf paarweises Zusammenhalten während der Begattungszeit.

Ob der ausgesprochene sexuelle Dimorphismus, wie er sich bei einer ganzen Reihe von Formen findet, besonders die gewaltige Ausbildung ron Scheren beim Niunnchen (Kacmpfferia, Cy'tomain, Echinoplax etc.) für das \%ustandekommen der Fortpflanzung von Belang ist, kann ich nicht sagen. Wissen wir doch über diese Verhältnisse auch bei den lilachwasserformen zu wenig. 
Tierformen, welche unter besonders gearteten, schwierigen Lebensverhältnissen existieren, sind in der Regel durch besonders günstige Fortpflanzungsverhältnisse ausgezeichnet; bei den einen ist die Zahl der produzierten Eier eine ungewöhnlich hohe, bei anderen finden wir Brutpflege, ungeschlechtliche Vermehrungsarten, Parthenogenesis oder sonst eine den Bestand der Art fördernde Einrichtung.

Bei den Krabben sind schon die typischen Flachwasserformen durch so sehr große Mengen von Eiern ausgezeichnet, daß es nicht als auffallend bezeichnet werden kann, wenn wir bei Homolochunia Valdiviae, Platymaia Wyille-Thomsoni, Geryon affinis u. a. die gleiche Erscheinung in der Tiefsee wiederfinden. Wir können darin keine Anpassungserscheinung erblicken, auch ist hervorzuheben, daß die Zahlen geringer sind als bei den sehr eierreichen Strandformen.

Dagegen finden wir bei vielen Formen des tieferen Wassers eine Erscheinung verbreitet, welche unser Interesse in hohem Grade verdient. In dem systematischen Teil habe ich bei einer ganzen Reihe von Arten auf die Größe und geringe Anzahl der Eier, welche je ein Weibchen unter dem Abdomen trägt, hinweisen können. Aus der am Schluß dieses Bandes angefügten Tabelle kann man ersehen, daß die gleiche Erscheinung von früheren Untersuchern bei einer ganzen Anzahl von Arten festgestellt worden ist. Besonders Alcock hat bei der Beschreibung vieler Arten mit Nachdruck darauf aufmerksam gemacht und besonders hervorgehoben, daß darin eine charakteristische Eigentümlichkeit von Tiefseeformen zu erblicken sei. Wir finden z. B. große Eier von $1 / 2$ bis über I mm Durchmesser bei den Arten der Gattungen Dicranodromia, Cymonomus, Cyclodoritpe, Physachaeus, Scyramathia. Bei allen ist zugleich mit dem Anwachsen der Grösse eine Verminderung der Anzahl eingetreten, so daß sich z. B. bei Cyclodorippe-Arten nur 6- I5 Eier nachweisen ließen. Am Schluß dieses Abschnittes drucke ich eine von mir etwas veränderte und vermehrte Tabelle von Sirtr ab, welche auch für Macruren, Anomuren und Cariden die erwähnten Thatsachen bestätigt.

Eine ganze analoge Erscheinung ist bekanntlich für Süßwasser-Decapoden nachgewiesen: bei ihnen, Potamobius, Cambarus, Potamon, Trichodactylus etc., hängt die Größe der Eicr nachgewiesenermaßen mit einer Abkürzung der Metamorphose zusammen. Die Jungen werden erst in einer dem erwachsenen Tier sehr ähnlichen Form aus den Eihüllen, welche die Mutter so lange unter dem Abdomen trägt, frei.

Aehnliches ist für eine Reihe von polaren Formen nachgewviesen; hier sind es vorwiegend Macruren und Cariden, welche sich anführen lassen; bei den wenigen aus polaren Gebieten bekannt gewordenen Brachyuren ist diese Erscheinung bisher nicht gefunden worden. Unzweifelhaft bedingt auch hier die Größe der Eier abgekürzte Metamorphose, und es ist dies für einige der Arten durch G. O. SARS (1890) nachgewiesen worden. So ist bei Sclerocrangon boreas die Metamorphose vollkommen verloren gegangen, die Jungen schlüpfen im Macrurenstadium aus.

Nicht anders wird sich die Entwickelung bei denjenigen Tiefsee-Decapoden verhalten, welche mit großen Eiern ausgestattet sind. Causrier (I895) hat bei Dicranodromia Mahyenxi nachweisen können, daß die Jungen in der Eihülle ein sehr fortgeschrittenes Stadium erreichen.

Dagegen konnte ich z. B. bei Geryon affinis M.-E. u. Bouv., dessen Eier klcin sind, die im Ausschlüpfen begriffenen Zoëen auffinden; bei dieser Art finden wir also eine vollkommene Netamorphose, entsprechend der relativ geringen Größe der Eier. 
Wenn wir nun die Formen mit großen Eiern denjenigen mit kleinen Eiern, oder mit anderen Worten, die Formen ohne Metamorphose den liormen mit Metamorphose gegenüberstellen, so erkennen wir, daß die beiden Gruppen sich je aus denselben Formen zusammensetzen, die wir bisher zu einer ganzen Reihe von Eigrenschaften vereinigt fanden: dic Formen mit Netamorphose sind die beweglichen Arten mit guten Gesichts- und Gleichgrewichtssimnesorganen, ohne Schutzanpassungen besonderer Art und ohne hoch entwickeltes Geruchsorgan; die Formen mit direkter Entwickelung dagegren haben rückgebildete Augen, mäßig entwickeltes Cleichgewichtssinnesorgan, viele Tasthaare, lange Antennen, hoch ausgrebildetes Geruchsorgan, es sind wenig bewegliche formen mit Schutzanpassung oder Maskierungen.

Die gleiche Erfahrung werden wir beim Studium der übrigen Decapodengruppen machen: die sämtlichen Eryoniden haben wenige und große Eier; Willemoesia leptodaclyla hat Eier von $I^{1} / 2 \mathrm{~mm}$ Durchmesser und, wie wir oben $(\mathrm{S} .244)$ sahen, eine unterdrückte Metamorphose. Wo wir in der Tiefe eine Form mit auffallend großen Eiern finden, können wir darauf rechnen, an ihren Organen die erwähnten Rückbildungen zu konstatieren.

Durchmesser und Zahl der Eier von Decapoden des Nordatlantik (nach SMTTH).

\begin{tabular}{|c|c|c|c|c|}
\hline Species & $\begin{array}{l}\text { Durchmesser } \\
\text { der Eier } \\
\text { in mm }\end{array}$ & Zabl der Eier & $\begin{array}{l}\text { Tiefe } \\
\text { des Fundortes } \\
\text { in } \mathrm{m}\end{array}$ & Zustand der Augen \\
\hline Brachyura. & & & & \\
\hline Callinectes hastatus & 0,28 & 4,500000 & weniger als $180 \mathrm{~m}$ & normal \\
\hline Geryon quinquedens & 0,74 & 47000 & $180-2000 \mathrm{~m}$ & Dämmerungsaugen ? \\
\hline Latreallia elegans & 0,54 & 1660 & $\begin{array}{c}\text { geringe Tiefe bis } \\
360 \mathrm{~m}\end{array}$ & $"$ \\
\hline Paguridea. & & & & \\
\hline Eupagueras bernhardies & 0,57 & & geringe Tiefe & normal \\
\hline$" \quad$ politus & 1,12 & 2000 & $\begin{array}{l}\text { geringe Tiefe bis } \\
\text { I } 100 \mathrm{~m}\end{array}$ & $"$ \\
\hline $\begin{array}{l}\text { Parapagurus pilosimanus } \\
\text { Galatheidea. }\end{array}$ & $\mathrm{I}, 2$ & & $550-7000 \mathrm{~m}$ & nornal? \\
\hline Ifunidopsis curvirostra & 1,6 & $14-52$ & $180-2400$ & \\
\hline$" \quad$ crassa & 3,5 & & $3100-4700$ & \\
\hline , rostrata & 3.7 & 230 & $2000-2600$ & \\
\hline $\begin{array}{l}\text { Anoplonolus politus } \\
\text { Macrura. }\end{array}$ & 1,1 & 25 & $\begin{array}{l}\text { geringe Tiefe bis } \\
360 \mathrm{~m}\end{array}$ & rudimentär \\
\hline $\begin{array}{l}\text { Penfacheles nanus } \\
\text { Homarus anericanus }\end{array}$ & $\begin{array}{l}0,77 \\
1,9\end{array}$ & $\begin{array}{c}1250-1500 \\
12000-20000\end{array}$ & $\begin{array}{l}\text { I300-3500 } \\
\text { geringe Tiefe }\end{array}$ & rudimentär \\
\hline Caridea. & & & & \\
\hline Crangon vulgaris & 0,47 & & geringe Tiefe & normal \\
\hline Sclerocrangon Agassizii & 2,5 & & $700-1800$ & rudimentär \\
\hline Pontophilus noriegicus & $1, I$ & & $180-1100$ & \\
\hline " brezirostris & 0,7 & & $\begin{array}{l}\text { geringe Tiefe bis } \\
300 \mathrm{~m}\end{array}$ & \\
\hline " $\quad a b y s s i$ & 0,7 & & $3500-4000$ & ndimentär \\
\hline Sabinca princeps & 1,8 & 353 & $550-1650$ & \\
\hline "Sarsii & $\mathbf{I}, 3$ & & $180-360$ & \\
\hline $\begin{array}{cl}\text { Glyphocrangon } & \text { sculptus } \\
& \text { longirostris }\end{array}$ & $\begin{array}{l}3,0 \\
3,0\end{array}$ & $\begin{array}{l}97 \\
86\end{array}$ & $\begin{array}{l}1800-2600 \\
1500-2000\end{array}$ & $\begin{array}{c}\text { rudimentär } \\
\qquad,\end{array}$ \\
\hline
\end{tabular}




\begin{tabular}{|c|c|c|c|c|}
\hline Species & $\begin{array}{l}\text { Durchmesser } \\
\text { der Exer } \\
\text { in } \mathrm{mm}\end{array}$ & Zahl der Eier & $\begin{array}{c}\text { Tiefe } \\
\text { des Fundortes } \\
\text { in } \mathrm{m}\end{array}$ & Zustand der Augen \\
\hline Palacmon forceps & 0,6 & 7000 & geringe Tiefe & normal \\
\hline Palaemonetes inlgaris & 0,7 & 360 & $"$ & " \\
\hline Tematocarinus ensiferus & 0,68 & $16000-21000$ & $1100-3650$ & $"$ \\
\hline " cursor & 0,64 & 20000 & $700-1500$ & $"$ \\
\hline Acanthephyna Agassizii & 0,85 & 5000 & $\begin{array}{c}\text { geringe Tiefe bis } \\
5500 \mathrm{~m}\end{array}$ & \\
\hline brevirostris & 0,70 & & $2600-5500$ & \\
\hline gracilis & 2,5 & 21 & $3000-4600$ & rudimentär \\
\hline Pasiphaë tarda & 5,0 & 94 & $180-360$ & $"$ \\
\hline .. princeps & 3,5 & & $700-2600$ & . \\
\hline Parapasiphaë sulcatifrons & 4,2 & $15-19$ & $900-5500$ & , \\
\hline
\end{tabular}

\section{Zusammenfassender Leberlulick über die Biologie der Tiefseekrabben.}

Es ist mir unmöglich, einen Teil eines Tieres zu untersuchen, ohne mir das ganze lebende Tier dazu zu rekonstruieren. Nur dann interessiert mich der Bau eines Organs, wenn ich mir dessen Rolle in der Ciesamtorganisation des Tieres, seine Funktion im Leben desselben vorstelle. So mache ich es denn wie jeder Paläontologe und suche in der Phantasie ein Bild von dem Tier und seinen Lebensverhältnissen zu erfinden. Je mehr positive Daten mir zur Verfügung stehen, um so näher kann dies Bild der Wirklichkeit kommen, und je mehr ich mir dessen bewußt bleibe, daß es sich um ein Phantasiebild handelt, um so bessere Dienste kann es mir bei der Erforschung der thatsächlichen Lebensverhältnisse der betreffenden Tierform leisten. So möge man es mir verzeihen, wenn ich ein solches Phantasiebild einmal schriftlich festhalte; ich bin überzeugt, daß die in dieser Zusammenfassung der bekannten Daten gegebene Formulierung der Probleme einiges zur Aufklärung der in so vielen Punkten noch rätselhaften Lebensweise der Tiefseetiere beitragen kann.

Die Brachyuren der Tiefsee sind biologisch in zwei Gruppen zu scheiden, deren jede Tiere aus den verschiedenen systematischen Abteilungen umfaßt und welche in ihrer Umgrenzung gar nichts mit den Kategorien des zoologischen Systemes zu thun haben. Beide Gruppen sind natürlich durch vielfache Uebergänge miteinander verbunden.

Nach ihren typischen Vertretern und ihren charakteristischsten Eigenschaften können wir die erste die Gruppe der sehenden Tiefseekrabben, die zweite die Gruppe der blinden Tiefseekrabben nennen.

Eine sehende Tiefseekrabbe kriecht als mit großen, wohlpigmentierten Augen versehene Zoëa aus dem kleinen Ei aus, welches das Muttertier unter seinem Abromen getragen hatte. Nit ihm ungefähr gleichzeitig kriechen noch einige Hundert bis Tausend Brüder und Schwestern aus den Eiern. Sie schweben sogleich im Wasser, und zwar sicherlich aufwärts. Stacheln und Schwebfortsätze erlauben ihnen, den Boden des Oceans zu vermeiden. Sie steigen vielleicht nicht nur einmal aufwärts, sondern halten sich, heranwachsend, in den oberen Regionen mit den wechselnden Temperaturen und Belichtungsverhältnissen, innerhalb von einigen hundert Metern auf- und niederschwebend. Ihre Nahrung wird aus kleinen Planktonorganismen bestehen. Ihre 
Augen können verschiedene Formen besitzen, meist gleichen sie denjenigen von Decapodenformen, welche dauernd ein pelagisches Leben führen.

So wachsen sie allmählich heran, die Substanzen des Körper werden mit der \%eit schwerer, und das Tier beginnt in die Tiefe zu sinken. Je mehr es sich dem Boden nähert, um so mehr gleicht es in seiner Form einem echten Bodentier. Die Schwebfortsätze sind verschwunden, die Stacheln des Körpers sind auf ein geringes Maß reduziert, die Augen nehmen allmählich die für einen Bodenbewohner geeignete Form an, indem sie nicht mehr nach allen Richtungen. sondern vorwiegend nach vorn und unten ihr fiesichtsfeld halen.

Der Körper wird gedrungen, die Beine, die vorher sehr zart waren, um das Schweben $z u$ unterstützen, werden stark und fest, und nunmehr begmnt das Tier seine ruhelosen Wanderungen am Meeresboden. Oft sind die Larven weit zerstreut worden; nicht selten finden sich aber größere Mengen von ihnen zusammen und bilden ganze Herden auf dem Boden des Oceans.

Unter zahlreichen weiteren Häutungen wachsen die Tiere heran. Bei ihren Wanderungren in dem unendlichen dunklen Raum mit seiner gleichmäßBigen Temperatur und seinem unbewegten Wasser stürzen sie wohl jedem in der Ferne auftauchenden Phosphorescenzlicht zu, von den Lichtstrahlen angezogren. Dabei dienen ihnen ihre großen, mit besonderen Anpassungen ausgrestatteten Augen in vortrefflicher Weise. Sie werden die verschiedensten Tiere, besonders sessile Formen, zu ihrer Nahrung wählen, auch mit Aas fürlieb nehmen, wenn sie einem tödlichen Kampf als glückliche Unparteiische beiwohnen, oder irgrend ein Ereignis ihnen eine tote Beute verschafft. Manche Formen, besonders in den mittleren Regionen, in die noch schwacher Tagesschein dringt, werden ruhig sitzend mit ihren leuchtenden Augen Beutetiere anlocken und mit den Scheren erhaschen.

Oft werden sie in der Lage sein, mit der ganzen Schnelligkeit ihrer Beine vor einem Verfolger sich retten zu müssen: bald wird es ein gefräßiger Fisch, bald eine Krake mit schrecklichen Saugarmen sein, denen sie entfliehen müssen. Bei ihrem raschen Lauf werden ihnen ihre Statocysten sehr zu statten kommen, welche ihnen ermöglichen, ihre Bewegungen aufs feinste zu regulieren. Oft werden sie aber nur nach Verlust von einer oder einigen Gliedmaßen sich retten können, um in einer stillen Ecke, oder eingewühlt im Schlamm, die Heilung und Regeneration des verlorenen Teiles zu erwarten.

Sind sie zu einer gewissen Größe herangewachsen, so werden ihre Geschlechtsorgane reifen. Entweder isolieren sie sich paarweise, oder die Fortpflanzung wird dadurch gesichert, daß sie in Herden bei einander bleiben. Andere Formen, welche zerstreut leben, werden sich vielleicht zu solchen Zeiten an gewissen Stellen in Mengen versammeln.

Dann findet die Begattung statt, die Weibchen produzieren große Mengen von Eiern, welche an den Pleopoden des Abdomens befestigt werden. Neist haben die Tiere zur Zeit der ersten Begattung bei weitem noch nicht ihre volle Größe und definitive Form erreicht. Während das Weibchen seine ersten Bruten unter dem Abdomen trägt, wächst es wahrscheinlich noch. Auch füllt sich sein Ovar mit einer neuen Menge von Eiern, und in den ersten Lebensabschnitten wird jede Brut an Zahl der Eier die vorhergehende übertreffen.

Meist wird wohl ein gewaltsamer Tod das Leben des Individuums beschließen.

Viel einfacher wird sich der Lebenslauf einer Tiefseekrabbe der blinden Gruppe abwickeln. Aus dem großen $\mathrm{Ei}$, das die Mutter mit nur ganz wenig anderen unter dem Abdomen 
trägt, wird eine Megalopa oder eine gar noch weiter entwickelte kleine Krabbe ausschlüpfen. Sie und ihre wenigen Geschwister werden sogleich am Boden bleiben und in der unmittelbaren Nachbarschaft ihrer Geburtsstätte ihren dauernden Aufenthaltsort wählen. Es wird dies ein selbstgewühltes Loch im Schlamm, ein Plätzchen auf den Aesten eines Cölenteraten, eine Ecke auf der Oberfläche einer Spongie oder ein ähnlicher Ort sein.

Die Nahrung wird aus Teilen der jeveiligen Unterlage bestehen, Stückchen des Schwammes, des Cölenteraten oder der Schlamm wird _- wie das ja auch bei zahlreichen Flachwasserformen der Fall ist — durch den Darm passieren und dort seinen Reichtum an organischem Material zurücklassen müssen.

Die Tiere sind ebenso viel Verfolgungen ausgesetzt wie die frei umherlaufenden Formen, aber da sie mit ihren Augen nichts sehen und mit ihren Statocysten ihre Bewegungren nicht so fein regulieren können, so suchen sie nicht zu entfliehen. Sie klammern sich fest an ihre Unterlage an und "stellen sich tot". Ihre Augen zeigten ihnen durch den Unterschied ron Licht und Dunkel eventuell das Nahen des Feindes an, ihre feinen Tasthaare am Körper und besonders an den Antennen kündeten ihnen schon von weitem dessen Bewegungen an. Regungslos erwarten sie ihn, und in den meisten Fällen werden sie ihm wohl unbemerkt bleiben, denn ihr Körper ist entweder mit feinen Haaren bedeckt, welche den Schlamm zurückhalten und sie so unkenntlich machen, oder sie gleichen auffallend ihrer Umgebung, entweder in der Struktur ihrer Körperoberfläche oder durch Maskierung. Viele Formen haben Reihen von Angelhaaren auf der Oberfläche ihres Cephalothorax, mit denen sie Hydroidpolypen, Schwammstïcke, Actinien, Tunicaten auf ihrem Rücken befestigen, andere halten mit den Scheren des 5. Pereiopodenpaares Schwämme, Muscheln oder Ascidien über sich und erreichen dadurch den gleichen Zweck.

Sind sie geschlechtsreif geworden, so sind Männchen und Weibchen nicht,zu weit voneinander, um sich zu finden. Ihr hochausgebildetes Geruchsorgan führt sie einander zu. Nach der Begattung legt das Weibchen nur eine ganz geringe Zahl der sehr großen Eier an seine Pleopoden ab. Diese werden wohl sehr lange vom Weibchen getragen, ehe die weit entwickelten Jungen auskriechen.

So sehen wir die Krabben der Tiefsee in ganz verschiedener Weise leben, wobei das Leben und die Organisationshöhe sich gegenseitig bedingen. Und wie wir zwischen den extrem ausgebildeten Organen eine Menge von Uebergangsstufen fanden, so werden auch die Lebensverhältnisse der Tiefseekrabben eine große Mannigfaltigkeit darbieten. 


\title{
Litteraturverzeichnis zum II. Teil.
}

\author{
Biologie der Tiefseekrabben.
}

Arcock, A., rg02, A Naturalist in Indian Seas, London, John Murray.

BATE, SPENCE, I888, Macrura, in: Challenger Reports, Vol. XXIV.

BeER, Tir., IgoI, Ueber primitive Sehorgane, in: Wien. klin. Wochenschr, Jahrg. 1901, No. I I, I2 u. I3.

C.ıustier, E., I895, Sur le développement embryonnaire d'un Dromiacé du genre Dicranodromia, in: Compt. Rend. Ac. Sci. Paris, T. CXX, p. 573.

Cruv, C., I887, Die pelagische Tierwelt in größeren Mecrestiefen und ihre Beziehungen zu der Oberflachenfauna in: Bibliotheca Zoologica, Bd. I, Heft 1, S. I.

- I890, Atlantis, in: Zoologica, Heft 19.

- I900, Aus den Tiefen des Weltmeeres, I. Aufl., I900, II. Aufl., I902, Jena.

Doederleix, L., 1883 , Faunistische Studien in Japan, Enoshima und der Sagamibai, in: Arch. f. Naturgesch., bd. IL, $\therefore$ I I I

DofleIN, F., I903, Die Augen der Tiefseekrabben, in: Biolog. Centralbl., Bd. XXIII, S. 570.

Eigenmanx, C. H., 1898, The Amblyopsidae, the blind fishes of America, in: Rep. 67. Meet. Brit. Ass. Adv. Sc., p. 685 .

- 1902, The History of the Eye of Amblyopsis, in: Proc. Indiana Acad. Sci. f. Igor, p. Ior (citiert nach Neapler Jahresbericht für 1902).

Exxer, S., I89i, Die Physiologie der facettierten Augen von Krebsen und Insekten, Leipzig u. Wien.

Faxos, 1895, Reports on an Exploration etc. XV. The stalk-eyed Crustacea, in: Mem. Mus. Compl. Zoology at Harvard College, Vol. XVIII.

Forbes, EDw, 1859, Natural History of the European Seas. Ed. by GodwiN-AUSTEN.

FRIES, 1874, Die Falkensteiner Höhle, ihre Flora und Fauna, in: Württemb. naturw. Jahreshefte, 1874, S. 3 I.

Gamble u. Kefbi.e, rgoo, Hippolyle varians: a Stucly in Colour-Change, in: Quarterly Journ. Mlicrusc. Science, London, New Series Vol. XLIII, p. 580 .

Goode, G. B., 1878, The voices of Crustaceans Proc. U. S. Nat. Museum, Vol. I, p. 7-8.

Grenacier, H., r879, Untersuchungen üher das Sehorgan der Arthropoden, Göttingen.

HAmann, O., I896, Europäische Höhlenfauna. Eine Darstellung der in den Hoblen Europas lebenden Tierwelt, Jena.

Henderson, I887, Anomura, in: Challenger Reports, Vol. XXVII.

Hexsex, V., 1863, Studien über das Gehürorgan der I)ecapuden, in: Zeitschr. wiss. Zoologie, Bd. XIII, p. 3 ro, 'Taf. In -22 .

- 1809, Wic steht es mit der Statocysten-Hypothese? in: Arch. Phys. PrLÜger, Bd. LXXIV, S. 22.

HrsSE, R., 1897 - I902, Untersuchungen über die Organe der Lichtempfindung bei niederen 'Tieren, I-VIII, in: \%eitsclur. wiss. Zool., Bd. LXI, LXII, LXIII, LXV, LXVIII, LXX, LXXII.

HoFEr, B., 1899 , Die Verbreitung der Tierwelt im Bodensee nebst vergleichenden Untersuchungen in einigen anderen Süßwasserbecken, in: Schriften des Vercins für Geschichte des Bodensecs und seiner Umgebung, Heft 128, der Bodenseeforschungen Io. Abschnitt.

Котте, E., I903, Beiträge zur Kenntnis der Hautsinnesorgane und des peripheren Nervensystems der TiefseeDekapoden, in: Zool. Jahrb), Abt. Anat., Vol. XVII, p. 619.

LAxg, A., 1903, Ob die Wasscrtiere hören? \% wei athademische Vortrïge, in: Mitteil. der Naturwissensch. Gesellsch. in Winterthur, Heft \&.

LANkester, Rar; 1903, On the Modification of the Eyc Peduncles in Crabs of the genus Cymonomus, in: Quart. Journ. Micr. Sci., New Scr. Vol. XlYII, I't. III, p. 437.

List, Tir, 1899, Ueber den Einfluß des Lichtes auf die Ablagerung von Pigment, in: Arch. Entwicklungsmech. Bd. VIII, S. oIs. 
Malard, I802, in: Bull. Soc. Philomat. Paris, Sér. 8, T. IV, p. 28.

Marshall, W., I888, Die Tiefsee und ihr Leben, Leipzig.

Milne-Edwards, A., u. Bouvier, E. L., I892, Observations préliminaires sur les Paguriens recueillis par les expéditions du Travailleur et du Talisman, in: Ann. Sci. nat., Sér. 7, Zoologie, T. XIII, p. I 85.

- Considérations générales sur la famille des Galathéidés, ibid., Sér. 7, Zoologie, T. XVI, p. I9I.

Newbigin, M. E., I898, Colour in Nature: a Study in Biology, London, John Murray.

Ortmann, A. E., I899, Malacostraca, in: Bronn's Klassen und Ordnungen des Tierreichs. Begonnen von Gerstäcker.

Ostwald, Wolfg., I902, Zur Theorie des Planktons, in: Biolog. Centralbl., Bd. XXII, S. 596 u. 609.

- Ig03, Theoretische Planktonstudien, in: Zool. Jahrb. Syst., Bd. XVIII, S. I.

PACKard, A. S., I888, The Cave fauna of North America, with remarks on the anatomy of the brain and origin of the blind species, in: Mem. Nat. Acad. Science, Vol. IV, Pt. I, Washington, p. 3-I56.

- 1894, On the origin of the subterranean fauna of North America, in: American Naturalist, Vol. XXVIII, p. 727.

PArker, G. H., I89I, The Compound Eyes in Crustaceans, in: Bull. MIus. Comp. Zoology, Vol. XXI, p. 45.

- 1895, The Retina and optic Ganglia in Decapods, especially in Astacus, in: Mitt. \%ool. Station Neapel, Bd. XII, S. I.

- 1899, The photomechanical Changes in the retinal Pigment of Gammanes, in: Bullet. Mus. Comp. Zoology, Cambridge, Vol. XXXV, p. I 43 .

Pouchet, 1872, Sur les rapides changements de coloration proroqués expérimentalement chez les Crustacés, in: Comptes Rendues Ac. Sci. Paris, T. LXXIV, p. $75 \%$

- I876, Changements de coloration sous l'influence des nerfs, in: Journal de l'Anatomie et Physiologie, T. XII, p. I-90 u. II 3 -I 65 .

Przibram, H., 1902 A, Experimentelle Studien über Regeneration (2. Mitteilung: Crustaceen), in: Archiv für Entwickelungsmechanik d. Org., Bd. XIII, S. 507.

-, 1902 B, Intraindividuelle Variabilitat der Carapaxdimensionen bei brachyuren Crustaceen, in: Archiv für Entwickelungsmechanik d. Org., Bd. XIII, S. 588.

Rosenstadt, 1896, Beiträge zur lienntnis des Baues der zusammengesetzten Augen bei den Decapoden, in Archiv fo mikrosk. Anatomie, Bd. XLVII, S. 748 .

SaRs, G. O., I885, Schizopoda, in: Challenger Reports, Vol. XIII.

*Schneider, R., I885 A, Ueber subterrane Organismen. Abhandlung zum Programm des K. Real-Gymnasiums zu Berlin, Ostem I 885 .

- 1885 B, Der unterirdische Gammans von Clausthal (G. pulex var. sublerranens), in: Sitzungsber. Akad. Wiss. Berlin, S. 1087 , Taf. I5.

- 1887, Ein bleicher Asellus in den Gruben von Freiberg im Erzgebirge, in: Sitzungsber. Akad. Wiss. Berlin, S. $723-742$, Taf. 12 , I3.

Suitil, Sidney J., I886, The abyssal Decapod Crustacea of the "Albatross" dredgings in the North Atlantic, in: Ann. Mag. Nat. Hist, Ser. 5, Vol. XVII, p. I87.

Thonison, C. Wrville, I873, The Depths of the Sea, London, Macmillan \& Co.

VERrill, A. E., I885, Results of the Explorations made by the Steamer "Albatross" of the Northern Coast of the United States, in $188_{3}$, in: U. S. Comm. Fish and Fisheries, Part XI, Report of the Commissioner for 1883 (1885), Appendix D, p. 503 .

Walter, Johaxxes, I893, Einleitung in die Geologie als historische Wissenschaft, Jena.

Weismann, A., 1902, Vorträge über Descendenztheorie, 2 Bde, Jena.

Wexdon, F. R., I 89.5, An attempt to measure the death rate due to the selective destruction of Carcimus maenas etc., in: P'roc. Roy. Soc. London, Vol. LVII, p. 360.

- 1898, Address to the Zool. Section of the British Assoc. for Advanc. Sc., Bristol I898; auch Nature, Vol. LVIII, p. 499 .

Willemoes-Sunm, R. v., I875, On some Atlantic Crustacea from the "Challenger" Expedition, in: Transactions of the Linnean Society, Ser. 2, Zoology; Vol. I, p. 23.

'Zeller, E., I889, Ueber die Fortpflanzung des Protens angminens und seine Larse, in: Jahresber. Ver. vaterl. Naturkunde in Württemberg, Jahrg. 45, S. I3 I. 


\section{Tiergeographischer Teil.}


• 
Urspringlich beabsichtigte ich, die tiergeographischen Ergebnisse meiner Untersuchung der "Valdivia"Brachyuren mit den Ergebnissen der verschiedenen Sammlungen, welche mir zur Bearbeitung anvertraut sind, und der großen ostasiatischen Sammlungen, welche in den letzten Jahren in unser Münchener Muscum gekommen sind, vereinigt darzustellen. Ich habe diese $\Lambda$ bsicht aufgegeben, weil jene anderen Sammlungen noch nicht hinreichend bearbeitet sind und weil ich auf einer Reise selbst noch weiteres Material in einigen Grenzgebieten zu sammeln hoffe.

Ich will in diesem Bericht nur die auffallenderen Verïnclerungren unserer Kenntnisse darstellen, wie sie sich auf Grund der Ausbeute der deutschen Tiefsec-Expedition für cine Anzahl von Arten und Gattungen ergeben, und daraus die allgemeinen Schlüsse ziehen.

\section{Horizontale Verbreitung litoraler und sublitoraler Brachyuren.}

\section{A. Atlantik.}

Die neucren Befunde zeigen ganz allgemein, wie mißlich die Abgrenzung von Regionen und Subregionen auf Grund unserer relativ noch so mangelhaften Kenntnisse der marinen Tiere und ihrer Verbreitung ist. Die von der "Valdivia“-Expedition berührten litoralen Gebiete des Atlantischen Oceans liegen im Gebiete der von OrTMann (1896) aufgestellten westafrikanischen Region, und zwar sowohl in der mediterranen als auch in der GuineaSubregion, und außerdem in dem Teil der antarktischen Region, welchen dieser Autor nach dem Vorgang von PFeffer (1890) zur Lokalfauna des Kaps der guten Hoffnung rechnet. Die „Valdivia“-Expedition hat nun, wie ich im I. Teil dieses Bandes festgestellt habe, in diesem Gebiet folgende auffälligen Funde gemacht:

Fundort der "Valdivia"-Expedition

Ethusa mascarone HBSt. charakteristisch für die medi- Kongomündung terrane Subregion

Doritpe lanata L.

Stenorhynchus rostratus L.

Pisa carinimana Mrs.

Micropisa violacea M.-E. Lambrus macrocheles (Нвsт.) Gonoplax angulata (PENN)

Ocypode cursor (L.) Uca Tangieri (EYD.) ebenso . . . . . Kongomündung

bisher von Norwegren bis zu Kongomündung den Capverden bekannt

bisher Canarische Inseln und Kongomündung Senegrambien

Marokko bis Angrola . . Große Fischbucht

Mittelmeer bis Liberia . . Kongomündung

England bis Marokiko: Mittel- Kapregion (so auch nach STEBmeer BING)

Mittelmeer bis Loanda . . . I Tigerhalbinsel (Große Fischbai)
Portugal bis Loanda. . . . 
Bedenken wir ferner noch, daß Scyramathia Hertzugi Dofu. vom Kap der Sc. Carpenteri Norn. aus dem Nordatlantik sehr nahesteht, daß die „Valdivia“-Expedition eine Inachus-Art, welche nordatlantischen Formen nahesteht, in der Kapregion fand, und daß auch sonst die Meeresfauna der Südspitze von Afrika Beziehungen zur nordatlantischen Fauna zeigt, so muß uns dies gegenüber der Unterscheidung zweier Subregionen an der westafrikanischen Küste vorsichtig machen. ORmann selbst hat ja hervorgehohen, wie außerordentlich wenig erforscht die litorale Neeresfauna der Westküste von Afrika ist. Sie scheint außerdem auch nicht sehr reich zu sein. Von der Fauna der deutsch-sïdwestafrikanischen Küste wissen wir so gut wie nichts, und über die übrigen Teile der Westküste ist das Material chenfalls sehr fragmentarisch.

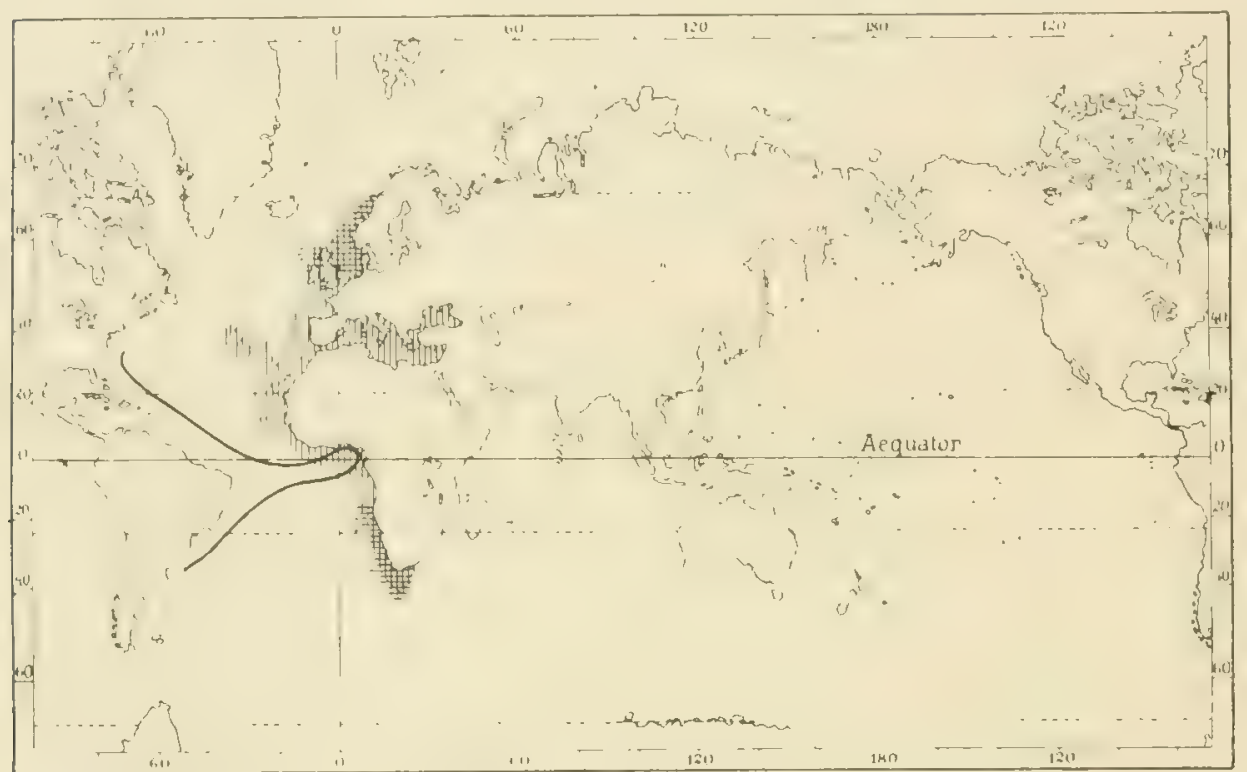

||||||||||| Ostatlantische Fauna.

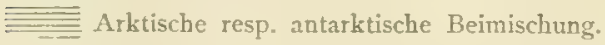

Die starke Kurve kennzeichnet die Verbreitung der tropisch-westatlantischen Litoralfauna und ihre Beziehung zur Litoralfauna von Westafrika.

Fig. 57. Verbreitung der ostatlantischen Litoralfauna.

Durch das, was wir bis jetzt wissen, erhalten wir aber den Eindruck, daß die lokalen Unterschiede der Fauna hauptsächlich auf den Unterschieden der Facies begruindet sind. So kommt es, daß die Mangroveküsten von Guinea und Kamerun eine scheinbare faunistische Barriere darstellen. Wir finden ihre Wirkung wesentlich an den Strandtieren sich äußern; aber trotzdem sehen wir mit der dürren, sandigen und steinigen Küste in der Nähe der Kongomündung und in Angola und Benguela Formen wiederkehren, die wir in der nördlich grelegenen faciell ähnlichen Litoralregion von Marokko und Senegambien gefunden.

Lassen wir aber die specifischen Strandformen beiseite und berücksichtigen nur die Formen des etwas tieferen Wassers von ca. $50 \mathrm{~m}$, so sehen wir, daß jene Scheinbarriere gar keine Wirkung äußert und daß nordatlantische Formen sich weit nach Süden erstrecken. Ja, die Analogie mit der westamerikanischen Litoralregion, auf welche ORTMAnN hinweist, scheint mir eine viel weiter grehende zu sein, als er annahm. Wie an der westamerikanischen Küste die panamische Region mit ihren indopacifischen Tropenformen nur einen geringen Raum einnimmt, so auch an der westafrikanischen Küste die Guinearegion, mit ihren tropisch-atlantischen (karibischen und brasilischen) Formen.

Wir sehen auch hier eine fast kontinuierliche Verbindung für die subarktischen und subantarktischen Formen bestehen, und ich bin überzeugt, daß diese Thatsache noch viel mehr in 
die Augen springen wird, wenn wir die Fauna der deutsch-südwestafrikanischen Küste kennen gelernt haben.

Alle Erfahrungen der letzten \%cit haben uns mehr und mehr gelehrt, daß die Verbreitung der Meerestiere am meisten von den Wasscrtemperaturen becinflußt wird. Ein Blick auf dic Karte in Scrotr's Atlas (Occanographie, Bd. I dieser Ergebnisse, Taf. X) läßt uns verstehen, wie die Verbreitung der atlantischen Tiere in Tiefen von ca. $50 \mathrm{~m}$ (bis $100 \mathrm{~m}$ ) mit den Wassertemperaturen in Zusammenhang steht.

Wir sehen, daß in dem ganzen westafrikanischen Litoralgebiet die Temperaturen in diesen geringen Tiefen zwischen $10^{\circ}$ und $20^{\circ}$ liegen, und sehen ferner, daß selbst da, wo clie Temperatur der oberflächlichsten '/onen höher steigt, in der Tiefe' von $50-100 \mathrm{~m}$, also in einer für die Flachwasserformen noch vollkommen zugänglichen Tiefe, VVassertemperaturen herrschen, welche dic Verbreitung der betreffenden Formen nur fördern können. Das Crebiet dieser günstigen Temperaturen ist noch dazu ein kontinuierliches, auch ist die Richtung der Strömungen eine derartige, daß cin Verbreitungshindernis nicht entsteht.

\section{B. Antarktis.}

Weder in der Antarktis noch im subantarktischen Ufergebiet fand die "Valdivia“ Expedition irgend eine für die Fauna dieser Gegenden neue Form auf. Dies ist gewiß ein Zeichen der Armut an Brachyuren, welche die antarktische Fauna in noch höherem Naße auszeichnet als die arktische. Keine der aufgefundenen Litoralformen ist für die Arktis und Antarktis gemeinsam. Einige der in tieferen Wasser gefundenen Formen enweisen sich allerdings als beiden Gebieten gemeinsam, wir werden aber unten bei deren Besprechung sehen, daß es sich um Tiere handelt, welche nach den Befunden der "Valdivia“-Expedition sich als nahezu kosmopolitisch erweisen. Wir können daher an dieser Stelle auf die antarktische Brachyurenfauna nicht näher eingehen.

\section{Indopacifik.}

Unsere Kenntnis der Verbreitung von litoralen liormen im Gebiet des Indopacifik ist durch die deutsche Tiefsce-Expedition naturgemäß nicht sehr gefördert worden, wenn sich auch eine Anzahl interessanter Befunde ergaben. Mehr neue Funde ergaben die Fïnge in der sublitoralen \%one (ca. 100-200 m). Die meisten derselben bestehen in der Feststellung von Formen, welche bisher im östlichen Indopacifik grefunden worden waren, in dessen westlichem Teil, besonders an der ostafrikanischen Küste; z. B. Cosmonohus Gray'i AD. u. Wri., Ly'reidus tridentahus I) H. u. S. W., ferner wurde eine ganze Reihe von Formen auf Grund von Material des Münchener Museums als den Meeren Japans, Indiens und Ostafrikas gemeinsam erkannt. Die Zahl dieser Formen werde ich noch sehr vermehren können, wenn ich das reiche japanische Material des Münchener Museums genau durchgearbeitet habe und veröffentliche.

Es ist schon längst bekannt, daß eine ganze Reihe von Arten, auch speciell unter den Brachyuren, in den Litoralgebieten sowohl des Atlantik als auch des Indopacifik vorkommen. Wihrend sich bei manchen dieser Arten absolut keine Unterschiede zwischen den atlantischen und indopacifischen Formen auffinden ließen, giebt es andere, welche deutlich in zwei Formen 
zerspalten sind, von denen die eine auf den Indopacifik, die andere auf den Atlantik beschränkt ist. Wie wir aus der beigedruckten Karte entnehmen können (Fig. 58) ist die Verbreitung von Homola barbata FABR. eine sehr eigenartige. Im Mittelmeer und im Ostatlantik sowie im West-

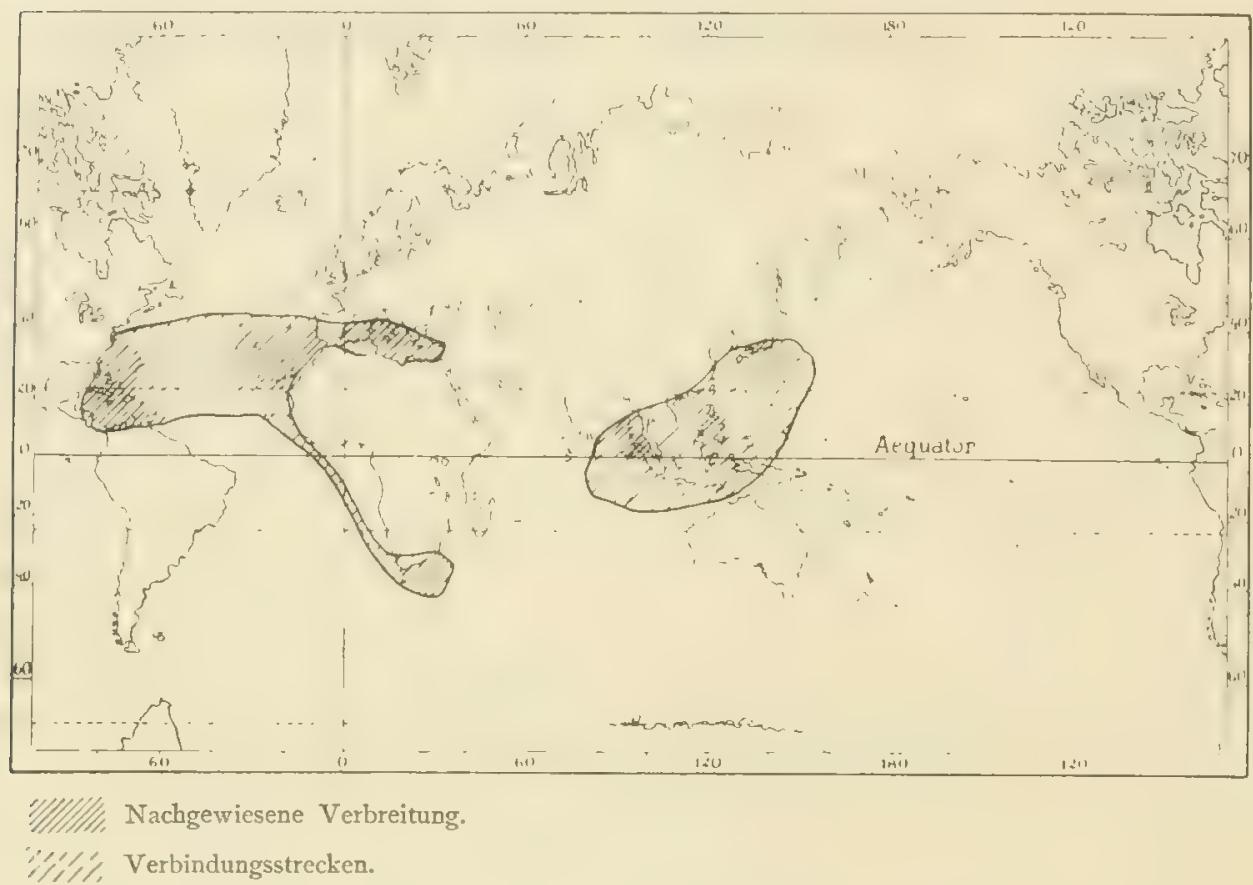

Fig. 58. Verbreitung von Homola barbata typica und IT. barbata orientalis. atlantik findet sich bemerkenswerterweise dieselbe Form, wie in der Kapregion. Im Indischen Ocean, im Japanischen Meer und anderen Teilen des Pacifik findet sich eine zweite Form, welche von der ersten durch so geringfügise Unterschiede getrennt ist, daß wir sie nur als Subspecies voneinander trennen können. Es scheint mir keinem Zweifel zu unterliegen, daß bei genauerer $\mathrm{Er}$ forschung der Meere die Verbreitung beider Formen sich als eine viel

weitere herausstellen wird. Sie ziehen sich nämlich in den heißen Oceanen in die mittleren Tiefen zurück, wo sie die ihnen entsprechende mäßige Temperatur vorfinden. So wird denn einerseits die kalte westamerikanische Region, andererseits die Kapregion die Grenze zwischen den beiden Formen darstellen.

Das Verhalten von $H$. barbata ist typisch für eine Reihe anderer Formen, welche allerdings nicht in dem Material der "Valdivia"-Expedition enthalten waren.

\section{Horizontale und vertikale Verbreitung der Brachyuren des tiefen Wassers.}

Es giebt merkwürdigerweise nur wenige Brachyuren, welche in kalten Temperaturen gedeihen; daher wird die Krabbenfauna immer ärmer, je mehr wir uns den Polen nähern, und die gleiche Erscheinung tritt uns entgegen, wenn wir die großen Tiefen des Oceans untersuchen. Wir kennen aus ihnen nur sehr wenig Brachyuren (vergl. die Tabellen am Schluß dieses Bandes). Die "Valdivia"-Expedition hat in dieser Beziehung unsere Kenntnisse nicht vermehrt. Die größte Tiefe, aus welcher sie eine Krabbe heraufbrachte, betrug nur $2068 \mathrm{~m}$ (Geryon panlensis DOFL.).

Um so mehr hat aber die Expedition unsere Kenntnisse von der Verbreitung der reichen Brachyurenfauna der mittleren Tiefen vermehrt. 
Für manche Formen hat sie das bekannte Verbreitungsgebict schr ausgedehnt. Vor allen Dingen gilt dies für die indopacifischen Tiefenformen, von denen eine große Anzahl an der ostafrikanischen Küste wiedergefunden wurden. So zeigt uns z. B. die beistehende Fig. 59, in welcher Weise Platymaia Wy'zille-Thomsoni Mrs. als indopacifische Tiefenform verbreitet ist.

Ihr schließen sich eine Reihe weiterer Formen an, deren Verbreitung eine ganz ähnliche ist, $z$. B. :

Physachaens ctemunes Atc.

Cyclodorippe uncifera Oтгтм.

Randallia pustulosa IV.-N.

Pleistacantha Moseleyi (Mrs.)

Scyramathia pulchra Mrs.

Scyramathia RiversAndersoni Atc.

Während alle diese Befunde uns darauf hinweisen, in den mittleren Tiefen des Indischen Oceans eine einheitliche tiergeographische Region zu erblicken, weisen andere Befunde auf eine gewisse Gliederung in Provinzen hin.

Sehr charakteristisch ist in dieser Beziehung die Verbreitung der Gattung Cyrtomaia. IVie die nebenstehende Kartenskizze angiebt, er-

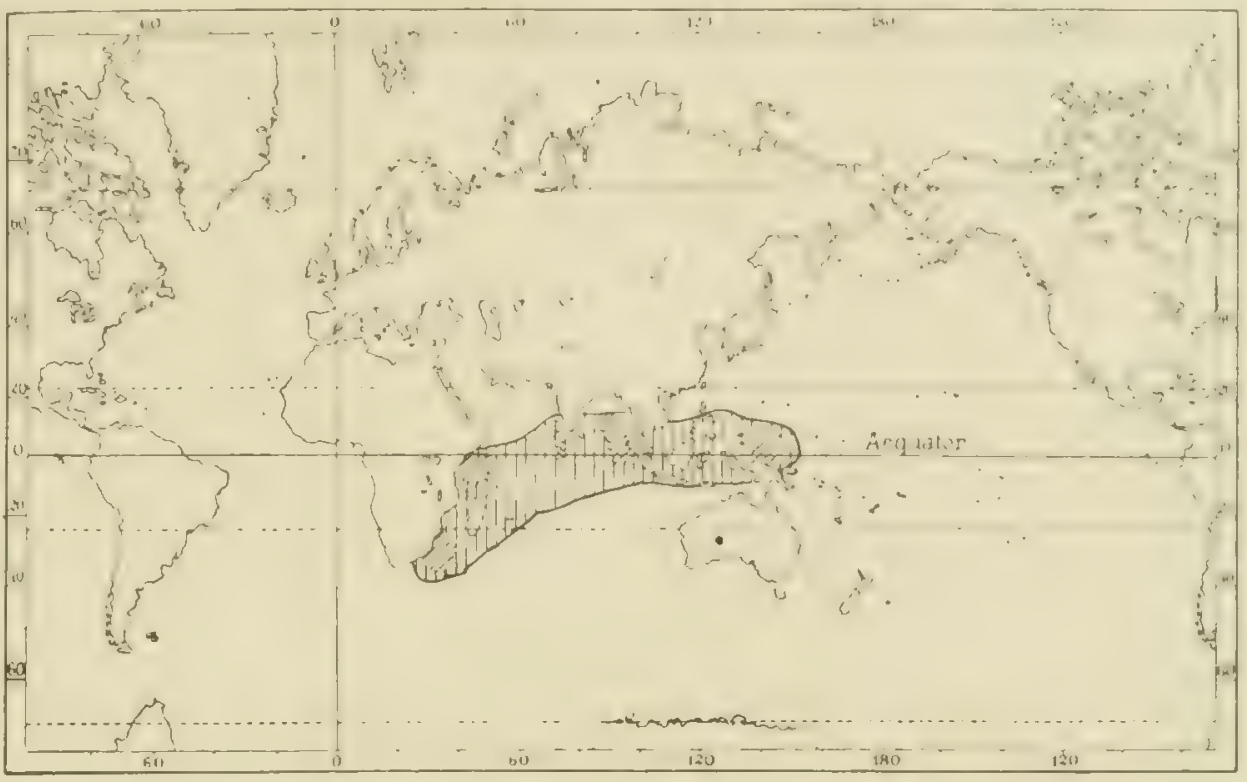

Ilililil Verbreitungsgebiet.

YIIIII/, Nachgewiesene Fundorte.

Fig. 59. Verbreitung von Platymaia Wyville-Thomsoni MrS

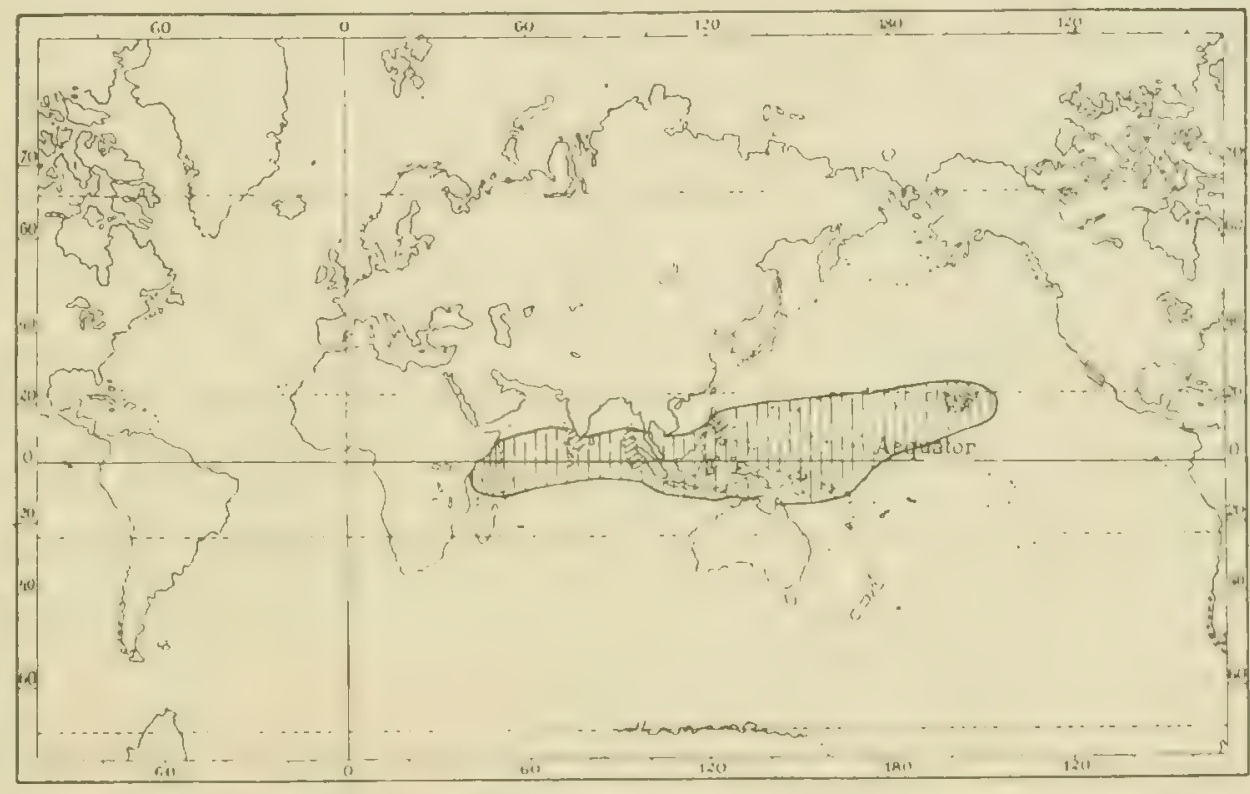

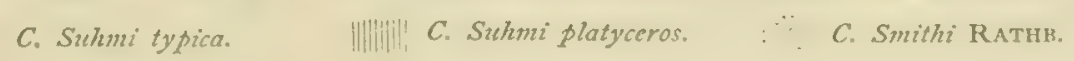

ili!il Bisher nachgewiesenes Ver- $C$. Mnurrayi MRs. breitungsgebiet der Gattung

Cyrtomaia.

Fig. 6o. Verbreitung der Gattung Cyrtomaia. streckt sich das Verbreitungsgebiet der Gattung durch den Indik und weit in den Pacifik hinein (s. Textfig. 6o). Aber statt wie Plalymaia nur in einer Form vorzukommen, lassen sich hier mehrere Formen 
unterscheiden: C. Smithi im Osten, C. Murrayi im Westen des Pacifik, C. Sulhni typica im Osten und C. Sulmmi platyceros im Westen des Indik. Die beiden letzteren Formen, die einzigen die in dieser Beziehung genauer untersucht sind, stehen einander außerordentlich nahe, so daß ich sie nur als Subspecies getrennt habe.

Diese Befunde erinnern ganz außerordentlich an diejenigen, welche DoEDERLEIN bei Echinodermen und Korallen erhalten hat. Nur können wir meist bei unseren Krabben nicht so deutlich die Zusammenhänge erkennen, welche den oben genannten ideenreichsten unter den deutschen Systematikern zu so interessanten Resultaten geführt haben. Unzweifelhaft sind es biologische Eigentümlichkeiten, vielleicht auch historische Zusammenhänge, welche es bedingen, daß die eine Gattung im gleichen Gebiet in mehrere scharf getrennte Arten, die andere nur in Unterarten zerfällt, während eine dritte im ganzen Gebiet nur durch eine einzige Form vertreten ist.

Wir werden weiter unten sehen, daß auch das DoEDERLEIN'sche Prinzip mit großem Vorteil zur Erklärung solcher' Verhältnisse herangezogen werden kann. Hier wollen wir jedoch zunächst mit der Erörterung der tiergeographischen Daten fortfahren.

Die weite Verbreitung von Formen der mittleren Tiefen beschränkt sich nicht nur auf einen Ocean. Wir können vielmehr feststellen, daß viele Formen des tiefen Wassers zu gleicher Zeit im Atlantik und im Indopacifik vorkommen. Es kann dies uns bei den pelagischen Tieren

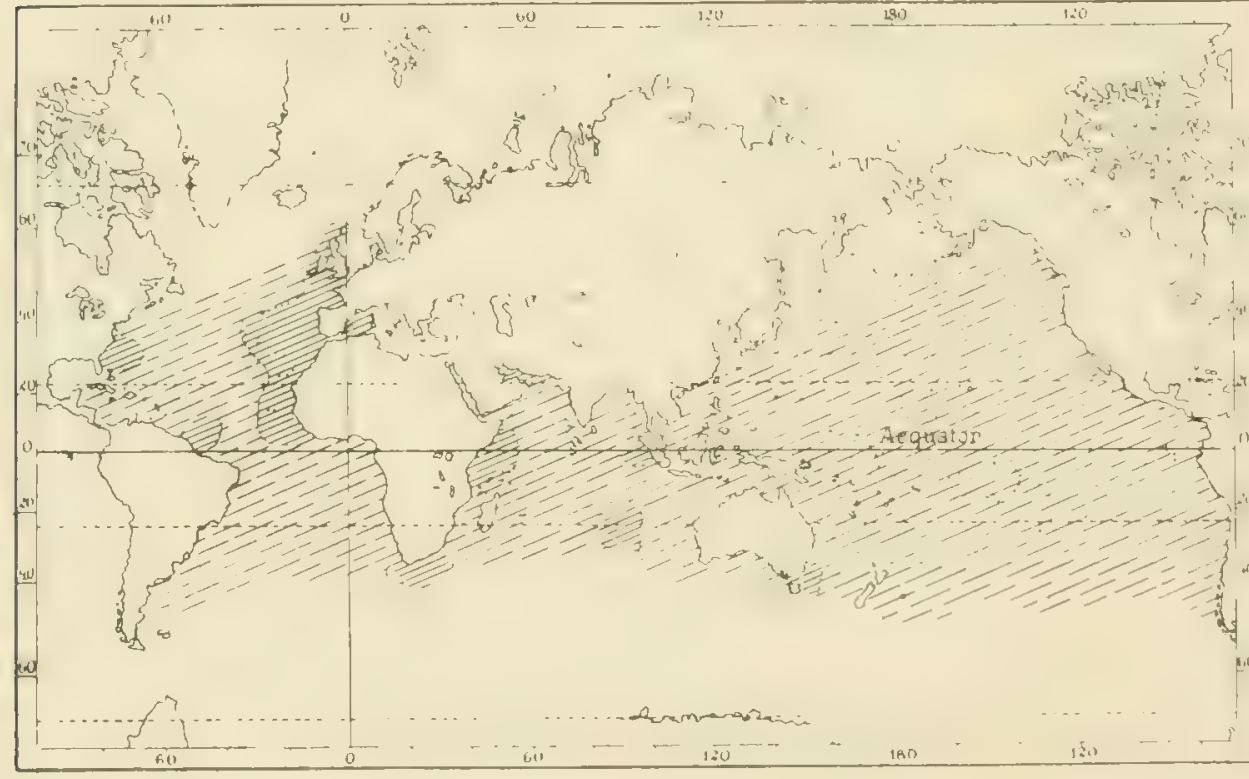

Nachgewiesene Verbreitung.

抎 $\div$ Wahrscheinliche Verbreitung.

Fig. Gr. Verbreitung von Lispognathus Thomsoni (NORM.) nicht so sehr verwundern wie bei den Bodenbewohnern. Für pelagische Tiere ist dies ja schon längst bekannt, und die Karten, auf denen die Wassenvärme der verschiedenen Tiefen eingetragen ist, belehren uns, daß es für solche pelagische Tiere, welche nicht gerade von gewissen hohen Temperaturen abhängig sind, keine Verbreitungshindernisse zwischen den beiden Oceanen giebt.

Bei den bodenbewohnenden Formen ist die Thatsache der Ver-

breitung in beiden Oceanen schon erstaunlicher, selbst wenn wir bedenken, daß viele von ihnen pelagische Larven besitzen. Bei solchen Formen vollends, bei denen die Metamorphose eine abgekürzte ist, bei denen also keine pelagischen Larven mehr vorkommen, verstehen wir die weite Verbreitung nur, wenn wir sehr große Zeiträume ihres Aufenthaltes in der Tiefsee annehmen. 
Thatsïchlich hat nun ALCOCK nachdrücklich darauf aufmerksam gremacht, daß eine ganze Anzahl von Formen bodenbewohnender Krabben dem Atlantik und dem Indopacifik gemeinsim sind, z. 13. Pihumnoplax ameriana Ratsm, Geryon affinis M.-E. U. Bour. etc. Auch war schon in früherer \%eit durch die "Challenger"-Jixpedition bekannt geworden, daß \%. B. I ispownathus Thomsoni (Norm.), jene bekannte J'orm der nordschottischen Tiefe, im Indopacifil workommt. Allerdings war dieser Befund etwas aweifelhaft. Die "Valdivia"-Expedition hat nun grerade für diese Form nachweisen können, daß sie im Indik weit verbreitet ist. In diesem Ocean wurde sie an nicht weniger als 4 weit voneinander entfernten neuen Fundorten entdeckt. Die Kartenskizze Textfig. 6 I zeigt die Verbreitung dieser $A r t$, und es ist auf derselben auch das wahrscheinlich kosmopolitische Vorkommen der Art angegeben. Die Verbreitung dieser $\Delta r t$ ist insofern besonders charakteristisch, als sie auch in der Kapregion, also gerade an der Grenze der beiden oceanischen Gebiete rorkommt. Ferner ist auffallend, daß die Art an den verschiedenen fiundorten in ganz verschiedenen Tiefen gefunden wurde. Verfolgen wir aber die Art des. Vorkommens genauer, so finden wir, daß das Verbreitungsgebiet zu yleicher \%eit ein kontinuierliches Temperaturgebiet für die Tempe-
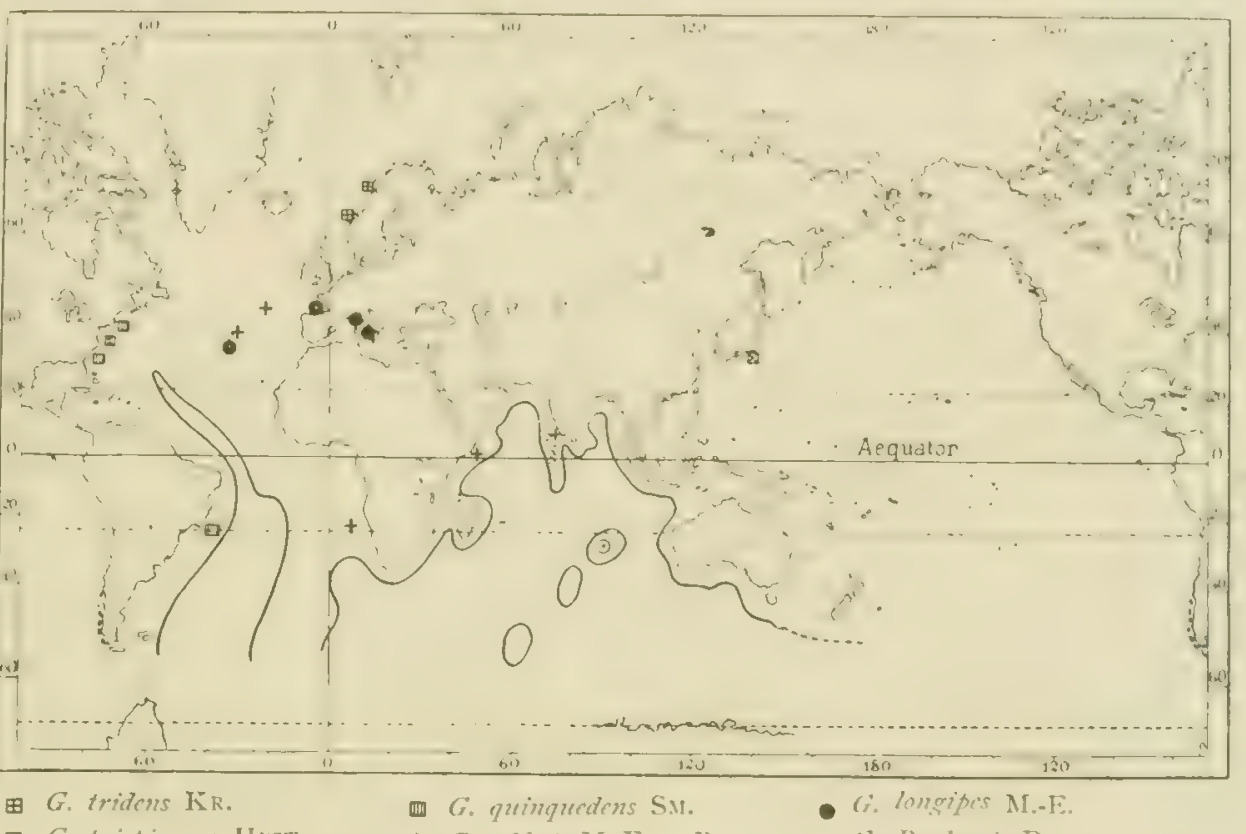

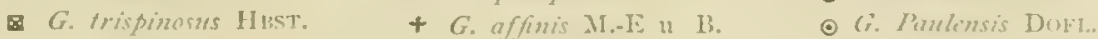

Fig. 62. Verbreitung der Gattung (icryon. ratur zwischen $+5^{\circ}$ und $+{ }^{\circ} 0^{\circ} \mathrm{C}$ darstellt. Schon Wvitue Tuoirson (1873) hatte Lisfognathus Thomsoni in der sog. warmen Area des nordatlantischen Oceans gefunden. Soweit Temperaturen gemessen wurden, lagen diese an all den bekannten Fundorten zwischen $+5^{\circ}$ und $+10^{\circ} \mathrm{C}$. Ich führe die Stationen der "Valdivia“-Expedition an:

$\begin{array}{crc}\text { Ort } & \text { Templeratur } \\ \text { Station } & 4 & +5.9^{\circ} \mathrm{C} \\ " & 10 & +5.4^{\circ} \mathrm{C} \\ \text { " } & 93 & ? \\ \text { " } & 100 & \text { ? } \\ \text { " } & 104 & ?\end{array}$

\begin{tabular}{ccc}
\multicolumn{2}{c}{ Ort } & Temperatur \\
Station & 113 & $+7,1^{\circ} \mathrm{C}$ \\
$"$ & 165 & $+9,9^{\circ} \mathrm{C}$ \\
$"$ & 198 & 5 \\
$"$ & 247 & $+7,2^{\circ} \mathrm{C}$ \\
$"$ & 249 & $+8,4^{\circ} \mathrm{C}$
\end{tabular}

Ganz ähnlich verhält es sich mit der fattung Geryon, deren verschiedene Arten sich nach meiner Ansicht viel nüher stehen, als man in der Regel annimmt. Trir finden, daß sämtliche Arten in Tiefen und Gebieten vorkommen, in denen die Temperaturen zwischen $+5^{0}$ und $+2^{0}$ liegen. Auf der Karte Textfig. 62 sind die sämtlichen Fundorte eingetragen, und es ist 
auffallend, zu sehen, wie streng die Abhängigkeit von der Temperatur ist. Die stark gezeichnete Kurve giebt die Grenze der Bodentemperaturen unter $+2^{0} \mathrm{C}$ an, und wir sehen, wie streng das Vorkommen der Geryon-Arten durch diese Kurve abgegrenzt ist. Sogar die nördlich von St. Paul und Neu-Amsterdam gefundene Form findet sich innerhalb einer Wärmeinsel, in welcher die Bodentemperatur über $+2^{0} \mathrm{C}$ steigt. Vergl. hierzu Schorr's Atlas (igo2), Taf. XXII.

Aehnlich verhält es sich noch bei einer ganzen Anzahl von Arten, deren Verbreitung in beiden Oceanen sich als Kosmopolitismus in Verbindung mit der Abhängigkeit von bestimmten

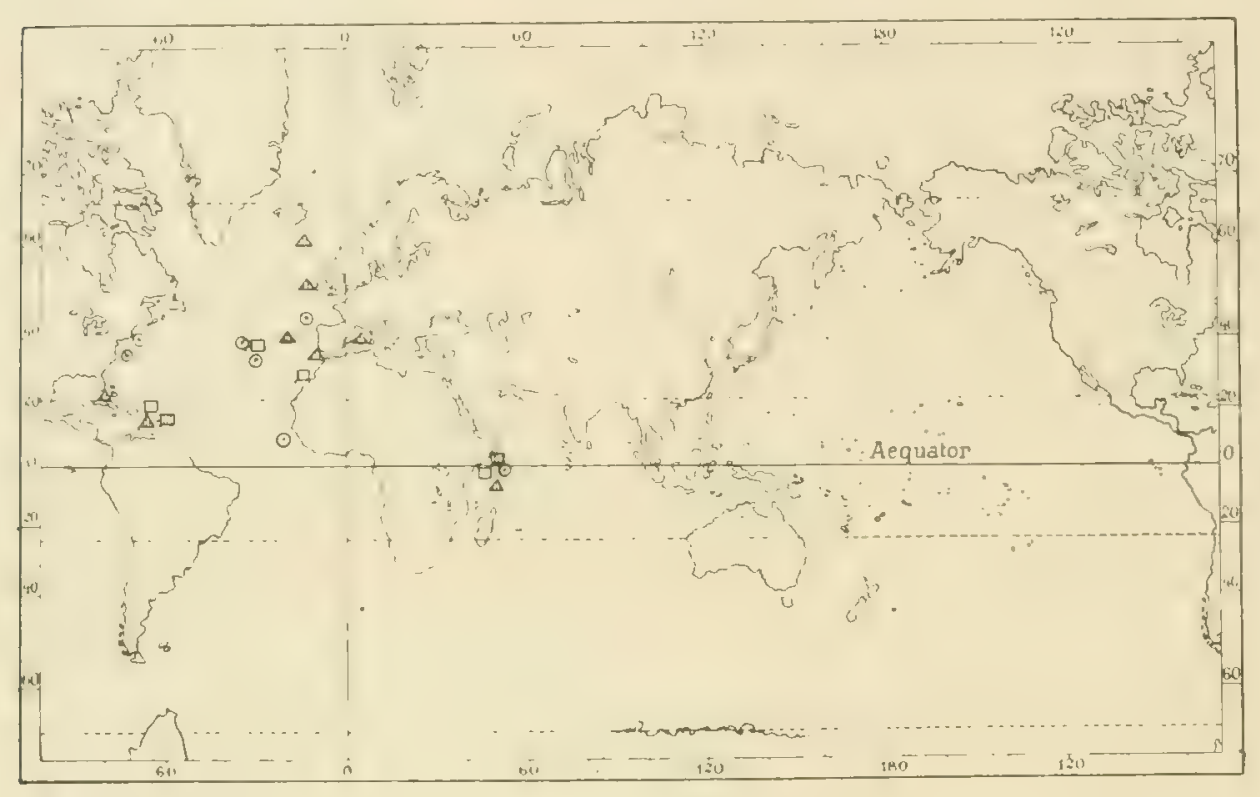

ITomolodromin.

ㄴ Homologenzs.
- Ethusina alyssicala.

$\Delta$ Cymonomis.
Fig. 63. Merkwürdige Verbreitung einiger Tiefseebrachyuren.

Temperaturen herausstellt.

Schwieriger liegt die Sache bei einer anderen Reihe von Funden, welche von der "Valdivia“-Expedition in der Nähe der ostafrikanischen Küste gemacht wurden. Dort tauchen mit einem Male mehrere atlantische Formen auf, welche bisher außerhalb des Atlantik noch nicht gefunden worden sind, und deren außeratlantische Fundorte sich bisher auf die ostafrikanische Küste beschränkterhaltı naben. Eine von diesen Formen ist von der atlantischen gar nicht zu unterscheiden, die übrigen sind subspecifisch oder specifisch abzutrennen, aber gehören zu atlantischen Gattungen, und auch von den Gattungen sind bisher Vertreter außerhalb des Atlantik noch nicht aufgefunden worden.

Ethusina abyssicola ist an zahlreichen Stellen des Atlantischen Oceans gefunden worden, (vergl. Kartenskizze Textfig. 63), niemals außerhalb desselben. Unsere Expedition erbeutete sie auf Station 240 nicht weit von Sansibar. In derselben Region wurde eine neue Homolodromia (Bonvieri Dofl.), ein neues Homologenus (Braneri Dofl.) und eine dem Cymonomus gramulatus (Norm.) sehr nahestehende Form der Gattung Cymonom entdeckt. Die 3 letztgenannten Gattungen sind bisher außerhalb des Atlantik noch nicht gefunden worden.

Wie erklärt sich diese auffallende Beziehung der ostafrikanischen Tiefsee zum Atlantik? Wir haben zwar gesehen, daß der ostafrikanische Teil des Indik durch besondere Formen, ja durch auffallende Gattungen, wie Homolochunia, ausgezeichnet ist. Auch aus den übrigen Tierstämmen fanden sich in diesem Gebiet auffallende Vertreter: so die mit Riesennadeln versehenen Kieselschwämme der Gattung Monorhaphis etc. Aber trotz alledem ist die Region als ein charakteristischer Teil des indopacifischen Gebietes gekennzeichnet. IVir künnen also in 
den auffallenden Funden vorläufig nichts anderes als einen glïcklichen Zufall erblicken, der uns hier von schwer zu fangenden Arten Exemplare in die Hïncle gespielt hat. Diese Arten werden aber wohl eine kosmopolitische Tiefseeverbreitung besitzen, wie die vorher angelührten Formen.

Schließlich möchte ich noch auf die kosmopolitische Verbreitung der Gattungen Ethuse und Elhusing aufmerksam machen. Die Vergleiche, welche ich dabei churchführen wollte, habe ich bisher aus Mangel an Material nicht vollenden können. Die Betrachtungr der beiden Kartenskizzen (Texfig. 6+ u. 65) lehrt aber schon einige bemorkenswerte Thatsachen kennen. In allen Meeren finden wir in Küstennähe in mittleren l"irefen ElhuserArten. Von ihnen steigen manche auch in ganz seichtes TVasser auf, wie Ethusa mascarone [Hвsr. $\left.]^{1}\right)$. Fast überall sahen wir im tiefen TVasser derselben Region Et/hatsina-Arten vorkommen.

$\mathrm{Ob}$ die Ethusina-

Arten mit bestimmten Ethusa-Arten in einem genetischen Zusammenhang stehen, vermag ich vorläufig noch nicht $z u$

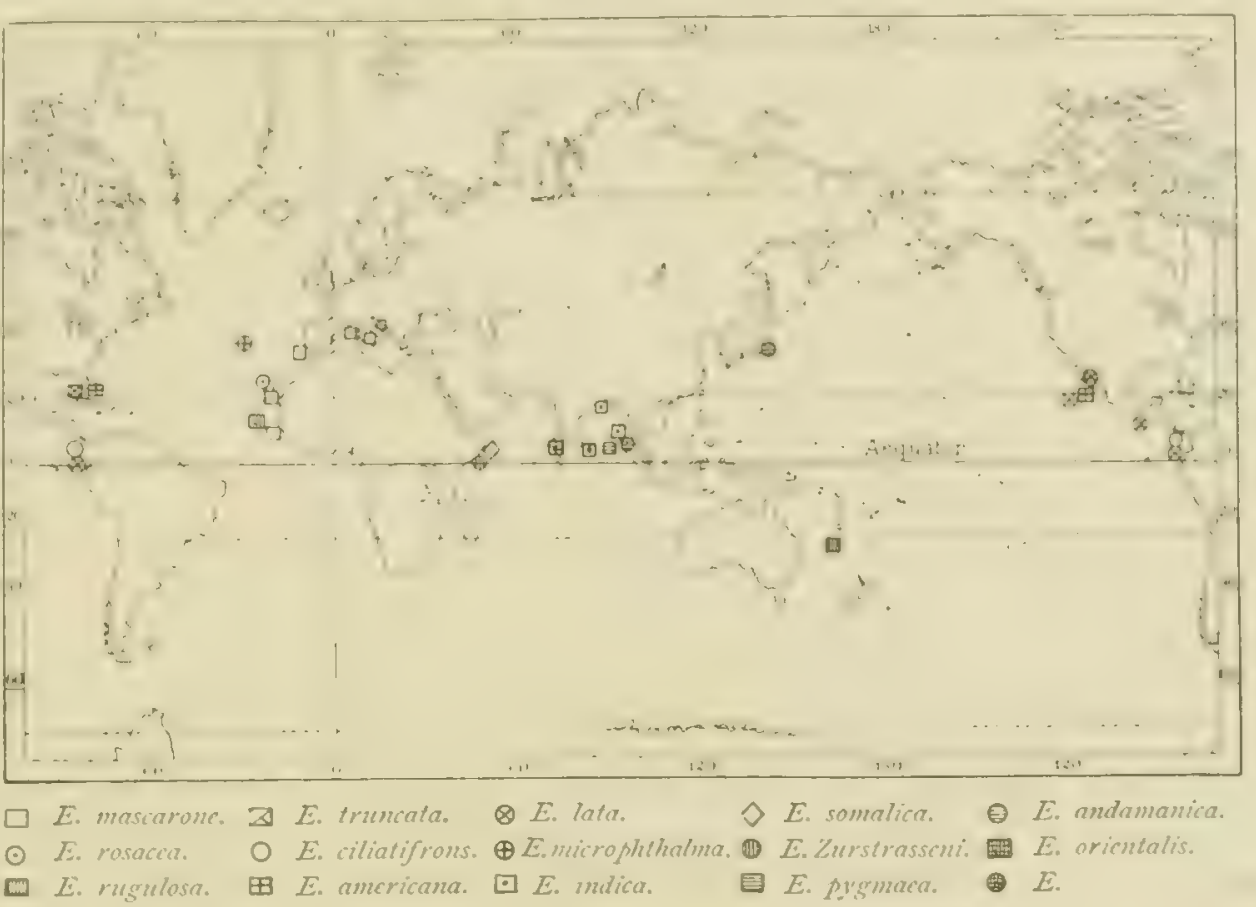

Fig. 64. Verbreitung der bekannten Arten der Gattung Ethusa.

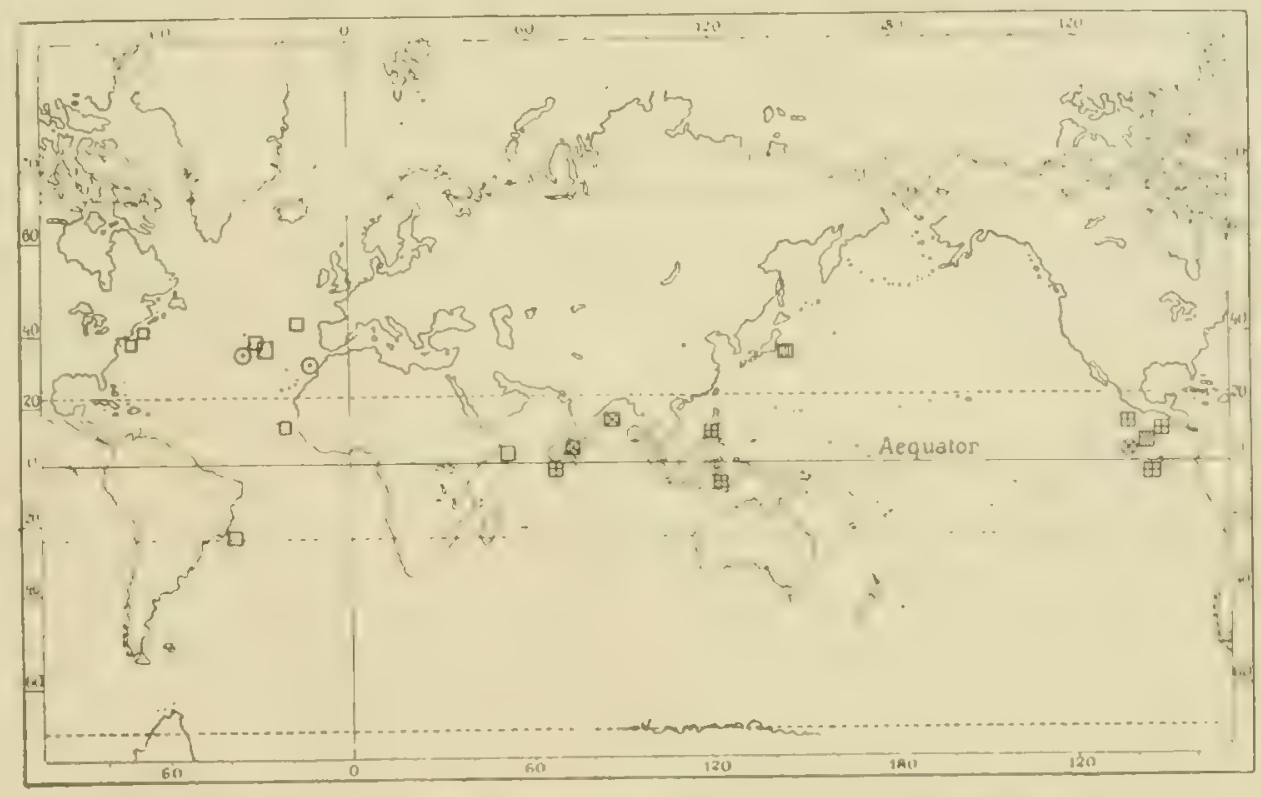
$\square$ E. abyssicola.
- E. Talismani.
E. Incestigatoris.
E. Smithiona.
E. Challengeri.
EH. gracilipes.

Fig. 65. Verbreitung der bisher bescluriebenen Arten der Gattung Ethusina. erörtern. Auch ist die Validität der vielen Species und ihre nähere oder entferntere Verwandtschaft untereinander noch 1) $\Delta$ uf der Kartenskizze ist durch ein Versehen leider der Fundort an der Mündung des Kongo nicht eingetragen worden. 
nicht untersucht. Jedenfalls liegt hier ein wichtiges Problem, welches an der Hand von genügendem Material untersucht, sicherlich zu bedeutenden Resultaten führen würde.

Wie man sieht, habe ich gar keinen Wert auf die Einteilung des Oceans in Regionen und Provinzen gelegt. Zwar können wir im allgemeinen erkennen, daß die topographischen Grenzen, welche die großen Kontinente bilden, Atlantik und Indopacifik scheiden. Wichtiger für die Verbreitung der marinen Tiere als die Umwälzungen der Landmassen in früheren Erdperioden erweisen sich die physikalischen Verhältnisse der Gegenwart. So wie wir durch den Suezkanal die Tierwelt alsbald eine Wanderung antreten sahen, da die physikalischen Verhältnisse auf beiden Seiten annähernd gleich waren, so werden auch alle Veränderungen der physikalischen Verhältnisse im freien Ocean Wanderungen der Tiere zur Folge haben. Unter den physikalischen Bedingungen ist die wichtigste die Temperatur.

Schon Alcock (1903) hat hervorgehoben, daß zahlreiche Gattungen, welche er in der Tiefe des Indischen Oceans fand (Homola, Latreillia, Maia, Sayramathia, Neplurops, Crangon, Pandahus, Pasiphaea), bisher als charakteristisch für die nördlichen gemäßigten Meeresgebiete angesehen wurden. Es wäre ein Irrtum, diese Gattungen und die von mir hinzugefügten als nordische Formen zu bezeichnen. Es sind „Kaltwasserformen“, welche überall in das kalte Wassergebiet einwandern, wo es die sonstigen oceanographischen Verhältnisse zulassen. Dabei sind sie bis zu einem gewissen Grade von der Tiefenlage der ihnen entsprechenden Isothermen unabhängig, so daß sie im Norden in geringeren Tiefen vorkommen und so der Wissenschaft früher bekannt wurden als in den größeren Tiefen, welche sie in niederen Breiten aufsuchen müssen. 


\section{Teil.}

1. Herkunft der Tiefseekrabben.

2. Die Artbildung bei den Tiefseekrabben und das Doederlein'sche Prinzip. 



\section{Herkunft der Tiefseekrabben.}

Während der Anfünge der Tiefsceforschung wurde man so oft durch die Erbeutung altertümlicher Tierformen überrascht, daß man in der Tiefsee den Zufluchtsort zahlreicher für ausgestorben gehaltener Tierformen erblickte, und auf die weitere Durchforschung die weitgehendsten Hoffnungen setzte. Ja, man ging so weit, die Tiefseeformen als eine jurassische oder cretaceische Reliktenfauna $\mathrm{zu}$ bezeichnen. Man ist von diesen Anschauungen im Laufe der Zeit durch verschiedenartige Ueberlegungen zurückgekommen. Vor allem hat man betont, daß auch in der Strandfauna und in der litoralen Fauna sich zahlreiche Vertreter altertümlicher Gruppen finden, man hat auf Lingula, Limulus, Nautihus und die im süßen Wasser "lebenden Ganoiden hingewiesen. Auch wurde man zum Aufgeben der Annahme, die Tiefseefauna sei älter als die Flachwasserfauna, durch folgende Erwägungen veranlaßt: da die Pflanzenwelt in größeren Tiefen nicht mehr selbständig assimilieren kann, so sind die Organismen der Tiefe von denjenigen der Oberfläche von jeher abhängig gewesen, und somit kann die Organismenwelt der Tiefsee erst entstanden sein, nachdem eine solche in der Flachwasserregion vorhanden war.

Wie dem auch sei, es gilt dies nur für die Gesamtheit des organischen L_ebens; wenn wir aber specielle Gruppen betrachten, zumal solche, welche in der Erdgeschichte so spät auftreten wie die Brachyuren, so haben andere Ueberlegungen einzutreten. Es wäre gar nicht unmöglich, daß die Brachyuren von Tiefseetieren abzuleiten wiren, welche in der Kreide sich entwickelten, und daß von der Tiefsee aus erst die übrigren Gebiete des Meeres und das Festland sich mit dieser vielgestaltigen Organismengruppe bevölkerten.

Thatsïchlich ist es überraschend, daß wie unter den Macruren die altertümlichen Eryoniden, so unter den Brachyuren die primitivsten Formen, die den Prosoponiden des J uras und der Kreide verwandten niederen Dromiaceen (Homolodromia, Dicranodromia) Tiefseebewohner sind. Sicherlich haben wir in dieser Thatsache mehr als einen \%ufall zu erblicken.

Aus fast allen Abteilungen des Tierreiches sind im Lauf der Jahre aus der Tiefsee Formen bekannt geworden, welche sich eng an geologisch ältere Formen anschließen, die außer in der Tiefsee recent nicht nachgewiesen worden sind.

Nun ist es aber sehr auffallend, daß jene primitiven Formen unter den Brachyuren speciell durchaus nicht zu jenen grehören, welche mit weitgehenden Anpassungen an die Tiefsec versehen sind. Wir haben ja in dem biologischen Abschnitt gesehen, daß z. B. Homolodromia zu den formen mit rückgebildeten Augen gehört. Auch die Dicranodromien scheinen keine hochentwickelten Anpassungen zu zeigen; sie alle scheinen, wie das Gros der Dromiace en, zu den Formen der mittleren Tiefen zu gehören. 
Wir konnten ja überhaupt feststellen, daß die Brachyuren keinen großen Bestandteil der Tiefseefauna ausmachen. Sie scheuen die Kälte, und in kalten Meeresgebieten ist die Zahl ihrer Arten und Gattungen eine sehr geringe, während sie im warmen und gemäßigten Wasser ihre höchste Formenfülle erreichen. Die meisten recenten Brachyuren sind ausgesprochen Tiere der litoralen und sublitoralen Zone, und ihre Anpassungen lassen mit großer Sicherheit darauf schließen, daß sie dort entstanden sind.

Die Formen der Tiefsee setzen sich, wie wir wiederholt erörtert haben, aus zwei Gruppen zusammen. Die einen sind jene, deren Rückbildungen wir in Zusammenhang mit dem Lichtmangel in der Tiefsee brachten. Unzweifelhaft haben wir in ihnen rückgebildete Nachkommen von Formen der belichteten Zone des Meeres zu sehen. Die Formen der zweiten Gruppe, bei denen wir mancherlei höhere Anpassungen an das Leben in der Tiefsee feststellten, gehören den verschiedensten Gruppen an, welche auch im flachen Wasser vorkommen. Wir können in ihnen ebensowohl die Nachkommen von Nachttieren des flachen Wassers, als in letzteren die Nachkommen von Formen des tiefen Wassers erblicken. Das Wahrscheinlichste ist - soweit bei solchen Problemen überhaupt von Wahrscheinlichkeit gesprochen werden kann - , daß die Brachyuren im noch von Licht durchdrungenen Wasser mittlerer Tiefen ihren Ursprung gefunden haben. In solchem werden auch die Prosoponiden der Kreide gehaust haben. Von solchen Formen der mittleren Tiefen haben sich sowohl die Küstenformen als auch die Tiefenbewohner abgeleiteț. Die Tiefenbewohner zeigen noch durch verschiedene Eigentümlichkeiten ihre Abstammung von Formen der Lichtregion an. Besonders gilt das für die Formen mit rudimentären Augen, von denen manche in der Rückbildung noch begriffen zu sein scheinen. Die Formen mit höher angepaßten Augen sind zum Teil recht specialisierte Formen, z. B. Platymaia.

Wie kommt es nun aber, daß sich in der Tiefsce gerade einige Vertreter der ältesten Brachyuren erhalten haben? Man kann heutzutage nicht mehr annehmen, daß sie gerade nur dort einen letzten Zufluchtsort vor dem heftigen Kampf ums Dasein gefunden haben. Sic werden vielmehr von vornherein an den Aufenthalt in den mittleren Tiefen - denn in solchen, und nicht in den großen Tiefen finden sie sich - angepaßt gewesen sein. Sie werden zu allen Zeiten seit dem Jura dort zu finden gewesen sein. Daß sie seit der Kreide kaum mehr nachweisbar sind, wird seinen Grund darin haben, daß die Ablagerungen seit jener Zeit immer seltener solche aus mittleren Tiefen gewesen sind und immer mehr nur solche aus dem flacheren Wasser darstellen. Aehnlich wird es sich wohl auch mit einer ganzen Reihe anderer Tiefseeformen verhalten, und vielleicht findet das altertümliche Gepräge der Tiefseefauna durch eine solche Auffassung die natürliche Erklärung.

\section{Die Artbildung bei den Tiefseekrabben und das DOEDERLEIn'sche Prinzip.}

In einer sehr interessanten Arbeit hat DoEDERLEIN (1902) dargelegt, wie er sich die Thatsache erklärt, daß bei den Tieren so große Schwankungen in Bezug auf die unterscheidenden Charaktere der Arten vorkommen. Es ist besonders überraschend, wie diese Gegensätze bei zwei Tiergruppen, wie den Riffkorallen einerseits und den Vögeln andererseits, sich darstellen. 
Bei den Riffkorallen ein Chaos von Formen, deren Unterscheidung fast rollkommen in der Villkür des einzelnen Untersuchers zu liegen scheint, bei den Vögeln so scharf unterschiedene Formen, daß selbst die Maße auscrewachsener Tiere übereinstimmen und zur Diagnose der Art dienen können. Die Vögel haben meist „formenarme" oder ganz "einfürmigre, die Riffkorallen dagegren vielfach äuBerst ,formeneiche“ Arten. Es sind nun verschiedene Gründe, welche die „Formen“ zum Teil so schwer unterscheidbar machen. Als solche führt DOIEDEREIN die verschiedene Höhe der Organisation, die verschiedene Variabilität der Merkmale und die verschieden große Neigung zur Ausbildung geographischer und adaptiver Formen bei den verschiedenen Tiergruppen an. Von den Faktoren, welche DOEDERLFin als wichtige Ursachen für die Bildung von Formen ansieht, interressiert uns hier besonders die "Vagilität". DOEIJELEIN weist den engen Zusammenhang zwischen Vagilität und Variabilität von Tierformen nach. In ähnlicher Weise, wie fruher Mormz IVAGNer, betont er, daß die Vagilität, d. h. die liähigkeit des Ortswechsels, für die Ausbildung von Formen von der höchsten Wichtigkeit sein muß, indem von ihr die Möglichkeit der geschlechtichen Vermischung zwischen den einzelnen Individuen einer Form mit ihren ausgleichenden Wirkungen abhängig ist. DoEderLfin's Verdienst und das Neue in seiner Arbeit liegt nun vor allem darin, daß er aus der allgemeinen theoretischen Idee eine Erfahrungsthatsache gemacht hat. Auf Grund seiner großen Kenntnisse von Tierformen und und ihres vervvandtschaftlichen Zusammenhanges hat er einen Satz aufgestellt, von dem ich glaube, daß er in der Wissenschaft unter der Bezeichnung des DOEDERLEIN'schen Prinzips von Dauer sein wird. Denn er enthält in der Fassung, welche ich sogleich anführen werde, nur Erfahrungsthatsachen und stellt sich somit als eine von theoretischen Anschauungen freie zusammenfassende Beschreibung vieler Einzelthatsachen dar. Der Satz lautet:

„Die Zahl der auf dem gleichen Gebiete vorhandenengeographischen und adaptiven Formen bei verschiedenen Tiergruppen steht in umgekehrtem Verhältnis zur Höhe der Vagilität derselben."

Sessile Tiergruppen, wie die Riffkorallen, sind auf dem gleichen Gebiet durch eine Unmenge von Formen vertreten, während pelagische Fischarten in ciner ganz konstant erscheinenden Form vorkommen. Bei den ersteren ist kaum ein Individuum dem anderen gleich; wenige hundert Kilometer Distanz lassen auf den Riffen lauter Korallenformen auftauchen, die wir für ganz fremde Arten halten müssen, während die pelagische Fischart sich über Tausende von Kilometern in lauter Individuen verbreitet, welche individuell weder durch die Dimensionen noch durch morphologische Charaktere sich unterscheiden lassen.

Bei den verschiedensten Tiergruppen konnte ich mich in den letzten Jahren von der Richtigkeit dieser Anschauungen überzeugen. Untersuchungen, welche im Münchener Museum von Hern H. Hetrmayer über südamerikanische Vögel gemacht wurden, ließen erkennen, daß die Standvögel, besonders unter ihnen die verborgen lebenden, jede Art in eine Unmenge von geographischen Formen zerspalten zeigen, während die Zugvögel vom Norden und Süden des Kontinents kaum Verschiedenheiten aufweisen. Dasselbe Prinzip läßt sich erkennen bei der Untersuchung der sehr variablen Skorpione, bei Reptilien u. s. w.

Am meisten freute es mich aber, das Prinzip in engstem Zusammenhang mit den ganzen Thatsachen zu finden, welche ich als Hauptresultat meiner Untersuchungen in dem II. Abschnitt dieses Werkes zusammengrestellt habe. 
IVir konnten dort einen durchgreifenden Unterschied zwischen den sehr vagilen Formen unter den Tiefseekrabben und den in ihrer Beweglichkeit gebundenen Formen feststellen. Dieser Unterschied erstreckt sich auch auf die Fähigkeit dieser Arten, geographische und adaptive Formen zu bilden.

IVir sehen, daß unter den Formen des tieferen Wassers die vagilen und insbesondere diejenigen, welche durch pelagische Larven einer weiten Verbreitung fähig sind, über weite Räume verteilt sind, ohne daß zahlreiche geographische Formen aufträten. Als Beispiele können uns die Gattungen Geryon, Platymaia, Lispognathus dienen. Ganz anders steht es bei den Formen von geringer Vagilität. WVir sehen da z. B., daß den ungemein zahlreichen Ethusa-Arten des seichten Wassers in der Tiefe eine große Mannigfaltigkeit von Arten der Gattung Ethusina entspricht. Der Grad der Verwandtschaft zwischen diesen vielen Formen muß ja erst noch näher untersucht werden, aber das steht jetzt schon fest, daß viele dieser Formen sich deutlich voneinander

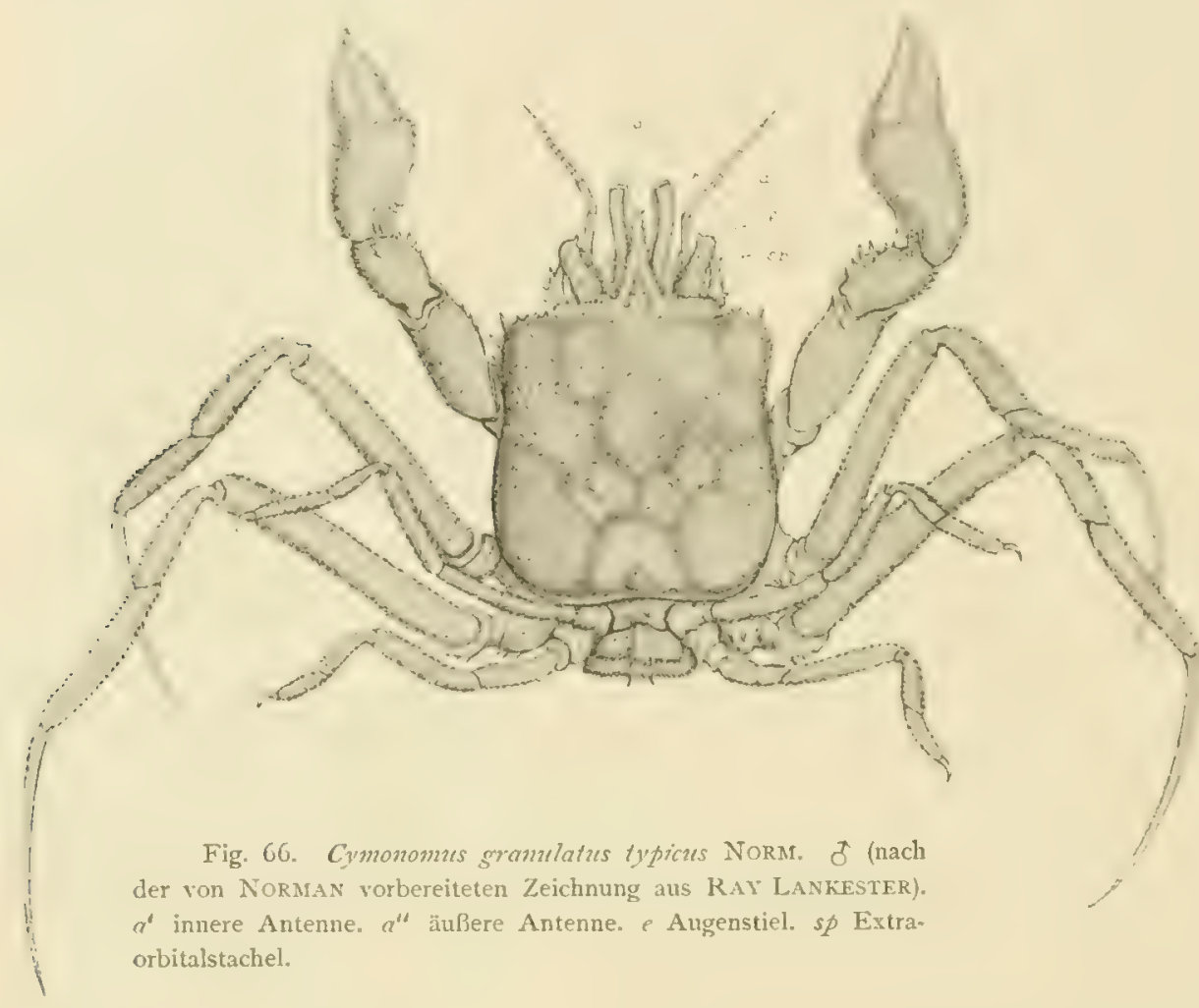
unterscheiden lassen und wiederholt in den gleichen Gegenden gefunden wurden. Ethusina aby'ssicola macht allerdings durch ihre Verbreitung eine Ausnahme.

Noch auffallender ist das gegenseitige Verhältnis der Gattung Cymonomns. Vir haben oben gesehen, daß diese Gattung durch die am stärksten rückgebildeten Augen, welche bei Brachyuren bekannt geworden sind, auffällt. IVir haben auch gesehen, daß die Riesengröße der Eier auf eine direkte Entwickelung ohne Metamorphose hinweist, und schließlich zeigt uns der ganze Habitus des Tieres, daß es kein sehr bewegliches Leben führen kann. Trotzdem ist die Gattung über ein ziemlich weites Areal verbreitet gefunden worden. Aber man hat an den verschiedenen Punkten die Formen stets untereinander etwas verschieden gefunden, ohne daß die Verschiedenheiten ausgereicht hätten, gut definierte Arten klar abzugrenzen. Rax Lankester (1903) ist neuerdings auf diese Gattung eingegangen, indem er von der Veröffentlichung der schon vor 3.5 Jahren von NORMAN vorbereiteten, jetzt erst aber durch LANKester publizierten, Diagnose von Cymonom gramulatus ausging.

Mit Recht hat er hervorgehoben, daß die verschiedenen Formen voneinander unterschieden werden müssen, und er hat auch die von mir beschriebene Form aus Ostafrika neu benannt. Er hebt ausdrücklich die theoretische Wichtigkeit der verschiedenen Cymonomus-formen hervor und sucht durch die Benennung Verwechslungen zu verhüten. 
Nach meiner Ansicht stehen sich aber die verschiedenen Formen der Gattung Cymonomus so nahe, daß wir sie nicht als besondere Species unterscheiden dürfen. Ihr thatsächliches Verhältnis zu cinander und ihre theoretische Wichtigkeit für die Auffassung von Standortsvarietäten und für das Problem der Artbildung kommt am besten zum Ausdruck, wenn wir sie als Subspecies einer einzigen Species auffassen. Sic stellen zusammen inen Formentireis dar, welcher vielleicht bei einer genauen Erforschung sich aus lauter Standortsvarietäten derselben Form zusammengesetzt erweisen wird.

Vir müssen also folgende Formen unterscheiden :

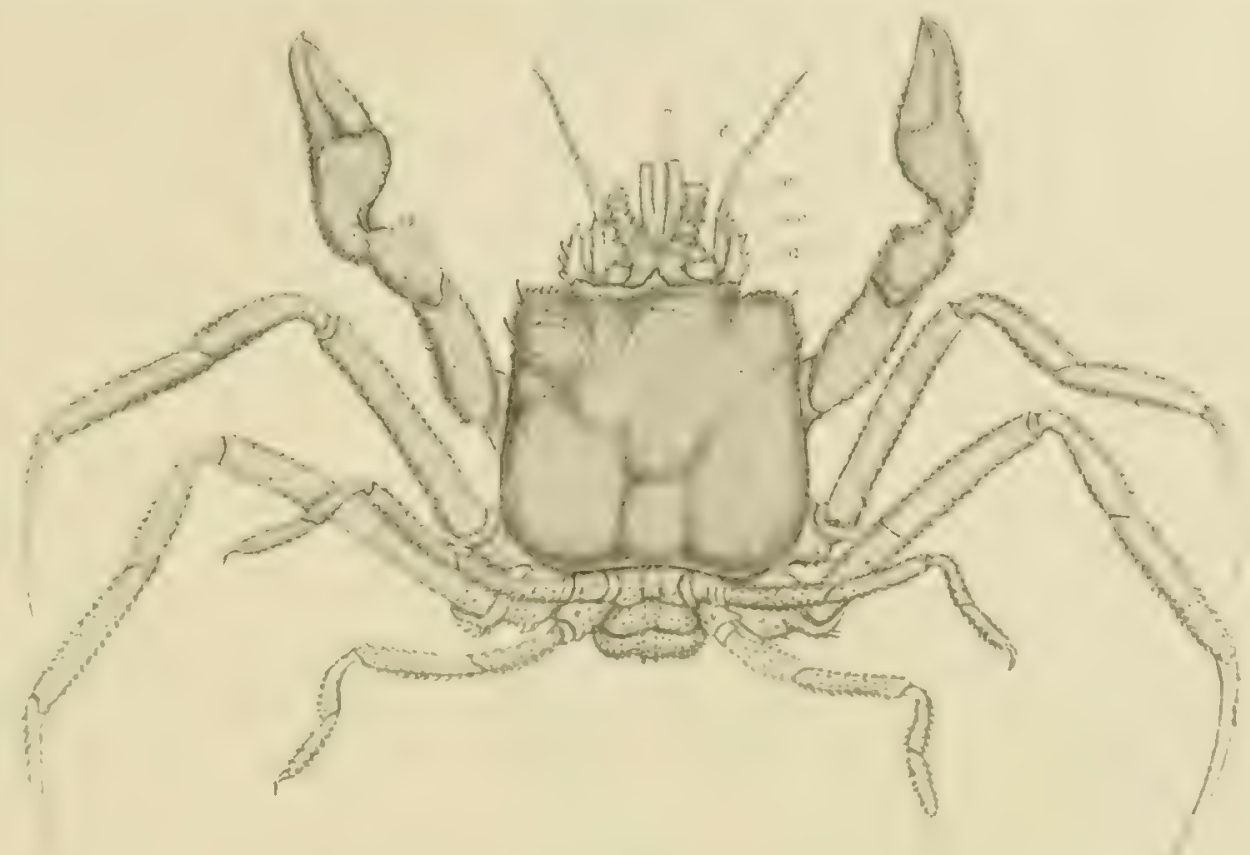

Fig. 67. Cymonomus granulatus Normani LANK. ठ (nach der von NoRMLiN vorbereiteten Zeichnung aus R.AY LANKESTER). $a^{\prime}$ innere Antenne. $a^{\prime \prime}$ äußere Antenne. $e$ Augenstiel. sp Extraorbitalstachel.

\section{Crmonomus gramulatus typicus NORMAN I873.}

(Mittelmeer und Nordantlatik.)

Es ist dies die zuerst beschriebene Form mit den beweglichen Augenstielen, den kleinen erkennbaren Corneaflächen und dem schlankeren, stachelbedeckten Cephalothorax. Vergl. LANKESTER I903, p. 455 und vorstehende Textfig. 66.

\section{Cymonomus granulatus Normani LANKESTER I9O3.}

\section{(Holteniagrund im Nordatlantik.)}

Es ist dies die Form des tiefen und kalten Wassers im Nordatlantik, welche NormaN zuerst beschrieb und wohl mit Recht als eine adaptive Form von C. granulatus typicus auffaßte. Sie ist durch das kurze Rostrum, die an der Basis verwachsenen Augenstiele und den plumperen Cephalothorax von der typischen Form unterschieden. Näheres findet sich bei LANKESTER 1903 p. 456; aus letzterer Arbeit ist auch vorstehende Textfig. 67 entnommen.

\section{Cymonomus granulatus n. subsp. HANSEN.}

Ebenfalls im Nordatlantik fand sich eine dritte Form, welche Dr. HANSEN in Kopenhagen mit der übrigen Ausbeute der "Ingolf“-Expedition zu veröffentlichen gredenkt. Infolgedessen will ich, ebensowenig wie LANKESTER dies that, ihm mit der Benennung der Form nicht vorgreifen und bezeichne sie nur als n. subsp. Sie ist, wie die nach Hansen's Skizze aus Lankester's Studie, umstehend reproduzierte Textfig. 68 zeigt, durch den fast vollständigen Mangel eines Rostrums, die Gestalt der verwachsenen Augenstiele, die Extraorbitalstacheln u. s. w. unterschieden. Sie steht C. granulatus Normani sehr nahe. 
(Ostafrika.)

\section{Cymonomus granulalus Valdiviae LANK.}

Diese Form steht in vieler Beziehung in der Mitte zwischen C. granulatus typicus und C. granulatus quadratus M.-E. Die Beschreibung befindet sich auf S. 33 dieses Werkes und Abbildungen auf den Taf. XI, Fig. 5 und Taf. XII, Fig. I-3. Die Form ist ohne Zweifel eng

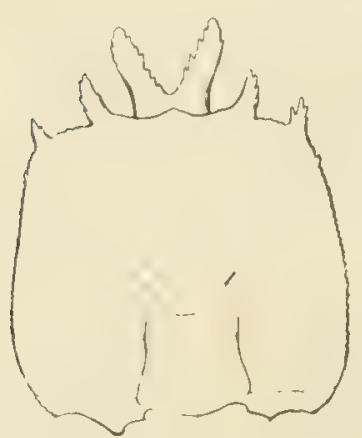

Fig. 68. Cymonomus granulatus n. subsp. (Nach HANSEN u. RAY LANKESTER.) Umriß des Cephalothorax. mit C. gramulatus typicus verwandt; die Beziehungen aber, welche sie zu $C$. quadratus M.-E. besitzt, zeigen auf das deutlichste, daß wir auch letztere Form in den hier behandelten Formenkreis einbeziehen dürfen.

\section{Cymonomus granulatus quadratus M.-E.}

(Karibisches Neer.)

Auch bei dieser Form hat Lankester I 903, p. 45 I und 453 die Beschreibung von Milne-Edwards und Bouvier ergänzt und in einigen Punkten richtiggestellt. Seine Angaben und die Abbildungen von Milne-Edwards und Bouvier 1902, Taf. XVI, und seine Textfigur ro auf p. 454 beweisen, daß die Form sehr variabel ist, wie das ja für Angehörige solcher Formenkreise charakteristisch ist. Die Form hat ein mäßiges Rostrum, noch mehr umgebildete Augenstiele als C. granulatus typicus; sie sind aber nicht verwachsen. Die Oberfläche des Tieres ist weniger stark granuliert und reicher an Haaren als bei C. granulatus typicus.

Wir sahen also bei dieser Gattung die Formen zu einem Formenkreis vereinigt, in dem die Formen um so unähnlicher von einander werden, je weiter sie voneinander entfernt gefunden wurden. Wir haben also in dieser Gattung eine glänzende Bestätigung für das DoedERLEIN'sche Prinzip vor uns.

Leider war mein Material nicht groß genug, um in anderen Gattungen das Vorhandensein von solchen Formenkreisen genauer zu verfolgen. Doch hoffe ich, mit der Zeit in manchen Gattungen über Verhältnisse, die auch noch unklar sind, Belehrung zu finden, und werde dann über meine Resultate berichten. Ganz allgemein genommen, sind ja die Decapoden ein ungemein günstiges Belegmaterial für das DoEderlern'sche Prinzip. Die Süßwasserformen mit Embryonalentwickelung ohne Metamorphose, die Potamoniden, bilden ja die formenreichste aller Decapodengruppen, und wo wir sonst „schwere Gattungen" antreffen, können wir meist nachweisen, daß es sich um Gruppen von beschränkter Vagilität handelt.

\section{Litteraturverzeichnis zum IV. Teil.}

Bouvier, E. L., 1897, Sur l'origine homarienne des Crabes, in: Bull. Soc. Philom. Paris, T. VIII, p. 34.

Doederleix, L., I go2, Ueber die Beziehungen nahe verwandter "Tierformen" zu einander, in: Zeitschr. f. Morph. u. Anthrop. Stuttgart, Bd. IV, S. 394 .

Marshall, W., I888, Die Tiefsee und ihr Leben, Leipzig.

Milne-Edwards, A., u. Bouvier, Igo2, Reports on the results of dredging of the "Blake". XXVII. Les Dromiacés et Oxystomes, in: Mem. Mus. Comp. Zool., Vol. XXVII, p. I.

RAY LANkester, E., 1903, On the modification of the eye peduncles in Crabs of the genus Cymonomus, in: The Quarterly Journal of microscopical Science, New Ser. Vol. XLII, Pt. 3, p. 439 ff.

Thomson, Wrville, 1873 , The depths of the sea, London. 


\section{Teil. Tabellen.}

Tabelle I. . . . . . . . . . . . . . . . . . . . . . . Seite 288 Tahelle II. . . . . . . . . . . . . . . . . . . . . . . . . . " 307

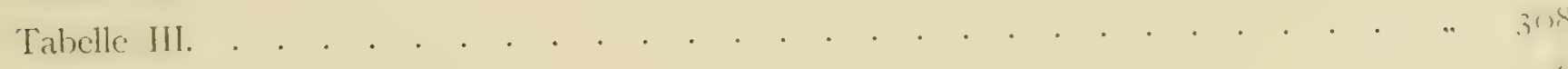
Tahelle IV. . . . . . . . . . . . . . . . . . . . . . . . . . . . . 308 

In der nachfolgenden Tabelle habe ich versucht, alle in Tiefen von mehr als $50 \mathrm{~m}$ bisher gefundenen Krabben zusammenzustellen, da ich oft den Nutzen von solchen Zusammenstellungen bei anderen Tiergruppen selbst erfahren habe. Für die in diesem Bande gegebene Bearbeitung hatte ich mir ohnehin die nötigen Notizen in Form eines Zettelkatalogs hergestellt; es war daher eine geringe Nühe, das Material, welches mir als Grundlage zu den in den allgemeinen Abschnitten erörterten Anschauungen gredient hatte, zu veröffentlichen, Dadurch wird einerseits die Prüfung meiner Ergebnisse erleichtert, andererseits wird auch anderen Bearbeitern ermöglicht, meine Tabellen zu anderen Zwecken zu verwerten.

Allerdings kann ich nicht den Ruhm einer absoluten Vollständigkeit für meine Tabellen in Anspruch nehmen. Manche Schriften blieben mir leider unzugänglich, andere werde ich überschen haben. Doch glaube ich, das Wichtigste in der Tabelle zusammengefaßt zu haben. Außer bathymetrischen und tiergeographischen Daten und einem Hinweis auf die Belegstellen habe ich in die Tabelle jene Beobachtungen aufgenommen, welche mich zu einigen meiner Schluß3folgerungen geführt haben.

Wenn Litteraturcitate abgekürzt wurden, so kamen folgende Formeln zur Anwendung:

ALCOCK $=$ Naterials for a carcinological fauna of India. Vergl. S. 134.

Albatross (ohne Jahreszahl) $=$ FAxon, Report on etc, in: Mem. Mus. Comp. Zool., Vol. XVII, I895. Vergl. S. 135 .

Blake = Minne-Eowrins A., et Bouvier, Les Dromiacés et Oxystomes, in: Mem. Mus. Comp. Zool., Vol. XXViI, I902. Vergl. S. I37.

Challenger $=$ MIneRs, Brachyura in Challenger Reports. Vergl. S. I37.

FAxox II = FAxon, W., I896, Report of the results etc. of the "Blake". XXXVII. Supplementary Notes on the Crustacea, in: Bull. Mus. Comp. '/toology, Vol. XXX, p. 134.

Investigator $=$ Alcock, An Account of the deap sea Brachyura of the „Investigator" 1899. Vergl. S. I34.

Mlonaco I = Milne-Edwards, A., et BuUvier, E. L., Crustacés décapodes in: Résult. des campagnes scientifiques du P'rince de Monaco, Vol. VII, I894.

Monaco II = MrLne-Edwards, A. et Bouvier, Crustacés décapodes, in: Résult. des camp. scient. du Prince de IIonaco, Vol. XIII, I899.

ORTMANN $=$ Decapoden-Krebse des Straßburger Museums. Vergl. S. 137.

R. I = Ratimun, Mary J., 1898 , The Brachyura collected by the U. S. Fish Commission Steamer "Albatross" on the voyage from Norfolk, Virginia, to San Francisco, California, I887-I888, in: Proc. U. S. Nat. IIuseum, Vol. XXI, I899, p. 567.

R. II $=$ Rathbun, Mary J., Catalogue of the Crabs of the family Periceridae in the U.S. National Museum, in: Proc. U. S. Nat. Mus., Vol. XV, 1892 , p. $23 \mathrm{I}$.

R. III = RAthbun, MARY J., 1894, Notes on the Crabs of the family Inachidac in the National Museum, in: Proc. U. S. Nat. MIus., Vol. XVII, I895, p. 43. 
R. IV = Rathbun, Mary J., 1894 B., Descriptions of a new genus and four new species of Crabs from the Antillean region, in: Proc. U. S. Nat. Mus., Vol. XVII, I895, p. 83.

R. $V=$ Rathiun, Mary J., I 893, Catalogue of the Crabs of the family Maiidae in the U. S. Nat. Museum, in: Proc. U: S. Nat. Museum, Vol. XVI, I894, p. 6 I.

R. VI = Rathbun, Mary J., 1893, Descriptions of new genera and species of Crabs from the West Coast of North America and the Sandwich Islands, in Proc. U. S. Nat. Mus., Vol. XVI, 1894, p. 223.

R. VII = RATHBUn, MARY J., I902, Descriptions of new decapod Crustaceans from the West Coast of North America, in: Proc. U. S. Nat. Mus., Vol. XXIV, I902, p. 885.

R. VIII = Rathbun, Mary J., I902, The Brachyura and Macrura of Porto Rico, in: Bull. U. S. Fish. Comm., Vol. XX, II for I900, I902, p. I.

Talisman = Milne-Enwards A., u. Bouvier E. L., Crustacés décapodes in: Expéditions scientifiques du „Travailleur" et du "Talisman". Paris I 900.

Valdivia $=$ die in diesem Bande niedergelegten Befunde.

Tabelle I. Systematisches Verzeichnis aller bisher in Tiefen von mehr als $50 \mathrm{~m}$ gefundenen Brachyuren.

\begin{tabular}{|c|c|c|c|c|c|c|}
\hline Art & Vorkommen & Tiefe & Habitus & Augen & Eier & Litteratur \\
\hline $\begin{array}{l}\text { Homolodromia paradoxa M.- } \\
\text { EDw. }\end{array}$ & Nevis (A.) & $650 \mathrm{~m}$ & $\begin{array}{l}\text { Cth. glatt, } \\
\text { Beine lang }\end{array}$ & klein & $?$ & Blake, p. II \\
\hline H. Bouvieri DofL. & $\begin{array}{l}\text { Ostafrikan. Kü̈ste } \\
\text { (Jp.) }\end{array}$ & $863 \mathrm{~m}$ & $\begin{array}{l}\text { behaart, Beine } \\
\text { lang }\end{array}$ & $\begin{array}{l}\text { klein, rückgebildet, } \\
\text { pigmentlos }\end{array}$ & $?$ & Valdivia, p. 3 \\
\hline $\begin{array}{l}\text { Dicranodromia Mahyeuxi M.- } \\
\text { E. }\end{array}$ & $\begin{array}{c}\text { Golf von Biskaya, } \\
\text { Cap Bojador, Su- } \\
\text { danküste, Azoren }\end{array}$ & $454-1190 \mathrm{~m}$ & $\begin{array}{l}\text { behaart, gelb- ! } \\
\text { lich }\end{array}$ & groß, bräunlich & $\begin{array}{l}\text { messer } \\
\text { mm Durch- }\end{array}$ & $\begin{array}{l}\text { Talisman, p. I4; } \\
\text { Monaco II, p. } 14\end{array}$ \\
\hline D. ovata M..E. & $\begin{array}{l}\text { Barbados, Havana } \\
\text { u. } 28^{\circ} \text { I } 5^{d} \text { N. Br., } \\
82^{0} 13^{4} \text { O. L. }\end{array}$ & $329 \mathrm{~m}$ & rauh & groß, dunkel & $\begin{array}{c}1,5 \mathrm{~mm} \\
\text { Durchmesser }\end{array}$ & Blake \\
\hline D. Doederleini ORTM. & Sagamibai & $274 \mathrm{~m}$ & $\begin{array}{c}\text { haarig und } \\
\text { borstig }\end{array}$ & $\begin{array}{l}\text { klein, aber wohl } \\
\text { pigmentiert }\end{array}$ & grol3 & ORTMANN V, p. $55^{\circ}$ \\
\hline D. Baffini ALC. & $\begin{array}{l}\text { Travancore, Anda- } \\
\text { manen }\end{array}$ & $435-786 \mathrm{~m}$ & $\begin{array}{l}\text { pelzig, } \\
\text { schmutzig } \\
\text { weiß mit } \\
\text { rötlich. und } \\
\text { bläul. Ton }\end{array}$ & mäßig, braun & - & Investigator \\
\hline Dynomene pilummoides ALC. & Laccadiven & $55-90 \mathrm{~m}$ & - & - & - & ALCock, $\rho .36$ \\
\hline D. Filholi Bouv. & Cap Verden & $60-275 \mathrm{~m}$ & stachelig, rot & Cornea verbreitert & - & \\
\hline $\begin{array}{l}\text { Acanthodromia margarita } \\
\text { ALC. }\end{array}$ & Andamanen & $137 \mathrm{~m}$ & $\begin{array}{l}\text { stachelig, } \\
\text { milchweil' }\end{array}$ & pigmentiert & - & Investigator \\
\hline A. crinaced M.-E. & $\begin{array}{l}\text { Guadeloupe, St. Vin- } \\
\text { cent }\end{array}$ & $274 \mathrm{ml}$ & stachelig & $\begin{array}{l}\text { ziemlich groß, dun- } \\
\text { kel? }\end{array}$ & $0,5 \mathrm{~mm}$ & Blake \\
\hline $\begin{array}{l}\text { Sphaerodromia Kindalli ALC. } \\
\text { 11. AND. }\end{array}$ & Bai ron Bengalen & $205 \mathrm{~m}$ & glatt & mäßig, unpigmentiert & - & Investigator \\
\hline S. $n u x$ ALC. & Golf von Martaban & $130 \mathrm{~m}$ & - & - & 一 & ALCOCK 1901, p. 40 \\
\hline $\begin{array}{l}\text { Conchoecetes arificiosus } \\
\text { (FABR.) }\end{array}$ & $\begin{array}{l}\text { Golf von Bengalen, } \\
\text { Andamanen etc. }\end{array}$ & $0-110 \mathrm{~m}$ & - & - & - & ALCOCK 190I, P. 41 \\
\hline Dromia anlgaris M.-E. & $\begin{array}{l}\text { Mlittelmeer, } \\
\text { Azoren, } \\
\text { Senegal }\end{array}$ & $\left|\begin{array}{c}80 \mathrm{~m} \\
98 \mathrm{~m} \\
\text { wohl nicht } \\
\text { tiefer als } 100 \mathrm{~m}\end{array}\right|$ & - & - & - & $\begin{array}{l}\text { Talisman, Monaco II, } \\
\text { p. } 15\end{array}$ \\
\hline
\end{tabular}




\begin{tabular}{|c|c|c|c|c|c|c|}
\hline$\Delta r t$ & Vorkommen & Tiefe & Habitus & Augen & $1 \cdots$ & Litteratur \\
\hline Dromia Rumphit FAsk. & $\begin{array}{l}\text { Persischer Golf, Golf } \\
\text { von Martaban etc.n } \\
\text { Japan }\end{array}$ & $0-125 \mathrm{~m}$ & & & & AlCOCK Igor, p. 44 \\
\hline D. nodoso M.aE. นt. Bouv. & Cap Verden & $75 \mathrm{~m}$ & $\begin{array}{l}\text { wenig stache- } \\
\text { ligg }\end{array}$ & $\begin{array}{l}\text { Augen nüßig, } \\
\text { schwary }\end{array}$ & & Talisman, p. I8 \\
\hline 1). bicorris (STUDER) & Agulhasbank & $100-318 \mathrm{~m}$ & stachelig & normal & grol's & $\begin{array}{l}\text { Gazelle; Challenger; } \\
\text { Valdivia }\end{array}$ \\
\hline D. spinosa (STUDFR) & $\begin{array}{l}\text { Südich vom Kaj d. } \\
\text { guten Hoffnung }\end{array}$ & $100-220111$ & stachelig & mäflig & & Gazelle: Valdivia \\
\hline Cryptodromia incisa HEND. & $\begin{array}{l}\text { Twofoldbay (Austra- } \\
\text { lien) }\end{array}$ & $220 \mathrm{~m}$ & glatt & klein & & Challenger \\
\hline C. Bullifera ALC. & Ceylon, Andamanen & $60-900 \mathrm{~m}$ & & - & & ALCOCK 190I, P. 5I \\
\hline Eudromia fromfalis HEND. & Agulhasbank & $282 \mathrm{~m}$ & Cth. glatt & mälsig & & Challenger \\
\hline Psendodromin latens STM. & Kapregion, Sansibar | & $20-100 \mathrm{~m}$ & maskiert & $\begin{array}{l}\text { mảlige Dämmc- } \\
\text { rungsaugen }\end{array}$ & & $\begin{array}{l}\text { Challenger, p. } \Varangle 8 ; \\
\text { Valdivia }\end{array}$ \\
\hline Petalomera indicn Ar.e. & Ceylon, Andamanen & bis $60 \mathrm{~m}$ & & & & Alcock 1901, p. 55 \\
\hline $\begin{array}{l}\text { Ilomolodromia Coppingeri } \\
\text { (MRS.) }\end{array}$ & Laccadiven, Ceylon & lis $60 \mathrm{~m}$ & & & & ALCoCk 1901, p. 57 \\
\hline $\begin{array}{l}\text { Honnologemes rostratus A. } \\
\text { W.-H. }\end{array}$ & $\begin{array}{l}\text { Azored, Marokko, } \\
\text { St. Thomas, Sta. } \\
\text { Cruz }\end{array}$ & ${ }^{\mathrm{I}} 435-\mathrm{I} 900 \mathrm{~m}$ & $\begin{array}{l}\text { Cth. stachelig, } \\
\text { rot }\end{array}$ & $\begin{array}{l}\text { A. mäligig, aber lang } \\
\text { gestielt }\end{array}$ & 1 mun & $\begin{array}{l}\text { Monaco II, p. 13; } \\
\text { Talisman, p. I1 }\end{array}$ \\
\hline H. Braneri Dof. & Somaliland & $1242 \mathrm{~m}$ & Cth. stachelig & $\begin{array}{l}\text { grol\}, Dämmerungs- } \\
\text { augen }\end{array}$ & & Valdivia \\
\hline H. sp. ?? HEN(). & Gilolo-Insel & $1510 \mathrm{~m}$ & Cth. stachelig & ziemlich groli & - & Challenger \\
\hline Homola barbata typica (FAliR.) & $\begin{array}{l}\text { Mittelmeer, bis } \Lambda z n- \\
\text { ren, Virginia, New } \\
\text { Jersey, Rarbados, } \\
\text { Cuba }\end{array}$ & $50-680 \mathrm{~m}$ & Cth. stachelig & groli & relativ groli & $\begin{array}{l}\text { Talisman, p. 10; } \\
\text { Blake, p. 26; Mo- } \\
\text { naco I, p. 6I; Mo- } \\
\text { naco II, p. II }\end{array}$ \\
\hline H. barbata orientalis (HEND.) & $\begin{array}{l}\text { Japan, I'hilippinen, } \\
\text { Ki-Inseln, Anda- } \\
\text { manen }\end{array}$ & $132-17+\mathrm{m}$ & Cth. stachelig & grob, pigmentient & grol; & $\begin{array}{l}\text { DofLEIN I900; Cbal- } \\
\text { lenger; Investiga- } \\
\text { tor; Valdivia }\end{array}$ \\
\hline 11. megalops Arc. & $\begin{array}{l}\text { Andamanen, Ben- } \\
\text { galen, Colombo }\end{array}$ & $260-750 \mathrm{~m}$ & Cth. stachelig & $\begin{array}{l}\text { sehr grol', pigmen- } \\
\text { tiert }\end{array}$ & & Investigator \\
\hline II. vigil M.-E. & $\begin{array}{l}\text { Cubn, Guadeloupe, } \\
\text { Martiniq̨ue }\end{array}$ & $300-730 \mathrm{~m}$ & Cth. stachelig & groli & & Blake, p. 2; \\
\hline f'aromoles Curvieri Rovx & $\begin{array}{l}\text { Mittelmeer, bis Cap } \\
\text { Bojador }\end{array}$ & $10-6,0 \mathrm{~m}$ & Cth. stachelig & grol's & $1 / \mathrm{s} \mathrm{mm}$ & Talisman, p. 10 \\
\hline P. profundonum AIC. & $\begin{array}{l}\text { Travancore - Küste, } \\
\text { Ostafrika }\end{array}$ & $780-1362 \mathrm{~m}$ & $\begin{array}{l}\text { Cth. mälig, } \\
\text { stachelig }\end{array}$ & grols, pigmentiert & & Valdivia \\
\hline Iaromolopsis Boasi W.-MI. & $\begin{array}{l}\text { Andamanen, Travan- } \\
\text { core, Laccadiven, } \\
\text { Colnmbo }\end{array}$ & $55^{8--1090 m}$ & $\begin{array}{l}\text { Cth. stache- } \\
\text { lig, rot bis } \\
\text { bläulich. } \\
\text { karmin }\end{array}$ & $\begin{array}{l}\text { ziemlich grol\}, pig- } \\
\text { mentiert }\end{array}$ & & Investigator \\
\hline $\begin{array}{l}\text { IIypsophry's superciliosa } 1 \mathrm{~V} \text {.- } \\
\text { M. }\end{array}$ & $\begin{array}{l}\text { Arabisches Meer, } \\
\text { Bai von Bengalen }\end{array}$ & $1350-1800 \mathrm{~m}$ & $\begin{array}{l}\text { Cih. wenig } \\
\text { stachelig. } \\
\text { rosa }\end{array}$ & $\begin{array}{l}\text { kiein, blals, wohl- } \\
\text { geformt und facet- } \\
\text { tiert }\end{array}$ & - & Investigator \\
\hline H. longipes ALC, u. $\Lambda \mathrm{ND}$. & $\begin{array}{l}\text { Travancore, } \\
\text { sumatra, } \\
\text { baren }\end{array}$ & $6 \mathrm{r}_{4}-805 \mathrm{~m}$ & $\begin{array}{l}\text { Cth. stachelig, } \\
\text { glatte Beine }\end{array}$ & $\begin{array}{l}\text { mälig, Dämme- } \\
\text { rungsaugen }\end{array}$ & - & $\begin{array}{c}\text { Investigator; } \\
\text { Valdivia }\end{array}$ \\
\hline
\end{tabular}




\begin{tabular}{|c|c|c|c|c|c|c|}
\hline Art & Vorkommen & Tiefe & Habitus & Augen & Eier & Litteratur \\
\hline Latrillia elegans $\mathrm{Rx}$. & $\begin{array}{l}\text { Mittelmeer, Azoren, } \\
\text { Sudan-Küste, Cap } \\
\text { Verden, New Jer- } \\
\text { sey }\end{array}$ & $130-405 \mathrm{~m}$ & \begin{tabular}{|} 
Cth. stachelig, \\
rot, lang- \\
beinig
\end{tabular} & $\begin{array}{l}\text { Cornea schwarz, } \\
\text { groß }\end{array}$ & - & Talisman, p. I 3 \\
\hline L. pennifern ALC. & $\begin{array}{l}\text { Golf von Martaban, } \\
\text { Bai von Bengalen, } \\
\text { Mergui-Inseln }\end{array}$ & $50-120 \mathrm{~m}$ & $\begin{array}{l}\text { Cth.stachelig, } \\
\text { rot, lang- } \\
\text { beinig }\end{array}$ & $\begin{array}{l}\text { Cornea schwarz, } \\
\text { groß }\end{array}$ & - & ALCOCK Igar, p. i I \\
\hline L. phalanginm D. H. & Japan & $10-180 \mathrm{~m}$ & $\begin{array}{l}\text { Cth. stachelig, } \\
\text { rot, lang- } \\
\text { beinig }\end{array}$ & $\begin{array}{l}\text { Cornea schwarz, } \\
\text { groß }\end{array}$ & - & $\begin{array}{l}\text { ORTMANN; DOF- } \\
\text { LEIN }\end{array}$ \\
\hline L. ralida D. H. & Cebú, Japan & $174 \mathrm{~m}$ & $\begin{array}{l}\text { Cth. stachelig, } \\
\text { rot, lang- } \\
\text { beinig }\end{array}$ & $\begin{array}{l}\text { Cornea schwarz, } \\
\text { groß }\end{array}$ & groß & $\begin{array}{l}\text { Challenger; ORT- } \\
\text { MANN ; DOFLEIN }\end{array}$ \\
\hline L. mustraliensis HEND. & $\mid \begin{array}{c}\text { Twofoldbay, } \\
\text { Jackson, Australien }\end{array}$ & $55-282 \mathrm{~m}$ & $\begin{array}{l}\text { Cth.stachelig, } \\
\text { langbeinig }\end{array}$ & groß & - & Challenger \\
\hline Latreillopsis bispinosa HENI. & $\begin{array}{l}\text { Cebí, Japan, Anda- } \\
\text { manen }\end{array}$ & $90-174 \mathrm{~m}$ & $\left|\begin{array}{l}\text { Cth. mäßig } \\
\text { stachelig }\end{array}\right|$ & $\begin{array}{l}\text { groß, Dämmerungs- } \\
\text { augen }\end{array}$ & | klein & $\begin{array}{l}\text { Challenger, Dof LEIN, } \\
\text { AlcoCK }\end{array}$ \\
\hline Homolochunia Toldiziac DorL. & Ostafrika & $693-977 \mathrm{~m}$ & | mäBig stache- | & $\begin{array}{l}\text { groß, Dämmerungs- } \\
\text { augen }\end{array}$ & | klein & | Valdivin \\
\hline Palicus aczetifrons M.-E. & $\begin{array}{l}\text { II }^{0} 49^{\prime} \text { S. Br., } 37^{\circ} 10^{\prime} \\
\text { O. L., Karibisches } \\
\text { Meer }\end{array}$ & $27 \mathrm{~m}$ & & groß & - & Blake \\
\hline P. affinis M.E. u. Bouv. & Sta. Cruz (Antillen) & $210 \mathrm{~m}$ & $\begin{array}{c}\text { Cth.stachelig, } \\
\text { langbeinig }\end{array}$ & groß & - & Blake \\
\hline P. Agassizit M.-E. u. Bouv. & Barbadoes, Sand Key | & $126-137 \mathrm{~m}$ & $\begin{array}{l}\text { Cth. stachelig, | } \\
\text { langbeinig | }\end{array}$ & $\begin{array}{l}\text { Augenstiel kurz, } \\
\text { dick, Cornea redu- } \\
\text { ziert, ohne Pigment }\end{array}$ & -- & Blake, p. 78 \\
\hline$P$ alternatus RATHBUN & St. Thomas & $35-110 \mathrm{~m}$ & - & 一 & - & R. VIII, p. I 2 \\
\hline P. asper M.-E. & Montserrat (Antillen) & $270 \mathrm{~m}$ & | Cth. staclielig | & 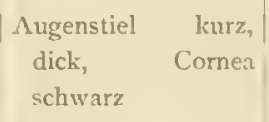 & - & Blake, p. 74 \\
\hline P. Blakei M.-E. u. Bouv. & $\begin{array}{l}24^{\circ} 49^{\circ} \mathrm{N} \cdot \mathrm{Br} \cdot 83^{\circ} 86^{\circ} \\
\text { (1. I.. }\end{array}$ & $68 \mathrm{~m}$ & | Cth. stachelig | & mäßig & - & Blake \\
\hline P. Caroni $\mathrm{R}$. & $\begin{array}{l}\text { Azoren, Atlantischer } \\
\text { Ocean }\end{array}$ & $50-\mathrm{I} 60 \mathrm{~m}$ & $\begin{array}{l}\text { | etwas stache- | } \\
\text { lig, Farbe } \\
\text { rötlich }\end{array}$ & mittelgroß & - & $\begin{array}{l}\text { Talisman, p. 2I ; } \\
\text { Monaco II, p. I7 }\end{array}$ \\
\hline$P$. cristatipes M.-E. & Grenada (Antillen) & $170 \mathrm{~m}$ & | langbeinig & groß, erweitert & - & Blake, p. 42 \\
\hline P. cursor M.-E. & $\begin{array}{l}\text { Barbados, Dominica, } \\
\text { St. Kitts }\end{array}$ & $250-350 \mathrm{~m}$ & | Cth. runzelig | & groß & - & Blake \\
\hline P. dentatus M.-E. & $\begin{array}{c}\text { Barbados, Charlotte } \\
\text { Hbr., Sta. Cruz }\end{array}$ & $9 \mathrm{I}-210 \mathrm{~m}$ & $\begin{array}{l}\text { |Cth.stachelig, } \\
\text { | langbeinig, } \\
\text { rötlich }\end{array}$ & mittelgroß & - & Blake \\
\hline$P$ alepressits R.1THB. & Barbados & I $50 \mathrm{~m}$ & $\begin{array}{l}\text { | runzelig, lang. | } \\
\text { beinig }\end{array}$ & groß & - & Blake \\
\hline P. fragilis (RАTнB.) & $\begin{array}{l}\text { Cocos-Ins., Malpelo- } \\
\text { Ins. (Panama-Re- } \\
\text { gion), Nieder-Kali- } \\
\text { fornien }\end{array}$ & $95-130 \mathrm{~m}$ & \begin{tabular}{|l|} 
abgeplattete \\
Beine \\
(Schweben?)
\end{tabular} & mäßig & - & $\begin{array}{l}\text { Albatross, p. } 40 \text {; } \\
\text { R. VI, p. } 259\end{array}$ \\
\hline P. gracilipes M.-E. & $\begin{array}{l}23^{\circ} \times 3^{\circ} \mathrm{N} \cdot \mathrm{Br} ., 89^{\circ} 16^{\circ} 1 \\
\text { O. L., Grenada } \\
\text { (Antillen) }\end{array}$ & $\mathrm{I} 70 \mathrm{~m}$ & | langbeinig & groß & - & Blake \\
\hline
\end{tabular}




Are
Palius obesus M.-E.
P. Rathurni M.E. u. Bouv.
P. sica (M.-E.)
P. tuberiviatus F.1xo.
P. innatus RuthB.

Ethusa andamanica ALC.

E. cilialifrons FAx.

E. lata Ratub.

E. indica Alc.

E. lata R.iTHB. (= pubescens Fix.)

E. mascarone Hiss?.

E. mascarone americana (M.-E.)

E. microphthalma SMTH

E. orientalis MRS.

E. pugmaea Aic.

E. rosacea M.-E. U. Bouv.

E. rugulosa M.-E. u. Bouv.

L. Iruncala M.-E. u. Botv.

E. somatice DOFI.

E. Zurstrasseni 1)okt.

Ethusina abyssicola S. Surtu

\section{\begin{tabular}{l|l|l} 
Vorkommen | Tiefe | Habius & \\
\end{tabular}}

$23^{0} 13^{\prime}$ N. Br., $89^{0} 16^{\prime} \mid \quad 153 \mathrm{~m} \quad$ | Cth. stachelig, / groß O. L.

Barbados

$130 \mathrm{~m} \mid$ Cth.stachelig, | grols

langbeinig

Barbados, Grenada, | $146-243 \mathrm{~m}$ | Cth.stachelig, / groli

Sand Key, Porto | langbeinig

Rico, Golf von

Mexikn

Mariato I'oint (West-

küste von Mexiko)

$435 \mathrm{~m}$ | lange Schweb-| mittelgroß

beine

Golf v. Kalifornien

Andamanen, Niko- $344-\mathrm{SO}_{5} \mathrm{~m} \mid$ Ceh. glatt | nichtsehrfreibewegbaren

Panama

|

Panama, Golf von
Kalifornien, Cap

Kalifornien,
St. Lucas

Gangesdelta, Anda-|439-1315 m - $\quad$ |kurzgestielt, aber be-

manen bis Ceylon,

Laccadiven, Male-

diven

\section{Cocos-Inseln}

Golf von Kalifornien

Mittelmeer, stlant.

Gorce.

Florida, Sand Key

(Atlantik), Cap St.

Lucas (Pacifik),

Japan?

Azoren

Fidschi-Inseln

Andamanen

|232-474 in | Cth. glatt; | klein, kurz gestielt,

junge Indi-| schwarz

viduen nicht

so breit wie alte

Canaren

$$
1930
$$

C

Cap Verden (Praya) $\left|{ }^{50-275} \mathrm{~m}\right|$ Cth. glatt |kurzgestielt, mittel.

$28^{\prime \prime} 52^{\prime} \mathrm{N} \cdot 13 \mathrm{r} \cdot, \mathrm{S1}^{\circ} \mathrm{O} 2^{\prime} \quad 215-220 \mathrm{~m}$

1. 1.. : $211^{\prime \prime} 31^{\circ} \times$.

Br., $85^{\circ} 3 \mathrm{~T}^{\circ}$ O. L.

Somaliküiste

Ostafrika

weglich, oft ein

wenig pigmentarm

Maryland, Delaware, $1230-426 \mathrm{Im}$ Cth. glatt, unbeweglich, klein,

Brasilien, Azoren,

Cap Verden, Ost-

Allantik, Ostafrika
$1362 \mathrm{~m}$

Cth. glatt

langgestielt

blau u.gelb- Dämmerungsaugen lich gefürbt
977 in Cth. glatt grols

Augenstiele kurz, dick, Cornea relativ groß, schwarz

Dämmerungsaugen klcin, pigmentiert

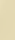

\author{
Blake, R. VIII, p. 13 \\ Nlbatross, R. VI, \\ p. 259 \\ R. VI, p. 259
}

Blake

Investigator, Valdiv

Albatross

R. I, p. 615

Investigator

R. V, p. $5^{8}$

Monaco II, p. 18

Talisman, p. 22

Blake, p. 67 ; RAtuBUN I, p. 615

Challenger

Challenger

Investigator

Talisman, p. 26

Talisman, p. 24

Blake, p. 69

Valdivia

Valdivia

Albatross, 1883 ;

Talisman, p. 29;

Raturue 1,p.615;

Valdivia

$3 \pi^{*}$ 


\begin{tabular}{|c|c|c|c|c|c|c|}
\hline Art & Vorkommen & Tiefe & Habitus & Augen & Eier & Litteratur \\
\hline Ethusind Challengeri Mrs. & $\begin{array}{l}\text { bei Yokohama, zwi- } \\
\text { sclien Galapagos } \\
\text { und Acapulco }\end{array}$ & $|3300-4081 \mathrm{~m}|$ & Cth. glatt & $\begin{array}{l}\text { klein, kurze unbe- } \\
\text { wegliche Stiele }\end{array}$ & - & | Challenger; Albatross \\
\hline E. desitiscens Alc. & $\begin{array}{l}\text { Andamanen, Lacca- } \\
\text { diven }\end{array}$ & $|486-1703 \mathrm{~m}|$ & - & $\begin{array}{l}\text { kurz, ein wenig be- } \\
\text { weglich }\end{array}$ & - & Investigator \\
\hline E. gracilipes (MRs.) & $\begin{array}{l}\text { Malediven } \\
\text { Philippinen } \\
\text { Banda-See, Cocos- } \\
\text { Ins., Panamagebret, } \\
\text { Galapagos, Aca- } \\
\text { pulco }\end{array}$ & $\mid \begin{array}{c}1280 \mathrm{~m} \\
-\quad 2600 \mathrm{~m} \\
-3350 \mathrm{~m}\end{array}$ & - & klein & - & $\begin{array}{l}\text { Challenger } \\
\text { Investigator } \\
\text { Albatross }\end{array}$ \\
\hline E. intestigatoris ALC. & $\begin{array}{l}\text { Bai ron Bengalen, } \\
\text { Laccadiven }\end{array}$ & $2154-2394 \mathrm{~m} \mid$ & $\begin{array}{l}\text { Cth. glatt, } \\
\text { milch weiß, } \\
\text { Beinenden } \\
\text { rosa }\end{array}$ & unbeweglich & 一 & Investigator \\
\hline E. Smithiand FAx. & Malpelo-Cocos-Ins. & $245-1645 \mathrm{~m}$ & 一 & $\mid \begin{array}{l}\text { kurzgestielt, } \\
\text { klein }\end{array}$ & - & Albatross \\
\hline E. talismani M.-E. & $\begin{array}{l}\text { Cap Guir, Marocco, } \\
\text { Azoren }\end{array}$ & $|20 \% 5-2212 \mathrm{~m}|$ & $\begin{array}{l}\text { Cth. grünlich- } \\
\text { gell) }\end{array}$ & \begin{tabular}{|} 
sehr reduziert,Cornea \\
aber größer als bei \\
abyssicola
\end{tabular} & - & $\begin{array}{l}\text { Talisman, p. } 30 ; \text { Mo- } \\
\text { naco II, p. } 19\end{array}$ \\
\hline Dorippe armata $\mathrm{W}_{\mathrm{HITE}}$ & $\begin{array}{c}\text { Cap Verden, Gorce, } \\
\text { Kongo, Benguela }\end{array}$ & $60 \mathrm{~m}$ & - & - & mäßig groß & | Talisman, p. 32 \\
\hline D. japonica $\mathrm{V}$. SIEB. & Kobe & $15-90 \mathrm{~m}$ & - & - & - & | Challenger \\
\hline D. lanafa (L.) & $\begin{array}{l}\text { Mittelmeer, Gibral- } \\
\text { tar, Kongo-Mün- } \\
\text { dung }\end{array}$ & $44-106 \mathrm{~m}$ & - & - & -- & $\begin{array}{l}\text { Talisman, p. } 34 \text {; Val- } \\
\text { divia }\end{array}$ \\
\hline $\begin{array}{l}\text { Cymonomus gramulatus typi- } \\
\text { cus (NORM.) }\end{array}$ & $\begin{array}{l}\text { Mittelmeer, Atlantik } \\
\text { von Islard bis zur } \\
\text { Sahara, Azoren }\end{array}$ & $|307-1350 \mathrm{~m}|$ & | Cth. stachelig | & \begin{tabular}{|l|} 
rückgebildet, ohne \\
Pigment
\end{tabular} & $\begin{array}{l}\text { groß, mehr } \\
\text { als } 1 / 2 \mathrm{~mm} \\
\text { Durchm. }\end{array}$ & $\begin{array}{l}\text { Talisman, p. } 34 ; \text { Mo- } \\
\text { naco I, p. } 58\end{array}$ \\
\hline C. granulatus Normani L.ANK. & Nordatlantik & - & | Cth.stachelig | & gänzlich ohne Cornea & - & $\begin{array}{l}\text { s. LANKESTEK } 1903 \\
\text { und oben S. } 283\end{array}$ \\
\hline C. granulatus quadratus M.-E. & $\begin{array}{c}\text { Santa Cruz, Habana, } \\
\text { Guadeloupe, Do- } \\
\text { minica, Grenada }\end{array}$ & $180-680 \mathrm{~m}$ & Cth. rauh & $\begin{array}{c}\text { Augenstiele schlank, } \\
\text { gar keine Cornea }\end{array}$ & $\begin{array}{r}8 / 4 \mathrm{~mm} \text {, nur } \\
\text { in der Zah? } \\
\text { von } 6 \text { Stück }\end{array}$ & Blake, p. 81 \\
\hline C. gramulatus Valdiziae LAxk. & Ostafrika & $658 \mathrm{~m}$ & | Cth. stachelig | & $\begin{array}{c}\text { Augenstiele schlank, } \\
\text { gar keine Cornea }\end{array}$ & $\begin{array}{l}\text { sehr groß, } \\
\text { ca. } 15 \text { Stück }\end{array}$ & | Valdivia \\
\hline Corycodus bullatus M.-E. & $\begin{array}{l}\text { Morro-Leuchtturm } \\
\text { bei Habana }\end{array}$ & $360 \mathrm{~m}$ & Cth. rauh & Cornea groß, dunkel & - & Blake, p. 86. \\
\hline Clythrocerus nitidus M.-E. & $\begin{array}{c}\text { Florida bis Grenada, } \\
\text { Golf von Mexiko }\end{array}$ & $200-400 \mathrm{~m}$ & Cth. glatt & $\begin{array}{l}\text { groß, Cornea ver- } \\
\text { breitert }\end{array}$ & - & | Blake, p. go. \\
\hline Cyclodorippe Agrassizii M.-E. & Habara & $230-440 \mathrm{~m}$ & Cth. rauh & $\begin{array}{l}\text { ziemlich groß, } \\
\text { dunkel }\end{array}$ & ${ }^{1} i_{2} \mathrm{~mm}$ & | Blake, p. 94. \\
\hline C. antennaria MI.-E. & $\begin{array}{l}\text { Kleine Antillen, } \mathrm{Ha} \text { - } \\
\text { bana }\end{array}$ & $100-650 \mathrm{~m}$ & Cth. rauh & $\begin{array}{l}\text { dick, kurz, Cornea } \\
\text { groß }\end{array}$ & $1 / 2 \mathrm{~mm}$ & Blake, p. 99. \\
\hline C. dromioides ORTII. & Japan, Saganibai & $50-180 \mathrm{~m}$ & | Cth. stachelig | & $\begin{array}{l}\text { dünn, klein, pig- } \\
\text { mentarm }\end{array}$ & - & ORTMANN V, p. 559 \\
\hline C. nitida M.-E. & Georgia & $470 \mathrm{~m}$ & Cth. glatt & mittelgroß & - & Blake, p. 80. \\
\hline $\begin{array}{l}\text { C. uncifera melanomma } \\
\text { DOFL. }\end{array}$ & Japan, Sagamibai & $50 \mathrm{~m}$ & - & pigmentiert & groß & s. oben \\
\hline
\end{tabular}




\begin{tabular}{|c|c|c|c|c|c|c|}
\hline$\Delta r t$ & Vorkommen & Tiefe & Ilabitus & Augen & Eict & Litteratur \\
\hline $\begin{array}{l}\text { Civlodorippe uncifera slatec- } \\
\text { omma Alce. }\end{array}$ & $\begin{array}{l}\text { Ostafrika, Bengalen } \\
\text { Bengalen, Anda- } \\
\text { manen, Japan }\end{array}$ & $180-739 \mathrm{~m}$ & $\begin{array}{c}\text { Cth. mäBig | } \\
\text { stachelig, } \\
\text { kalkig, rosa }\end{array}$ & $\mid \begin{array}{l}\text { rïckgebildet, pig- } \\
\text { mentlos }\end{array}$ & | grols & $\begin{array}{l}\text { OkTuls: V, p. } 560 \text {; } \\
\text { Investigator; Valdi- } \\
\text { via }\end{array}$ \\
\hline Acanthocarpus Alexandri STM. & $\begin{array}{l}\text { Massachusetts bis } \\
\text { Kl. Antillen }\end{array}$ & $130-375 \mathrm{~m}$ & $\begin{array}{l}\text { |Cth. rot ge- | } \\
\text { färbt }\end{array}$ & - & - & Blake, p, 126 \\
\hline A. bispinosus M.E. & $\begin{array}{l}\text { Grenadinen ( } \mathrm{An}- \\
\text { tillen) }\end{array}$ & $250 \mathrm{~m}$ & - & - & - & BLAKE, P. 12; \\
\hline Mursia armata typita d. II. & Japan & $90-180 \mathrm{~m}$ & - & - & - & s. oben S. 40 \\
\hline 11. armeata curtispina MKS. & $\begin{array}{l}\text { Malediven, Nias, } \\
\text { Fidschi-Ins., Japan }\end{array}$ & $384-5 ; 6 \mathrm{~m}$ & - & - & - & 15. oben S. 40 \\
\hline $\begin{array}{l}\text { 17. armala haztaicnsis } \\
\text { R.ITHB. }\end{array}$ & Sandwich-Inseln & $540 \mathrm{~m}$ & - & - & - & |s. oben S. 4 I \\
\hline 1\%. armata bicristimana $\mathrm{ALC}$. & Ccylon, Nikobaren & $260-732 \mathrm{~m}$ & $\begin{array}{l}\text { Cth. granu- } \\
\text { liert, lachs- } \\
\text { rot }\end{array}$ & mäßig & - & |s. oben S. $4 \mathrm{I}$ \\
\hline 1\%. aspere MLC. & Malediven & $384 \mathrm{~m}$ & $\begin{array}{c}\text { Cth. rauh, fast } \\
\text { stachelig }\end{array}$ & - & - & Investigator \\
\hline 1\%. Cristimana (DEsM.) & $\begin{array}{l}\text { Kapregion, Tafelbai, } \\
\text { Agulhasbank }\end{array}$ & $70-318 \mathrm{~m}$ & - & - & - & $\begin{array}{l}\text { Challenger; Gazelle; } \\
\text { Valdivia }\end{array}$ \\
\hline Patymera Gasulichandi M.-E. & $\begin{array}{l}\text { Chile bis Panama } 11 . \\
\text { Californien }\end{array}$ & $40-370 \mathrm{~m}$ & & $\cdots$ & & $\begin{array}{l}\text { Albatross, p. } 32 ; 1 \mathrm{I} \text {, } \\
\text { p. } 160\end{array}$ \\
\hline Ilia muilens Нвsт. & $\begin{array}{l}\text { Mittelmeer, Nordost- } \\
\text { atlantik }\end{array}$ & $60-162 \mathrm{~m}$ & - & & & Talisman, p. 40 \\
\hline lliacantha subglobosa STM. & $\begin{array}{l}\text { Barbados, Montser- } \\
\text { rat (Antillen) }\end{array}$ & $128-215 \mathrm{~m}$ & - & & & Blake, p. II 3 \\
\hline Lewosia craniolaris (L.) & $\begin{array}{l}\text { Arafura-See, Kolse } \\
\text { (Japan) }\end{array}$ & $90 \mathrm{~m}$ & & $=$ & & Challenger \\
\hline Osachila acuta SrM. & I'anama, Manzanillo & $:$ & - & & & $\begin{array}{l}\text { Simuson, Ann. Lyc. } \\
\text { N. 1., 1871, Vol. } \\
\text { X, p. } 114\end{array}$ \\
\hline O. leite Fix. & Tres Marias (P’acific) & $146 \mathrm{~m}$ & & & & Alhatross \\
\hline O. Stimpsoni STUDER & Ascension & $110 \mathrm{~m}$ & $\begin{array}{l}\text { Cth. purpur- } \\
\text { rot his } \\
\text { fleischfarben }\end{array}$ & & & Gazelle \\
\hline O. Inberosa STM. & $\begin{array}{l}\text { Antillen, Cap, Hat- } \\
\text { teras }\end{array}$ & $6 \%-300 \mathrm{~m}$ & $=$ & - & & $\begin{array}{l}\text { Strmpsos, Bull. Mlus. } \\
\text { Comp. Znol. II, } \\
\text { ז8\%o, p. 154 }\end{array}$ \\
\hline Caloppe angusta M.-L. & Kleine Antillen & $150-210 \mathrm{~m}$ & Cth. glatt & grol & & Blake, I). I 23 \\
\hline $\begin{array}{l}\text { C. japonica ORTM. (= exan- } \\
\text { thematosa Alc. u. Avn.) }\end{array}$ & Madras, Japan & $160-205 \mathrm{~m}$ & \begin{tabular}{|} 
Cth. höckerig, \\
bei Jungen \\
mitscharfen \\
Domen
\end{tabular} & & & $\begin{array}{l}\text { Investigator; } \\
\text { DOEDERI:FIN }\end{array}$ \\
\hline C. gramulata (L.) & $\begin{array}{l}\text { Mittelmeer, Spanien, } \\
\text { Cap Verden, Azo- } \\
\text { ren, Westindien }\end{array}$ & $10-105 \mathrm{~m}$ & 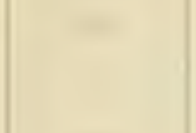 & & & $\begin{array}{l}\text { Talisman, p. } 59 ; \\
\text { Challenger }\end{array}$ \\
\hline C. lophos (HBSI.) & $\begin{array}{l}\text { Indopacifik, Port } \\
\text { Jackson (Austra- } \\
\text { lien) }\end{array}$ & to $\mathrm{m}$ & 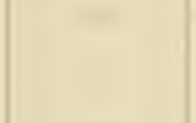 & & & Challenger \\
\hline $\begin{array}{l}\text { Paracjeloës Milne-Litherardsi } \\
\text {.lks. }\end{array}$ & Admiralitäts-Inseln & $274 \mathrm{~m}$ & - & & - & Challenger \\
\hline
\end{tabular}




\begin{tabular}{|c|c|c|c|c|c|c|}
\hline Art & Vorkommen & Tiefe & Habitus & Augen & Eier & Litteratur \\
\hline Ebalia algirica LUCAs & $\begin{array}{l}\text { Madeira, Canaren, } \\
\text { Mittelmeer }\end{array}$ & $100-790 \mathrm{~m}$ & & - & -- & Talisman, p. 47 \\
\hline E. americana R.ıTHв. & Golf ron Californien & $3^{6-130 \mathrm{~m}}$ & - & & - & R. VI, p. 255 \\
\hline E. atlantica M.E. u. B. & $\begin{array}{l}\text { Cap Verden, Seine- } \\
\text { Bank }\end{array}$ & $50-60 \mathrm{~m}$ & | Cth. höckerig & klein, schwarz & - & $\begin{array}{r}\text { Talisman, p. 5I; } \\
\text { Valdivia }\end{array}$ \\
\hline E. Cranchiz LCH. & $\begin{array}{l}\text { Schottland bis Ma- } \\
\text { rocco, Azoren, } \\
\text { Nittelmeer }\end{array}$ & $\mathrm{I} 5-550 \mathrm{~m}$ & - & - & - & $\begin{array}{c}\text { Talisman, p. } 4 \mathbf{1} \text {; } \\
\text { Monaco I, p. } 54\end{array}$ \\
\hline E. crassipes BELL & $\begin{array}{l}\text { Bass-Str., Port Jack- } \\
\text { son (Australien) }\end{array}$ & $70 \mathrm{~m}$ & - & - & - & Challenger \\
\hline E. cristato R.ATHв. & Pta.Abreojos(Pacifik) & $85 \mathrm{~m}$ & - & - & - & R. I, p. 6 I 2 \\
\hline E. Edzuardst Costa & $\begin{array}{l}\text { Setubal, Mittelmeer } \\
\text { und Canaren }\end{array}$ & $30-100 \mathrm{~m}$ & & - & - & Talisman, p. 43 \\
\hline E. granulosa M.-E. & Mittelmeer & $445 \mathrm{~m}$ & Cth. rauh & normal & - & Talisman, p. 42 \\
\hline E. intermedia MRs. & $\begin{array}{l}\text { Port Philip (Austra- } \\
\text { lien) }\end{array}$ & $60 \mathrm{~m}$ & - & & - & Challenger \\
\hline E. lacvis BeLL & Neuseeland & $274 \mathrm{~m}$ & - & - & - & Challenger \\
\hline E. longimana ORTMr. & Jарап & his $180 \mathrm{~m}$ & - & & - & ORTMAANN V, P. 579 \\
\hline E. mux NORM. & $\begin{array}{l}\text { England bis Azoren } \\
\text { und Cap Verden, } \\
\text { Nittelmeer }\end{array}$ & $134-2500 \mathrm{~m}$ & $\begin{array}{l}\text { Cth. rauh, im } \\
\text { allgem. rot }\end{array}$ & - & - & $\begin{array}{l}\text { Talisman, p. } 45 ; \\
\text { Monaco I, p. } 55 ; \\
\text { Monaco II, p. } 20\end{array}$ \\
\hline E. salamensis Dor. & Dar-es-Salâm & $400 \mathrm{~m}$ & Cth. glatt & klein, pigmentiert & - & , Valdivia \\
\hline E. scabriuscula ORTM. & Japan & $180 \mathrm{~m}$ & - & & & ORTMANN V, p. 580 \\
\hline E. tuberculata MRS. & $\begin{array}{l}\text { Azoren, Canaren, } \\
\text { Senegambien }\end{array}$ & $60-750 \mathrm{~m}$ & . & - & & Talisman, P. 50 \\
\hline E. tuberculosa M.-E. & $\begin{array}{l}\text { Agulhasbank, Bass- } \\
\text { Str., Twofold-Bay, } \\
\text { Port Jackson, Neu- } \\
\text { seeland }\end{array}$ & $1,0 \quad 275 \mathrm{~m}$ & & -- & - & Challenger \\
\hline E. tubcrasa (PENN.) & $\begin{array}{l}\text { Ostatlantic, Canal, } \\
\text { Azoren, Canaren, } \\
\text { Sudan }\end{array}$ & $30-160 \mathrm{~m}$ & $\begin{array}{l}\text { Cth. der südl. } \\
\text { Form gra- } \\
\text { nulierter } \\
=\text { insignis } \\
\text { Luc. }\end{array}$ & & - & $\begin{array}{l}\text { Talisman, p. } 47 \text {; } \\
\text { Monaco I. p. 53; } \\
\text { Monaco II, p. } 2 \text { I }\end{array}$ \\
\hline E. tumefacta (MONT.) & Nordost- $\Lambda$ tlantik & his $180 \mathrm{~m}$ & & & & Monaco I, p. 54 \\
\hline Persephona subornata RATHE. & $\begin{array}{l}\text { Panama, Pta. } \Delta \text { breo- } \\
\text { jos }\end{array}$ & $60-90 \mathrm{~m}$ & & & & R. I, 1., 113 \\
\hline $\begin{array}{l}\text { Merocryptus boletifer M..E. } \\
\text { u. B. }\end{array}$ & Azoren & $54-629 \mathrm{~m}$ & - & . & & $\begin{array}{l}\text { Talisman, p. } 54 \text {; } \\
\text { Monaco I, p. } 56 \text {; } \\
\text { Monaco II, I. } 2 \text { I }\end{array}$ \\
\hline Ar. lambriformis M.-E. & $\begin{array}{c}\text { Bass-Str., Twofold- } \\
\text { Bay, Australien }\end{array}$ & $70-274 \mathrm{~m}$ & & & & Challenger \\
\hline 1\% obssoletus M.-E. und B. & Cap Verden & $75 \mathrm{~m}$ & & & - & Talismann, p. 56 \\
\hline Myyra fregax (FABR.) & Arafura-See & $90 \mathrm{~m}$ & & & - & Challenger \\
\hline 1. Torensendi RATHв. & Golf von Californien & $36-105 \mathrm{~m}$ & - & & - & R. VI, P. 255 \\
\hline Myropsis constricte MI.-E. & Barbados & $150-185 \mathrm{~m}$ & Cth. whatt & mäßig & & Blake, p. IIo \\
\hline If. quinquespinosa STM. & $\begin{array}{l}\text { Tenessee, Florida, } \\
\text { Kleine Antillen }\end{array}$ & $36-310 \mathrm{~m}$ & - & - & - & $\begin{array}{l}\text { Blake, p.I Io; F.Mxon, } \\
\text { I } 96, \text { p. } 154\end{array}$ \\
\hline
\end{tabular}




\begin{tabular}{|c|c|c|c|c|c|c|}
\hline Art & Vorkommen & Tiefe & Habitus & Augen & Fier & Litteratur \\
\hline ISymopsis solinith M.-E. & Caricou & $300 \mathrm{~m}$ & Celh. sylatt & maßig & - & - \\
\hline Cryplocnemus obolus ORTat. & Jap̧an & $180 \mathrm{~m}$ & - & - & - & ORTMMN V, $), 5,6$ \\
\hline Sursia inberculata RATuB. & Golf von Californien & $85 \mathrm{~m}$ & - & - & - & R. VI, p. 258 \\
\hline Rinutullia distincta R.ATHE. & Sindwich-Inseln & $540 \mathrm{~m}$ & - & - & - & R. VI, 1) 257 \\
\hline R. sranulatar MRS. & $\begin{array}{l}\text { Tongatabu, lidschi- } \\
\text { Inseln }\end{array}$ & $440-576 \mathrm{~m}$ & - & - & - & Challenger \\
\hline R. lancllidintato WV.-M. & Andamanen & $639 \mathrm{~m}$ & $\mid \begin{array}{c}\text { Cth. gekïr. } \\
\text { nelt }\end{array}$ & - & - & Investigator \\
\hline$R$. ornata (RAND.) & $\begin{array}{l}\text { Magdalena-Bity, } \\
\text { Pt. Abreojos } \\
\text { (Nied.-Californien) }\end{array}$ & $10-90 \mathrm{~m}$ & - & - & - & R. I, P. 163 \\
\hline R. prestulosa IV.-Ml. & $\begin{array}{l}\text { Ostafrika, Travan- } \\
\text { core, Laccadiven, } \\
\text { Andamanen, Nikn- } \\
\text { baren }\end{array}$ & $290-977 \mathrm{~m}$ & $\left\{\begin{array}{l}\text { Cth. granu- } \\
\text { liert }\end{array}\right.$ & $\begin{array}{l}\text { pigmentiert, } \\
\text { klein, wenig le- } \\
\text { weglich }\end{array}$ & klein & Investigator; Valdivia \\
\hline Mityra laminate DOFL. & Nias & $141 \mathrm{~m}$ & $\begin{array}{l}\text { Cth. granu- | } \\
\text { liert }\end{array}$ & | pigmentiert & - & Valdivia \\
\hline Lithatia Cumingi BE.L. & $\begin{array}{l}\text { Golf von Californien, } \\
\text { Magdalena-Bay }\end{array}$ & $45-90 \mathrm{~m}$ & - & - & - & R. I, p. 613 \\
\hline L. gramulosa M.-E. & Sta. Cruz (Antillen) & $210 \mathrm{~m}$ & Cth. rauh & | mïßig & - & Blake, p. I 20 \\
\hline L. pontifere STM. & $\begin{array}{r}\text { Florida, Barbados, } \\
\text { Nieder-Californien }\end{array}$ & $20-225 \mathrm{~m}$ & - & - & - & R. VIII, p. 88 \\
\hline Spelacophorus triansylus M.-E. & Florida & $20-225 \mathrm{~m}$ & Cth. rauh & - & - & Blake, p. 120 \\
\hline Prnilia Aliocki WV.-M. & $\begin{array}{l}\text { Ostküste von Indien, | } \\
\text { Nias }\end{array}$ & $128-457 \mathrm{~m}$ & $\begin{array}{l}\mid \text { Cth. rauh, } \mid \\
\text { | rötlich }\end{array}$ & |klein & - & Insestigator; Valdivia \\
\hline $\begin{array}{l}\text { Parriplicalues coranatus } \mathrm{ALC} \text {. } \\
\text { u. Avis. }\end{array}$ & $\begin{array}{l}\text { Coromandel-Küste, } \\
\text { Nikobaren }\end{array}$ & $205-296 \mathrm{~m}$ & $\begin{array}{l}\text { Cuh. filzig, } \\
\text { feine Tu- } \\
\text { berkel }\end{array}$ & pigmentiert & - & Investigator; Taldivia \\
\hline Nolopus oralis HEND. & Little ki-Insel & $256 \mathrm{~m}$ & Cth. glatt & $\begin{array}{l}\text { groß, dunkel, pig- } \\
\text { mentiert }\end{array}$ & - & Challenger \\
\hline N. atlanticus STUneR & Ascension & $110 \mathrm{~m}$ & | Cth. pupurrot | & - & - & Gazelle \\
\hline Dopopoides lntus IIExis. & Little ki-Insel & $256 \mathrm{~m}$ & Cth. glatt & mäßig & - & | Challenger \\
\hline Lurcilus tridentatus 1 ). II. & $\begin{array}{l}\text { Australien, Japan bis } \\
\text { Ostafrika }\end{array}$ & $50-400 \mathrm{~m}$ & Cth. glatt & mäl3ig schwarz & - & s. oben S. 52 \\
\hline L. Channeri IV:-AI. & $\begin{array}{l}\text { Ceylon, 13ay von Ben- } \\
\text { galen, Andamanen, } \\
\text { Malabar-Küiste }\end{array}$ & $360-710 \mathrm{~m}$ & $\mid \begin{array}{l}\text { Cth. glatt, } \\
\text { lachsfarbig }\end{array}$ & $\begin{array}{l}\text { klein, wenig pig- } \\
\text { mentiert }\end{array}$ & - & Investigator \\
\hline Raninops formicata $\mathrm{FAX}$. & $\begin{array}{l}\text { Cocos-Inseln (1ª- } \\
\text { nama-Region) }\end{array}$ & $95 \mathrm{~m}$ & - & - & - & Albatross \\
\hline Podocatactes hamifer ORTM. & Japan & $90-180 \mathrm{~m}$ & - & - & 一 & ORTMAnN VI, p. 29 \\
\hline IIalicarcinus planalus (FABR.) & $\begin{array}{l}\text { Marion-Insel, Prinz } \\
\text { Eduard-Inseln }\end{array}$ & $90-1.70 \mathrm{~m}$ & - & - & - & | Challenger \\
\hline H. oratus Stm. & $\begin{array}{l}\text { Port Pbilip (Austra- } \\
\text { lien) }\end{array}$ & $60 \mathrm{~m}$ & - & - & - & Challenger \\
\hline Leplopodia sagitfaria (FNBR.) & $\begin{array}{l}\text { Cap Hatteras bis } \\
\text { Karibisches Meer, } \\
\text { St. Thomas, Bahia, } \\
\text { Canaren, Madeira, } \\
\text { Cap Verden }\end{array}$ & $16-1500 \mathrm{~m}$ & - & - & - & $\begin{array}{l}\text { Talismann, p. I53; } \\
\text { Challenger; R. III, } \\
\text { p. } 4 t\end{array}$ \\
\hline
\end{tabular}




\begin{tabular}{|c|c|c|c|c|c|c|}
\hline Art & Vorkonmen & Tiefe & Habitus & Augen & Eier & Litteratur \\
\hline Stenorhynchus aegyptius M.-E. & $\begin{array}{l}\text { Mittelmeer, Atlantik: } \\
\text { England bis Cap } \\
\text { Verden }\end{array}$ & $1-180 \mathrm{~m}$ & 一 & - & - & Talisman, p. 155 \\
\hline St. falcifer STM. & Kapregion & $100 \mathrm{~m}$ & Cth. stachelig & mäßig bla $B$ & - & $\begin{array}{l}\text { Challenger; STIMP- } \\
\text { Son; Gazelle; Val- } \\
\text { divia }\end{array}$ \\
\hline St. longicornis M.-E. u. B. & Cap Verden & $150-275 \mathrm{~m}$ & - & - & - & $\begin{array}{l}\text { Talisman, p. 160; } \\
\text { Monaco }\end{array}$ \\
\hline St. longipes M.-E. u. B. & Mittelmeer & bis $445 \mathrm{~m}$ & - & - & - & $\begin{array}{l}\text { Talisman, p. I57; } \\
\text { Monaco }\end{array}$ \\
\hline Si. longirostris ( $\mathrm{F} \wedge \mathrm{BR}$.) & $\begin{array}{l}\text { NO.-Atlantik, Cap } \\
\text { Bojador }\end{array}$ & bis $1635 \mathrm{~m}$ & Cth. stachelig & mäßig & - & $\begin{array}{l}\text { Monaco I, p. } 4 ; \mathrm{Ta}- \\
\text { lisman, Valdivia } \\
\text { s. oben }\end{array}$ \\
\hline St. macrocheles M.-E. u. B. & $\begin{array}{l}\text { Cap Blanco (NW.- } \\
\text { Afrika) }\end{array}$ & $240 \mathrm{~m}$ & - & - & - & Talisman, p. 159 \\
\hline St. rostratus (L.) & $\begin{array}{c}\text { NO. - Atlantik bis } \\
\text { Kongo-Muindung }\end{array}$ & $1-130 \mathrm{~m}$ & $\begin{array}{l}\text { Cth.stachelig, } \\
\text { zinnoberrot }\end{array}$ & $\begin{array}{l}\text { mäßsiggroß, Dämme- } \\
\text { rungsaugen }\end{array}$ & ziemlich groß & s. oben S. 69 \\
\hline Oregonia bifurca RATHB. & nördlich der Aleuten & $494 \mathrm{~m}$ & - & - & - & R. VII \\
\hline Podochela gracilipes Sтм. & $\begin{array}{c}\text { Süd-Carolina bis } \\
\text { Golf von Mexiko } \\
\text { 1. Karib. Meer }\end{array}$ & $40-145 \mathrm{~m}$ & - & - & - & R. III, p. 50 \\
\hline P. lamelligera (STM.) & $\begin{array}{c}\text { Golf von Mexiko, } \\
\text { Florida-Straße }\end{array}$ & $55-80 \mathrm{~m}$ & - & - & - & R. III, p. 49 \\
\hline P. lobifrons $\mathrm{K}$. & Nieder-Californien & $105 \mathrm{~m}$ & 一 & - & - & R. VI, p. 225 \\
\hline P. Riisei (Sтм.) & Barra Grande & $55-730 \mathrm{~m}$ & - & - & - & Challenger \\
\hline$P$. spinifrons $\mathbf{R}$. & Vestindien & $238-370 \mathrm{~m}$ & - & - & - & IR. III, p. 5 I \\
\hline P. tenuipes $\mathbb{R}$. & $\begin{array}{l}\text { Süd- und Niecler- } \\
\text { Californien }\end{array}$ & $30-90 \mathrm{~m}$ & - & - & - & 1R. VI, p. 224 \\
\hline Euprognatha bifidn R. & Golf von Californien & $54-75 \mathrm{~m}$ & - & - & - & R. VI, p. 231 \\
\hline E. sracilipes M.-E. & Habana, Porto-Rico & $140-368 \mathrm{~m}$ & 一 & - & - & $\begin{array}{l}\text { R. III, p. } 56 ; \text { R. } \\
\text { VIII, p. } 5^{8}\end{array}$ \\
\hline E. granulato FAXON & $\begin{array}{l}\text { Cocos-Inseln } \\
\text { nama-Region) }\end{array}$ & $95 \mathrm{~m}$ & Cth. stachelig & mäßig & - & Albatross \\
\hline E. mastellifera STM. & $\begin{array}{c}\text { Massachusetts, New } \\
\text { Jersey, Virginia, } \\
\text { Delaware, Habana, } \\
\text { Karab. Meer }\end{array}$ & $80-710 \mathrm{~m}$ & $\begin{array}{l}\text { Cth.stachelig, } \\
\text { langbeinig }\end{array}$ & mäßig & - & $\begin{array}{l}\text { Blake, p. } 80 \text {; R. III, } \\
\text { P. } 55\end{array}$ \\
\hline E. rastellifera spinosa RATHB. & Habana & $180-390 \mathrm{~m}$ & - & & & R. III. I. 55 \\
\hline Collodes depressuts M.-E. & $\begin{array}{c}\text { Cap Hatteras bis } \\
\text { Golf von Mexiko }\end{array}$ & $40-145 \mathrm{~m}$ & & - & & R. III, p. 52 \\
\hline C. leptocheles RATHB. & Golf von Mexiko & $125-310 \mathrm{~m}$ & - & - & & R. III, P. 53 \\
\hline C. malabariczes ALC. & Malabar-Küste & ca. $5^{\circ} \mathrm{m}$ & - & -- & - & Alcock, p. 189 \\
\hline C. robustus Smiтн & Virginia, Delaware & I $5-680 \mathrm{~m}$ & - & & - & $\begin{array}{l}\text { Albatross, Proc. U. } \\
\text { S. Nat. Museum, } \\
\text { Vol. VI, I883: p.5; } \\
\text { R. III, p. } 52\end{array}$ \\
\hline C. rostratus MI.E. & $\begin{array}{l}\text { Rio de la } \\
\begin{array}{c}\text { Matias } \\
\text { tinien) }\end{array}\end{array}$ & $95 \mathrm{~m}$ & - & & - & R. I, p. 569 \\
\hline
\end{tabular}




\begin{tabular}{|c|c|c|c|c|c|c|}
\hline Art & Vorkommen & Tiefe & Ilabitus & Augen & Eier & Litteratur \\
\hline Collodes tenuirostris $\mathrm{R}$. & $\begin{array}{l}\text { Nicder-Californien, } \\
\text { (rnlf v. Californien }\end{array}$ & $60-265 \mathrm{~m}$ & - & - & 一 & 12. I, p. 560 \\
\hline Mefoporaphis calcaratus (SAY) & $\begin{array}{l}\text { Cap Hatteras bis } \\
\text { Florida }\end{array}$ & $90 \mathrm{~m}$ & - & - & - & | R. III, |). 45 \\
\hline 1\%. forficulatus (M.-E.) & Barra Grande & $55-730 \mathrm{~m}$ & - & - & - & Challenger \\
\hline $\begin{array}{l}\text { Neorhynchus mextiames } \\
\text { RATHB. }\end{array}$ & Golf von Californien & $10-60 \mathrm{~m}$ & - & - & - & R. VI, p. 234 \\
\hline Loxorluynchus crispatus STM. & Californien & $46-95 \mathrm{~m}$ & - & - & - & R. 11I, P. 74 \\
\hline L. grandis STM. & Californien & $\mathrm{I} 25 \mathrm{~m}$ & - & - & - & R. III, p. 74 \\
\hline Anasimues fugax M.E. & $\begin{array}{l}\text { Karibisches Meer, } \\
\text { Porto-kico }\end{array}$ & $180-220 \mathrm{~m}$ & - & - & - & R. VIII, p. 59 \\
\hline A. latus R.ATHB. & $\begin{array}{l}\text { Sid-Carolina bis } \\
\text { Golf von Mexiko } \\
\text { und Karib. Meer }\end{array}$ & $50-160 \mathrm{~m}$ & - & - & - & R. III, p. 58 \\
\hline A. rostratus $\mathrm{R}$. & Nicder-Californien & $105 \mathrm{~m}$ & - & - & - & R. VI, p. 22\% \\
\hline Araclenopsis filipes STM. & $\begin{array}{l}\text { Straße von Florida, } \\
\text { Golf von Mexiko }\end{array}$ & $40-85 \mathrm{~m}$ & - & - & - & R. III, p. 5i \\
\hline Anomalothir furcillatus (STM.) & $\begin{array}{l}\text { Jamaica, Habana, } \\
\text { Karibisches Meer }\end{array}$ & $60-510 \mathrm{~m}$ & - & - & - & $\begin{array}{l}\text { Faxox } 1896, \text { p. I5t; } \\
\text { IR. III, p. } 65\end{array}$ \\
\hline Holoplites armalus (M.-IE.) & Habana & $720 \mathrm{~m}$ & - & - & - & R. III, P. 64 \\
\hline Apocremnus indious AI.C. & Indamaneis, Ceylon & $55-180 \mathrm{~m}$ & | Cth. stachelig & $\begin{array}{l}\text { mäligig, fast unle- } \\
\text { weglich }\end{array}$ & - & | ALCOCK, p. 188 \\
\hline $\begin{array}{l}\text { Inachus Aguiarî BRITO Co. } \\
\text { PELLO }\end{array}$ & $\begin{array}{l}\text { Atlantik, Lissabon } \\
\text { bis Madeirn }\end{array}$ & $100 \mathrm{~m}$ & - & 一。 & - & | Talisman, p. 146 \\
\hline 1. antarcticis DoF. & Agulbasbank & $155 \mathrm{~m}$ & Cth. stachelig | & $\begin{array}{l}\text { mälig, pigment- } \\
\text { anm }\end{array}$ & groß & s. oben S. 74 \\
\hline I. dorsettcnsis (PENN.) & $\begin{array}{l}\text { Norwegen bis Cap } \\
\text { Bojador und Caps } \\
\text { Verde }\end{array}$ & $10-748 \mathrm{~m}$ & Cth. stachelig & Dämmerungsaugen & mittelgrols & s. oben S. 72 \\
\hline 7. dorynchus LCH. & NO-Atlantik & $92-300 \mathrm{~m}$ & - & - & - & Monaco I, p. 6 \\
\hline 7. leptochirus $\mathrm{LCH}$. & $\begin{array}{l}\text { England bis Azoren } \\
\text { und Saharaliiste, } \\
\text { Mittelmeer }\end{array}$ & $\mid \begin{array}{c}\text { sublitoral bis } \\
550 \mathrm{~m}\end{array}$ & Cth. stachelig & |nälig & - & $\begin{array}{l}\text { Challenger; Talis- } \\
\text { man, P. I } 45 ; \mathrm{Mo-} \\
\text { naco I, p. } 7\end{array}$ \\
\hline 1. thoracicus ( $\mathrm{Rx}$.) & $\begin{array}{l}\text { Mittelmeer, Azoren, } \\
\text { Canaren, Sencgal }\end{array}$ & $\begin{array}{l}\text { litoral bis } \\
3 \mathrm{I} 4 \mathrm{~m}\end{array}$ & - & - & - & $\begin{array}{l}\text { Talisman, p. Ifto; } \\
\text { Monaco II, P. } 46\end{array}$ \\
\hline $\begin{array}{l}\text { Inachoides magdalenensis } \\
\text { R.THB. }\end{array}$ & $\begin{array}{l}\text { Caj. St. Lucas, } \\
\text { Nieder-Californien }\end{array}$ & $10-120 \mathrm{~m}$ & - & - & - & $\begin{array}{l}\text { R. I, p. } 57 \text { I; R. VI, } \\
\text { p. } 228\end{array}$ \\
\hline Erileptzis spinosus RaTHI. & Süd-Californien & $65 \mathrm{~ms}$ & - & 一 & - & 1R. VI, p. 227 \\
\hline Kaempfleria Kaempfleri (r. H.) & Japan, Sagamibai & bis $630 \mathrm{~m}$ & | stachelig & |groß & klein & $\begin{array}{l}\text { Challenger; Dorder- } \\
\text { I.EIN }\end{array}$ \\
\hline Batrachonotus Nicholsi R.ATHB. & Nieder-Californien & $22-93 \mathrm{~m}$ & - & - & - & 1R. I, p. 570 \\
\hline Mesorhoen Gulli R.ıтни. & $\begin{array}{l}\text { Panama, Golf von } \\
\text { Californien, } \\
\text { Nieder-Californien }\end{array}$ & $20-130 \mathrm{~m}$ & - & - & - & $\left\{\begin{array}{l}\text { R. I, p. } 58 \mathrm{r} ; \text { R. } \mathrm{VI}, \\
\text { P. } 236\end{array}\right.$ \\
\hline Achaeres japonicuts D. II. & Japan, Kobc & $90 \mathrm{~m}$ & - & - & - & Challenger \\
\hline A. tenuicollis MiRs. & $\begin{array}{l}\text { I'ort l'hilip, l3ass- } \\
\text { Siralic (Australien) }\end{array}$ & $60-70 \mathrm{~m}$ & - & - & - & Challenger \\
\hline A. Puberculatus MRs, & Japan, Forea-Stralie & $75 \mathrm{~m}$ & - & $\ldots$ & - & $\begin{array}{l}\text { ORTMAN VI, p. } 34 \text {; } \\
\text { MiEks }\end{array}$ \\
\hline
\end{tabular}




\begin{tabular}{|c|c|c|c|c|c|c|}
\hline Art & Vorkommen & Tiefe & Habitus & Augen & Eier & Litteratur \\
\hline Physachaezs ctenumis ALC. & $\begin{array}{l}\text { Andamanen, Nilko. } \\
\text { baren, Malabar- } \\
\text { küste, Ostafrika, } \\
\text { Somaliküste }\end{array}$ & $33^{8}-823 \mathrm{~m}$ & Cth. wenig & $\begin{array}{c}\text { klein, unbeweglich, } \\
\text { pigmentlos, s. oben }\end{array}$ & $\begin{array}{l}\text { sehr groß u. } \\
\text { wenige }\end{array}$ & $\begin{array}{l}\text { Investigator; Valdivia } \\
\text { s. oben }\end{array}$ \\
\hline Ph. tonsor ALC. & Andamanen & $495 \mathrm{~m}$ & Cth. stachelig & $\begin{array}{l}\text { Augenstiele starr, } \\
\text { fast kein Pigment }\end{array}$ & groß u. wenig | & Investigator \\
\hline $\begin{array}{l}\text { Grypachaens hyalimus ALC. u. } \\
\text { AUD. }\end{array}$ & $\begin{array}{l}\text { Malabarküste, } \\
\text { Trincomali(Ceylon) }\end{array}$ & $126-270 \mathrm{~m}$ & $\begin{array}{l}\text { Cth. stachelig, } \\
\text { aufgetrieb. } \\
\text { Kiemen- } \\
\text { höhlen }\end{array}$ & groß, langstielig & - & Investigator, p. 83 \\
\hline Achreopsis supercilinris ORTM. & Japan & $90-180 \mathrm{~m}$ & Cth. stachelig & - & - & ORTMIANN VI, p. 36 \\
\hline $\begin{array}{l}\text { Lispognathus Thomsoni } \\
\text { (NoRu.) }\end{array}$ & Kosmopolit, 5. oben & $106-1385 \mathrm{~m}$ & $\begin{array}{l}\text { Cth. stachelig, | } \\
\text { rötlich-weiß }\end{array}$ & $\begin{array}{l}\text { | mäßig, Dämmerungs- } \\
\text { augen }\end{array}$ & mittelgrol's & s. oben \\
\hline Pleistacantha Clowei M.-E. & $\begin{array}{l}\text { Golf von Biscaya bis } \\
\text { Cap Verden }\end{array}$ & $70-1000 \mathrm{~m}$ & $\begin{array}{l}\text { Cth. stachelig, } \\
\text { zinnoberrot, } \\
\text { gelbbraun }\end{array}$ & - & $=$ & $\begin{array}{l}\text { Talisman, p. I } 40 \text {; } \\
\text { Gazelle; Monaco I, } \\
\text { p. Io; Monaco II, } \\
\text { p. } 44\end{array}$ \\
\hline P. Naresii Mrs. & Admiralitäts-Inseln & $274 \mathrm{~m}$ & stachelig & - & & Challenger \\
\hline$P$. oryx ORTM. & Japan & $90-180 \mathrm{~m}$ & stachelig & & & ORTMANN VI, p. 39 \\
\hline P. Moscleyi MrS. & $\begin{array}{l}\text { Philippinen, Anda- } \\
\text { manen, Nikobaren, } \\
\text { Ostafrika }\end{array}$ & $205-686 m$ & $\begin{array}{l}\text { Cth. sehr } \\
\text { stachelig,im } \\
\text { Alter we- } \\
\text { niger }\end{array}$ & $\begin{array}{l}\text { große Dämmerungs- } \\
\text { augen }\end{array}$ & .. & s. oben S. 76 \\
\hline P. mebita ALC. & Andamanen & $165-413 \mathrm{~m}$ & $\begin{array}{l}\text { Cth. stachelig, } \\
\text { braun }\end{array}$ & $\begin{array}{l}\text { große Dämmerungs- } \\
\text { augen }\end{array}$ & & Investigator \\
\hline P. Sancti-Johannis MRS. & Ost-Japan,Süd-Japan & bis $180 \mathrm{~m}$ & sehr stachelig & & & ORTMANN VI, p. 39 \\
\hline Cyrtomaia Murvayi MRs. & Ki-Inseln & $256 \mathrm{~m}$ & $\begin{array}{l}\text { Cth. stachelig, } \\
\text { sehr lang- } \\
\text { beinig }\end{array}$ & & & Challenger \\
\hline C. Smithi RAthr. & Sandwich-Inseln & $540-700 \mathrm{~m}$ & & - & & R. VI, 13. 22S \\
\hline C. Suhmi typion MRs. & $\begin{array}{l}\text { Tulur-Inseln, Philip- } \\
\text { pinen, Travancore- } \\
\text { küste, Nias, Niko- } \\
\text { baren }\end{array}$ & $752-914 \mathrm{~m}$ & $\begin{array}{l}\text { stachelig,lang- } \\
\text { beinig }\end{array}$ & Dämmerungsaugen & & s. oben S. 54 \\
\hline C. Sukmi platyceros DoF. & $\begin{array}{l}\text { Ostafrika. Somali- } \\
\text { küste }\end{array}$ & $746-10,9 \mathrm{~m}$ & Cth. stanchelig | & | Dämmerungsaugen & & s. oben S. 55 \\
\hline $\begin{array}{l}\text { Plullmen "Wyathe-Thomsoni } \\
\text { MRs. }\end{array}$ & $\begin{array}{l}\text { Admiralităts - Inseln, } \\
\text { Andamamen, Niko- } \\
\text { baren, Ostafrika, } \\
\text { Kapregion }\end{array}$ & $23 x \quad-50 m$ & $\begin{array}{l}\text { Cth, stachelig, } \\
\text { abgeplattet, } \\
\text { langbeinig }\end{array}$ & Reflektoraugen & $\begin{array}{l}\text { klein, l.arve } \\
\text { Zoëa }\end{array}$ & $\begin{array}{l}\text { s. oben S. } 59 \text { 11. ล. ล. } \\
\text { O. }\end{array}$ \\
\hline Oncinopus maned D. $\mathrm{H}$. & Molukken, Indien & $55-1510 \mathrm{~m}$ & & klein & & Challenger; Arcock \\
\hline Eurypodius Latreillei GU. MI. & $\begin{array}{l}\text { Argentinien, Magal- } \\
\text { haes-Straße, Chile }\end{array}$ & I $8-128 \mathrm{~m}$ & Cth. stachelig & & & $\begin{array}{l}\text { Challenger; R. I, } \\
\text { p. } 57 \mathrm{I}\end{array}$ \\
\hline E. longirostris MIRs. & Chiloe & $320 \mathrm{~m}$ & & - & 一 & Challenger \\
\hline $\begin{array}{l}\text { Encephuloiles Armstronget } \\
\text { ALC. }\end{array}$ & Bay von Bengalen & $110-183 \mathrm{~m}$ & $\begin{array}{l}\text { Cth.d.Jungen } \\
\text { stachelig. } \\
\text { später ge- } \\
\text { körnelt,rosa- } \\
\text { gelblich ge- } \\
\text { färbt }\end{array}$ & $\begin{array}{l}\text { klein, schlecht pig- } \\
\text { mentiert }\end{array}$ & & Investigator \\
\hline
\end{tabular}




\begin{tabular}{|c|c|c|c|c|c|c|}
\hline int & Vorkommen & Tiefe & Habitus & Augen & It: & I.itteratur \\
\hline $\begin{array}{l}\text { Encophatoiles Rizers-Ander- } \\
\text { soni Al.c. }\end{array}$ & Travancore-Kïste & $270 \mathrm{~m}$ & Cth. stachelig i & $\begin{array}{l}\text { viel blasser als bei } \\
\text { Armstrongi }\end{array}$ & & Investigator \\
\hline Othonin Witholsi RATHB. & Golf von Californien & in $m$ & & & & K. 11, 13. 25i \\
\hline Libinin spinimana RATHu. & $\begin{array}{l}\text { Nord-Carolina, fiolf } \\
\text { ron Mexiko }\end{array}$ & $460-230 \mathrm{~m}$ & - & $w^{2}$ & & R. II, P. 2,40 \\
\hline 1.. Smithi Mrs. & $\begin{array}{l}\text { Magalhaes - Serake, } \\
\text { Chiloe }\end{array}$ & $100-1900 \mathrm{~m}$ & & & & $\begin{array}{l}\text { Challenger; R. I, } \\
\text { P. } 574\end{array}$ \\
\hline 1. schosiz I.OCK. & Nieder-Californien & $10-95 \mathrm{~m}$ & - & & & R. I, p. 574 \\
\hline I. grailipes MRs. & Chilne & $82 \mathrm{~m}$ & 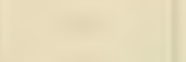 & & - & Challenger \\
\hline L., Meridonaleti R.iturs. & Golf von Californien & $130-270 \mathrm{~m}$ & - & & - & R. II, I) 238 \\
\hline I.. coicinca (D.LNA) & $\begin{array}{l}\text { S. Matias, Argren- } \\
\text { tinien }\end{array}$ & $95 \mathrm{~m}$ & - & & - & R. I, p. 574 \\
\hline Mithrax acuticomis (STM.) & $\begin{array}{l}\text { Golf von Mexiko, } \\
\text { Karibisches Mcer }\end{array}$ & $36-220 \mathrm{~m}$ & & & 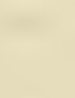 & R. II, p, 260 \\
\hline 17. cormutus SAUsS. & $\begin{array}{l}\text { Westindien, Florida- } \\
\text { Stralie, Bahia }\end{array}$ & bis $1140 \mathrm{~m}$ & - & - & - & R. II, P. 274 \\
\hline $\begin{array}{l}\text { 11. hispiatus plewracanthus } \\
\text { Siтs. }\end{array}$ & Barra grande & $55-730 \mathrm{~m}$ & & & $=$ & Challenger \\
\hline .14. rostrutas $\mathrm{M} . \mathrm{E}$. & $\begin{array}{c}\text { Golf yon Mexiko, } \\
\text { Karibisches Meer }\end{array}$ & bis $300 \mathrm{~m}$ & & & & R. II, P. 274 \\
\hline 11. spinosissimus (LAM.) & $\begin{array}{l}\text { Florida, Habana, } \\
\text { Guadeloupe }\end{array}$ & bis $220 \mathrm{~m}$ & - & & & K.. II. I. $2+11$ \\
\hline Macrocioloma culbeca (STM.) & Tortugas, Habana etc. & $20-300 \mathrm{~m}$ & - & $=$ & & R. $11,11.251$ \\
\hline .1\%. seplemspinosa Srs. & $\begin{array}{l}\text { Süd-Carolina } \\
\text { Key West } \\
\text { Grolf von Mexiko bis } \\
\text { Bahia }\end{array}$ & $\begin{array}{c}145 \mathrm{~m} \\
80 \mathrm{~m} \\
40-55 \mathrm{~m}\end{array}$ & - & 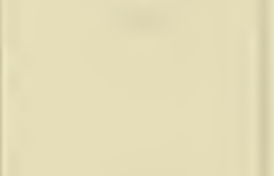 & 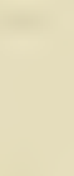 & K. II, p. 250 \\
\hline 11. mummifira $\triangle \mathrm{LC}$ & Andamanen, Ceylon & $30-60 \mathrm{~m}$ & Cth. maskiert & 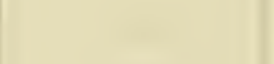 & & Alcock, p. 255 \\
\hline Paramithrax lonsyispinus $\mathrm{D}_{\mathrm{S}} \mathrm{H}$. & $\begin{array}{l}\text { Ceylon, Andainanen, } \\
\text { Madras }\end{array}$ & $60-80 \mathrm{~m}$ & - & - & - & ALCOCK, p. 241 \\
\hline P. bifidus ORTM. & Japan & $90-180 \mathrm{~m}$ & Cth. stachelig & - & - & ORTMANs VI, P. 52 \\
\hline Escria arachnoudes (RUMPH) & Arafura-Sec & $90 \mathrm{~m}$ & - & - & - & Challenger \\
\hline E. inzestigatoris ALC. & Ceylon & fo $\mathrm{m}$ & Cth. stachelig & - & & ALCOCK, p. 225 \\
\hline $\begin{array}{l}\text { Sphenoiarcimus Agassizii R.ıTH- } \\
\text { HEN }\end{array}$ & $\begin{array}{l}\text { Cocos-Ins. (Lanama- } \\
\text { gebiet), Golf von } \\
\text { Californien }\end{array}$ & $25-130 \mathrm{~m}$ & Cth. filzig & mittelgrols & & $\begin{array}{l}\text { Albatross; R. VI, } \\
\text { P. } 232\end{array}$ \\
\hline S. nurorac Arc. & Travancore & $410-520 \mathrm{~m}$ & $\begin{array}{l}\text { Cth. mäßig } \\
\text { stachelig, } \\
\text { rosig rot }\end{array}$ & & & Investigator, p. 84 \\
\hline S. corrosus M.-E. & Nord-Carolina & $165 \mathrm{~m}$ & - & & - & R. III, p. 66 \\
\hline S. runeus (W'.-M.) & Andamanen & $290-460 \mathrm{~m}$ & - & $\begin{array}{l}\text { klein, wenig be- } \\
\text { weglich }\end{array}$ & & $\begin{array}{l}\text { Investigator; AL. } \\
\text { cock, p. I93 }\end{array}$ \\
\hline Chlorinoides Coppingeri HAsw. & Bass-Stralie & \% $\mathrm{m}$ & - & - & $\cdots$ & Challenger \\
\hline Iynstemus brezirostris DOFL. & westlich von Sumatra & $614 \mathrm{~m}$ & Cth. stachelig & Dämmerungsaugen & $\ldots$ & $\begin{array}{l}\text { Valdivia, s. oben } \\
\text { \$. } 85\end{array}$ \\
\hline H. diacanthus (D. H.) & Arafura-Sec & $90 \mathrm{~m}$ & $=$ & & & Challenger \\
\hline 11. clegans MRs. & Ki-Inseln & $256 \mathrm{~m}$ & & & & Challenger \\
\hline
\end{tabular}




\begin{tabular}{|c|c|c|c|c|c|c|}
\hline Art & Vorkommen & Tiefe & Habitus & Augen & Eier & Litteratur \\
\hline $\begin{array}{c}\text { Hyastenus longipes DANA } \\
\text { (wobl }=\text { japonicus MrRs. })\end{array}$ & $\begin{array}{l}\text { Kadiak (Alaska) bis } \\
\text { San Diego, Cali- } \\
\text { fornien }\end{array}$ & $40-1100 \mathrm{~m}$ & - & - & - & R. V, p 85 \\
\hline Nibitio erinacea $\mathrm{M}$.- E. & $\begin{array}{l}\text { Cap Hatteras, Kari- } \\
\text { bisches Meer, Golf } \\
\text { von Mexiko }\end{array}$ & $100-110 \mathrm{~m}$ & - & - & - & R. V, p. 90 \\
\hline Naxia hystrix Mrs. & $\begin{array}{l}\text { Amboina } \\
\text { manen }\end{array}$ & $75-183 \mathrm{~m}$ & 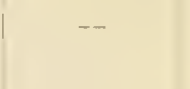 & & & $\begin{array}{l}\text { Challenger; } A L C O C K, \\
\text { p. } 220\end{array}$ \\
\hline N. inzestigatoris ALC. & Andamanen, Ceylon & bo $\mathrm{m}$ & - & & & ALCock, p. 218 \\
\hline N. tanerzes PCK. & Andamanen & $60 \mathrm{~m}$ & - & - & & ALCOCK, p. 219 \\
\hline Micippe spinosa affinis MIRS. & Bass-Strabe & io m & - & & - & Challenger \\
\hline Acanthony:x brezifrons ML-E. & Azoren, Cap Verden & $1-180 \mathrm{~m}$ & - & & . & Talisman, p. 152 \\
\hline Oxypleurodon Stimpsoni MRs. & $\begin{array}{l}\text { Ǩ̈i-Iuseln, Philip- } \\
\text { pinen, Japan, Co- } \\
\text { lomlı }\end{array}$ & $180-686 \mathrm{~m}$ & - & & & $\begin{array}{l}\text { Challenger; Investi- } \\
\text { gator; ORTMANN } \\
\text { VI, p. } 43\end{array}$ \\
\hline Scyra compressipes STM. & Japan, Kobe & $10-110 \mathrm{ml}$ & - & - & - & $\begin{array}{l}\text { Challenger; R. V, } \\
\text { P. } 9 f\end{array}$ \\
\hline S. acutifrons DANA & $\begin{array}{l}\text { Kadiak (Aleuten) bis } \\
\text { Siid-Californien }\end{array}$ & $35-60 \mathrm{~m}$ & - & & & R. V, p. 88 \\
\hline $\begin{array}{l}\text { Scyramathia beauchampi (ALC. } \\
\text { u. AnD.) }\end{array}$ & Bengal bai & $348-384 \mathrm{~m}$ & $\begin{array}{l}\text { Cth.stachelig, } \\
\text { erdfarbig mit } \\
\text { rosa Scheren }\end{array}$ & $\begin{array}{l}\text { klein, fast pigment- } \\
\text { los }\end{array}$ & $\begin{array}{c}\text { groß, I mm } \\
\text { Durchmesser, } \\
\text { wenige }\end{array}$ & Investigator \\
\hline S. Carpenteri Norne. & $\begin{array}{l}\text { Norwegen und Faer- } \\
\text { Oer bis Azoren u. } \\
\text { Sahara-Küste } \\
\text { Nordsee }\end{array}$ & $350-1350 \mathrm{~m}$ & $\begin{array}{l}\text { Cth. stachelig, } \\
\text { rosig }\end{array}$ & - & - & $\begin{array}{l}\text { Talisman, p. I35; } \\
\text { SARs, p. 6; ML- } \\
\text { naco I, p. I34; } \\
\text { MIonaco II, p. } 43\end{array}$ \\
\hline S. globulifera W.-M. & $\begin{array}{l}\text { Andamanen, Niko- } \\
\text { baren }\end{array}$ & $23^{8}-75^{2} \mathrm{~m}$ & Cth. stachelig & $\begin{array}{l}\text { pigmentarm } \\
\text { (Valdivia } 752 \mathrm{~m})\end{array}$ & - & s. oben S. 85 \\
\hline S. Hertwigi DorL. & Kapregion & $318-500 \mathrm{~m}$ & & Dänmmerungsaugen & - & s. oben S. $8 \mathbf{I}$ \\
\hline S. pulchra MIRS. & $\begin{array}{l}\text { Philippinen, Anda- } \\
\text { manen, Ostafrika, } \\
\text { Somali-Küste }\end{array}$ & $23^{8}-1026 \mathrm{~m}$ & Ctin. stachelig & klein pigmentlos & sehr groß & $\begin{array}{l}\text { Challenger; Investi- } \\
\text { gator; Valdivia, s. } \\
\text { oben S. } 84\end{array}$ \\
\hline S. Rizers-Andersoni AIC. & $\begin{array}{l}\text { Malabar-Küste, Ni- } \\
\text { kobaren, Ostafrika. } \\
\text { Somali-Küste }\end{array}$ & $740-1362 \mathrm{~m}$ & Cth. stachelig & $\begin{array}{l}\text { klein, blaß, unberreg- } \\
\text { lich, pigmentlos }\end{array}$ & ziemlich groß & s. oben S. 84 \\
\hline Anamathia Agassizii SмIтн & $\begin{array}{l}\text { Delaware, Nord- } \\
\text { Carolina, Georgia, } \\
\text { Süd-Carolina }\end{array}$ & $260-603 \mathrm{~m}$ & $\begin{array}{l}\text { Cth. stachelig, } \\
\text { Junge mehr } \\
\text { als Alte }\end{array}$ & - & - & Albatross; Blake \\
\hline 1. comuta Rathв. & Galapagos & $725 \mathrm{~m}$ & - & & 一 & R. I, p. 571 \\
\hline 1. crassa (MI.-E.) & Süd-Carolina, Florida & $396-500 \mathrm{~m}$ & . & - & - & R. III, p. 60 \\
\hline 1. hystrix (SтM.) & Porto Rico, Habana & $400-725 \mathrm{~m}$ & - & - & & $\begin{array}{l}\text { R. III, p. }, \text { I : } \\
\text { R. VIII, p. } 62\end{array}$ \\
\hline 1. accidentalis Fix. & Galapagos & $70+\mathrm{m}$ & - & . & - & Albatross \\
\hline A. rissoana $\mathrm{Rx}$. & $\begin{array}{l}\text { Mittelmeer, Desertas, } \\
\text { Madeira, Azoren }\end{array}$ & $400-600 \mathrm{~m}$ & & - & - & $\begin{array}{l}\text { Talisman, p. I38; } \\
\text { Monaco II, p. } 43\end{array}$ \\
\hline A. zembonata (STM.) & Georgia, Florida & & - & & & R. III, p. 6I \\
\hline Pugettia minor ORTM. & Japan & $10-3: 5 \mathrm{~m}$ & - & - & 一 & ORTMLANN VI, p. 44 \\
\hline P. z'elutina MRS. & Ki-Inseln & $256 \mathrm{~m}$ & 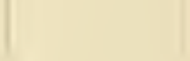 & - & - & Challenger \\
\hline Indaens Hasuelli MrS. & Neu-Süd-Wales & $2 \pi+m$ & - & - & - & ¡ Challenger \\
\hline
\end{tabular}




\begin{tabular}{|c|c|c|c|c|c|c|c|}
\hline . $\Delta r t$ & Vorkommen & Tiefe & Habitus & Augen & & Eier & Litteratur \\
\hline Eurymome aspera I'ENN. & $\begin{array}{l}\text { Nutelmeer, NO.- } \\
\text { \tlantik, Kanal } \\
\text { bis Cap Verden | }\end{array}$ & $10-700 \mathrm{~m}$ & [Ch. rosaweiß\}] & | pigmenticrt & & - & $\begin{array}{l}\text { Talisman, P. 125; } \\
\text { | Valdivia, S. oben } \\
\text { S. } 79\end{array}$ \\
\hline $\begin{array}{l}\text { Stenoitionops tring gulark R.ATH- } \\
\text { Bus }\end{array}$ & I'anamaregion & $90 \mathrm{~ms}$ & - & - & & - & R. I, p. 577 \\
\hline Pisre antilocapra STM. & Florida & $95-210 \mathrm{~m}$ & - & - & & - & R. V. p. 93 \\
\hline l. armata (LATR.) & $\begin{array}{l}\text { Mittelmeer, Azoren, } \\
\text { Cap Verden }\end{array}$ & his $100 \mathrm{~m}$ & - & - & & & Talisman, 1) 12? \\
\hline I. erinacen M.-E. & Florida-Sitrafie & ;o m & & 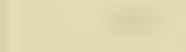 & & & R. V. p. 93 \\
\hline l. Gibsi (LcH.) & $\begin{array}{l}\text { England, Aittelmeer } \\
\text { bis Cap Verden }\end{array}$ & $70-100 \mathrm{~m}$ & & & & - & $\begin{array}{l}\text { Talisman, F. } 129 ; \\
\text { Grazelle }\end{array}$ \\
\hline I'. praclonga STsi. & Filorida & $210-225 \mathrm{~m}$ & & & & & 'R. V, p. 93 \\
\hline I. setruoton (I'ENx.) & $\begin{array}{l}\text { England bis Mittel- } \\
\text { meer }\end{array}$ & bis $100 \mathrm{~m}$ & & & & & Talisman, p. 128 \\
\hline P. Iribulus (I...) & Teneriffa, Azoren & $90-165 \mathrm{~m}$ & & & & & Chatlenger \\
\hline Micropisa aroluca M.-E. & $\begin{array}{l}\text { Westafrika, Sahara } \\
\text { bis Gr. Fischbucht }\end{array}$ & $110-180 \mathrm{~m}$ & & & & & $\begin{array}{l}\text { Talisman, p. } 130 \text {; } \\
\text { Valdivia, s. oben } \\
\therefore \text {. } 80 .\end{array}$ \\
\hline 4. orafe Sine. & Cap Verden & $30-180 \mathrm{~m}$ & . & & & - & Talisman, p. 130 \\
\hline Lepteces ornatues R.TTHв. & Yucitan & $238 \mathrm{~m}$ & -. & & & & R. V, p. 84 \\
\hline Coclocerus grandis RATHB. & Golf von Mlexiko & $60 \mathrm{~m}$ & & & & $=$ & R. V, 79 \\
\hline ISerbstia camptucantha (SrM.) & $\begin{array}{l}\text { Sud-Californien, } \\
\text { Nieder-Californien, } \\
\text { Acapulco, Mazatlan }\end{array}$ & $60-70 \mathrm{~m}$ & & & & - & R. V, p. 79 \\
\hline II. depressa STM. & $\begin{array}{l}\text { St. Thomas, Barra } \\
\text { Grande, Brasilien }\end{array}$ & $50-730 \mathrm{~m}$ & - & . & & & $\begin{array}{l}\text { Challenger; R. V, } \\
\text { p. } 93\end{array}$ \\
\hline II. mbra M.E. & Cap Verden & $75 \mathrm{~m}$ & - & 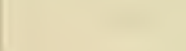 & & - & Talisman, p. 128 \\
\hline Pericera cormeta callinta MI.E. & Westindien & $90 \mathrm{~m}$ & - & - & & - & FAXON 1896 , p. $15 t$ \\
\hline Hyas arancus (Lo.) & Arktisch & $50-630 \mathrm{~m}$ & - & . & & -- & $\begin{array}{l}\text { Doflers, Fauna arc- } \\
\text { tica }\end{array}$ \\
\hline II. coarctutres I.ch. & Arktisch cirkumpolar & $10-1650 \mathrm{~m}$ & & & & - & $\begin{array}{l}\text { DorLeIN, Pauna arct., } \\
\text { Albatross; Blake }\end{array}$ \\
\hline 11. lyratus DaNi & $\begin{array}{l}\text { Aleuten bis I'uget } \\
\text { Sound }\end{array}$ & $8-200 \mathrm{~m}$ & - & - & & & R. V, p. 72 \\
\hline Iraine zerrucosa M.-E. & $\begin{array}{l}\text { Nittelmeer, NO.- } \\
\text { Atlantik bis Cap } \\
\text { Blanco, Cap Verde }\end{array}$ & $1-120 \mathrm{~m}$ & - & & & - & Talisman, p. 127 \\
\hline AH. gibba ALC. & Andamanen & $480 \mathrm{~m}$ & Cth.stachelig & $\begin{array}{l}\text { sehr grol3, } \\
\text { ventral }\end{array}$ & Cornea & & $\begin{array}{l}\text { Investigator; AL. } \\
\text { Cock, p. 239 }\end{array}$ \\
\hline Maropsis panamensis lisx. & Mariato Pt. (Yacifik) & $355 \mathrm{~m}$ & - & & & & Albatross \\
\hline Majella brezipes ORTM. & Japan & $130-220 \mathrm{~m}$ & - & - & & & ORTMANN VI, P. 5I \\
\hline Chorilia longipes DANA & $\begin{array}{l}\text { S. Clemente - Ins., } \\
\text { Californien }\end{array}$ & $750 \mathrm{~m}$ & 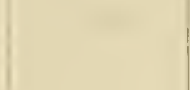 & - & & & R. 1, p. 572 \\
\hline Lencippa pentagona M..E. & $\begin{array}{r}\text { Argentinien: Rio de } \\
\text { la Plata, S. Mratias }\end{array}$ & $20-95 \mathrm{~m}$ & - & & & - & R. I, p. 572 \\
\hline Chionoccetes opilio FABR. & $\begin{array}{l}\text { Arktisch cirkum- } \\
\text { polar (Japan: Mu- } \\
\text { seum München) }\end{array}$ & $5-375 \mathrm{~m}$ & - & & & & $\begin{array}{l}\text { Dorleis, fauna arc- } \\
\text { tica; R. V, p. } 74 \\
\text { u. } 75\end{array}$ \\
\hline
\end{tabular}




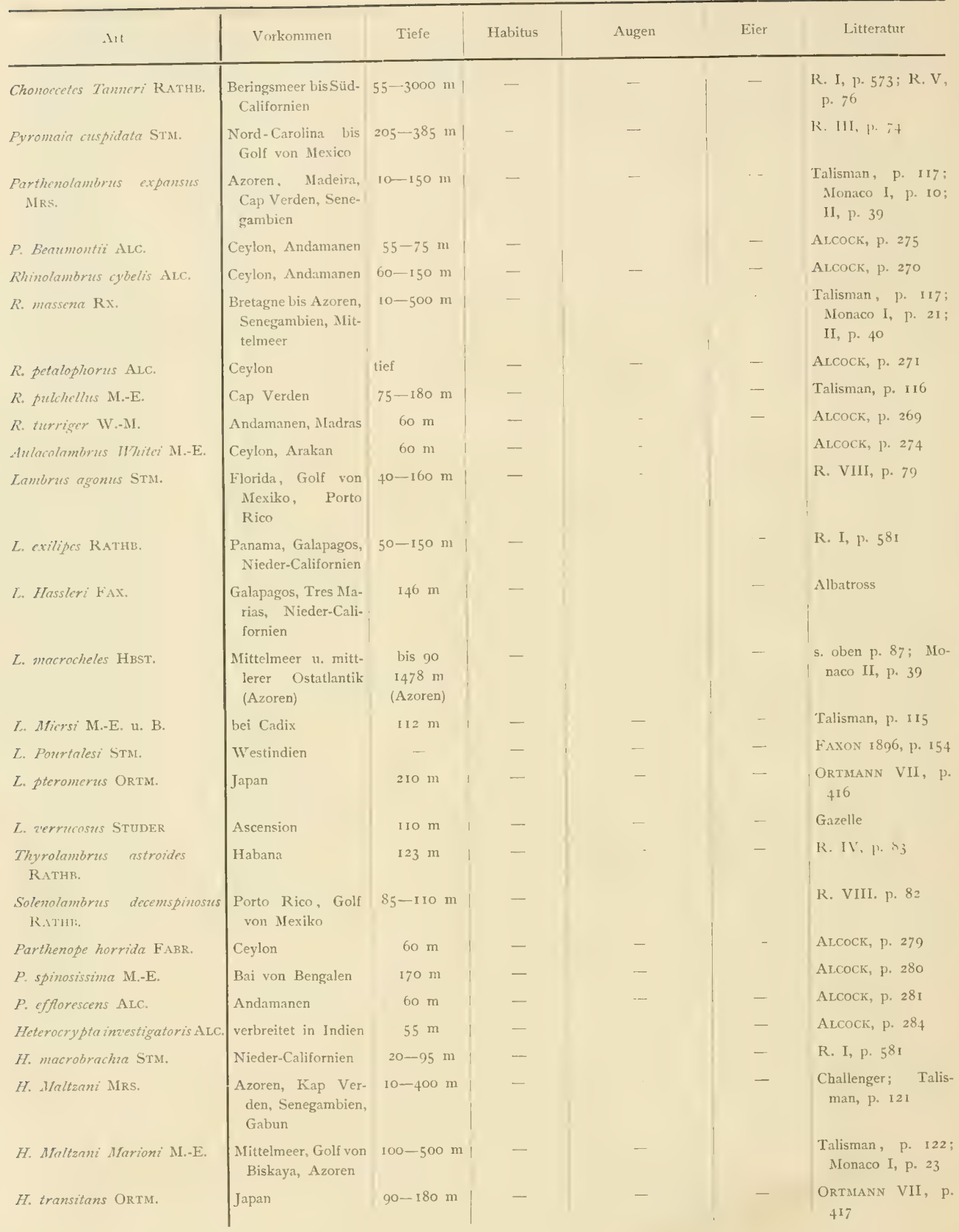




\begin{tabular}{|c|c|c|c|c|c|c|}
\hline Art & Vorkommen & Tiefe & Habitus & Augen & Eier & Litteratur \\
\hline Eumedonzes sebra ALC. & Ceylon & $60 \mathrm{mn}$ & - & -- & - & ALCOCK, p. 288 \\
\hline Temnonotus granulosus MRS. & Barlbados & $188 \mathrm{~m}$ & - & - & - & K. V, p. 93 \\
\hline$T$. lamellatues STM. & Barbados & $183 \mathrm{~m}$ & - & - & - & R. $V$, p. 93 \\
\hline Atelecyclus septemudentatus Lcr. & $\begin{array}{c}\text { Schottland 11. Nor- } \\
\text { wegen bis Mittel- } \\
\text { meer, Azoren }\end{array}$ & $|10-1262 \mathrm{~m}|$ & - & $一$ & - & $\begin{array}{l}\text { Talisman, p. Go; Mo- } \\
\text { naco II, P. 23; } \\
\text { Valdivia }\end{array}$ \\
\hline A. heterodon MLNT. & $\begin{array}{l}\text { No.-Atlantik, Azo- } \\
\text { ren, Cap Verden, } \\
\text { Senegambien, } \\
\text { Mittelmeer }\end{array}$ & $|230-250 \mathrm{~m}|$ & - & - & $一$ & $\left\{\begin{array}{c}\text { Talisman, p. GI } \\
\text { Monaco I, p. } 50\end{array}\right.$ \\
\hline $\begin{array}{l}\text { IIypopeltarium spinulosum } \\
\text { W"HTF. }\end{array}$ & $\begin{array}{c}\text { Argentinien, Maga]. } \\
\text { haes-Str., Chiloe }\end{array}$ & & - & - & - & $\begin{array}{l}\text { Challenger; R. I, } \\
\text { p. } 599\end{array}$ \\
\hline Trichopeltarium Alcocki Dorr. & Siberut-Ins. (Indik) & $750 \mathrm{~m}$ & Cth. stachelig | & rückgebildet & - & $\begin{array}{l}\text { Valdivia, s. oben } \\
\text { S. } 88\end{array}$ \\
\hline T. orale AvD. & Ceylon & $|329-396 \mathrm{~m}|$ & $\begin{array}{l}\text { Cth. dornig, } \\
\text { blal3bläulich | } \\
\text { u. gelblsch }\end{array}$ & $\begin{array}{l}\text { Augenstiel lang, } \\
\text { Cornea klein }\end{array}$ & $\longrightarrow$ & | Investigator \\
\hline Trachycarcinus corallinus FAx. & $\begin{array}{c}\text { Acapulco, Mariato- } \\
\text { Pt., Galapagos }\end{array}$ & $998-12 ; 2 \mathrm{~m}$ & $\left|\begin{array}{c}\text { Cth. reich } \\
\text { skulptiert }\end{array}\right|$ & $\begin{array}{l}\text { mäßig groß, unvoll- } \\
\text { kommen facettiert, } \\
\text { pigmentlos }\end{array}$ & $\left|\begin{array}{c|}\text { groß, }{ }^{1} \frac{1}{3} \\
-11 / 2 \mathrm{~mm},\end{array}\right|$ & $\begin{array}{l}\text { Albatross; R. I, } \\
\text { p. } 599\end{array}$ \\
\hline T: Elancus ALC. u. Axm. & Travancore-Küste & $786 \mathrm{~m}$ & $\begin{array}{l}\text { Cth. höckerig, } \\
\text { weiß mit } \\
\text { bläulich }\end{array}$ & $\begin{array}{l}\text { Augenstiele schlank, } \\
\text { Augen wenig pig- } \\
\text { mentiert und ohne } \\
\text { Facetten }\end{array}$ & $\begin{array}{l}\text { wenig und } \\
\text { grols, } \mathrm{I}, 3 \mathrm{~mm}\end{array}$ & Investigator \\
\hline Cancer amplizocus RATHu. & $\begin{array}{l}\text { Nieder-Californien, } \\
\text { Hakodate, Tokio, } \\
\text { Korea }\end{array}$ & $\begin{array}{l}20-80 \mathrm{~m} \\
310 \mathrm{~m} \\
\text { (Tokio) }\end{array}$ & - & & - & R. I, p. $5^{82}$ \\
\hline C. belliamus JoHNs. & Azoren & $195-620 \mathrm{~m}$ & - & - & & Monaco I, p. 36 \\
\hline C. borealis STM. & $\begin{array}{l}\text { Massachusetts bic } \\
\text { Georgia, Bermudas } \\
\text { und Antillen }\end{array}$ & $\begin{array}{l}\text { im Norden } \\
90-365 \mathrm{~m} \text {, } \\
\text { im Süden } \\
\text { im tieferen } \\
\text { Wasser bis } \\
\text { ca. } 700 \mathrm{~m}\end{array}$ & . & & - & $\begin{array}{l}\text { Albatross } 1883 ; \\
\text { Blake } 1880\end{array}$ \\
\hline C. irromalus SAY & $\begin{array}{l}\text { Massachusetts bis } \\
\text { Georgia }\end{array}$ & $\begin{array}{l}\text { im Norden am } \\
\text { itrundhül1: } \\
\text { selten tiefer } \\
\text { als } 36 \mathrm{~m} \text {; im } \\
\text { Süden am } \\
\text { Strand selten; } \\
\text { dort bis } 325 \mathrm{~m}\end{array}$ & & & - & $\begin{array}{l}\text { Albatross I883; } \\
\text { Blake I880 }\end{array}$ \\
\hline C. longipes BrLL & $\begin{array}{l}\text { Panamabai } \\
\text { Chile, Bolivia }\end{array}$ & $\begin{array}{c}\text { bis } 522 \mathrm{~m} \\
\text { litoral }\end{array}$ & - & & - & Albatross, 1). 16 \\
\hline C. gibbulosus D. H. & $\begin{array}{c}\text { Japan, Mlaska bis } \\
\text { Nieder-Californien } \\
\text { (Magdalena-Bay) }\end{array}$ & bis $95 \mathrm{~m}$ & - & . & & K. I. 1. $5 \$ 1$ \\
\hline Pihummus diomedear RАтнг. & Habana, lucatan & $238-335 \mathrm{~m}$ & 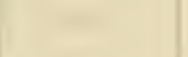 & - & 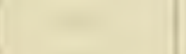 & R. IV, p. 85 \\
\hline I. floridanzes Siт. & Barra grande & $55-730 \mathrm{~m}$ & - & - & - & Challenger \\
\hline I. globesus DANA & Fobe & yo m & & & - & Challenger \\
\hline P. hirtellus typicus (1..) & $\begin{array}{l}\text { Schweden bis Ma. } \\
\text { deira, Azoren, Cap } \\
\text { Verden, Mittel- } \\
\text { meer }\end{array}$ & $1-523 \mathrm{~m}$ & & $=$ & - & $\begin{array}{l}\text { Talisman, P. } 73 ; \\
\text { Monaco II, భ., } 28\end{array}$ \\
\hline
\end{tabular}




\begin{tabular}{|c|c|c|c|c|c|c|}
\hline Art & Vorkommen & Tiefe & Habitus & Augren & lier & Litteratur \\
\hline $\begin{array}{l}\text { Pilumnus hirtellus inermis } \\
\text { MI.E. U. B. }\end{array}$ & $\begin{array}{l}\text { Azoren, Cap Boja- } \\
\text { dor, Cap Verden }\end{array}$ & $80-318 \mathrm{~m}$ & - & -. & - & $\begin{array}{l}\text { Talisman, p. } 73 ; \\
\text { Monaco I, p. } 38\end{array}$ \\
\hline P. minutus harsutus STMt. & Kobe & $90 \mathrm{~m} \quad$ । & 一 & - & - & Challenger \\
\hline P. Normani MRS. & Ki-Inseln & $256 \mathrm{~m}$ & - & - & - & Challenger \\
\hline P. Pervieri M.-E. u. В. & Cap Verden & $75 \mathrm{~m} \quad 1$ & - & - & - & Talisman, p. 73 \\
\hline P. spinifer M.-E. & Azoren & $90-165 \mathrm{~m}$ ! & - & - & - & Challenger \\
\hline$P$. tomentoszes LATR. & $\begin{array}{l}\text { Port Philip, Bass- } \\
\text { StraBe (Australien) }\end{array}$ & $60-70 \mathrm{~m}$ & - & - & - & Challenger \\
\hline $\begin{array}{l}\text { Xanthodes melanodactylus } \\
\text { M..E. }\end{array}$ & $\begin{array}{l}\text { Azoren, Canaren, } \\
\text { Cap Verden, As- } \\
\text { cension }\end{array}$ & $10-355 \mathrm{~m}$ & - & - & - & $\begin{array}{c}\text { Talisman, p. } 85 \\
\text { Monaco I, p. } 34 ; \\
\text { Monaco II, p. } 28\end{array}$ \\
\hline $\begin{array}{l}\text { I. melanodactylues mopuncta. } \\
\text { ths M.E. }\end{array}$ & Cap Verden & $75-225 \mathrm{~m}$ & - & 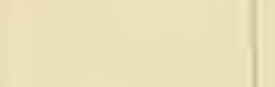 & - & Talisman, p. 87 \\
\hline I. sulcatues FAx. & $\begin{array}{l}\text { Golf von Panama, } \\
\text { Mariato } \mathrm{Pt} .\end{array}$ & $278-335 \mathrm{~m}$ & - & - & - & Albatross \\
\hline X. talismani M.-E. u. B. & Cap Verden & $20-180 \mathrm{~m}$ & - & - & - & Talisman, p. 9I \\
\hline Xantho floridus MoNT. & $\begin{array}{l}\text { Nordsee bis Azoren, } \\
\text { Madeira, Cap Ver- } \\
\text { den }\end{array}$ & $0-77 \mathrm{~m}$ & - & - & 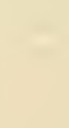 & Talisman, p. 95 \\
\hline X. tuberulatus Couch. & $\begin{array}{l}\text { England, Golf ron } \\
\text { Biskaya, Azoren, } \\
\text { NW.-Afrika bis } \\
\text { Cap Verden }\end{array}$ & $\begin{array}{l}\text { (nicht weniger| } \\
\text { als } 100 \mathrm{~m} \text { ) } \\
100-1200 \mathrm{~m}\end{array}$ & - & & - & $\begin{array}{l}\text { Talisman, p. } 93 \text {; } \\
\text { Monaco I, p. } 33 \text {; } \\
\text { Monaco II, p. } 32\end{array}$ \\
\hline Actaea Peronit M.-E. & $\begin{array}{l}\text { Bass-Straße (Austra. } \\
\text { lien) }\end{array}$ & $70 \mathrm{~m}$ & - & - & - & Challenger \\
\hline A. gramilata (ALD.) & Japan & $90-180 \mathrm{~m}$ & - & & - & $\begin{array}{l}\text { ORTMANN VII, p. } \\
+55\end{array}$ \\
\hline Sphaerozius nitidius STM. & Kole & $90 \mathrm{~m}$ & - & - & - & Challenger \\
\hline Leptodius convexus M.-E. & Cap Verden, Gabun & $1-225 \mathrm{~m}$ & - & - & - & Talisman, p. 97 \\
\hline $\begin{array}{l}\text { Lophozozymiss bellies STM. leze } \\
\text { comonies Lock. }\end{array}$ & Kobe & $90 \mathrm{~m}$ & - & & - & Challenger \\
\hline $\begin{array}{l}\text { Orphnoxanthus microps Atc. } \\
\text { u. AND. }\end{array}$ & Bengal-Bay & $192-640 \mathrm{~m}$ & $\begin{array}{l}\text { Cth. glatt, } \\
\text { haarig, } \\
\text { braun }\end{array}$ & $\begin{array}{l}\text { klein, wenig pigmen- } \\
\text { tiert }\end{array}$ & & Investigator \\
\hline Panopers Tanneri INAx. & $\begin{array}{l}\text { Cocos-Inseln, Gala- } \\
\text { pagos }\end{array}$ & $97-120 \mathrm{~m}$ & $\begin{array}{l}\text { bei den Jun- } \\
\text { gen mehr } \\
\text { Granulation } \\
\text { an den Ex- } \\
\text { tremitäten } \\
\text { als bei den } \\
\text { Alten }\end{array}$ & & - & Albatross, p. 20 \\
\hline$P$ latus FAX. & Panama & $155 \mathrm{~m}$ & - & - & & Albatross \\
\hline $\begin{array}{l}\text { Platypilumms gracilipes } \mathbf{W}_{\text {-- }} \\
\text { M. }\end{array}$ & Andamanen & $344-403 m$ & $\begin{array}{l}\text { Cth. granu- } \\
\text { liert, gelb- } \\
\text { lich-rot }\end{array}$ & $\begin{array}{l}\text { Augenstiele dick, } \\
\text { kleine Cornea }\end{array}$ & - & Investigator \\
\hline Micropanope polita RATHB. & Nieder-Californien & $64 \mathrm{~m}$ & - & & & R. VI, p. 238 \\
\hline M. xanthiformis (M.-E.) & Cap Frio (Brasilien) & $110 \mathrm{~m}$ & - & - & - & R. I, 1. $5 x-$ \\
\hline $\begin{array}{l}\text { Neclopanope rhodounphes } \mathrm{W} \text {.- } \\
\text { M. }\end{array}$ & $\begin{array}{l}\text { Godávari- } \mathrm{K} \text { üste (In- } \\
\text { dien) }\end{array}$ & $179-186 \mathrm{~m}$ & Cth. rosa & grols & & Investigator \\
\hline
\end{tabular}




\begin{tabular}{|c|c|c|c|c|c|c|c|}
\hline Art & Vorkommen & Tiefe & Habitus & Augen & & Eier & Litteratur \\
\hline $\begin{array}{l}\text { Sphenomerides trapezioides } \\
\text { ALC. }\end{array}$ & Andamanen & $238-530 \mathrm{~m}$ & $\left|\begin{array}{c}\text { Cth. glatt, } \\
\text { gelbweis }\end{array}\right|$ & - & & - & Investigator \\
\hline Tetraxanthus bridentatus.M.-F. & Cap Frio (Brasilien) & $110 \mathrm{~m}$ & - & - & - & - & R. 1, P. 590 \\
\hline Lupocyclus oricntulis MRS. & $\begin{array}{l}\text { Ki.Inseln, } \Lambda \text { dmirnli- } \\
\text { täts-Inseln }\end{array}$ & $256-27+m$ & - & - & & - & Challenger \\
\hline Pletyonychus iridescens Mirs. & Ki-Inseln & $256 \mathrm{~m}$ & - & - & & - & Challenger \\
\hline P. IIensloz'i LEACH & NO.-Atlantik & $\begin{array}{l}\mid \text { Oberfläche bis } \\
240 \mathrm{~m}(573)\end{array}$ & - & - & & - & $\begin{array}{l}\text { Talisman, p. 62; } \\
\text { Monaco I, p. 3I }\end{array}$ \\
\hline Portumes cormegatus (PRNX.) & Kosmopolit? & $10-200 \mathrm{~m}$ & - & - & & - & $\begin{array}{l}\text { Talisman, p. } 64 \text {; } \\
\text { Challenger; Mo- } \\
\text { raco II, p. } 25\end{array}$ \\
\hline P. alepurator (L.) & $\begin{array}{l}\text { Norwegen bis Mit- } \\
\text { telmeer }\end{array}$ & $10-200 \mathrm{~m}$ & - & - & & - & Talisman, p. 63 \\
\hline I. pusillus $\mathrm{Lcn}$. & $\begin{array}{l}\text { Norwegen bis Mit- } \\
\text { telmeer, Azoren, } \\
\text { Senegambien }\end{array}$ & $10-250 \mathrm{~m}$ & - & - & & - & $\begin{array}{l}\text { Talisman, p. 64; } \\
\text { Monaco I, p. 27 }\end{array}$ \\
\hline P. Iuberculatus Rx. & $\begin{array}{r}\text { Shetland-Inseln bis } \\
\text { Mittelmeer, } t \text { zoren }\end{array}$ & $100-560 \mathrm{~m}$ & - & - & & - & $\begin{array}{l}\text { Talisman, p. } 63 \text {; } \\
\text { Monaco I, p. } 25\end{array}$ \\
\hline dihelons spinimanus L.1TR. & Cocos-Inseln & $97 \mathrm{~m}$ & - & 一 & & - & Albatross \\
\hline A. affinis IF.ux. & Panama-Gebiet & $\begin{array}{l}\text { Oberfläche } \\
95-102 \mathrm{~m}\end{array}$ & - & - & & - & Albatross \\
\hline $\begin{array}{l}\text { Teptumus (Amphitrite) hasta- } \\
\text { tus (L.) }\end{array}$ & Teneriffa & $143 \mathrm{~m}$ & - & - & & - & Challenger \\
\hline N. (A.) hastatoides (FABR.) & Kobe & $90 \mathrm{~m}$ & - & - & & - & Challenger \\
\hline $\begin{array}{l}\text { 1: (Ifrllenus) iridescens RATH- } \\
\text { HuX }\end{array}$ & $\begin{array}{l}\text { Golf von Californien, } \\
\text { Westküste von } \\
\text { Nieder-Californien }\end{array}$ & $30-130 \mathrm{~m}$ & - & - & & - & R. VI, P. 240 \\
\hline . (II.) spinicarpus STM. & $\begin{array}{l}\text { Barra Grande, West- } \\
\text { indien }\end{array}$ & $(55-730 \mathrm{~m})$ & - & - & & - & $\begin{array}{l}\text { Challenger; FAxoN } \\
1896, \text { p. } 154\end{array}$ \\
\hline deptunus Seyi (GIrBEs) & $\begin{array}{l}\text { Sargasso-Meer pela. } \\
\text { gisch; } \\
\text { Marokko bis Mexilo, } \\
\text { Florida,Südcarolina }\end{array}$ & $\left\{\begin{array}{c}\text { lis }(\cos 4 \mathrm{~m}) \\
?\end{array}\right.$ & - & - & & - & Talisman, p. 70 \\
\hline Goniosoma hoplites W...M. & Coromandel.Küste & $146-200 \mathrm{~m}$ & - & - & & - & Investigator \\
\hline G. ornatum M.-S. & Arafura-Sec & $90 \mathrm{~m}$ & - & - & & - & Challenger \\
\hline $\begin{array}{l}\text { G. zariegatum bimaculntum } \\
\text { MRS. }\end{array}$ & Kobe & $90 \mathrm{~m}$ & - & - & & - & | Challenger \\
\hline $\begin{array}{l}\text { Denthochascon Ilemingi Are. } \\
\text { 16. AxIs. }\end{array}$ & $\begin{array}{l}\text { Andamanen, Niko- } \\
\text { baren }\end{array}$ & $296-738 \mathrm{~m}$ & $\begin{array}{l}\text { Cth. glatt, } \\
\text { blaPorange }\end{array}$ & sehr groß, dunkel & klein u & u. viele & $\begin{array}{l}\text { Investigator; Valdi- } \\
\text { via s. oben }\end{array}$ \\
\hline Diatliznectes superba (Costi) & $\begin{array}{l}\text { Irland bis Azoren, } \\
\text { Cap Verden, Ost- } \\
\text { küstevon Amerika, } \\
\text { Antillen }\end{array}$ & $100-1410 \mathrm{~m}$ & - & - & & - & $\begin{array}{l}\text { Talisman, P. 65; Mo- } \\
\text { naco I, p. 29; II, } \\
\text { p. } 25\end{array}$ \\
\hline Geryon affinis M.E. u. B. & $\begin{array}{l}\text { Non-u. Süd-Atlan- } \\
\text { tik. Indik (s. oben } \\
\text { S. } 105 \text { ) }\end{array}$ & $|+10-2000 \mathrm{~m}|$ & | Cik. glatt, rot | & $\begin{array}{l}\text { grol’, echte Dämme- } \\
\text { rungsaugen }\end{array}$ & $\mid \begin{array}{r}\text { klein, } \\
\text { viele }\end{array}$ & selir & s. oben S. 105 \\
\hline$G$. incerlus MIIERS & Bermudas & $795 \mathrm{~m}$ & & & & & Challenger \\
\hline G. longipes MI-IE. & $\begin{array}{l}\text { Golf von Biskaya, } \\
\text { Mittelmeer }\end{array}$ & $600-1500 \mathrm{~m}$ & Cth. glatt, rot & grol\}, schwarz & & - & $\begin{array}{l}\text { Ialisman, p. } 103 \text {; } \\
\text { Monaco II, p. } 34\end{array}$ \\
\hline
\end{tabular}




\begin{tabular}{|c|c|c|c|c|c|c|}
\hline Art & Vorkommen & Tiefe & Habitus & Augen & Eier & Litteratur \\
\hline Geryon quinquedens SM. & $\begin{array}{l}\text { Massachusetts, Süd- } \\
\text { Carolina, Cap Frio } \\
\text { (Brasilien) }\end{array}$ & $\begin{array}{l}190-1350 \mathrm{~m}, \\
\text { südl. Fund. } \\
\text { orte tiefer als } \\
\text { nördliche }\end{array}$ & - & - & - & $\begin{array}{l}\text { Albatross I883; } \\
\text { Blake } 1880\end{array}$ \\
\hline G. paulensis DOFL. & $\begin{array}{l}\text { nördlich St. Paul u. } \\
\text { Nen-Amsterdam }\end{array}$ & $2068 \mathrm{~m}$ & Cth. glatt & groß, dunkel & - & $\begin{array}{l}\text { Valdivia, s. oben } \\
\text { S. II } 2\end{array}$ \\
\hline Carcinoplax dentaties RATHB. & Golf von Californien & $55-135 \mathrm{~m}$ & - & - & 一 & R. VI, p. 243 \\
\hline C. longipes WV.-MI. & $\begin{array}{l}\text { Nikobaren, Anda- } \\
\text { manen u. Travan- } \\
\text { core-Kiiste }\end{array}$ & $403-786 \mathrm{~m}$ & $\begin{array}{l}\text { Cth. glatt, } \\
\text { rosi }\end{array}$ & klein, dunkel & - & $\begin{array}{l}\text { Investigator; Valdi- } \\
\text { via, s. oben S. II }\end{array}$ \\
\hline C. longimanus japonicus D. H. & Japan, Sagamibai & ca. $150 \mathrm{~m}$ & $\begin{array}{l}\text { Cth. glatt, } \\
\text { rosa }\end{array}$ & groß, dunkel & - & s. oben S. II 5 \\
\hline C longinanus indicus DoFL. & $\begin{array}{l}\text { Andamanen, Niko- } \\
\text { baren, Martaban- } \\
\text { Golf }\end{array}$ & $110-126 \mathrm{~m}$ & $\begin{array}{l}\text { Cth. glatt, } \\
\text { rosa }\end{array}$ & groß, dunkel & 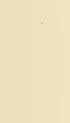 & s. oben S. II4 \\
\hline Goneplax angulata (PENN.) & $\begin{array}{l}\text { NO.-Atlantik bis } \\
\text { Agulhasbank }\end{array}$ & $\begin{array}{l}\text { sublitoral } \\
\text { bis } 618 \mathrm{~m}\end{array}$ & - & - & . & s. oben S. 117 \\
\hline Psopheticus insignis ALC. & Golf von Martalun & $\mathrm{I} 20 \mathrm{~m}$ & -. & - & - & Investigator \\
\hline P. stridulaus W.-M. & $\begin{array}{l}\text { Andamanen, Nilio- } \\
\text { baren }\end{array}$ & $316-766 \mathrm{~m}$ & Cth. glatt & groß & - & $\begin{array}{l}\text { Investigator; Valdi- } \\
\text { via, s. oben S. II } 8\end{array}$ \\
\hline $\begin{array}{l}\text { Bathyplax typhlus oculiferus } \\
\text { MRS. }\end{array}$ & Barra Grande & $(55-730 \mathrm{~m})$ & & - & - & Challenger \\
\hline Pilumnoplax americana RAтнв. & $\begin{array}{l}\text { West-Sumatra, Tra- } \\
\text { vancure (Indien), } \\
\text { Florida, Georgia }\end{array}$ & $125-800 \mathrm{~m}$ & - & $\begin{array}{l}\text { blein, beweglich, } \\
\text { pigmentiert }\end{array}$ & & s. oben S. I 20 \\
\hline P. heterochir STUDER & $\begin{array}{l}\text { Kapregion, Agulhas- } \\
\text { bank, Tristan da } \\
\text { Cunha, St. Paul, } \\
\text { Nett-Amsterdam }\end{array}$ & $183-500 \mathrm{~m}$ & $\begin{array}{l}\text { Cth. glatt, } \\
\text { orangerot }\end{array}$ & mittelgroß, dunkel & - & S. oben S. I I \\
\hline P. aby'ssicola MrRs. & Fidschi-Inseln & $576 \mathrm{~m}$ & - & - & - & Challenger \\
\hline Litocheira K̈̈ngsley'i MRs. & Agulhasbank, Kap & $275-318 \mathrm{~m}$ & - & mittelgroß, dunkel & - & S. oben S. I 2 I \\
\hline Catoptrus nitidus M.-E. & Ceylon & $60 \mathrm{~m}$ & - & - & - & Investigator \\
\hline Camatopsis rubida AI.C. u. AND. & $\begin{array}{l}\text { Andamanen, West- } \\
\text { Sumatra }\end{array}$ & $355-660 \mathrm{~m}$ & $\begin{array}{l}\text { Cth. glatt, } \\
\text { braun }\end{array}$ & $\begin{array}{l}\text { nur mit kleiner Cor- } \\
\text { nea auf der Unter- I } \\
\text { seite der dicken } \\
\text { Stiele }\end{array}$ & - & $\begin{array}{l}\text { Investigator; Valdi- } \\
\text { via, s. oben S. I2I }\end{array}$ \\
\hline Chasmocarcinus latipes RAтнв. & Nieder-Californien & $90 \mathrm{~m}$ & - & - & - & R. I, p. 602 \\
\hline Ch. cylindricus RATHB. & Porto Rico & $10-300 \mathrm{~m}$ & - & - & - & R. VIII, p. Io \\
\hline Ch. typicus RATHB. & Kap Trio & I IO $\mathrm{m}$ & - & & - & R. I, p. 602 \\
\hline Dediplux gramulatus RATHB. & Nieder-Californien & $60 \mathrm{~m}$ & - & - & - & R. VI, p. 242 \\
\hline Hephthopelta lugubris ALC. & Andamanen & $896 \mathrm{~m}$ & $\begin{array}{l}\text { Cth. glatt, } \\
\text { gelb }\end{array}$ & $\begin{array}{l}\text { klein, unbeweglich, } \\
\text { sonst normal }\end{array}$ & - & Investigator \\
\hline Ceratoplax ciliata STM. & Andamanen etc. & $100 \mathrm{~m}$ & -- & $\begin{array}{l}\text { pigmentiert, unbe- } \\
\text { weglich }\end{array}$ & - & $\begin{array}{l}\text { Investigator; STIMP- } \\
\text { sON; Challenger; } \\
\text { CANO, WALKER }\end{array}$ \\
\hline Eucratodes Agassizii M..E. & Porto Rico & $200-350 \mathrm{~m}$ & & - & - & R. VIII, p. 35 \\
\hline Euryplax nitida STM. & $\begin{array}{l}\text { Florida, St. Thomas, } \\
\text { Porto Rico }\end{array}$ & $90 \mathrm{~m}$ & & - & - & R. VIII, p. 8 \\
\hline
\end{tabular}




\begin{tabular}{|c|c|c|c|c|c|c|}
\hline Art & Vorkommen & Tiefe & Habitus & . Iugen & Fier & Litteratur \\
\hline Ceratoplav hispida AIC. & Palls-Stralie & tief & 一 & $\begin{array}{l}\text { unleweglich, pig-! } \\
\text { mentlos }\end{array}$ & - & Investigator \\
\hline Aotony.x vitreus AIC. & Andamanen & $100 \mathrm{~m}$ & - & $\begin{array}{l}\text { klein, pigmentiert, } \\
\text { unbeweglich }\end{array}$ & 一 & Investigator \\
\hline Lambitophallus sexpess $\lambda \mathrm{LC}$. & Bengal-13ay & $11 ; \mathrm{m}$ & - & klein, pigmentict & - & Investigator \\
\hline Pinnotheres icterum Bnsc. & $\begin{array}{l}\text { Mittelmeer, NO.- } \\
\text { Mtlantik }\end{array}$ & bis $80 \mathrm{~m}$ & - & - & - & Nonaco II, p. $3^{8}$ \\
\hline 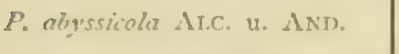 & Travancore & $786 \mathrm{~m}$ & Cth. glatt & blaß & - & Investigator \\
\hline Pinnixa brezipollex RATHB. & $\begin{array}{l}\text { St. Matias, Mrgen- } \\
\text { tinien }\end{array}$ & $80 \mathrm{~m}$ & - & - & - & R. I, p. 605 \\
\hline P. californiensis RATHB. & Californien & $65-80 \mathrm{~m}$ & - & - & - & K VI, p. 249 \\
\hline l. minula RАтнв. & Porto Rico & $300-350 \mathrm{~m}$ & - & - & - & R. VIII, p. 2 I \\
\hline P. occidentalis R. RTHR. & $\begin{array}{l}\text { Unalaska, Alaska, } \\
\text { Washington bis } \\
\text { Süd-Californien }\end{array}$ & $35-435 \mathrm{~m}$ & - & - & - & R. VI, p. 248 \\
\hline Exacsthesius bifrons RaTHB. & Galapagos & 8o $\mathrm{m}$ & - & $\longrightarrow$ & - & IR. I, p. 591 \\
\hline Plntygrapszes depressus (1). H.) & $\begin{array}{l}\text { Japan, Kobe, Sa- } \\
\text { gamibai }\end{array}$ & bis $90 \mathrm{~m}$ & - & - & - & $\begin{array}{l}\text { Challenger; ORT- } \\
\text { MINN VIII, p. } 716\end{array}$ \\
\hline ITeterograpsus sanguinezes Luc. & Japan & bis $75 \mathrm{~m}$ & - & - & - & $\begin{array}{l}\text { ORTMANN VIII, p. } \\
719\end{array}$ \\
\hline $\begin{array}{l}\text { Euchirograpsus americanus } \\
\text { M.-E. }\end{array}$ & $\begin{array}{l}\text { Barbados, Azoren, } \\
\text { Marokko, Cap } \\
\text { Verden }\end{array}$ & $150-318 \mathrm{~m}$ & - & 1 & - & Talisman, p. 10\% \\
\hline Itexaplax megalops DoFu. & Nias & $470 \mathrm{~m}$ & Cth. glatt & $\begin{array}{l}\text { sehr groß, Cornea } \\
\text { erweitert }\end{array}$ & - & $\begin{array}{l}\text { Valdivia, s. oben } \\
\text { S. } 122\end{array}$ \\
\hline $\begin{array}{l}\text { Encraiopsis macrophthalma } \\
\text { R.Iтnв. }\end{array}$ & Panama & $90 \mathrm{~m}$ & - & - & - & R. I, p. 6or \\
\hline Spcocarcinus carolincnsis STM. & $\begin{array}{l}\text { Charleston S. C., } \\
\text { Tortugas, Porto } \\
\text { Rico }\end{array}$ & $15-150 \mathrm{~m}$ & - & - & - & IR. VIII, p. II \\
\hline Retropluma notopus (AIC.) & $\begin{array}{l}\text { Bengal, Coromandel- } \\
\text { Küste, Andamanen }\end{array}$ & I $83-457 \mathrm{~m}$ & $\begin{array}{l}\text { Cth. gylatt, } \\
\text { braun }\end{array}$ & $\begin{array}{l}\text { klein, reduzicrte } \\
\text { Stiele, lang und } \\
\text { schlank }\end{array}$ & - & | Investigator \\
\hline R. Chumi Dor.. & Nias & $6 \mathrm{I}+\mathrm{m}$ & $\begin{array}{l}\text { Cth. linarig, } \\
\text { ausladende } \\
\text { Beine }\end{array}$ & klein, pigmentlos & 一 & s. oben S. 131 \\
\hline
\end{tabular}

Tabelle II. Verzeichnis der in Tiefen zwischen 7oo und rooo m grefundenen Brachyuren.

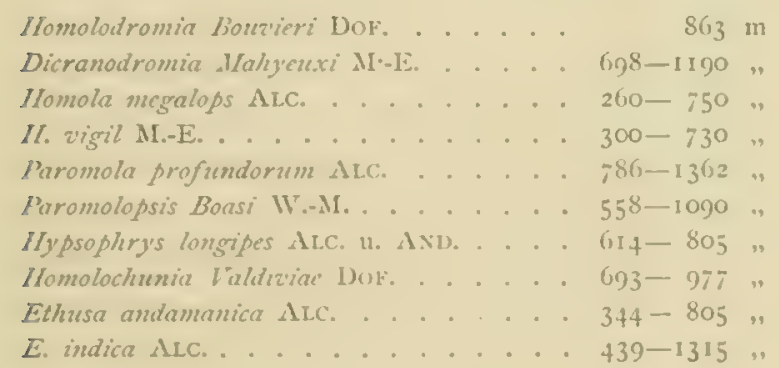

Ethuesa rosacca M.-E. 11. 13. . . ... 930-1113 m

E. Zurstrasseni Dor......... . . 97;,

Elhusina desciscens A.C. . . . . . 486-1703 "

E. smithiand FAX. . . . . . 245-1645

Cymonomus granulatus (NokMr.) . . . 30j-1350,

Cyclodorippe uncifera glancomma Al.c. . 180- 739 ,

Mursia armata bicristimana A.C. U. AND. . 260- 732 ",

Ebalia algirica Luc.1s . . . . . 100-790,

E. nux NORM. . . . . . . . . 134-2500 ,

Randallia piestulosa W.M. . . . . 2 $296-977$. 
Lyreidus Chameri W.-M. . Leptopodia sagittaria FABR. Stenorhynches longirostris FABR. Euprognatha rostellifera STM. Iloloplites armatus (M.-E.) Inachus dorsettensis PENN. physachacus ctenums ALC. Lispognathus Thomsoni (Norar.) Ergasticus Clouci M.-E. Crrtomaia Smithi RATHB.

C. Suhmi typica Mrs. C. Suhmi platyceros DoF. Ilatymair II'rille-Thomsoni Mrs. Encephalondes Rizers-Andersoni ALC Lithinin Smuthi MRS.

Mithrax commizs SACss.

I\% hispidzes STM.

Hyastenus longipes DANA. Soyramathin Carpenteri (NokM.)

S. globulifern W.-M.

S. palchra MRs.

S. Riters-Andersoni ALC.

Anomathic cometa RATHB.

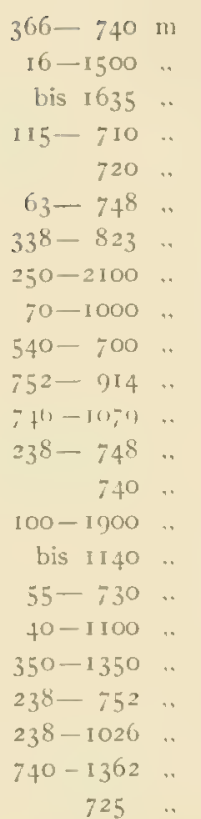

A. hystrix (STM.) . . . . . . . . . .

A. occidentalis FAX. . . . . . . .

Hy'as coarctatus LEACH.

Chorilia longipes DANA .

Chionoecetes Tanneri RATHB.

Lambrus macrocheles HBST.

Atelecyclus septemdentatiss LCH.

Trichopeltarium Alcacki DoF.

Trachycarcinus corallinus FAx.

T. glazecus ALC. 12. AND. .

Xantho tuberculatus Couch.

Benthochascon Hemingi ALC. u. AND.

Bathynectes superba Costa

Geryon affinis (M.-E. u. B.) .

G. incertus MRs.

$G$. longipes MI.-E.

G. quinquedens SuITH

Carcinoplax longipes (W.-M.)

Psopheticus stridulans W.-M.

Lathyplax typhlus oculiferus MRS. .

Pilumnoplax americana RATHB.

Hephthopelta lugubris ALC.

Pinnotheres abyssicole ALC. 1. ANI.

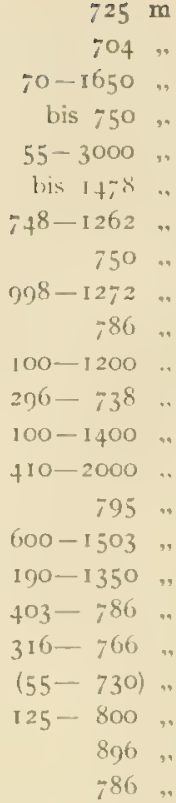

-1650 ,

bis 750 ,

$48-1262$

750

$-86$

$100-1200$

$296-738$

$100-1400$

795

$600-1503$,

$90-1350$

$403-786$

$316-706$

$(55-730)$

896

786

Tahell, III. Verzeichnis der in Tiefen von rooo-20oo m gefundenen Brachyuren.

Dirranodromia Mahyewri M.-E. llomologenus rostratus M..E. II. Braueri DoF.

II. sp. MIERS

Paromola profundomem ALC.

Paromolopsis Boasi W.-M.

Ilypsophrys supercitiosa TV.-M. Elhusa indica ALC.

E. microphthalma SMrTH

E. rosaced M.-E. u. B.

E. somalica DoF.

Ethusina abyssicola SMTH

E. desciscens ALC.

E. gracilipes (MIRS.)

E. smithiona FAx.

E. talismani M.-E. 11. B.

Cymonomus gramelatus (NORM.)

Eunlia mux NoRM.

Leptopodia sagittaria FABR.

Stenorhyncluzes longirostris FABR.

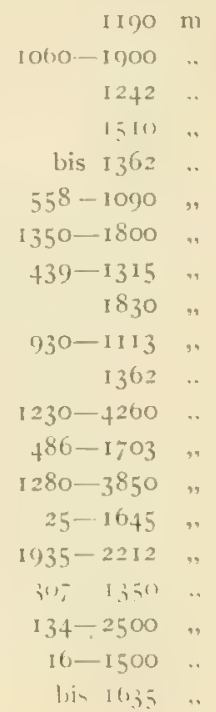

$250-2100 \mathrm{mI}$ $746-1079$ 1510 ."

$100-1900$.

bis 1140 ,

40- 1100 .

$350-1350$,

$238-1026$

$740-1362$.

$10-1650$

$55-3000$

bis 1.78 ,

$748-1262$

$998-1272$

$100-1200$

$100-1410$.

his 2000 .

bis 1503 .

$190-1350$

Tabelle IV. A. Verzeichnis der in Tiefen von 2000-300o m gefundenen Brachyuren.

Ethusina abyssicola S. SMith .

E. gracilipes MRs.

E. movestigatoris ALC.

E. talismanis M.-E. u. B.
Ebalia mux NORM. .....

Lispognathus Thomsoni NORM.

Chionoccetes Tanneri RATHB.

Geryon paulensis DoF. .
$225-2500 \mathrm{~m}$

$250-2100$

2068 .

B. Verzeichnis der in Tiefen von 3000-400o m gefundenen Brachyuren. Ethusina abyssicola S. Smith.

E. challengeri (MRs.) . . . . . 3300-4081 m

Ethusina sracilipes (Mrs.)

$1678-3350 \mathrm{~m}$

C. Verzeichnis der in Tiefenvon über $4000 \mathrm{~m}$ gefundenen Brachyuren.

Ethusina abyssicola S. SMitH. . . . bis $426 \mathrm{I} \mathrm{m} \mathrm{Ethusina} \mathrm{challengeri} \mathrm{(Mrs.)}$

bis $408 \mathrm{rm}$ 


\section{Alphabetisches Register.}

Acanthephyra 23\%

Acanthephyra microphthaima 23 t Acanthocarpus STIMPon 38.

Acanthopus Gibbesi H. MiNI-EINW: 131 Acanthopus planissimus U15. HA.AN 131 .

Achelous pubescons MILNE-EDW. 98.

Actra DE HAAN 102.

Actaen hirsutissima (Rërrit.) 102.

Actaeomorpha Mitiks 49 .

Actaen parvula (I) HA.N) 102.

Alonck 235 .

Allgemeine Oberflächenvergrïferung bei Tief. seckrabuen 196.

Amblyopsis 243 .

Amblyopsis, Entwicklung $=43$

Anamathia Livermorii $1 \mathrm{H}$ OOI-MAsox $\delta_{4}$

Anamathia pulchra Miers $S_{4}$

Angelhaare bei I'hysachacus 204.

Angriffs- und Schutzorrichtungen bei Tiefseekrabben 202.

Anisopus trimaculata 1DE II.I.IN 02 .

Antarctis 26 .

Antennen, innere 246 .

Antennen, innere, hei den Irachyuren 179 .

Anthozoen als transportable ILichtquellen rüt

Paguriden 236.

Appositionsbild $20 \%$.

Appositionsuild bei Lispognathus 218.

Arachnodromia Baffini (ALCOCK u. ANuERsoN) 5.

$\Lambda$ rachnomysis I.cuckarti 220 .

Arachnomysis Leuckarti, Antennen-Ganglion $25 \mathrm{I}$.

Archaeoplax Arcock $13 \mathrm{I}$.

Dic Artbildung bei den Ticfscckrabben un

das Dofuerleax'sche Prinzip 27\%. 280.

Asellus 199

Asellus aquaticus var. fribergensis 242

Asellus cavaticus 232.

Atelecyclidae 88

Atelecyclus heterodon I.E.ıcıI no.

Atelecyclus Lisici go.

Atelecyclus septemdentatus Moxi:iriv 90

Atlantik $26 \%$.

Atlantotlos n. g. 49.

Atlantotlos rhombifer n. sp. 49 .

$\Lambda$ tmung bei den Tiefseekrabben 201.

Attacus atlas $250^{\circ}$

Augenbau bei den Galatheiden 234.

Augenbau der nordatlantischen Tiefseedecapoden 234.

Augenbau und Metamorphose 240.

Augenganglien der Tiefseekrabben 2 I3.

Augengröße und Beweglichkcit 229.

Augen von Ticfseckrabben,
Vergrölicbung 204).

Verkleincrung 209.

Beweglichkeit und Unbeweglichkeit 209.

Augen von Tiefseekrabben

Zahl der Augenkile 209.

Augenstiele 209.

Größe der Augenkcile 2 Io.

Vergleich der Dimensionen der verschiecienen Teile 210.211.

Firm der Stähchen $21 x$.

Augen ron Tiefseckrabluen

l'igment 212.

Tapetum 212 .

farbige Pigmente 212 ,

Pigmentanordnung 213.

Ausladende Stellung der Beine vei Tiefseekrabben 197.

Außcngeißel 246.

B.1T: 199-232.

Bathynomus 199 .

Bathyplax typhlus, Ticht- und Dunkelform 238.

13athyscia 232.

Bau der Augen ciner Anzahl ron Firabben aus verschiedenen Tiefen I 4 I.

Bau der Geruchsorgane einiger Tiefseckrabben 178 .

Bau der nervösen Endapparate des Geruchsorganes $24^{8}$.

Bedeutung des Augenbanes von

Hypsophrys 145.

IIomolochunia 148 .

Bedcutung des Baues der Genuchsorgane für dic Lebensweise der Tiefseekrabben 2.45

Bedeutung der Stäbchenform 217.

Bedeutung der Statocystengröße 254.

Benthochascon AICock 90

Benthochascon Hemingi AI.C. u. ANis. go.

Benthonectes 234 .

Beschreibung von Sinnesorganen einiger Tjef-Cancer Mascarone Herrist 29.

seckrabben $14 \%$. Cancer minutus LiNNi 130.

Bewegung und IIabitus bei Tiefseekrabben Cancer natator HERIsST 96. 106.

Beziehung der ostafrikanischen Tiefsee zum Atlantik 274.

Bildung der Daktylopoditen bei Tiefseekrabluen 199.

Biologische Bedeutung des Augenbaucs bei Cancer rostratus LiNwi 69 . den Krabben 206 . Cancer sanguinolentus HEKHT 94

Biologische Bedeutung der Statocysten bei den Cancer scorpio FAIRICIUSt 72. Tiefseckrabben 252. Cancer serratus ForskAl 98

Biolngie der Tiefseekrabben 101. Cancer variolosus FAnRICIL's 104.

Biologic der Tiefseckrabben, Zusammenfassen- Caphyra Guiris 95.

der Ueberblick 260 .

Biologischer II. Teil 139 .

Camptonyx HELLEK 05
I3latthaare 203 .

molochunia 203.

Brachygrapsus Kingsleyi Ml1:ks 121.

liythinus $229-232$.

201303 133.

Colappa lophas (HERIST) 35 .

Callinectes laryatus ORIMW: 39

Camatopsis rubida Arcock u. ANLERSON 12 I.

mbarus 23 I.

Cancer angulatus PENN INT I17.

Cancer ceratophthalmus I'Al.t.1S 126.

Cancer cursor Livil: I 27.

Cancer dentalus HFREST 103.

Cancer hippa septemdentatus Mostisu go.

Cancer (Curtonotus) longimanus (I)E HAAN) Cancer pairus HEREST 104 Cancer pelagicus LiNixi: 98. Cancer perlatus HERINT 104. Cancer plapatus Farricies 87.

Capliyra laevis 66.

Caplyyra rotundifrons MILNE-Enw. 95. 
Carcinoplaciden-Beweglichkeit 204.

Carcinoplax longimanus (DE HAAN) ir 4 .

Carcinoplax longimanus indicus n. sbsp. II $4 \cdot \mid$ Cyclodorippe uncifera, Licht- und Dunkelform

Carcinoplax longimanus japanicus (DE H.) II5. 238

Carcinoplax longipes (WOOD-MASON) i17. Cyclometopa 87.

Carcinoplax MILNE-EDWiRDS i i 4 .

Carcinus maenas Iro-202, 205.

Cardisoma guanhumi LATREILI.E I 3 I.

Cardisoma IATREILIE I3I.

Catapaguroides microps 234 .

Catocala nupta 230.

Catometopa 114 .

Caustia $25^{8}$.

Chalaepus GERstïcker 105

Challenger 199

Charybdis DE HAAN 96.

Charybdis (Goniosoma) annulata FABRICIUS 96

Charybdis (Goniohellenus) hoplites Woo1)- Cymonomus granulatus n. subsp. 283.

MASON 94.

Charybdis (Goniosoma) natator (HFRRST) 96. Cymonomus granulutus Valdivine 284

Charyludis (Goniosoma) quadrimaculata A. Cymonomus quadratus 33

Milne-EDW. 96.

Charybdis oceanus DE HAAN 96 .

Chemoreceptorische Sinnesorgane 245.

Chionoecetes Ig9.

Chionoecetes apilio 202.

Chionoecetes Tanneri 202.

Chlaenopagurus Andersoni 236.

Chlorodius niger 247 .

Chlorodius sanguineus MILNE-EIN, ror.

Chlorodius ungulatus MrLnE-EIw, 102.

Chologaster Agassizii 244.

Chologaster cornutus 243 .

Chologaster papilliferus 243 .

CHUN 178. 206.

CHUN, Schizopoden- und Sergestidenaugen 236.

Clausthaler Gammarus 24I.

Corallineenregion 194.

Correlation von Corneafacette und Krystall. kegel 210.

Corneafacettengrölie 210.

Cosmonotus ADAMS u. WHITE 5 I.

Cosmonotus Grayi ADAMS u. WVHite 5I.

Cryptocnemus Stimpson 49.

Cryptosoma Brulté 38 .

Cryptosoma orientis Adams u. IVIrITt 38.

Curtonotus DE HAAN II 4 .

Cyclodorippe A. Milne-Edwardos 34

Cyclodorippe dromioides ORTM.

A u ge 157 .

Malse der Augenteile [58.

Cyclodorippe uncifera glaucomma ALC.

Auge 156.

Malie der Augenteile 157.

Geruchsorgan 184 .

Cyclodorippe uncifera glaucomma Statocyste Igo.

Cyclodorippe uncifera melanomma DoFL. A uge I54.

Maße der Augenteile I55.

Cyclodorippe uncifera ORTMANN 34-209.
Cyrtomaia MIERS 53 .

Cyrtomaia Murrayi 54.

Cyrtomaia murrayi 49.

Cyrtomaia Smithi RATHBUN 53.

Cyrtomaia Suhmi MIters 53.

A uge 158 .

Maße der Augenteile 160.

Cyrtomaia Suhmi platyceros n. susp. 55 .

Cyrtomaia Suhmi platyceros DorL. Geruchsorgan $18_{4}$.

Statocyste 190.

Cyrtomaia Suhmi typica MIERS 54.

Cyrtosoma Neptuni 228.

Daira DE HAAN 140

Daira perlata HERBST 104.

Dämmerungsaugen 216.

Dicranodromia Baffini (Atcock u. Anintessos)

\section{Diptychus 234.}

DOEDERLEIN 196.280.

DOFLEIN 20\%-237.

Dorippe armata WHITE 32.

Dorippe FABRICIUS 32.

Dorippe lanata (L.) 32.

Dorippe Mascarone ROEMER 29.

Dorippe spinifrons LAMARCK I5.

Dorsoventrale Abplattung des Cephalothorax

bei Tiefseekrabben 197.

Dorynchus Thomsoni Normin 75 .

Dotilla fenestrata HiLGENDORF I 28

Dotilla Stimpson 128.

Doto sulcatus KRAUSS I 28.

Dromia 8-I Io.

Dromia atlantica n. sp. Io.

Dromia atlantica, Statocyste $18 \mathrm{~g}$.

Dromia bicornis (STUDER) 8 .

Dromiacea 4 .

Dromidia bicornis STUDER 8.

Dromidia spinosa (STUDER) 9.

Dunkelaugen, geringe Facettenzahl 229.
Ebalia atlantica MILNE-EDw. u. Bouvier 46. Ebalia (Phlyseia) atlantica MunE-EDW-1RDS u. Bouvier 46.

Ebalia LEACH 46.

Ebalia salamensis n. $\mathrm{sp} .47$.

Echinoplax Miers 76 .

Echinoplax Moseleyi Mrers 76 .

Echinoplax Moseleyi, Facettengröße 219.

Echinoplax pungens WVood-MAsox 76 .

Eier

Größe und geringe Anzahl der Tiefseekrabben 258.

Eier von Decapoden des Nordatlantik 259.

EIgexmlanN 241 .

Elasmonotus 234.

Elasmonotus squamosus 235

Elliptodactylus n. g. 83 .

Elliptodactylus rugosus n. sp. 94.

Encephaloides Armstrongi, Branchialregionen 201 .

Ergasticus M.-EDw. 76 .

Ernährung u. Atmung bei Tiefseetieren 200. Ethusa 27

Ethusa americana MI.-EDW. 20.

Ethusa andamanica ALCOCK $2 \%$.

Ethusa indica Alcock 30.

Ethusa mascarone HeRsst 29.

Ethusa orientalis MIIERS 27.

Ethusa pygmaea ALC. 30.

Ethusa somalica n. sp. 30

Ethusa somalica DoFL.

Auge I5 I.

Ethusa Zurstrasseni n. sp. 28.

Ethusa (Ethusina) abyssicola S. J. SurTH 3 I -209 .

Ethusina abyssicola S. J. SMITix

Auge I 50 .

Maße der Augenteile $15 \mathrm{r}$.

Ethusina abyssicola, Dämmerungsauge 216.

Ethusina Challengeri MIERs 3 I -209.

Ethusina investigatoris 209.

Etisus dentatus HERBST I03.

Etisus MILne-Eidv. I03.

EXNER 207. 214.

Facettenaugen 141. 206

Facettenaugen Terminologie $14 \mathbf{I}$.

Facettenaugen, Untersuchungstechnik 14 I. 1.42. Facettenlosigkeit 231 .

Facettenpigment in pseudokonen Auge 227.

Farbe der Tiefseekrabben 20.4.

Färbung der Tiefseetiere, eine Anpassung 205.

FAXON 205-236.

Filzbedeckung 203.

Filzbedeckung bei Homolochunia und Hyostenus 203.

FORBES 194

Form der optischen Bestandteile bei den Tiefseekrabben 215.

Form der Stälıchen 211 .

Fortpflanzung und definitive Größe 200

Fortpflanzung der Tiefseekrabben 257 . 
FiRISS $2+1$.

Front- und scitenauge 128 .

Galacantha 23٪.

Galathea 234.

Galathodes 234.

G.1MHIE 202-205.

Gammarus 107 .

Gammarus pulex 231 .

Gammarus putreanus 232.

Ganglien, G eruchsorgan 180 .

Gicarcinus lagostoma MILxT.Evit. I 3 I.

Gecarcinus Ientritul: 131 .

Gecarcinus ruricola DREW I

Gehürbläschen $18 \%$.

Gehürorgane 253.

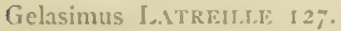

Gelasimus annulipes M(LNF,-Euw. 128.

Gelasimus Marionis MIL.NE-LiJw. 128.

Gelasimus minor OWFX 128.

Gelasimus perlatus Herkiots 127.

Gelasimus perplexus MrL.N.-Ew: 128.

Gelasimus pulchellus Srimsion 128.

Gelasimus Tangieri EYDntx 127.

Geograpsus Grayi MII.NE-IÊW. I29

Geograpsus rubidus STMLisox 129.

Geograpsus Strminox I29.

Germinalselektion 139 .

Geruchscylinder 179 .

Feruchsnerv 180.

Geruchsorgan 245 .

Geruchsorgan bei ơ 11 . 우 250 .

Geruchsorgan der Krabben, drei Bautypen $2.48-249$.

Geruchsorgane von Aasfressern I5I.

Geruchszapfen 180.

Geryon affinis MfHLNE-EDw. u. Bouvier Iou -208 .

Geryon affinis MIITE-Linw. u. Bouvis, Anatomie 110

Geryon affinis, Appositionsbild 220. Geryon affinis

Auge, erwachsenes Tier 175 .

Larve $17 \%$.

Maße der Augenteile 177.

Geryon, Beweglichkeit 20.4.

Geryon, Enddarmanhang III.

Geryon affinis, Facettengrüßc 219 .

Geryon affinis

Geruchsorgan 186.

Statocyste Igo.

verschiedene liärbungen 206.

Versteifungscinrichtungen der Riechhare 180.

Geryon incertus MIIERs 106.

Geryon IRRöYer 105.

Geryon longipes Milne-Euw: IoG

Geryon paulensis DOFLEIN II2.

Geryon paulensis I09.

Geryon, Pylorusanbänge iro.

Geryon quinquedens S. SMrı IOG-233.

Geryon tridens KRörer 106.

Geryon trispinosus Hekbst 105. rileichgowichtssinnosorgine 253.

(ilyplocrangon $234-237$.

(roneplax angulata (Plix.N.XI) $197-118$.

(ioneplax LEscir II

Goneplax rhomboides II8.

Cioniosoma A. M[It.Nm-Finw. 86,

Goniosoma hoplites WonI-MAso: 97.

Goniosoma luciferum J. R. He.Mnerion go.

fioniosoma quadrimaculatum MII,VF- EIMW. 96.

Cromtscin:sche Theoric $22 \%$.

Grapsus simplex Herkiots 129.

GrEvacher 225.

(irüße der Isopoden 199.

$3+4$

lirolizelligkeit von I'hysachaeus ctenurus iso.

firuinea Subregion 267 .

GIVIN JEFEKEI 200

Haarfansen an den Kanten der Beinglieder 197

[Iabitus der "Iicfseckrabben InG

Hakenhare I 88 .

Halicarcinus planatus lid RRICIU's 87 .

Halicarcinus WHTE 87 .

HIESSEX 187 .

Herkunft der Tiefseekrabben 27\%. 279.

HESSE 214.

Hetcrocarpus $23 \%$.

Heteronucia $\Lambda$ LCock 49.

Hexaplax DE HLLWN 122

Hexaplax n. g. 122.

Hexaplax megalops n, sp. I 22.

Hexaplax megalops Dori. 209.

A uge 177.

Maße der Augenteile 178 .

Hippolyte varians 205.

HOFER 23 I.

Homola andamanica AlCock 15.

Homola barbata 15 .

Homola barbata Faibicius 14 .

Homola barbata F.IBRICIts orientalis HExISERso. 14.

Homola barbata typica 15 .

Homola Cuvieri RIsso I6-26.

Homola LEICH I4

H. megalops ALC. I6.

Homolochunia nov. gen. 21 .

Homola orientalis HFxtBerson 15.

Homola (Paromola) profundorum AI.COCK A.NIFRSON If?.

Homola profundorum Alcock u. Avinersoy 16.

Homola spinifrons LE.ACII 15 .

11. vigil M.-Enw. 16 .

Ifomolochunia Valdiviae n. 5p. 22-200

Homolochunia Valdiviae Dort.

Auge 137

Malie der Augenteile 150.

Geruchsorgan 183 .

Schuppenhaare $14 \%$.

Homolochunia Valdiviae, Statccyste 189.
IIomolochunia, verschiedene Lainge der Stäb. chen in stuge 210.

flomoladromia lkonvieri n. sp).

IJomolodromia Bonvieri Dofi..

Auge $1 . \$ 3$.

Maße der Augenteile 145.

Statocyste i88.

Geruchsorgan $18 \mathrm{r}$.

Versteifungseinrichtungen der Riechluare 180.

IIomolodromia paradoxa M.-EuW.

IIomologenus Braneri n. sp). I8.

IIOmologenus HENIJERSON I8.

Homologenus rostratus MILNE-EDIFARIS is

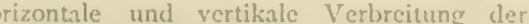
Brachyuren des tiefen IVassers 2 o. Brachyuren 26\%.

Ifyastenus brevirostris 85 .

IIyastenus Hilgendorfi 86 .

Hyastenus longipes 202.

IIystenus pleione 86 .

IIyastenus WIITTE 85 .

Hymenodora 234.

IIymenosoma geometricum Stmpsox 88

Hymenosoma LE.icH 88.

Hymenosoma Leachi Gcik1x 87.

IIymenosoma orbiculare DEMAREST 88.

IIymenosoma planatum F.Abicies S8.

Hymenosomidac 87 .

IIypsophrys longipes 17-209.

IIypsophrys longipes ALC. U. AND.

A uge I45.

Maße der Augenteile 147.

Hypsophrys IVoOD-MASON I7.

Imprägnierung der optischen Bestandteile 212. Inachus 202.

Inachus antarcticus n. sp. 74

Inachus dorsettensis (Plix..) 72. 200

Inachus F.IBRICIUS 72 .

Inachus leptochirus $74-200$.

Inachus leptochirus IoE.tcIt 73 .

Inachus leptorhynchus MILNE-EIWIRIS ; 3

Inachus scorpio FAIRICIUs 72.

Indopacifik 269

Innengeißel 240

Investigator $\mathbf{2 3 5}$.

Iridopigmentäre Augen 213-2 I0

Irispigment 207

Irrlinge in der Tiefsee 193.

Jollannes MÜLLER'sche Theoric des musivischen Sehens 207.

JOURDAIN 205.

Jugendstadien von Tiefseckrabben 198.

Kaemplferia 200-203.

Kaempfferia Kacmpfferi 196.

Kampf ums Dasein in der Tiefsee 200. 204.

KEEBLE 202-205.

Kiolossalfasem von Physachacus ctenurus 180

Fiongomündung $26 \%$. 
Förpergröße bei einigen lzöhlenbewohnenden Crustaceen I99.

Körpergröße von Tiefseelirabben 199.

КотTE 257 .

Krystallkegel, große 210

Lapnstoma palata HERBST I0.f. Lambdophallus sexpes ALCOCK 122 ,

Lambrus LEACH 87.

Lambrus macrocheles HERBST 8\%.

Lambrus mediterraneus Roux 87.

L.ANG 254 .

Länge der Augensticle bei Tiefseekrabben 209

LANKESTER $23 \% .282$

Lasiocampa quercifolia 230.

Latreillopsis bispinosa 26-209.

Latreillopsis HENDERSON $2 \mathrm{I}$.

Latreillia Roux $2 \mathrm{I}$.

Leachium orbiculare MAC LEAT 88.

Lebensweise der Galatheiden 235

Leiolophus MIERS I3I.

Leiolophus planissimus (HERIST) I 3 I

Leistungsfähigkeit des Auges von Ethusina abyssicola 2 r $\mathrm{r}$.

Leptodora hyalina 250.

Leucosia planata FABRICIUS 87-

Lichtbrechung in den Cornealinsen 215.

Lichtbrechung in den Krystallkegeln 215.

Lichteindringen in die Meerestiefe nach Surt 233

Lichtempfindliche Stellen im Stäbchen von Pleistacantha 220

Licht- und Pigmentvermehrung 2.11.

Limulus 226.

Linseraugen 224.

Liomera DANA IOI

Liomera sp. IOI.

Lispognathus A. MILNE-Entwards 75 .

Lispognathus furcillatus $\mathrm{A}$. MIL.N F.-ENWARUs 75

Lispognathus Thomsoni NoRMuN 75.

Auge I68.

Maße der Augenteile 168

LIST $194-24$ I.

Lithodes Agassizii 233.

Lithodomus dactylus $25 \mathrm{I}$

Litocheira Kingsleyi (MIERs) r2r.

Litocheira KINAHAN 12 I.

Lithodes 199.

Lithodes antarcticus 198.

Litteraturverzeichnis zum I. Teil 134

Litteraturverzeichnis zum II. Teil 263.

Litteraturverzeichnis zum III. Teil 284

Lobus osphradicus $18 \mathrm{I}-249$.

Lucifer 254.

Lupa LEACH 97.

Lupa pubescens DANA 98 .

Lupa sanguinolenta HERBST 94.

Lupea MILNE-EDw. 97.

Lupocyclus AD. u. WHITE 93.

Lyreidus Channeri WOOD-MISON 53.

Lyreidus elongatus MIERs 52.

Lyreidus DE HAAN 52

Lyreidus tridentatus DE HAAN 52.
Macrophthalmus LATREILLE 129.

Mlaja squinado I IO

MALARD 205.

Mlaskierung bei Krabben 203.

Iaskierung bei Tiefseekrabben 203.

Vaße der Corneafacetten 210.

IIaße der Krystallkegel 2 Io.

IIaße der Stäbchen 2 I I.

Mediterrane Region 267

Megalopa von TVillemoesia leptodactyla 244

Menaethius monoceros (LATR.) 225.

Menippe parvulus DE HAAN 102.

Merocryptus M.-EDw. 49.

Metamorphose, Abkürzung 258.

MIILNE-EDWARDS 234.

Muelleria lecanora JÄGER 126

II unida 234 .

Munida andamanica 236 .

Munidopsis 234 .

Munidopsis robusta 235 .

Munidopsis Antoni 235.

Munidopsis spinoculata 235 .

Nursia armata bicristimana ALCOCK 12. ANIFRsoN $36-4$ I.

Iursia armata DE HAAN $36-39$.

Mursia armata typica DE HAAN 40 .

Mursia armata curtispina MIIERs 40.

Mursia armata hawaiensis RatubUN 41.

Trursia aspera Alcock 36-40.

Mursia bicristimana ALCOCK u. ANIERson 41

Mursia cristimana IAtreille $36-38$.

Ilursia cristata MiLNE-EDwatios 38 .

Mursia curtispina Miers $36-40$.

Mursia Desmarest 36

Mursia hawaiensis Rathius 36-41.

Mytilus I94.

Mytilus galloprovincialis $24 \mathrm{I}$.

Mytilus minimus $24 \mathrm{r}$.

Nachtfärbung bei Crustaceen 205.

Nachtstellung 230 .

Nachtstellung des Pigments 207 .

Nahrungsregen 200.

Nautilograpsus minutus (L.) I30.

Nectopanope longipes IVOOD-MASON 117.

Nematocarcinus 237.

Nematocarcinus cursor 233.

Nematocarcinus ensiferus 233.

Nephrops 236.

Nephrops andamanica 236 .

Neptunus (Achelous) pubescens DANA 98.

Neptunus DE HAAN 97.

Neptunus pelagicus L. 98.

Neptunus (Neptunus) sanguinolentus (HERzsT) Philyra laminata n. sp. 46. 97.

Neptunus (Hellenus) tuberculosus MILNE-EDW ] ] 98

Normalauge der Brachyuren 20\%.

NORMLAN 282.

Nursia 49.

Ocypoda ceratophthalma (FARSK.) 225.

Ocypoda cordimana DE HAAN 126.
Ocypoda Edwardsi O\%OKIO $12 \%$

Ocypoda FABRICIUS 126

Ocypoda macleayana Hess 126.

Ocypoda. Urvillei MrLNE-Euw. I 26.

Ocypoda Ryderi KingsLeY 126.

Ocypoda Kunhli Dr HAAN 126.

Ocypoda brevicomis MILNE-EUW: I26.

Ocypoda ippeus OLIVIER 127.

Ocypoda cursor LEACH 127.

Ocypoda hexagonura Hilgendorf 127 , Ocypoda ceratophthalma PALLAS 126.

Ocypoda Fabricii Kingsuer 126

Ocypoda africana DE MAN 127.

Olm 23I.

Ommatidien 2 I 5 .

Ommatocarcinus WVHTE II 8 .

Optische Einrichtungen des Krablenauges 215.

Oreophoroida ALCOCK 49

Oreophorus RÜPPEL. 49

Orophorhynchus 234 .

Orophorhynchus lividus 235

Orophorhynchus Marionis 235.

Orophorhynchus Parfaiti 235

Otocysten 252.

Ovalipes bipustulatus MILNE-EDI: 92 .

Ovalipes Rathoun 9I.

Ovalipes trimaculatus DE HAAN 92.

Oxyrrhyncha 53 .

Oxystomata 27

Parweises Vorkommen von Tiefseekrabben 257.

Pachygrapsus I 10

Pachygrapsus aethiopicus HILGRNDORF I3O.

Pachygrapsus RANDALI I29.

Pachygrapsus simplex (HERKLOTS) 129.

Panmixie I39.

Paracyclois MIrens 38

Parapagurus pilosimanus 233.

Parapasiphaë cristata 234

Parapasiphaë sulcatifrons 234

Parapylocheles scorpio 236.

Parilia Alcocki WVOOD-MAsON 44.

Parilia WVOD-MASON 44

Pariphiculus ALCOCK $4 \mathrm{I}$.

Pariphiculus coronatus AlCoCk u. AND. $4 \mathrm{I}$.

PARKIR 2I4.

Parthenopidae 87

Pentacheles 232-234. 236

Petalophthalmus armiger 236 .

Pentacheles, rudimentäre Augen 234.

Pfeffer 267.

Philyra 203.

Philyra LEACH 45.

Philyra punctata BELL 45.

Philyra verrucosa Henderson 46.

Phoberus 236.

Phoberus caecus 236 .

Phosphorescenzlicht der Tiefsee 235.

Phymodius A. MIILNE-EDTV, IO2.

Phymodius monticulosus 103.

Phymodius ungulatus 103 . 
Phymodius ungulatus MiLNe-Enw, 102.

Physachaeus AlCock 71 .

P'hysachaeus ctenurus AlCoCk $7 \mathrm{I}$.

Auge 165 .

Maße der Augenteile 167 .

Physachaeus cterums ALC. u. AND. Geruchsorgan 185.

I'hysachaeus ctenurus

Sinneshaare des Augenstiels 165

Zelien in Augenstiel 166. 167.

Maße der Augenteile 167 .

Physachaeus, Bedeut Sehvorgang 225.

Physachaeus ctenurus. Statocyste 190.

Pigmentarmut 230.

Pigmentlosigkeit 231.

Pigmentansammlung hinter der Lamina fene. strata 217.

Pigment in den Augen der Brachyuren 230.

Pigmentlose Augen 213-222.

Pilumnoplax abyssicola MuEs 120.

Pilumnoplax americana RATHBUN 120

Pilumnoplax Sinclairi ALCOCK I20.

Pilumnoplax STIMPSON 119.

Pilumnus Andreosayi Aubouin 100.

Pilumnus heterochir STUDER IIg.

Pilumnus hirtellus var. inermis MILNE.Evw. 11. Bouv. 100

Pilumnus LEACH 100.

Pilumnus verrucosipes STIMPSON 100.

Pinnixa occidentalis 194.

Pinnotheriden 194.

Pinnotheres abyssicola 194.

Pinnotheres bolothuriae 244 .

Pinnotheres LATREILLE 124

Pinnotheres sp. 12.

Psopheticts stridulans WOOD-MASON II 8 226.

Pinnotheres villosissimus n.sp . 125 .

Planarien $23 \mathrm{I}$.

Planes LEACH-BELL 130.

Planes minutus (LiNNê) 130.

Plastocrangon caeca 236.

Platymaia MIIERS 59

Platymaia Wyville- Thomsoni MTERS 209.

Platymaia Wyville-Thomsoni Mrs.

A uge I6o.

Stadium I $\$ 60$

Stadium II - IV I62.

Stadiun VII 163 .

Platymaia WVyville-Thomsoni

Geruchsorgan 185 .

Platymaia, Reflektorauge $22 \mathrm{I}$.

Platymaia turbynei 61.62.

Platymaia turbynei STEBBing 59.

I'latymaia Gaudichaudii 38

1'latyonychus africanus MILNE-EDw, 92.

I'Jatyonychus bipustulatus MILNE-Eviv. 92,

P'atyonychus LATR.MLE 91.

I'leistacintha Miers emend 76 .

I'leistacintha Moseleyi (MirRs) 76
Meistacantha Moseleyi

Auge 168 .

Jugendstadium 168.

erwachsenes Tier 170 .

Maße der Augenteile 1 \%

P'lcurancodes 134

P'olycheles 232 .

I'ontophilus $23 \%$

P'ontophilus abyssi $233-234$.

Pontophilus gracilis 233

P'ortumnus 94

P'ortunidae 90.

l'ortunus FABRICiUS 95.

l'ortunus holsatus F $\wedge$ BRICIUS 95

P'ortunus puber I Io.

P’otamobius fluviatilis 180 .

Potamonautes MACLEar 105

105.

Potamonidae 105.

Potamon (Potamonautes) perlatum MircNeEDW. 105.

Potamon SAvigni I05.

POUCheT 205.

PRZTBRAM 202-205.

Prentiss 188-254.

Prionocrangon ommatosteres 236

Prosoponiden 279

Proteus anguineus 241.

Psalidopus 236.

Pseudoconus 225.

Pseudodromia latens Stimpson 12.

Pseudodromia Stinipson I2.

Pseudokone Augen 2 II.

Pseudorhombila (Pilumnoplax) Normanni MIIERs II 9

236.

Psopheticus IVOOD-MASON II8.

Ptenoplax Alcock u. ANDERSON 131 .

Pugettia $8 \mathrm{I}$.

Pugettia globulifera WVOD-MASON 85

Pylocheles Miersii 236.

Randallia coronata ALCOCK 12. ANDERson 41. Sesarma Meinerti DE MAN 130

Randallia pustulosa WVOOD-MASON 42 .

Randallia STIMPSoN 42.

VOM RATH $180-248$.

Reflektoraugen 220.

Reflexion, totale 223.

Regeneration bei Tiefseekrabben 204.

Retinapigment $20 \%$.

Retinopigmentäre Augen 213.

Retropluma Chuni n. sp. I3I.

Retropluma GiLL 13x.

Retropluma notopus ALCock I3I.

Riechhaare 179. 246 .

Riechlappen 181 .

Riechspindeln $18 \mathrm{r}$.

Riesenaugen der pelagischen Schizopoden und Sergestiden 228.

ROSENST.ADT 230

Rote liarbe bei Tiefsechrabben 205.

Serolis antarctica 239.
Rotfärbung nach Blendung 205.

Rudimentire Augen 223. 225 .

SARS 232.

Scharenweises Vorkommen von Tiefseekrabben $25 \%$

Schichtung der Cornea 215.

Schlammfresser 201 .

Schlammüberzug bei Tiefseekrabben 204.

SCHNEIDER, R. 199-230. 241.

Schutzinstinkte, Gruppierung der Tiere nach solchen 202 .

Scylla DE HAAN 98 .

Scylla serrata FORSKAL 93.

Scyra 81 .

Scyramathia Beauchampi Alcock u. ANDER son 81 .

Scyramathia Carpenteri (NORMANs) 8I.

Scyramathia globulifera WOOD-MIASON 81. 85.

Scyramathia Livermorii AL.Cock 84 .

cyramathia Hertwigi DofLEIN 8 r.

Scyramathia Hertwigi

A uge 17 I.

Maße der Augenteile 172.

Scyramathia pulchra MIERS 81. 84,

Scyramathia Rivers-Andersoni ALCock 81.84 . Scyramathia Rivers-Andersoni

A uge 172

Maß3e der Augenteile 173 .

Scyramathia velutina Miers $8 \mathrm{I}$.

Seespinnen 196.

Sehvorgang

bei Cyrtomaia 217 .

bei Lispognathus 217 .

bei Ocypode ceratophthalma 226 .

bei Menaethius 215.

bei Pinnotheres 227 .

Sehvorgang im Auge der Tiefseekrabben 2 I4.

SEMIPER 244.

Sergestes 254.

Serolis bromleyana 239

Serolis gracilis 239 .

Serolis Schytei 230 .

Sesarma SAY 130.

Sesarma tetragona MILNE-EDW. I30.

Sexueller Dimorphismus 257.

Sinkgeschwindigkeit $19 ;$

Sinnesorgane der Tiefseelarabben 206.

SMITH 200-233

Spelaephorus M.-EvW, 49

Stäbchenform, Bedeutung der 217 .

Stäbchen als Sitz der Lichtempfindung 217 .

Stachelkorb $24 \%$.

Statocysten 252

Statocysten einiger Tiefseekrabben 187

Statocysten, geschlossene $\mathbf{2 5}$.

Statocysten, kugelige 25 .

Statocysten, offene 253.

Stenorhynchus 203.

Stenorhynchus falcifer Strmison ;o.

Stenorhynchus L.AMARCK 69. 
Stenorhynchus longirostris (FABRICIUS) 70. Stenorhynchus phalangium (PEvN) 69.

Stenorhynchus rostratus LINNÉ 69 Stenorhynchus rostratus var. spinulosus 69 . Stenorhynchus tenuirostris (LEACH) ;o. Superpositionsbild 207.

Superpositionsbild bei Cyrtomaia 215.

Sympagurus pictus 233.

Synandrocarpa domuncula MichaElseN I 2 .

Tabellen 285.

Tagauge 207 .

Tapetum 230.

Tapetum, Bedeutung 221.

Terminalnerven I8I.

Terminalstrang ISo.

Tetralia DANa 105.

Tetralia glaberrima HERBST 105

Thalamita crenata DANA 89.

Thalamita Danae STrupsos 99.

Thalamita LATREILLE 99.

Thalamita prymna var. Danae STIMP. 99.

Thalamitoides quadridens MiLvE-EDw. 99.

Thalamitoides A. MILNE-Enw. 99.

Tiergeographischer Teil 265.

Thealia acanthophora LuCAs 40.

Thelphusa africana A. MILNE-EDw. I05.

Thelphusa anchietae BRITO-CAPELlo 105.

Thelphusa Aubryi A. Mrr.ve-EDw. 105.

Thelphusa aurantia HERKLOTS 105.

Thaumastocheles 232 .

Thaumastocheles Zaleucus 233.

Thelphusa Pelii Herkiots 105.

Thelphusa perlata MiLNE-EDw. 105.

Tiefschwarzes Pigment der Strandformen 212.

Tiefsee

Temperatureinfluß 194

Dunkelheit 193. 194.

Unbewegtheit des Wassers 198.

Tiefsee, Lebensbedingungen 193-194.

Tiefseekrabben, Definition 193.

Tiefseekrabben, Vorkommen 193.

Tiefseeschlanm, Anpassung an 197. 199.

Tlos ADAMs und THite 49.
Trapezia cymodoce HERBST I04.

Trapezia ferruginea guttata RÜPPEL 104.

Trapezia guttata RỦPPEL I04.

Trapezia LAtREILLE 104.

Trechus 229. 231.232.

Trichopeltarium Alcocki Iog.

Trichopeltarium Alcocki DofleiN 88.

Trichopeltarium Alcocki DoFL.

A uge 173 .

Maße der Augenteile 174 .

Trichopeltarium MI.-EDw. 88.

Trichopeltarium ovale AvDERSON 88.

Tridacna 229.

Tastsinn bei den Tisfseekrabben 255 .

Troglichthys 243 .

Troglocaris Schmidti $23 \mathrm{I}$.

Typhlichthys 243.

Typhlogobius 244.

Uca tangieri Eydoux 127.

Uca LEACH 127.

Uca annulipes MILNE-EDw, I 28.

Uhlias STIMPSON 49.

Ursachen der Rückbildung der Augen 237

Vagilität $28 \mathrm{r}$.

Var. tridens 96

var. vadorum ALC. u. var. pusilla ALC. 94. Westafrikanische Region 267.

Verbreitung von Cyclodorippe uncifera ORTM. V. WILLEMOES-SUHM 205-232. 271 .

Verbreitung der Gattung Cyrtomaia 271.

Verbreitung der bekannten Arten der Gattung Ethusa 275.

Verbreitung der bisher beschriebenen Arten der Gattung Ethusina 275.

Verbreitung der Gattung Geryon 273.

Verbreitung von Homola barhata orientalis 270.

Verbreitung von Homola barbata typica 270. Xantho LEAcH IOI
Verbreitung von Lispognathus Thomsoni Xantho (Leptodius)

Verbreitung von Lispognathus Thomsoni Xantho (Leptodius) sanguineus (EDw.) IoI. (NORM.) 272.

| Verbreitung der ostatlantischen Litoralfauna

i 268.
Verbreitung von Platymaia IVyville-Thomsoni MrS. 271 .

Verbreitung von Physachaeus ctenurus ALC. 271.

Verbreitung von Pleistacantha Moseleyi (MRS.) 271 .

Verbreitung von Randallia pustulosa W.-M. 271.

Verbreitung von Scyramathia pulchra MIERS 271.

Verbreitung von Scyramathia Rivers-Andersoni ALC. 27 I. brachyuren 274.

Vergleich des Augenbaues bei Tieren mit verschiedener Lebensweise 227.

Verkürzung der Außengeißel 247.

VERRILL 205.

Verschiedenbeit der Stäbchenlänge im Auge von Homolochunia 219.

Versteifungseinrichtungen der Riechhaare I8o.

VIGIER 242.

Virbius varians 202

Wassertemperaturen 269 .

IVEISMANN 239

Willemoesien I $99-232$

Willemoesia leptodactyla 244.

WOOD-MASON 235.

Xawa bipustulata BERG 92.

Xanthidae 100 .

Xantho exaratus (MחNE-EDw.) var. sanguinea MILNE-EDW, IOI

Xantho hirsutissimus RÜPPEL 102.

Xantho Lamarcki Milne-EDwards ior.

Xantho sp. Ior.

$\mathbf{Z}$ wergformen 200.
Verbreitung einiger merkwürdiger Tiefsee-

Vergrößerung der Kiemenhöhle 202. 



\section{Texttafel.}

\section{Schematische Figuren zur Erklärung der in diesem Band angewandten Terminologie.}

Fig. I. Schema des Cephalothorax (von der Rückenseite) zur Bezeichnung der Regionen.

"2. Schema des Cephalothorax (von der Bauchseite) und des I. und 2. Pereiopods = Thorakalfußes.

" 3. Schema des Cephalothorax der niedersten Brachyuren (von der Rückenseite) zur Bezeichnung der Linien und Suturen.

" 4. Dasselbe von der rechten Seite.
Gn I I. Gnathopod
Mx II 2. Maxille
Gn II 2. Gnathopod
Mx I I. Maxille
MIx III 3. Maxille
MId Nandibel

\section{Allgemein angewandte Abkürzungen.}

\author{
$A_{1}$ I. Antenne \\ $A_{2}$ 2. Antenne \\ a Abdomen \\ $a, a_{2}, a_{3} \ldots$ I., $_{2}, 3 . \ldots$ Abdominalsegment. \\ $B$ Branchialregion \\ $B i$ Regio branchialis inferior $=$ untere Kiemenregion \\ C Regio cardiaca (Herzregion) \\ E Epigastricalregion \\ ep Epipodit \\ end Endopodit \\ Ex Exopodit \\ $F$ Frontalregion \\ ft Flagellum (Geißelanhang) \\ $G$ Regio gastrica (Magenregion) \\ $H$ Regio hepatica (Leberregion) \\ $H i$ Regio hepatica inferior \\ Hr Hinterrand \\ Hs Hinterseitenrand \\ J Regio intestinalis (Darmregion) \\ $K$ Seitenkante \\ $L$ Linea cervicalis \\ MI Mundöffnung \\ Mes Regio mesogastrica \\ Met R. metagastrica \\ $N$ Branchialfurche \\ Oc Auge \\ Orb. o oberer Orbitalrand
}

Orb. $u$ unterer Orbitalrand

$P I-V$ I -5 . Pereiopod-Thorakalfuß

$I p$ Coxopodit

2 Basopodit

$3 p$ Ischiopodit

$+p$ Meropodit

5 p Carpopodit

6 p Propodit, bei der Schere auch Palma

7 P Daktylopodit, bei der Schere auch beweglicher Finger

I $p$ Coxognathit

II p Basognathit

III $p$ Ischiognathit Kaum gebräuchlich; gewöhn-

I $p$ Merogmathit lich iverden auch für die

$\checkmark$ p Carpognathit $\quad$ Kauwerkzeuge die obigen

VI $p$ Prognathit Ausdrücke angewandt

VII $p$ Dactylognathit

pal Palpus

$P d b$ Podobranchie

$P l$ Pleuralnaht

Pr Regio progastrica

Pt Regio pterygostomialis

$O$ Linea homolica

$R$ Rostrum

St Stirn, Stirnwand

$U$ Regio urogastrica

IS Vorderseitenrand 


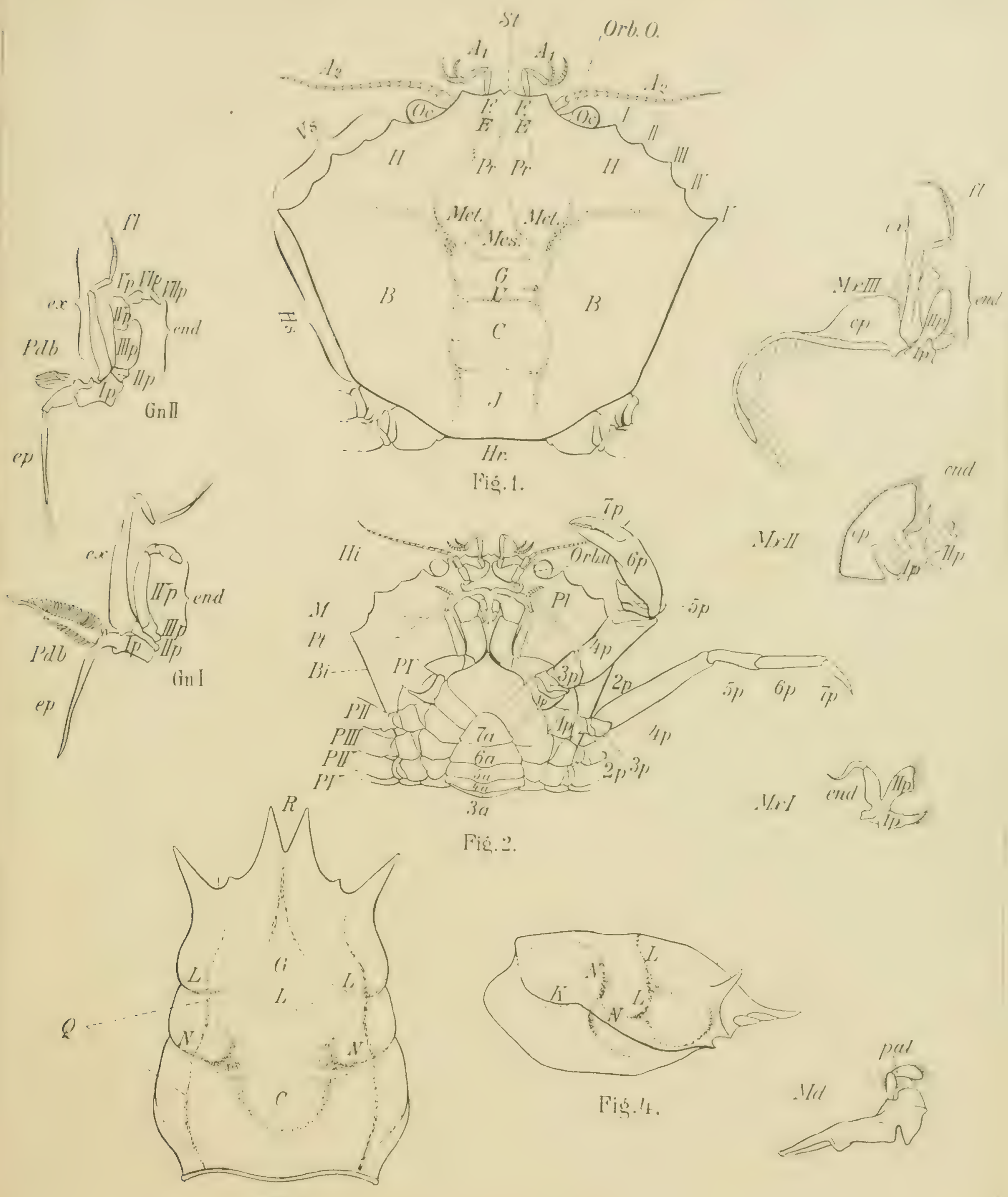

Fiǵ..3.

Schematische Figuren zur Erklarung der in diesem IBand angewandten Terminologie. 







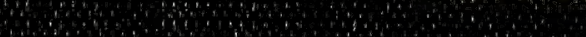

